\title{
CONTRIBUIÇÕES AO PROJETO ESTRUTURAL DE EDIFÍCIOS EM ALVENARIA
}

\author{
KRISTIANE MATTAR ACCETTI
}

\begin{abstract}
Dissertação apresentada à Escola de Engenharia de São Carlos, da Universidade de São Paulo, como parte dos requisitos para a obtenção do Título de Mestre em Engenharia de Estruturas.
\end{abstract}

ORIENTADOR: Prof. Dr. Márcio Roberto Silva Corrêa

São Carlos

1998 
TESE

Cutt. 0099

Tonbo

Ficha catalográfica preparada pela Seção de Tratamento da Inform ação do Serviço de Biblioteca - EESC-USP

Accetti, Kristiane Mattar

Contribuições ao projeto estrutural de edifícios em alvenaria / Kristiane Mattar Accetti. -- São Carlos, 1998.

Dissertação (Mestrado) -- Escola de Engenharia de São Carlos-Universidade de São Paulo, 1998. Área: Engenharia de Estruturas. Orientador: Prof. Dr. Márcio Roberto Silva Corrêa.

1. Projeto estrutural de edifícios.

2. Alvenaria estrutural. 3. Tomadas de decisão. I. Título. 


\section{Candidata: Engenheira KRISTIANE MATTAR ACCETTI}

Dissertação defendida e aprovada em 17-04-1998 pela Comissão Julgadora:

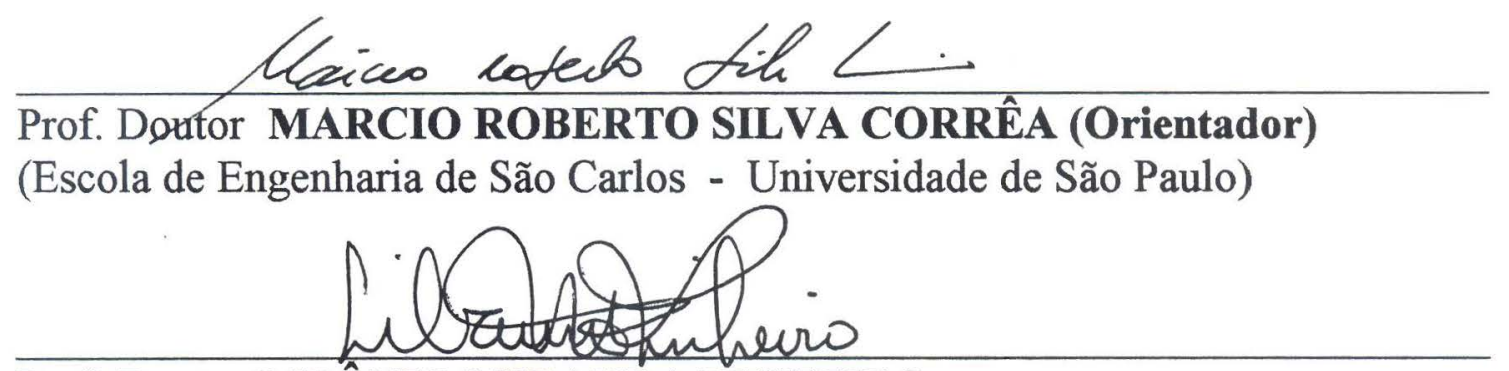

Prof. Doutor LIBÂNIO MIRANDA PINHEIRO

(Escola de Engenharia de São Carlos - Universidade de São Paulo)

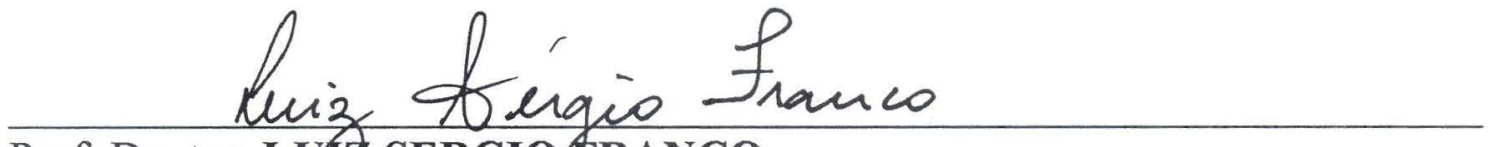

Prof. Doutor LUIC SERGIOGRANCO

(Escola Politécnica - Universidade de São Paulo)

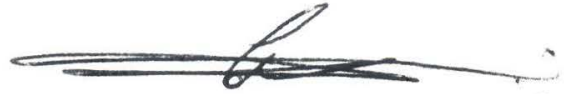

Prof. Titular CARLITO CALIL JUNIOR

Coordenador da Área de Engenharia de Estruturas

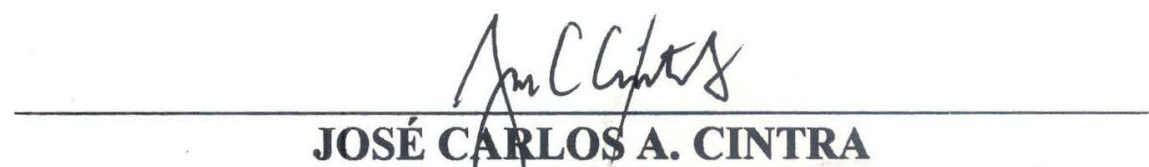

Presidente da Comissão de Pós-Graduação da EESC 
Aos meus pais,

Ângelo e Nida

e irmãos,

Leonardo e Fernando. 


\section{AGRADECIMENTOS}

A Deus, que me iluminou em todos os momentos, e tornou possível a obtenção deste título, que representa mais uma etapa muito importante alcançada em minha vida.

Ao Prof. Márcio Roberto Silva Corrêa, pela brilhante orientação, sugestões, dedicação, paciência e muito empenho demonstrados durante a elaboração deste trabalho.

A Reinaldo de Castro Takeda, pelo constante incentivo, apoio e compreensão, demonstrados durante todo esse período.

À minha avó Branca, pelo carinho e cujo apoio foi imprescindível à minha estadia em São Carlos.

À Vanessa Cristina de Castilho, pela agradável convivência, pelo carinho, pelo companheirismo e pelo apoio constante.

A todos os amigos do Departamento de Engenharia de Estruturas da Escola de Engenharia de São Carlos - USP, pelo agradável convívio.

A Osvaldo Gomes de Holanda Júnior, pelos ensinamentos de Autocad 3D, sem os quais não seria possível a elaboração de várias figuras encontradas no texto.

À Maria Nadir Minatel, pela paciência e pelas orientações fornecidas para a produção deste trabalho.

À Coordenadoria de Aperfeiçoamento de Pessoal de Nível Superior CAPES, pela bolsa de estudo concedida no primeiro ano.

À Fundação de Amparo à Pesquisa do Estado de São Paulo - FAPESP, pela bolsa de estudo concedida no segundo ano. 


\section{SUMÁRIO}

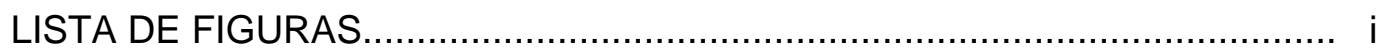

LISTA DE TABELAS ............................................................................ iv

LISTA DE ABREVIATURAS E SIGLAS ………………......................

LISTA DE SÍMBOLOS ..................................................................... vi

RESUMO .

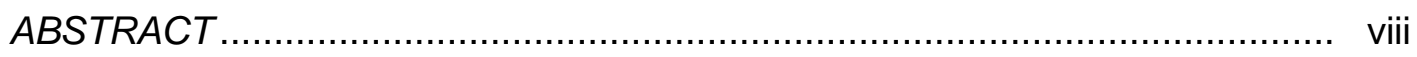

1 INTRODUÇÃO

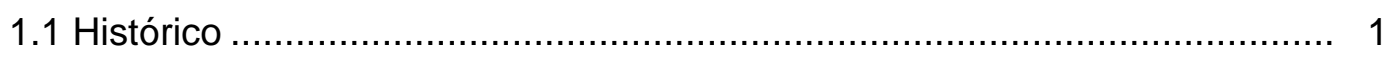

1.2 Objetivos do trabalho......................................................................... 4

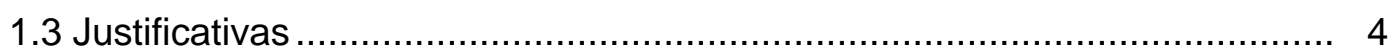

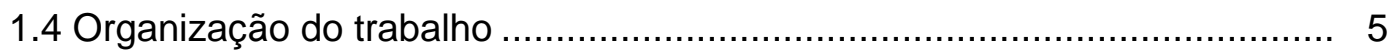

2 DEFINIÇÕES PRELIMINARES .......................................................... 7

2.1 Alvenaria armada ou não-armada ...................................................... 7

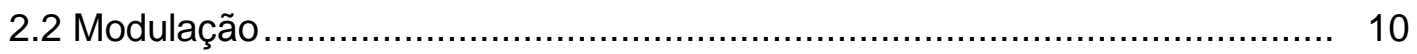

2.2.1 Tipo de bloco

2.2.2 Amarração de paredes ................................................................... 11

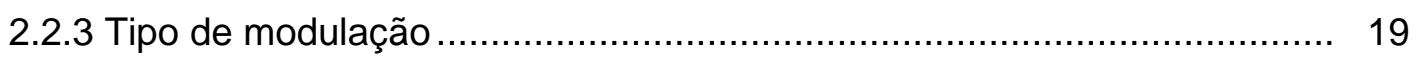

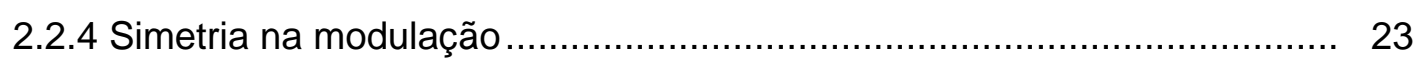

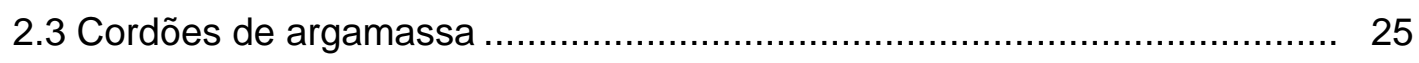

2.4 Passagem das tubulações................................................................ 28

2.4.1 Instalações elétricas, de telefone, de TV e de interfone ......................... 28

2.4.2 Instalações hidro-sanitárias ............................................................ 29

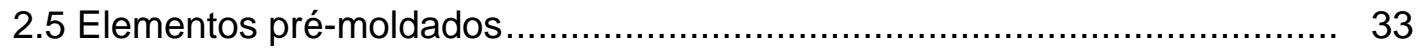

2.5 .1 Lajes

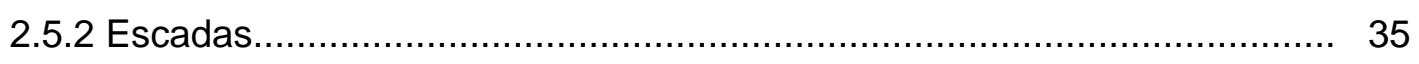

2.5.3 Vergas para portas ................................................................. 41

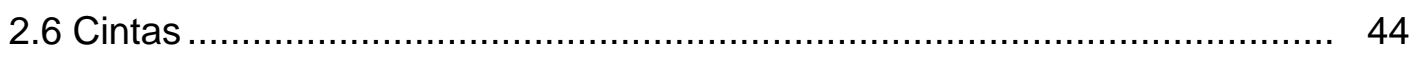

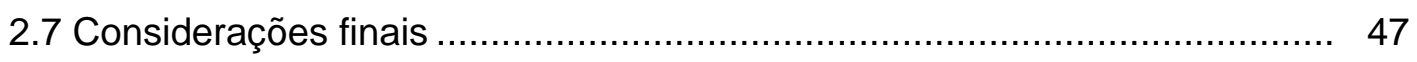

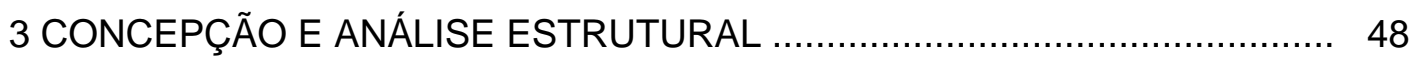

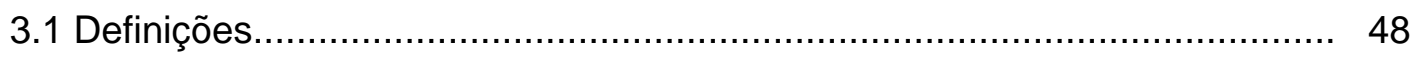

3.1.1 Concepção estrutural ................................................................... 48 
3.1.2 Análise estrutural ...................................................................... 52

3.2 Determinação das ações verticais .......................................................... 53

3.3 Determinação das ações horizontais ................................................ 55

3.4 Distribuição das ações verticais......................................................... 59

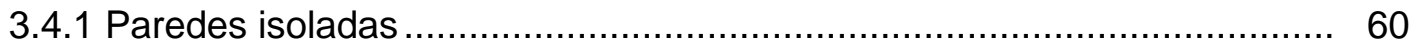

3.4.2 Grupos isolados de paredes ...................................................... 61

3.4.3 Grupos de paredes com interação.................................................. 61

3.4.4 Modelagem tridimensional em elementos finitos ................................ 63

3.4.5 Exemplos de aplicação.............................................................. 63

3.5 Distribuição das ações horizontais .................................................. 72

3.5.1 Consideração das abas ou flanges................................................... 72

3.5.2 Paredes isoladas ............................................................................. 74

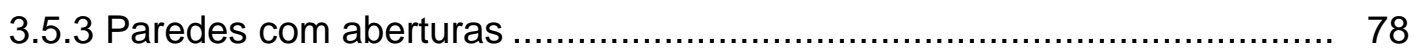

3.5.4 Consideração de trechos rígidos ...................................................... 81

3.5.5 Exemplo de aplicação................................................................ 84

3.6 Considerações finais ............................................................................ 100

4 DIMENSIONAMENTO ............................................................... 101

4.1 Método das tensões admissíveis ........................................................ 101

4.2 Determinação das tensões admissíveis................................................. 102

4.3 Tensões admissíveis na alvenaria ...................................................... 103

4.4 Tensão de tração admissível nas armaduras ............................................ 106

4.5 Tensão de compressão admissível nas armaduras ................................... 106

4.6 Tensão de cisalhamento admissível em parafusos e ancoragens .............. 107

4.7 Dimensionamento das vergas e vigas ................................................ 108

4.7.1 Dimensionamento à flexão simples ................................................... 109

4.7.2 Dimensionamento ao cisalhamento ............................................... 115

4.7.3 Exemplos......................................................................... 117

4.8 Dimensionamento de paredes e pilares.............................................. 119

4.8.1 Conceitos básicos .......................................................................... 119

4.8.2 Dimensionamento à compressão axial ............................................. 121

4.8.3 Dimensionamento à compressão localizada ......................................... 121

4.8.4 Dimensionamento à flexão composta ................................................. 122

4.8.5 Dimensionamento ao cisalhamento ..................................................... 128

4.8.6 Dimensionamento à flexão simples .................................................. 129

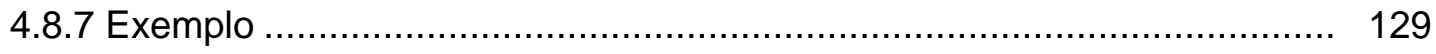


4.9 Disposições construtivas ................................................................... 131

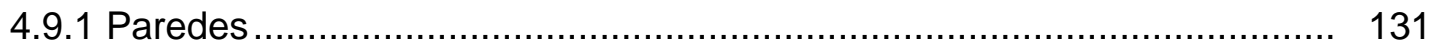

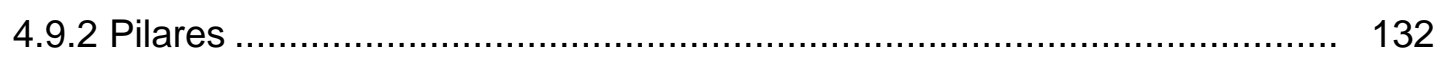

4.10 Efeitos de segunda ordem .............................................................. 133

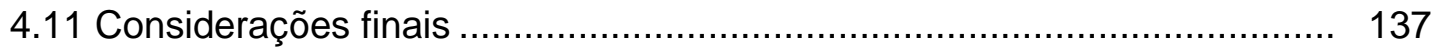

5 EXEMPLOS NUMÉRICOS ............................................................ 139

5.1 Definições preliminares .................................................................... 142

5.2 Edifício com 4 (quatro) pavimentos ................................................ 146

5.2.1 Alvenaria armada ou não-armada .................................................. 146

5.2.2 Determinação das ações verticais ................................................... 150

5.2.3 Determinação das ações horizontais .................................................. 153

5.2.4 Distribuição das ações ao longo do edifício ............................................ 154

5.3 Edifício com 8 (oito) pavimentos .......................................................... 169

5.3.1 Alvenaria armada ou não-armada .................................................... 169

5.3.2 Determinação das ações verticais ................................................... 170

5.3.3 Determinação das ações horizontais................................................ 170

5.3.4 Distribuição das ações ao longo do edifício ........................................ 171

5.3.5 Dimensionamento......................................................................... 189

5.4 Considerações finais ...................................................................... 198

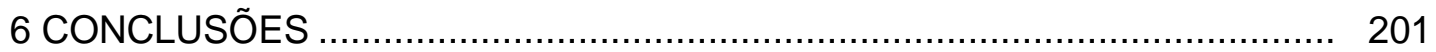

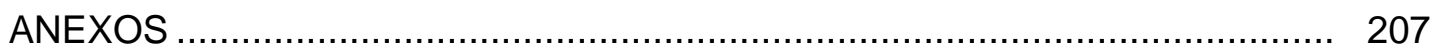

REFERÊNCIAS BIBLIOGRÁFICAS .................................................... 242 


\section{LISTA DE FIGURAS}

FIGURA 1.1 - Pirâmide de Queops................................................ 1

FIGURA 1.2 - Catedral de Reims................................................... 2

FIGURA 1.3 - Monadnock Building.............................................. 3

FIGURA 2.1 - Amarração direta de paredes..................................... 12

FIGURA 2.2 - Seqüência de fiadas................................................. 13

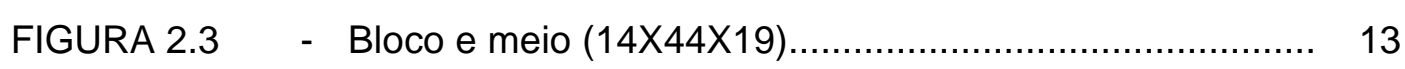

FIGURA 2.4a - Seqüência de fiadas $-1^{a}$ fiada...................................... 14

FIGURA 2.4b - Seqüência de fiadas $-2^{\mathrm{a}}$ fiada.................................... 15

FIGURA 2.5a - Bloco e meio - $1^{\mathrm{a}}$ fiada................................................... 15

FIGURA 2.5b - Bloco e meio - $2^{\mathrm{a}}$ fiada................................................... 16

FIGURA 2.6 - Juntas a prumo na modulação....................................... 16

FIGURA 2.7 - Ligação de paredes estruturais com JP......................... 17

FIGURA 2.8 - Ligação de parede estrutural com parede não-estrutural.. 18

FIGURA 2.9a - Arquitetura ......................................................... 20

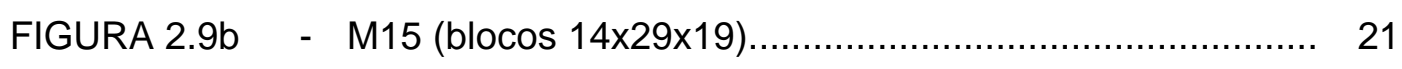

FIGURA 2.9c $\quad$ - M20 (blocos 14x39x19) .......................................... 21

FIGURA 2.10a - Exemplo de situação de fechamento compensada com a utilização do bloco e meio............................................ 24

FIGURA 2.10b - Exemplo de situação de fechamento compensada com a utilização do bloco em trânsito........................................ 24

FIGURA 2.11 - Cordões de argamassa apenas nos septos longitudinais. 25

FIGURA 2.12 - Cordões de argamassa nos septos transversais............. 26

FIGURA 2.13 - Testes dos prismas como vigas................................... 27

FIGURA 2.14 - Bloco hidráulico.................................................... 30

FIGURA 2.15 - "Shaft" hidráulico............................................... 31

FIGURA 2.16 - Enchimento em cozinha.......................................... 32

FIGURA 2.17 - Sanca............................................................... 32

FIGURA 2.18 - Aplicações de elementos de "laje pré-moldada"............. 34

FIGURA 2.19 - Degraus moldados no local........................................ 35

FIGURA 2.20 - Escada com patamar pré-moldado.............................. 37

FIGURA 2.21 - Escada com patamar maciço embutido na parede sobre cinta de concreto......................................................... 38 
FIGURA 2.22 - Escada com patamar maciço apoiado sobre peça prémoldada ou escada "jacaré".......................................... 40

FIGURA 2.23 - Verga moldada no local................................................ 41

FIGURA 2.24 - Verga pré-moldada para portas...................................... 43

FIGURA 2.25 - Verga pré-moldada em modulação de 15....................... 44

FIGURA 2.26 - Cintas em parede externa - armadura construtiva.......... 45

FIGURA 2.27 - Detalhe da ligação laje de cobertura e alvenaria............. 46

FIGURA 2.28 - Detalhe da colocação de isopor entre a laje e o bloco "J" 46

FIGURA 3.1 - Sistema de paredes transversais................................ 49

FIGURA 3.2 - Sistema de paredes celulares....................................... 50

FIGURA $3.3 \quad$ - Sistema complexo.................................................... 51

FIGURA 3.4 - Detalhe da laje sobre o bloco "J".................................. 52

FIGURA 3.5 - Ligação de engastamento entre duas lajes em desnível... 52

FIGURA 3.6 - Bloco revestido com argamassa e gesso........................ 53

FIGURA $3.7 \quad$ - Fissuras sobre apoios.................................................. 55

FIGURA 3.8 - Distribuição das ações do vento entre painéis de contraventamento..................................................... 56

FIGURA 3.9 - Parâmetros para cálculo do desaprumo......................... 58

FIGURA 3.10 - Alvenaria entre a abertura e a laje................................... 62

FIGURA 3.11 - Planta do exemplo 1................................................... 64

FIGURA 3.12 - Planta do exemplo 2 …................................................ 70

FIGURA 3.13 - Definição das abas ou flanges......................................... 73

FIGURA 3.14 - Representação dos painéis de contraventamento........... 75

FIGURA 3.15 - Movimentação das lajes de acordo com a atuação do

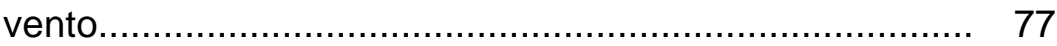

FIGURA 3.16 - Elementos de barra tridimensional................................. 77

FIGURA 3.17 - Paredes com abertura - modelo de pórtico plano............ 79

FIGURA 3.18 - Associação plana de painéis....................................... 80

FIGURA 3.19 - Elementos de barra tridimensionais unidos por lintéis..... 81

FIGURA 3.20 - Trechos rígidos....................................................... 82

FIGURA 3.21 - Comprimento flexível das barras horizontais................... 82

FIGURA 3.22 - Comprimento dos trechos rígidos................................... 84

FIGURA 3.23 - Comprimento dos trechos rígidos................................. 84

FIGURA 3.24 - Modulação e definição dos painéis de contraventamento 85

FIGURA 3.25 - Representação das abas ou flanges............................. 91 
FIGURA 4.1 - Prisma.................................................................. 102

FIGURA 4.2 - Tensões de tração na flexão............................................. 104

FIGURA 4.3 - Contato.................................................................... 106

FIGURA 4.4 - Carga distribuída dentro do triângulo de carga................ 108

FIGURA 4.5 - Carga concentrada fora do triângulo de carga................. 109

FIGURA 4.6 - Flexão simples em seção retangular - armadura simples 110

FIGURA 4.7 - Flexão simples em seção retangular - armadura dupla..... 114

FIGURA 4.8 - Distribuição das cargas verticais................................... 120

FIGURA 4.9 - Distribuição de carga vertical quando há abertura............ 120

FIGURA 4.10 - Compressão localizada................................................ 122

FIGURA 4.11 - Flexão composta - Estádio II.......................................... 125

FIGURA 4.12 - Diagramas de tensões................................................ 127

FIGURA 5.1a ～- Planta baixa do pavimento-tipo...................................... 140

FIGURA 5.1b - Planta do ático e esquemas verticais do edifício.............. 141

FIGURA 5.2a - Modulação da $1^{\mathrm{a}}$ fiada................................................ 144

FIGURA 5.2b - Modulação da $2^{a}$ fiada............................................... 145

FIGURA 5.3 - Forma das lajes.................................................. 151

FIGURA 5.4 - Nomenclatura das paredes......................................... 155

FIGURA 5.5 - Definição dos grupos de paredes................................. 166

FIGURA 5.6 - Paredes PY1 e PY18................................................. 190

FIGURA 5.7 - Detalhe da armadura em ambas as extremidades da parede ........................................................................ 190

FIGURA 5.8 - Detalhamento das armaduras de flexão das paredes PY1 e PY18............................................................. 191

FIGURA 5.9 - Parede PY1 / PY18 - $1^{\circ}$ pavimento................................ 193

FIGURA 5.10 - Verga da janela da sala............................................. 195

FIGURA 5.11 - Verga da porta do quarto.......................................... 197

FIGURA 5.12 - Esquema de cálculo para edifícios com mais de 4 ou 8 pavimentos................................................................ 199 


\section{LISTA DE TABELAS}

TABELA 2.1 - Resistências de blocos estruturais de concreto disponíveis no mercado.............................................. 22

TABELA 3.1 - Dados do exemplo 1.................................................. 64

TABELA 3.2 - Resultados considerando paredes isoladas..................... 65

TABELA 3.3 - Resultados considerando grupos de paredes sem interação..................................................................... 66

TABELA 3.4 - Resultados considerando grupos de paredes com interação................................................................... 67

TABELA 3.5 - Comparação dos três procedimentos............................. 68

TABELA 3.6 - Cargas distribuídas nas paredes abaixo do $1^{\circ}$ pavimento 71

TABELA 4.1 - Tensões admissíveis na alvenaria não-armada................ 103

TABELA 4.2 - Tensões admissíveis na alvenaria armada...................... 105

TABELA 4.3 - Tensões de cisalhamento admissíveis em parafusos e ancoragens............................................................. 107

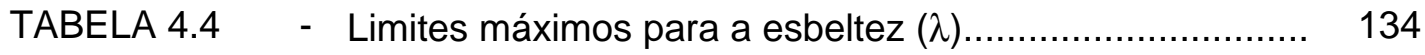

TABELA 5.1 - Resultado do cálculo das armaduras verticais das paredes................................................................ 147

TABELA 5.2 - Resultado do cálculo do volume de graute das paredes... 149

TABELA 5.3 - Resultado de grauteamento fornecido pelo programa..... 156

TABELA 5.4 - Resultado de grauteamento econômico........................... 160

TABELA 5.5 - Resultado de grauteamento fornecido pelo programa..... 162

TABELA 5.6 - Resultado de grauteamento econômico............................. 162

TABELA 5.7 - Resultado de grauteamento fornecido pelo programa...... 167

TABELA 5.8 - Resultado de grauteamento econômico............................ 167

TABELA 5.9 - Armaduras verticais das paredes tracionadas................. 174

TABELA 5.10 - Resultado de grauteamento econômico............................ 174

TABELA 5.11 - Resultado de grauteamento econômico.......................... 178

TABELA 5.12 - Armaduras verticais das paredes 181 tracionadas..

TABELA 5.13 - Resultado de grauteamento econômico........................... 182

TABELA 5.14 - Resultado de grauteamento econômico.......................... 186 
LISTA DE ABREVIATURAS E SIGLAS

EESC Escola de Engenharia de São Carlos

SET Departamento de Engenharia de Estruturas

USP Universidade de São Paulo 


\section{LISTA DE SÍMBOLOS}

\begin{tabular}{|c|c|}
\hline$A_{e}$ & Área da superfície onde o vento atua \\
\hline $\mathrm{C}_{\mathrm{a}}$ & Coeficiente de arrasto \\
\hline $\mathrm{F}$ & Força de arrasto \\
\hline$F_{d}$ & $\begin{array}{l}\text { Ação lateral equivalente ao desaprumo aplicada ao nível de cada } \\
\text { pavimento }\end{array}$ \\
\hline$f_{a}$ & resistência da argamassa \\
\hline $\mathrm{f}_{\mathrm{alv}, \mathrm{c}}$ & tensão normal de compressão axial atuante \\
\hline $\bar{f}_{a l v, c}$ & tensão normal de compressão axial admissível \\
\hline$f_{a l v, f}$ & tensão normal de compressão atuante, devida à flexão \\
\hline$\overline{f_{a l v}, f}$ & tensão normal de compressão admissível, devida à flexão \\
\hline $\bar{f}_{a l v, t}$ & tensão normal de tração admissível na alvenaria não-armada \\
\hline$f_{b k}$ & resistência característica do bloco \\
\hline$f_{\text {cis }}$ & tensão de cisalhamento atuante \\
\hline$f_{\text {con }}$ & tensão normal de contato atuante \\
\hline$f_{g k}$ & resistência característica do graute \\
\hline$f_{p}$ & resistência de prisma \\
\hline$f_{\mathrm{pa}}$ & resistência da parede \\
\hline $\mathrm{H}$ & altura total da edificação \\
\hline JP & junta a prumo \\
\hline M15 & modulação com blocos de comprimento múltiplo de $15 \mathrm{~cm}$ \\
\hline M20 & modulação com blocos de comprimento múltiplo de $20 \mathrm{~cm}$ \\
\hline $\mathrm{R}$ & fator de redução da resistência associado à esbeltez \\
\hline $\mathrm{R}_{\mathrm{i}}$ & rigidez de um painel de contraventamento \\
\hline $\mathrm{S}_{1}$ & fator topográfico \\
\hline $\mathrm{S}_{2}$ & fator de rugosidade e regime \\
\hline $\mathrm{S}_{3}$ & fator estatístico \\
\hline$v_{k}$ & velocidade característica do vento \\
\hline$\Delta \mathrm{P}$ & peso total do pavimento \\
\hline$\gamma$ & peso específico da alvenaria \\
\hline$\eta$ & eficiência \\
\hline$\varphi$ & ângulo para o desaprumo do eixo da estrutura \\
\hline
\end{tabular}




\section{RESUMO}

ACCETTI, K. M. (1998). Contribuições ao projeto estrutural de edifícios em alvenaria. São Carlos. 247p. Dissertação (Mestrado) - Escola de Engenharia de São Carlos, Universidade de São Paulo.

Este trabalho versa sobre as principais tomadas de decisão efetuadas durante a elaboração de projetos estruturais de edifícios em alvenaria. Inicialmente são abrangidas definições a respeito de armação de paredes, modulação, técnicas construtivas e utilização de elementos pré-moldados. Apresentam-se ainda critérios para a concepção estrutural e procedimentos de determinação das ações atuantes, bem como sua distribuição ao longo do edifício. São fornecidas orientações para o dimensionamento dos elementos estruturais, fundamentadas na ABNT (NBR10837). Baseado na teoria exposta, alguns exemplos são elaborados com a finalidade de direcionar as tomadas de decisão no sentido de garantir segurança e economia.

Palavras-chave: projeto estrutural de edifícios; alvenaria estrutural; tomadas de decisão 


\begin{abstract}
ACCETTI, K. M. (1998). Contributions to the structural design of masonry buildings. São Carlos. 247 p. Dissertação (Mestrado) - Escola de Engenharia de São Carlos, Universidade de São Paulo.
\end{abstract}

This work deals with the main decisions in structural masonry buildings design. At first, some definitions regarding reinforced masonry, modulation, construction techniques and use of precast concrete elements are discussed. In addition, some structural conception criteria and applied forces determination procedures, as well as forces distribution through out the building's height, are presented. Some orientations are given to structural elements design, according to brazilian code ABNT (NBR-10837). Based on the discussed theory, some examples are presented in order to direct the decision making process to assure safety and economy.

Keywords: structural design of buildings; structural masonry; decision making process 


\section{INTRODUÇÃO}

\subsection{Histórico}

A alvenaria está entre as mais antigas formas de construção empregadas pelo homem. Desde a Antigüidade ela tem sido utilizada largamente pelo ser humano em suas habitações, monumentos e templos religiosos. Como exemplos famosos podem ser citados: a pirâmide de Queops (Figura 1.1), em que foram utilizados mais de dois milhões de bloco de pedra, o farol de Alexandria, com altura superior a $130 \mathrm{~m}$, e as grandes catedrais góticas (Figura 1.2), construídas na Idade Média, com vãos expressivos e arquitetura belíssima, realizada com a utilização de arcos e abóbadas.

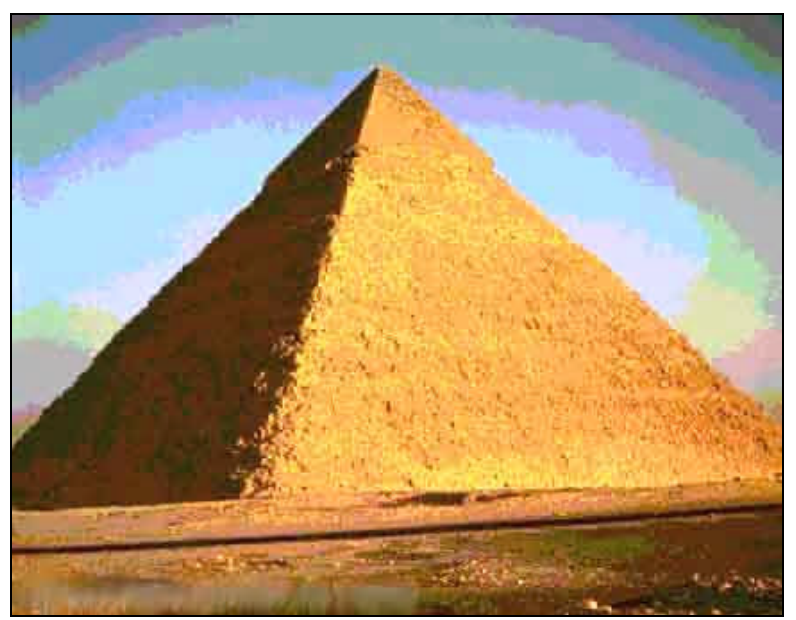

FIGURA 1.1 - Pirâmide de Queops ${ }^{1}$

\footnotetext{
${ }^{1}$ MICROSOFT ENCARTA 96 ENCYCLOPEDIA (1996). Microsoft Corporation.
} 


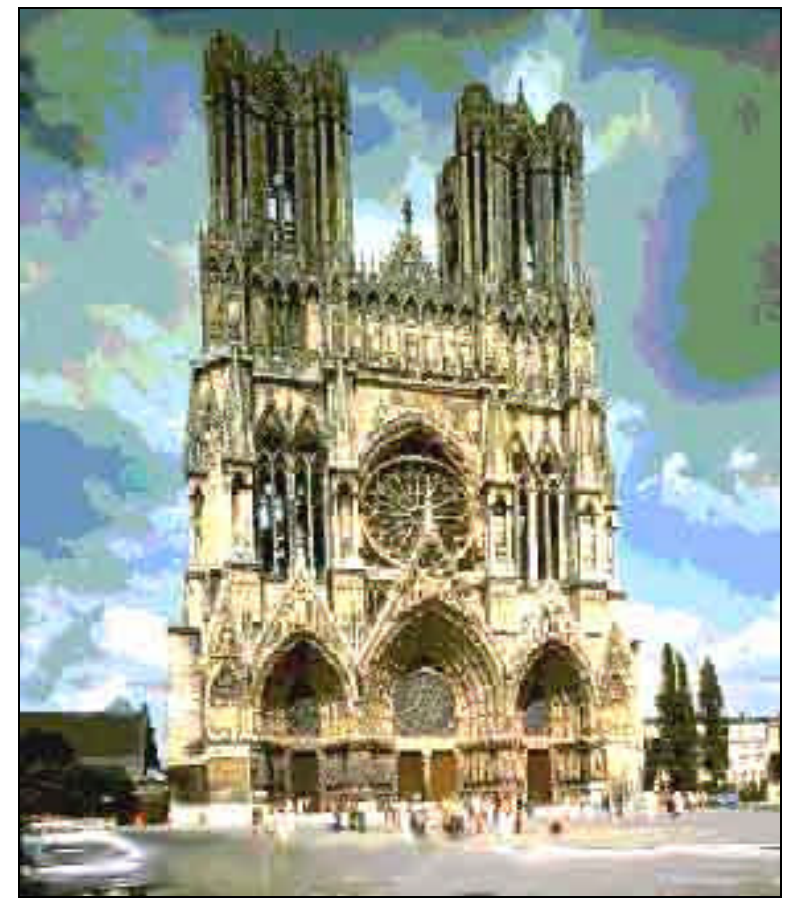

FIGURA 1.2 - Catedral de Reims ${ }^{2}$

Apesar do uso intenso da alvenaria, apenas no início de presente século, por volta de 1920, passou-se a estudá-la com base em princípios científicos e experimentação laboratorial. Esta postura possibilitou o desenvolvimento de teorias racionais que fundamentam a arte de se projetar em alvenaria estrutural.

A partir daí, edifícios cujas paredes tinham espessuras exorbitantes $(\sim 1,80 \mathrm{~m})$, como o Monadnock Building (Figura 1.3), construído em Chicago no final do século XIX, cederam lugar a edifícios com paredes mais esbeltas.

${ }^{2}$ MICROSOFT ENCARTA 96 ENCYCLOPEDIA (1996). Microsoft Corporation. 


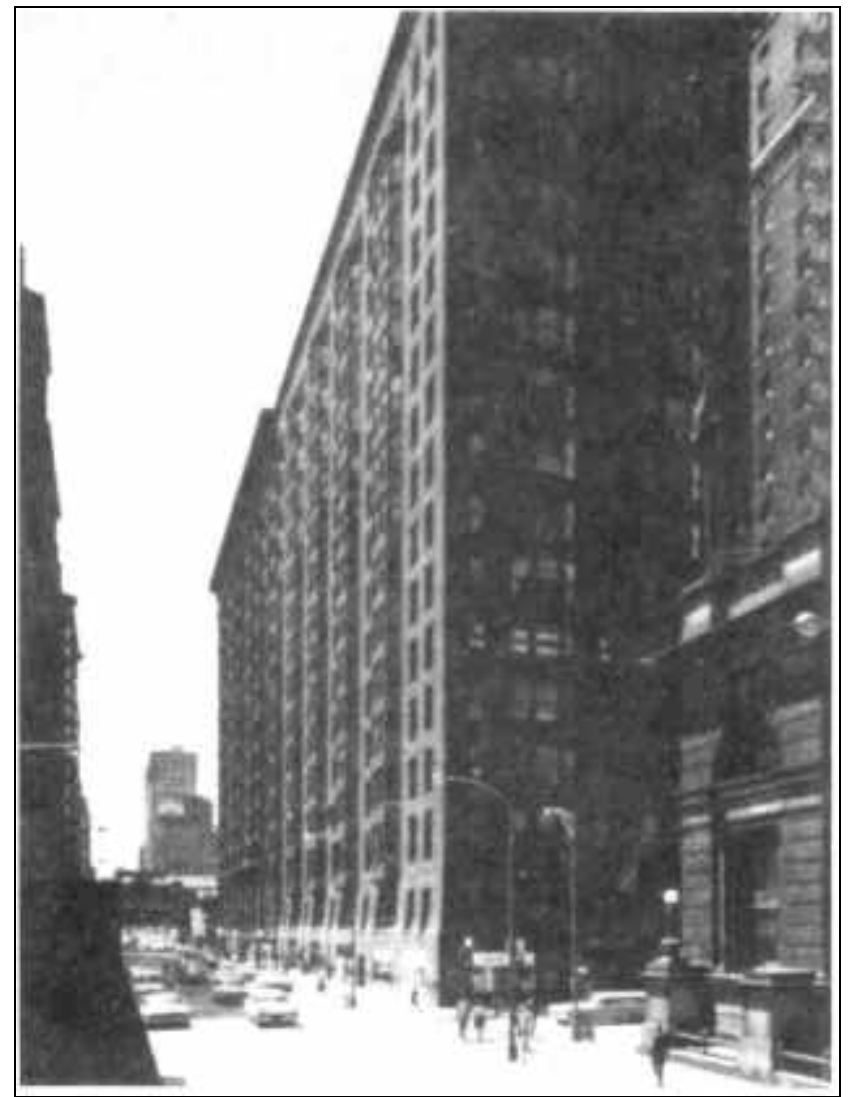

FIGURA 1.3 - Monadnock Building [ASSOCIAÇÃO BRASILEIRA DA CONSTRUÇÃO INDUSTRIALIZADA (1990)]

Com a utilização do concreto armado e do aço estrutural, que possibilitaram a construção de edifícios com peças de reduzidas dimensões, a utilização da alvenaria dirigiu-se, prioritariamente, às edificações de pequeno porte.

$\mathrm{Na}$ década de 50 a utilização da alvenaria ganhou novo impulso, após a realização de uma série de experimentações na Europa. Em 1951, Paul Haller dimensionou e construiu na Suíça um edifício de 13 pavimentos em alvenaria nãoarmada, com paredes internas de $15 \mathrm{~cm}$ de espessura e externas de $37,5 \mathrm{~cm}$. Muitos edifícios foram construídos na Inglaterra, Alemanha e Suíça, e também nos Estados Unidos, onde a alvenaria estrutural passou a ser empregada mesmo em zonas sujeitas a abalos sísmicos, sendo neste caso utilizada a alvenaria armada.

No Brasil, após a sua implantação em 1966, quando em São Paulo foram construídos alguns prédios de quatro pavimentos, o desenvolvimento da alvenaria estrutural tem se dado de maneira lenta e reservada. Isso tem ocorrido não 
obstante o seu caráter econômico, especialmente associado ao fato de se utilizarem as paredes não apenas como elementos de vedação, mas também, como elementos portantes. Por muitos anos a alvenaria estrutural foi pouco utilizada devido a muitos fatores, tais como: preconceito, maior domínio da tecnologia do concreto armado por parte de construtores e projetistas e pouca divulgação do assunto nas universidades durante o processo de formação do profissional. Muitos projetistas são leigos no que se diz respeito a este sistema construtivo e acabam, assim, optando pelo concreto armado. Isto é também influenciado pelo reduzido número de publicações sobre o assunto em português, pois a maior parte da bibliografia é estrangeira e voltada para as peculiaridades de cada país.

Com este trabalho está-se procurando contribuir para o aumento do acervo técnico em alvenaria estrutural, de uma forma simples e objetiva, buscando enfatizar as fases naturais de desenvolvimento do projeto estrutural.

\subsection{Objetivos do trabalho}

Um dos objetivos do presente trabalho foi a produção de um texto que possa ser utilizado como auxiliar nos cursos de graduação em Engenharia Civil, no tema projetos de edifícios em alvenaria estrutural.

Além disto, pretende-se que esta dissertação possa auxiliar projetistas de alvenaria estrutural, funcionando como um texto simples que assinale os principais pontos do desenvolvimento do projeto estrutural. Além dos aspectos teóricos mais importantes sobre o assunto, foram discutidas as alternativas de desenvolvimento com que o projetista depara, buscando contribuir nas tomadas de decisão.

\subsection{Justificativas}

Atualmente, percebe-se uma tendência irreversível de construção de edifícios em alvenaria estrutural. Muitas construtoras brasileiras, com forte concentração no interior do estado de São Paulo, têm percebido a vantagem deste sistema construtivo. A redução de formas, armação e revestimentos, a possibilidade de pré-fabricação de muitos componentes estruturais, a limpeza do canteiro de obras, a redução de desperdícios e a diminuição dos procedimentos em 
obra, notadamente quando do emprego da alvenaria não-armada, têm incentivado tal procura.

Como qualquer sistema construtivo, este também possui algumas limitações. Entre elas pode-se dizer que exige mão-de-obra qualificada, impede a execução de reformas que alterem a disposição das paredes estruturais, além do que a concepção estrutural pode acabar condicionando o projeto arquitetônico.

É crescente o interesse de projetistas, construtores e proprietários. Mesmo sem o domínio da tecnologia necessária, as iniciativas privada e estatal vêm, ao longo dos anos, descobrindo na alvenaria estrutural uma alternativa muito competitiva para a construção de habitações.

Desde sua implantação, a alvenaria estrutural passou a ser empregada sem que se dispusesse de normalização adequada nem métodos eficientes que visassem o controle de qualidade do processo e dos produtos envolvidos. Sendo assim, muitas vezes, as técnicas de execução usadas são produto da transmissão oral e os métodos de concepção e projeto baseiam-se em normas nacionais pouco consolidadas ou na aplicação de normas estrangeiras baseadas em outras condições e critérios. A falta de mecanismos como estes tem comprometido as edificações, principalmente devido à ocorrência generalizada de patologias.

O tema alvenaria estrutural foi escolhido por ser bastante atual e por exigir maiores contribuições por parte do meio universitário.

\subsection{Organização do trabalho}

Antes de iniciar o cálculo estrutural, o projetista deve estabelecer algumas definições a respeito de utilização de materiais, técnicas construtivas e procedimentos de projeto, sendo muitas vezes obrigado a tomar decisões a respeito da escolha de uma entre várias alternativas.

É sabido que as tomadas de decisão são feitas usualmente, tendo este trabalho o intuito de apenas aglutiná-las e fornecer orientações em cada caso. É claro que não se tem a pretensão de abordar todos os aspectos que gerem tomadas de decisão, mas sim alguns considerados essenciais.

No capítulo 2 serão levantados alguns itens com que se depara o projetista estrutural ao receber o projeto arquitetônico, e buscar-se-á orientar nas definições 
preliminares. Dentro destas definições serão abrangidas as questões da armação de paredes, da modulação, de técnicas construtivas e da utilização de elementos pré-moldados.

No capítulo 3 serão mostrados critérios para fazer a concepção estrutural de um edifício, discutindo temas como espessura das lajes, rebaixos e utilização ou não de armaduras negativas nas mesmas. Também serão abordadas questões relativas à determinação das ações atuantes e sua distribuição ao longo do edifício. Para isto, serão feitos alguns exemplos ilustrando diversos procedimentos de distribuição de ações verticais e horizontais.

Determinados os esforços e tensões atuantes nas paredes estruturais, no capítulo 4 será mostrado como fazer o dimensionamento de todos os elementos, sendo a teoria acompanhada, sempre que possível, de exemplos ilustrativos. É importante destacar que o dimensionamento será baseado no Método das Tensões Admissíveis, o mesmo utilizado pela ABNT (NBR-10837). Além disso, este capítulo tratará dos efeitos de segunda ordem nos edifícios em alvenaria estrutural.

O capítulo 5 resumirá, em forma de exemplos práticos, toda a teoria apresentada nos capítulos anteriores e mostrará como são feitas, na prática, as tomadas de decisão, baseadas nas orientações fornecidas no decorrer do trabalho. Para os exemplos será utilizada uma planta de um edifício em alvenaria estrutural, alternando o número de pavimentos e o tipo de procedimento de distribuição de ações verticais. Com isso, obter-se-á várias alternativas de resolução, e o objetivo será compará-las e optar pelo melhor resultado, em termos de segurança e economia. Além disso, como procedimento de projeto, será efetuado o dimensionamento dos elementos estruturais.

Finalmente, no capítulo 6, serão expostas as conclusões do trabalho. 


\section{DEFINIÇõES PRELIMINARES}

O projetista estrutural, ao receber o projeto arquitetônico de um edifício em alvenaria estrutural, deve, antes de iniciar os cálculos, tomar certas decisões a respeito de itens fundamentais relativos ao projeto, sem as quais não poderá iniciar seu trabalho. Estas decisões são pontos de partida, e, a maioria delas, opções que deverão ser feitas buscando sempre a melhor alternativa, dentro de cada projeto.

Nesse sentido, serão levantados neste capítulo alguns itens com os quais se depara o projetista e buscar-se-á fornecer orientações em cada caso.

\subsection{Alvenaria armada ou não-armada}

Segundo a ABNT (NBR-10837), alvenaria estrutural não-armada de blocos vazados de concreto é "aquela construída com blocos vazados de concreto, assentados com argamassa, e que contém armaduras com finalidade construtiva ou de amarração, não sendo esta última considerada na absorção dos esforços calculados". Já alvenaria estrutural armada de blocos vazados de concreto, segundo a mesma referência, é "aquela construída com blocos vazados de concreto, assentados com argamassa, na qual certas cavidades são preenchidas continuamente com graute, contendo armaduras envolvidas o suficiente para absorver os esforços calculados, além daquelas armaduras com finalidade construtiva ou de amarração". 
Recomenda-se intensificar o uso da alvenaria não-armada sempre que possível, pois não se têm sismos no país, tomando o cuidado de não apenas absorver a tradição americana. Nos EUA, as normas americanas obrigam os projetistas a empregarem sempre a alvenaria armada, mesmo em edifícios baixos, devido à presença de sismos naquele país. A alvenaria não-armada não é, portanto, utilizada.

É consenso entre construtores que um edifício em alvenaria estrutural nãoarmada pode ficar mais econômico que o mesmo executado em estrutura convencional. Além disso, é preciso salientar que as alvenarias não-armadas são de mais simples execução, uma vez que não exigem grauteamento. $O$ grauteamento exige interrupção do trabalho de assentamento das paredes, sendo que o tempo necessário para grautear é equivalente ao tempo necessário para levantar a parede. Outro problema decorrente do grauteamento é que ele prejudica a passagem das instalações elétricas nos vazados dos blocos.

Existe uma regra empírica, utilizada por projetistas, a qual sugere que a resistência à compressão dos blocos nos primeiros pavimentos de um edifício pode ser dada pela quantidade de pavimentos do mesmo. Para a utilização desta regra, a resistência deve ser referida à área bruta do bloco e deve ser expressa em MPa. Por exemplo, se um edifício tiver 6 pavimentos, então o bloco de maior resistência utilizado seria, então, o de 6,0 MPa. Esta regra é válida somente para prédios com mais de 4 (quatro) pavimentos, pois a resistência mínima de um bloco estrutural é 4,5 MPa.

No caso dos edifícios de alvenaria não-armada mais comuns, de até 10 (dez) pavimentos, o bloco utilizado para os primeiros pavimentos, segundo a regra anterior, seria o de 10,0 $\mathrm{MPa}$. Este bloco, entretanto, é encontrado atualmente no mercado com maior facilidade nas dimensões horizontais múltiplas de $20 \mathrm{~cm}$, levando com isso o projetista a escolher para estes edifícios a modulação M20, a qual será melhor detalhada no próximo subitem. Apesar dos blocos com resistências elevadas serem encontrados mais facilmente na modulação M20, existe atualmente uma crescente oferta de blocos de resistências elevadas na modulação M15. Por isso, vê-se que há uma necessidade de consulta aos fabricantes por parte do projetista estrutural. Além disso, é importante que haja uma interação do projetista estrutural com o arquiteto durante a fase de elaboração do projeto arquitetônico, pois a escolha da modulação define as dimensões possíveis a serem utilizadas no projeto. 
A armação de paredes é sempre necessária quando as tensões de tração superam os valores admissíveis indicados na ABNT (NBR-10837), que, por sinal, são relativamente baixos. Desde que isto não aconteça, não parece indicado utilizar armadura. Em geral, as armaduras são utilizadas nos prédios mais elevados, onde as ações horizontais provenientes do vento e do desaprumo são mais significativas.

Com relação à resistência à compressão, será feito a seguir um estudo comparativo, baseado na ABNT (NBR-10837), entre paredes armadas e nãoarmadas. O objetivo este estudo é mostrar numericamente o acréscimo de resistência quando do emprego da armadura. Cabe ressaltar que não se tem a pretensão de indicar todos os detalhes relativos ao dimensionamento, mas apenas mostrar o acréscimo de resistência à compressão referente à armadura.

Segundo a ABNT (NBR-10837), as tensões admissíveis em paredes de alvenaria não-armada devem ser calculadas pela seguinte expressão:

$$
\bar{f}_{\text {alv,c }}=0,20 f_{p}\left[1-\left(\frac{h}{40 t}\right)^{3}\right]
$$

onde:

$$
\begin{aligned}
& f_{p}=\text { resistência média dos prismas } \\
& h=\text { altura efetiva } \\
& t=\text { espessura efetiva }
\end{aligned}
$$

Para paredes de alvenaria armada, a norma estabelece que as tensões admissíveis em paredes resistentes com armadura mínima não devem exceder 0 valor determinado pela seguinte expressão:

$$
\bar{f}_{\text {alv }, c}=0,225 f_{p}\left[1-\left(\frac{h}{40 t}\right)^{3}\right]
$$


onde:

$$
\begin{aligned}
& f_{p}=\text { resistência média dos prismas cheios }(\text { se } \rho \geq 0,2 \%) \\
& h=\text { altura efetiva } \\
& t=\text { espessura efetiva }
\end{aligned}
$$

Comparando a expr. (2.1) com a expr. (2.2) conclui-se que o ganho de resistência à compressão com o emprego da alvenaria armada (12,5\%) é inexpressivo, o que sugere, mais uma vez, o emprego de alvenaria não-armada sempre que possível.

\subsection{Modulação}

\subsubsection{Tipo de bloco}

A primeira definição a ser feita é o tipo de bloco que será utilizado. Para tanto, devem ser consideradas todas as características dos materiais e produtos existentes no mercado onde será construído o edifício, para que seja tomada uma decisão segura, econômica e com um conforto ambiental adequado à finalidade a que se destina. Existem os blocos cerâmicos, os blocos de concreto, os blocos sílico-calcáreos, os blocos de concreto celular, com as mais variadas dimensões e resistências.

No Brasil, a maioria das construções em alvenaria estrutural é feita com blocos de concreto. A vantagem desta opção é que as normas brasileiras de cálculo e execução em alvenaria estrutural são apropriadas para esses blocos, talvez por influência da tecnologia americana, em lugar da européia. No caso de se utilizarem blocos cerâmicos é necessário fazer certas adaptações nos coeficientes das normas ou mesmo consultar normas internacionais, como, por exemplo, a BS 5628/78.

O bloco cerâmico, apesar de ser menos utilizado, tem como vantagem o aspecto estético da construção, permitindo, em alguns casos, reduzir ou dispensar revestimentos. Além disso, são mais leves que os blocos de concreto, facilitando com isso seu manuseio na obra, uma vez que os pedreiros normalmente seguramnos com apenas uma das mãos e necessitam de agilidade para assentá-los, para não prejudicar o ritmo da produção. $O$ fato de serem mais leves implica também 
em menor ação sobre a fundação, o que também é vantajoso, do ponto de vista econômico.

A escolha pelo tipo de bloco deve ser do construtor, apoiado pelo projetista. Isto vai depender do conforto que se deseja aos usuários, dos aspectos mercadológicos (oferta nos aspectos dimensão, resistência e tipos), comerciais e culturais. As características mecânicas do bloco também interferem na escolha, por exemplo: os blocos vazados são melhores que os perfurados para a passagem das instalações; as paredes maciças são mais fáceis de serem assentadas que as vazadas ou perfuradas.

\subsubsection{Amarração de paredes}

Estudos realizados por CORRÊA \& RAMALHO (1989) ${ }^{3}$, mediante modelagem por elementos finitos, demonstram a grande influência das amarrações entre paredes estruturais na distribuição de tensões, o que consiste num dos mecanismos essenciais do seu desempenho estrutural, tanto da capacidade portante individual dos painéis, como do conjunto da edificação.

$\mathrm{Na}$ modulação de uma planta deve-se procurar, sempre que possível, amarrar duas ou mais paredes que se encontrem. Esta amarração garante a transmissão de ações de uma parede para outra, o que alivia uma parede muito carregada e acrescenta tensões em outra menos carregada, promovendo uniformização de tensões. Esta uniformização é ótima para a economia, pois a resistência dos blocos de um pavimento é dada pela tensão atuante na parede mais solicitada, já que não se usam blocos com resistências diferentes em um mesmo pavimento, por razões operacionais.

A amarração de paredes contribui na prevenção do colapso progressivo, pois provê a estrutura de caminhos alternativos para transferência de forças no caso de ocorrência de uma ruína localizada provocada por uma ação excepcional. Além disso, a amarração serve de contraventamento para as paredes.

${ }^{3}$ CORRÊA, M. R. S. ; RAMALHO, M. A. (1989). Projeto girassol. / $5^{\circ}$ Relatório elaborado para a ENCOL S.A. / 
Segundo a ABNT (NBR-10837), item 5.4.9, a união e solidarização de paredes que se cruzam podem ocorrer por um dos seguintes métodos: amarração direta ou amarração indireta.

A amarração direta é feita através da própria disposição dos blocos nas fiadas, com $50 \%$ deles penetrando alternadamente na parede interceptada (Figura 2.1).

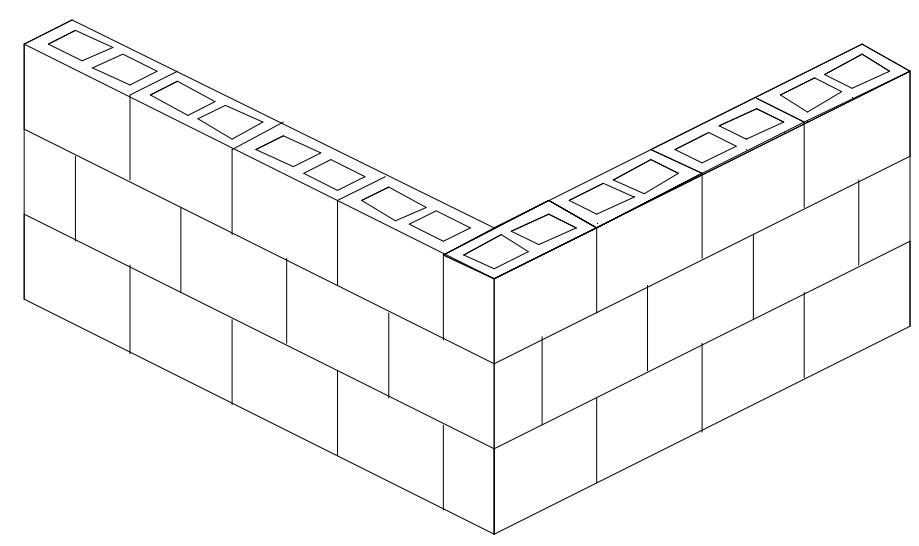

FIGURA 2.1 - Amarração direta de paredes

No caso de união de mais de duas paredes, a amarração pode ser feita de duas formas: através da "seqüência de fiadas" (Figura 2.2) ou através da utilização do "bloco e meio" (Figura 2.3). Nestas figuras optou-se por representar os blocos da modulação M15; contudo, deve-se atentar para o fato de que, na M20, o bloco de 34 aparece na seqüência de fiadas, e também que existe o bloco e meio de 54

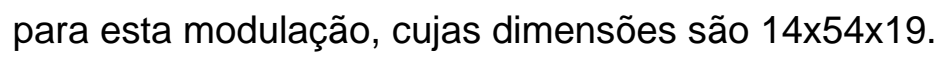




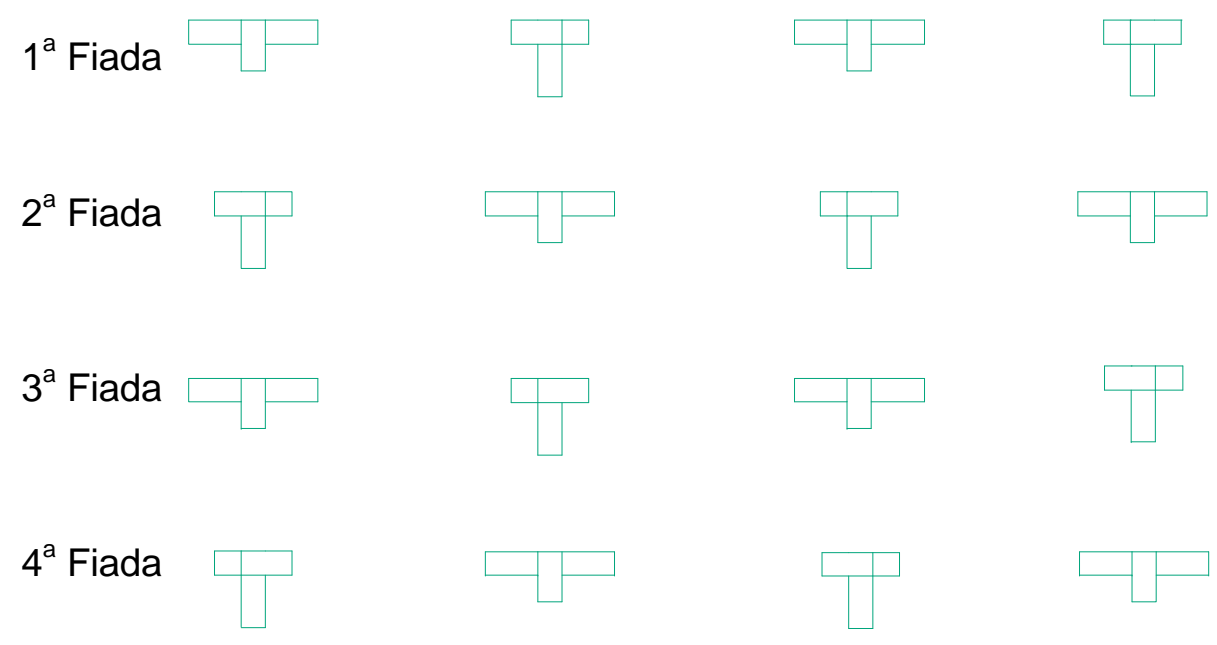

FIGURA 2.2 - Seqüência de fiadas

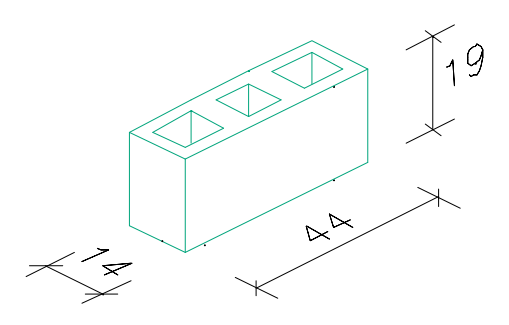

FIGURA 2.3 - Bloco e meio (14X44X19)

A seqüência de fiadas foi elaborada de tal forma que uma junta a prumo não persista em um mesmo alinhamento vertical por mais de três fiadas consecutivas.

O bloco e meio é um bloco especial oferecido nas dimensões $14 \times 44 \times 19$, quando utilizado na modulação $M 15$, e nas dimensões $14 \times 54 \times 19$, quando utilizado na modulação M20, para paredes com espessura $15 \mathrm{~cm}$ (bloco + argamassa).

O emprego da seqüência de fiadas implica na existência de quatro fiadas diferentes nos cantos, o que proporciona um pequeno trabalho adicional para o projetista, porém um bem maior para os funcionários da obra, havendo necessidade de um perfeito detalhamento do projeto a fim de se evitarem erros de 
execução. Já com o bloco e meio, pode-se trabalhar apenas com duas fiadas diferentes, inclusive nos cantos, sendo ele, portanto, a opção mais favorável, se acessível ao construtor. É preciso salientar que o bloco e meio promove uma ligação mais eficiente que a seqüência de fiadas. Pelo fato de ser um componente com características similares aos demais, não incorre em dificuldades para sua produção ou execução. Deve-se observar, entretanto, que nem sempre os fabricantes de blocos estruturais oferecem este tipo de bloco. Faz-se aqui um alerta quanto ao peso do bloco e meio para a parte operacional, principalmente o bloco de 54, o que pode dificultar o andamento da construção, uma vez que os pedreiros têm que segurá-lo com apenas uma das mãos para poder levantá-lo.

Encontra-se a seguir a modulação de parte de uma planta utilizando blocos 14×29x19, feita primeiramente empregando a seqüência de fiadas (Figuras 2.4) e posteriormente o bloco e meio (Figuras 2.5). Apresentam-se, no $1^{\circ}$ caso, apenas as modulações das $1^{\mathrm{a}}$ e $2^{\mathrm{a}}$ fiadas, ficando subentendidas as $3^{\mathrm{a}}$ e $4^{\mathrm{a}}$ fiadas (diferentes nos cantos) pela seqüência de fiadas mostrada na Figura 2.2.

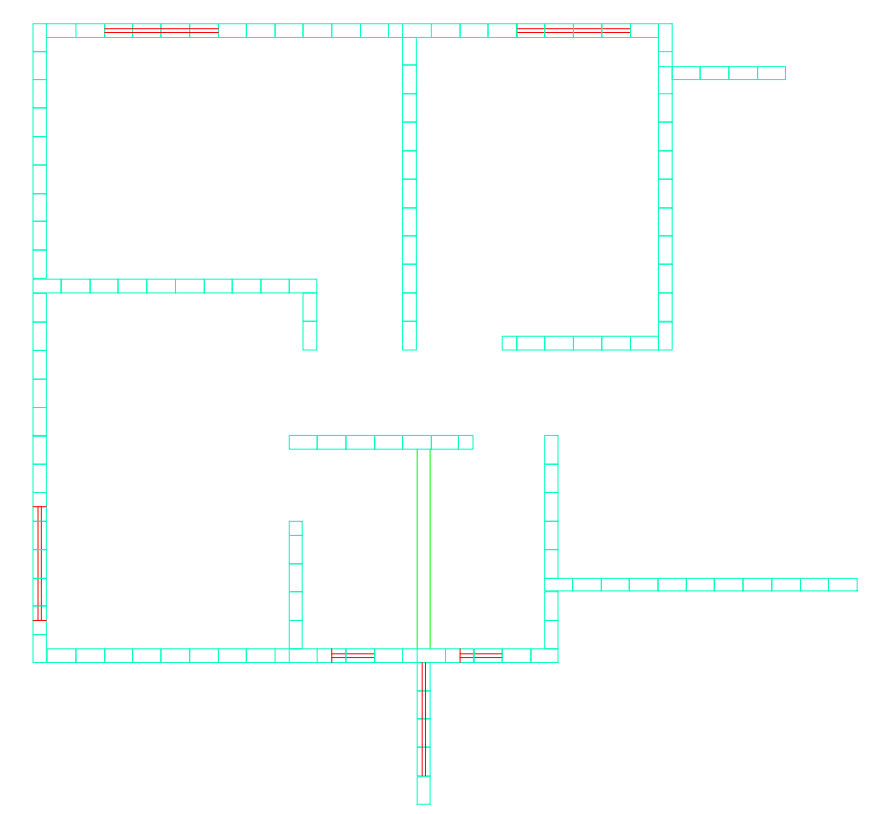

FIGURA $2.4 a$ - Seqüência de fiadas - $1^{a}$ fiada 


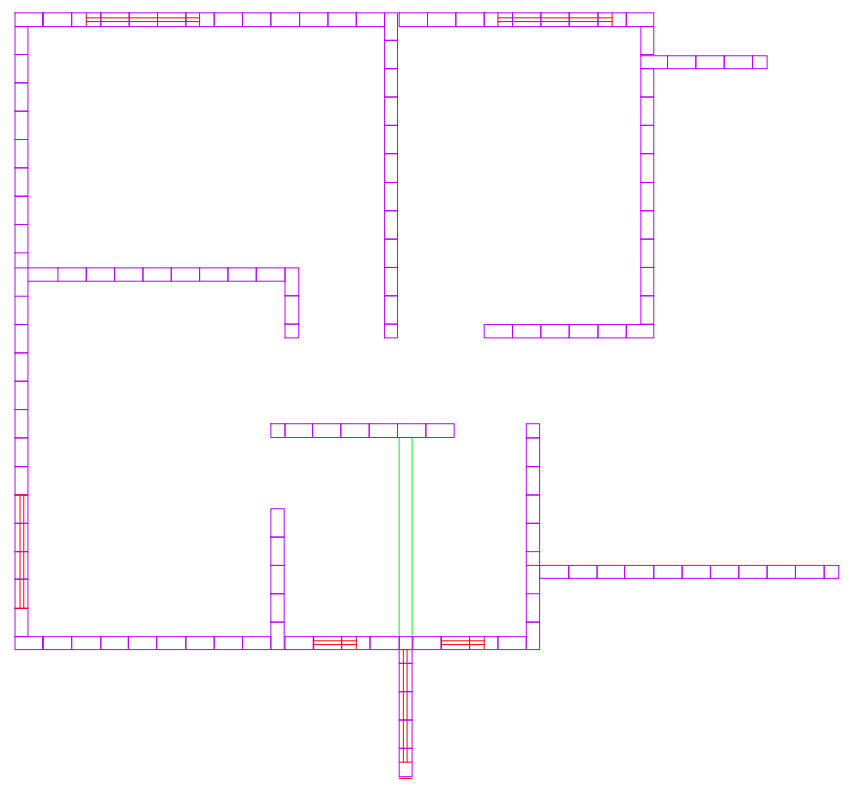

FIGURA 2.4b - Seqüência de Fiadas $-2^{a}$ fiada

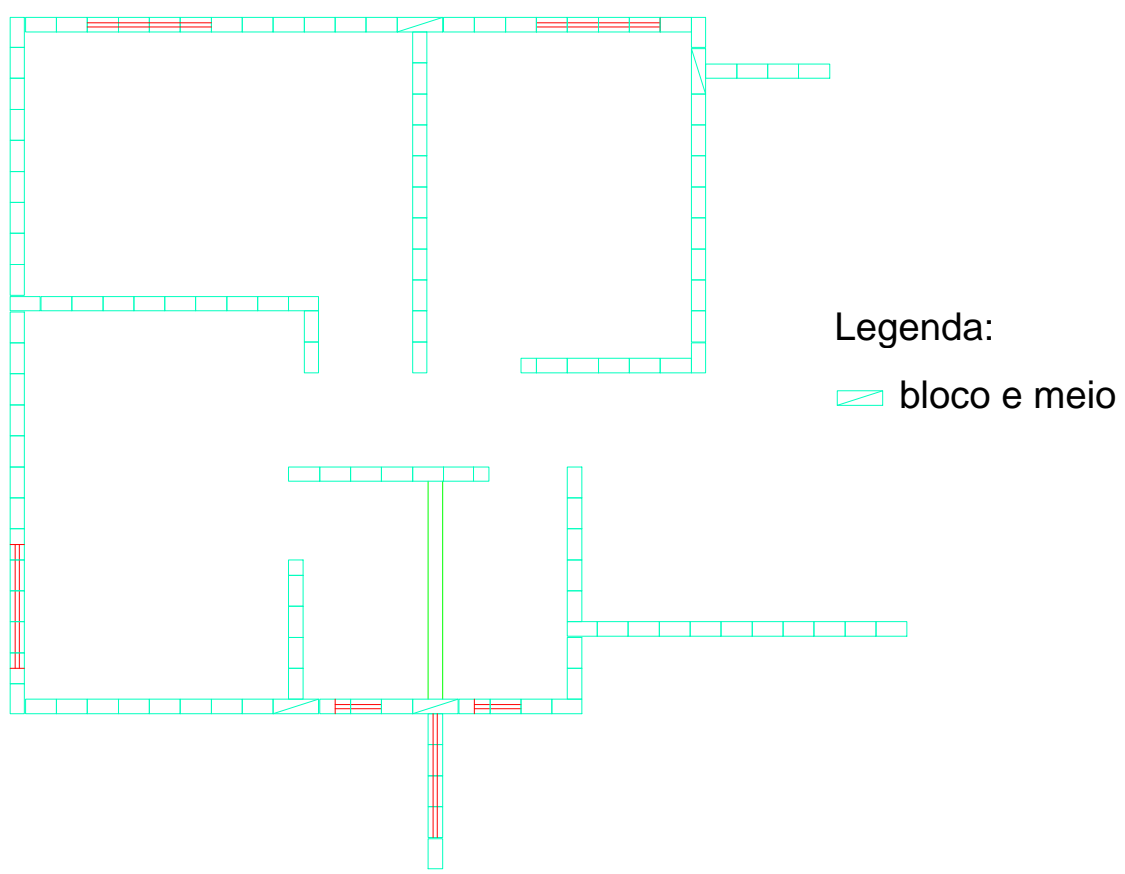

FIGURA 2.5a - Bloco e meio - $1^{\mathrm{a}}$ fiada 


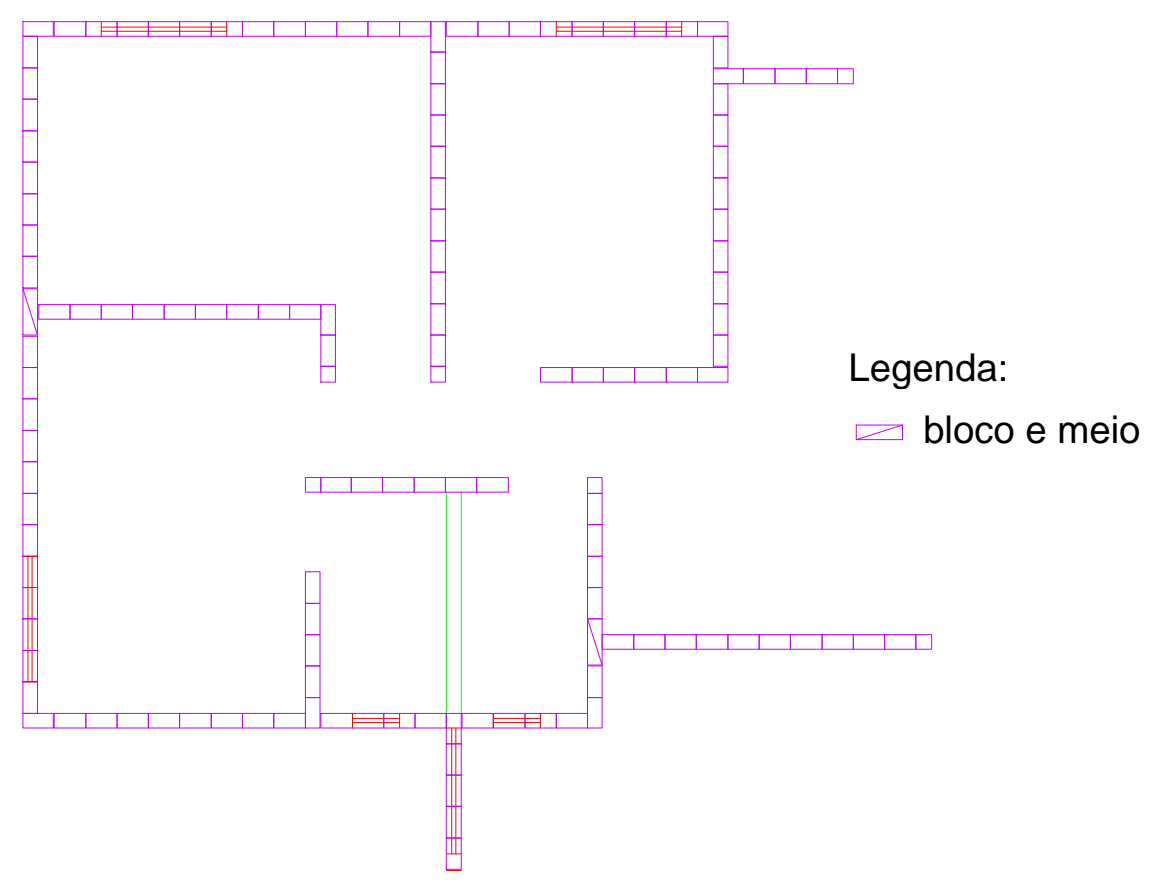

FIGURA 2.5b - Bloco e meio - $2^{\mathrm{a}}$ fiada

Em determinadas ocasiões não se consegue fazer a modulação com todas as paredes amarradas, ocasionando com isto algumas juntas a prumo (JP) devido às dimensões da arquitetura não serem compatíveis com a modulação. A Figura 2.6 retrata um exemplo onde ocorre este tipo de situação.

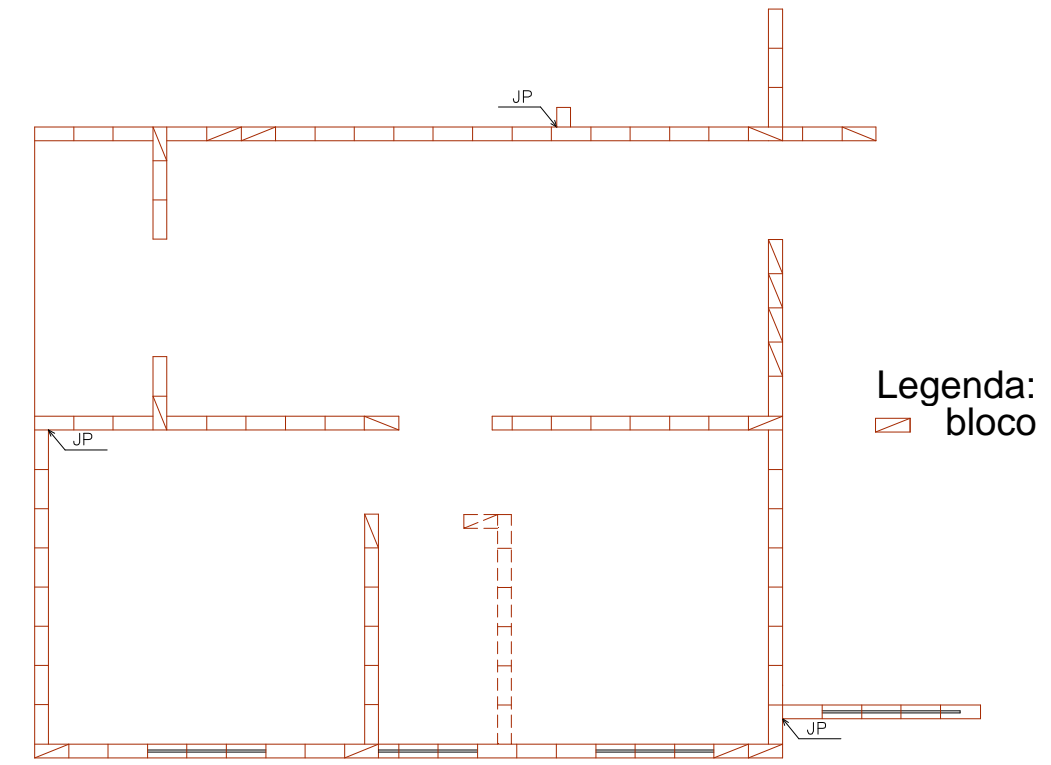

FIGURA 2.6 - Juntas a prumo na modulação 
Nestes casos, a ABNT (NBR-10837) recomenda a amarração indireta para as paredes, na qual se utilizam barras metálicas convenientemente dispostas ou em forma de treliças soldadas, ou mesmo peças em forma de chapa metálica de resistência comprovada. Estas ligações devem ser feitas à distância máxima de três fiadas umas das outras. Um exemplo deste tipo de amarração é o uso de armaduras em forma de ganchos unindo as duas paredes (Figura 2.7). Outra opção é a utilização de telas metálicas na junta de assentamento, que têm a vantagem, em relação à anterior, de melhor manutenção da posição. Contudo, não se pode assegurar que estas paredes trabalhem em conjunto, pois este artifício não proporciona uma amarração perfeita. Apesar de muitos projetistas confiarem neste tipo de amarração, não há resultados experimentais que assegurem a eficiência desta ligação. As armaduras, nestes casos, funcionam como redutoras de fissuração.

\section{ELEVAÇÃO}
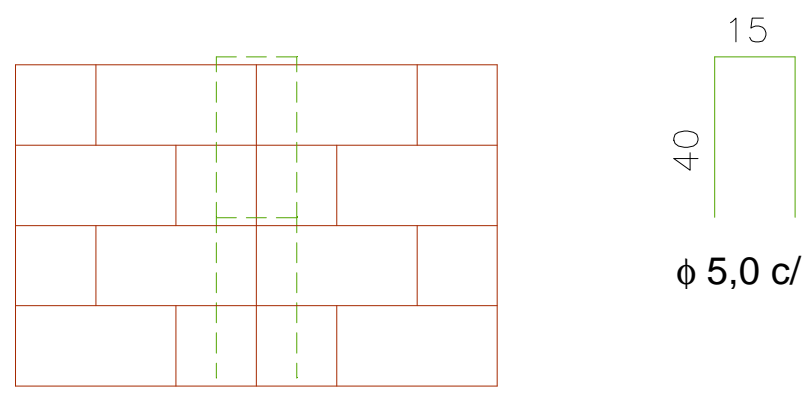

$\phi 5,0 \mathrm{c} / 40$

\section{PLANTA}

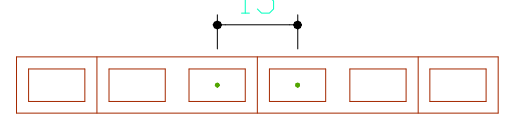

FIGURA 2.7 - Ligação de paredes estruturais com JP

Existe, também, junta a prumo em locais de união de paredes estruturais com paredes não-estruturais. Nestes casos, é oportuna a disposição, no mínimo a cada três fiadas, de armaduras horizontais na argamassa nos locais de união das paredes, com o objetivo de se evitarem fissuras nessas regiões (Figura 2.8). Existe 
também a opção de se utilizarem telas metálicas na junta de assentamento, que são mais eficientes.

Segundo a ABNT (NBR-10837), item 5.4.3.1.3, o diâmetro desta armadura não deve exceder a metade da espessura da camada de argamassa $(1,0 \mathrm{~cm}) \mathrm{na}$ qual a barra está colocada, ou seja, diâmetro máximo $5 \mathrm{~mm}$. Já no item 5.2.3.1.3 da mesma norma, que trata de alvenaria armada, fica estabelecido que as armaduras em paredes com barras de diâmetro máximo igual a 6,3 mm podem ser colocadas na argamassa e consideradas como parte da armadura necessária. Fica aqui, portanto, uma crítica à norma, por seu aspecto dúbio.

Como orientação, nestes casos de ligação de paredes estruturais com JP, recomenda-se utilizar armadura $\phi 5 \mathrm{~mm}$ nas duas faces longitudinais do bloco, sendo também aceitável $\phi 6,3 \mathrm{~mm}$ como alternativa.

\section{PLANTA}

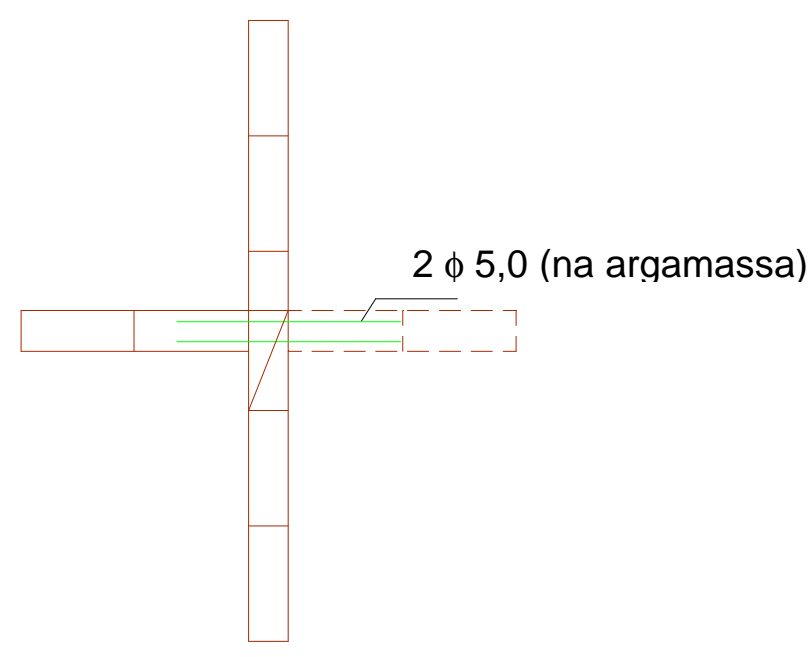

\section{ELEVAÇÃO}

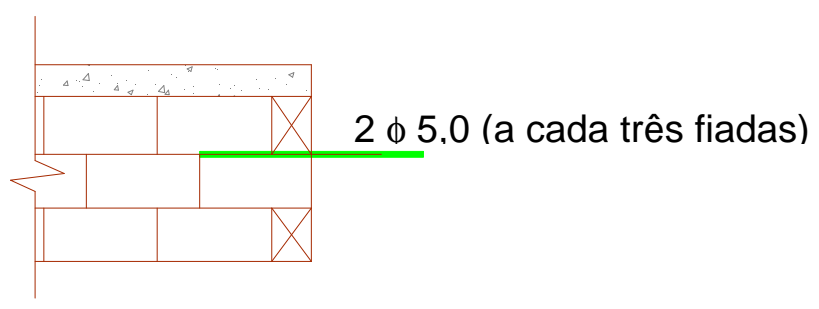

FIGURA 2.8 - Ligação de parede estrutural com parede não-estrutural 
Apesar de comprovado o fato que amarrar paredes estruturais seja a melhor solução do ponto de vista de uniformização de tensões e de monolitismo da edificação, há ainda construtores que preferem fazer junta a prumo em todo encontro de paredes. Obviamente, a obra fica muito mais onerosa quanto ao consumo de armadura e graute. As razões que os levam a tomar essa decisão são, geralmente, a mão-de-obra disponível. Alguns pedreiros preferem evitar a amarração, argumentando ser este um procedimento demorado, pois as paredes não podem ser executadas independentemente umas das outras.

\subsubsection{Tipo de modulação}

Definidos o material do bloco e a forma de união das paredes, parte-se para a modulação propriamente dita.

Dentre a enorme variedade de blocos com relação às suas dimensões, em geral opta-se pela modulação com blocos de comprimento múltiplo de $15 \mathrm{~cm}$ (M15) ou pela modulação com blocos de comprimento múltiplo de $20 \mathrm{~cm}$ (M20). Em determinadas ocasiões, quando a maior dimensão do bloco não é múltipla de nenhum destes dois números, pode optar-se por outras modulações, como por exemplo com o bloco de $24 \mathrm{~cm}$ pode utilizar a M12.

Deve-se ressaltar que a nomenclatura utilizada acima (M15, M20) não é a mesma utilizada pela ABNT (NBR-6136), na qual o módulo se refere à largura do bloco. Cabe salientar que a norma está ultrapassada, pois não contempla as dimensões dos blocos que normalmente são empregados, nem mesmo se refere aos blocos de comprimento $30 \mathrm{~cm}$.

No caso das dimensões do projeto arquitetônico não serem modulares, quanto menor o módulo utilizado mais fácil é o ajuste necessário. Nesse sentido a M15 é mais adequada, já que a ABNT (NBR-10837) no seu item 5.4 fixa, tanto para alvenaria armada como para alvenaria não-armada, espessura mínima de parede $14 \mathrm{~cm}$. Esta prescrição, portanto, elimina a possibilidade de emprego da M12 para blocos vazados de concreto, em edifícios com mais de dois pavimentos. Além disso, pode-se ressaltar a falta de adequabilidade da M20 quando a espessura dos blocos é $14 \mathrm{~cm}$, pois o comprimento dos mesmos não é múltiplo de sua espessura.

A seguir será apresentado um pequeno exemplo de modulação de parte de um pavimento de edifício cujos compartimentos têm dimensões internas não 
modulares (Figuras 2.9). Como geralmente as paredes internas são definidas na arquitetura com espessura $15 \mathrm{~cm}$, usar-se-ão blocos de espessura $14 \mathrm{~cm}$, a fim de que este exemplo retrate uma situação típica.

O exemplo será feito primeiramente utilizando blocos $14 \times 29 \times 19$ e

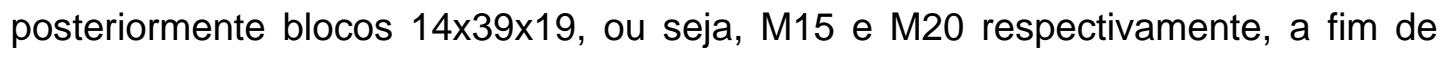
que se possam comparar os dois tipos de modulação.

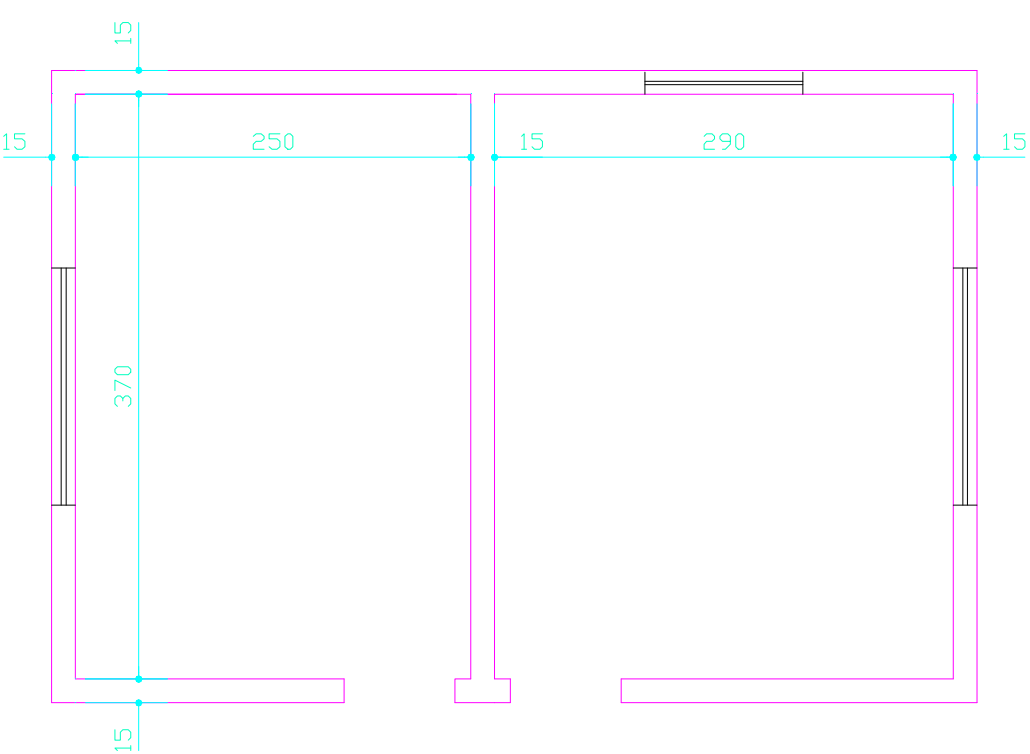

FIGURA 2.9a - Arquitetura 


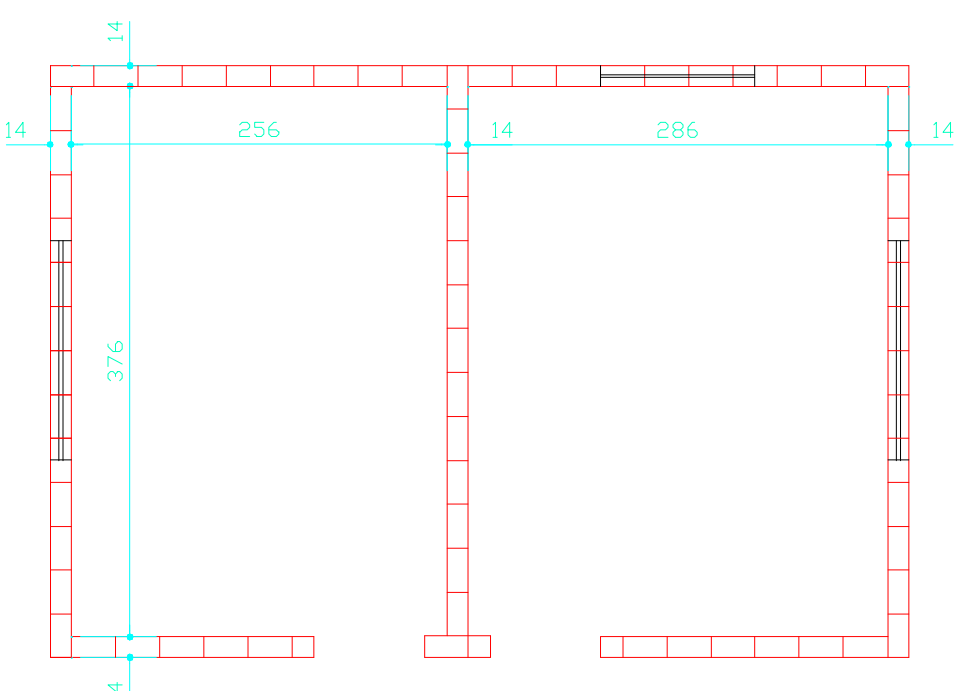

FIGURA 2.9b - M15 (blocos 14x29x19)

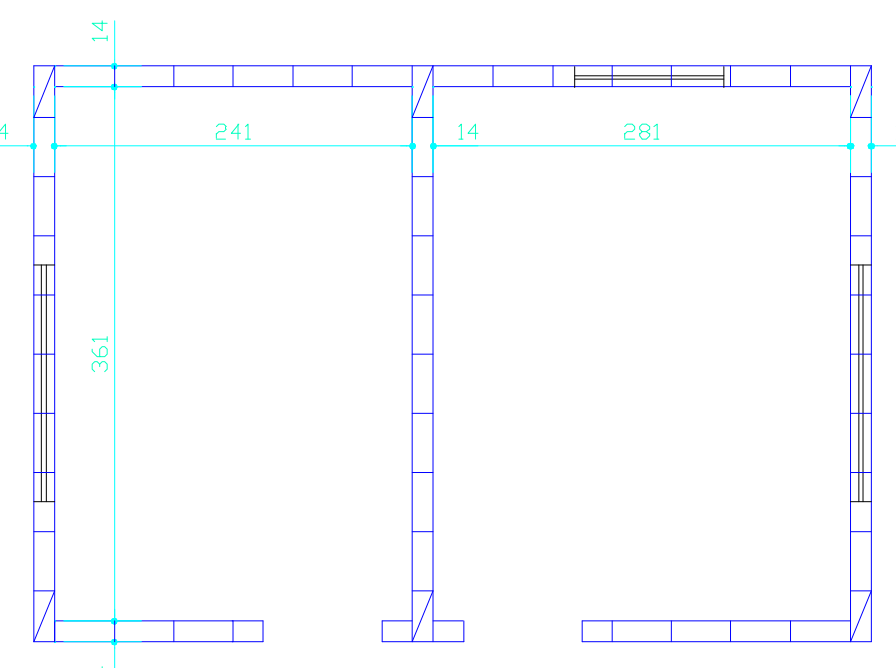

FIGURA 2.9c - M20 (blocos 14x39x19)

Pelo que pôde ser observado, na modulação de 20 são necessários blocos especiais de dimensões $14 \times 34 \times 19$ para se fazer a amarração das paredes, os quais encarecem o custo da obra, além de serem outro tipo de bloco presente no canteiro de obras.

Neste exemplo, tomou-se o cuidado de deixar as dimensões modulares o mais próximo possível das da arquitetura, aumentando-as em algumas vezes e 
reduzindo-as em outras. Entretanto, se, por exemplo, a dimensão horizontal do compartimento à esquerda tivesse que ser não inferior a 2,50 m, seria necessário aumentar mais meio bloco $(20 \mathrm{~cm})$ na Figura 9c, passando de 2,41 $\mathrm{m}$ a 2,61 $\mathrm{m}$, o que a tornaria mais distante ainda da dimensão original da arquitetura (2,50 m). Verifica-se, portanto, que as dimensões internas quando do emprego da M15 ficaram mais próximas às da arquitetura do que quando do emprego da M20.

Percebe-se, neste sistema construtivo, que não cabe ao arquiteto definir as dimensões finais dos cômodos, devido ao fato que a estrutura é a parede e os blocos não podem ser cortados, ficando esta função a cargo do projetista estrutural.

A disponibilidade dos blocos existentes no mercado quanto aos quesitos de dimensão e faixa de resistência é outro agravante que interfere na escolha do tipo de modulação a ser empregada.

Para efeito de orientação ao projetista, foi efetuada uma pesquisa junto a alguns fornecedores de blocos de concreto estruturais do Estado de São Paulo, e o resultado das resistências disponíveis nas modulações usualmente empregadas estão mostrados na Tabela 2.1.

TABELA 2.1 - Resistências de blocos estruturais de concreto disponíveis no mercado

\begin{tabular}{|l|l|}
\hline \multicolumn{1}{|c|}{$\mathrm{M} 15$} & \multicolumn{1}{c|}{$\mathrm{M} 20$} \\
\hline $\begin{array}{l}\text { - usual } \\
4,5 \mathrm{MPa} \text { a 6,0 MPa }\end{array}$ & $\begin{array}{l}\text { - usual } \\
4,5 \mathrm{MPa} \text { a 10,0 MPa } \\
\text { - sob encomenda } \\
\text { de 6,0 MPa a 10,0 MPa }\end{array}$ \\
& $\begin{array}{l}\text { sob encomenda } \\
\text { de 10,0 MPa a 20,0 MPa }\end{array}$ \\
\hline
\end{tabular}




\subsubsection{Simetria na modulação}

Ainda com relação à modulação, outro item a ser destacado é o uso ou não de simetria na mesma.

Em geral, o que se faz em edifícios de planta simétrica é modular metade do pavimento e rebatê-la no outro lado, ajustando os pontos de encontro das duas partes. No caso bastante usual dos edifícios de 4 apartamentos por andar, pode-se fazer a modulação de apenas um deles e rebatê-la duas vezes para obter os demais, fazendo pequenos ajustes nas regiões de escada, elevadores e hall.

Existem casos em que, devido às dimensões internas dos compartimentos cortados pelo eixo de simetria, sobra meio bloco justamente no meio da parede central do pavimento. Para se fazer o fechamento do painel, sem a ocorrência de sobreposição de juntas, é preciso que na elevação desta parede se utilize um dos seguintes artifícios: bloco e meio (Figura 2.10a) ou "bloco em trânsito" (Figura 2.10b).

O bloco e meio ocupará os três últimos espaços junto ao fechamento do painel, intercaladamente nas fiadas pares e ímpares. O uso deste bloco fora da zona de encontro de paredes, nos poucos casos onde se fizer necessário o ajuste, mantém a amarração.

Alternativamente, pode-se substituir nas fiadas pares ou ímpares o bloco e meio por um bloco e um meio bloco, que se movimentará ao longo das fiadas, não permitindo a ocorrência de mais de três juntas a prumo consecutivas. É o que se denomina, aqui, "bloco em trânsito". 
PAREDE CENTRAL DO PAVIMENTO
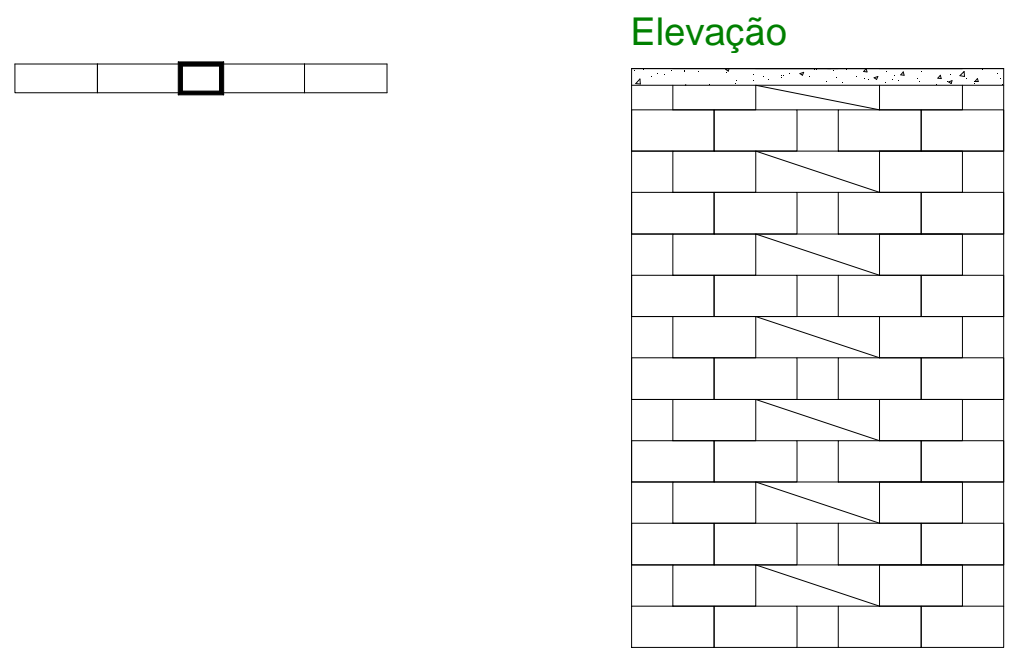

FIGURA 2.10a - Exemplo de situação de fechamento compensada com a utilização do bloco e meio

\section{PAREDE CENTRAL DO PAVIMENTO}

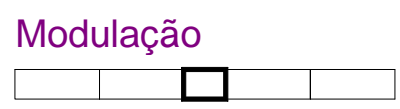

Elevação

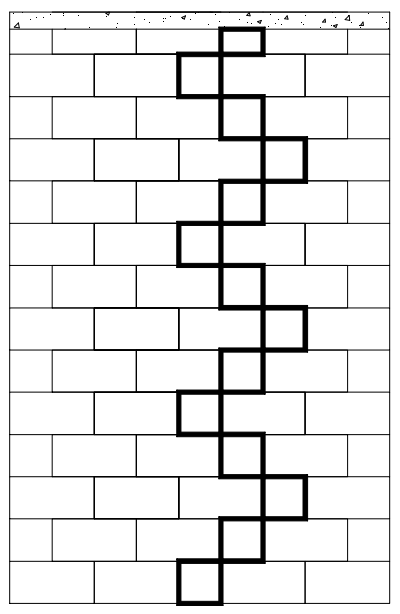

FIGURA 2.10b - Exemplo de situação de fechamento compensada com a utilização do bloco em trânsito 
É importante destacar que, se o projetista optar pela perda da simetria na modulação, tal procedimento levará à ocorrência de juntas a prumo em vários locais das paredes, mesmo que não sejam pontos de encontro das mesmas. Portanto, é recomendável, sempre que possível, o uso da simetria, pois estas juntas impedem a transferência de ações de uma parede para a outra, conforme já estudado no item 2.2.2.

\subsection{Cordões de argamassa}

Este item tratará das juntas de argamassa horizontal e vertical executadas entre os blocos estruturais, enfocando a possibilidade do seu não preenchimento (total ou parcial) e as vantagens e desvantagens advindas deste procedimento.

Segundo a ABNT (NBR-8798), a argamassa deve ser aplicada em todas as paredes do bloco para formação da junta horizontal, e em dois cordões verticais nos bordos de uma das extremidades do bloco para formação da junta vertical.

O não preenchimento dos septos transversais das juntas de assentamento implica na redução da resistência à compressão e ao cisalhamento da alvenaria. De acordo com TECMOLD $(1997)^{4}$, para os blocos desta fábrica, quando o assentamento da argamassa for feito apenas nas faces laterais dos mesmos (Figura 2.11), os valores das tensões admissíveis à compressão deverão ser minorados em $25 \%$.

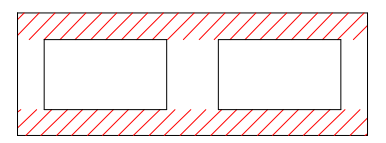

FIGURA 2.11 - Cordões de argamassa apenas nos septos longitudinais

${ }^{4}$ TECMOLD (1997). Guia Tecmold de alvenaria estrutural: diretrizes básicas para projeto arquitetônico, hidráulico e estrutural. / Apresentado no I Seminário Internacional de Alvenaria Estrutural, Porto Alegre / 
VARGAS (1988), porém, propõe que devam ser aplicados cordões de argamassa longitudinais nas duas faces dos blocos, cobrindo toda a sua espessura, e que, nas bordas transversais, devam ser aplicados cordões de argamassa somente nos furos que contiverem armadura vertical (Figura 2.12).

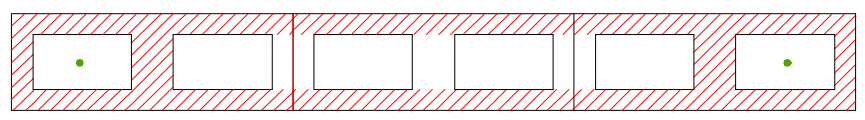

FIGURA 2.12 - Cordões de argamassa nos septos transversais

Deve-se ressaltar o fato da redução de resistência e de eficiência advinda deste procedimento e de que os prismas, neste caso, devem ser executados nas mesmas condições da parede, ou seja, com os septos transversais das juntas de assentamento não preenchidos.

Com relação às juntas verticais de argamassa que unem os blocos entre si, o seu não preenchimento implica em vantagens e desvantagens.

Como vantagens cita-se a redução do tempo de execução da obra e a redução do consumo de materiais. Entretanto, o não preenchimento só é adequado para juntas de 0,5 cm de espessura, e não para juntas de $1,0 \mathrm{~cm}$, que são as mais comuns. No caso da junta de $1,0 \mathrm{~cm}$, o não preenchimento da mesma pode acarretar em falhas durante o revestimento da parede. Outra vantagem do não preenchimento dessas juntas é a redução da fissuração provocada por deformações intrínsecas (retração, deformação térmica, etc.).

Como desvantagens do não preenchimento das juntas verticais, encontrase a possibilidade de agravamento de problemas de fissuração na parede sob a laje de cobertura, quando não tomadas as devidas precauções, devido à redução da resistência ao cisalhamento da parede [BASSO et al (1997)]. Observa-se que a redução da resistência ao cisalhamento da parede não é tão importante nos demais locais com o é sob a laje de cobertura, pois a resistência remanescente é suficiente para a parede. Sob a laje de cobertura exige-se uma resistência maior, daí o problema. 
ROMAN (1993) ${ }^{5}$ realizou ensaios de prismas de alvenaria por solicitação da ENCOL S.A., com o objetivo de verificar a resistência ao cisalhamento de paredes de alvenaria de blocos de concreto sem argamassa na junta vertical.

Os prismas foram ensaiados como vigas de grande altura com dois pontos de carregamento e dois apoios simples (Figura 2.13).

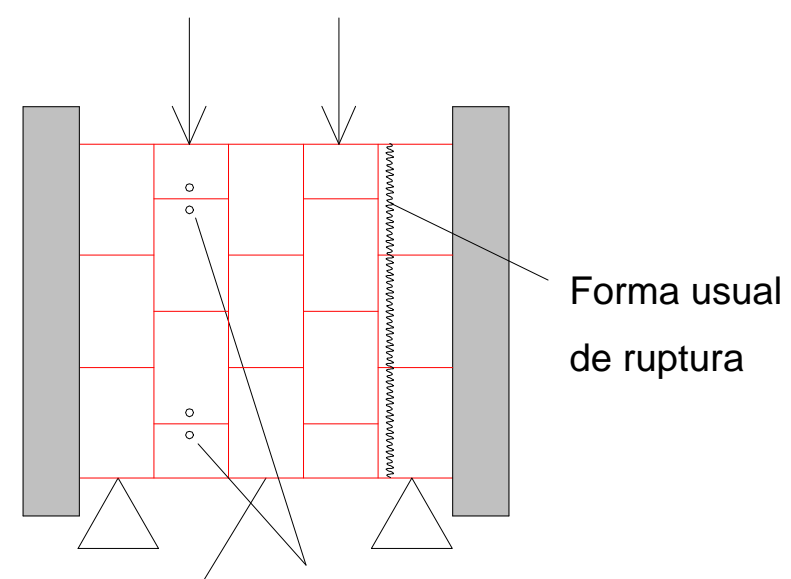

Pontos de medição das deformações

Pontos de medição da deflexão

FIGURA 2.13 - Testes dos prismas como vigas

Os resultados dos ensaios com os prismas deram valores de resistência ao cisalhamento em torno de $20 \%$ menores para os prismas sem argamassa nas juntas verticais, em relação aos prismas com juntas verticais preenchidas com argamassa.

Portando, baseado no que foi exposto, recomenda-se preencher, sempre que for necessário em função da resistência da parede, as juntas verticais e os septos transversais das juntas horizontais de argamassa, quando do assentamento dos blocos estruturais.

${ }^{5}$ ROMAN, H. R. (1993). Resistência ao cisalhamento de paredes de alvenaria de blocos de concreto sem junta vertical. / Relatório $n^{0} 1$ elaborado para a ENCOL S. A., Departamento de Engenharia Civil da Universidade Federal de Santa Catarina / 


\subsection{Passagem das tubulações}

\subsubsection{Instalações elétricas, de telefone, de TV e de interfone}

As instalações elétricas, de telefone, de TV e de interfone passam, em sua maioria, dentro dos vazados verticais dos blocos estruturais e pelas lajes. É essencial, em termos de racionalização construtiva, que estas instalações não exijam o rasgamento das paredes, de acordo com FRANCO et al (1991) .

Ensaios feitos por PRASAN et al ${ }^{1}$ apud HENDRY (1981) indicaram que cortes verticais executados em paredes estruturais tiveram pouca influência em sua resistência. Em outra ocasião, FISHER ${ }^{2}$ apud HENDRY (1981), também ensaiando paredes estruturais, concluiu que o decréscimo de resistência devido aos cortes verticais é maior nas paredes mais esbeltas. Enquanto não há ainda um comportamento bem claro da redução de resistência observada nos ensaios, os resultados indicam que os cortes podem reduzir a resistência da parede em torno de $20 \%$ ou mais.

A Especificação Modelo ( "Model Specification"), publicada pela BRITISH CERAMIC RESEARCH ASSOCIATION ${ }^{3}$ apud HENDRY (1981), sugere que os cortes e vazados nos blocos devam ser previstos durante o assentamento da parede, utilizando, apropriadamente, blocos já cortados. No caso de ter que cortálos na obra, recomenda-se que se utilizem ferramentas especiais e que se evitem cortes horizontais e diagonais.

Um procedimento simples e seguro é descontar as partes da parede por onde passam os cortes verticais, como se faz com as aberturas para colocação de quadros de força, observando o inconveniente de redução de área resistente.

${ }^{1}$ PRASAN, S. ; HENDRY, A. W. ; BRADSHAW, R. E. (1965). Crushing tests on storey height walls $4 \frac{1 / 2}{2}$ "thick. Proc. Br. Ceram. Soc., v.4, p.67-81. apud HENDRY (1981) p. 58

${ }^{2}$ FISHER, K. (1973). The effect of low-strength bricks in high-strenght brickwork. Proc. Br. ceram. Soc., v. 21, p. 79-98. apud HENDRY (1981) p. 58

${ }^{3}$ BRITISH CERAMIC RESEARCH ASSOCIATION (1975). Model specification for load bearing clay brickwork. Stoke-on-Trent, BCRA. (Special publication 56) apud HENDRY (1981) p. 59 
Recomenda-se também evitar os cortes horizontais e diagonais sempre, pois implicam na perda de seção transversal da parede.

$\mathrm{Na}$ obra, os eletrodutos são lançados concomitantemente com a distribuição horizontal das lajes e com o assentamento das paredes.

Nos pontos de luz ou tomadas são colocadas as caixas apropriadas, fazendo pequenos recortes nos blocos, de preferência faceando uma junta horizontal, para facilitar o corte destes e o embutimento daquelas. As caixas e os aparelhos a serem embutidos na alvenaria devem ter medidas preferencialmente modulares, visando otimizar os procedimentos de assentamento e fixação.

$\mathrm{Na}$ instalação do quadro geral, os eletrodutos devem ser centralizados em vazados contínuos, sendo que a interrupção em cada pavimento se dá através de uma caixa modular. As caixas para quadros de distribuição e caixa de passagem devem ser projetadas com dimensões que evitem cortes nas alvenarias para sua perfeita acomodação. O projetista estrutural deverá ser informado das dimensões e posições dos quadros de distribuição para que detalhe o reforço necessário, de modo que a abertura não prejudique a integridade estrutural da parede, e para que ele possa considerar a redução de área resistente.

Após o término da elevação das paredes, os fios são, então, colocados dentro dos conduítes.

\subsubsection{Instalações hidro-sanitárias}

O grande problema de passagem das tubulações em alvenaria estrutural são as instalações hidro-sanitárias, pelo fato de possuírem diâmetros maiores e poderem apresentar problemas de vazamento ou qualquer outro que requeira manutenção. É importante salientar que eventuais necessidades de cortes para manutenção em caso de vazamento poderá atingir a integridade das paredes e alterar sua função estrutural. Portanto, o projeto das instalações hidro-sanitárias deve prever o embutimento da forma mais racionalizada possível, podendo empregar uma das seguintes soluções para sua localização: paredes nãoestruturais, "shafts" hidráulicos, enchimentos, sancas, forros falsos, etc.

A primeira opção consiste em se definir, no projeto arquitetônico, algumas paredes como não portantes, ou seja, que não farão parte da estrutura do edifício; paredes de vedação, cujos pesos próprios serão descarregados nas lajes que as sustentam. Nestas paredes é permitida a execução de rasgos para o embutimento 
das tubulações. Geralmente são paredes pequenas, localizadas em banheiros, cozinhas ou áreas de serviço.

O inconveniente de se executarem paredes não-estruturais é a perda de racionalidade do processo, pois isto implica em duplo trabalho, desperdício, maior consumo de material e de mão-de-obra. O tempo de execução da obra fica comprometido, uma vez que se torna necessário prever o encunhamento destas paredes às lajes, ou seja, o processo construtivo das mesmas é diferente do das estruturais. Recomenda-se que a última fiada das paredes não-estruturais seja executada depois de prontas todas as lajes, começando da cobertura e indo até o $1^{\circ}$ pavimento, para que estas paredes não sirvam como apoio das lajes. Além disso, é necessário executar o fechamento das aberturas das faces dos blocos onde ocorreram quebras para a introdução das canalizações.

Cabe aqui salientar que a presença de um elevado número de paredes nãoestruturais prejudica o sistema estrutural, sobrecarregando as demais paredes e diminuindo as possíveis trajetórias de força.

Entre as paredes não-estruturais existem as executadas com "blocos hidráulicos" , que são componentes com dimensões externas modulares iguais às do bloco estrutural, providos de uma concavidade nos três septos transversais e de ranhuras verticais em uma das faces longitudinais (Figura 2.14). Estas ranhuras servem para direcionar a quebra de uma placa na face do bloco, criando assim uma "canaleta vertical" para o embutimento da tubulação.

As ranhuras dos blocos hidráulicos servem também para identificá-los, uma vez que se deve ter bastante cuidado de não misturar blocos na obra, tanto de resistências como de funções diferentes.

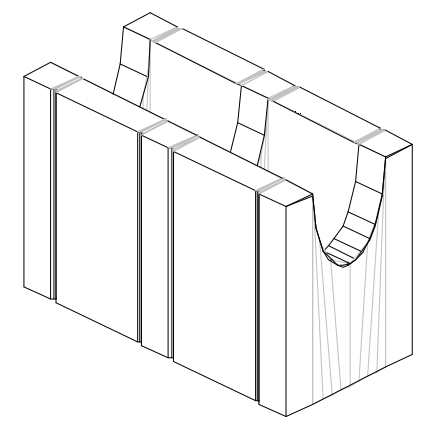

FIGURA 2.14- Bloco hidráulico [adaptado de FRANCO et al (1991)] 
A segunda opção são os "shafts" hidráulicos, normalmente executados junto aos boxes de banheiros e em áreas de serviço. "Shafts" são passagens deixadas nas lajes, de alto a baixo do edifício, especialmente para a locação das prumadas primárias (Figura 2.15).

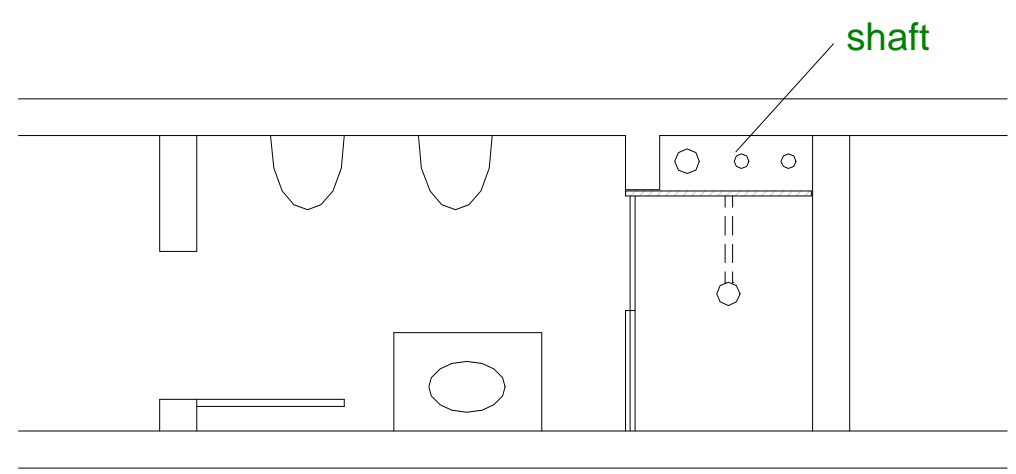

FIGURA 2.15 - "Shaft" hidráulico

A utilização deste elemento significa uma grande facilidade na execução das instalações, uma vez que praticamente elimina a interferência do trabalho do pedreiro com o instalador e soluciona a passagem de tubulações de grande diâmetro sem a necessidade de quebra e enchimento das paredes.

Os "shafts" podem ser visitáveis, o que é vantajoso para a manutenção. Algumas desvantagens são a transmissão de sons e a comunicação contínua de vazamentos.

A opção de enchimento consiste em aumentar a espessura do revestimento em determinado trecho por onde passa a tubulação, que fica externa ao bloco. É o caso que ocorre em situações como a tubulação sob a pia da cozinha, onde o enchimento sob a bancada não chega a comprometer os aspectos arquitetônicos (Figura 2.16).

As sancas são enchimentos executados entre 0 teto e a parede, semelhante ao anterior, por onde podem passar tubulações horizontais (Figura 2.17). Juntamente com o forro falso de gesso, são opções bastante utilizadas para resolver o problema da passagem do trecho horizontal de tubulações de grande diâmetro.

O rebaixamento de lajes, embora menos utilizado, constitui outra alternativa para o embutimento de instalações hidro-sanitárias horizontais em banheiros, 
cozinhas e áreas de serviço, também podendo ser adotado em sacadas, varandas e outros ambientes, para proporcionar o desnível e declividades exigíveis.

\section{PLANTA}
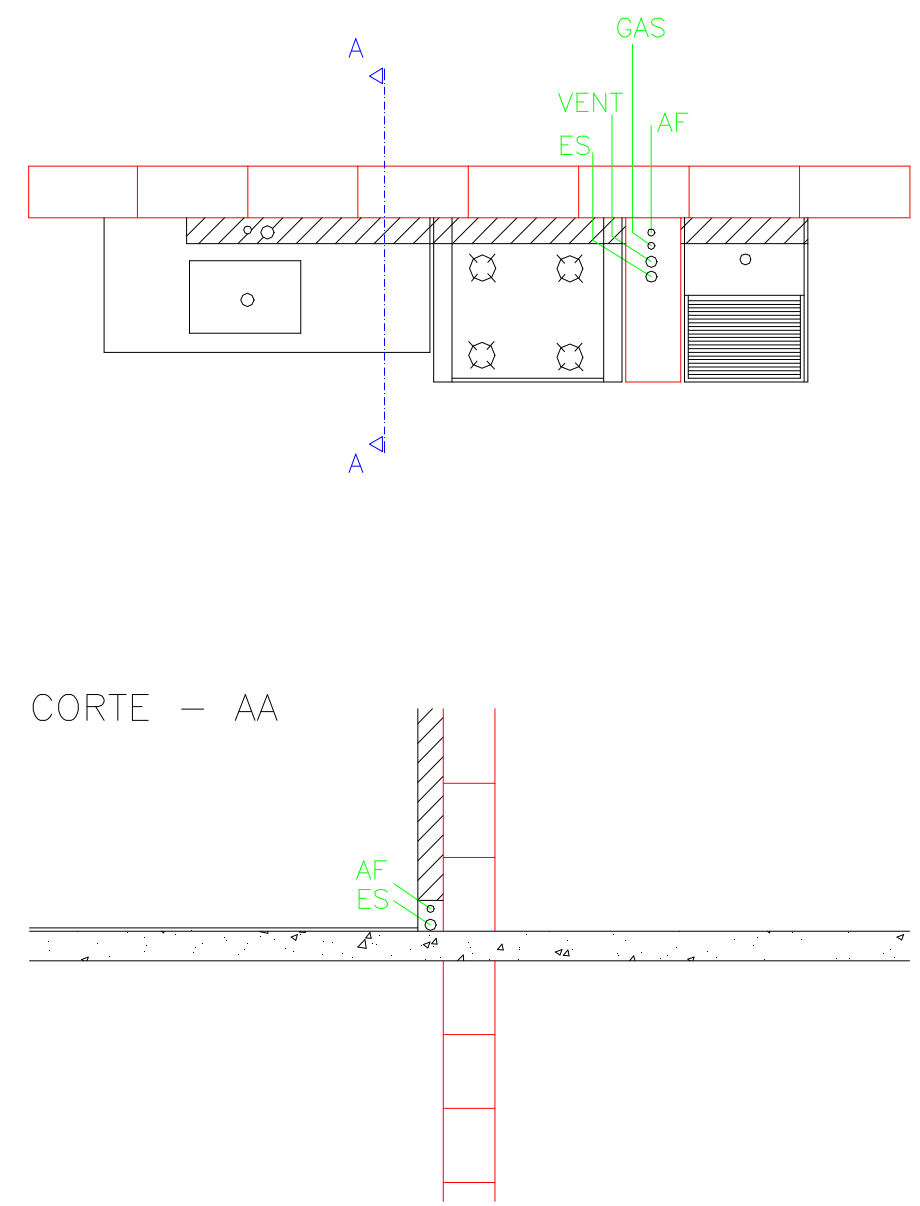

FIGURA 2.16 - Enchimento em cozinha [adaptado do ABCI (1990)]

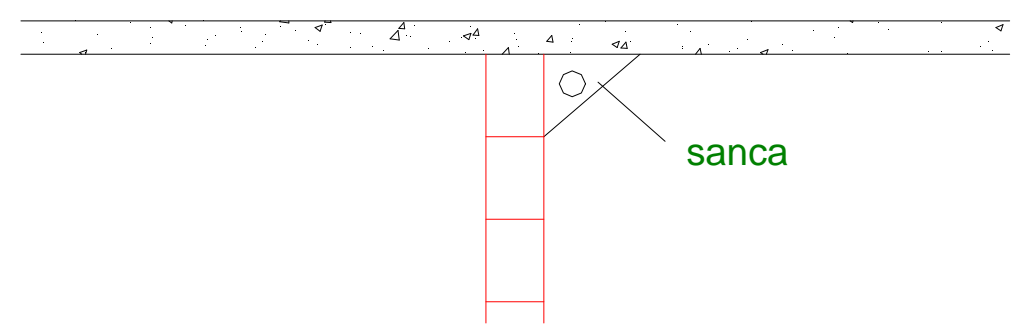

FIGURA 2.17 - Sanca 
Preferencialmente é recomendável o emprego de paredes hidráulicas e do "shaft" hidráulico, por serem opções que propiciam maior racionalização e independência entre serviços. Estas também têm a vantagem de não interferirem na estrutura da edificação, bem como facilitarem a posterior manutenção das instalações, quando da edificação em uso.

Outro motivo para o emprego dessas duas opções citadas é a redução de tempo conseguida na execução do serviço, em função de que, tanto a parede hidráulica como o "shaft" hidráulico são executados em conjunto com o assentamento das demais paredes de alvenaria.

A escolha da melhor solução para a passagem das instalações hidrosanitárias constitui, entretanto, uma decisão de cada projeto, em função das condicionantes e fatores intervenientes gerais de cada empreendimento.

Cabe aqui salientar que foi dada ênfase aos detalhes das soluções alternativas para a passagem das tubulações, devido ao fato que não se pode seccionar as paredes estruturais. Apesar de serem soluções adequadas a qualquer sistema construtivo, no caso da alvenaria estrutural os cuidados devem ser maiores.

\subsection{Elementos pré-moldados}

Tem sido bastante notável a utilização de elementos pré-moldados nos edifícios em alvenaria estrutural, sejam em lajes, em escadas ou até mesmo em vergas sobre vãos de portas. A pré-moldagem, assim como a alvenaria estrutural, oferece como vantagens: rapidez de execução, economia de formas e de armação, elementos de boa qualidade e um rigoroso controle na execução, sendo portanto sistemas que se ajustam perfeitamente.

\subsubsection{Lajes}

No caso de edifícios onde a ação do vento é significativa, é conveniente utilizar lajes maciças, pois neste caso as lajes devem ter rigidez transversal suficiente para garantir o seu funcionamento como diafragma, ou seja, transferir os esforços horizontais atuantes na construção às paredes portantes. 
Segundo VARGAS (1988), perante vento ou ações sísmicas, os diafragmas funcionam como vigas horizontais de grande altura e devem amarrar o conjunto de paredes e distribuir entre elas as forças horizontais neles aplicadas.

Existe a possibilidade de se utilizarem, ao invés de lajes maciças, lajes prémoldadas com capa de concreto, ou seja, elementos de seção parcial. A capa de concreto, moldada no local, fica com a responsabilidade de efetuar a transferência do cisalhamento da laje para as paredes, que são os elementos de contraventamento da estrutura [EL DEBS (1996)].

Com base no exposto anteriormente, o uso de lajes pré-moldadas de seção completa é mais adequado para edifícios baixos, onde o vento não exerce influência significativa. Mesmo quando tecnicamente adequado, o uso de lajes prémoldadas depende da viabilidade de sua aquisição por parte do construtor. Esta viabilidade implica em custo de material, despesas de transporte, etc..

Um exemplo de laje pré-moldada bastante utilizada no país para a faixa de vãos relativamente pequenos é a constituída por nervuras e blocos vazados ou outro material de enchimento, como poliestireno, que recebem uma camada de concreto moldada no local.

As nervuras podem ser em forma de seção T invertida, em concreto armado ou protendido, ou de seção retangular com armadura em forma de treliça que se projeta para fora da seção, denominada laje treliça (Figura 2.18).
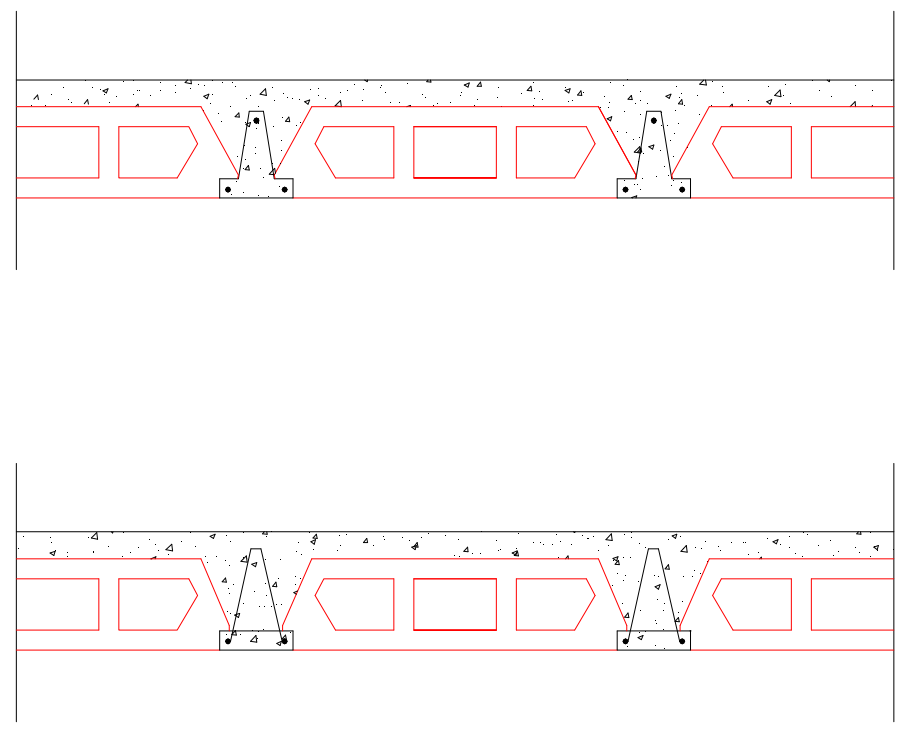

FIGURA 2.18 - Aplicações de elementos de "laje pré-moldada" 


\subsubsection{Escadas}

As escadas dos edifícios em alvenaria estrutural podem ser pré-moldadas ou moldadas no local.

Dentre as escadas moldadas no local, existem as moldadas por inteiro na obra e as de seção parcial, onde a laje é pré-moldada (vigotas e lajotas) e os degraus são moldados no local (Figura 2.19).

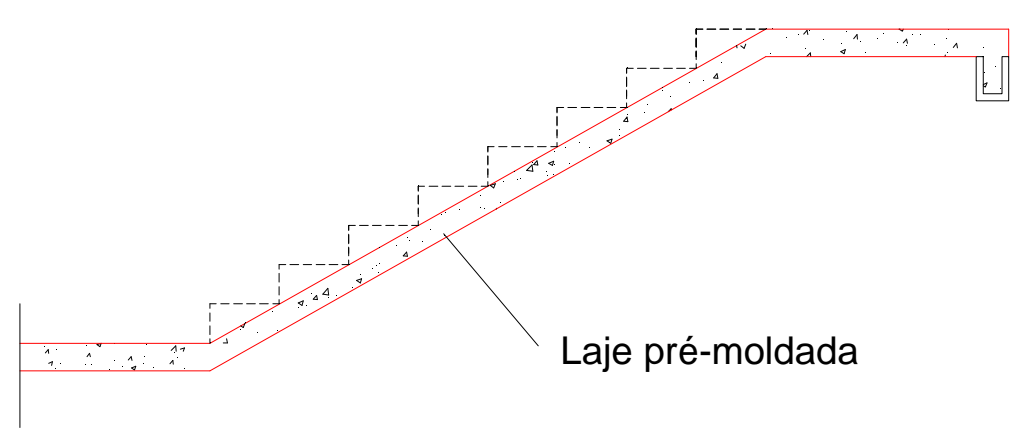

FIGURA 2.19 - Degraus moldados no local

Em razão do transtorno de se executá-las no local, as escadas de concreto pré-moldado são a melhor alternativa quando já se emprega o concreto prémoldado na estrutura, pois os custos de frete já estão embutidos no orçamento, além do que se trabalha com elementos leves e de melhor qualidade. Mesmo quando a laje for moldada no local, as escadas pré-moldadas não deixam de ser uma solução a ser considerada.

As escadas pré-moldadas podem ter seus patamares maciços ou prémoldados. A Figura 2.20 retrata um exemplo de escada com patamar pré-moldado. 

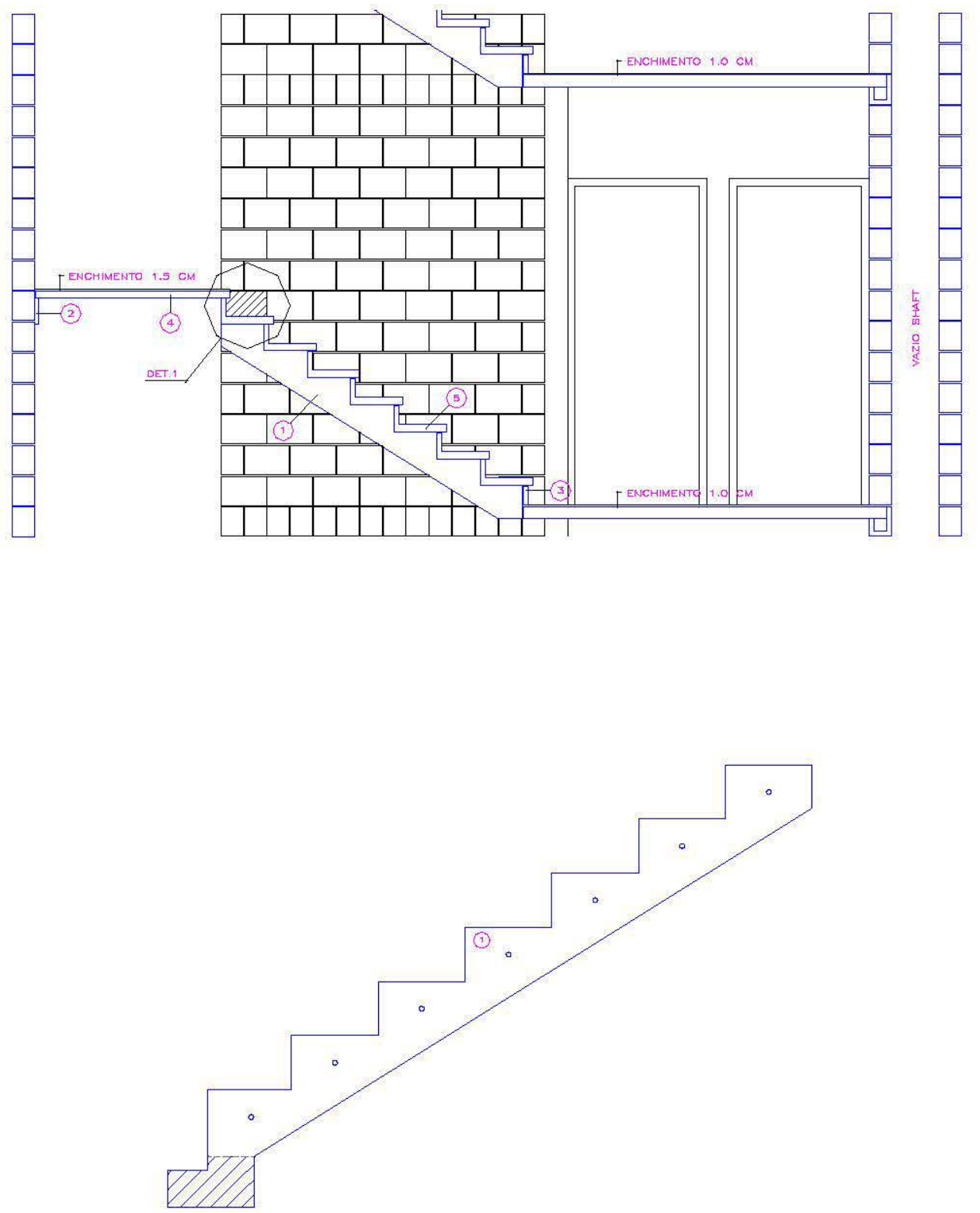

VISTA LATERAL DA PLACA SUPORTE

DOS DEGRAUS. ESPESSURA $=4 \mathrm{CM}$.

\begin{tabular}{|llllllllll}
\hline 3 & 0 & 0 & 0 & 0 & 0 & 0 & 0 & 0 & 0 \\
\hline
\end{tabular}

VISTA LATERAL DA PLACA SUPORTE

DO PATAMAR. ESPESSURA $=4 \mathrm{cM}$.

ESCALA $1: 10$ 


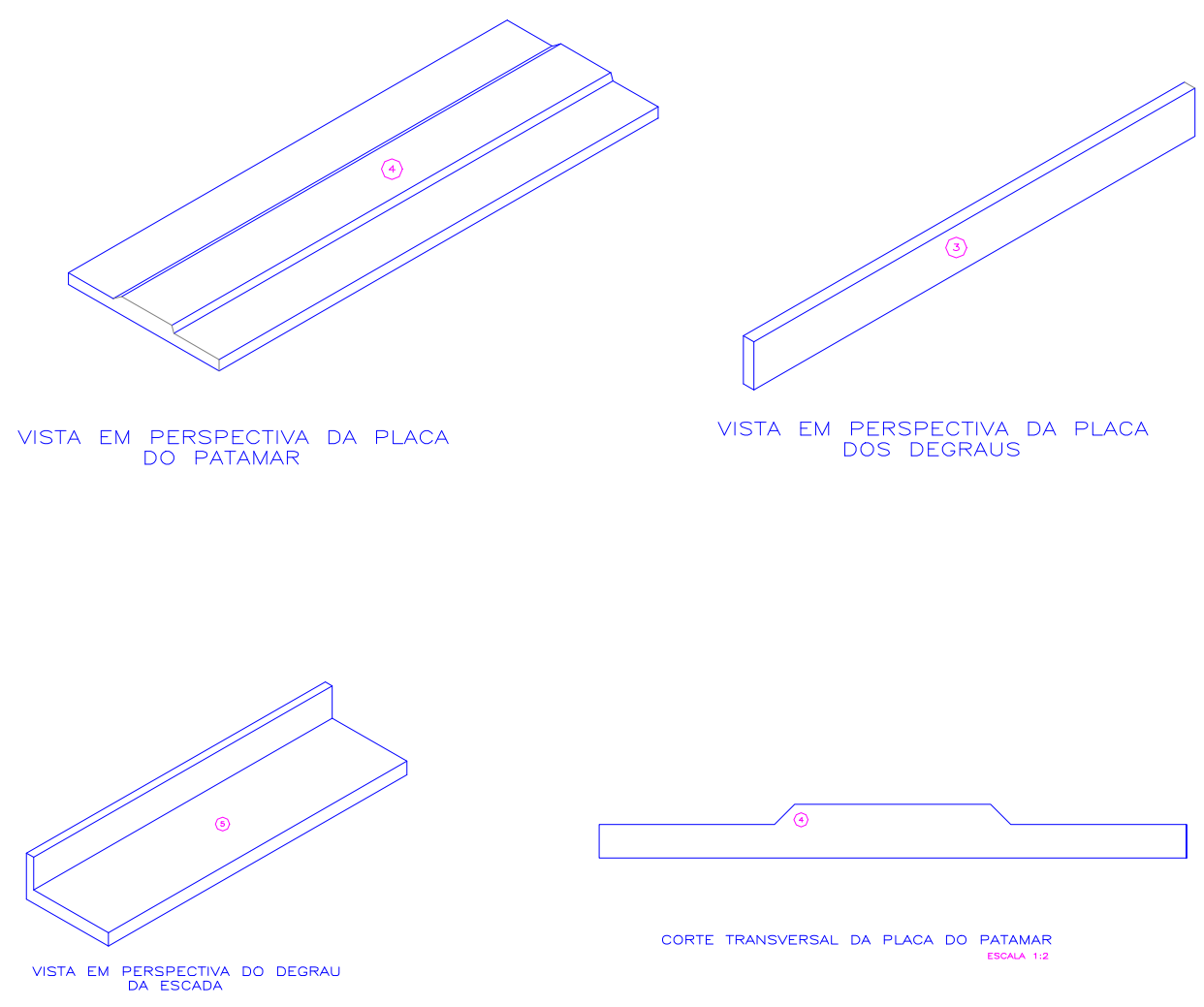

FIGURA 2.20 - Escada com patamar pré-moldado [cortesia do Arq. Júlio B. Magalhães]

Observando o corte transversal da placa do patamar, vê-se que a seção com altura variável é bastante apropriada, por proporcionar leveza e ao mesmo tempo suficiente inércia de flexão ao elemento.

No caso das escadas pré-moldadas com patamares maciços, estes podem ser embutidos na parede estrutural, ou apoiados sobre peças pré-moldadas fixadas na alvenaria. A Figura 2.21 mostra uma alternativa para se apoiar o patamar na alvenaria, que é fazer uma cinta de concreto embutida na parede; no entanto, existem outras formas de se embutir o patamar, como por exemplo sobre um bloco "J". 


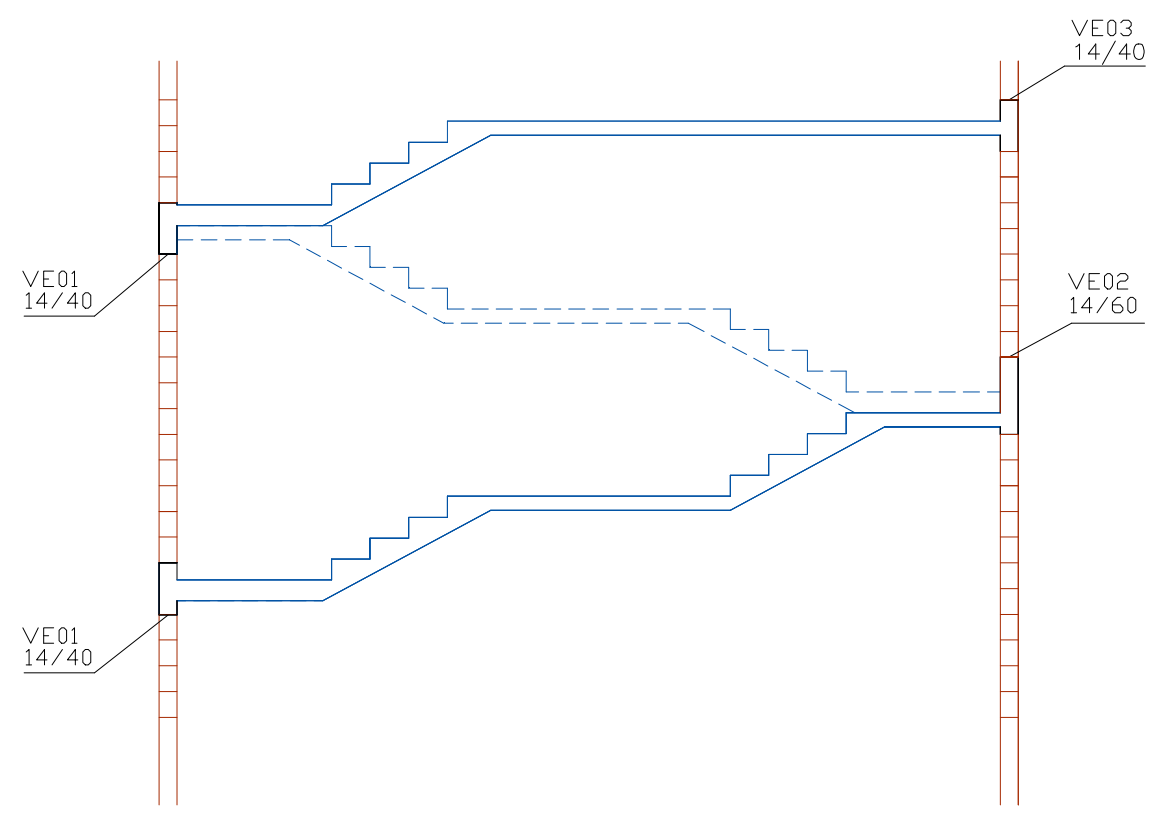

FIGURA 2.21- Escada com patamar maciço embutido na parede sobre cinta de concreto

$\mathrm{Na}$ Figura 2.22 tem-se ilustrado um exemplo de escada com patamar maciço apoiado sobre peça pré-moldada. 


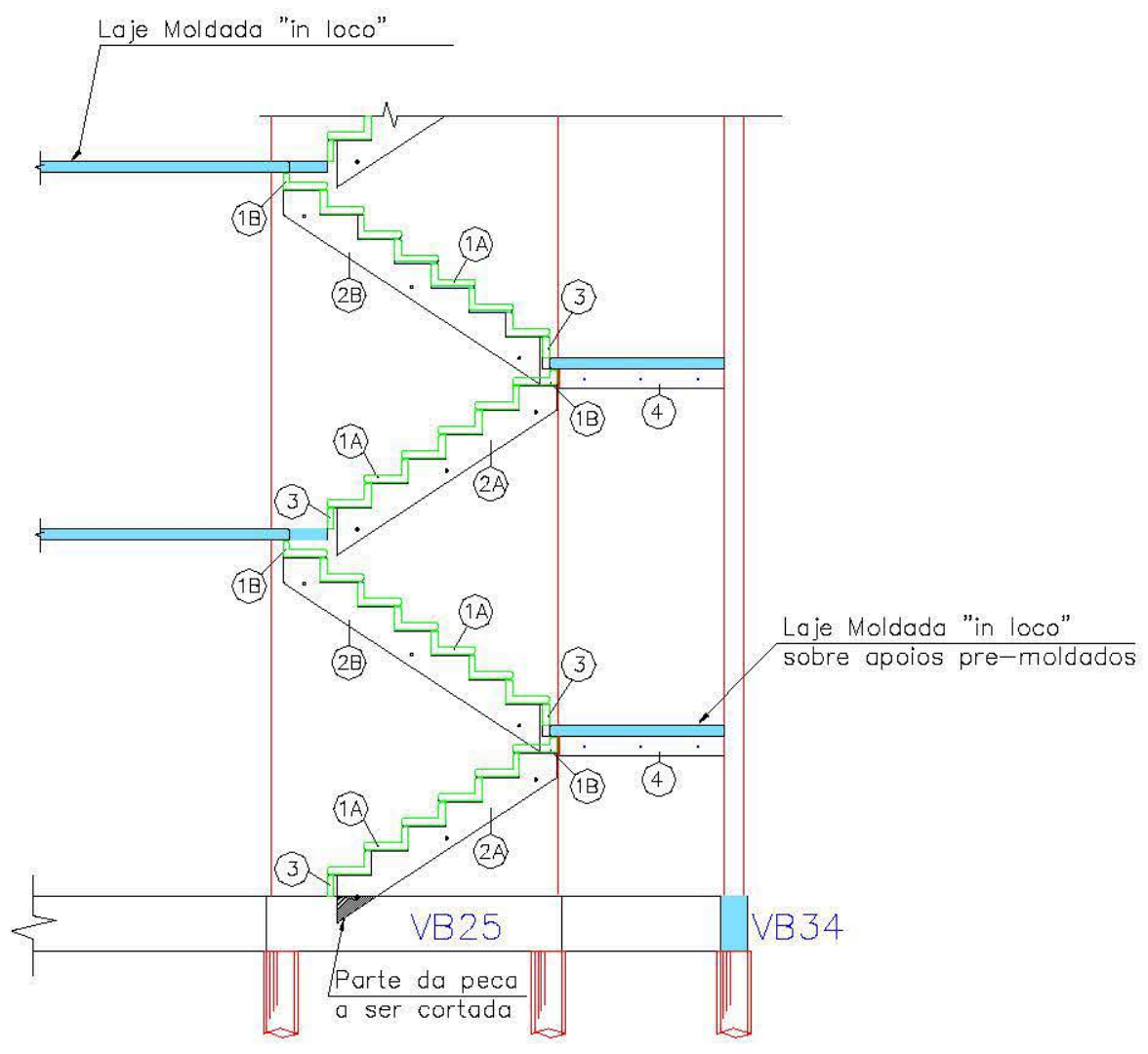

Peca No. 1A

Escala 1:20

Planta

Corte

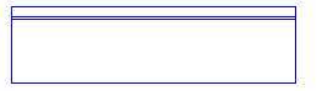

$\square$

Peca No. 1B

Escala 1:20

Planta

Corte

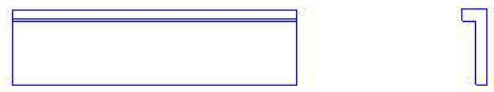



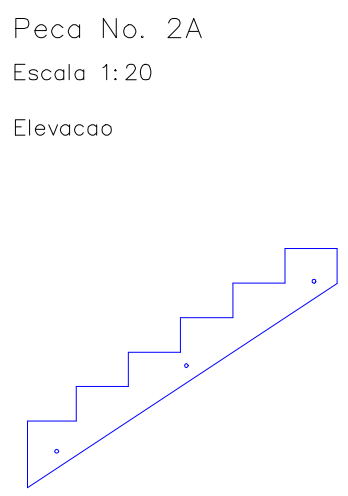

Peca No. 3

Escala 1:20

Elevacao
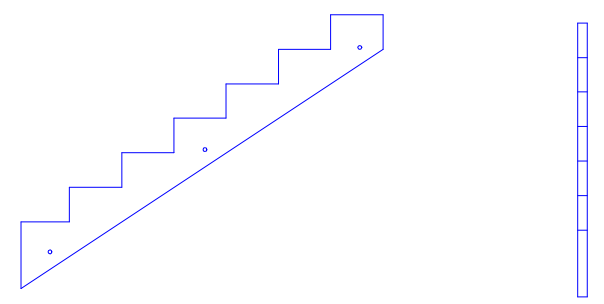

Peca No. 4

Escala 1:20

Elevacao

FIGURA 2.22 - Escada com patamar maciço apoiado sobre peça pré-moldada ou escada "jacaré" [cortesia da TecSof Engenharia de Estruturas S/C Ltda.]

De acordo com FRANCO et al (1991), a escada "jacaré" é composta de elementos pequenos e leves que são fixados na alvenaria depois desta e das lajes de piso terem sido executadas. Os componentes que formam o elemento escada são:

- viga dentada tipo "jacaré" (fixação);

- degrau e espelho pré-fabricado;

- patamares pré-fabricados.

As peças, após a moldagem, são estocadas no canteiro de obras e depois assentadas e coladas sobre as vigas dentadas, previamente fixadas com parafusos ou outro tipo de ancoragem às paredes laterais da caixa de escada. Para facilitar a fixação das vigas "jacaré", deve-se prever o preenchimento dos blocos com graute nas posições em que os elementos de fixação serão colocados.

A utilização de escadas pré-moldadas é uma questão que depende da racionalidade, da rapidez atingida e da disponibilidade do construtor. É importante 
salientar que as escadas pré-moldadas, apesar das vantagens advindas de serem elementos confeccionados com alto controle de qualidade, exigem grauteamento adicional e cuidados na fixação.

Neste item procurou-se dar mais ênfase aos detalhes das escadas por serem elementos mais difíceis de serem executados que as lajes.

\subsubsection{Vergas para portas}

Segundo a ABNT (NBR-10837), "denomina-se verga o elemento estrutural colocado sobre vãos de aberturas não maiores que $1,20 \mathrm{~m}$, a fim de transmitir cargas verticais para as paredes adjacentes aos vãos."

Em geral, as vergas são obtidas através do assentamento de blocos canaleta, colocação de armadura e posterior grauteamento. Esta solução, entretanto, pode ser inconveniente do ponto de vista da produção, pois normalmente o pedreiro tem que parar o assentamento da parede para a execução e grauteamento do elemento. Além disso, como em geral as portas têm altura $2,10 \mathrm{~m}$ e os blocos têm módulo vertical $20 \mathrm{~cm}$, são necessários elementos de enchimento (argamassa, pedaços de tijolo, etc.) para preencher o espaço que resulta entre a porta e a alvenaria (Figura 2.23).

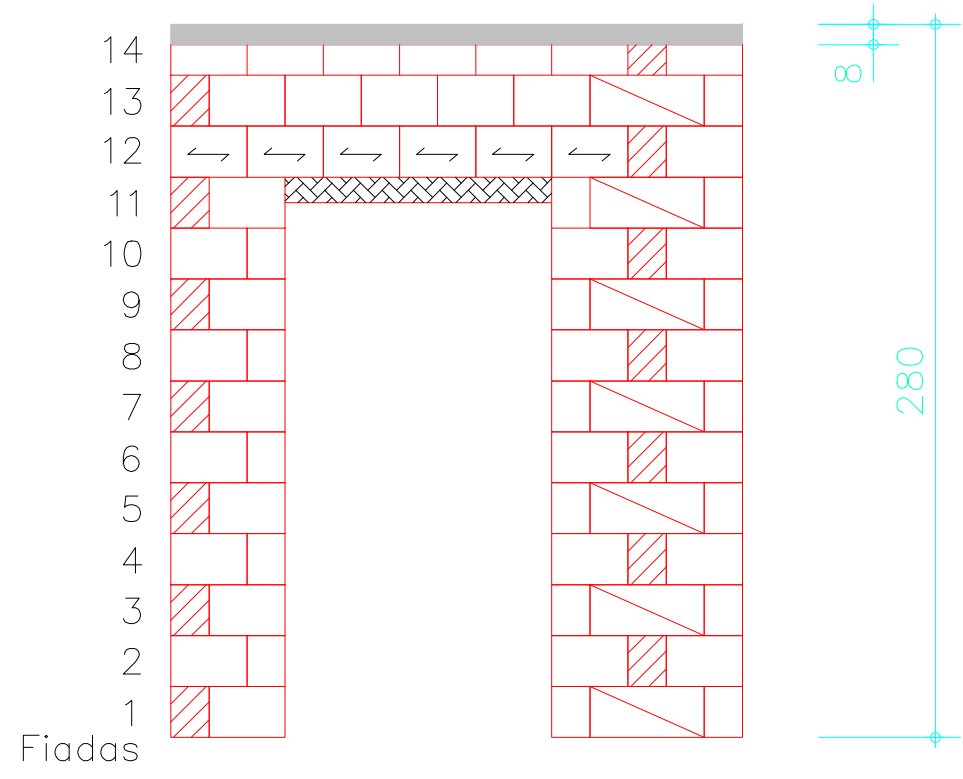

FIGURA 2.23 - Verga moldada no local 
Uma boa alternativa, em termos de facilidade construtiva, é a utilização de uma vigota pré-moldada de concreto armado no caso das vergas para portas, pelo fato destas possuírem vãos relativamente pequenos e com isso resultar em elementos leves.

As vergas pré-moldadas podem ser executadas pela construtora, no próprio canteiro de obras, já com as dimensões e armaduras necessárias para cada ponto de utilização do projeto.

Encontra-se a seguir um detalhe de uma verga utilizada em projeto elaborado pela TecSof Engenharia de Estruturas S/C Ltda. (Figura 2.24).

\section{PLANTA}

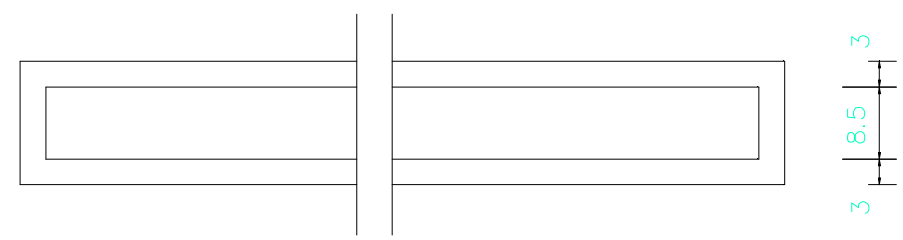

\section{ELEVACÃO}

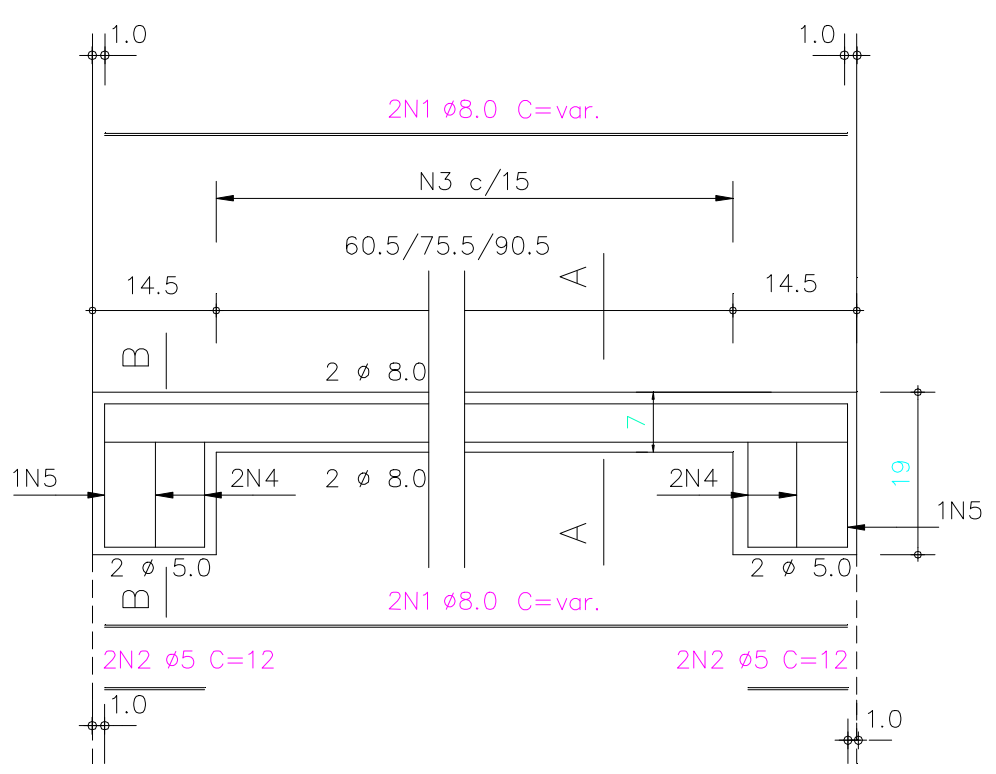



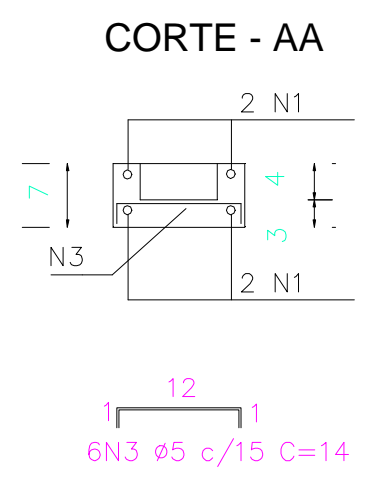

CORTE - BB

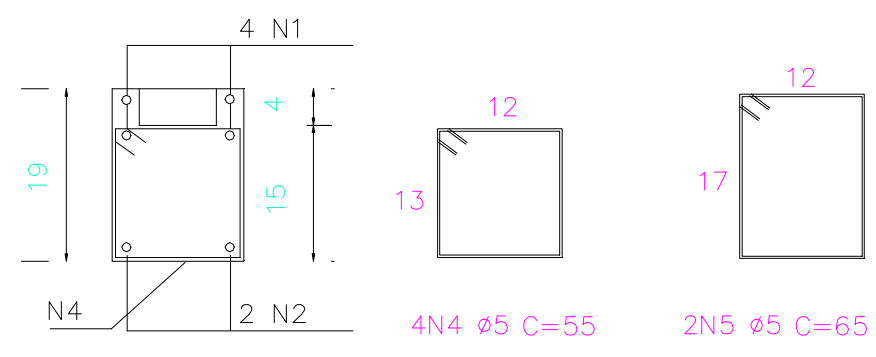

FIGURA 2.24 - Verga pré-moldada para portas

Além de otimizar o ritmo da produção, as vergas pré-moldadas são simplesmente encaixadas na alvenaria, não necessitando de ligações especiais.

Outro ponto positivo da utilização de vergas pré-moldadas é que elas são executadas com dimensões iguais aos módulos vertical e horizontal do bloco estrutural, dispensando assim eventuais enchimentos com argamassa.

Tem-se a seguir a ilustração de uma verga pré-moldada utilizada na modulação M15 (Figura 2.25). 

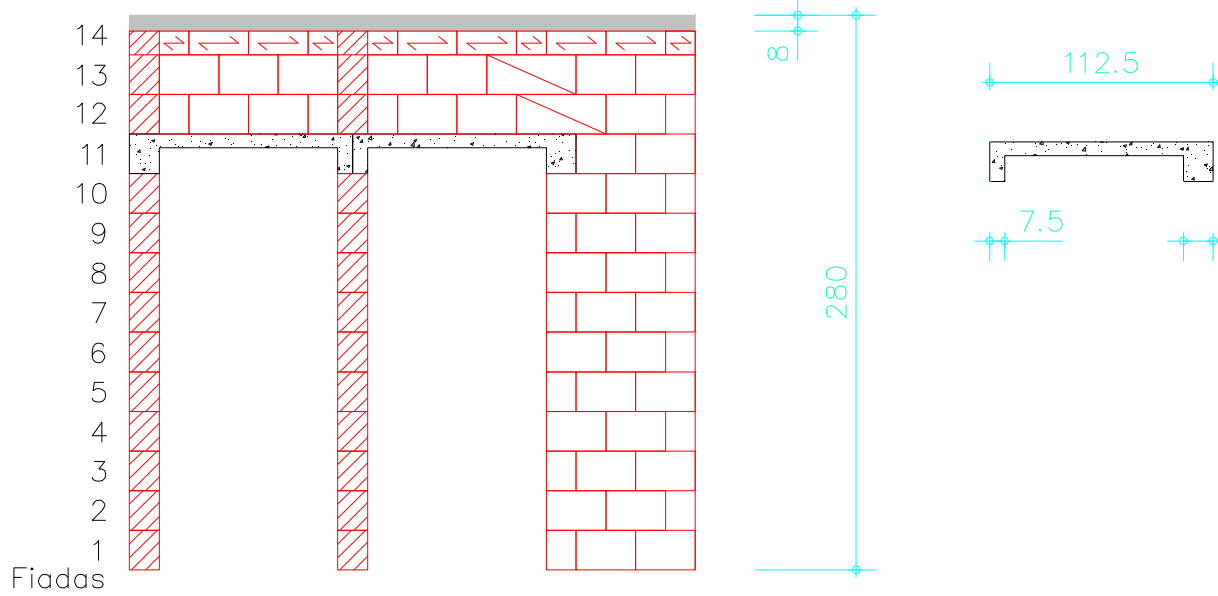

FIGURA 2.25 - Verga pré-moldada em modulação de 15

\subsection{Cintas}

As cintas são fiadas compostas por blocos canaleta preenchidos com graute e armadura.

A função das cintas é dar travamento ao prédio como um todo, transmitir a reação da laje à alvenaria, uniformizando-a, e combater efeitos provocados por variações volumétricas (retração, variação de temperatura e efeitos higroscópicos). Deste modo, são indicadas abaixo da laje em todas as paredes e a meia altura, em especial nas paredes externas, por estarem expostas às intempéries.

A cinta a meia altura executada nas paredes externas pode ser aproveitada como contra-verga de algumas aberturas, o que é favorável para o aspecto econômico.

As cintas em geral não são calculadas, admitindo-as de altura igual a um bloco canaleta e armadura construtiva, que pode ser, por exemplo, $1 \phi 10,0 \mathrm{~mm}$ corrido ou $2 \phi 8,0 \mathrm{~mm}$ corridos. Na Figura 2.26 encontra-se um exemplo que retrata este tipo de situação.

Existe também a possibilidade de se unir a cinta com a verga, quando as duas coincidem na mesma fiada. Neste caso o trecho da cinta correspondente à verga deve ser calculado à flexão simples, conforme será visto no capítulo 4 . 


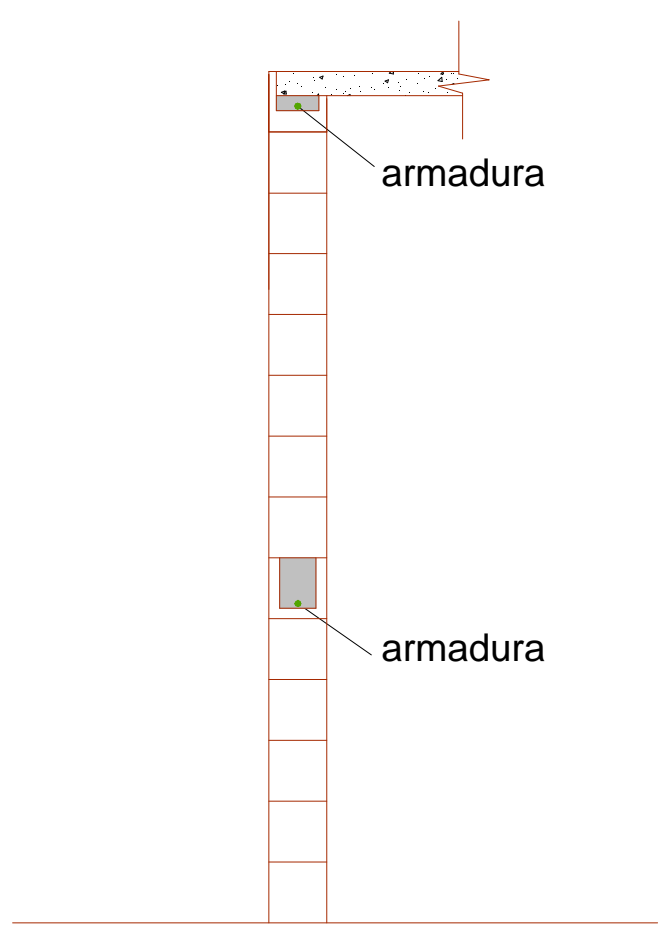

FIGURA 2.26 - Cintas em parede externa - armadura construtiva

No caso de lajes de cobertura, devido a problemas de fissuração no último pavimento dos edifícios, causada pela movimentação da laje sujeita a elevadas variações térmicas, o procedimento adotado deve ser um pouco diferente dos demais pavimentos.

As lajes são executadas simplesmente apoiadas nas paredes, permitindo sua livre movimentação no plano, o que pode ser facilitado, por exemplo, pela introdução de papel betumado entre as duas.

Abaixo da laje pode ser feita uma cinta dupla para dar maior travamento horizontal às paredes (Figura 2.27). É recomendável a colocação de isopor entre a laje e o bloco "J", a fim de protegê-lo quando da movimentação da mesma, causada por variações térmicas (Figura 2.28). Neste detalhe, a argamassa fraca deve ser retirada após a concretagem, e pode-se substituir a junta de borracha por uma manta asfáltica, pois a primeira pode não funcionar por falha de execução. 


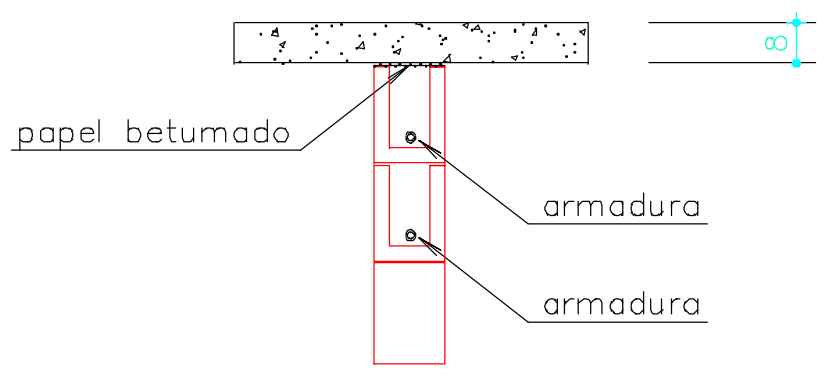

FIGURA 2.27 - Detalhe da ligação laje de cobertura e alvenaria

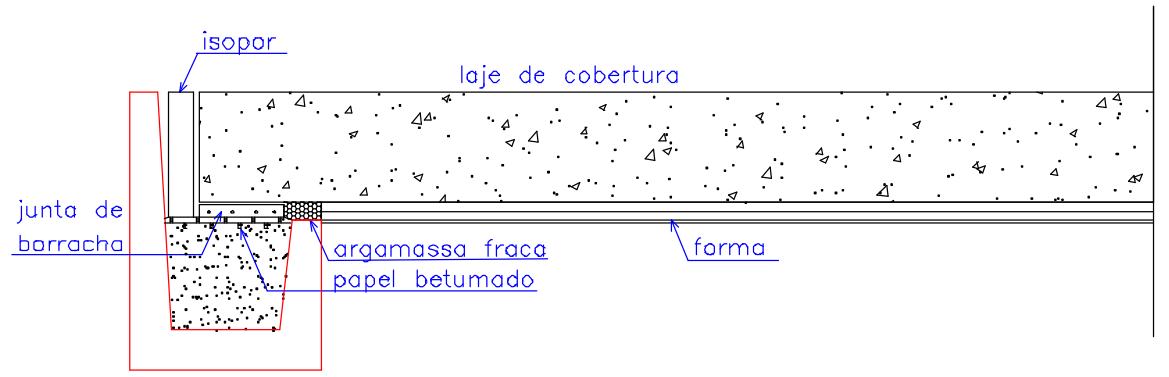

FIGURA 2.28 - Detalhe da colocação de isopor entre a laje e o bloco "J" [adaptado de FRANCO et al (1991)]

Recomenda-se que a laje de cobertura, por sua vez, possua juntas horizontais de dilatação, e que seja dividida em vários panos, separando apartamentos e áreas comuns.

A junta horizontal de dilatação da laje de cobertura tem como função atenuar o problema causado pela deformação térmica, mesmo quando se superpõem soluções como ventilação do telhado e isolamento térmico [BASSO et al (1997)]. 


\subsection{Considerações finais}

Neste capítulo, foram levantados alguns pontos com os quais se depara o projetista estrutural ao receber o projeto arquitetônico de um edifício em alvenaria estrutural, e buscou-se fornecer orientações para as tomadas de decisão em cada caso. É claro que não se teve a pretensão de abordar todos os aspectos que gerem tomadas de decisão, mas sim alguns considerados essenciais. Dentre os itens destacados, alguns deles serão retomados em capítulos posteriores.

É conveniente salientar a importância das reuniões entre os projetistas arquitetônico, estrutural, hidráulico, elétrico, etc., durante a fase de elaboração do projeto arquitetônico. A interação de projetos proporciona, sem dúvida, maior ganho de produtividade e economia, assim como evita posteriores modificações ou adaptações necessárias. Pode-se dizer que estas reuniões são essenciais no caso deste processo construtivo, pois as mudanças produzidas são realizadas na própria estrutura da edificação. 


\section{3 concepção E ANÁLISE ESTRUTURAL}

Este capítulo foi embasado em grande parte por CORRÊA \& RAMALHO (1996), dispensando, assim, a constante referência a esta publicação.

\subsection{Definições}

\subsubsection{Concepção estrutural}

A concepção estrutural de um edifício consiste em se definir no projeto quais os elementos que suportarão os carregamentos provindos das ações verticais e horizontais.

No caso dos edifícios em alvenaria estrutural, os elementos componentes da estrutura são as paredes portantes e as lajes, e, na eventualidade de se terem pilotis, também os pilares e as vigas.

A escolha das paredes portantes é condicionada por fatores como a utilização da edificação, a existência ou não de simetria na estrutura, passagem de tubulações e outros.

O fator passagem de tubulações já foi analisado no capítulo anterior. Portanto, tratar-se-ão por hora das questões da simetria estrutural e da utilização da edificação.

A simetria estrutural afeta a distribuição das ações horizontais. Sabe-se que a distribuição das paredes é responsável pela rigidez do edifício. Estruturas de 
contraventamento significativamente assimétricas devem ser evitadas, sem contudo comprometer a geometria definida na arquitetura. Quando a ação do vento se dá segundo um eixo de simetria da estrutura, as lajes apenas transladam nessa direção. Entretanto, se a mesma se dá segundo um eixo que não seja de simetria, ocorrem também rotações que provocam a torção do edifício. Estes esforços são indesejáveis por tornarem o cálculo da distribuição da ações mais complexo.

Segundo HENDRY (1981), o arranjo em planta das paredes estruturais de um edifício é importante para fornecer resistência e rigidez lateral ao mesmo, assim como para suportar a ocorrência de um possível dano localizado, sem contudo permitir um colapso progressivo.

Com relação à utilização da edificação, HENDRY (1981) classifica os sistemas estruturais em:

\section{a) Sistema de paredes transversais}

Neste sistema, as lajes são armadas em uma única direção e apoiam-se nas paredes estruturais perpendiculares ao eixo do edifício. As paredes das fachadas longitudinais não são portantes (Figura 3.1).

É um sistema bastante utilizável em edifícios de planta retangular e alongada, e suas aplicações principais são em hotéis, hospitais, escolas, etc..

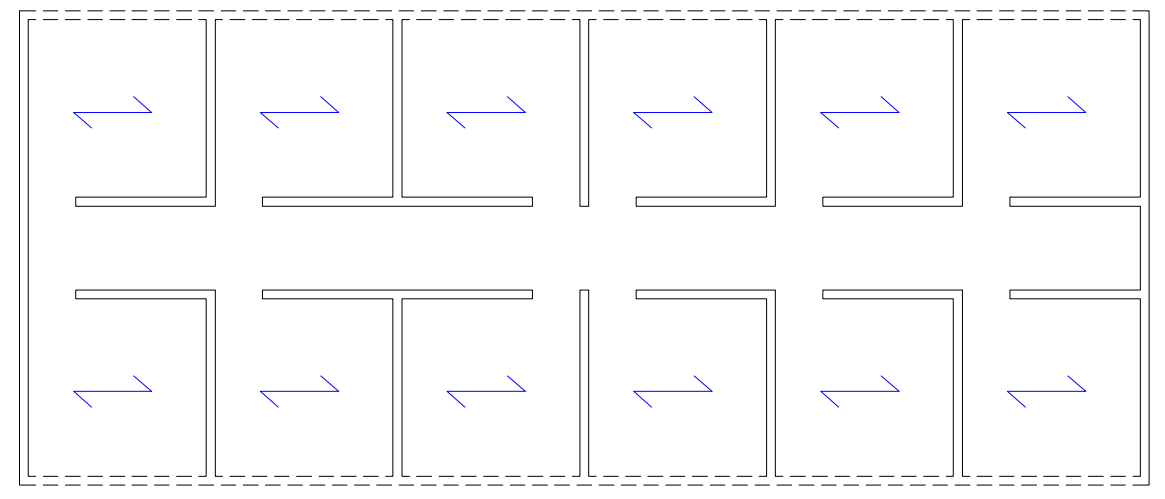

FIGURA 3.1 - Sistema de paredes transversais [adaptado de HENDRY (1981)] 
b) Sistema de paredes celulares

Neste sistema, as lajes são armadas em duas direções e todas as paredes são estruturais (Figura 3.2).

A vantagem deste sistema em relação ao anterior é que as ações verticais e horizontais se distribuem entre um número maior de paredes, que ficam menos solicitadas. Outra vantagem do sistema é proporcionar contraventamento para resistir às ações horizontais em qualquer direção.

As principais aplicações do sistema de paredes celulares são em edifícios residenciais em geral.

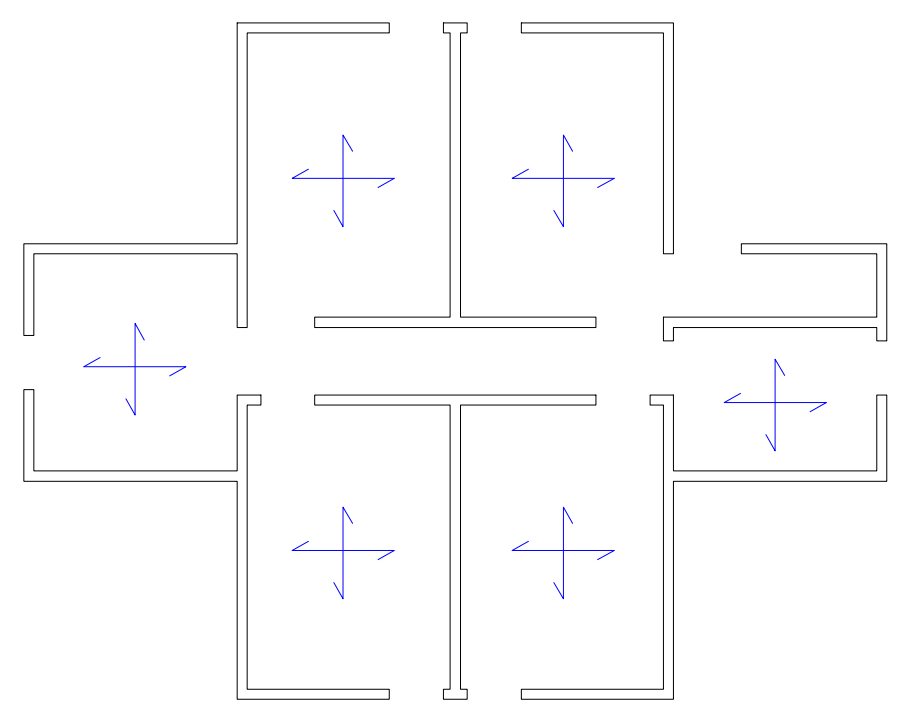

FIGURA 3.2 - Sistema de paredes celulares [adaptado de HENDRY (1981)]

c) Sistema complexo

Este sistema é uma combinação dos sistemas anteriores, ou seja, é a utilização de cada um deles em regiões distintas da edificação. Pode haver algumas paredes externas não estruturais, mas a maioria é estrutural.

O sistema é bastante utilizado em edifícios de planta mais complexa, como o exemplo da Figura 3.3. 


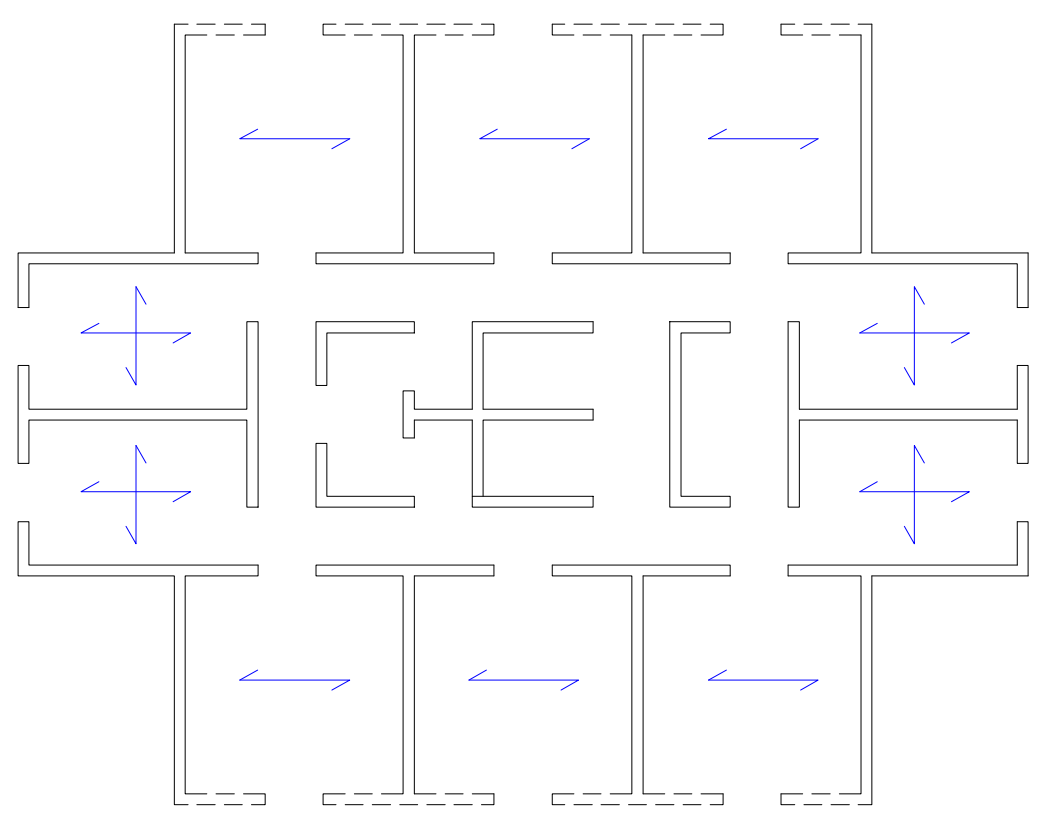

FIGURA 3.3 - Sistema complexo [adaptado de HENDRY (1981)]

A utilização da classificação dos sistemas estruturais segundo HENDRY (1981), embora tradicional, não é necessária para a concepção estrutural. Mais importante que a classificação é a identificação, em cada caso, do arranjo mais adequado. Para edificações mais altas, as paredes estruturais não devem estar dispostas em apenas uma direção, a fim de proporcionar contraventamento para resistir às ações horizontais em qualquer uma delas. Além disso, a não existência de paredes estruturais em uma das direções compromete os apoios para as lajes.

Existem alguns pontos importantes para tomada de decisão com relação à concepção estrutural, que serão aqui tratados. O primeiro deles, com relação às lajes, é que para acertar o módulo vertical das paredes é necessário que se tenham lajes de mesma espessura. Para isto, não se devem ter vãos muito distintos que possam inviabilizar a uniformidade. No Brasil, quando se utiliza o bloco "J " na última fiada, é usual fazer a laje $\operatorname{com} \mathrm{h}=8 \mathrm{~cm}$, quando maciça (Figura 3.4). Portanto, a concepção estrutural deve ser tal que permita vencer os vãos com esta espessura. 


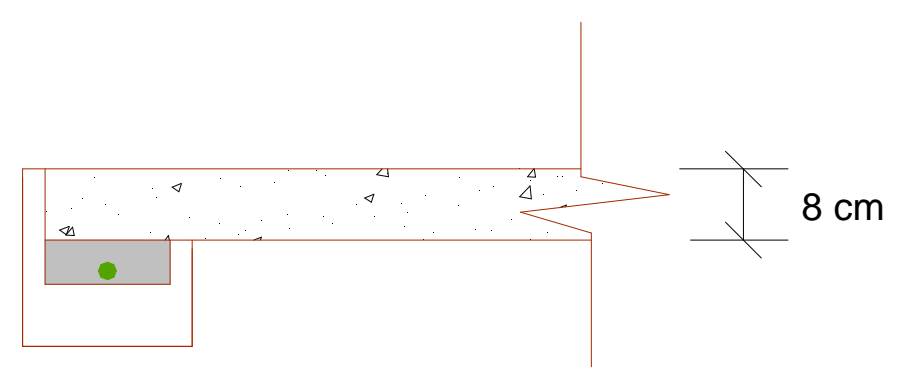

FIGURA 3.4 - Detalhe da laje sobre o bloco "J"

Outro ponto importante para a tomada de decisão é a existência ou não de rebaixos nas lajes. Deve-se lembrar que no caso de emprego da laje de $\mathrm{h}=8 \mathrm{~cm}, 0$ rebaixo máximo permitido é de $1 \mathrm{~cm}$, pois as lajes de piso não devem ter espessura inferior a $7 \mathrm{~cm}$ [ABNT (NB-1)].

Se a laje rebaixada estiver em balanço, como no caso de sacadas, é necessário que se faça uma ligação que promova engastamento entre esta e a laje adjacente, semelhante às ligações das estruturas de concreto armado, envolvendo o uso de formas, concreto e armadura (Figura 3.5).

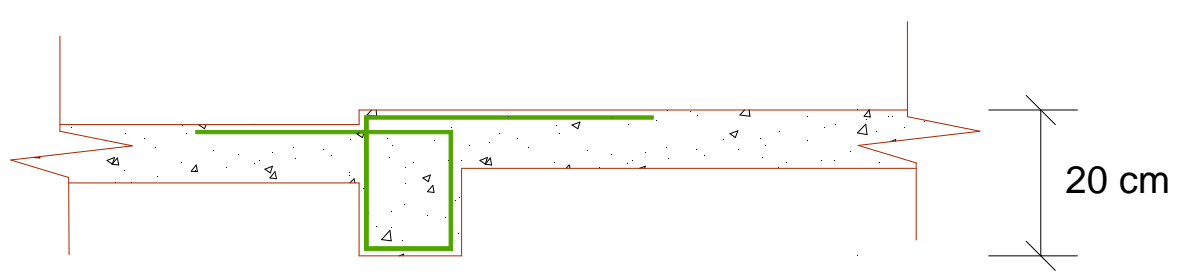

FIGURA 3.5 - Ligação de engastamento entre duas lajes em desnível

\subsubsection{Análise estrutural}

A análise estrutural engloba todos os procedimentos necessários à determinação dos esforços para os elementos lineares, e das tensões para os demais elementos, de modo que se possa dimensionar todos os elementos da estrutura considerada. 
"Os carregamentos atuantes e os esforços resultantes nas lajes, bem como as reações destes carregamentos nas paredes são determinados da maneira usual adotada para estruturas em concreto armado, conforme as normas específicas." (SILVA, 1996, p.11)

\subsection{Determinação das ações verticais}

As principais ações verticais atuantes nas paredes estruturais são o seu peso próprio e as reações das lajes.

O peso próprio das paredes é obtido pela multiplicação do peso específico da alvenaria estrutural $(\gamma$ ) pela espessura do bloco e pela altura da parede.

Para a determinação do peso específico da alvenaria estrutural $(\gamma)$ deve-se fazer uma composição dos pesos específicos aparentes de seus componentes (bloco e revestimento). A seguir encontra-se um exemplo de como isto é feito.

Seja o bloco da Figura 3.6 de dimensões 14×39x19 revestido com gesso em uma das faces e com argamassa de cimento, cal e areia nas demais.

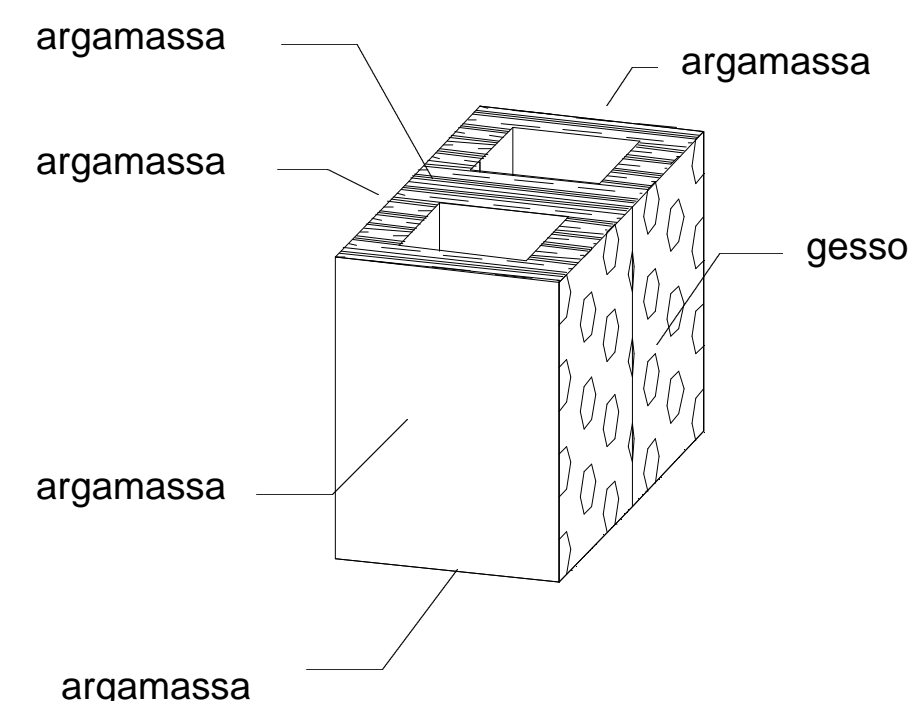

FIGURA 3.6 - Bloco revestido com argamassa e gesso

O peso específico da alvenaria estrutural $(\gamma)$, neste caso, pode ser calculado fazendo a composição do peso específico aparente do bloco, $\gamma_{\mathrm{ap}}=12 \mathrm{kN} / \mathrm{m}^{3}$, com o peso específico aparente da argamassa, $\gamma_{\mathrm{a}}=19 \mathrm{kN} / \mathrm{m}^{3}$, e 
com o peso específico aparente do gesso, $12,5 \mathrm{kN} / \mathrm{m}^{3}$, dados estes retirados da ABNT (NB-5). Tem-se, portanto:

$$
\begin{aligned}
& \gamma=\frac{(0,14 \times 0,19 \times 0,39) 12+2[(0,14 \times 0,19 \times 0,05)+(0,14 \times 0,05 \times 0,39)] 19}{0,15 \times 0,20 \times 0,40}+ \\
& +\frac{(0,39 \times 0,19 \times 0,05) 19+(0,39 \times 0,19 \times 0,05) 12,5}{0,15 \times 0,20 \times 0,40}=32,96 \mathrm{kN} / \mathrm{m}^{3}
\end{aligned}
$$

O peso específico real do bloco de concreto é, segundo a ABNT (NB-5), $24 \mathrm{kN} / \mathrm{m}^{3}$. Supondo, em média, que os vazados correspondam a $50 \%$ da área bruta do bloco, estima-se que o peso específico aparente do mesmo seja $12 \mathrm{kN} / \mathrm{m}^{3}$. Deve-se atentar para o fato de que, quando houver grauteamento, o peso específico do bloco, a ser considerado, deve ser $\gamma=24 \mathrm{kN} / \mathrm{m}^{3}$, que é o peso específico aparente do concreto.

Nas lajes devem ser consideradas agindo as ações permanentes (peso próprio, revestimento, piso, paredes não-estruturais) e as variáveis (sobrecarga devido à utilização).

As lajes descarregam sobre as paredes estruturais que the servem de apoio. Há vários processos para cálculo destas reações, entre eles o das linhas de ruptura, as Tabelas de Marcus, as Tabelas de Czerny, a Teoria da Elasticidade e outros. A ABNT (NRB-6118) sugere, para lajes retangulares com cargas uniformemente distribuídas, o procedimento das linhas de ruptura.

Não se deve esquecer que as paredes estruturais são apoios rígidos para as lajes, ao contrário das vigas em uma estrutura de concreto armado, permitindo melhor adequação às hipóteses usuais de cálculo com as tabelas disponíveis dos processos acima mencionados. Entretanto, este fato faz com que a rotação dos cantos das lajes sobre os apoios rígidos seja maior, o que sugere, com maior intensidade, o emprego de armaduras de canto nas lajes apoiadas para resistirem ao momento volvente. Segundo PARSEKIAN (1996), alguns projetistas utilizam, para o cálculo das lajes, procedimentos que consideram a contribuição do momento volvente, porém as detalham utilizando os valores de momentos fletores normais às suas direções preferenciais e desconsideram o valor do momento volvente. Na prática, os efeitos da desconsideração do momento volvente no 
detalhamento é sentida apenas em regiões onde os valores deste momento são relativamente altos, o que acontece neste sistema construtivo, nos cantos.

Ainda com relação às lajes, deve ser feita uma definição clara quanto à utilização ou não de armaduras negativas, para que se possa adequar o modelo de cálculo. Elas são importantes para o combate ao momento volvente nos cantos e absolutamente necessárias ao equilíbrio das sacadas.

Além da questão do cálculo, o emprego ou não de armaduras negativas é um ponto importante de tomada de decisão, uma vez que elas podem ser necessárias para alterar o fluxo de cargas a fim de se evitarem acúmulos de tensão em determinadas paredes. Outro ponto importante é o cuidado que se deve ter com as fissuras, que em geral são invisíveis sobre os apoios (Figura 3.7), mas nem sempre. Neste caso, é necessário consultar o construtor a respeito de usar a armadura ou correr o risco de uma fissura exposta, em especial quando o piso é entregue sem revestimento superior.

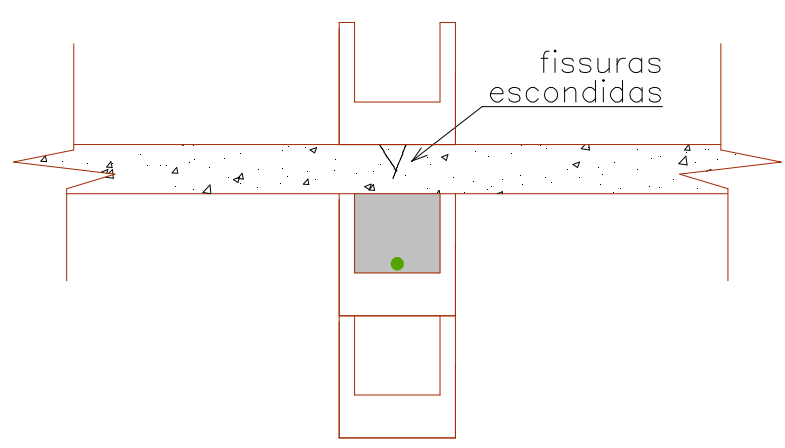

FIGURA 3.7 - Fissuras sobre apoios

\subsection{Determinação das ações horizontais}

As principais ações horizontais que devem ser consideradas no Brasil são a ação do vento e o desaprumo. No caso de áreas sujeitas a abalos sísmicos, a sua consideração é indispensável no cálculo do edifício.

O vento atua sobre as paredes dispostas na direção perpendicular à sua direção, as quais passam a ação às lajes dos pavimentos. Sendo as lajes diafragmas rígidos no seu plano, distribuem parcelas da ação do vento aos painéis de contraventamento, proporcionalmente à rigidez de cada um (Figura 3.8). Os 
painéis de contraventamento são, portanto, no caso de não haver torção do edifício, aqueles paralelos à direção do vento. Uma vez que, usualmente, o vento atua nas duas direções preferenciais de um edifício, considera-se um grupo de painéis em cada direção.

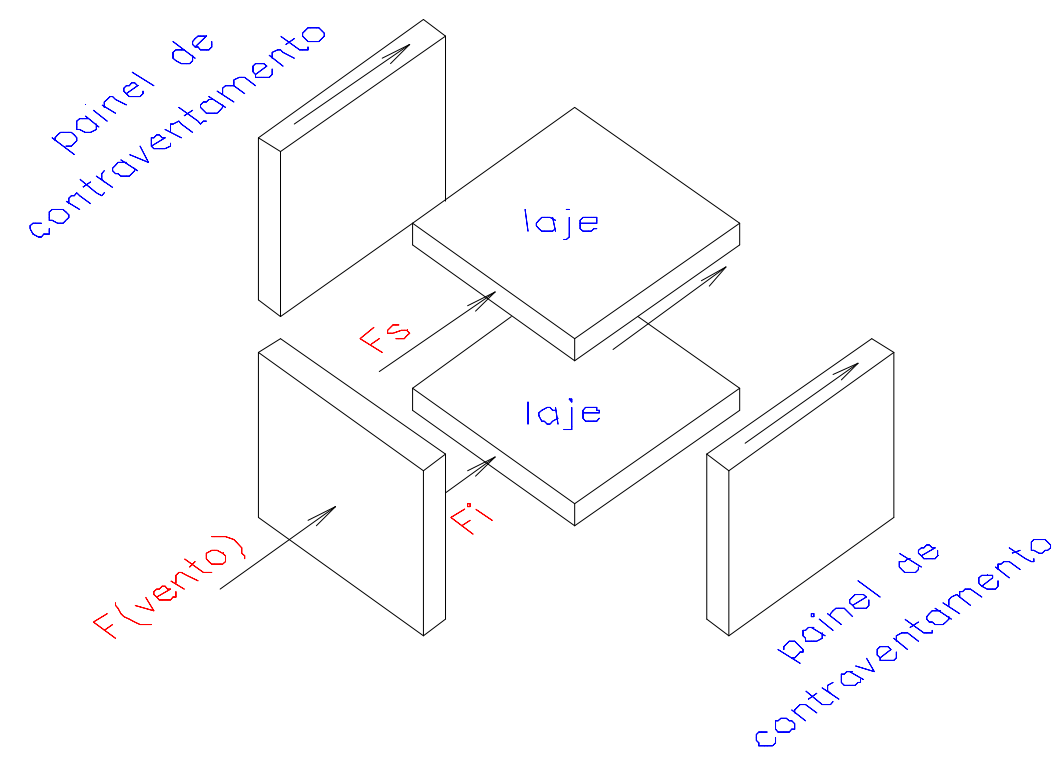

FIGURA 3.8 - Distribuição das ações do vento entre painéis de contraventamento [SILVA (1996)]

Para a determinação das ações do vento utilizam-se as prescrições da ABNT (NBR-6123).

Segundo SILVA (1996), em termos de análise do efeito do vento em uma edificação é necessário determinar a componente da força global na direção do vento, a chamada força de arrasto, dada pela seguinte expressão retirada da referida norma:

$$
F=C_{a} \cdot q \cdot A_{e}
$$


onde:

$q=$ pressão de obstrução $\left[\mathrm{N} / \mathrm{m}^{2}\right]$

$A_{e}=$ área da superfície onde o vento atua $\left[\mathrm{m}^{2}\right]$

$\mathrm{C}_{\mathrm{a}}=$ coeficiente de arrasto

O coeficiente de arrasto $\left(C_{a}\right.$ ) depende da direção e do regime do vento. Se for vento de baixa turbulência, consultar 0 gráfico da Figura 4 da ABNT (NBR-6123), se for de alta turbulência, consultar o gráfico da Figura 5 da mesma referência.

A pressão de obstrução ( q ) é calculada através da eq.(3.2):

$$
q=0,613 \cdot v_{k}^{2}
$$

onde:

$$
\mathrm{V}_{\mathrm{k}}=\text { velocidade característica do vento }[\mathrm{m} / \mathrm{s}]
$$

Por fim, a velocidade característica é obtida pela eq.(3.3):

$$
\mathrm{v}_{\mathrm{k}}=\mathrm{S}_{1} \cdot \mathrm{S}_{2} \cdot \mathrm{S}_{3} \cdot \mathrm{v}_{0}
$$

onde:

$\mathrm{v}_{0}=$ velocidade básica do vento (isopletas da Figura 1)

$\mathrm{S}_{1}=$ fator topográfico (item 5.2)

$\mathrm{S}_{2}=$ fator de rugosidade e regime (Tabela 2)

$\mathrm{S}_{3}=$ fator estatístico (Tabela 3)

Obs.: As figuras e tabelas mencionadas acima referem-se à ABNT (NBR-6123).

CORRÊA \& RAMALHO (1996) sugerem que o desaprumo seja considerado tomando por base a norma alemã DIN 1053.

A ação lateral equivalente ao desaprumo, a ser aplicada ao nível de cada pavimento, é dada pela eq.(3.4): 


$$
F_{d}=\Delta P \cdot \varphi
$$

onde:

$$
\begin{aligned}
\Delta \mathrm{P} & =\text { peso total do pavimento considerado } \\
\varphi & =\text { ângulo para o desaprumo do eixo da estrutura (em radianos) }
\end{aligned}
$$

O ângulo para o desaprumo do eixo da estrutura é dado eq.(3.5):

$$
\varphi=\frac{1}{100 \sqrt{\mathrm{H}}}
$$

onde:

$\mathrm{H}=$ altura total da edificação [m]

A Figura 3.9 esclarece os parâmetros que aparecem nas equações:
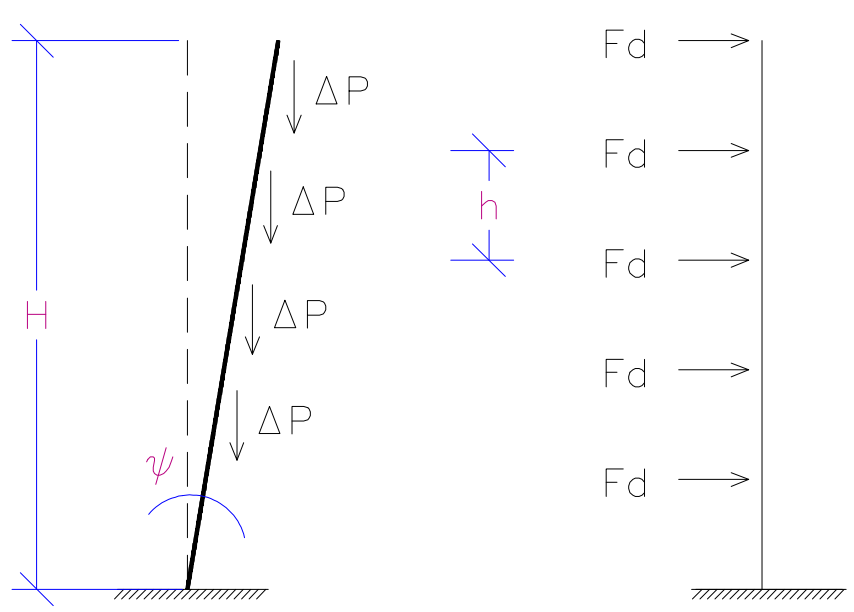

FIGURA 3.9 - Parâmetros para cálculo do desaprumo

De acordo com a ABNT (NBR-8798), o desaprumo máximo permitido é $1: 400$, o que equivale a $\varphi=0,0025 \mathrm{rad}$. Para que este valor pudesse ser alcançado, seria preciso que todas as paredes fossem construídas com inclinação 
para o mesmo lado, o que, na prática, tem pouquíssima probabilidade de acontecer. Por isso, parece mais indicado o critério da norma DIN 1053 para o cálculo do desaprumo, pois, de acordo com ela, o ângulo de desaprumo tende a diminuir com o aumento da altura. Isso é bem razoável, já que se pode corrigir o prumo do prédio à medida que se constróem mais andares.

Não é objetivo deste capítulo tratar das ações sísmicas, uma vez que não ocorrem no Brasil. Para a sua definição recomenda-se consultar normas específicas do local onde será construída a edificação.

\subsection{Distribuição das ações verticais}

Nos edifícios em alvenaria estrutural, as paredes são normalmente solicitadas de maneira bastante diferenciada umas das outras. Isto levaria a diversas especificações de resistências de blocos para um mesmo pavimento, o que não é recomendável por razões óbvias. Assim sendo, a parede mais carregada tenderia a definir a resistência dos blocos a serem utilizados para todas as paredes do pavimento, o que oneraria em excesso o custo da obra.

Segundo OLIVEIRA JR. \& PINHEIRO (1994b), estudos realizados têm mostrado que as paredes estruturais, trabalhando em conjunto com as lajes, possuem capacidade de distribuição das ações, o que conduz a efeitos favoráveis na redução das resistências necessárias e ao comportamento estrutural das mesmas, pois as mais carregadas servem das menos solicitadas para aliviarem seus excessos.

Quanto maior for a uniformização das cargas verticais ao longo da altura da edificação, maior a economia obtida, pois haverá uma tendência à redução das resistências dos blocos a serem especificados. Entretanto, se a suposta uniformização não ocorrer na prática, corre-se o risco de uma redução significativa da segurança da edificação. Para que tal uniformização se dê de fato, é preciso que as paredes estejam diretamente amarradas, conforme capítulo anterior. A pior condição em que não ocorreria uniformização seria a de paredes não amarradas e lajes armadas em apenas uma direção, devendo ser evitada sempre que possível.

Conforme CORRÊA \& RAMALHO (1994b), dois pontos básicos devem estar bem estabelecidos para que o projetista possa desenvolver sua análise: como 
tratar a ação das lajes sobre as paredes estruturais e como simular a interação destas paredes.

Para a consideração da ação das lajes sobre as paredes que the servem de apoio, um procedimento muito simples consiste em considerar as paredes isoladas entre si e recebendo as reações das lajes, que podem ser calculadas segundo os procedimentos convencionais utilizados para o cálculo de estruturas de concreto armado, prescritos na ABNT (NB-1). A rigor, as lajes não carregam as paredes de maneira uniforme. Entretanto, CORRÊA \& RAMALHO (1990-1992) mostraram, através de simulações teóricas com a utilização do Método dos Elementos Finitos, que as diferenças nas cargas aplicadas pelas lajes em uma parede tendem a desaparecer à medida que se afastam da região de aplicação. Isto ocorre devido aos vínculos promovidos pelas outras paredes, associadas entre si pela laje.

Encontram-se, a seguir, alguns procedimentos utilizados para se fazer a distribuição das ações verticais, suas vantagens e desvantagens.

\subsubsection{Paredes isoladas}

Trata-se de considerar as paredes não interagindo entre si, isto é, independentes umas das outras. É um procedimento simples, rápido e seguro ${ }^{6}$, porém anti-econômico, pois resulta em especificação de blocos com resistências relativamente elevadas.

Além disso, de acordo com CORRÊA \& RAMALHO (1994b), é fato comprovado teórica e experimentalmente a interação de paredes, mesmo que não estejam alojadas em um mesmo plano vertical e desde que estejam ligadas por linhas de interseção verticais providas pela amarração.

\footnotetext{
${ }^{6}$ Do ponto de vista das paredes. Deve-se ter cuidado com as fundações.
} 


\subsubsection{Grupos isolados de paredes}

SUTHERLAND (1969) ${ }^{7}$ apud HENDRY (1981) propõe que o pavimento seja dividido em áreas de influência em torno de grupos de paredes interligadas, separados uns dos outros por aberturas. Este procedimento é bastante interessante, pois contempla o fato de que paredes interligadas interagem, com tendência de uniformização de tensões ao longo da altura do edifício.

Admitem-se as cargas totalmente uniformizadas em cada grupo de paredes considerado, mas que não interagem uns com os outros.

Também é um procedimento simples, porém um pouco mais trabalhoso que o anterior, podendo se tornar pouco econômico ou inseguro dependendo dos grupos considerados. A definição dos grupos fica a cargo do projetista, não havendo regras bem definidas que possam orientar este trabalho. Existe alguma indicação que consiste em separá-los pelas aberturas, sendo esta uma regra segura. É muito importante nesta ocasião a experiência do profissional, pois escolhas incorretas podem resultar em especificações inadequadas de resistências de blocos.

\subsubsection{Grupos de paredes com interação}

A diferença entre este procedimento e o anterior é que os grupos anteriormente definidos agora interagem segundo uma taxa pré-definida, formando macrogrupos. Esta idéia é baseada no fato de que há interação de grupos quando houver alvenaria entre a abertura e a laje (Figura 3.10).

${ }^{7}$ SUTHERLAND, R. J. M. (1969). Design engineer's approach to masonry construction. In: DESIGNING, ENGINEERING AND CONSTRUCTING WITH MASONRY PRODUCTS. Houston, U.S.A., Ed. F. B. Johnson Gulf, p. 375-385. apud CORRÊA \& RAMALHO (1994b) p. 314 


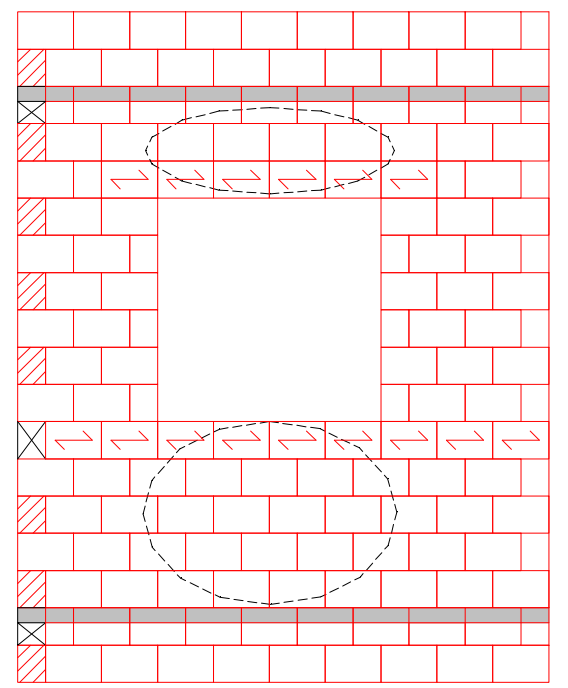

FIGURA 3.10 - Alvenaria entre a abertura e a laje

A taxa de interação representa a parcela da diferença de cargas que deve ser uniformizada em cada nível entre os grupos que interagem. Ela pode ser estimada mediante modelo teórico ou por algum procedimento experimental que esteja disponível durante o desenvolvimento do projeto. $\mathrm{Na}$ falta deste, pode-se adotar, para a uniformização das diferenças das cargas verticais entre os grupos, o modelo da ABNT (NBR-10837), embora conservador, que é o espalhamento a $45^{\circ}$. Atualmente está sendo desenvolvida uma pesquisa no SET-EESC-USP, buscando definir taxas de interação seguras e com respaldo teórico e experimental.

É muito importante que se definam quais os grupos de paredes que estão interagindo, pois grupos com diferenças de cargas muito grandes não devem tê-las uniformizadas entre si.

Mais uma vez, neste procedimento é essencial a experiência do projetista, tanto na escolha dos macrogrupos como na determinação da taxa de interação, pois são fatores que levam a diferenças apreciáveis nas cargas das paredes, podendo afetar de maneira significativa a segurança e a economia. 


\subsubsection{Modelagem tridimensional em elementos finitos}

Trata-se do procedimento ideal, entretanto ainda não viável para projetos usuais, devido ao grande esforço computacional envolvido e o tempo necessário para a modelagem.

Consiste em modelar a estrutura com elementos de membrana ou chapa, colocando os carregamentos no nível de cada pavimento. A uniformização se dá através da compatibilização dos deslocamentos ao nível de cada andar.

O processo apresenta como inconveniente a dificuldade de montagem dos dados e de interpretação dos resultados.

É imprescindível, além de pré e pós-processadores eficientes para a manipulação de dados e resultados, um processador preciso e de grande capacidade para produzir a análise estrutural do edifício.

\subsubsection{Exemplos de aplicação}

\section{Exemplo 1}

Para maior clareza dos procedimentos de distribuição das ações verticais será feito um pequeno exemplo comparando todos eles, com exceção do procedimento de modelagem tridimensional em elementos finitos. Este exemplo foi retirado de CORRÊA \& RAMALHO (1996), sendo feitas as modificações necessárias para adequá-lo ao presente trabalho.

Considere parte de um pavimento do projeto arquitetônico de um edifício de 7 (sete) pavimentos em alvenaria estrutural, executado com blocos de $14 \mathrm{~cm}$ de espessura (Figura 3.11), sendo os dados referentes ao mesmo encontrados na Tabela 3.1. 


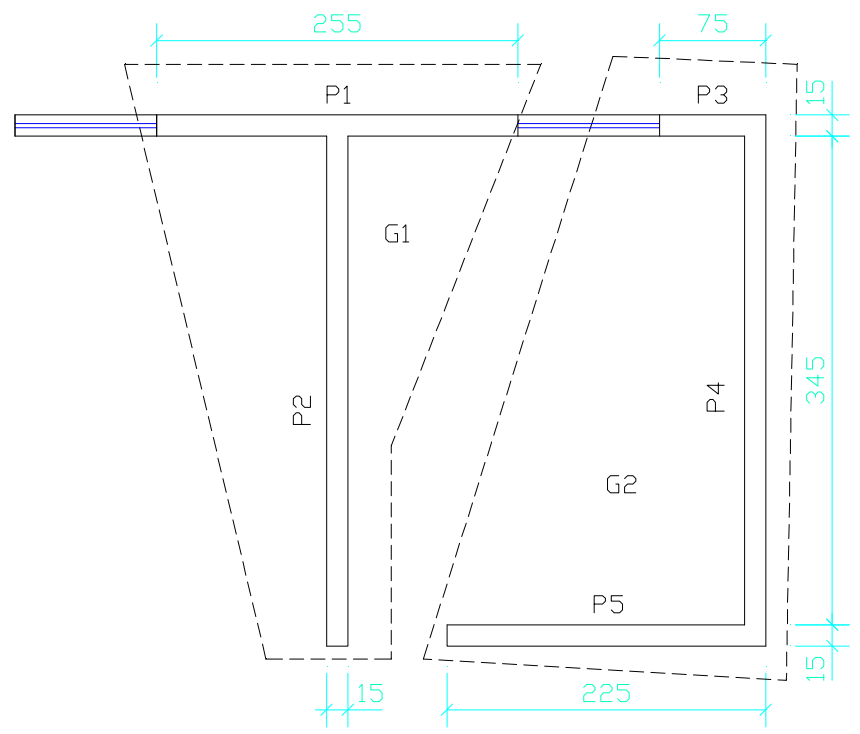

FIGURA 3.11 - Planta do exemplo 1

TABELA 3.1 - Dados do exemplo 1

\begin{tabular}{|c|c|c|c|}
\hline PAREDE & $\begin{array}{c}\text { COMPR. } \\
(\mathrm{m})\end{array}$ & $\begin{array}{c}\text { REAÇÃO DA } \\
\text { LAJE }(\mathrm{kN} / \mathrm{m})\end{array}$ & $\begin{array}{c}\text { P. PRÓPRIO } \\
(\mathrm{kN} / \mathrm{m})\end{array}$ \\
\hline P1 & 2,55 & 7,50 & 5,50 \\
\hline P2 & 3,60 & 12,75 & 5,50 \\
\hline P3 & 0,75 & 5,50 & 5,50 \\
\hline P4 & 3,45 & 6,00 & 5,50 \\
\hline P5 & 2,25 & 15,25 & 5,50 \\
\hline
\end{tabular}

Utilizando o procedimento das paredes isoladas, para encontrar a carga em uma parede em um determinado nível, basta multiplicar o valor descarregado por um pavimento pelo número de pavimentos acima do nível considerado. Dividindo o valor da carga distribuída pela espessura da parede encontram-se as tensões normais. A Tabela 3.2 fornece os resultados do cálculo. 
TABELA 3.2 - Resultados considerando paredes isoladas

\begin{tabular}{|c|c|c|c|}
\hline PAREDE & $\begin{array}{c}\text { CARGA 7 } \\
\text { PAV. } \\
(\mathrm{kN} / \mathrm{m})\end{array}$ & CARGA 1 $^{\circ}$ PAV. & $\begin{array}{c}\text { TENSÃO }{ }^{\circ} \\
\text { PAV. } \\
(\mathrm{kN} / \mathrm{m})\end{array}$ \\
\hline P1 & 13,00 & 91,00 & 650,00 \\
\hline P2 & 18,25 & 127,75 & 912,50 \\
\hline P3 & 11,00 & 77,00 & 550,00 \\
\hline P4 & 11,50 & 80,50 & 575,00 \\
\hline P5 & 20,75 & 145,25 & 1037,50 \\
\hline
\end{tabular}

Considere agora o procedimento de grupos isolados de paredes. Os grupos a serem considerados são os definidos na Figura 3.11. O cálculo consiste em se determinarem as cargas totais de cada parede, e assim as cargas totais de cada grupo. A seguir calculam-se as cargas distribuídas em cada grupo e, a partir delas, as tensões normais nas paredes componentes dos grupos.

Observar que os grupos foram definidos de forma a comportarem paredes que se interceptam e são separados uns dos outros por aberturas.

Os resultados dos cálculos para este procedimento encontram-se na Tabela 3.3. 
TABELA 3.3 - Resultados considerando grupos de paredes sem interação

\begin{tabular}{|c|c|c|c|c|c|}
\hline GRUPO & PAREDE & COMP. & $\begin{array}{c}\text { CARGA 7 } \\
\text { PAV. } \\
(\mathrm{kN} / \mathrm{m})\end{array}$ & $\begin{array}{c}\text { CARGA 7 } \\
\text { PAV. } \\
(\mathrm{kN})\end{array}$ & CARGA GRUPO \\
\hline \multirow{2}{*}{ G1 } & P1 & 2,55 & 13,00 & 33,15 & \multirow{2}{*}{98,85} \\
\cline { 2 - 5 } & P2 & 3,60 & 18,25 & 65,70 & \\
\hline \multirow{3}{*}{ G2 } & P3 & 0,75 & 11,00 & 8,25 & \multirow{2}{*}{94,61} \\
\cline { 2 - 5 } & P4 & 3,45 & 11,50 & 39,68 & \\
\cline { 2 - 5 } & P5 & 2,25 & 20,75 & 46,69 & \\
\hline
\end{tabular}

\begin{tabular}{|c|c|c|c|c|c|}
\hline PAV. & GRUPO & COMP. & $\begin{array}{c}\text { CARGA } \\
\text { GRUPO } \\
(\mathrm{kN})\end{array}$ & $\begin{array}{c}\text { CARGA } \\
\text { GRUPO } \\
(\mathrm{kN} / \mathrm{m})\end{array}$ & TENSÃO \\
\hline \multirow{2}{*}{7} & G1 & 6,15 & 98,85 & 16,07 & 114,81 \\
\cline { 2 - 6 } & G2 & 6,45 & 94,61 & 14,67 & 104,77 \\
\hline \multirow{2}{*}{1} & G1 & 6,15 & 691,95 & 112,51 & 803,66 \\
\cline { 2 - 6 } & G2 & 6,45 & 662,27 & 102,68 & 733,41 \\
\hline
\end{tabular}

Refazendo o exemplo, considerando agora o procedimento de grupos de paredes com interação, e adotando uma taxa de uniformização do diferencial de carga de $30 \%$, obtêm-se os resultados mostrados na Tabela 3.4. 
TABELA 3.4 - Resultados considerando grupos de paredes com interação

\begin{tabular}{|c|c|c|c|c|c|c|}
\hline PAV. & $\begin{array}{c}\text { C. MÉDIA } \\
(\mathrm{kN} / \mathrm{m})\end{array}$ & GRUPO & $\begin{array}{c}\text { CARGA } \\
(\mathrm{kN} / \mathrm{m})\end{array}$ & $\begin{array}{c}\Delta \text { CARGA } \\
(\mathrm{kN} / \mathrm{m})\end{array}$ & $\begin{array}{c}\text { CAR. UNIF. } \\
(\mathrm{kN} / \mathrm{m})\end{array}$ & $\begin{array}{c}\text { TENSÃO } \\
\left(\mathrm{kN} / \mathrm{m}^{2}\right)\end{array}$ \\
\hline 7 & 15,36 & G1 & 16,07 & $-0,213$ & 15,86 & 113,26 \\
\cline { 3 - 7 } & & G2 & 14,67 & 0,207 & 14,88 & 106,26 \\
\hline 6 & \multirow{2}{*}{30,72} & G1 & 31,93 & $-0,363$ & 31,57 & 225,48 \\
\cline { 3 - 7 } & & G2 & 29,55 & 0,351 & 29,90 & 213,58 \\
\hline 5 & \multirow{2}{*}{46,08} & G1 & 47,64 & $-0,468$ & 47,17 & 336,94 \\
\cline { 3 - 7 } & & G2 & 44,57 & 0,453 & 45,02 & 321,59 \\
\hline 4 & \multirow{2}{*}{61,44} & G1 & 63,24 & $-0,540$ & 62,70 & 447,86 \\
\cline { 3 - 7 } & & G2 & 59,69 & 0,525 & 60,22 & 430,11 \\
\hline 3 & \multirow{2}{*}{76,8} & G1 & 78,77 & $-0,591$ & 78,18 & 558,42 \\
\cline { 3 - 7 } & & G2 & 74,89 & 0,573 & 75,46 & 539,02 \\
\hline 2 & \multirow{2}{*}{92,16} & G1 & 94,25 & $-0,627$ & 93,62 & 668,74 \\
\cline { 3 - 7 } & & G2 & 90,13 & 0,609 & 90,74 & 648,14 \\
\hline 1 & \multirow{2}{*}{107,52} & G1 & 109,69 & $-0,651$ & 109,04 & 778,85 \\
\cline { 3 - 7 } & & G2 & 105,41 & 0,633 & 106,04 & 757,45 \\
\hline
\end{tabular}

Neste caso, foi calculada uma carga média para o grupo, que é uma média ponderada das cargas de cada grupo com ponderador igual ao comprimento total em planta das paredes do grupo. Por exemplo, para o $7^{\circ}$ pavimento, a carga média foi calculada pela seguinte expressão:

$$
C_{\text {med }}=\frac{16,07 \times 6,15+14,67 \times 6,45}{6,15+6,45}=15,36
$$

A seguir foi montada a coluna do diferencial de carga ( $\Delta$ Carga), cuja expressão é dada pela eq.(3.6):

$$
\Delta \text { Carga }=(\text { C.Med. }- \text { C.Linear }) \times 0,30
$$

$\lfloor$ taxa de uniformização 
A carga uniformizada foi então obtida através da correção da carga do grupo pelo diferencial de carga. A partir dela, calculou-se a tensão no grupo.

Conclusão:

Comparando os resultados dos três procedimentos na Tabela 3.5, tem-se para o $1^{\circ}$ pavimento:

TABELA 3.5 - Comparação dos três procedimentos

\begin{tabular}{|c|c|c|c|c|}
\hline GRUPO & PAREDE & PROCEDIMENTO & $\begin{array}{l}\text { TENSÃO } \\
\left(\mathrm{kN} / \mathrm{m}^{2}\right)\end{array}$ & $\begin{array}{c}\text { VARIAÇÕES } \\
(\%)\end{array}$ \\
\hline \multirow{6}{*}{1} & \multirow{3}{*}{ P1 } & par. isoladas & 650,0 & \\
\hline & & $\begin{array}{c}\text { grupos sem } \\
\text { interação }\end{array}$ & 803,7 & $+23,6$ \\
\hline & & $\begin{array}{c}\text { grupos com } \\
\text { interação }\end{array}$ & 778,9 & $+19,8$ \\
\hline & \multirow{3}{*}{ P2 } & par. isoladas & 912,5 & \\
\hline & & $\begin{array}{l}\text { grupos sem } \\
\text { interação }\end{array}$ & 803,7 & $-11,9$ \\
\hline & & $\begin{array}{l}\text { grupos com } \\
\text { interação }\end{array}$ & 778,9 & $-14,6$ \\
\hline \multirow{9}{*}{2} & \multirow{3}{*}{ P3 } & par. isoladas & 550,0 & \\
\hline & & $\begin{array}{c}\text { grupos sem } \\
\text { interação }\end{array}$ & 733,4 & $+33,3$ \\
\hline & & $\begin{array}{l}\text { grupos com } \\
\text { interação }\end{array}$ & 757,4 & $+37,7$ \\
\hline & \multirow{3}{*}{ P4 } & par. isoladas & 575,0 & \\
\hline & & $\begin{array}{l}\text { grupos sem } \\
\text { interação }\end{array}$ & 733,4 & $+27,5$ \\
\hline & & $\begin{array}{c}\text { grupos com } \\
\text { interação }\end{array}$ & 757,4 & $+31,7$ \\
\hline & \multirow{3}{*}{ P5 } & par. isoladas & 1037,5 & \\
\hline & & $\begin{array}{c}\text { grupos sem } \\
\text { interação }\end{array}$ & 733,4 & $-29,3$ \\
\hline & & $\begin{array}{l}\text { grupos com } \\
\text { interação }\end{array}$ & 757,4 & $-27,0$ \\
\hline
\end{tabular}


Pode-se observar que as paredes P1 e P2 são solicitadas de forma bastante diferenciada, gerando tensões de $650,0 \mathrm{kN} / \mathrm{m}^{2}$ e $912,5 \mathrm{kN} / \mathrm{m}^{2}$ em cada uma, respectivamente. A P2, por ser parede interna, recebe uma maior parcela de carga devido às reações das lajes que nela se apoiam, apresentando, portanto, tensão normal no $1^{\circ}$ pavimento bem maior que a $\mathrm{P} 1$, que é externa.

Se a especificação das resistências dos blocos deste pavimento fosse feita considerando as paredes com estas tensões, certamente resultaria em um valor elevado, pois sua determinação seria baseada na parede mais solicitada (P2).

Quando da consideração de grupos de paredes sem interação, as paredes P1 e P2 foram agrupadas no grupo 1, possuindo assim o mesmo valor de tensão $\left(803,7 \mathrm{kN} / \mathrm{m}^{2}\right)$. Observa-se que este valor é intermediário aos valores anteriores de cada uma delas, ou seja, a tensão da P1 aumentou $23,6 \%$ e a da P2 diminuiu 11,9\%. Especificando as resistências dos blocos por esta tensão, seu resultado será menor que no $1^{\circ}$ caso, assegurando com isso maior economia.

No terceiro procedimento, considerou-se que as paredes do grupo 1 interagiram com as do grupo 2 , segundo uma taxa de uniformização de $30 \%$. Isto significa que as paredes mais carregadas (do grupo 1) transferiram parte de suas cargas às menos carregadas (do grupo 2), ficando assim ainda menos solicitadas que no caso anterior. Como conseqüência, a tensão da P1 aumentou 19,8\% e a da P2 diminuiu 14,6\%, valores estes relativos às paredes isoladas, caindo para 778,9 MPa, sendo este procedimento ainda mais econômico que o anterior.

O mesmo estudo pode ser feito para as paredes P3, P4 e P5, pertencentes ao grupo 2, sendo as conclusões análogas.

Quando da consideração de paredes isoladas, verifica-se que a diferença entre a parede mais carregada (P5) e a menos carregada (P3) é de 46,9\%. Ao se considerarem grupos sem interação, a diferença entre os grupos 1 e 2 cai para $8,7 \%$. Finalmente, ao se interagirem os grupos mediante uma taxa de $30 \%$, a diferença entre eles cai para $2,8 \%$, o que promoveria uma mesma especificação de resistências para os blocos deste pavimento.

\section{Exemplo 2}

O exemplo a seguir foi retirado de CORRÊA \& RAMALHO (1994b) e tem por objetivo mostrar as modificações dos valores das cargas atuantes nas paredes estruturais quando se varia a taxa de uniformização. 
Trata-se de um edifício de 10 (dez) pavimentos em alvenaria estrutural não armada, cuja planta do pavimento-tipo está esquematizada na Figura 3.12.

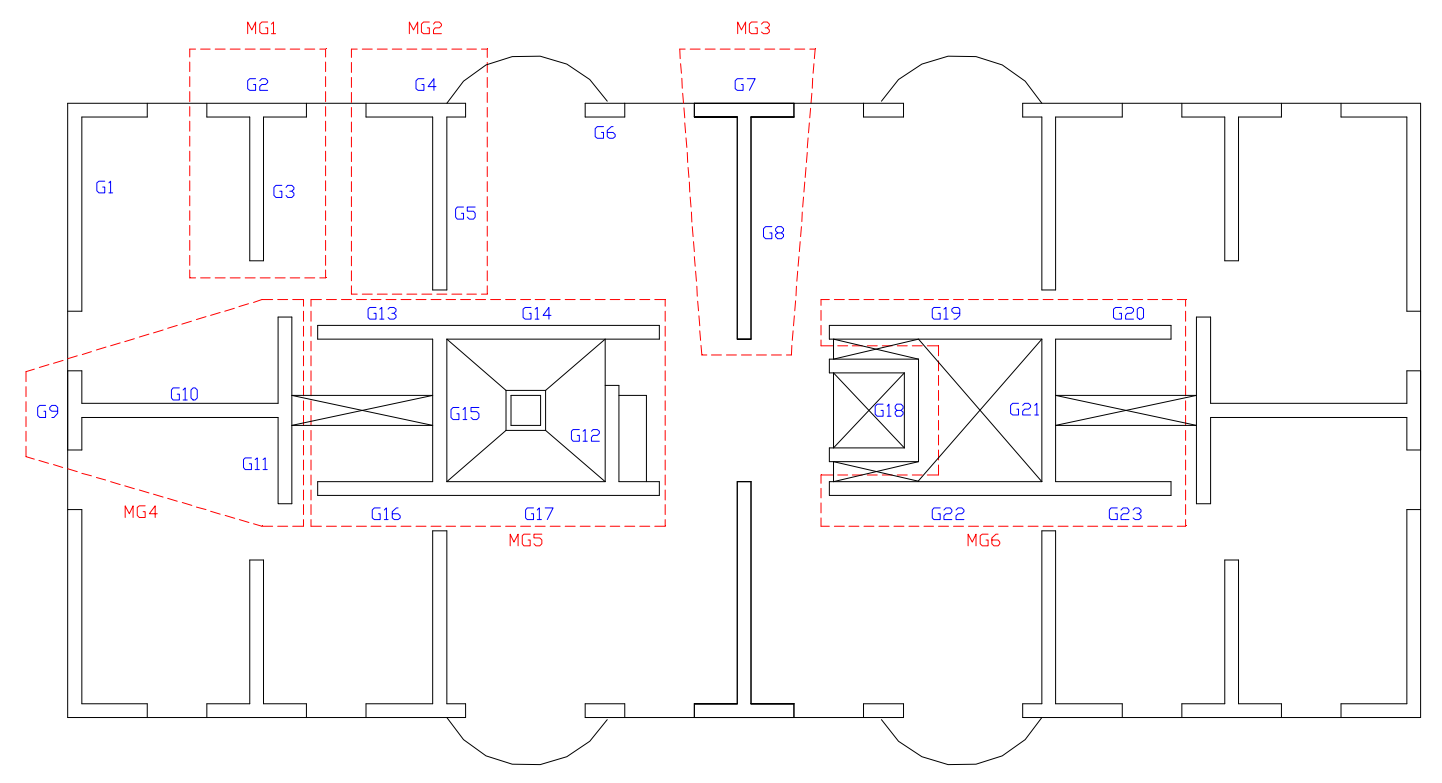

FIGURA 3.12 - Planta do exemplo 2

Os procedimentos de distribuição das ações verticais utilizados serão grupos de paredes sem interação e grupos de paredes com interação. Os grupos e macrogrupos a serem considerados são os definidos na Figura 3.12 pelas letras $G$ e MG respectivamente. Observa-se que a maioria dos grupos é formada por apenas uma parede, com exceção do G1, o que representa, na verdade, o procedimento de paredes isoladas, quando a taxa de interação for nula.

Considerar-se-ão três diferentes taxas de interação, 0, 100\% e 50\% para o procedimento de grupos de paredes com interação. No caso da taxa $=0$ pode-se considerar que esteja-se utilizando o procedimento de grupos de paredes sem interação.

Os resultados obtidos para as cargas distribuídas no nível mais carregado da estrutura, ou seja, no trecho de parede abaixo do $1^{\circ}$ pavimento, são os apresentados na Tabela 3.6. 
TABELA 3.6 - Cargas distribuídas nas paredes abaixo do $1^{\circ}$ pavimento

\begin{tabular}{|c|c|c|c|c|}
\hline $\begin{array}{c}\text { GRUPO } \\
\text { G }\end{array}$ & $\begin{array}{c}\text { MACROGRUPO } \\
\text { MG }\end{array}$ & $\begin{array}{c}\text { CARGA }(\mathrm{kN} / \mathrm{m}) \\
\text { taxa }=0\end{array}$ & $\begin{array}{c}\text { CARGA }(\mathrm{kN} / \mathrm{m}) \\
\operatorname{taxa}=50 \%\end{array}$ & $\begin{array}{c}\text { CARGA }(\mathrm{kN} / \mathrm{m}) \\
\operatorname{taxa}=100 \%\end{array}$ \\
\hline 1 & - & 117,1 & 117,1 & 117,1 \\
\hline 2 & 1 & 182,9 & 166,4 & 164,7 \\
\hline 3 & 1 & 155,7 & 163,8 & 164,7 \\
\hline 4 & 2 & 321,0 & 252,3 & 244,8 \\
\hline 5 & 2 & 218,4 & 242,2 & 244,8 \\
\hline 6 & - & 255,4 & 255,4 & 255,4 \\
\hline 7 & 3 & 396,7 & 283,5 & 269,5 \\
\hline 8 & 3 & 243,4 & 266,7 & 269,5 \\
\hline 9 & 4 & 176,3 & 172,6 & 172,4 \\
\hline 10 & 4 & 119,9 & 167,0 & 172,4 \\
\hline 11 & 4 & 216,3 & 177,0 & 172,4 \\
\hline 12 & 5 & 205,8 & 201,9 & 200,4 \\
\hline 13 & 5 & 228,8 & 204,7 & 200,4 \\
\hline 14 & 5 & 212,2 & 200,5 & 200,4 \\
\hline 15 & 5 & 176,0 & 198,6 & 200,4 \\
\hline 16 & 5 & 252,5 & 204,7 & 200,4 \\
\hline 17 & 5 & 169,5 & 197,2 & 200,4 \\
\hline 18 & - & 69,7 & 69,7 & 69,7 \\
\hline 19 & 6 & 168,9 & 174,8 & 176,6 \\
\hline 20 & 6 & 212,7 & 181,8 & 176,6 \\
\hline 21 & 6 & 154,6 & 175,3 & 176,6 \\
\hline 22 & 6 & 168,9 & 174,7 & 176,6 \\
\hline 23 & 6 & 212,7 & 181,8 & 176,6 \\
\hline
\end{tabular}

Observa-se que a influência da forma de tratamento do sistema estrutural leva a diferenças nos valores de cargas e tensões muito significativas. Por exemplo, tomando os grupos 2 e 3 interagindo através do macrogrupo 1, as paredes consideradas isoladamente são carregadas com 182,9 kN/m e 155,7 kN/m respectivamente. Considerando interação total, o que não é aconselhável porque 
as paredes são solicitadas de maneira bastante diferenciada, a carga uniformizada fica em 164,7 kN/m. Com a taxa de interação de 50\%, as cargas aproximaram-se um pouco mais das originais de cada grupo, ou seja, a do grupo 2 aumentou 1,03\% e a do grupo 3 diminuiu $0,55 \%$.

Este exemplo reforça, portanto, a afirmativa de que a consideração de taxas alternativas de interação leva a diferenças apreciáveis nos resultados de cargas e tensões nas paredes, podendo afetar de maneira significativa a segurança e a economia da edificação.

Concluindo, pode-se dizer que a análise de paredes isoladas é um procedimento seguro e antieconômico, enquanto que o procedimento de grupos isolados de paredes é seguro, se os grupos forem delimitados pelas aberturas, e medianamente econômico. Já o procedimento de grupos de paredes com interação é o mais econômico de todos, e as pesquisas em andamento indicarão taxas de interação adequadas. As primeiras simulações parecem indicar 20\% uma taxa segura para interação de grupos próximos.

\subsection{Distribuição das ações horizontais}

\subsubsection{Consideração das abas ou flanges}

Conforme já mencionado, as ações horizontais devidas ao vento são distribuídas às paredes de contraventamento da estrutura pelas lajes dos pavimentos, proporcionalmente à rigidez de cada painel. Para a correta determinação da rigidez dos painéis de contraventamento, a ABNT (NBR-10837) recomenda que se considere a contribuição de trechos perpendiculares a estas paredes, formando seções compostas com elas. Tais trechos são denominados abas ou flanges (Figura 3.13). 

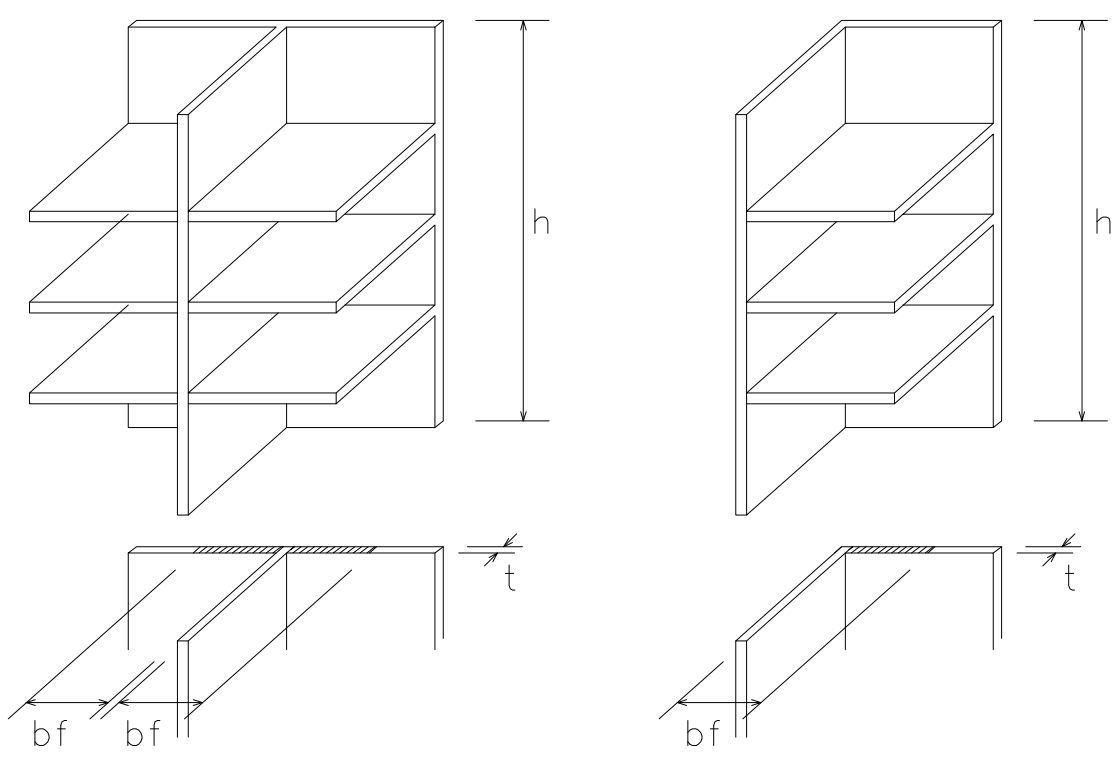

FIGURA 3.13 - Definição das abas ou flanges

De acordo com a referida norma, o comprimento das abas não deve exceder os seguintes valores:

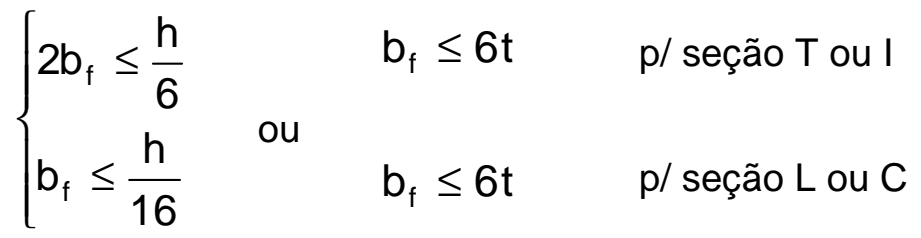

$\mathrm{h} \rightarrow$ altura de parede acima da seção considerada

As abas só devem ser consideradas quando as duas paredes perpendiculares entre si estiverem unidas por amarração direta, não sendo permitido para casos de junta a prumo.

As vantagens da consideração das abas são muitas, entre elas a redução de tensões nas paredes e a diminuição dos deslocamentos das lajes, pois as abas, para os vãos usuais de edifícios residenciais, dobram as inércias dos painéis, e portanto praticamente dividem por dois as tensões a serem obtidas na análise. A não consideração dos flanges pode fazer com que os painéis tenham sua rigidez 
subestimada ou superestimada, ocasionando com isso uma distribuição incorreta das ações, devido à incorreta representação de suas rigidezes relativas.

A determinação dos carregamentos, esforços e tensões atuantes nas paredes de contraventamento pode ser feita através de diversos procedimentos. Neste capítulo serão tratados apenas os procedimentos de paredes isoladas e de paredes com aberturas. Maiores informações poderão ser encontradas em HENDRY (1981), HENDRY et al (1981) e SILVA (1986).

\subsubsection{Paredes isoladas}

Este procedimento é o mais usual. Entretanto, os resultados de tensões obtidos são relativamente altos, já que não se considera a interação de paredes separadas por aberturas.

O procedimento pode ser bastante simples e eficiente, sobretudo nos casos de ações que atuem segundo eixos de simetria da estrutura. Basta fazer a compatibilização dos deslocamentos dos diversos painéis para se encontrar o quinhão de carga em cada um.

A aplicação do processo consiste em se determinar a rigidez relativa de cada painel, a partir daí a ação atuante em cada um deles, e consequentemente os momentos fletores. Obtidos estes momentos, calculam-se as tensões normais atuantes.

Inicialmente deve-se calcular a rigidez de cada painel, que depende de sua inércia, de seu módulo de elasticidade e de sua altura. Segundo ABCI (1990), nos painéis constituídos de paredes sem aberturas e em balanço, a rigidez é dada por (Figura 3.14): 


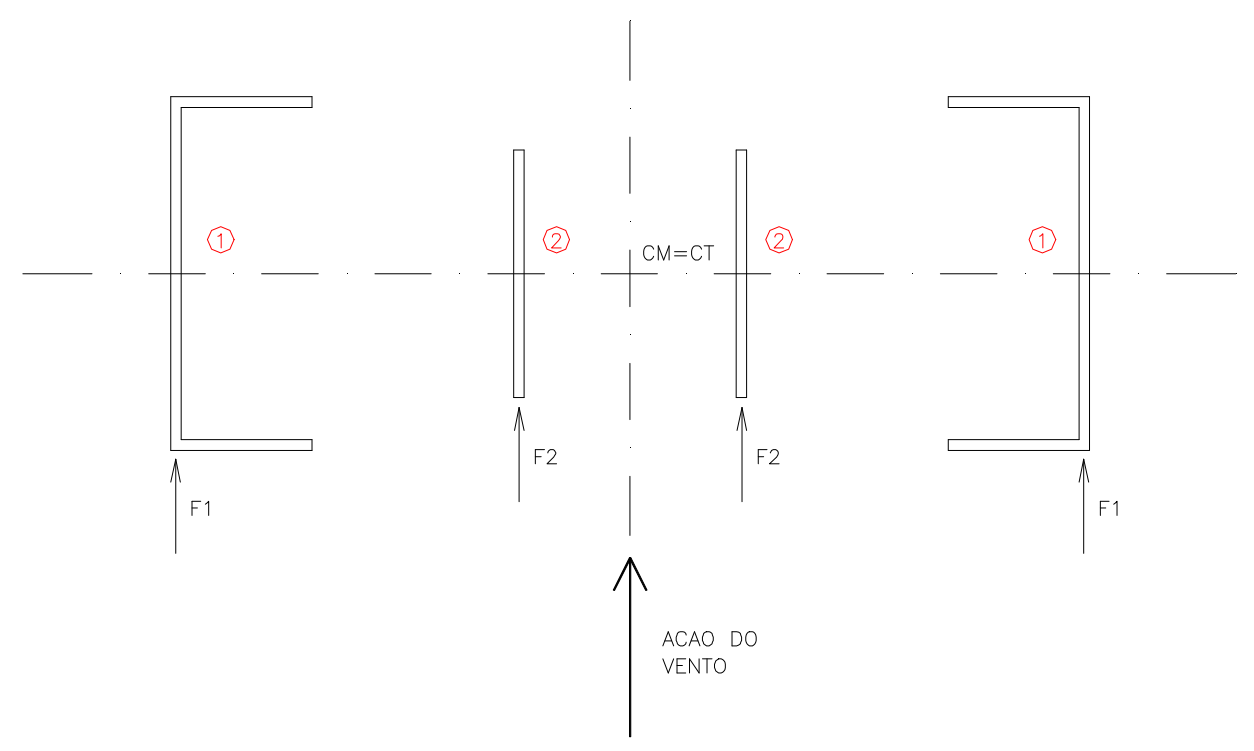

FIGURA 3.14 - Representação dos painéis de contraventamento

$$
\begin{gathered}
\mathrm{R}_{\mathrm{i}}=\frac{\Delta_{\mathrm{i}}}{\sum \Delta} \\
\Delta_{\mathrm{i}}=\frac{\mathrm{H}^{3}}{3 \mathrm{E}_{\mathrm{m}} \mid}+\frac{1,2 \mathrm{H}}{\mathrm{AE_{v }}}=\Delta_{\mathrm{f}}+\Delta_{\mathrm{c}}
\end{gathered}
$$

onde:

$I$ = momento de inércia da parede

$\mathrm{H}=$ altura da parede

$\mathrm{E}_{\mathrm{m}}=$ módulo de elasticidade longitudinal da alvenaria

$\mathrm{E}_{\mathrm{v}}=$ módulo de elasticidade transversal da alvenaria

$A=$ área da seção transversal da parede

$\Delta_{\mathrm{f}}=$ parcela do deslocamento devido à flexão

$\Delta_{\mathrm{c}}=$ parcela do deslocamento devido aos esforços cortantes

Nas paredes altas predomina a parcela do deslocamento devido à flexão, enquanto que nas baixas predomina a parcela devida ao esforço cortante. Paredes altas são aquelas em que a altura total é superior a cinco vezes a maior dimensão em planta, conforme indicações da resistência dos materiais. 
No caso de se terem paredes altas com rigidez constante ao longo da altura, a rigidez corresponde ao seu próprio momento de inércia (I), ou seja, despreza-se a parcela do deslocamento devido aos esforços cortantes $\left(\Delta_{\mathrm{c}} \cong 0\right)$. Desta forma, pode-se definir a somatória de todas as rigidezes:

$$
\sum \mathrm{I}=\mathrm{I}_{1}+\mathrm{I}_{2}+\mathrm{I}_{3}+\ldots+\mathrm{I}_{\mathrm{n}}
$$

A rigidez relativa de cada painel, será, portanto:

$$
\mathrm{R}_{\mathrm{i}}=\frac{\mathrm{I}_{\mathrm{i}}}{\sum \mathrm{l}}
$$

Calcula-se, então, a ação sobre cada painel:

$$
F_{i}=F_{\text {tot }} \times R_{i}
$$

onde:

$$
F_{\text {tot }}=\text { ação total em um determinado pavimento }
$$

Através das ações calculam-se os momentos fletores, e então obtêm-se as tensões devidas a estes esforços internos, utilizando a clássica expressão da resistência dos materiais:

$$
\sigma=\frac{M}{W}
$$

onde:

$$
\begin{aligned}
& \mathrm{M}=\text { momento fletor atuante na parede } \\
& \mathrm{W}=\text { módulo de resistência à flexão }\left(\mathrm{W}=\frac{\mathrm{I}}{\mathrm{y}_{\max }}\right)
\end{aligned}
$$

Nos casos em que a ação do vento não atua segundo um eixo de simetria da estrutura, o procedimento de paredes isoladas torna-se impraticável de ser 
executado sem um programa computacional. Conforme já mencionado, ocorrem rotações nas lajes (Figura 3.15), que precisam ser consideradas na distribuição.
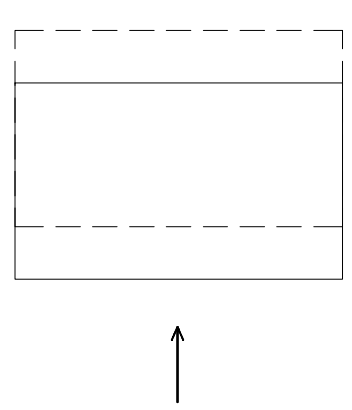

ação segundo um eixo de simetria
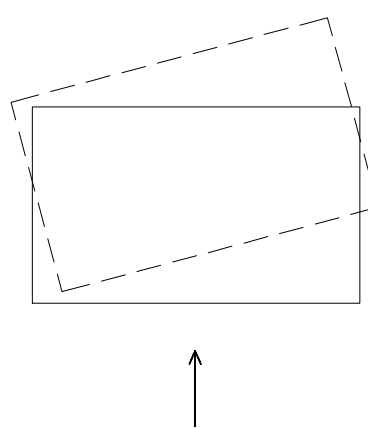

ação segundo um eixo qualquer

FIGURA 3.15 - Movimentação das lajes de acordo com a atuação do vento

CORRÊA \& RAMALHO (1996) sugerem, para estes casos, a utilização de um programa que possua elementos de barra tridimensionais e um recurso conhecido como nó mestre. As paredes devem ser discretizadas com um elemento para cada nível da estrutura e todos os nós de um pavimento devem ser ligados ao nó mestre daquele pavimento (Figura 3.16).

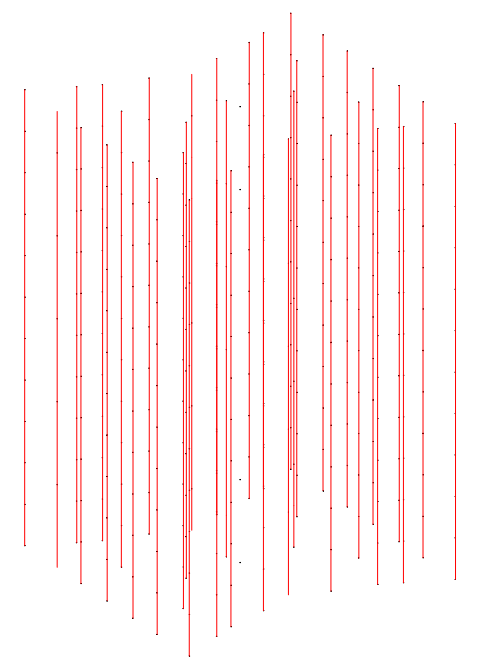

FIGURA 3.16 - Elementos de barra tridimensional 
As translações dos nós no plano do pavimento são transferidas para o nó mestre, como se existissem segmentos totalmente rígidos ligando-o aos nós da estrutura. Desta forma, acaba-se definindo um plano rígido ao nível do pavimento, simulando a existência da laje de concreto. Todos os nós do pavimento perdem os graus de liberdade de translação e de rotação em torno do eixo normal ao plano, ficando as rigidezes concentradas no nó eleito como mestre do pavimento.

Como os carregamentos são colocados apenas no nó mestre, após a solução do sistema global de equações do edifício, os deslocamentos e rotações de cada nó são obtidos através dos do nó mestre. Assim, consegue-se garantir total compatibilidade de translações e rotação do plano.

Não é objetivo deste texto entrar no mérito da elaboração do programa computacional com o recurso do nó mestre, mas apenas dar indicações de como resolver o problema do cálculo de paredes isoladas quando a ação do vento não atuar sobre um eixo de simetria da estrutura.

DAVIES \& KESKIN (1974) propuseram um método para se considerar o efeito da torção do edifício que não requer o uso de recursos computacionais.

O método consiste em um equacionamento que leva à determinação do ângulo de torção da seção e, a partir daí, dos deslocamentos, dos esforços solicitantes e das tensões atuantes.

Foi feito um estudo teórico e experimental e os resultados analíticos aproximaram-se dos experimentais, o que justificou a recomendação do método, que pode ser aplicado tanto para seções simétricas como assimétricas.

\subsubsection{Paredes com aberturas}

Neste procedimento, as paredes com aberturas são consideradas como pórticos, com pilares e vigas, como mostrado na Figura 3.17. Os pilares são os trechos verticais de parede, e as vigas são os lintéis (trechos entre as aberturas). 

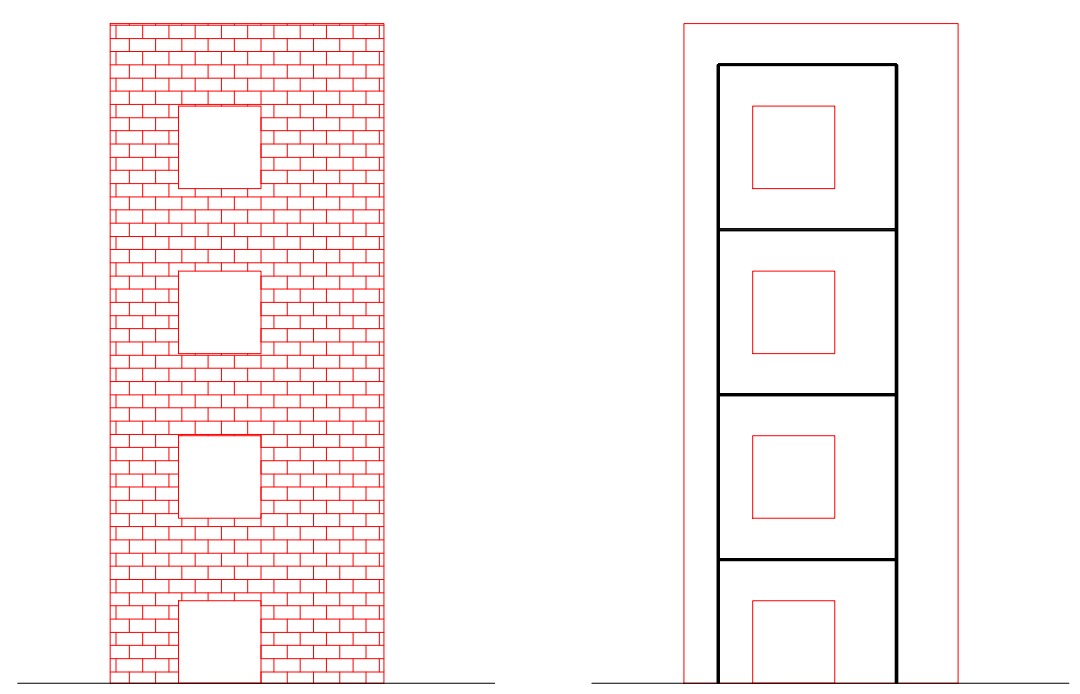

FIGURA 3.17 - Paredes com abertura - modelo de pórtico plano

Da mesma forma que no procedimento anterior de paredes isoladas, os painéis de contraventamento absorvem esforços proporcionais às suas rigidezes.

Este procedimento, menos simples que o anterior, envolve a utilização de recursos computacionais, mesmo que a estrutura de contraventamento seja simétrica.

Para o caso em que a ação do vento atuar segundo um eixo de simetria da estrutura de contraventamento, CORRÊA \& RAMALHO (1996) sugerem a utilização de um programa para pórticos planos, sem quaisquer recursos especiais. Basta que metade dos painéis, pórticos ou paredes isoladas, sejam modelados em um esquema chamado de associação plana de painéis (Figura 3.18). 


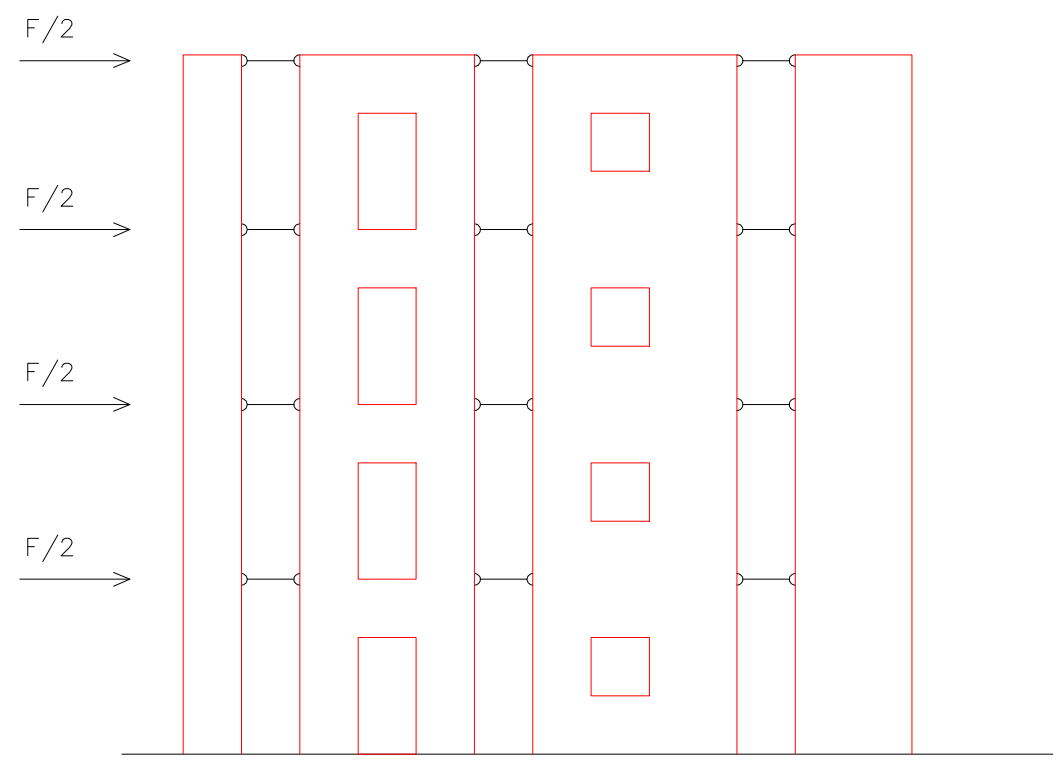

FIGURA 3.18 - Associação plana de painéis

Neste esquema, as barras que ligam os painéis ao nível de cada andar, simulando as lajes de concreto, devem ser suficientemente rígidas para que os deslocamentos de todos os nós do pavimento sejam iguais. Além disso, as barras devem ser articuladas em seus extremos a fim de que suas rigidezes à flexão sejam desprezadas, em conformidade com a hipótese de comportamento de diafragma das lajes.

Outro ponto a ser destacado no esquema de associação plana de painéis é a colocação do carregamento, normalmente metade da ação total do pavimento, apenas no primeiro painel. A distribuição desta ação para o restante da estrutura se faz pela compatibilidade dos deslocamentos dos nós.

Os resultados de tensões nas paredes costumam ser bem menores quando utilizado este procedimento, do que no caso de paredes isoladas, pois ao se considerarem os trechos de alvenaria acima e abaixo das aberturas tem-se mais vínculos, e portanto maior rigidez do painel.

Para o caso da ação do vento atuar em um eixo que não seja de simetria, CORRÊA \& RAMALHO (1996) indicam a utilização de um programa que possua elementos de barra tridimensionais unidos por barras horizontais que simulem os lintéis (Figura 3.19). 


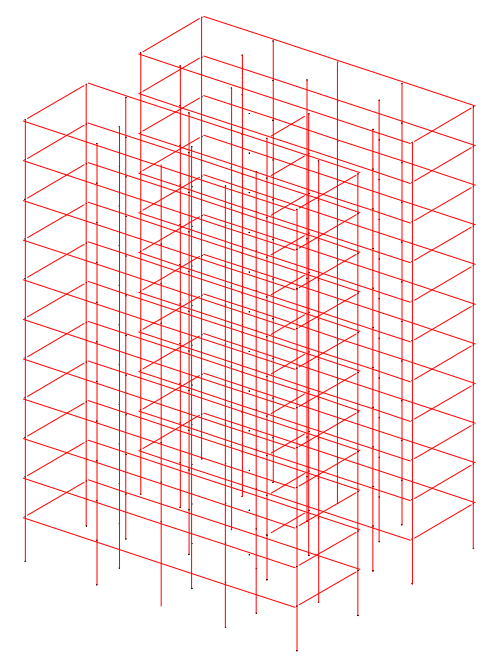

FIGURA 3.19 - Elementos de barra tridimensionais unidos por lintéis

O programa deverá, assim como no caso de paredes isoladas, ter o recurso do nó mestre, no qual todos os nós do pavimento serão ligados, e no qual estará aplicada a ação total do mesmo.

As tensões obtidas neste caso também resultam em valores bem menores que no caso das paredes isoladas.

Mais uma vez, é preciso salientar que não é do escopo deste trabalho entrar no mérito da elaboração dos programas computacionais mencionados no texto. A intenção é apenas atentar para as possíveis soluções do problema da distribuição das ações horizontais nas paredes de contraventamento.

\subsubsection{Consideração de trechos rígidos}

A consideração de trechos rígidos nas barras que simulam lintéis, no modelo de pórtico para paredes com aberturas, é tão essencial para a correta distribuição das ações horizontais quanto a consideração das abas ou flanges (Figura 3.20). 


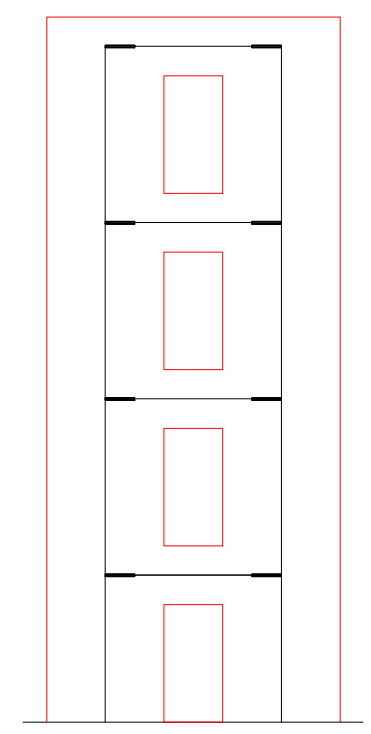

FIGURA 3.20 - Trechos rígidos

A colocação das barras horizontais, nos eixos dos elementos que se comportam como pilares do pórtico, faz com que o comprimento flexível delas seja, na verdade, menor que o comprimento total (Figura 3.21). A consideração de comprimentos menores destas barras leva a painéis mais rígidos.

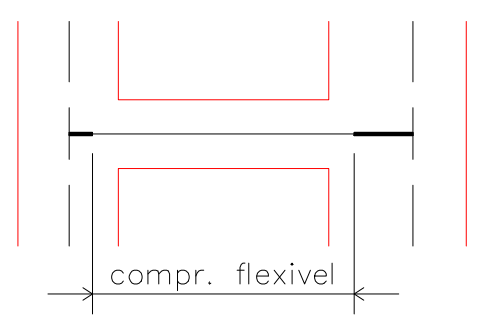

FIGURA 3.21 - Comprimento flexível das barras horizontais

A não consideração dos trechos rígidos pode provocar perturbações importantes na distribuição de ações horizontais, pois alguns painéis sofrem um acréscimo significativo de sua rigidez e outros permanecem inalterados. Desta forma, os quinhões de carga são, também, bastante modificados. 
Para a consideração dos trechos rígidos existem basicamente dois procedimentos. O primeiro deles, muito mais eficiente, exige que o programa utilizado tenha trechos rígidos como recurso de modelagem, ou seja, ao se definir uma barra, possa se indicar, junto às suas extremidades, o comprimento dos trechos sem deformação. Assim, ao montar a matriz de rigidez do elemento, o programa pode considerar apenas o trecho efetivamente flexível, transferindo as rigidezes através de um procedimento padrão de translação. Os resultados obtidos são, então, correspondentes às extremidades flexíveis da barra.

O segundo procedimento, utilizado quando o programa não dispõe do recurso anteriormente citado, consiste em considerar os trechos rígidos como barras independentes de grande rigidez em relação às demais.

Segundo CORRÊA (1991), a deficiência desta técnica em relação à anterior consiste no acréscimo de nós e barras à estrutura, resultando em uma matriz de rigidez bem maior, e consequentemente em um aumento no tempo de processamento.

Outro problema a ser resolvido, é que características geométricas adotar para estes trechos que não devem apresentar deformação. Valores muito elevados condicionam mal a matriz de rigidez, proporcionando resultados incoerentes; valores muito reduzidos podem não ser representativos, se o trecho não apresentar deformações significativas. CORRÊA (1991) sugere para a seção da barra largura igual à espessura da parede e altura igual à média dos pés-direitos adjacentes.

O EUROCODE ${ }^{8}$ apud SILVA (1986) faz algumas recomendações a respeito dos comprimentos a serem considerados para os trechos rígidos. De acordo com suas prescrições, o trecho flexível de um elemento estrutural contido no elemento transversal é dado pela metade de sua altura (Figura 3.22).

${ }^{8}$ EUROPEAN COMMITTEE FOR STANDARTIZATION (1991). Eurocode 2: Design of concrete structures - Part 1: general rules and rules for buildings. Brussels. 


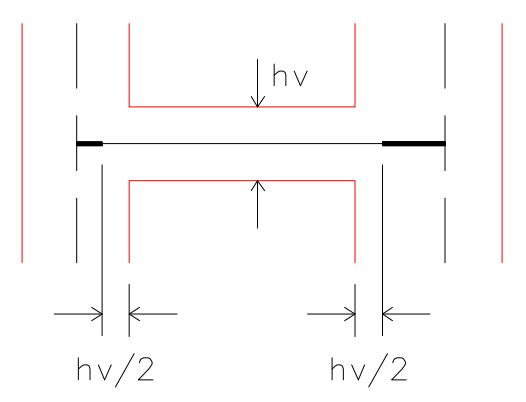

FIGURA 3.22 - Comprimento dos trechos rígidos - EUROCODE

CORRÊA \& RAMALHO (1994a) propõem que o comprimento dos trechos rígidos seja a distância entre a face da abertura e o eixo da barra vertical (Figura 3.23).

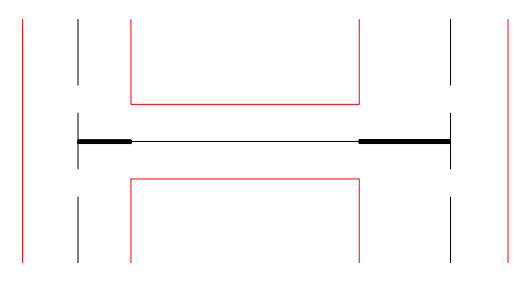

FIGURA 3.23 - Comprimento dos trechos rígidos - CORRÊA \& RAMALHO (1994a)

\subsubsection{Exemplo de aplicação}

Este exemplo tem por objetivo mostrar a distribuição de ações horizontais através do procedimento de paredes isoladas.

Considere um edifício de 8 (oito) pavimentos em alvenaria estrutural, de planta simétrica, cuja modulação encontra-se na Figura 3.24. O edifício analisado localiza-se na cidade de São Carlos, em terreno plano, e tem fins comerciais. Para efeito de simplificação dos cálculos, considerar-se-á a ação do vento em apenas uma direção.

Os blocos estruturais utilizados têm dimensões $12 \times 19 \times 39$ e o pé-direito do edifício tem altura $2,60 \mathrm{~m}$. 


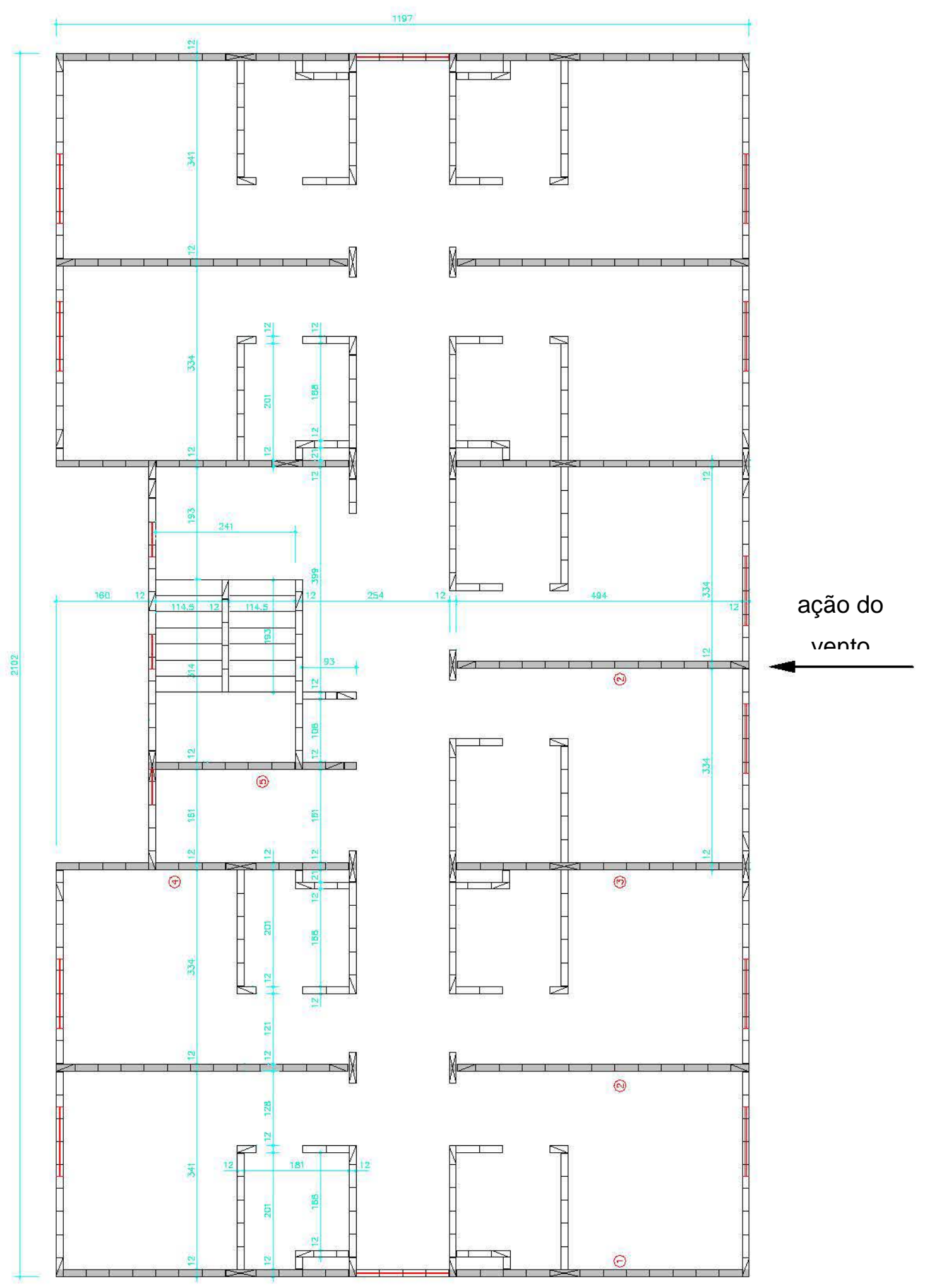

FIGURA 3.24 - Modulação e definição dos painéis de contraventamento 
Observa-se que, na definição dos painéis de contraventamento, foram excluídas as paredes de dimensões menores, por não contribuírem de forma significativa na absorção dos esforços horizontais.

A análise estrutural, neste exemplo, englobará a determinação das ações horizontais devidas à ação do vento e ao desaprumo, e sua distribuição ao longo dos andares do edifício.

Determinação das ações horizontais devidas ao vento

Conforme visto no item 3.2, as ações horizontais devidas ao vento são determinadas a partir de expressões retiradas da ABNT (NBR-6123), cujo roteiro se encontra nesse item. Tem-se, portanto:

- velocidade básica do vento: $\mathrm{v}_{\mathrm{o}}=38 \mathrm{~m} / \mathrm{s}$

- fator topográfico: $S_{1}=1,0$

- fator estatístico: $S_{3}=1,0$

- fator de rugosidade e regime:

categoria IV

classe B

\begin{tabular}{|c|c|}
\hline$z(m)$ & $S_{2}$ \\
\hline 2,60 & 0,76 \\
\hline 5,20 & 0,76 \\
\hline 7,80 & 0,80 \\
\hline 10,40 & 0,83 \\
\hline 13,20 & 0,86 \\
\hline 16,00 & 0,89 \\
\hline 18,80 & 0,90 \\
\hline 21,60 & 0,92 \\
\hline
\end{tabular}

Através das eq.(3.3) e eq.(3.2) calculam-se, então, a velocidade característica e a pressão de obstrução para cada nível: 


\begin{tabular}{|c|c|c|}
\hline$z(m)$ & $v_{k}(\mathrm{~m} / \mathrm{s})$ & $q\left(\mathrm{kN} / \mathrm{m}^{2}\right)$ \\
\hline 2,60 & 28,88 & 0,511 \\
\hline 5,20 & 28,88 & 0,511 \\
\hline 7,80 & 30,40 & 0,567 \\
\hline 10,40 & 31,54 & 0,610 \\
\hline 13,20 & 32,68 & 0,655 \\
\hline 16,00 & 33,82 & 0,701 \\
\hline 18,80 & 34,20 & 0,717 \\
\hline 21,60 & 34,96 & 0,749 \\
\hline
\end{tabular}

Para a determinação do coeficiente de arrasto será feita uma média dos coeficientes de arrasto para vento de alta e baixa turbulência.

- vento de baixa turbulência

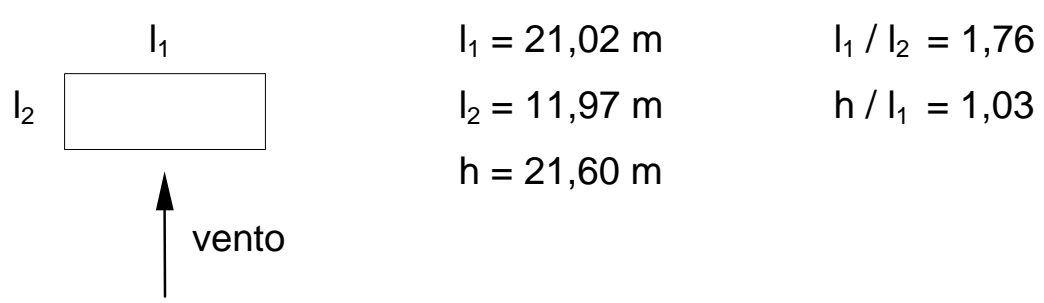

$$
\therefore \mathrm{C}_{\mathrm{a}}=1,26
$$

- vento de alta turbulência

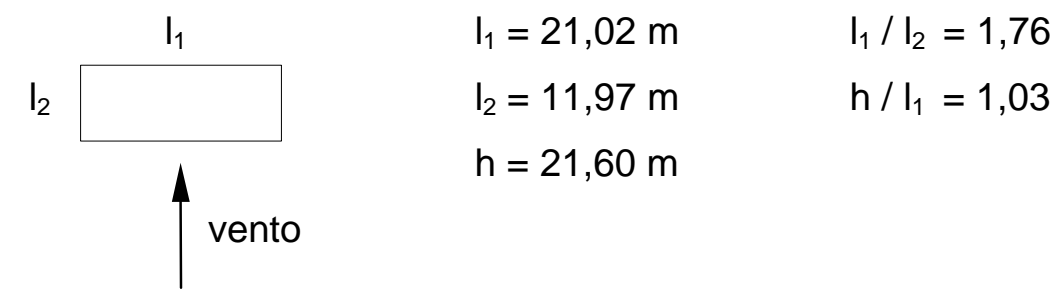

$$
\therefore \mathrm{C}_{\mathrm{a}}=1,02
$$

Fazendo a média, tem-se: $\quad \mathrm{C}_{\mathrm{a}}=1,14$ 
A partir do coeficiente de arrasto calculam-se, através da eq.(3.1), as forças de arrasto características ao nível de cada andar:

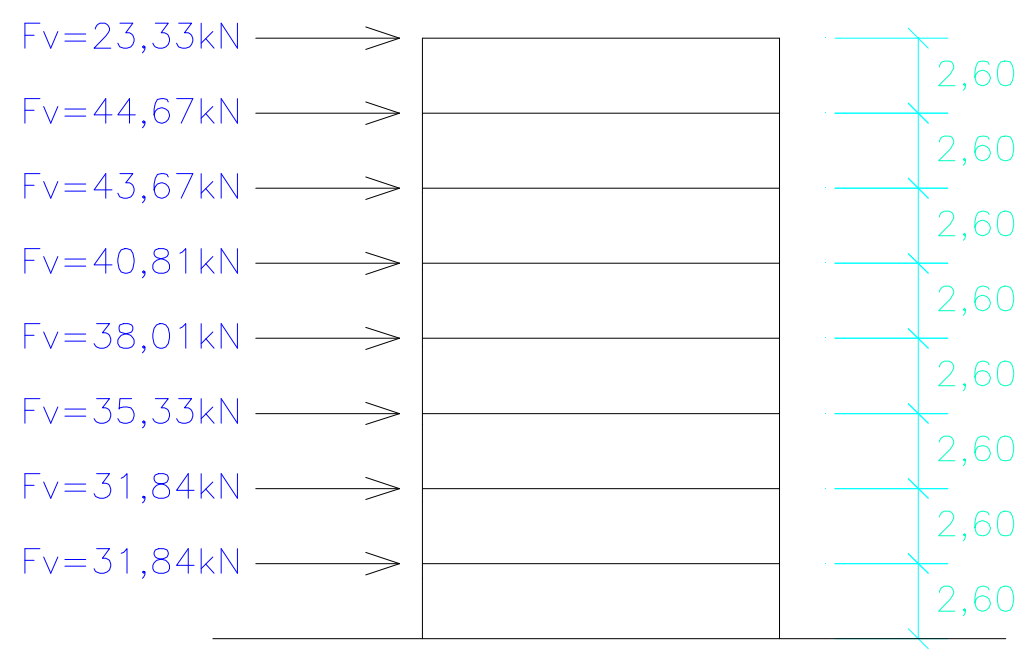

Determinação das ações horizontais devidas ao desaprumo

De acordo com a eq.(3.5), o ângulo para o desaprumo é dado por:

$$
\varphi=\frac{1}{100 \sqrt{\mathrm{H}}}=\frac{1}{100 \sqrt{21,60}}=0,00215 \mathrm{rad}
$$

O peso total de cada pavimento pode ser estimado por:

- peso da laje: $4,5 \times 21,02 \times 11,97 \cong 1132,24 \mathrm{kN}$

- peso das paredes estruturais: $14 \times 2,52 \times 0,12(2 \times 11,97+9 \times 5,18+3,58+10 \times$ $2,05+0,93+8 \times 1,04+2 \times 21,02+5 \times 4,42+5 \times 4,02+3,13+1,93) \cong 817,89$ $\mathrm{kN}$

$\therefore$ peso total do pavimento: $\Delta \mathrm{P} \cong 1951 \mathrm{kN}$

Por questão de simplicidade, considerou-se o peso da laje de cobertura igual ao peso das lajes dos pavimentos-tipo.

As ações laterais de cálculo, equivalentes ao desaprumo, a serem aplicadas ao nível de cada pavimento, são dadas pela eq.(3.4). Tem-se, portanto: 


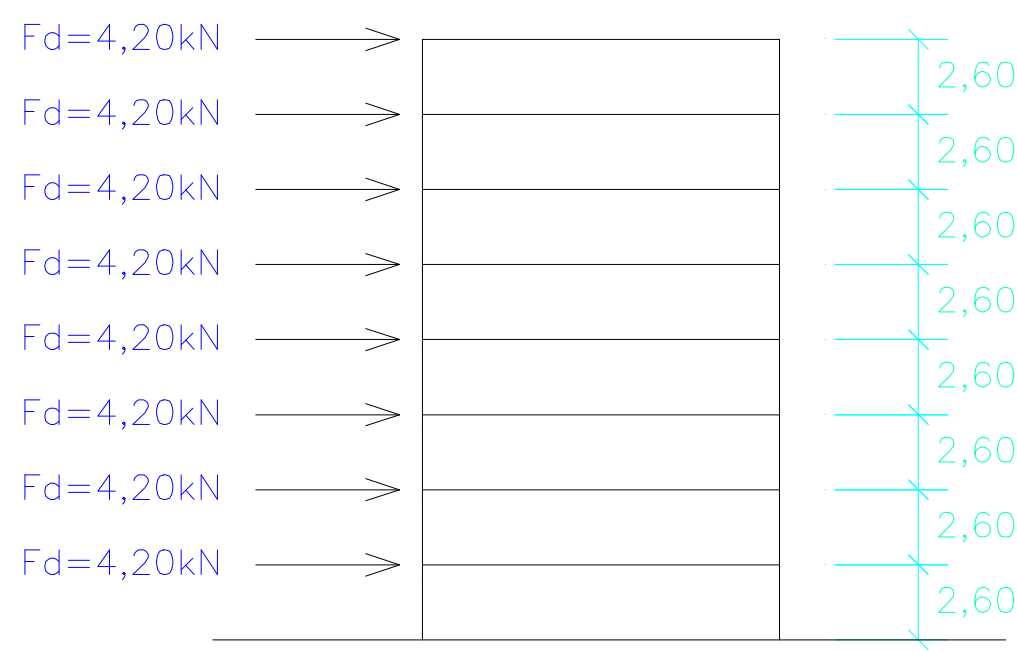

Somando as ações horizontais devidas ao vento com as ações horizontais devidas ao desaprumo, obtêm-se as ações horizontais totais atuantes ao nível de cada andar:

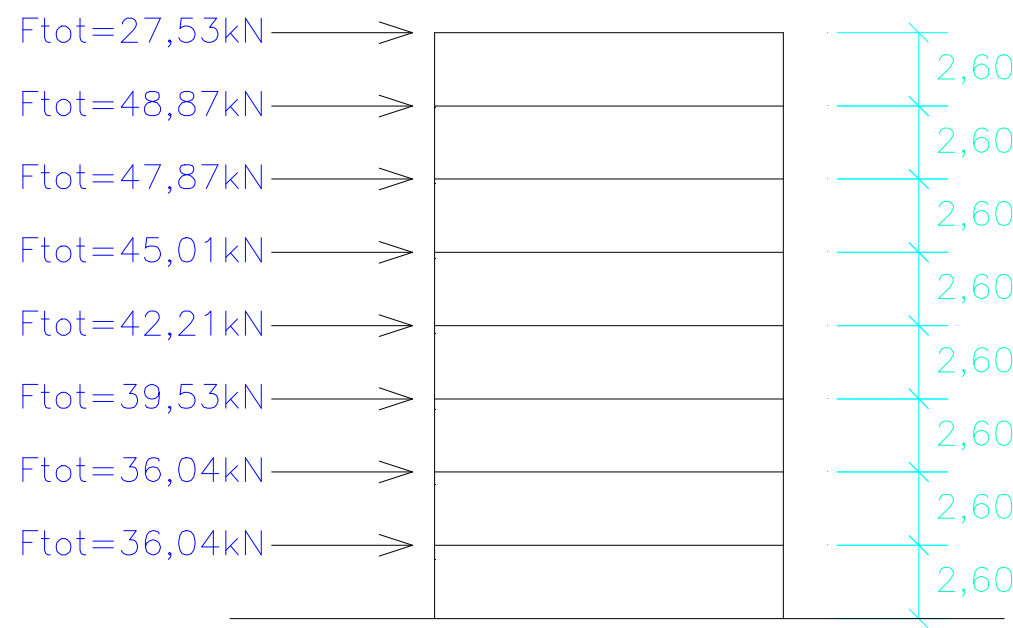

Obtidas as ações horizontais passa-se agora à distribuição das mesmas ao longo dos andares do edifício.

Como já foi dito, neste exemplo será utilizado apenas o procedimento de paredes isoladas. Para a aplicação do mesmo pode-se ou não considerar as abas ou flanges nas paredes estruturais, sendo este um ponto importante de tomada de decisão. Portanto, este exemplo será feito, primeiramente, considerando-as, e, posteriormente, desconsiderando-as, a fim de que se possa comparar os resultados. 


\section{A - Resolução considerando as abas ou flanges}

Na Figura 3.25 encontram-se definidos o comprimento das abas, trechos perpendiculares aos painéis de contraventamento.

De acordo com a eq.(3.7), a medida do comprimento destes trechos é dada por:

- seção T ou l: $b_{f} \leq\left\{\begin{array}{l}\frac{h}{12} \\ 6 \times 0,12=0,72\end{array}\right.$

\begin{tabular}{c|c|c} 
pavimento & $\mathrm{h}$ & $\mathrm{b}_{\mathrm{f}}$ \\
\hline 1 & 19,60 & 0,72 \\
2 & 16,80 & 0,72 \\
3 & 14,00 & 0,72 \\
4 & 11,20 & 0,72 \\
5 & 8,40 & 0,70 \\
6 & 5,60 & 0,47 \\
7 & 2,80 & 0,23 \\
8 & 0 & 0
\end{tabular}

- seção L ou C: $b_{f} \leq\left\{\begin{array}{l}\frac{h}{16} \\ 6 \times 0,12=0,72\end{array}\right.$

\begin{tabular}{c|c|c} 
pavimento & $\mathrm{h}$ & $\mathrm{b}_{\mathrm{f}}$ \\
\hline 1 & 19,60 & 0,72 \\
2 & 16,80 & 0,72 \\
3 & 14,00 & 0,72 \\
4 & 11,20 & 0,70 \\
5 & 8,40 & 0,52 \\
6 & 5,60 & 0,35 \\
7 & 2,80 & 0,17 \\
8 & 0 & 0
\end{tabular}




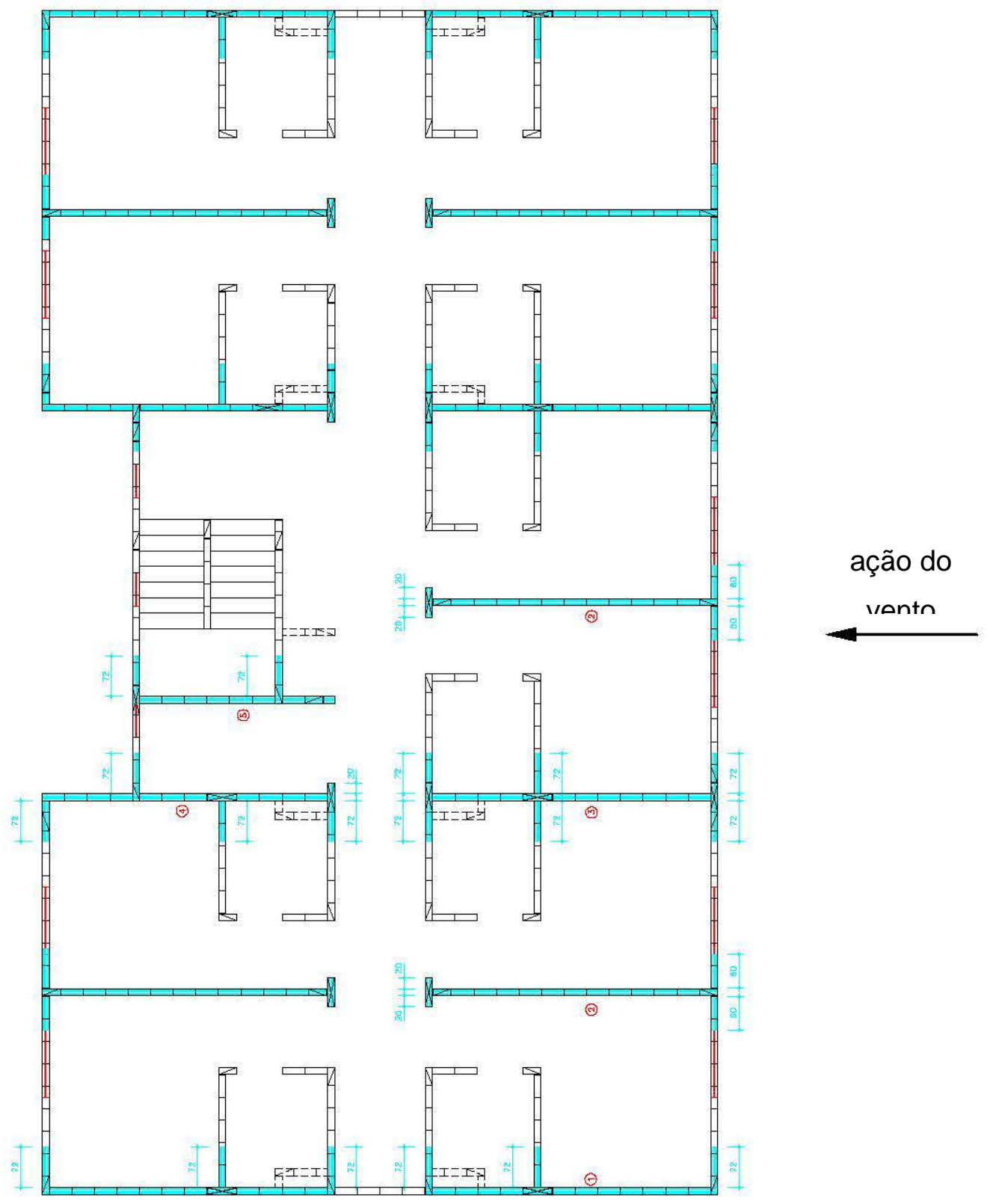

FIGURA 3.25 - Representação das abas ou flanges 
Dando início ao procedimento de distribuição, calculam-se as rigidezes de cada painel que, supondo constantes ao longo da altura, correspondem ao seu momento de inércia ( I ). Para isto o valor das abas foi considerado constante e igual, no máximo, a 0,72 m.

A consideração da alteração das abas ao longo da altura não é prática, pois, em edifícios altos, ela se dá apenas nos últimos pavimentos, e, em edifícios baixos, a ação do vento não é significativa.

Painel (1) $-4 x$

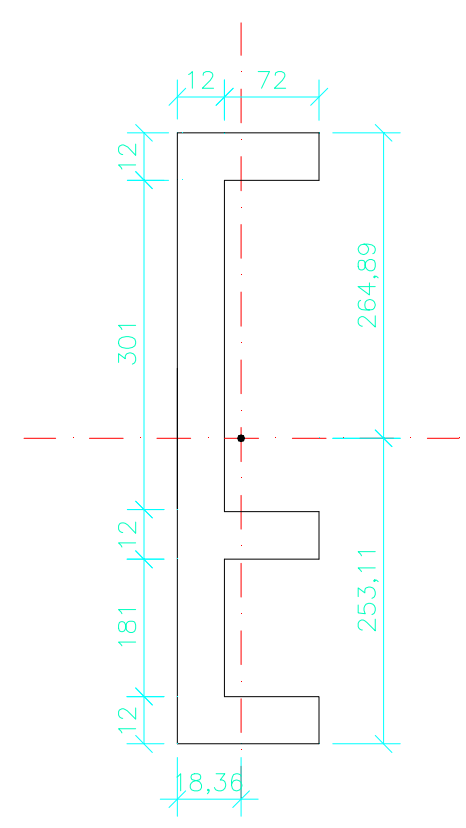

$$
\begin{aligned}
& \mathrm{x}_{\mathrm{CG}}=\frac{12 \times 72 \times 512+12 \times 72 \times 199+12 \times 72 \times 6}{3 \times 12 \times 72+12 \times 518}+ \\
& +\frac{12 \times 518 \times 259}{3 \times 12 \times 72+12 \times 518}=253,11 \mathrm{~cm} \\
& y_{C G}=\frac{3(12 \times 72 \times 48)+12 \times 518 \times 6}{3 \times 12 \times 72+12 \times 518}=18,36 \mathrm{~cm} \\
& \mathrm{I}_{1}=\frac{72 \times 12^{3}}{12}+258,89^{2} \times 72 \times 12+\frac{72 \times 12^{3}}{12}+54,11^{2} \times \\
& 72 \times 12+\frac{72 \times 12^{3}}{12}+247,11^{2} \times 72 \times 12+\frac{12 \times 518^{3}}{12}+ \\
& +5,89^{2} \times 12 \times 518=252.435 .781 \mathrm{~cm}^{4}
\end{aligned}
$$


Painel (2) - $5 x$

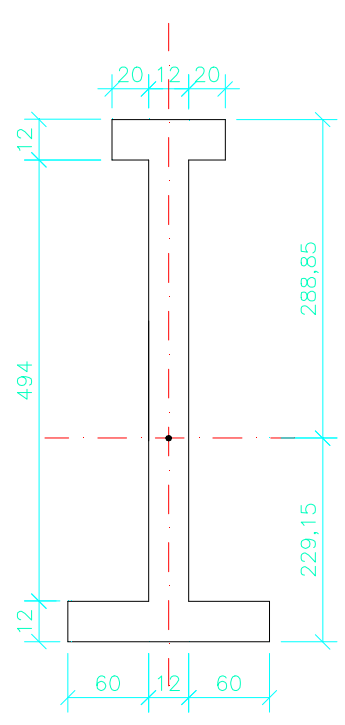

$$
\begin{aligned}
& X_{C G}=\frac{12 \times 494 \times 259+12 \times 52 \times 512+12 \times 132 \times 6}{12 \times 494+12 \times 52+12 \times 132}= \\
& =229,15 \mathrm{~cm}
\end{aligned}
$$$$
\mathrm{I}_{2}=\frac{52 \times 12^{3}}{12}+282,85^{2} \times 12 \times 52+\frac{12 \times 494^{3}}{12}+
$$$$
+29,85^{2} \times 12 \times 494+\frac{132 \times 12^{3}}{12}+223,15^{2} \times 12 \times 132=
$$$$
=254.661 .575 \mathrm{~cm}^{4}
$$

Painel (3) - 2x

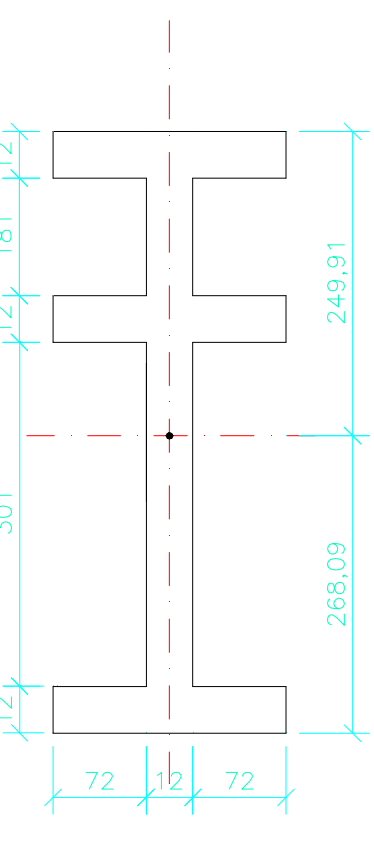

$$
\begin{aligned}
& x_{\mathrm{CG}}=\frac{2(12 \times 72 \times 6)+2(12 \times 72 \times 319)+2(12 \times 72 \times 512)}{6 \times 12 \times 72+12 \times 518}+ \\
& +\frac{12 \times 518 \times 259}{6 \times 12 \times 72+12 \times 518}=268,09 \mathrm{~cm}
\end{aligned}
$$$$
\mathrm{I}_{3}=2\left(\frac{72 \times 12^{3}}{12}+262,09^{2} \times 72 \times 12\right)+
$$$$
+2\left(\frac{72 \times 12^{3}}{12}+50,91^{2} \times 72 \times 12\right)+
$$$$
+2\left(\frac{72 \times 12^{3}}{12}+243,91^{2} \times 72 \times 12\right)+\frac{12 \times 518^{3}}{12}+
$$$$
+9,09^{2} \times 12 \times 518=365.547 .002 \mathrm{~cm}^{4}
$$ 
Painel (4) - 2x

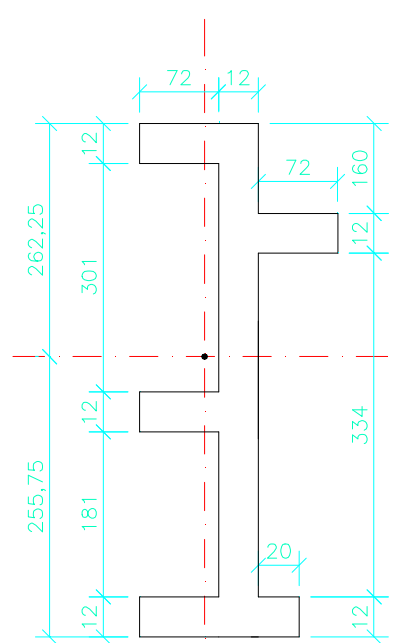

$$
\begin{aligned}
& x_{\mathrm{CG}}=\frac{104 \times 12 \times 6+72 \times 12 \times 199+72 \times 12 \times 512}{104 \times 12+3 \times 12 \times 72+12 \times 506}+ \\
& +\frac{72 \times 12 \times 352+12 \times 506 \times 265}{104 \times 12+3 \times 12 \times 72+12 \times 506}=255,75 \mathrm{~cm}
\end{aligned}
$$$$
y_{C G}=\frac{104 \times 12 \times 52+2(72 \times 12 \times 36)+72 \times 12 \times 120}{104 \times 12+3 \times 72 \times 12+12 \times 506}+
$$$$
+\frac{12 \times 506 \times 78}{104 \times 12+3 \times 72 \times 12+12 \times 506}=71,07 \mathrm{~cm}
$$

$\mathrm{I}_{4}=\frac{104 \times 12^{3}}{12}+249,75^{2} \times 104 \times 12+\frac{72 \times 12^{3}}{12}+$

$+56,75^{2} \times 72 \times 12+\frac{72 \times 12^{3}}{12}+96,25^{2} \times 72 \times 12+$

$+\frac{72 \times 12^{3}}{12}+256,25^{2} \times 72 \times 12+\frac{12 \times 506^{3}}{12}+9,25^{2} \times$

$12 \times 506=275.484 .376 \mathrm{~cm}^{4}$

Painel (5) $-1 x$

$$
\begin{aligned}
& x_{C G}=\frac{12 \times 84 \times 352+12 \times 346 \times 173+12 \times 72 \times 99}{12 \times 84+12 \times 346+12 \times 72}= \\
& =192,34 \mathrm{~cm}
\end{aligned}
$$$$
\mathrm{y}_{\mathrm{CG}}=\frac{12 \times 84 \times 42+12 \times 346 \times 6+12 \times 72 \times 48}{12 \times 84+12 \times 346+12 \times 72}=
$$$$
=18,05 \mathrm{~cm}
$$

$I_{5}=\frac{84 \times 12^{3}}{12}+159,66^{2} \times 84 \times 12+\frac{12 \times 346^{3}}{12}+$

$+19,34^{2} \times 346 \times 12+\frac{72 \times 12^{3}}{12}+93,34^{2} \times 72 \times 12=$

$=76.219 .917 \mathrm{~cm}^{4}$ 
Desta forma, pode-se definir a somatória de todas as rigidezes:

$$
\sum \mathrm{I}=4 \mathrm{I}_{1}+5 \mathrm{I}_{2}+2 \mathrm{I}_{3}+2 \mathrm{I}_{4}+\mathrm{I}_{5}=3.641 .333 .672 \mathrm{~cm}^{4}
$$

A rigidez relativa de cada painel será, de acordo com a eq.(3.1):

$$
\begin{array}{ll}
\mathrm{R}_{1} \cong 0,0693 & \mathrm{R}_{4} \cong 0,0757 \\
\mathrm{R}_{2} \cong 0,0699 & \mathrm{R}_{5} \cong 0,0209 \\
\mathrm{R}_{3} \cong 0,1004 &
\end{array}
$$

Calcula-se, então, a ação sobre cada painel pela eq.(3.12):

$$
F_{i}=F_{\text {tot }} \times R_{i}
$$

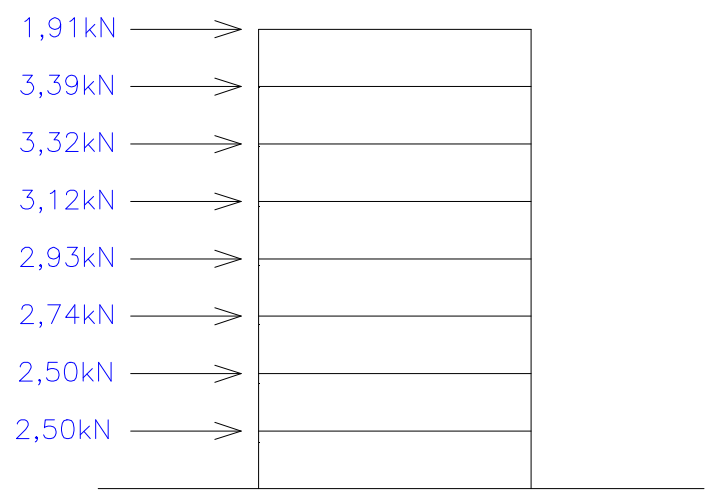

painel (1)

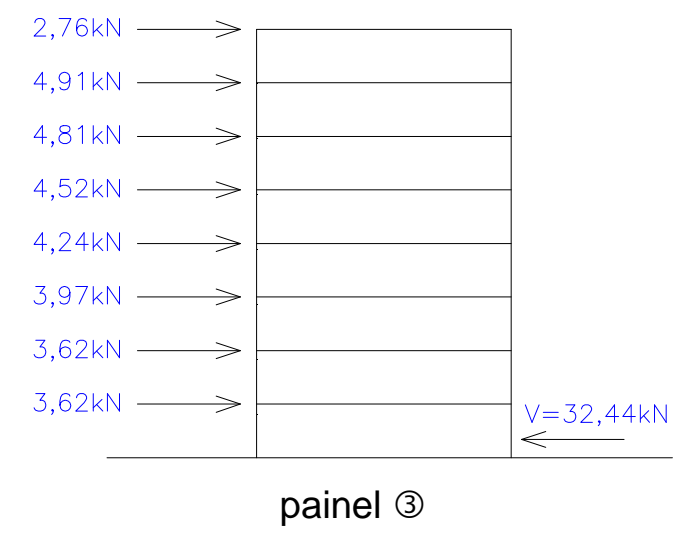

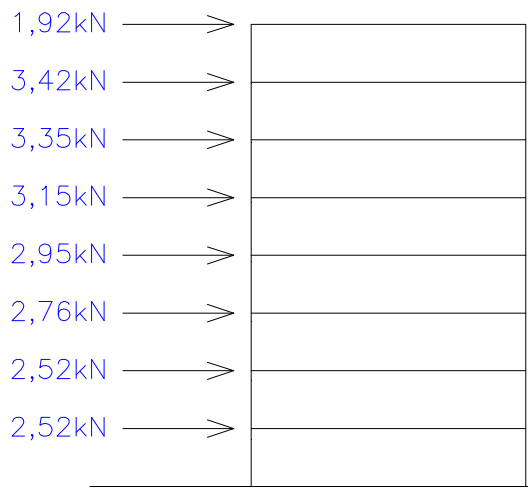

painel (2)

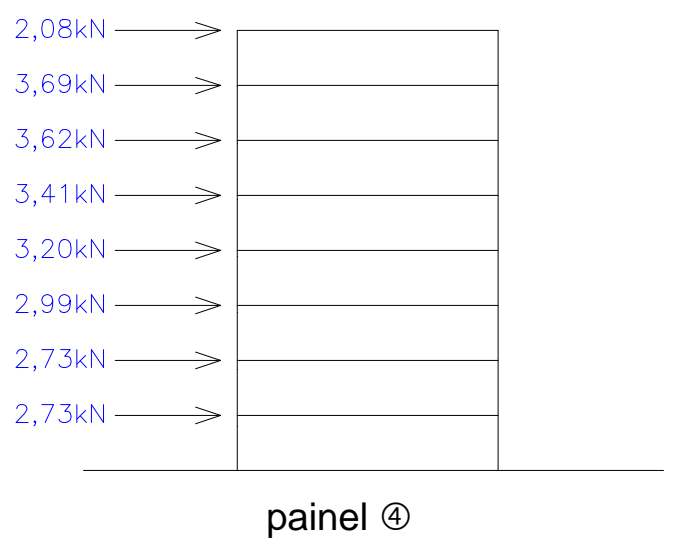




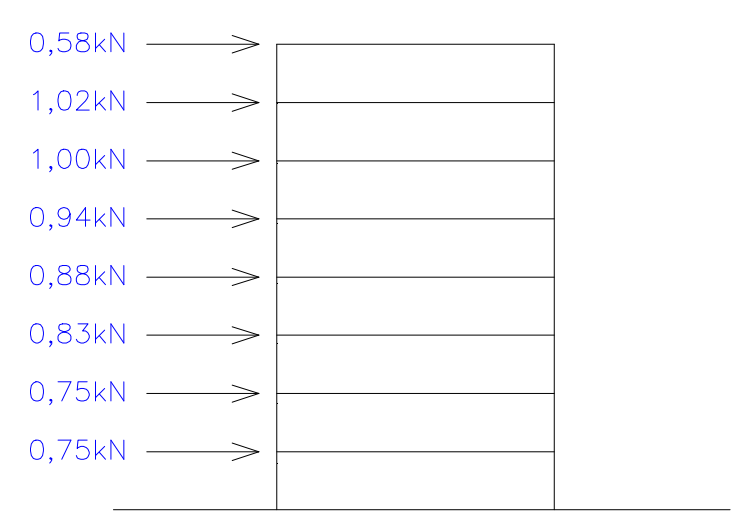

painel (5)

Através das ações pode-se calcular os momentos fletores na base para os cinco painéis:
painel (1): $M_{1}=270,40 \mathrm{kN} \cdot \mathrm{m}$
painel (2): $\mathrm{M}_{2}=272,81 \mathrm{kN} \cdot \mathrm{m}$
painel (3): $M_{3}=391,85 \mathrm{kN} \cdot \mathrm{m}$
painel (4): $\mathrm{M}_{4}=295,13 \mathrm{kN} \cdot \mathrm{m}$
painel (5): $M_{5}=81,59 \mathrm{kN} \cdot \mathrm{m}$

As tensões normais na base dos painéis podem ser obtidas pela eq.(3.13), onde o módulo de resistência à flexão é dado por:

$$
\begin{array}{ll}
W_{1}=\frac{252.435 .781}{264,89}=952.983 \mathrm{~cm}^{3} & W_{4}=\frac{275.484 .376}{262,25}=1.050 .465 \mathrm{~cm}^{3} \\
W_{2}=\frac{254.661 .575}{288,85}=881.640 \mathrm{~cm}^{3} & W_{5}=\frac{76.219 .917}{192,34}=396.277 \mathrm{~cm}^{3} \\
W_{3}=\frac{365.547 .002}{268,09}=1.363 .523 \mathrm{~cm}^{3} &
\end{array}
$$

Portanto, as tensões normais nas fibras extremas das paredes do $1^{\circ}$ pavimento, devidas às ações horizontais, considerando as abas nos painéis, são: 


$$
\begin{aligned}
& \sigma_{1}= \pm \frac{M_{1}}{W_{1}}=\frac{27.040}{952.983}=0,0284 \mathrm{kN} / \mathrm{cm}^{2}=284 \mathrm{kN} / \mathrm{m}^{2} \\
& \sigma_{2}= \pm \frac{M_{2}}{W_{2}}=\frac{27.281}{881.640}=0,0309 \mathrm{kN} / \mathrm{cm}^{2}=309 \mathrm{kN} / \mathrm{m}^{2} \\
& \sigma_{3}= \pm \frac{M_{3}}{W_{3}}=\frac{39.185}{1.363 .523}=0,0287 \mathrm{kN} / \mathrm{cm}^{2}=287 \mathrm{kN} / \mathrm{m}^{2} \\
& \sigma_{4}= \pm \frac{M_{4}}{W_{4}}=\frac{29.513}{1.050 .465}=0,0281 \mathrm{kN} / \mathrm{cm}^{2}=281 \mathrm{kN} / \mathrm{m}^{2} \\
& \sigma_{5}= \pm \frac{M_{5}}{W_{5}}=\frac{8.159}{396.277}=0,0206 \mathrm{kN} / \mathrm{cm}^{2}=206 \mathrm{kN} / \mathrm{m}^{2}
\end{aligned}
$$

\section{B - Resolução não considerando as abas ou flanges}

Dando início ao procedimento de distribuição, calculam-se as rigidezes de cada painel que, supondo constantes ao longo da altura, correspondem ao seu momento de inércia ( I ). 
Painéis (1), (2), (3), (4)

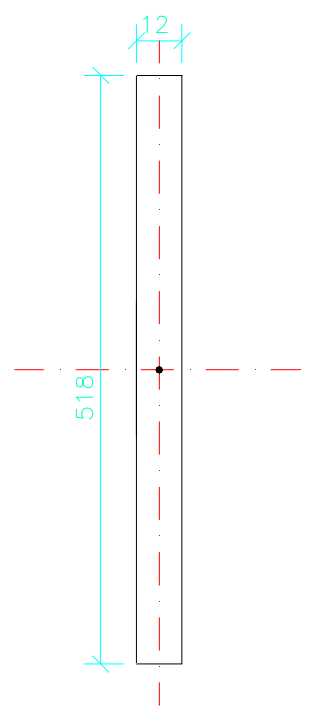

$$
\mathrm{I}=\frac{12 \times 518^{3}}{12}=138.991 .832 \mathrm{~cm}^{4}
$$

Painel (5)

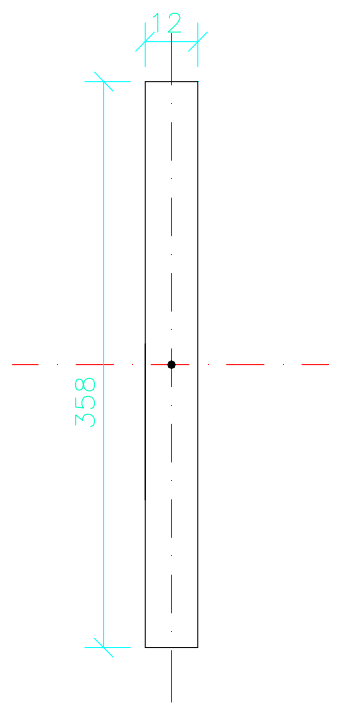

$$
I=\frac{12 \times 358^{3}}{12}=45.882 .712 \mathrm{~cm}^{4}
$$

Desta forma, pode-se definir a somatória de todas as rigidezes:

$$
\sum \mathrm{I}=4 \mathrm{I}_{1}+5 \mathrm{I}_{2}+2 \mathrm{l}_{3}+2 \mathrm{I}_{4}+\mathrm{I}_{5}=1.852 .776 .528 \mathrm{~cm}^{4}
$$


A rigidez relativa de cada painel será, de acordo com a eq.(3.1):

$$
\begin{aligned}
& R_{1}=R_{2}=R_{3}=R_{4} \cong 0,0750 \\
& R_{5} \cong 0,0248
\end{aligned}
$$

Calcula-se, então, a ação sobre cada painel pela eq.(3.12):

$$
F_{i}=F_{\text {tot }} \times R_{i}
$$

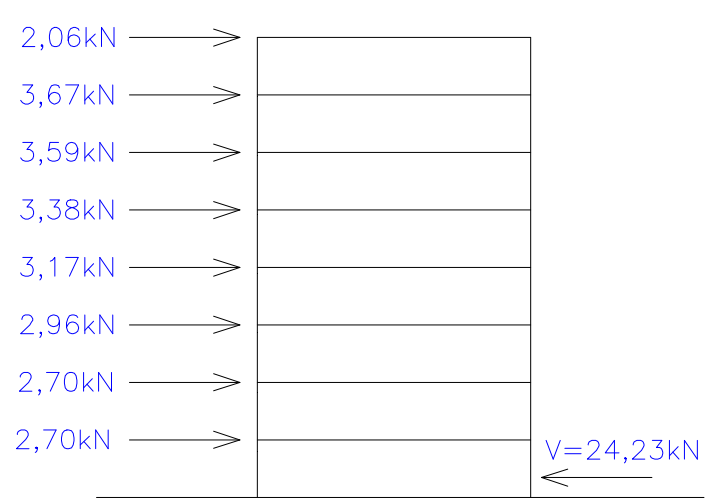

painéis (1), (2), (3), (4)

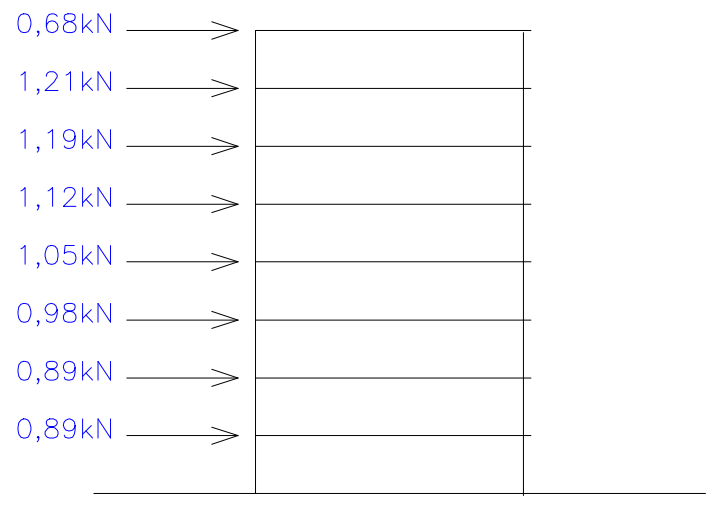

painel (5)

Através das ações pode-se calcular os momentos fletores na base para os cinco painéis:

painéis (1), (2), (3), (4): $M=292,66 \mathrm{kN} \cdot \mathrm{m}$

painel (5): $\mathrm{M}=96,77 \mathrm{kN} \cdot \mathrm{m}$

As tensões normais na base dos painéis podem ser obtidas pela eq.(3.13), onde o módulo de resistência à flexão é dado por:

$$
\begin{aligned}
& W_{1}=W_{2}=W_{3}=W_{4}=\frac{138.991 .832}{259}=536.648 \mathrm{~cm}^{3} \\
& W_{5}=\frac{45.882 .712}{179}=256.328 \mathrm{~cm}^{3}
\end{aligned}
$$


Portanto, as tensões normais no $1^{\circ}$ pavimento devidas às ações horizontais, não considerando as abas nos painéis, são:

$$
\begin{aligned}
& \sigma_{1}=\sigma_{2}=\sigma_{3}=\sigma_{4}= \pm \frac{29.266}{536.648}=0,0545 \mathrm{kN} / \mathrm{cm}^{2}=545 \mathrm{kN} / \mathrm{m}^{2} \\
& \sigma_{5}= \pm \frac{9.677}{256.328}=0,0378 \mathrm{kN} / \mathrm{cm}^{2}=378 \mathrm{kN} / \mathrm{m}^{2}
\end{aligned}
$$

Comparando as tensões devidas às ações horizontais nos procedimentos $A$ e $B$, verifica-se que as tensões quando da consideração das abas são bem menores (cerca da metade) que as mesmas não considerando estes trechos, o que gera maior economia.

Comparando a força cortante na base do painel (3) nas duas situações, observa-se que esta força, para o caso de não consideração das abas, é 33,8\% menor que no caso de consideração das mesmas. Isto significa que a não consideração das flanges seria contra a segurança, já que a determinação da tensão de cisalhamento depende do valor da cortante e da largura da alma.

Portanto, a consideração dos flanges é sempre recomendável para a correta determinação da rigidez dos painéis, conforme visto no item 3.5.1 deste capítulo.

\subsection{Considerações finais}

Neste capítulo procurou-se mostrar critérios para fazer a concepção estrutural de um edifício, a determinação das ações atuantes e sua distribuição ao longo da estrutura.

Procurou-se sempre que possível fornecer orientações nos pontos que gerassem tomadas de decisão, como é objetivo deste trabalho.

Após a determinação dos esforços e tensões, resta agora dimensionar todos os elementos da estrutura considerada, o que será feito no capítulo seguinte. 


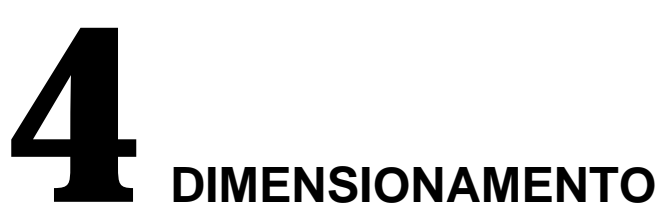

\subsection{Método das Tensões Admissíveis}

A ABNT (NBR-10837) adota o Método das Tensões Admissíveis para o dimensionamento dos elementos de alvenaria estrutural.

Neste método as solicitações provenientes das cargas permanentes e acidentais não devem causar tensões que excedam as tensões admissíveis dos materiais, ou seja:

$$
\mathrm{S} \leq \overline{\mathrm{R}}
$$

onde:

$$
\begin{aligned}
& \mathrm{S} \rightarrow \text { máxima tensão solicitante } \\
& \overline{\mathrm{R}} \rightarrow \text { máxima tensão admissível } \\
& \qquad \bar{R}=\frac{\mathrm{R}}{\gamma_{\mathrm{i}}} \\
& \mathrm{R} \rightarrow \text { tensão de ruptura ou de escoamento do material } \\
& \gamma_{i} \rightarrow \text { coeficiente de segurança interno }
\end{aligned}
$$

O método das tensões admissíveis introduz a segurança no projeto estrutural mediante o estabelecimento do coeficiente interno $\gamma_{i}$. Existem críticas com relação a este método, por ser determinístico ao invés de probabilístico. 
Segundo CASTRO (1997), como a resistência disponível e a solicitação real não podem ser determinadas precisamente, elas podem ser descritas como pertencentes a determinados intervalos, podendo ser modeladas como variáveis aleatórias. Nestes termos, a confiabilidade de um sistema de engenharia pode ser mais realisticamente medida em termos de probalidade.

Trabalha-se no concreto armado com o Método dos Estados Limites, que é probabilístico, ao contrário do Método das Tensões Admissíveis, que é determinístico. É provável que na próxima revisão da ABNT (NBR-10837) passe-se a adotar tal método de dimensionamento para a alvenaria. OLIVEIRA JR. \& PINHEIRO (1994a) mostram o cálculo através deste método.

\subsection{Determinação das tensões admissíveis}

De acordo com a ABNT (NBR-10837), as tensões admissíveis para a alvenaria armada e para a alvenaria não-armada devem ser baseadas na resistência dos primas $\left(f_{p}\right)$ aos 28 dias ou na idade na qual a estrutura estará submetida ao carregamento total.

Os prismas são formados pela justaposição de dois blocos de concreto unidos por junta de argamassa, destinados ao ensaio de compressão axial (Figura 4.1).

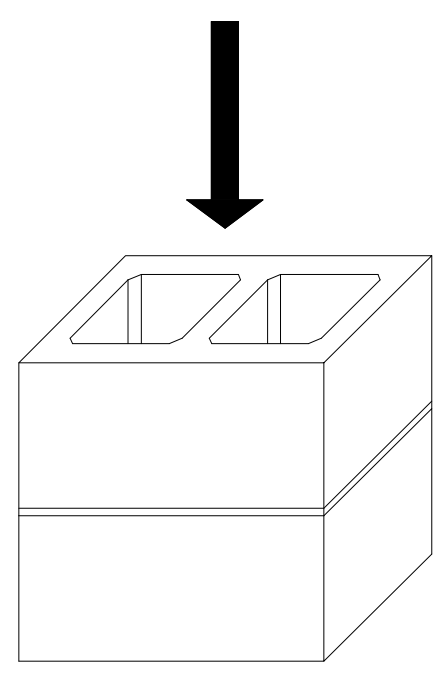

FIGURA 4.1 - Prisma 
Os prismas a serem ensaiados devem ser construídos com blocos e argamassa iguais aos que serão efetivamente usados na estrutura. A norma brasileira que regulamenta estes ensaios é a ABNT (NBR-8215).

As tensões admissíveis de compressão axial na alvenaria podem também ser determinadas por meio de ensaios de paredes. A norma brasileira que regulamente estes ensaios é a ABNT (NBR-8949).

Usualmente, na prática, opta-se pelo ensaio de prismas, devido à maior facilidade e economia dos ensaios, cujos resultados são suficientes. Os ensaios de paredes são menos utilizados, por exigirem um aparato laboratorial mais complexo.

A relação entre a resistência axial do prisma $\left(f_{p}\right)$ e a resistência do bloco $\left(f_{b}\right)$ é denominada eficiência $(\eta)$. No Brasil, a prática costuma indicar valores que variam de 0,5 a 0,9 para este parâmetro, no caso de blocos de concreto.

\subsection{Tensões admissíveis na alvenaria}

TABELA 4.1 - Tensões admissíveis na alvenaria não-armada

\begin{tabular}{|c|c|c|}
\hline \multirow{2}{*}{ Tipo de solicitação } & \multicolumn{2}{|c|}{ Tensão admissível (MPa) } \\
\cline { 2 - 3 } & $12,0 \leq \mathrm{f}_{\mathrm{a}} \leq 17,0$ & $5,0 \leq \mathrm{f}_{\mathrm{a}} \leq 12,0$ \\
\hline Compressão simples & $0,20 \mathrm{f}_{\mathrm{p}} \mathrm{R}$ ou $\left(0,286 \mathrm{f}_{\mathrm{pa}} \mathrm{R}\right)^{*}$ & $0,20 \mathrm{f}_{\mathrm{p}} \mathrm{R}$ ou $\left(0,286 \mathrm{f}_{\mathrm{pa}} \mathrm{R}\right)^{*}$ \\
Parede & $0,18 \mathrm{f}_{\mathrm{p}} \mathrm{R}$ & $0,18 \mathrm{f}_{\mathrm{p}} \mathrm{R}$ \\
Pilar & $0,30 \mathrm{f}_{\mathrm{p}}$ & $0,30 \mathrm{f}_{\mathrm{p}}$ \\
Compressão na flexão & & 0,10 \\
\hline Tração na flexão & 0,15 & 0,20 \\
Normal à fiada & 0,30 & 0,15 \\
\hline Paralela à fiada & 0,25 & \\
\hline Cisalhamento & & 0 \\
\hline
\end{tabular}

Notas: a) (*) Valor admissível, caso seja usada a resistência de paredes.

b) Os limites da resistência média da argamassa $\left(\mathrm{f}_{\mathrm{a}}\right)$ também se aplicam à alvenaria armada, isto é: $5,0 \mathrm{MPa} \leq \mathrm{f}_{\mathrm{a}} \leq 17,0 \mathrm{MPa}$.

c) $R=1-\left(\frac{h}{40 t}\right)^{3}$ é o fator de redução da resistência associado à esbeltez (h/t), aplicável também à alvenaria armada. 
Diferenciam-se os casos de tração normal e paralela às fiadas, o que pode ser melhor compreendido com o auxílio da Figura 4.2.

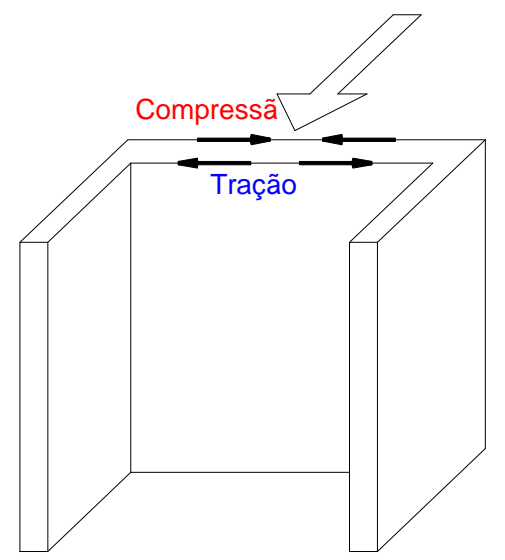

a) Paralela à fiada

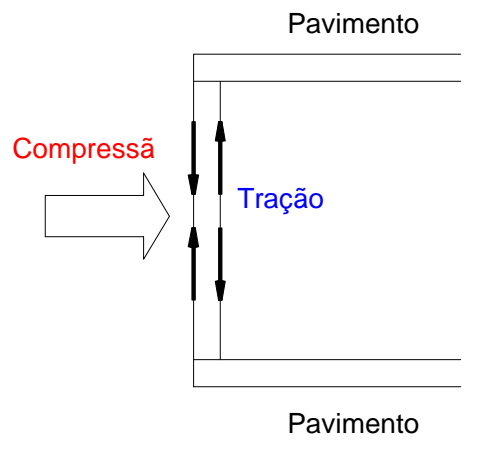

b) Normal à fiada

FIGURA 4.2 - Tensões de tração na flexão 
TABELA 4.2 - Tensões admissíveis na alvenaria armada

\begin{tabular}{|c|c|c|}
\hline Tipo de solicitação & $\begin{array}{c}\text { Tensão admissível } \\
(\mathrm{MPa})\end{array}$ & $\begin{array}{c}\text { Valores máximos } \\
(\mathrm{MPa})\end{array}$ \\
\hline $\begin{array}{l}\text { Compressão: } \\
\text { Compressão simples } \\
\text { Parede } \\
\text { Pilar } \\
\text { Compressão na flexão }\end{array}$ & $\begin{array}{c}0,225 f_{p} R\left(0,286 f_{p a} R\right) \\
\left(0,20 f_{p}+0,30 \rho f_{s, c}\right) R \\
0,33 f_{p}\end{array}$ & $\begin{array}{l}0,33 \mathrm{f}_{\mathrm{p}}, \text { mas não } \\
\text { exceder } 6,2 \mathrm{MPa}\end{array}$ \\
\hline $\begin{array}{l}\text { Cisalhamento: } \\
\Rightarrow \text { peças fletidas sem armaduras } \\
\text { de cisalhamento } \\
\Rightarrow \text { pilares e paredes sem } \\
\text { armaduras de cisalhamento } \\
\qquad \text { Se } \frac{M}{V . d} \geq 1 \\
\text { Se } \frac{M}{V . d}<1\end{array}$ & $\begin{array}{l}0,09 \sqrt{f_{p}} \\
0,07 \sqrt{f_{p}} \\
0,17 \sqrt{f_{p}}\end{array}$ & $\begin{array}{l}0,25 \\
0,35\end{array}$ \\
\hline $\begin{array}{l}\Rightarrow \text { peças fletidas com armaduras } \\
\text { para absorver todas as tensões } \\
\text { de cisalhamento } \\
\Rightarrow \text { pilares e paredes com } \\
\text { armaduras para absorver todas } \\
\text { as tensões de cisalhamento } \\
\qquad \text { Se } \frac{M}{V \cdot d} \geq 1 \\
\text { Se } \frac{M}{V . d}<1\end{array}$ & $\begin{array}{l}0,25 \sqrt{f_{p}} \\
0,12 \sqrt{f_{p}} \\
0,17 \sqrt{f_{p}}\end{array}$ & $\begin{array}{l}0,50 \\
0,80\end{array}$ \\
\hline $\begin{array}{l}\text { Aderência: } \\
\text { Barras de aderência normal }\end{array}$ & & 1,00 \\
\hline $\begin{array}{l}\text { Tensão de contato } \\
\text { Em toda a área } \\
\text { Em } 1 / 3 \text { da área, pelo menos }\left(^{*}\right)\end{array}$ & & $\begin{array}{c}0,25 f_{p} \\
0,375 f_{p}\end{array}$ \\
\hline $\begin{array}{l}\text { Módulo de deformação } \\
\text { Módulo de deformação } \\
\text { transversal }\end{array}$ & $\begin{array}{l}400 f_{p} \\
200 f_{p}\end{array}$ & $\begin{array}{l}8000 \\
3000\end{array}$ \\
\hline
\end{tabular}

Nota: $\left(^{*}\right)$ Este aumento é permitido quando a largura da zona carregada é no mínimo 1/3 da espessura da parede. A tensão de contato admissível, de um carregamento concentrado, de dimensão maior que 1/3 e menor que a área total deve ser interpolada. Vide Figura 4.3. 


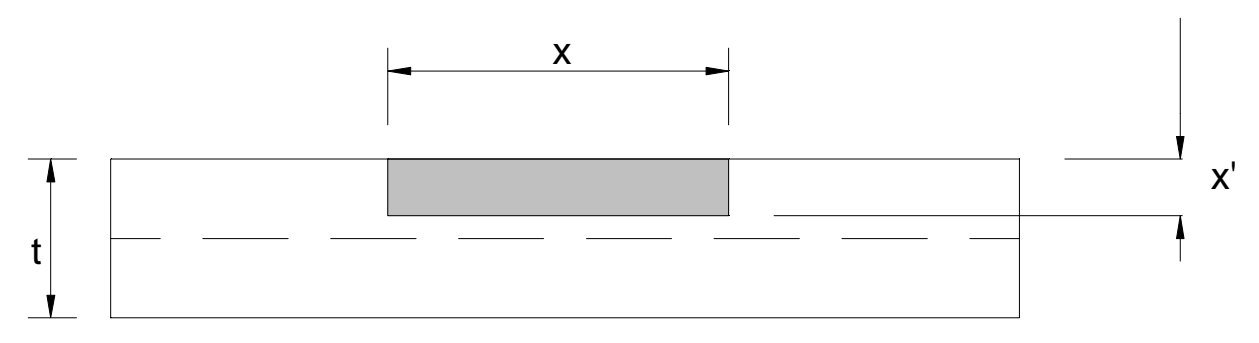

FIGURA 4.3 - Contato

\subsection{Tensão de tração admissível nas armaduras}

A tensão de tração admissível nas barras com mossas, cuja tensão de escoamento é maior ou igual a $412 \mathrm{MPa}$, e de diâmetros iguais a $32 \mathrm{~mm}$ ou menores, não deve exceder $165 \mathrm{MPa}$.

A tensão de tração admissível nas barras usadas como armaduras horizontais (colocadas na argamassa de assentamento) deve ser limitada a 50\% da tensão de escoamento do aço empregado, mas não deve exceder $206 \mathrm{MPa}$.

Outros tipos de armaduras tracionadas devem ter sua tensão admissível limitada a $137 \mathrm{MPa}$.

\subsection{Tensão de compressão admissível nas armaduras}

A tensão de compressão admissível nas armaduras de pilares deve ser admitida como sendo $40 \%$ da tensão de escoamento mínima, e não deve exceder $165 \mathrm{MPa}$.

A tensão de compressão admissível nas armaduras verticais de paredes deve ser admitida como sendo no máximo $62 \mathrm{MPa}$.

Nos projetos, a tensão característica do graute $\left(\mathrm{f}_{\mathrm{gk}}\right)$ deve ser adotada de modo a atender a seguinte relação:

$$
f_{g k} \geq 2,00 f_{b k}^{9}
$$

\footnotetext{
${ }^{9}$ Resistência referida à área bruta
} 
Nesta expressão está implícito que ao se considerar um bloco grauteado, sua área bruta é o dobro da área líquida do bloco vazio, e que o graute deve ser no mínimo igualmente resistente ao bloco.

\subsection{Tensão de cisalhamento admissível em parafusos e ancoragens}

A tensão de cisalhamento admissível em parafusos de aço e ancoragens não deve exceder os valores indicados na Tabela 4.3.

TABELA 4.3 - Tensões de cisalhamento admissíveis em parafusos e ancoragens

\begin{tabular}{|c|c|c|}
\hline $\begin{array}{c}\text { Diâmetro do parafuso ou } \\
\text { ancoragem } \\
(\mathrm{mm})\end{array}$ & $\begin{array}{c}\text { Embutimento } \\
(\mathrm{mm})\end{array}$ & $(\mathrm{MPa})$ \\
\hline 6,3 & 100 & 1,8 \\
9,5 & 100 & 2,8 \\
12,7 & 100 & 3,8 \\
15,9 & 100 & 5,1 \\
19,0 & 130 & 7,5 \\
22,2 & 150 & 10,3 \\
25,4 & 180 & 12,7 \\
28,4 & 200 & 15,4 \\
\hline
\end{tabular}

Notas: a) Ao se determinarem as tensões na alvenaria de blocos de concreto, as excentricidades devido a parafusos carregados e ancoragens devem ser consideradas.

b) Os parafusos ou ancoragens devem estar solidamente envolvidos pela argamassa de assentamento ou pelo graute.

\subsection{Dimensionamento das vergas e vigas}

Vergas e vigas são elementos estruturais lineares destinados a suportar e transmitir ações verticais mediante um comportamento predominante de flexão. 
De acordo com a ABNT (NBR-10837), para o cálculo das vergas, só é necessário tomar como carregamento as ações atuantes no triângulo isósceles definido sobre a mesma (Figura 4.4).

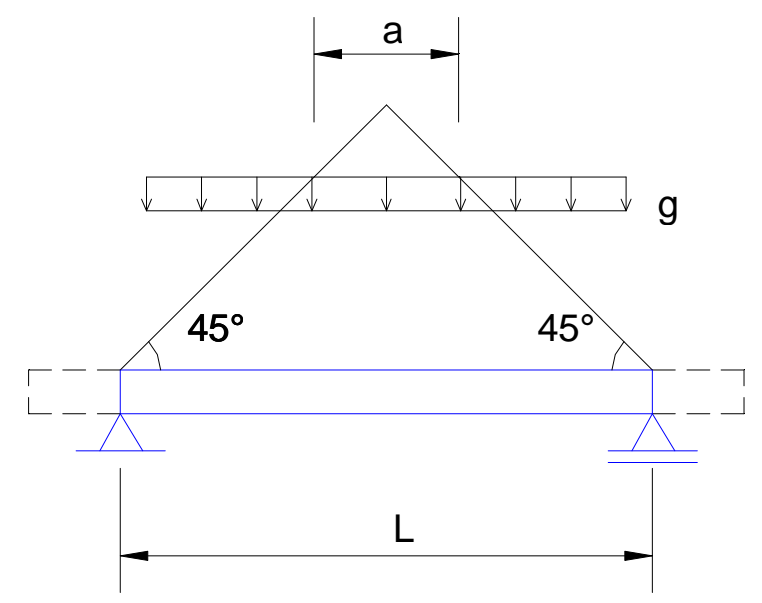

FIGURA 4.4 - Carga distribuída dentro do triângulo de carga

Para cargas concentradas sobre vergas de portas ou janelas, que se apliquem no interior ou na proximidade do triângulo de carga, é adotada uma distribuição a $60^{\circ}$. 


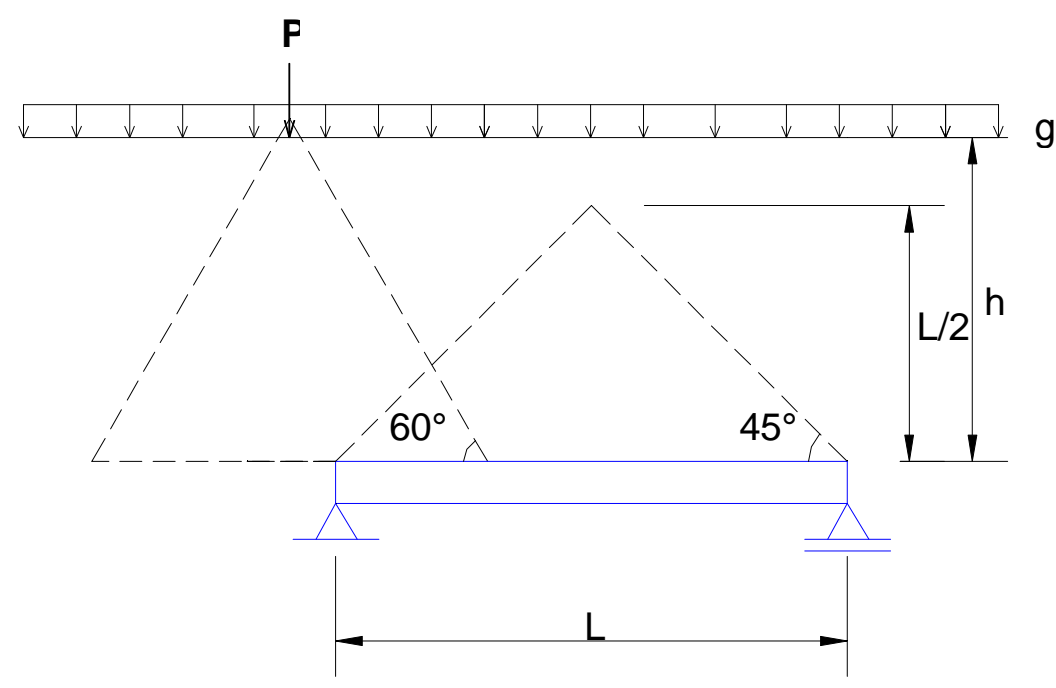

FIGURA 4.5 - Carga concentrada fora do triângulo de carga

\subsubsection{Dimensionamento à flexão simples}

De acordo com o item 5.2.2 da ABNT (NBR-10837), os componentes fletidos são calculados no Estádio II. Neste estádio admite-se que a alvenaria não resiste à tração e que o comportamento do material é linear, ou seja, obedece a Lei de Hooke. As hipóteses básicas para estes cálculos são:

“ a) a seção que é plana antes de fletir permanece plana após a flexão;

b) o módulo de deformação da alvenaria e da armadura permanece constante;

c) as armaduras são completamente envolvidas pelo graute e pelos elementos constituintes da alvenaria, de modo que ambos trabalhem como material homogêneo dentro dos limites das tensões admissíveis."

O equacionamento abaixo encontra-se em AMRHEIN (1978), juntamente com todas as demonstrações envolvidas. Como o objetivo deste trabalho é enfocar os pontos de tomadas de decisão, não se aterá a estas demonstrações. O que será feito é apenas um resumo das principais fórmulas utilizadas no dimensionamento à flexão simples.

A Figura 4.6 auxilia na definição dos parâmetros principais. 


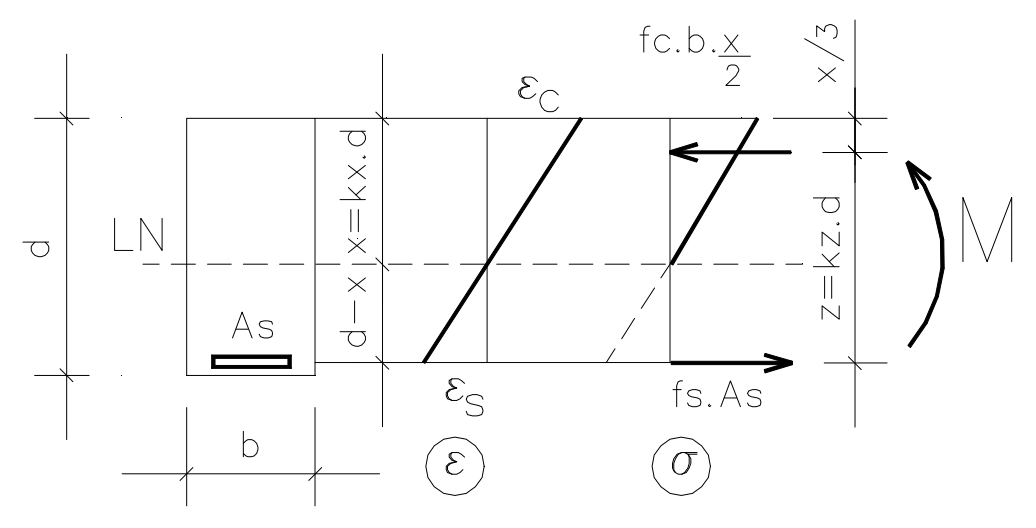

FIGURA 4.6 - Flexão simples em seção retangular - armadura simples

Inicialmente, devem-se definir duas grandezas adimensionais auxiliares, a razão de tensões $(\mathrm{m})$ e a razão modular $(n)$ :

$$
\begin{gathered}
m=\frac{f_{s}}{f_{c}} \\
n=\frac{E_{s}}{E_{c}}
\end{gathered}
$$

onde:

$$
\begin{aligned}
& f_{s} \rightarrow \text { tensão de tração nas armaduras }\left(f_{s, t}\right) \\
& f_{c} \rightarrow \text { máxima tensão de compressão na alvenaria }\left(f_{a l v, f}\right) \\
& E_{s} \rightarrow \text { módulo de elasticidade do aço } \\
& E_{c} \rightarrow \text { módulo de elasticidade da alvenaria }
\end{aligned}
$$

Aplicando a Lei de Hooke, a compatibilidade de deformações, e a equivalência estática, define-se a posição da linha neutra (LN):

$$
k_{x}=-\rho n+\sqrt{(\rho n)^{2}+2 \rho n}
$$

onde:

$$
\begin{gathered}
\rho \rightarrow \text { taxa geométrica de armadura } \\
\rho=\frac{A_{s}}{b . d}
\end{gathered}
$$


Daí, a armadura pode ser calculada pela seguinte expressão:

$$
A_{s}=k_{s} \frac{M}{d}
$$

onde:

$$
k_{s}=\frac{1}{f_{s} \cdot k_{z}}
$$

A máxima tensão na alvenaria é dada por:

$$
f_{c}=\frac{2}{k_{x} k_{z}} \cdot \frac{M}{b \cdot d^{2}}
$$

O melhor aproveitamento de todos os materiais é conseguido quando a armadura e a alvenaria atingem simultaneamente as suas tensões admissíveis, ou seja:

$$
f_{c}=\bar{f}_{a l v, f} \quad \text { e } \quad f_{s}=\bar{f}_{s, t}
$$

O dimensionamento nessas condições é chamado balanceado e a seção é dita normalmente armada. $O$ valor de $k_{x}$, neste caso é representado por $k_{b}$. $A$ taxa de armadura balanceada é calculada por:

$$
\rho_{b}=\frac{n}{m_{b}+n} \cdot \frac{1}{2 m_{b}}
$$

onde:

$$
m_{b}=\frac{\bar{f}_{s, t}}{\bar{f}_{\text {alv }, f}}
$$




\section{a) Dimensionamento da seção retangular com armadura simples}

$1^{\circ}$ caso

Dados: $\mathrm{n}=\frac{\mathrm{E}_{\mathrm{s}}}{\mathrm{E}_{\mathrm{c}}} ; \overline{\mathrm{f}}_{\mathrm{s}, \mathrm{t}} ; \overline{\mathrm{f}}_{\mathrm{alv}, \mathrm{f}} ; \mathrm{b} ; \mathrm{M}$

Pedem-se: $d=? ; A_{s}=?$

O problema admite várias soluções; uma delas é fazer o dimensionamento balanceado. Daí, tem-se:

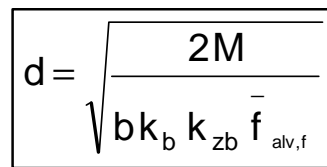

$$
\text { onde: } k_{b}=\frac{n}{n+m_{b}} \quad \text { e } \quad k_{z b}=1-\frac{k_{b}}{3}
$$

$$
A_{s}=\frac{M}{f_{s, t} k_{z b} d}
$$

$2^{\circ}$ caso

Dados: $\mathrm{n}=\frac{\mathrm{E}_{\mathrm{s}}}{\mathrm{E}_{\mathrm{c}}} ; \overline{\mathrm{f}}_{\mathrm{s}, \mathrm{t}} ; \overline{\mathrm{f}}_{\mathrm{alv}, \mathrm{f}} ; \mathrm{b} ; \mathrm{M} ; \mathrm{d}$

Pedem-se: $A_{s}=$ ?

Inicialmente determina-se a altura útil correspondente ao dimensionamento balanceado:

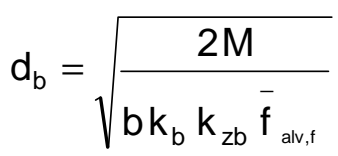


- Se $d_{b}<d \Rightarrow f_{s}=\bar{f}_{s, t}$ e $\quad f_{c} \leq \bar{f}_{a l v, f}$ (seção subarmada)

O cálculo, neste caso, pode ser feito com a utilização da planilha a seguir, conforme CORRÊA \& RAMALHO (1996):

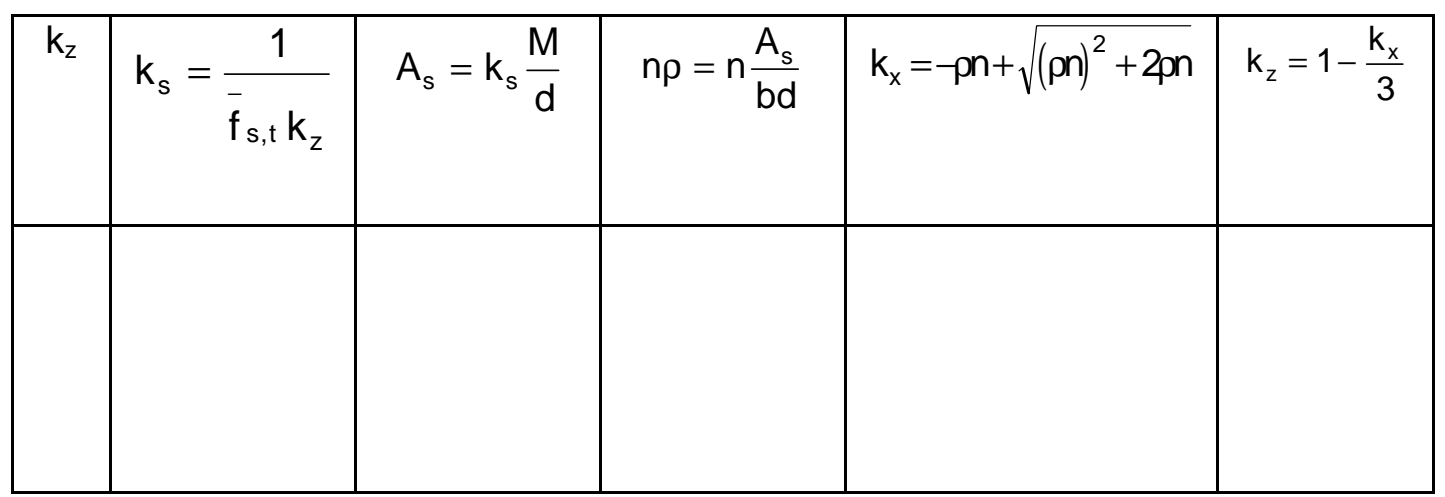

O primeiro valor de $\mathrm{k}_{\mathrm{z}}$ a ser utilizado é o do dimensionamento balanceado. $\mathrm{O}$ cálculo termina quando $\mathrm{o}$ valor de $\mathrm{k}_{\mathrm{z}}$ obtido da última coluna não diferir significativamente do valor da primeira coluna. Pode-se adotar como convergência suficiente a tolerância de 0,1\%, conforme CORRÊA \& RAMALHO (1996). Em geral o processo iterativo é rápido, e necessita de no máximo três iterações.

No final do processo deve-se chegar a:

$$
f_{c}=\frac{2}{k_{x} k_{z}} \cdot \frac{M}{b \cdot d^{2}}<\bar{f}_{a l v, f}
$$

- Se $d_{b}>d \Rightarrow$ seção superarmada com $f_{s} \leq f_{s, t}$ e $f_{c}=f_{a l v, f}$

ou

armadura dupla

Admitindo seção superarmada, a posição da L.N. é determinada por:

$$
k_{x}^{2}-3 k_{x}+\frac{6 M}{b d^{2} \bar{f}_{a l v, f}}=0
$$


Com o valor de $\mathrm{k}_{\mathrm{x}}$ determina-se $\mathrm{k}_{\mathrm{z}}$ :

$$
\mathrm{k}_{\mathrm{z}}=1-\frac{\mathrm{k}_{\mathrm{x}}}{3}
$$

Portanto, a seção de armadura é calculada por:

$$
A_{s}=\rho b d
$$

onde:

$$
\rho=\frac{k_{x}{ }^{2}}{2 n\left(1-k_{x}\right)}
$$

No final deve-se verificar a tensão de tração na armadura:

$$
f_{s}=\frac{M}{A_{s} k_{z} d}<\bar{f}_{s, t}
$$

\section{b) Dimensionamento da seção retangular com armadura dupla}

O roteiro de cálculo descrito a seguir pode ser melhor compreendido com o auxílio da Figura 4.7.

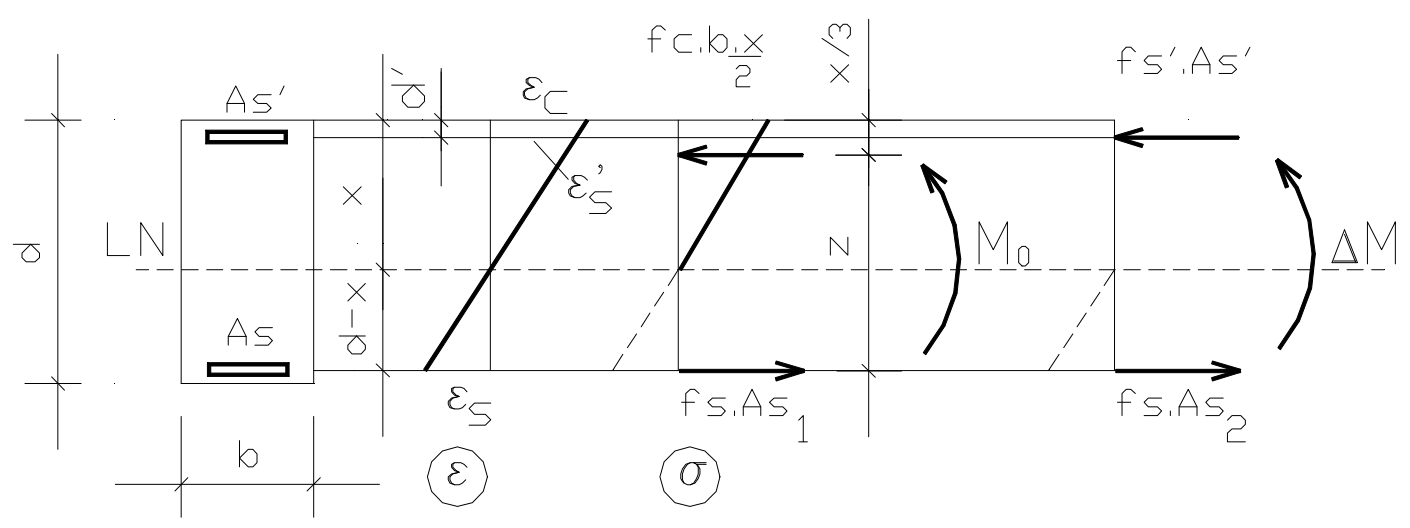

FIGURA 4.7 - Flexão simples em seção retangular - armadura dupla 
Determina-se, inicialmente, a parcela do momento fletor que é absorvida com armaduras simples e dimensionamento balanceado:

$$
M_{0}=\bar{f}_{a l v, f} k_{b} k_{z b} \frac{b d^{2}}{2}
$$

A seção de armadura tracionada correspondente ao momento $M_{0}$ é calculada por:

$$
A_{s 1}=\frac{M_{0}}{f_{s, t} k_{z b} d}
$$

Determina-se a parcela complementar do momento $\left(\Delta M=M-M_{0}\right)$, que deve ser absorvida apenas pelo binário de forças correspondentes às armaduras adicionais $A_{s 2}$ (na região tracionada) e $A_{s}^{\prime}$ (na região comprimida).

As seções de armadura adicionais são calculadas pelas eq. (4.12) e eq. (4.13).

$$
\begin{gathered}
A_{s 2}=\frac{\Delta M}{f_{s, t}\left(d-d^{\prime}\right)} \\
A_{s}^{\prime}=\frac{\Delta M}{\left(d-d^{\prime}\right)} \frac{(d-x)}{\left(x-d^{\prime}\right)} \frac{1}{f_{s, t}}
\end{gathered}
$$

\subsubsection{Dimensionamento ao cisalhamento}

De acordo com a ABNT (NBR-10837), a tensão convencional de cisalhamento atuante nas vergas e vigas de alvenaria deve ser calculada pela seguinte expressão:

$$
f_{\text {cis }}=\frac{V}{b \cdot d}
$$


onde:

$$
\begin{aligned}
& V \rightarrow \text { esforço cortante atuante } \\
& b \rightarrow \text { largura efetiva da verga ou viga } \\
& d \rightarrow \text { altura útil da verga ou viga }
\end{aligned}
$$

A norma adverte que no caso de seção $T$ ou $L$, o valor da largura efetiva deve ser o da alma.

Conforme visto no item 4.3, existem dois limites de tensão admissível de cisalhamento: um para peças fletidas sem armadura de cisalhamento e outro para peças fletidas com tais armaduras.

No caso da tensão atuante de cisalhamento superar o limite de tensão admissível correspondente a peças fletidas sem armadura de cisalhamento, é necessário calcular esta armadura. Ao contrário das vigas em concreto armado, que necessitam sempre de uma armadura mínima para combater o cisalhamento, as vigas em alvenaria podem ter trechos completamente não-armados.

De acordo com a norma, a área das barras que funcionam como estribos pode ser calculada pela fórmula:

$$
A_{s w, 90^{\circ}}=\frac{V s}{f_{s, t} d}
$$

onde:

$$
\begin{aligned}
V & \rightarrow \text { esforço cortante atuante } \\
\mathrm{s} & \rightarrow \text { espaçamento dos estribos } \\
\overline{\mathrm{f}}_{\mathrm{s}, \mathrm{t}} & \rightarrow \text { tensão admissível do aço dos estribos } \\
\mathrm{d} & \rightarrow \text { altura útil da verga ou viga }
\end{aligned}
$$

Quanto ao espaçamento dos estribos, deve-se observar a modulação horizontal, devido ao alojamento de armaduras nos vazados do bloco.

Quando a armadura consistir de barras paralelas dobradas a uma mesma distância do apoio, a área necessária deve ser calculada pela seguinte expressão:

$$
A_{s w, \alpha}=\frac{V}{f_{s, t} \operatorname{sen} \alpha}
$$


onde:

$$
\alpha \rightarrow \text { menor ângulo entre a armadura e o eixo longitudinal da viga }
$$

Quando a armadura consistir de barras paralelas dobradas a distâncias diferentes do apoio, a área necessária deve ser calculada pela seguinte expressão:

$$
A_{s w, \alpha}=\frac{V s}{f_{s, t} d(\operatorname{sen} \alpha+\cos \alpha)}
$$

\subsubsection{Exemplo}

Determinar as armaduras de flexão e cisalhamento para a verga de seção $14 \times 40$ ilustrada a seguir:

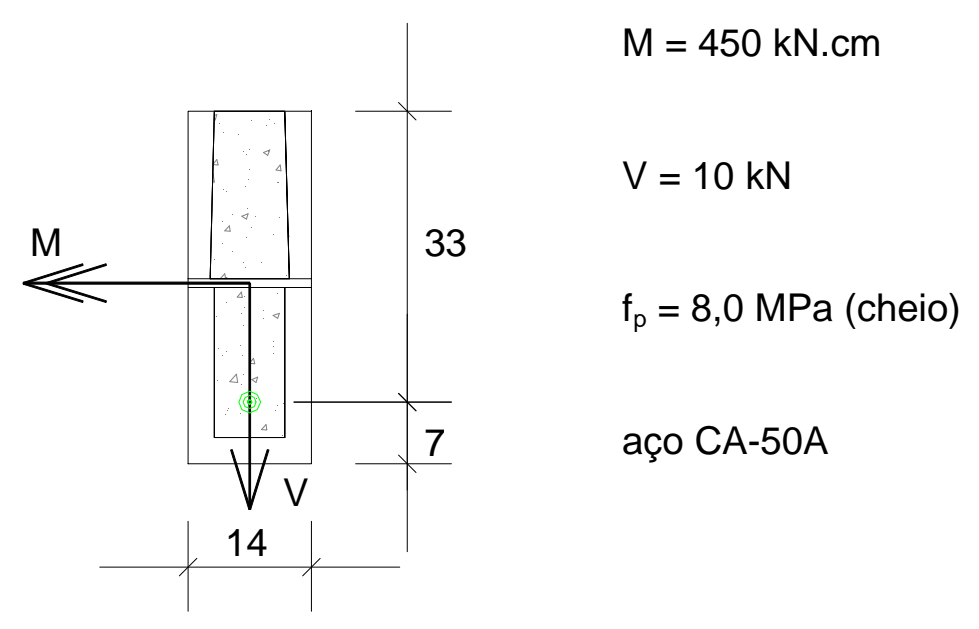

a) Dimensionamento à flexão simples

Neste caso, como foi fornecido o valor de $d$, deve-se calcular $d_{b}$ (dimensionamento balanceado), e comparar os dois valores. Portanto:

$$
\bar{f}_{\text {alv }, f}=0,33 f_{p}=0,33 \times 0,8=0,264 \mathrm{kN} / \mathrm{cm}^{2}
$$




$$
\begin{array}{ll}
\mathrm{n}=\frac{\mathrm{E}_{\mathrm{s}}}{\mathrm{E}_{\text {alv }}}=\frac{21000}{400 \times 0,8}=65,63 & \mathrm{~m}_{\mathrm{b}}=\frac{16,5}{0,264}=62,5 \\
\mathrm{k}_{\mathrm{b}}=\frac{65,63}{65,63+62,5}=0,512 & \mathrm{k}_{\mathrm{zb}}=1-\frac{0,512}{3}=0,829 \\
\mathrm{~d}_{\mathrm{b}}=\sqrt{\frac{2 \mathrm{M}}{\mathrm{bk}_{\mathrm{zb}} \mathrm{k}_{\mathrm{b}} \mathrm{f}_{\text {alv }, f}}}=23,95<\mathrm{d} \rightarrow \text { seção subarmada }
\end{array}
$$

Para a condução do cálculo, será utilizada a planilha a seguir:

\begin{tabular}{|c|c|c|c|c|c|}
\hline$k_{z}$ & $k_{s}=\frac{1}{f_{s, t} k_{z}}$ & $A_{s}=k_{s} \frac{M}{d}$ & $n \rho=n \frac{A_{s}}{b d}$ & $k_{x}=-\rho n+\sqrt{(\rho n)^{2}+2 \rho n}$ & $k_{z}=1-\frac{k_{x}}{3}$ \\
\hline 0,829 & 0,0731 & 0,997 & 0,1416 & 0,409 & 0,864 \\
\hline 0,864 & 0,0702 & 0,957 & 0,1359 & 0,403 & 0,866 \\
\hline 0,866 & 0,0700 & 0,955 & 0,1356 & 0,403 & 0,866 \\
\hline
\end{tabular}

A área de aço a ser utilizada é:

$$
A_{s}=0,955 \mathrm{~cm}^{2} \quad(2 \phi 8 \mathrm{~mm})
$$

Deve-se verificar a tensão máxima na alvenaria:

$$
f_{c}=\frac{2}{k_{x} k_{z}} \frac{M}{b d^{2}}=0,169<\bar{f}_{a l v, f} \quad \text { ok! }
$$

\section{b) Dimensionamento ao cisalhamento}

Inicialmente, calcula-se a tensão atuante de cisalhamento:

$$
f_{\text {cis }}=\frac{V}{b . d}=\frac{10}{14 \times 33}=0,022 \mathrm{kN} / \mathrm{cm}^{2}=0,22 \mathrm{MPa}
$$

O limite de tensão admissível para peças fletidas sem armadura é:

$$
\mathrm{f}_{\text {cis } 1}=0,09 \sqrt{\mathrm{f}_{\mathrm{p}}}=0,25 \mathrm{MPa}<0,35 \mathrm{MPa}
$$


Como $f_{c i s}<f_{\text {cis } 1}$ não há necessidade de dispor armaduras de cisalhamento na viga analisada.

Este exemplo reforça a afirmação feita anteriormente sobre a diferença entre as vigas em alvenaria e as de concreto armado, as quais necessitam sempre de armadura mínima de cisalhamento.

\subsection{Dimensionamento de paredes e pilares}

\subsubsection{Conceitos básicos}

De acordo com a ABNT (NBR-10837), paredes são elementos laminares verticais, apoiados de modo contínuo em toda a sua base, com comprimento maior que cinco vezes a espessura. De acordo com a mesma norma, pilares são elementos estruturais em que a seção transversal utilizada no cálculo dos esforços resistentes possui relação de lados inferior a cinco.

Paredes e pilares são elementos verticais preponderantemente comprimidos, e o cálculo é feito em função das cargas de serviço sem majoração. No Método das Tensões Admissíveis o único coeficiente de segurança que se emprega é o coeficiente interno $\gamma_{i}$, que se aplica somente às tensões admissíveis.

Nas paredes estruturais, a ABNT (NBR-10837) admite uma distribuição a $45^{\circ}$ das cargas concentradas ou parcialmente distribuídas, conforme pode ser visto na Figura 4.8. 


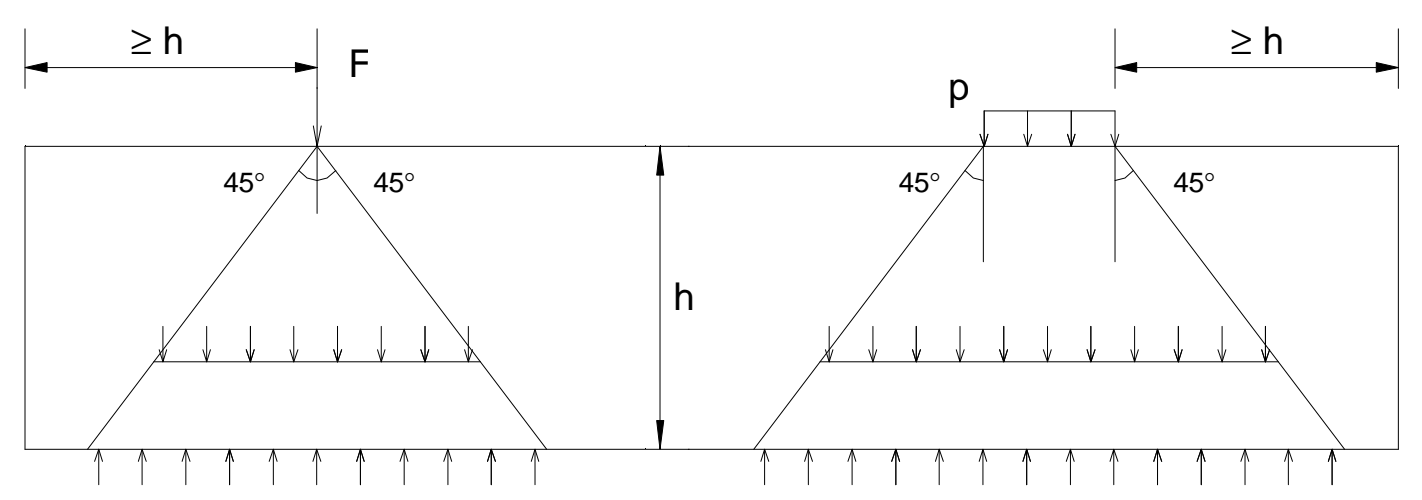

FIGURA 4.8 - Distribuição das cargas verticais

No caso de haver aberturas, a distribuição das cargas verticais é feita excluindo as zonas limitadas por planos inclinados a $45^{\circ}$, tangentes às bordas da abertura (Figura 4.9).

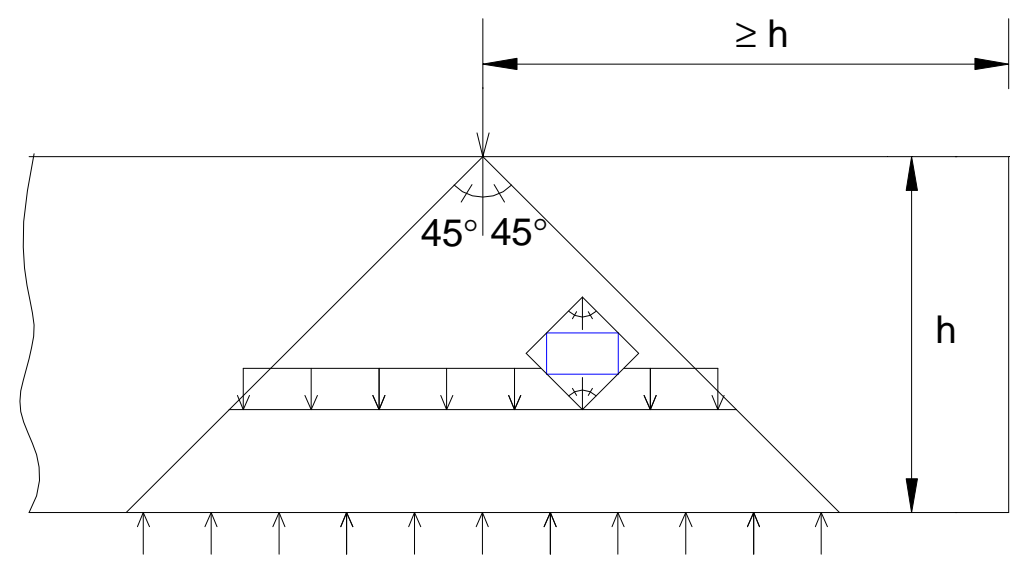

FIGURA 4.9 - Distribuição de carga vertical quando há abertura

Com a utilização da regra de espalhamento a $45^{\circ}$, utilizada pela norma, obtém-se uniformização de tensões ao longo da altura do edifício, fato já comprovado teórica e experimentalmente. Esta uniformização é altamente benéfica ao comportamento estrutural das paredes, conforme visto no item 2.2.2 do capítulo 2. 


\subsubsection{Dimensionamento à compressão axial}

Para o dimensionamento de paredes e pilares à compressão axial basta calcular as tensões normais de compressão axial atuantes e compará-las com as tensões admissíveis cujos valores foram dados no item 4.2.1.

A tensão normal de compressão axial atuante em uma parede ou pilar é dada por:

$$
f_{\text {alv }, c}=\frac{P}{A_{\text {ef }}}
$$

onde:

$\mathrm{f}_{\mathrm{alv}, \mathrm{c}} \rightarrow$ tensão de compressão axial atuante

$\mathrm{P} \rightarrow$ carga vertical de compressão atuante

$\mathrm{A}_{\mathrm{ef}} \rightarrow$ área efetiva da parede ou do pilar

O cálculo da área pode ser feito tanto em relação à seção líquida como em relação à seção bruta, basta que a resistência do prisma seja dada em função da mesma área. Se, com a finalidade de aumentar a capacidade resistente da parede, alguns furos dos blocos forem grauteados, basta computar o aumento de área correspondente.

\subsubsection{Dimensionamento à compressão localizada}

As tensões de contato surgem quando vigas, vergas ou outros elementos apoiam sobre uma parede, de forma que a carga que aplicam seja considerada concentrada (Figura 4.10). 


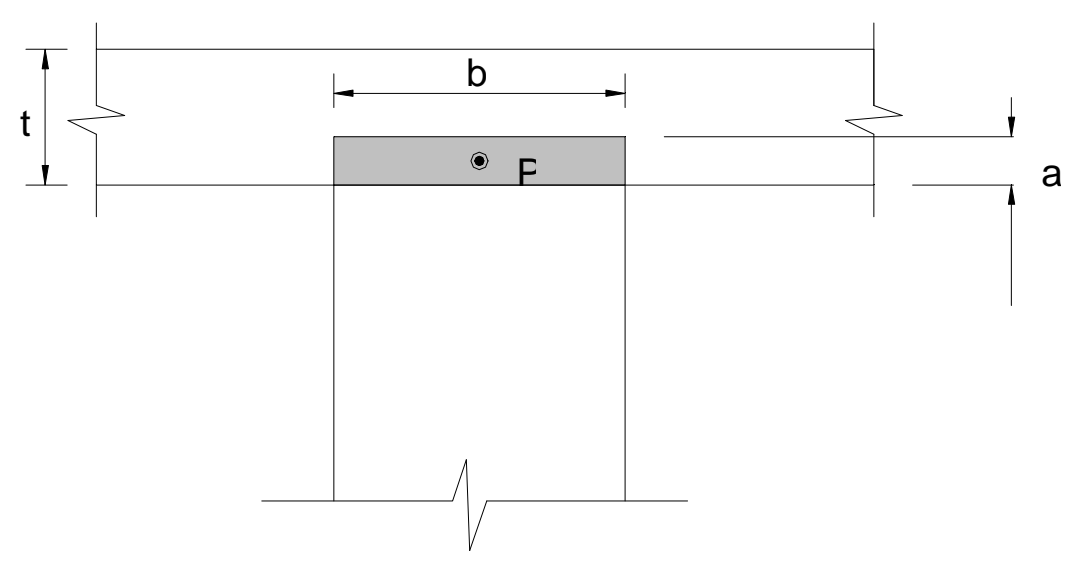

FIGURA 4.10 - Compressão localizada

A compressão localizada é limitada de forma que a tensão de contato atuante, calculada pela expressão (4.19) não supere a tensão de contato admissível, dada no item 4.3.

$$
f_{\text {con }}=\frac{P}{a b}
$$

A ABNT (NBR-10837) fixa para a largura da zona carregada (a), o valor mínimo de $50 \mathrm{~mm}$.

\subsubsection{Dimensionamento à flexão composta}

A flexão composta ocorre em pilares e paredes sujeitos à ações verticais (peso próprio, sobrecargas de utilização, etc.) e à ações horizontais (vento, desaprumo), o que é o caso mais comum nos edifícios em alvenaria estrutural.

De acordo com a ABNT (NBR-10837), quando a excentricidade resultante, calculada pela expressão (4.20), não exceder 1/6 da espessura do elemento, as tensões podem ser calculadas supondo a seção não fissurada (exclusivamente comprimida). 


$$
e=\frac{M}{P}
$$

onde:

$$
\begin{aligned}
& \mathrm{M} \rightarrow \text { momento fletor atuante } \\
& \mathrm{P} \rightarrow \text { força axial atuante }
\end{aligned}
$$

Se a excentricidade resultante exceder o valor que produz tração na parede ou no pilar, as tensões devem ser calculadas admitindo a seção fissurada e, neste caso, é necessário dispor armaduras para absorver a resultante de tração.

\section{a) Alvenaria não-armada}

Os elementos de alvenaria não-armada, quando submetidos às condições de carregamentos combinados, devem satisfazer à seguinte relação:

$$
\frac{f_{a l v, c}}{f_{\text {alv }, c}}+\frac{f_{a l v, f}}{f_{\text {alv }, f}} \leq 1^{*}
$$

* Pode-se substituir o segundo membro da inequação por 1,33, quando a combinação de ações incluir o vento, conforme item 4.3.2.4 da ABNT (NBR-10837).

onde:

$\mathrm{f}_{\mathrm{alv}, \mathrm{c}} \rightarrow$ tensão de compressão axial atuante (item 4.8.2)

$\overline{\mathrm{f}}_{\mathrm{alv}, \mathrm{c}} \rightarrow$ tensão de compressão axial admissível (item 4.3)

$\mathrm{f}_{\mathrm{alv}, \mathrm{f}} \rightarrow$ tensão de compressão atuante, devido à flexão

$\overline{\mathrm{f}}_{\mathrm{alv}, \mathrm{f}} \rightarrow$ tensão de compressão admissível, devido à flexão (item 4.3)

Se a excentricidade resultante for tal que produza tração, os componentes (paredes ou pilares) devem ser dimensionados de modo que:

$$
\mathrm{f}_{\mathrm{alv}, \mathrm{f}}-0,75 \mathrm{f}_{\mathrm{alv}, \mathrm{c}} \leq \overline{\mathrm{f}}_{\mathrm{alv}, \mathrm{t}}
$$


onde:

$$
\begin{aligned}
\mathrm{f}_{\mathrm{alv}, \mathrm{f}} & \rightarrow \text { tensão de compressão atuante, devido à flexão } \\
\mathrm{f}_{\mathrm{alv}, \mathrm{c}} \rightarrow & \text { tensão de compressão axial atuante } \\
\overline{\mathrm{f}}_{\mathrm{alv}, \mathrm{t}} \rightarrow & \text { tensão de tração admissível na alvenaria não-armada } \\
& \quad \text { (item } 4.3)
\end{aligned}
$$

Nesta equação, a ABNT (NBR-10837) está implicitamente admitindo que $75 \%$ das cargas são permanentes, o que pode ser bastante conservador. Na visão da autora, parece ser mais indicado utilizar a real porcentagem de carga permanente atuante em cada caso.

\section{b) Alvenaria armada}

Não havendo tração, as tensões nos elementos de alvenaria armada devem satisfazer a expressão (4.21).

Se as tensões de tração forem tais que atendam a expressão (4.22), não há necessidade de prover armaduras para absorção da tração.

Se a condição expressa em (4.22) não for atendida, deve-se dispor armaduras para combate à tração, com o cálculo no Estádio II (seção fissurada).

O equacionamento para este último caso pode ser encontrado em AMRHEIN (1978) e, portanto, aqui será fornecido apenas um resumo das equações principais para o dimensionamento da seção no Estádio II.

A Figura 4.11 auxilia na definição dos parâmetros principais. 


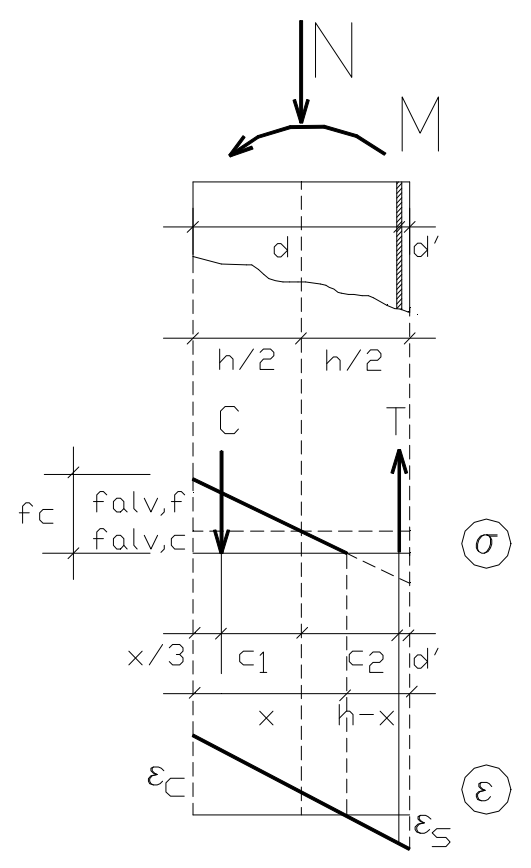

FIGURA 4.11 - Flexão composta - Estádio II

Inicialmente, deve-se calcular a máxima tensão de compressão devida à flexão que se pode ter:

$$
\mathrm{f}_{\mathrm{alv}, \mathrm{fmáx}}=\left(\alpha-\frac{\mathrm{f}_{\mathrm{alv}, \mathrm{c}}}{\bar{f}_{\mathrm{alv}, \mathrm{c}}}\right) \overline{\mathrm{f}}_{\mathrm{alv}, \mathrm{f}}
$$

com $\alpha=1,33$ ou 1,00 , dependendo da combinação incluir ou não a ação do vento.

Como primeira tentativa, pode-se admitir que a máxima tensão de

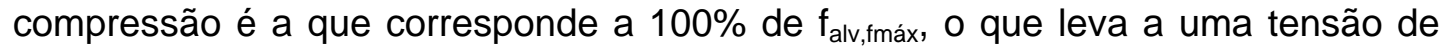
compressão total de:

$$
\mathrm{f}_{\mathrm{c}}=\mathrm{f}_{\mathrm{alv}, \mathrm{c}}+\mathrm{f}_{\mathrm{alv}, \mathrm{fmáx}}
$$

Aplicando a Lei de Hooke, a compatibilidade de deformações, e a equivalência estática, define-se a posição da linha neutra (LN): 


$$
\left(\frac{1}{6} f_{c} t\right) x^{2}-\left(\frac{1}{2} f_{c} t d\right) x+M+N\left(\frac{h}{2}-d^{\prime}\right)=0
$$

Com o valor de "x" determina-se a tensão de tração no aço:

$$
f_{s}=n \frac{d-x}{x} f_{c}
$$

Se o valor de $\mathrm{f}_{\mathrm{s}}$ for superior ao $\overline{\mathrm{f}}_{\mathrm{s}, \mathrm{t}}$, deve-se buscar uma nova solução, que corresponde a uma nova tensão de compressão e a uma nova posição da linha neutra. A solução econômica é aquela em que $f_{s}$ se aproxima de $\overline{f_{s, t}}$. Nestas condições, determina-se a resultante de compressão na alvenaria:

$$
C=\frac{1}{2} f_{c} \cdot x \cdot t
$$

e também a resultante de tração na armadura:

$$
\mathrm{T}=\mathrm{C}-\mathrm{N}>0
$$

Determina-se, então, a área de armadura de tração:

$$
A_{s}=\frac{T}{\alpha f_{s}}
$$

onde " $\alpha$ " é o mesmo valor utilizado na expressão (4.23).

A seguir será apresentado um outro método para o dimensionamento à flexão composta, o denominado aqui "Método Simplificado", encontrado em BASTOS (1993). Este método assume que a seção é homogênea e não fissurada.

Os diagramas de tensão normal devida à compressão, à flexão e o diagrama resultante da combinação das duas estão indicados na Figura 4.12. 


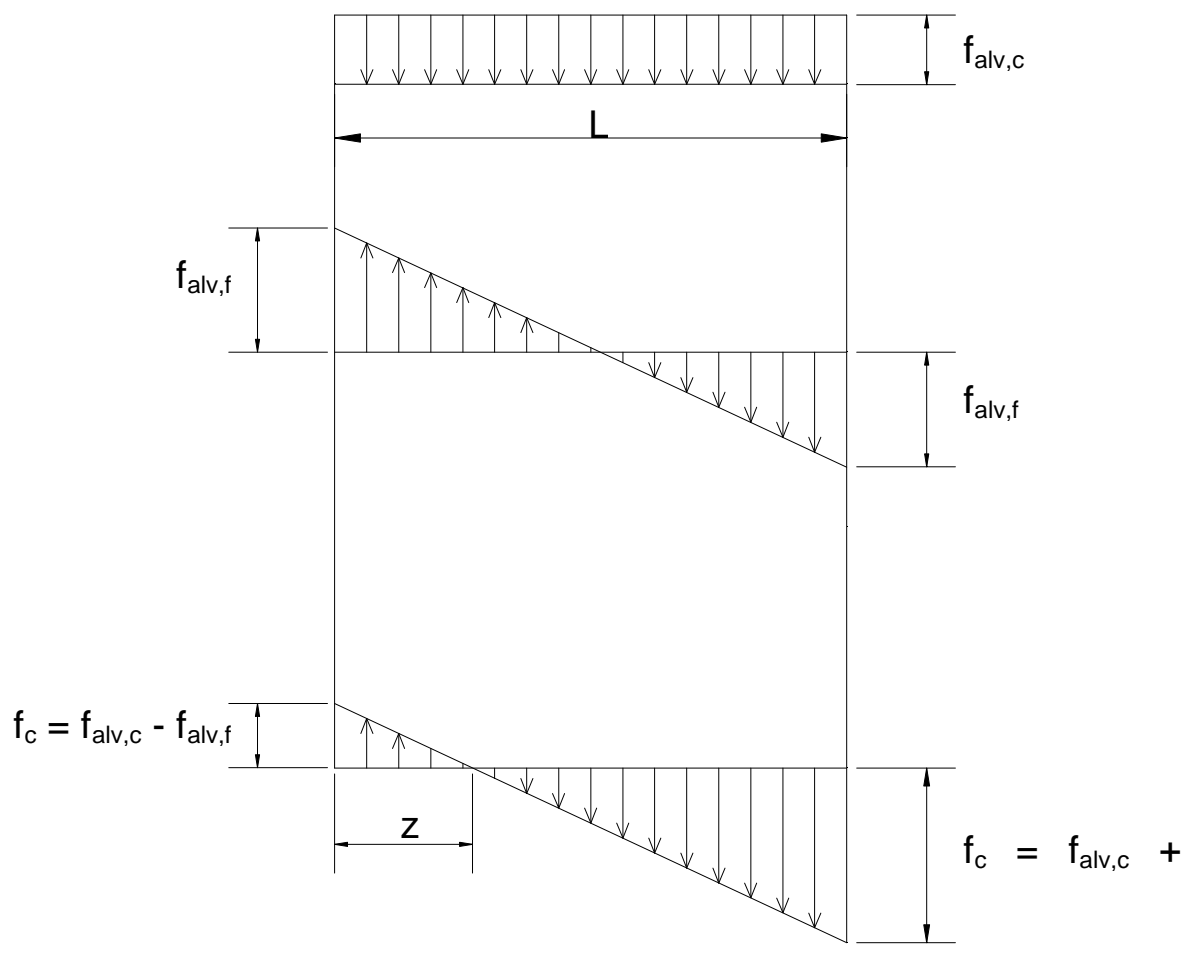

FIGURA 4.12 - Diagramas de tensões

Com base na Figura 4.12 determina-se a força de tração T resultante.

$$
T=\int \sigma_{+} d A
$$

A armadura de tração pode ser determinada, simplificadamente, pela seguinte equação:

$$
A_{s}=\frac{T}{1,33 \bar{f}_{s, t}}
$$




\subsubsection{Dimensionamento ao cisalhamento}

A tensão convencional de cisalhamento atuante nas paredes e pilares de alvenaria deve ser calculada pela seguinte expressão:

$$
f_{\text {cis }}=\frac{V}{b t}
$$

onde:

$$
\begin{aligned}
& V \rightarrow \text { esforço cortante horizontal atuante } \\
& b \rightarrow \text { largura efetiva da seção transversal } \\
& t \rightarrow \text { espessura efetiva }
\end{aligned}
$$

Da mesma forma que para vergas e vigas, no caso de seção $T$ ou $L$, o valor da largura efetiva deve ser o da alma.

Conforme visto no item 4.3, existem dois limites de tensão admissível de cisalhamento: um para pilares e paredes sem armadura de cisalhamento e outro para pilares e paredes com tais armaduras.

No caso da tensão atuante de cisalhamento superar o limite de tensão admissível correspondente a paredes e pilares sem armadura de cisalhamento, é necessário calcular esta armadura.

A armadura de cisalhamento pode ser calculada pela seguinte expressão:

$$
A_{s w}=\frac{V s}{\bar{f}_{s, t} d}
$$

onde:

$$
\begin{aligned}
V & \rightarrow \text { esforço cortante atuante } \\
\mathrm{s} & \rightarrow \text { espaçamento dos estribos } \\
\overline{\mathrm{f}}_{\mathrm{s}, \mathrm{t}} & \rightarrow \text { tensão admissível do aço dos estribos } \\
\mathrm{d} & \rightarrow \text { altura útil da seção transversal }
\end{aligned}
$$

O espaçamento "s" dos estribos é usualmente múltiplo da distância modular vertical, ou seja, $20 \mathrm{~cm}$. 


\subsubsection{Dimensionamento à flexão simples}

O dimensionamento à flexão simples de parede e pilares de alvenaria é feito da mesma forma que o de vergas e vigas.

\subsubsection{Exemplo}

Dimensionar a parede estrutural indicada na figura abaixo, sendo dados:

$\mathrm{t}=14 \mathrm{~cm} ; \mathrm{h}=2,80 \mathrm{~m} ; \eta=0,70 ; \mathrm{f}_{\mathrm{ak}}=5,0 \mathrm{MPa}$

bloco de concreto: $14 \times 19 \times 39$

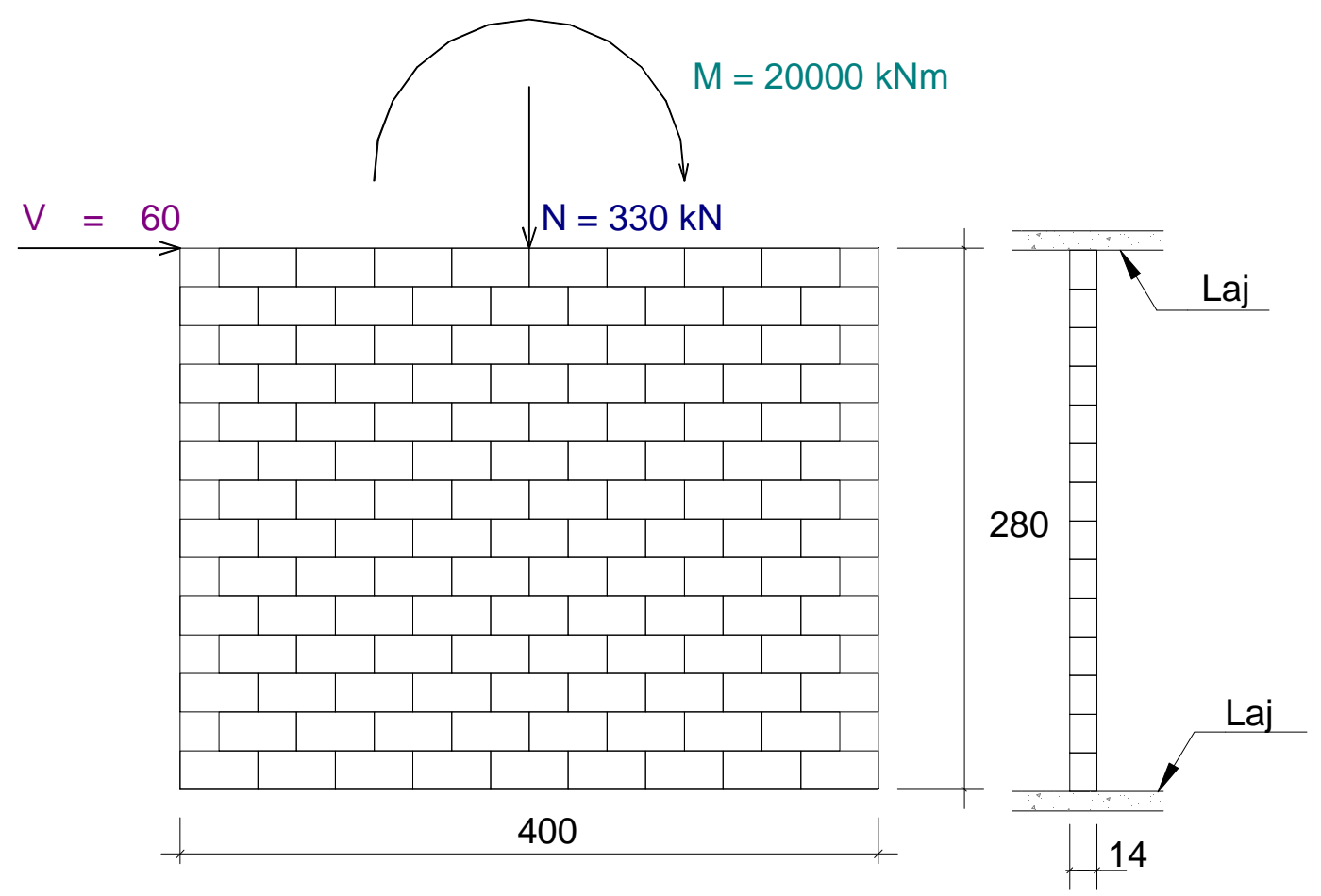

a) Dimensionamento à flexão composta

Cálculo das tensões atuantes:

$$
f_{a l v, c}=\frac{330}{400 \times 14}=0,0589 \mathrm{kN} / \mathrm{cm}^{2}=0,589 \mathrm{MPa}
$$




$$
f_{a l v, f}=\frac{20000}{\frac{14 \times 400^{3}}{12}} \times 200=0,0536 \mathrm{kN} / \mathrm{cm}^{2}=0,536 \mathrm{MPa}
$$

Cálculo das tensões admissíveis:

$$
\begin{aligned}
& \bar{f}_{\text {alv,c }}=0,20 f_{p}\left[1-\left(\frac{h}{40 t}\right)^{3}\right]=0,20 f_{p}\left[1-\left(\frac{280}{40 \times 14}\right)^{3}\right]=0,175 f_{p} \\
& \bar{f}_{a l v, f}=0,30 f_{p} \\
& \bar{f}_{\text {alv }, t}=0,10 \mathrm{MPa} \text { (normal às fiadas) }
\end{aligned}
$$

Deve-se inicialmente verificar a condição de tração, com a expressão (4.22):

$0,536-0,75 \times 0,589 \leq 0,100$

$0,094<0,100 \quad \therefore$ é admissível!

Impondo a condição (4.21) relacionada à compressão na flexão composta, tem-se:

$$
\frac{0,589}{0,175 f_{p}}+\frac{0,536}{0,30 f_{p}} \leq 1,33 \quad \Rightarrow \quad f_{p} \geq 3,87 \mathrm{MPa}
$$

Com eficiência $\eta=0,70$ determina-se a mínima resistência de bloco que se deve ter:

$$
\begin{aligned}
& \mathrm{f}_{\mathrm{b}}=\frac{3,87}{0,70}=5,53 \mathrm{MPa} \rightarrow \mathrm{f}_{\mathrm{b}}=6,0 \mathrm{MPa} \\
& \therefore \mathrm{f}_{\mathrm{p}}=4,20 \mathrm{MPa}
\end{aligned}
$$


b) Dimensionamento ao cisalhamento

Cálculo da tensão de cisalhamento atuante, segundo a expressão (4.32):

$$
\mathrm{f}_{\text {cis }}=\frac{60}{14 \times 400}=0,0107 \mathrm{kN} / \mathrm{cm}^{2}=0,107 \mathrm{MPa}
$$

Cálculo da tensão de cisalhamento admissível:

$$
\begin{gathered}
\frac{\mathrm{M}}{\mathrm{Vd}}=\frac{\mathrm{VH}}{\mathrm{Vd}}=\frac{280}{390}=0,72<1 \\
\bar{f}_{\text {cis1 }}=0,17 \sqrt{\mathrm{f}_{\mathrm{p}}}=0,17 \sqrt{4,20}=0,348<0,35 \mathrm{MPa} \\
\therefore \mathrm{f}_{\text {cis }}<\overline{\mathrm{f}}_{\text {cis1 }} \Rightarrow \text { não há necessidade de dispor armaduras de cisalhamento }
\end{gathered}
$$

\subsection{Disposições construtivas}

\subsubsection{Paredes}

De acordo com o item 5.4.3.1.1 da ABNT (NBR-10837), as paredes resistentes devem ser armadas vertical e horizontalmente. A taxa de armadura mínima total deve ser $0,2 \%$ vezes a área bruta da parede. A taxa de armadura mínima em cada direção deve ser de $0,07 \%$ da área da seção transversal bruta tomada perpendicular à armadura considerada.

De acordo com o item 5.2.3.1.3 da mesma norma, as paredes resistentes devem ser armadas com uma taxa de armadura não inferior a 0,2\% vezes a área bruta da parede, e não mais do que 2/3 devem estar em uma direção e 1/3 na outra.

As armaduras com barras de diâmetro máximo $6,3 \mathrm{~mm}$ podem ser colocadas na argamassa e consideradas como parte da armadura necessária. A ABNT (NBR-10837) é bastante confusa nas suas especificações. De acordo com o item 5.4.3.1.3, o diâmetro da armadura horizontal na argamassa de assentamento não deve exceder a metade da espessura da camada de argamassa na qual a barra está colocada (em geral $1 \mathrm{~cm}$ ). Ainda de acordo com este item, as armadura longitudinais situadas na argamassa de assentamento devem ter diâmetro mínimo 
de 3,8 mm, mas não maior que a metade da espessura especificada da argamassa de assentamento. Se a armadura longitudinal for constituída de malhas ou barras com fios treliçados, os fios cruzados devem ter, no máximo, $5 \mathrm{~mm}$ de diâmetro.

O espaçamento máximo das armaduras verticais deve ser o necessário para acomodar adequadamente o número de barras correspondentes à taxa de armadura mínima. O espaçamento mínimo das barras não deve ser inferior a $2 \mathrm{~cm}$.

De acordo com o item 5.4.3.1.4 da ABNT (NBR-10837), a armadura na argamassa de assentamento deve ser contínua; existindo necessidade de emenda de justaposição, o trecho da emenda deve ter:

a) $15 \mathrm{~cm}$ - quando se usam fios com mossas ou saliências

b) $30 \mathrm{~cm}$ - quando se usam fios lisos

De acordo com o item 5.4.3.1.5 da mesma norma, na alvenaria parcialmente armada só é disposta armadura para resistir a esforços de flexão, porventura existentes, e ao longo dos lados das aberturas. O máximo espaçamento das armaduras verticais em paredes exteriores parcialmente armadas deve ser de $240 \mathrm{~cm}$.

De acordo com o item 5.4.1 da ABNT (NBR-10837), a espessura mínima de uma parede de alvenaria não-armada deve ser $1 / 20$ da sua altura efetiva e não inferior a $14,0 \mathrm{~cm}$, e a espessura mínima de uma parede resistente de alvenaria armada deve ser $14,0 \mathrm{~cm}$.

\subsubsection{Pilares}

De acordo com o item 5.4.3.2 da ABNT (NBR-10837), a taxa de armadura $(\rho)$ das barras verticais deve estar entre $0,30 \%$ e $1 \%$, inclusive os valores extremos. A armadura deve consistir, no mínimo, em quatro barras de 12,5 mm de diâmetro, dispondo pelo menos uma em cada furo. O diâmetro das barras de armadura horizontal não deve ser inferior a $5 \mathrm{~mm}$.

As armaduras transversais são constituídas de estribos de diâmetros de $4 \mathrm{~mm}$ a $6,3 \mathrm{~mm}$, espaçados a cada $20 \mathrm{~cm}$. 
O espaçamento mínimo das barras em um pilar ou enrijecedor deve ser o maior valor entre $2,5 \phi$ ou $4 \mathrm{~cm}$, medido de centro a centro das barras, inclusive no caso de emendas.

O comprimento de emendas por justaposição não deve ser inferior a 40ф.

O cobrimento das armaduras dos pilares ou enrijecedores deve ser de $4 \mathrm{~cm}$.

De acordo com o item 5.4.1 da ABNT (NBR-10837), a espessura mínima de um pilar de alvenaria não-armada deve ser $1 / 15$ da sua altura efetiva e não inferior a 19,0 cm, e a espessura mínima de um pilar de alvenaria armada deve ser $19,0 \mathrm{~cm}$.

\subsection{Efeitos de segunda ordem}

A utilização de estruturas altas e esbeltas, portanto suscetíveis a problemas de instabilidade global e local, leva à preocupação de se considerar os efeitos de segunda ordem no dimensionamento das mesmas.

Os efeitos globais de segunda ordem referem-se aos esforços decorrentes do deslocamento lateral dos nós da estrutura submetida às ações verticais e horizontais [CARMO (1995)].

A instabilidade também pode ocorrer devida aos efeitos locais de segunda ordem, correspondentes a desvios de linearidade dos eixos dos elementos que compõem a estrutura, afetando somente os esforços solicitantes ao longo do seu comprimento.

De acordo com BRANDÃO (1996), mesmo que os efeitos globais de segunda ordem possam ser desprezados (estrutura de nós fixos), é necessário que se faça uma análise da estabilidade de cada elemento isoladamente.

A ABNT (NBR-10837) permite que os efeitos locais de segunda ordem nas estruturas de alvenaria estrutural sejam estimados em função da esbeltez dos elementos $(\lambda)$, definida pela razão altura efetiva sobre espessura efetiva. Segundo a norma, os limites máximos para a esbeltez dos elementos constam da Tabela 4.4. 
Tabela 4.4 - Limites máximos para a esbeltez $(\lambda)$

\begin{tabular}{|c|c|c|}
\cline { 2 - 3 } \multicolumn{1}{c|}{} & alvenaria não-armada & alvenaria armada \\
\hline parede & 20 & 30 \\
\hline pilar & 20 & 30 \\
\hline
\end{tabular}

$\mathrm{Na}$ realidade, os efeitos locais de segunda ordem nos elementos em alvenaria estrutural já estão contemplados, de forma aproximada, no parâmetro redutor de resistência por efeitos de esbeltez $(R)$, pertencente às expressões das tensões admissíveis à compressão axial.

Existem vários métodos com a finalidade de estimar os efeitos globais de segunda ordem, entre eles o efeito $P-\Delta$, com o qual se pode calcular tais efeitos por processo iterativo. Além disso, existem também alguns parâmetros, como 0 coeficiente de estabilidade $\alpha$ e o parâmetro $\gamma_{z^{*}}$, que avaliam a necessidade de se considerar ou não esses efeitos.

Segundo FRANCO \& VASCONCELOS (1991), o parâmetro $\gamma_{z}$ é suficiente para avaliar a necessidade de se considerar ou não os efeitos de segunda ordem, e para estimar tais efeitos quando relevantes, com boa aproximação, desde que $\gamma_{z} \leq 1,2$. Recomenda-se, portanto, a utilização deste método e, a seguir, encontrase um resumo do mesmo.

O método do coeficiente $\gamma_{z}$ consiste em estimar o valor dos esforços solicitantes finais, considerando efeitos globais de segunda ordem, a partir dos esforços de primeira ordem, multiplicando-os por um coeficiente $\left(\gamma_{z}\right)$. Assim, temse:

$$
\begin{aligned}
& M=\gamma_{z} M_{1} \\
& \gamma_{z}=\frac{1}{1-\frac{\Delta M}{M_{1}}}
\end{aligned}
$$

onde:

$\gamma_{z} \rightarrow$ coeficiente de majoração dos esforços de primeira ordem para obtenção dos esforços finais 
$\Delta \mathrm{M} \rightarrow$ primeira avaliação dos esforços de segunda ordem calculados com a estrutura deslocada pelos esforços de primeira ordem

$$
\begin{aligned}
& M_{1} \rightarrow \text { momento total de primeira ordem } \\
& M \rightarrow \text { momento final }
\end{aligned}
$$

A consideração dos efeitos globais de segunda ordem depende das seguintes condições:

- Se $\gamma_{z} \leq 1,1$ os esforços de segunda ordem podem ser desprezados.

- Se $1,1<\gamma_{z} \leq 1,2$ os esforços de segunda ordem devem ser considerados e os esforços finais podem ser calculados pela expressão (4.34).

- Se $\gamma_{z}>1,2$ deve-se calcular os esforços de segunda ordem utilizando um método mais preciso.

\section{Exemplo}

Seja a estrutura representada na Fig. 3.24 do capítulo 3, cujo esquema estático encontra-se a seguir.

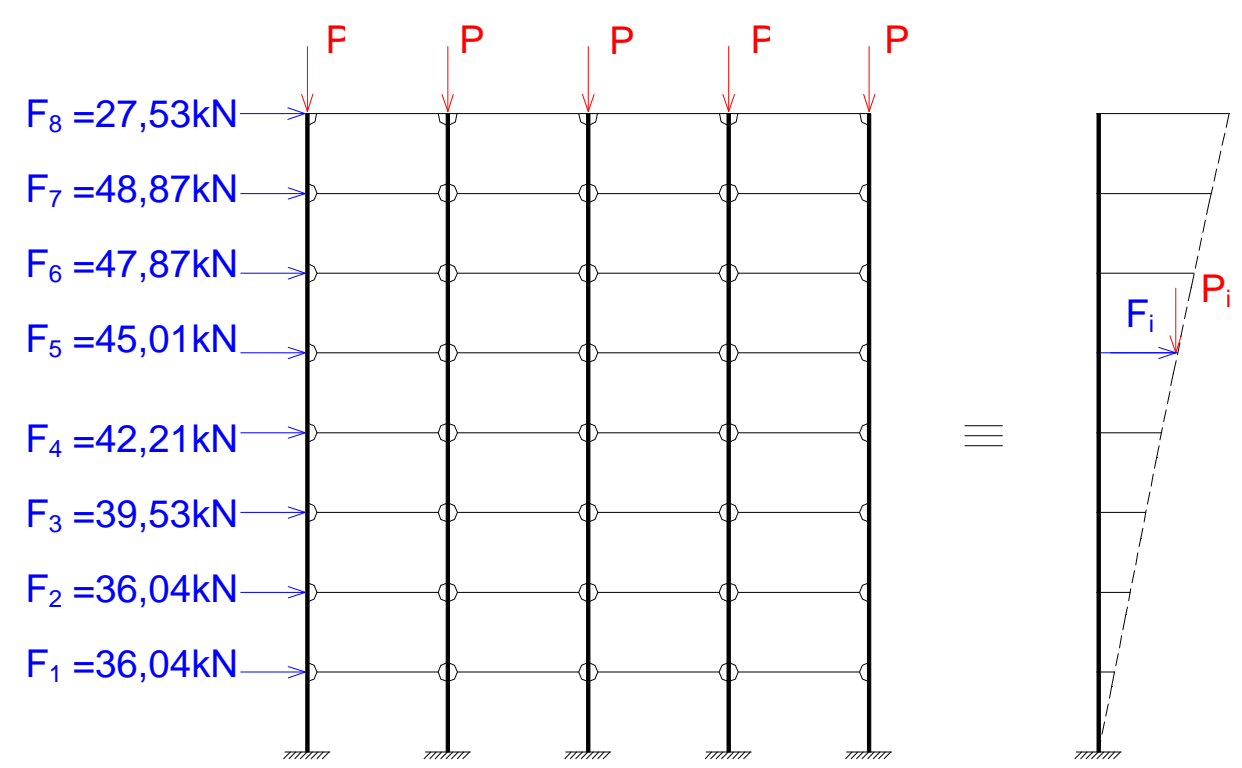




\section{Aplicação do Método do $\gamma_{z}$}

- Determinação da resistência do prisma e do módulo de elasticidade longitudinal da alvenaria

Supondo para $01^{\circ}$ pavimento bloco de concreto de resistência característica $f_{b k}=8,0 \mathrm{MPa}$, e considerando uma eficiência $\eta=0,7$, obtém-se a resistência de prisma:

$$
\mathrm{f}_{\mathrm{pk}}=5,6 \mathrm{MPa}
$$

Com a resistência de prisma, consultando a Tabela 4.2, calcula-se o módulo de elasticidade longitudinal da alvenaria:

$$
E_{\text {alv }}=2240 \mathrm{MPa}=224 \mathrm{kN} / \mathrm{cm}^{2}
$$

- Cálculo de $\Delta \mathrm{M}$

$$
\Delta \mathrm{M}=\sum \mathrm{P}_{\mathrm{i}} \delta_{\mathrm{i}}
$$

A determinação do peso total de cada pavimento $\left(P_{i}\right)$ pode ser encontrada no item 3.5.5 do capítulo 3. Tem-se, portanto:

$$
P_{i} \cong 1951 \mathrm{kN}
$$

Os deslocamentos $\left(\delta_{\mathrm{i}}\right)$ ao nível de cada andar foram encontrados utilizando o programa SAP90 (1991). Tem-se, portanto:

$$
\begin{array}{lll}
\delta_{9}=0,824888 \mathrm{~cm} & \delta_{6}=0,414743 \mathrm{~cm} & \delta_{3}=0,085209 \mathrm{~cm} \\
\delta_{8}=0,686127 \mathrm{~cm} & \delta_{5}=0,288868 \mathrm{~cm} & \delta_{2}=0,023079 \mathrm{~cm} \\
\delta_{7}=0,548555 \mathrm{~cm} & \delta_{4}=0,176639 \mathrm{~cm} & \delta_{1}=0
\end{array}
$$

$$
\begin{aligned}
\therefore \Delta \mathrm{M} & =1951(0+0,023079+0,085209+0,176639+0,288868+ \\
& +0,414743+0,548555+0,686127+0,824888)=5946,86 \mathrm{kN} . \mathrm{cm}
\end{aligned}
$$

- Cálculo de $\mathrm{M}_{1}$ 


$$
\begin{aligned}
& M_{1}=\sum F_{i} h_{i} \\
\therefore M_{1} & =36,04 \times 2,8+36,04 \times 5,6+39,53 \times 8,4+42,21 \times 11,20+45,01 \times 14,00+ \\
& +47,87 \times 16,80+48,87 \times 19,60+27,53 \times 22,40=4116,42 \mathrm{kN} . \mathrm{m}= \\
& =411.642 \mathrm{kN} . \mathrm{cm}
\end{aligned}
$$

- Cálculo do coeficiente $\gamma_{z}$

$$
\gamma_{z}=\frac{1}{1-\frac{\Delta M}{M_{1}}}=\frac{1}{1-\frac{5946,86}{411.642}}=1,01<1,1
$$

O resultado indica que a estrutura em questão pode ser considerada de nós fixos e, portanto, uma análise global de primeira ordem é suficiente para a obtenção dos esforços solicitantes.

\subsection{Considerações finais}

Com este capítulo encerram-se as etapas relativas ao projeto estrutural de um edifício em alvenaria, que vão desde as definições preliminares, a concepção, a análise estrutural até o dimensionamento dos elementos.

Como ilustração dos documentos de projeto recomendados pela ABNT (NBR-10837), optou-se por transcrevê-los aqui:

- "Memória de cálculo: composta pelos cálculos estáticos, da verificação da estabilidade global e local e da verificação da resistência dos diversos componentes estruturais da obra.

- Planta da $1^{\text {a }}$ fiada, elevações de todas as paredes resistentes contendo localização de armaduras, grauteamento, detalhes das amarrações de paredes, aberturas para passagem de canalizações e detalhes do projeto arquitetônico.

- Especificação dos materiais e componentes de acordo com a norma de execução e controle, além da relação das quantidades dos componentes utilizados. 
- Resistências características dos blocos $\left(f_{b k}\right)$, dos prismas $\left(f_{p}\right)$, da argamassa de assentamento $\left(f_{a}\right)$, bem como as características do aço a ser empregado.

- Citação dos itens da norma de execução e controle relativos à utilização dos materiais. Deve também conter informações relativas aos outros componentes ou materiais utilizados, bem como suas ligações com a alvenaria. Devem estar claramente assinaladas todas as juntas construtivas, quando for o caso, as juntas de dilatação. Deve conter os valores assumidos no projeto para as sobrecargas fixas e as sobrecargas de utilização. Deve conter a seqüência de execução quando esta influenciar a estabilidade ou a resistência da obra, e as ações parciais e totais a que a estrutura estiver sujeita.

- Memorial descritivo: composto de informações atinentes ao projeto, de forma a observar a execução em consonância com a execução deste. Nele são sempre indicadas as ações adotadas e, no caso de construções de caráter especial, deve-se incluir esquema de localização das cargas com indicações para montagem e manutenção." 


\section{EXEMPLOS NUMÉRICOS}

Neste capítulo tem-se o objetivo de mostrar, através de exemplos práticos, os principais passos do projeto estrutural de um edifício em alvenaria estrutural, enfocando os pontos mais importantes de tomada de decisão, buscando sempre a melhor alternativa em cada caso. Para isto, serão feitas diversas comparações de modelos de resolução para um edifício padrão ${ }^{10}$ com dimensões usuais dos cômodos, sendo seu comprimento total em planta bem maior que a largura, a fim de evidenciar os efeitos da ação do vento.

Inicialmente considerar-se-á o edifício com 4 (quatro) pavimentos, já que é grande o número de projetos deste tipo, pelo seu caráter econômico de não precisar de elevadores. Posteriormente, considerá-lo-á com 8 (oito) pavimentos, por ser o limite estabelecido por muitos códigos de obra para a necessidade de apenas um elevador.

É importante destacar que os exemplos serão processados em programas computacionais, elaborados pela TecSof Engenharia de Estruturas S/C Ltda., o que implicará no não detalhamento dos cálculos, uma vez que este procedimento já se encontra nos capítulos 3 e 4.

A planta baixa do pavimento-tipo e do ático, juntamente com o esquemas verticais do edifício analisado, encontram-se representados na Figura 5.1.

\footnotetext{
${ }^{10}$ Este edifício não foi construído; o projeto foi elaborado apenas como exemplo para esta dissertação.
} 

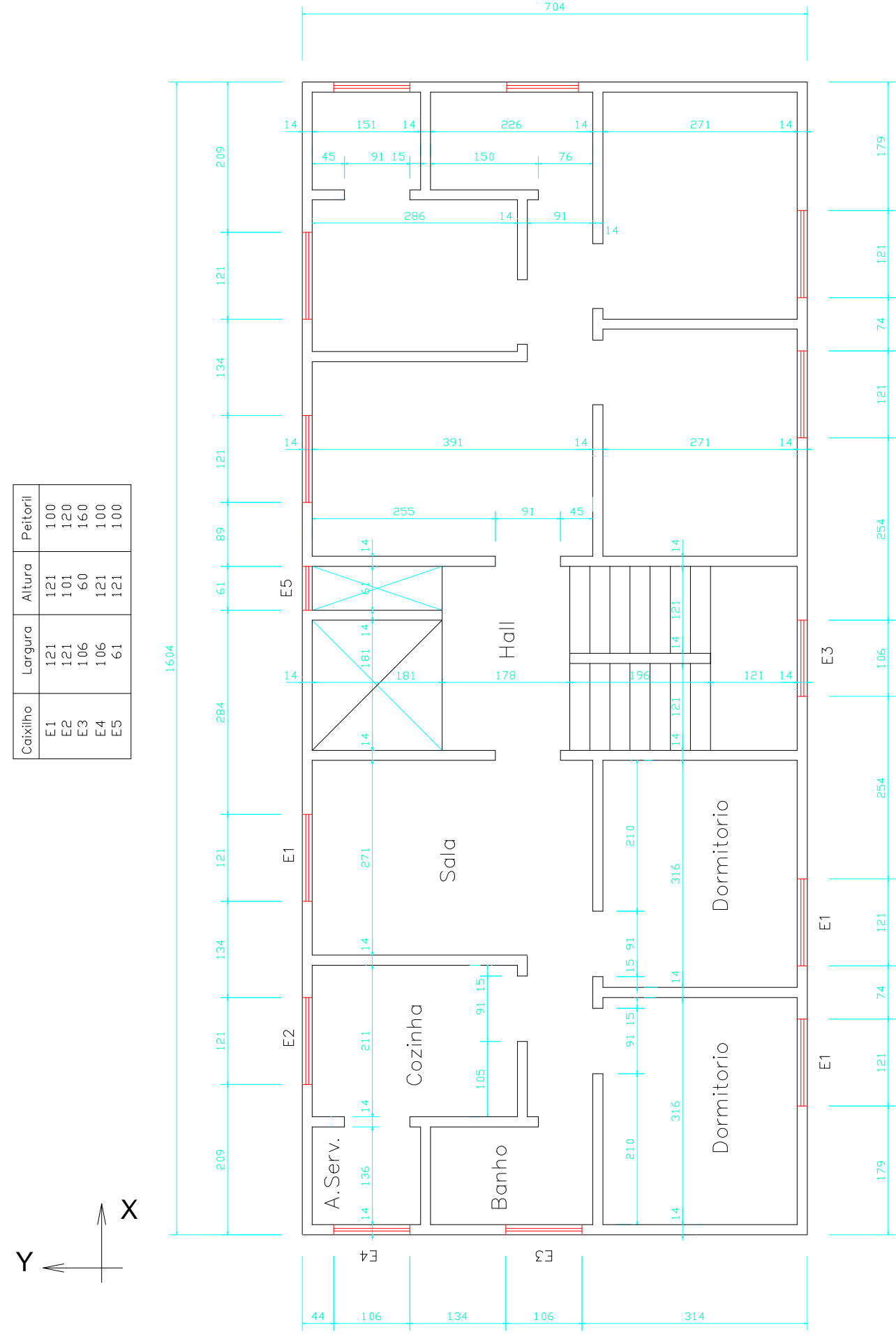

䍃

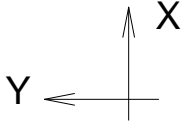

FIGURA 5.1a - Planta baixa do pavimento-tipo 
Casa de Maquinas

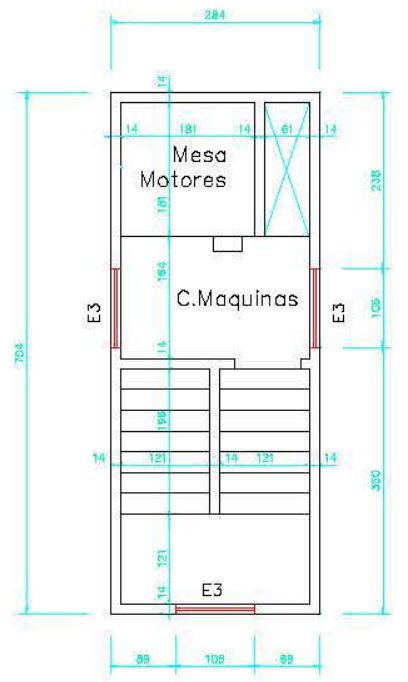

Esquemas Verticais
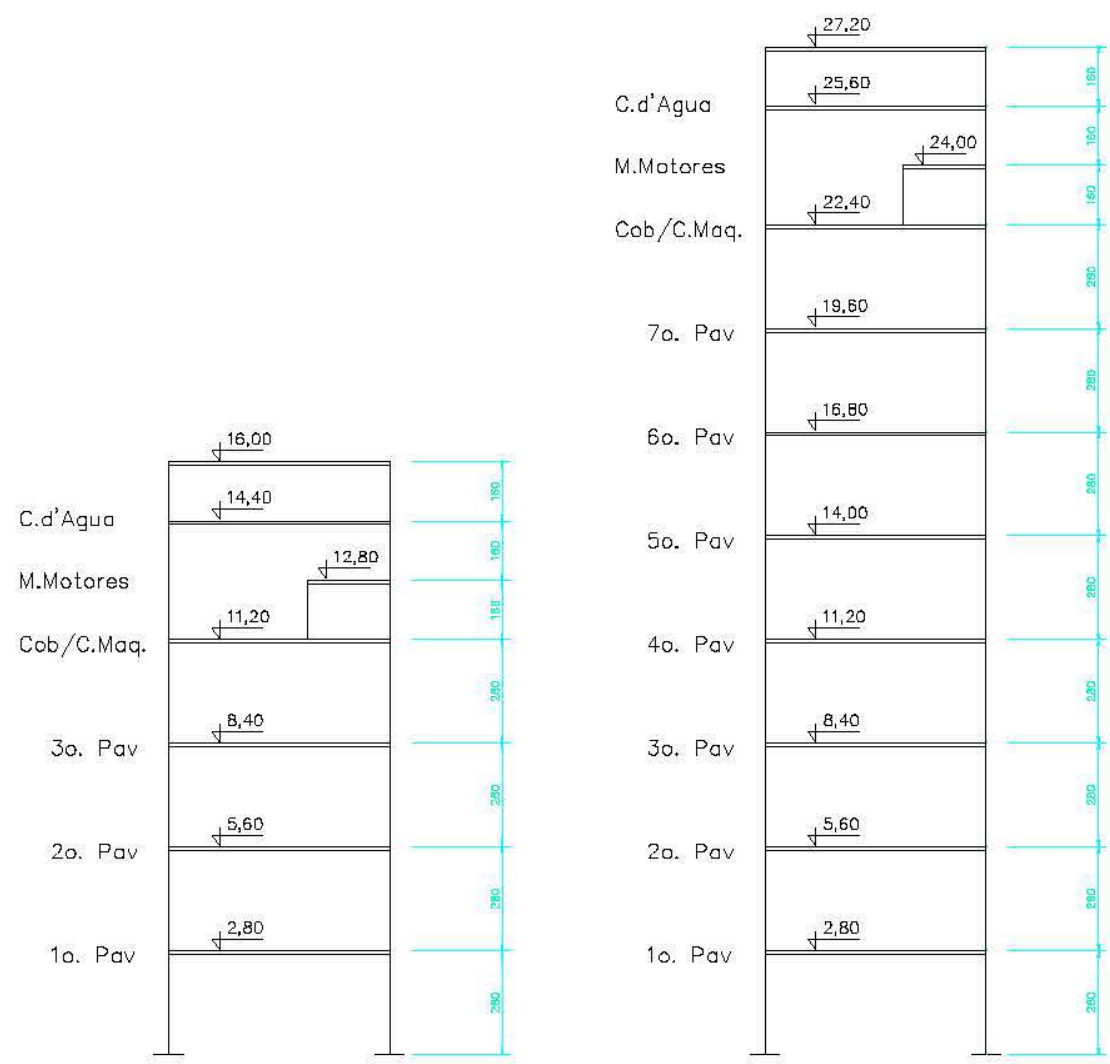

FIGURA 5.1b - Planta do ático e esquemas verticais do edifício 


\subsection{Definições preliminares}

A definição quanto à utilização de alvenaria armada ou não-armada será feita a seguir, separadamente para o edifício com 4 (quatro) pavimentos e para o edifício com 8 (oito) pavimentos.

Com relação à modulação, a primeira definição a ser feita é o tipo de bloco que será utilizado. Neste exemplo foi escolhido o bloco de concreto, pela maior disponibilidade de fornecedores, e a não necessidade de adaptação de normas estrangeiras que tratem de alvenaria cerâmica.

Tratando das dimensões, optou-se pelo bloco de dimensão horizontal múltipla de $15 \mathrm{~cm}$ (incluindo a junta), opção feita de comum acordo com o arquiteto. Conforme já foi visto no capítulo 2, quanto menor o módulo, mais fácil é o ajuste das dimensões. Portanto, foram utilizados os seguintes blocos:

- $14 \times 29 \times 19$ (bloco comum inteiro)

- $14 \times 14 \times 19$ (meio bloco comum)

- $14 \times 14 \times 19$ (meio bloco canaleta)

- $14 \times 14 \times 11$ (bloco compensador)

- 14 x 14 x 11 x 19 (bloco "J")

Na modulação (Figura 5.2) procurou-se, sempre que possível, conectar duas ou mais paredes que se encontram, através de amarração direta, conforme recomendado no capítulo 2. Utilizou-se a seqüência de fiadas (item 2.2.2 do capítulo 2) como recurso de amarração para o encontro de três paredes. Neste caso, como as dimensões da arquitetura são compatíveis com a modulação, não ocorreram juntas a prumo.

Neste edifício, observa-se que na modulação sobrou meio bloco justamente no meio da parede central do pavimento. Para resolver o problema do fechamento do painel sem a sobreposição de juntas, optou-se pelo artifício do bloco em trânsito, conforme pode ser visto no item 2.2.4 do capítulo 2 .

Observando a Figura 5.2, percebe-se a inexistência de paredes nãoestruturais. No caso deste exemplo, optou-se pela utilização de "shafts" hidráulicos 
para resolverem o problema da passagem das tubulações verticais. As vantagens do emprego destes elementos podem ser encontradas no item 2.4.2 do capítulo 2.

Com relação às lajes, optou-se por lajes maciças de espessura $\mathrm{h}=8 \mathrm{~cm}$, por serem suficientes para suportarem os carregamentos verticais e comportaremse como diafragmas para a distribuição das forças horizontais devidas à ação do vento. Além disso, esta espessura encaixa-se perfeitamente sobre os blocos $\mathrm{J}$ e compensador usuais. Optou-se pela não utilização de armaduras negativas, uma vez que o construtor argumentou que elas apresentam problemas no posicionamento durante a concretagem.

Já para as escadas, preferiu-se elementos pré-moldados, para se obter maior rapidez no processo construtivo.

Neste edifício, resolveu-se por fazer cintas abaixo da laje em todas as paredes, e a meia altura nas paredes externas, para dar travamento ao prédio como um todo e combater efeitos provocados por variações térmicas. As cintas não foram calculadas, admitindo-as de altura igual a um bloco "J" ou compensador e armadura construtiva de $1 \phi 10,0 \mathrm{~mm}$ corrido. 


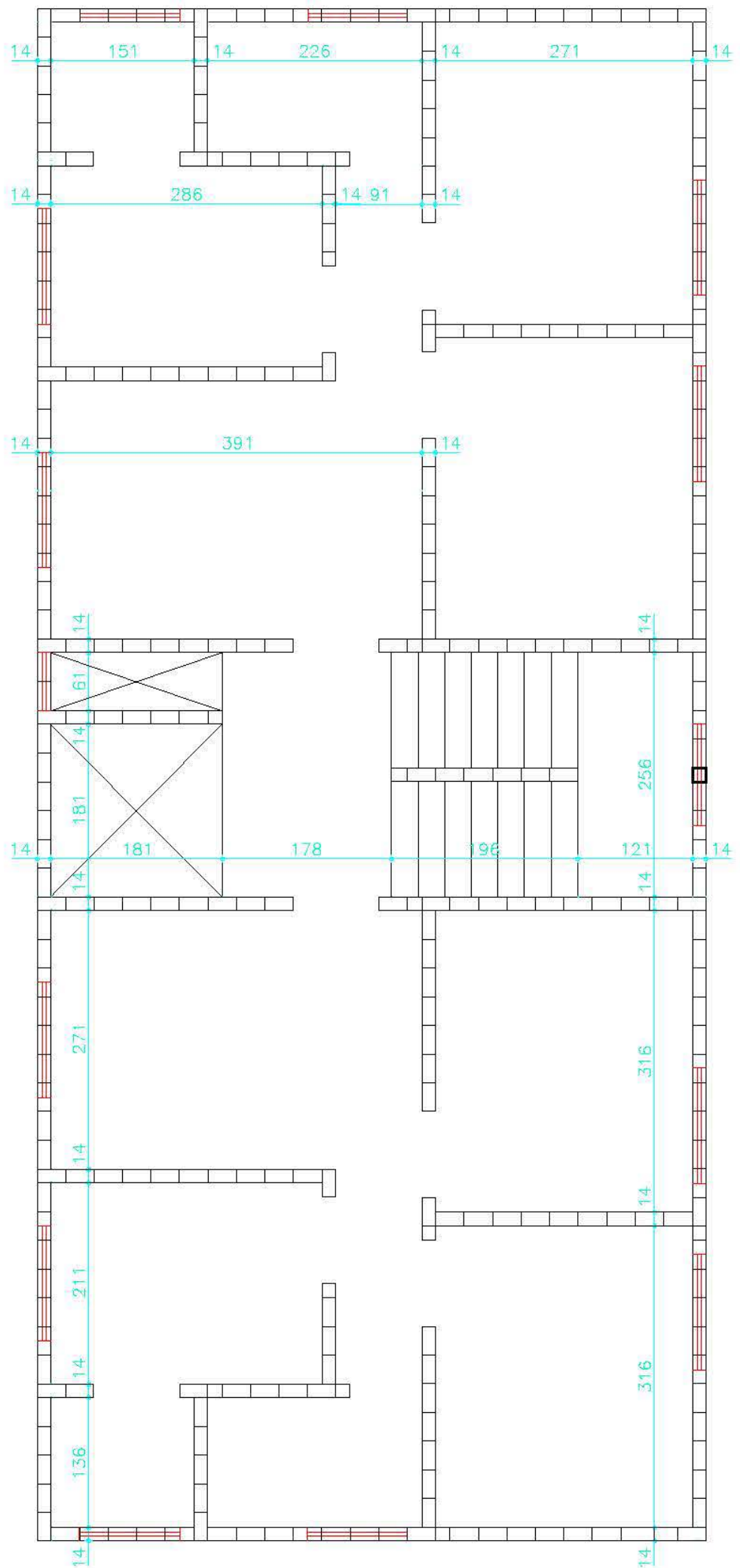

FIGURA 5.2a - Modulação da $1^{a}$ fiada 


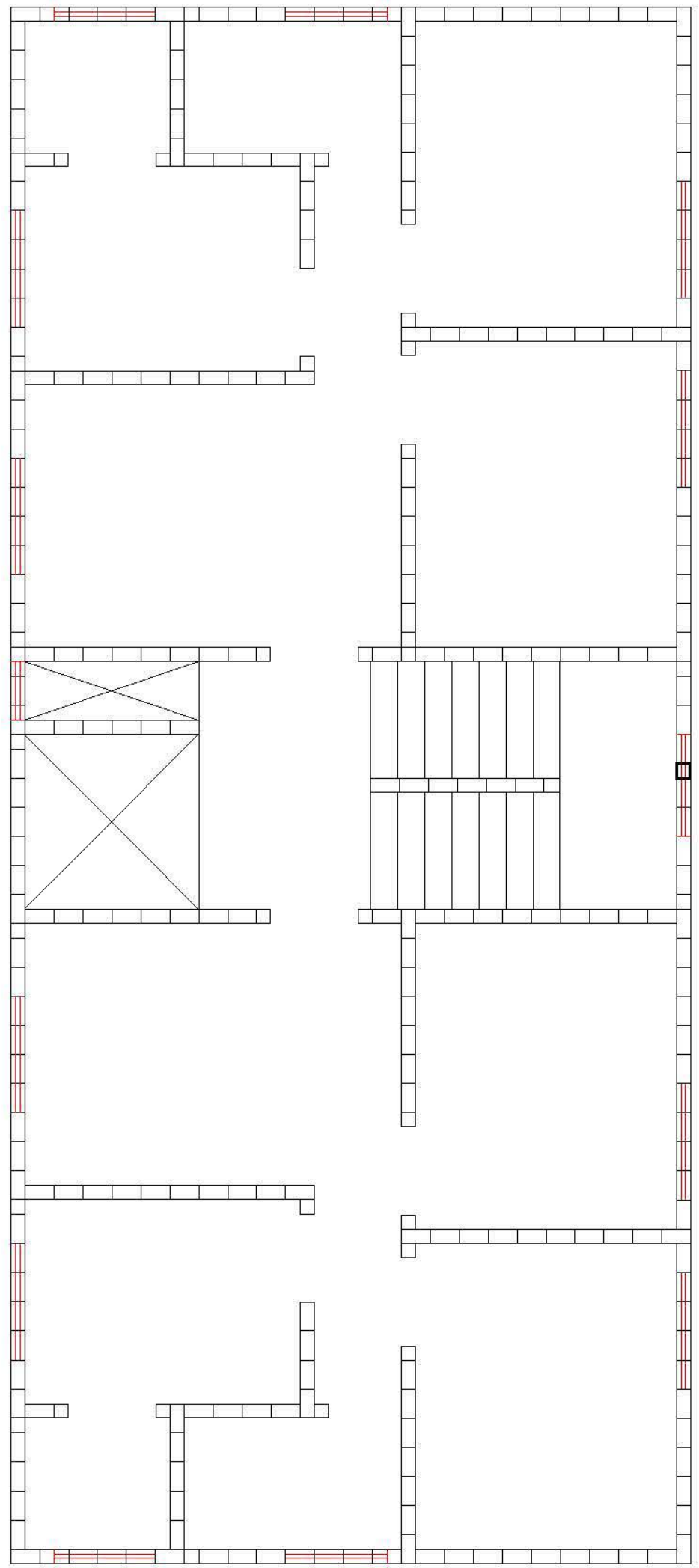

FIGURA 5.2b - Modulação da $2^{a}$ fiada 


\subsection{Edifício com 4 (quatro) pavimentos}

\subsubsection{Alvenaria armada ou não-armada}

Conforme visto no capítulo 2, recomenda-se o uso da alvenaria não-armada sempre que possível, pois além da economia de graute e armadura, são de mais simples execução.

A armação de paredes só é absolutamente necessária quando as tensões de tração superam os valores admissíveis recomendados pela ABNT (NBR-10837). Não é o caso deste edifício de 4 (quatro) pavimentos, onde não se obteve tração em nenhuma parede, conforme será mostrado nos itens posteriores.

A fim de se visualizar o consumo de graute e armadura adicionais que seriam necessários, caso se optasse por alvenaria armada, fez-se uma simulação destas quantias, utilizando as taxas de armadura mínimas indicadas pela ABNT (NBR-10837). Estas taxas podem ser encontradas no item 4.9 do capítulo 4.

\section{A - Consumo de aço}

Para exemplificar o cálculo das armaduras das paredes foi escolhida a parede PX1, sendo o procedimento análogo para as demais.

Ex.: $\underline{P X 1}$

$$
\begin{gathered}
A_{s v}=0,002 \times 14 \times 202 \times 2 / 3=3,77 \mathrm{~cm}^{2}(3 \phi 12,5) \\
A_{s h}=0,002 \times 14 \times 272 \times 1 / 3=2,54 \mathrm{~cm}^{2}-0,8 \mathrm{~cm}^{2}=1,74 \mathrm{~cm}^{2}(3 \times 2 \phi 6,3) \\
\backslash \begin{array}{l}
\text { cinta abaixo da } \\
\text { laje }(1 \phi 10,0)
\end{array}
\end{gathered}
$$

$\rightarrow$ espaçamento máximo das armaduras verticais: $240 \mathrm{~cm}$ 


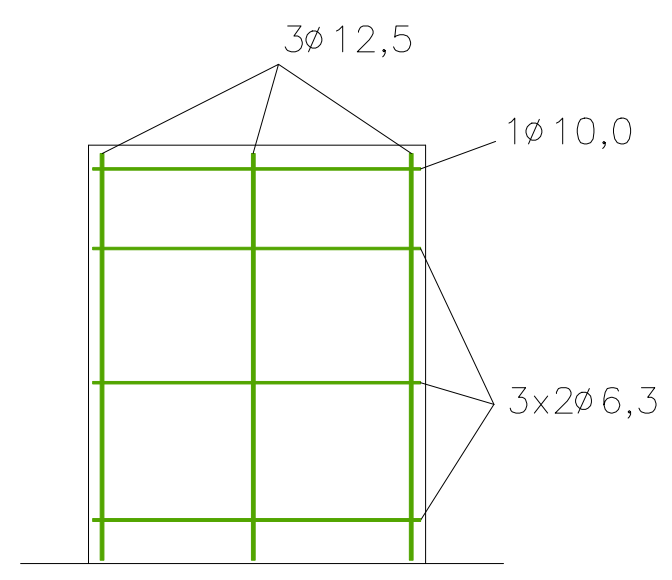

Os resultados do cálculo das armaduras verticais encontram-se na Tabela 5.1, e a área de armadura horizontal encontrada para a parede PX1 é a mesma para todas as paredes.

TABELA 5.1 - Resultado do cálculo das armaduras verticais das paredes

\begin{tabular}{|c|c|}
\hline Parede & Armadura vertical \\
\hline PX1 e PX6 & $3 \phi 12,5$ \\
\hline PX2 e PX5 & $2 \phi 12,5$ \\
\hline PX3 & $7 \phi 10,0$ \\
\hline PX4 & $2 \phi 10,0$ \\
\hline PX7 e PX8 & $4 \phi 10,0$ \\
\hline PX9 e PX12 & $3 \phi 10,0$ \\
\hline PX10 e PX11 & $2 \phi 12,5$ \\
\hline PX13 e PX18 & $6 \phi 10,0$ \\
\hline PX14 e PX17 & $2 \phi 12,5$ \\
\hline PX15 e PX16 & $6 \phi 10,0$ \\
\hline PX19 e PX24 & $3 \phi 12,5$ \\
\hline PX20 e PX23 & $2 \phi 10,0$ \\
\hline PX21 e PX22 & $4 \phi 12,5$ \\
\hline PY1 e PY18 & $5 \phi 12,5$ \\
\hline PY2 e PY19 & $2 \phi 12,5$ \\
\hline PY3 e PY20 & $2 \phi 12,5$ \\
\hline PY4 e PY16 & $3 \phi 12,5$ \\
\hline
\end{tabular}




\begin{tabular}{|c|c|}
\hline PY5 e PY17 & $2 \phi 12,5$ \\
\hline PY6 e PY15 & $5 \phi 12,5$ \\
\hline PY7 e PY14 & $5 \phi 12,5$ \\
\hline PY8 e PY12 & $8 \phi 10,0$ \\
\hline PY9 e PY13 & $4 \phi 12,5$ \\
\hline PY10 & $3 \phi 12,5$ \\
\hline PY11 & $3 \phi 12,5$ \\
\hline Total: 94 $\phi 12,5$ e $67 \phi 10,0$ \\
\hline
\end{tabular}

A partir destes resultados pode-se calcular a massa de aço adicional, por pavimento, caso de optasse por alvenaria armada:

- barras verticais de $\phi 12,5: 1,00 \mathrm{~kg} / \mathrm{m} \times\left[94 \phi \times\left(272+80^{11}\right)\right] \mathrm{m}=330,88 \mathrm{~kg}$

- barras verticais de $\phi 10,0: 0,63 \mathrm{~kg} / \mathrm{m} \times(67 \phi \times 3,52) \mathrm{m}=148,58 \mathrm{~kg}$

- barras horizontais de $\phi 6,3: 0,25 \mathrm{~kg} / \mathrm{m} \times(6 \phi \times 77,25) \mathrm{m}=115,88 \mathrm{~kg}$

$$
m=595,34 \mathrm{~kg} / \mathrm{pav}
$$

\section{B - Consumo de graute}

O volume de graute adicional, caso se optasse por alvenaria armada, seria o acréscimo de graute utilizado para acomodar as armaduras verticais. O cálculo deste volume, para cada pavimento, pode ser feito com o auxílio dos dados encontrados na Tabela 5.1, e este resultado encontra-se na Tabela 5.2.

${ }^{11}$ Considerou-se, em cada barra vertical, a presença de duas emendas de $30 \phi$, que equivalem a aproximadamente $40 \mathrm{~cm}$, conforme item 4.9 do capítulo 4 . 
TABELA 5.2 - Resultado do cálculo do volume de graute das paredes

\begin{tabular}{|c|c|c|}
\hline Parede & Armadura vertical & Graute $\left(\mathrm{m}^{3}\right)$ \\
\hline PX1 e PX6 & $3 \phi 12,5$ & 0,083 \\
\hline PX2 e PX5 & $2 \phi 12,5$ & 0,055 \\
\hline PX3 & $7 \phi 10,0$ & 0,193 \\
\hline PX4 & $2 \phi 10,0$ & 0,055 \\
\hline PX7 e PX8 & $4 \phi 10,0$ & 0,110 \\
\hline PX9 e PX12 & $3 \phi 10,0$ & 0,083 \\
\hline PX10 e PX11 & $2 \phi 12,5$ & 0,055 \\
\hline PX13 e PX18 & $6 \phi 10,0$ & 0,166 \\
\hline PX14 e PX17 & $2 \phi 12,5$ & 0,055 \\
\hline PX15 e PX16 & $6 \phi 10,0$ & 0,166 \\
\hline PX19 e PX24 & $3 \phi 12,5$ & 0,083 \\
\hline PX20 e PX23 & $2 \phi 10,0$ & 0,055 \\
\hline PX21 e PX22 & $4 \phi 12,5$ & 0,110 \\
\hline PY1 e PY18 & $5 \phi 12,5$ & 0,138 \\
\hline PY2 e PY19 & $2 \phi 12,5$ & 0,055 \\
\hline PY3 e PY20 & $2 \phi 12,5$ & 0,055 \\
\hline PY4 e PY16 & $3 \phi 12,5$ & 0,083 \\
\hline PY5 e PY17 & $2 \phi 12,5$ & 0,055 \\
\hline PY6 e PY15 & $5 \phi 12,5$ & 0,138 \\
\hline PY7 e PY14 & $5 \phi 12,5$ & 0,138 \\
\hline PY8 e PY12 & $8 \phi 10,0$ & 0,221 \\
\hline PY9 e PY13 & $4 \phi 12,5$ & 0,110 \\
\hline PY10 & $3 \phi 12,5$ & 0,083 \\
\hline PY11 & $3 \phi 12,5$ & 0,083 \\
\hline
\end{tabular}

$$
\mathrm{V}=2,430 \mathrm{~m}^{3} / \text { pav. }
$$




\subsubsection{Determinação das ações verticais}

Conforme já foi dito, a determinação destas ações é feita através de procedimento automatizado, e portanto não serão feitos, aqui, todos os passos. Serão mostrados apenas os dados utilizados e alguns resultados.

- Lajes

Conforme o item 5.1, as lajes foram consideradas maciças, de espessura $\mathrm{h}=8 \mathrm{~cm}$.

As lajes, em geral, foram consideradas apoiadas em todos os lados, sendo que as da região da escada e do hall possuem algumas bordas livres. Não houve lajes engastadas, em virtude da opção de eliminar as armaduras negativas. A forma das mesmas encontra-se representada na Figura 5.3.

Considerou-se concreto de classe C-20 e aço CA-50A; portanto, utilizou-se $\mathrm{f}_{\mathrm{ck}}=20.000 \mathrm{kN} / \mathrm{m}^{2}$ e $\mathrm{f}_{\mathrm{yk}}=500.000 \mathrm{kN} / \mathrm{m}^{2}$.

Para a determinação dos carregamentos permanente e variável atuantes nas lajes, utilizou-se a ABNT (NB-5). Tem-se, então:

- p.p $=25 \mathrm{kN} / \mathrm{m}^{3} \times 0,08 \mathrm{~m}=2 \mathrm{kN} / \mathrm{m}^{2}$

- piso + contrapiso $=1,0 \mathrm{kN} / \mathrm{m}^{2}$

- sobrecarga de utilização:

$$
\begin{aligned}
& q=1,5 \mathrm{kN} / \mathrm{m}^{2} \rightarrow \text { em geral } \\
& q=2,0 \mathrm{kN} / \mathrm{m}^{2} \rightarrow \text { área de serviço } \\
& q=2,0 \mathrm{kN} / \mathrm{m}^{2} \rightarrow \text { escada pré-moldada }
\end{aligned}
$$




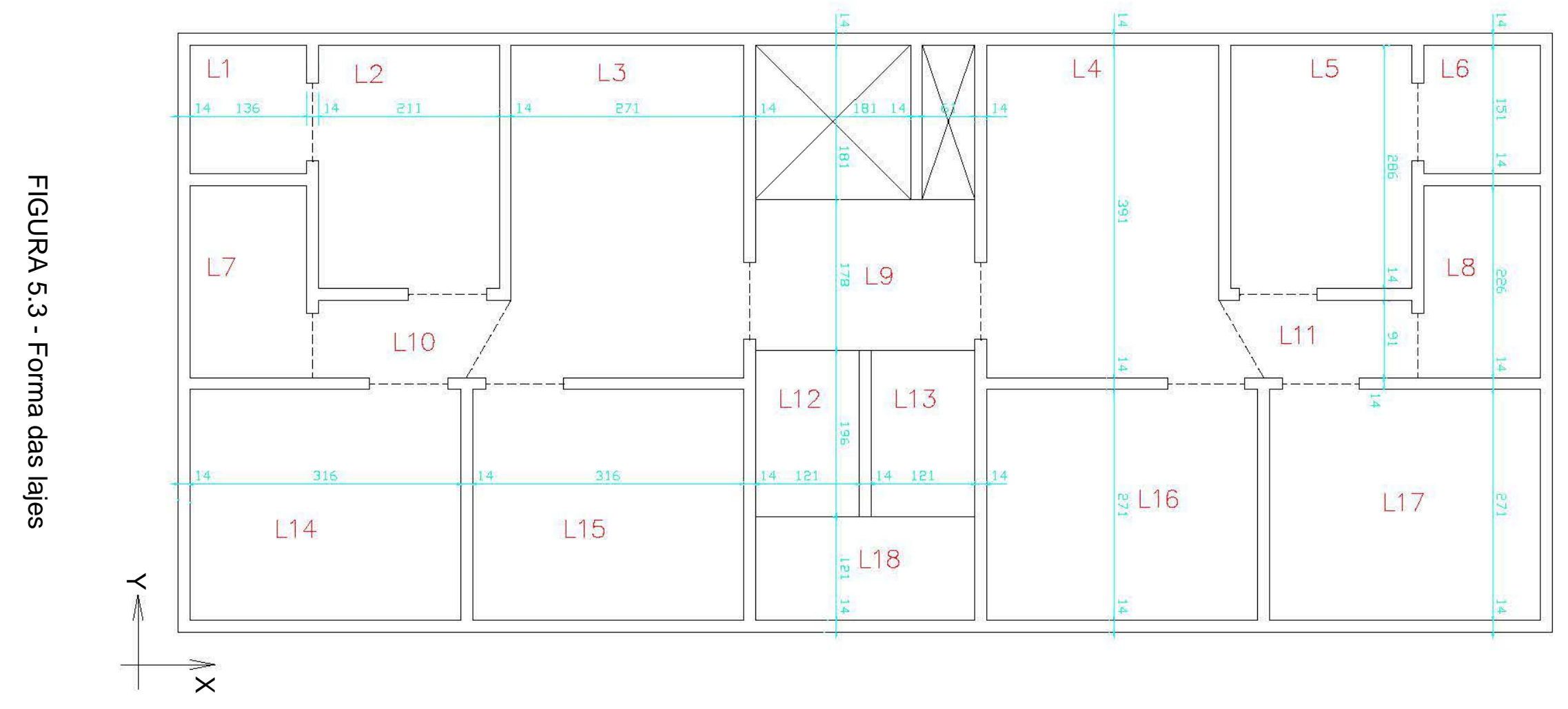


O cálculo das reações das lajes sobre as paredes estruturais é baseado no critério das linhas de ruptura, sugerido pela ABNT (NB-1) para lajes retangulares com cargas uniformemente distribuídas.

Os resultados do processamento das lajes do pavimento tipo encontram-se no Anexo A. A título de ilustração, transcreveram-se aqui apenas os resultados da laje L1. Para fins de simplificação do cálculo, considerou-se para a laje de cobertura o mesmo carregamento das lajes dos pavimentos-tipo.

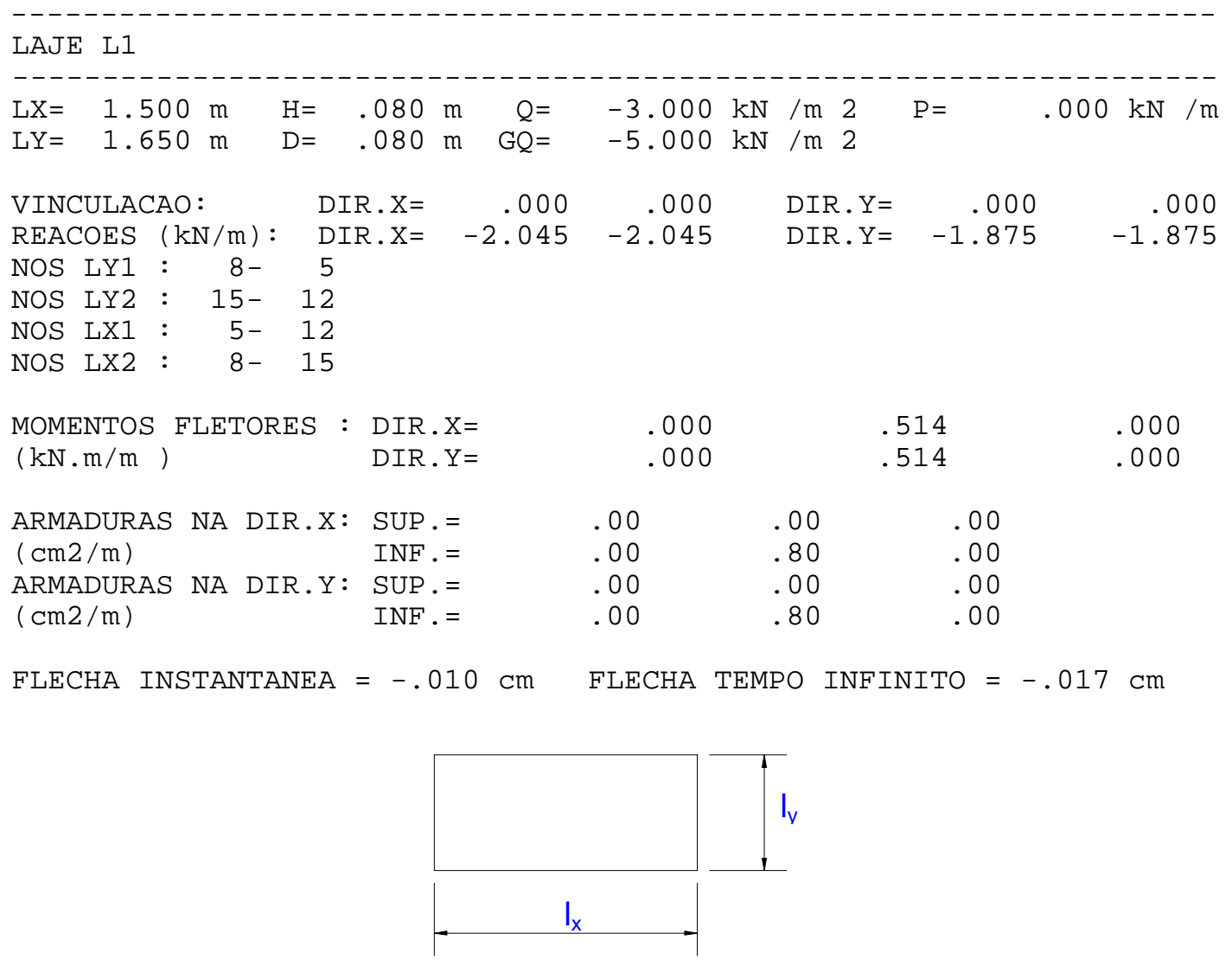

O lado $\mathrm{I}_{\mathrm{x}}$ das lajes é o paralelo à maior dimensão em planta do edifício, e o lado $I_{y}$ é o paralelo à menor dimensão em planta, conforme pode ser melhor compreendido na Figura 5.3.

Observando o valor da flecha no tempo infinito, verifica-se que a fluência é muito pequena para todas as lajes, o que sugere que com a espessura utilizada $(\mathrm{h}=8 \mathrm{~cm})$, não haverá problemas futuros devidos à utilização da estrutura. 
- Paredes estruturais

Para o cálculo do peso próprio das paredes estruturais, utilizou-se para o peso específico da alvenaria estrutural $\gamma_{\mathrm{alv}}=14 \mathrm{kN} / \mathrm{m}^{3}$. Este número é um valor médio, obtido através da composição dos pesos específicos aparentes dos componentes bloco e revestimento, conforme pode ser visto no item 3.2 do capítulo 3.

\subsubsection{Determinação das ações horizontais}

$\mathrm{Na}$ consideração das ações horizontais, foram incluídas apenas as ações devidas ao vento. Não se preocupou com as devidas ao desaprumo, por representarem cerca de apenas $11 \%$ das primeiras para o edifício com oito pavimentos, e $6 \%$ para o edifício com quatro pavimentos.

Os parâmetros necessários à determinação das ações devidas ao vento foram retirados da ABNT (NBR-6123).

Para a velocidade básica do vento, adotou-se um valor comum para grande parte do estado de São Paulo, de $\mathrm{v}_{\mathrm{o}}=38 \mathrm{~m} / \mathrm{s}$.

O fator topográfico $\left(S_{1}\right.$ ) leva em consideração as variações do relevo do terreno. Neste caso, considerou-se terreno plano ou fracamente acidentado, ou seja, $\mathrm{S}_{1}=1,0$.

$\mathrm{O}$ fator $\mathrm{S}_{2}$ considera o efeito combinado da rugosidade do terreno, da variação da velocidade do vento com a altura acima do terreno e das dimensões da edificação. A rugosidade do terreno é classificada em categorias, e neste caso considerou-se que o edifício será construído em uma cidade pequena, portanto categoria IV. As dimensões da edificação são avaliadas por classes. Neste caso, como a maior dimensão vertical ou horizontal não excede $20 \mathrm{~m}$, o edifício é de classe A.

O valor mínimo para o fator estatístico $\left(S_{3}\right)$, para edificações residenciais, é $S_{3}=1,0$.

O coeficiente de arrasto $\left(C_{a}\right)$ depende da direção e do regime do vento. Por não se conhecer o regime de vento do local, decidiu-se fazer uma média entre os coeficientes para vento de alta e baixa turbulência, encontrando os valores $C x=0,85$ e $C y=1,18$. 
Os valores das forças devidas ao vento ao nível de cada andar, e dos esforços na cota superior das fundações, obtidos pelo programa, encontram-se a seguir.

$\begin{array}{ccccc}\text { FORÇAS DEVIDAS AO VENTO } \\ \text { Nível } & \text { Cota }(\mathrm{m}) & \text { Coef S2 } & \text { FX }(\mathrm{kN}) & \text { FY }(\mathrm{kN}) \\ & & & & \\ 1 & 2.800 & .738 & 8.24 & 26.06 \\ 2 & 5.600 & .802 & 9.73 & 30.78 \\ 3 & 8.400 & .842 & 10.73 & 33.92 \\ 4 & 11.200 & .872 & 11.49 & 36.35\end{array}$

VALORES NA BASE

Vento X - Cortante $=40.189 \mathrm{kN}$

Vento Y - Cortante $=127.115 \mathrm{kN}$

Momento $=296.373 \mathrm{kN} \cdot \mathrm{m}$ Momento $=937.419 \mathrm{kN} . \mathrm{m}$

\subsubsection{Distribuição das ações ao longo do edifício}

O programa utilizado, após determinar as ações verticais e horizontais atuantes nos elementos estruturais, faz sua distribuição ao longo do edifício.

É importante salientar que, em todos os instantes, considerou-se a contribuição das abas ou flanges nos painéis de contraventamento. Outra consideração que deve ser feita é que, para a distribuição das ações horizontais, utilizou-se apenas o procedimento de paredes isoladas.

Inicialmente, o exemplo foi processado considerando o procedimento de paredes isoladas para a distribuição das accões verticais. Deste modo, foi feita a seguinte comparação:

A - Todos os pavimentos com blocos de resistência característica 4,5 MPa, por ser usual para um edifício de quatro pavimentos.

B - $1^{\circ}$ e $2^{\circ}$ pavimentos com blocos de resistência característica 6,0 MPa e os demais com blocos de 4,5 MPa, já que os resultados encontrados na Situação $A$ indicaram a necessidade de grauteamentos em algumas paredes, como será visto posteriormente. 
A nomenclatura utilizada para as paredes, nas tabelas a seguir, está de acordo com a Figura 5.4.
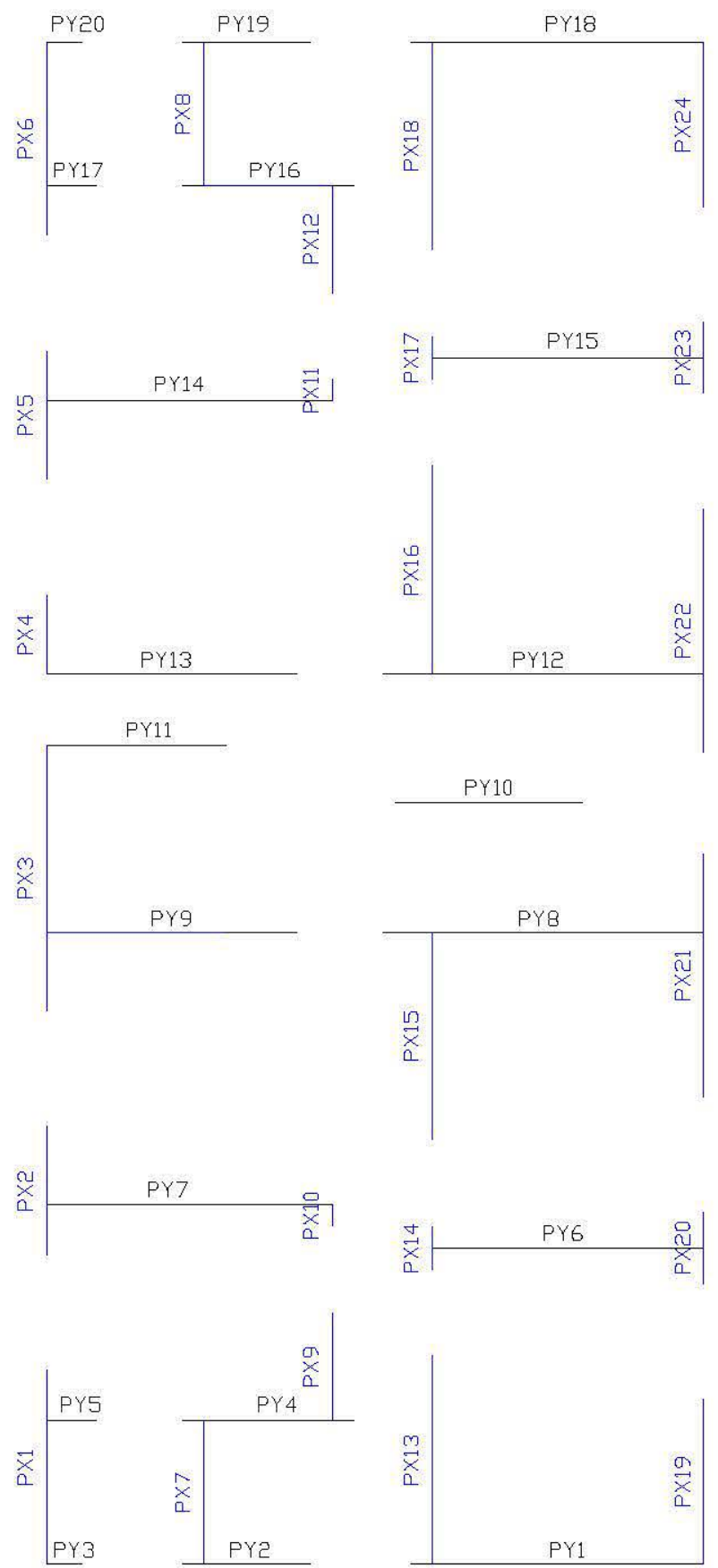

FIGURA 5.4 - Nomenclatura das paredes 


\section{Situação A}

Observando os resultados, verifica-se que as únicas paredes que necessitariam de algum grauteamento foram as paredes PX10 e PX11, PX14 e PX17, PY8 e PY12, PY9 e PY13, cujos resultados fornecidos pelo programa encontram-se na Tabela 5.3.

TABELA 5.3 - Resultado de grauteamento fornecido pelo programa

\begin{tabular}{cccccccccccc}
\hline Parede & \multicolumn{3}{c}{ PX10 e PX11 } & \multicolumn{3}{c}{$\mathrm{Q} / \mathrm{G}+\mathrm{Q}=0.150$} & \multicolumn{4}{c}{ Unidade de tensão: kN/m² } \\
Niv. & $\mathrm{R}$ & $\mathrm{G}+\mathrm{Q}$ & $\mathrm{G}+\mathrm{Q}+\mathrm{W}$ & $\mathrm{G}-\mathrm{W}$ & $\mathrm{Fp} 1$ & $\mathrm{Fp} 2$ & $\mathrm{~F} / 0.80$ & $\mathrm{~F} / 1.20$ & $\mathrm{~F} / 1.50$ & $\mathrm{Fbk}$ & $\mathrm{Gr}$ \\
\hline 4 & .885 & -197. & -200. & -166. & 1115. & 842. & 1394. & 930. & 744. & 4500. & - \\
3 & .885 & -395. & -401. & -329. & 2231. & 1689. & 2789. & 1859. & 1487. & 4500. & - \\
2 & .885 & -592. & -605. & -491. & 3346. & 2541. & 4183. & 2789. & 2231. & 4500. & - \\
1 & .885 & -790 & -810. & -651. & 4462. & 3397. & 5577. & 3718. & 2975. & 4500. & $\mathrm{G} 1$ \\
\hline
\end{tabular}

\begin{tabular}{cccccccccccc}
\hline Parede & \multicolumn{4}{c}{ PX14 e PX17 } & \multicolumn{4}{c}{$\mathrm{Q} / \mathrm{G}+\mathrm{Q}=0.150$} & \multicolumn{4}{c}{ Unidade de tensão: $\mathrm{kN} / \mathrm{m}^{2}$} \\
Niv. & $\mathrm{R}$ & $\mathrm{G}+\mathrm{Q}$ & $\mathrm{G}+\mathrm{Q}+\mathrm{W}$ & $\mathrm{G}-\mathrm{W}$ & $\mathrm{Fp1}$ & $\mathrm{Fp2}$ & $\mathrm{F} / 0.80$ & $\mathrm{~F} / 1.20$ & $\mathrm{~F} / 1.50$ & $\mathrm{Fbk}$ & $\mathrm{Gr}$ \\
\hline 4 & .885 & -233. & -235. & -196. & 1315. & 991. & 1644. & 1096. & 877. & 4500. & - \\
3 & .885 & -466. & -472. & -390. & 2631. & 1988. & 3288. & 2192. & 1754. & 4500. & - \\
2 & .885 & -698. & -710. & -582. & 3946. & 2989. & 4932. & 3288. & 2631. & 4500. & $\mathrm{G} 1$ \\
1 & .885 & -931. & -951. & -772. & 5261. & 3994. & 6576. & 4384. & 3507. & 4500. & $\mathrm{G} 1$ \\
\hline
\end{tabular}

\begin{tabular}{cccccccccccc}
\hline Parede & \multicolumn{3}{c}{ PY8 e PY12 } & \multicolumn{3}{c}{$\mathrm{Q} / \mathrm{G}+\mathrm{Q}=0.150$} & \multicolumn{4}{c}{ Unidade de tensão: $\mathrm{kN} / \mathrm{m}^{2}$} \\
Niv. & $\mathrm{R}$ & $\mathrm{G}+\mathrm{Q}$ & $\mathrm{G}+\mathrm{Q}+\mathrm{W}$ & $\mathrm{G}-\mathrm{W}$ & $\mathrm{Fp1}$ & $\mathrm{Fp2}$ & $\mathrm{F} / 0.80$ & $\mathrm{~F} / 1.20$ & $\mathrm{~F} / 1.50$ & $\mathrm{Fbk}$ & $\mathrm{Gr}$ \\
\hline 4 & .885 & -475. & -500. & -379. & 2686. & 2076. & 3357. & 2238. & 1790. & 4500. & - \\
3 & .885 & -572. & -645. & -413. & 3232. & 2607. & 4040. & 2694. & 2155. & 4500. & - \\
2 & .885 & -669. & -811. & -426. & 3779. & 3190. & 4724. & 3149. & 2519. & 4500. & $\mathrm{G} 1$ \\
1 & .885 & -766. & -995. & -421. & 4326. & 3818. & 5407. & 3605. & 2884. & 4500. & $\mathrm{G} 1$ \\
\hline
\end{tabular}

\begin{tabular}{cccccccccccc}
\hline Parede & \multicolumn{2}{c}{ PY9 } & \multicolumn{4}{c}{$\mathrm{Q} / \mathrm{G}+\mathrm{Q}=0.150$} & \multicolumn{4}{c}{ Unidade de tensão: $\mathrm{kN} / \mathrm{m}^{2}$} \\
Niv. & $\mathrm{R}$ & $\mathrm{G}+\mathrm{Q}$ & $\mathrm{G}+\mathrm{Q}+\mathrm{W}$ & $\mathrm{G}-\mathrm{W}$ & $\mathrm{Fp1}$ & $\mathrm{Fp2}$ & $\mathrm{F} / 0.80$ & $\mathrm{~F} / 1.20$ & $\mathrm{~F} / 1.50$ & $\mathrm{Fbk}$ & $\mathrm{Gr}$ \\
\hline 4 & .885 & -507. & -529. & -408. & 2862. & 2203. & 3577. & 2385. & 1908. & 4500. & - \\
3 & .885 & -602. & -668. & -445. & 3400. & 2716. & 4250. & 2833. & 2267. & 4500. & - \\
2 & .885 & -697. & -827. & -463. & 3938. & 3278. & 4923. & 3282. & 2626. & 4500. & $\mathrm{G} 1$ \\
1 & .885 & -792. & -1001. & -465. & 4477. & 3880. & 5596. & 3731. & 2984. & 4500. & $\mathrm{G} 1$ \\
\hline
\end{tabular}




\begin{tabular}{cccccccccccc}
\hline Parede & \multicolumn{2}{c}{ PY13 } & \multicolumn{4}{c}{$\mathrm{Q} / \mathrm{G}+\mathrm{Q}=0.150$} & \multicolumn{4}{c}{ Unidade de tensão: $\mathrm{kN} / \mathrm{m}^{2}$} \\
Niv. & $\mathrm{R}$ & $\mathrm{G}+\mathrm{Q}$ & $\mathrm{G}+\mathrm{Q}+\mathrm{W}$ & $\mathrm{G}-\mathrm{W}$ & $\mathrm{Fp1}$ & $\mathrm{Fp} 2$ & $\mathrm{~F} / 0.80$ & $\mathrm{~F} / 1.20$ & $\mathrm{~F} / 1.50$ & $\mathrm{Fbk}$ & $\mathrm{Gr}$ \\
\hline 4 & .885 & -507. & -527. & -410. & 2862. & 2197. & 3577. & 2385. & 1908. & 4500. & - \\
3 & .885 & -602. & -661. & -452. & 3400. & 2699. & 4250. & 2833. & 2267. & 4500. & - \\
2 & .885 & -697. & -813. & -477. & 3938. & 3243. & 4923. & 3282. & 2626. & 4500. & $\mathrm{G} 1$ \\
1 & .885 & -792. & -979. & -487. & 4477. & 3824. & 5596. & 3731. & 2984. & 4500. & $\mathrm{G} 1$ \\
\hline
\end{tabular}

A razão da carga variável pela carga total $(Q / G+Q)$ foi calculada da seguinte forma:

- peso total da edificação: 4763,43 kN (Anexo B)

- área total da edificação: 112,92 $\mathrm{m}^{2}$

$\therefore$ carga distribuída na fundação: $p=g+q=42,18 \mathrm{kN} / \mathrm{m}^{2}$

Por ser a sobrecarga variável de acordo com os ambientes do edifício, optou por fazer uma homogeneização da mesma e chegou-se ao seguinte valor:

$$
q=1,60 \mathrm{kN} / \mathrm{m}^{2} \times 4 \text { lajes }=6,40 \mathrm{kN} / \mathrm{m}^{2}
$$

Assim, pode-se calcular as porcentagens de carga permanente e variável em relação à carga total:

$$
\frac{q}{g+q}=\frac{6,40}{42,18}=0,15 \quad ; \quad \frac{g}{g+q}=0,85
$$

$\mathrm{O}$ parâmetro $\mathrm{R}$ da tabela representa $\mathrm{o}$ fator de redução da resistência à compressão por efeito da esbeltez, definido no item 4.3 do capítulo 4.

A coluna $G+Q$ representa as tensões de compressão simples devidas às cargas permanentes diretas e às cargas variáveis acidentais (verticais).

A coluna $G+Q+W$ representa as tensões de compressão devidas à flexocompressão, resultantes da combinação das ações permanentes diretas, das ações variáveis acidentais (verticais) e da ação do vento.

A coluna G-W representa o alívio nas tensões de compressão provocado pela combinação das tensões de compressão devidas às ações permanentes diretas com as de flexão devidas à ação do vento. $O$ resultado positivo indica ocorrência de tração em determinado trecho da parede. 
As colunas $F_{p 1}$ e $F_{p 2}$ representam a resistência de prisma mínima que se deve ter não se considerando a ação do vento e considerando-a, respectivamente.

Adotando uma eficiência de $\eta=0,8^{12}$, a partir da resistência do prisma (maior valor entre $F_{p 1}$ e $F_{p 2}$ ) obtém-se a resistência do bloco, dada pela coluna $\mathrm{F} / 0,80$. Quando este valor supera o $\mathrm{f}_{\mathrm{bk}}$ imposto $(4,5 \mathrm{MPa})$, deve-se grautear determinados vazados dos blocos. A coluna $F / 1,20$ representa as tensões considerando grauteamente em 1 a cada 2 furos, e a coluna F/1,50 representa as tensões considerando todos os furos grauteados. Estas duas situações são representadas pelos símbolos G1 e G2 na última coluna, onde Gr significa grauteamento.

Além das opções de grauteamento fornecidas pelo programa, foram estudadas outras alternativas intermediárias para se obter maior economia de material, que são: 1 a cada 3 furos e 1 a cada 4 furos grauteados.

Seja a seguinte definição de área bruta $\left(A_{b}\right)$ e área efetiva $\left(A_{e}\right)$ de um bloco:

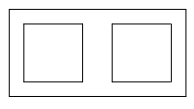

$A_{b}=4 a$

$\Delta-20$

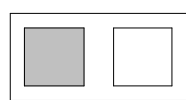

$A_{e}=3 a$

A partir daí, tem-se o estudo das seguintes alternativas de grauteamento:

\section{- $1 \mathrm{c} / 3$ furos}

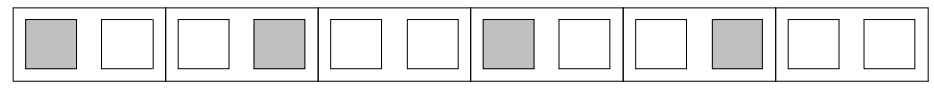

\footnotetext{
${ }^{12}$ Para a adoção deste valor de eficiência supõe-se que foram solicitados ensaios de prisma.
} 


$$
\begin{aligned}
& \mathrm{f}_{\mathrm{p}(\mathrm{s} / \text { graute })}^{\mathrm{e}}=\frac{\mathrm{N}}{6 \times 2 \mathrm{a}}=\frac{\mathrm{N}}{12 \mathrm{a}} \\
& f_{p(c / \text { graute })}^{e}=\frac{N}{4 \times 3 a+2 \times 2 a}=\frac{N}{16 a} \\
& \therefore \mathrm{f}_{\mathrm{p}(\mathrm{c} / \text { graute })}^{\mathrm{e}}=0,75 \mathrm{f}_{\mathrm{p}(\mathrm{s} / \text { graute })}^{\mathrm{e}} \\
& \mathrm{f}_{\mathrm{bk}}=\frac{\mathrm{f}_{\mathrm{p}}}{\eta} \Rightarrow \mathrm{f}_{\mathrm{bk}(\mathrm{c} / \text { gratue })}^{\mathrm{e}}=\frac{\mathrm{f}_{\mathrm{p}(\mathrm{c} / \text { graute })}^{\mathrm{e}}}{0,8}=\frac{0,75 \mathrm{f}_{\mathrm{p}(\mathrm{s} / \text { graute })}^{\mathrm{e}}}{0,8}=\frac{\mathrm{f}_{\mathrm{p}(\mathrm{s} / \text { graute })}^{\mathrm{e}}}{1,07} \\
& \mathrm{f}_{\mathrm{bk}(\mathrm{c} / \text { graute })}^{\mathrm{e}}=\frac{\mathrm{f}_{\mathrm{p}(\mathrm{s} / \text { graute })}^{\mathrm{e}}}{1,07}
\end{aligned}
$$

\section{- $\underline{1 \mathrm{c} / 4 \text { furos }}$}

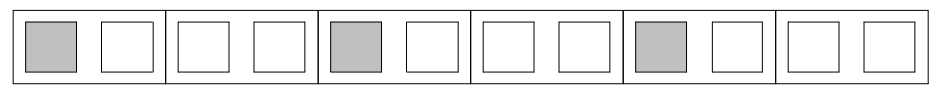

$$
\mathrm{f}_{\mathrm{p}(\mathrm{s} / \text { graute })}^{\mathrm{e}}=\frac{\mathrm{N}}{12 \mathrm{a}}
$$$$
f_{p(c / \text { graute })}^{e}=\frac{N}{15 a}
$$

$$
\therefore \mathrm{f}_{\mathrm{p}(\mathrm{c} / \text { graute })}^{\mathrm{e}}=0,80 \mathrm{f}_{\mathrm{p}(\mathrm{s} / \text { graute })}^{\mathrm{e}}
$$

$$
f_{b k}=\frac{f_{p}}{\eta} \Rightarrow f_{b k(c / \text { gratue })}^{e}=\frac{f_{p(c / \text { graute })}^{e}}{0,8}=\frac{0,80 f_{p(s / \text { graute })}^{e}}{0,8}=f_{p(s / \text { graute })}^{e}
$$

$$
\mathrm{f}_{\mathrm{bk}(\mathrm{c} / \text { graute })}^{\mathrm{e}}=\mathrm{f}_{\mathrm{p}(\mathrm{s} / \text { graute })}^{\mathrm{e}}
$$


A partir do estudo anterior, conclui-se que os grauteamentos das paredes citadas podem ser os encontrados na Tabela 5.4.

TABELA 5.4 - Resultado de grauteamento econômico

\begin{tabular}{|c|c|c|c|c|}
\hline Parede & Nível & Grauteamento & $\mathrm{f}_{\mathrm{bk}}{ }^{\prime}\left(\mathrm{kN} / \mathrm{m}^{2}\right)$ & $\mathrm{f}_{\mathrm{bk}}\left(\mathrm{kN} / \mathrm{m}^{2}\right)$ \\
\hline PX10 e PX11 & 1 & $1 \mathrm{c} / 4$ & 4462. & 4500. \\
\hline \multirow{2}{*}{$\begin{array}{l}\text { PX14 e } \\
\text { PX17 }\end{array}$} & 2 & $1 \mathrm{c} / 4$ & 3946. & 4500. \\
\hline \multirow{2}{*}{$\begin{array}{c}\text { PY8 e } \\
\text { PY12 }\end{array}$} & 2 & $1 \mathrm{c} / 2^{(*)}$ & 4384. & 4500. \\
\hline PY9 e \\
PY13
\end{tabular}

Notas: a) $f_{b k}{ }^{\prime}=f_{b k}(c /$ graute $)$

b) ${ }^{(*)}$ permaneceu igual ao da tabela do Anexo $\mathrm{C}$

O volume de graute necessário para esta situação pode ser calculado por:

- graute para aumentar a resistência das paredes:

$$
\begin{aligned}
& 1^{\circ} \text { pav.: } V=2(0,0552)+2(0,0552)+2(0,138)+2(0,166)=0,829 \mathrm{~m}^{3} \\
& \begin{array}{llll}
P X 1 & P X 1 & P Y & P Y
\end{array} \\
& 2^{\circ} \text { pav.: } V=2(0,138)+2(0,0552)+2(0,166)=0,718 \mathrm{~m}^{3} \\
& \begin{array}{lll}
\text { PY9 } & \text { PX14 PY }
\end{array}
\end{aligned}
$$

$$
\therefore \mathrm{V}_{1}=1,547 \mathrm{~m}^{3}
$$


- graute para a cinta sob a laje:

$$
V=0,09 \times 0,095 \times 77,25=0,660 \mathrm{~m}^{3}
$$

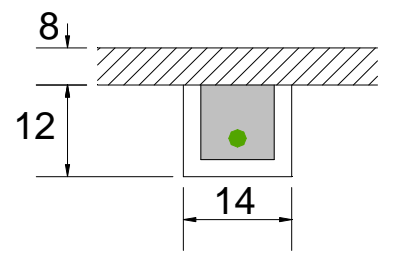

- graute para cinta a meia altura nas paredes externas:

$$
V=0,09 \times 0,175 \times 29,87=0,470 \mathrm{~m}^{3}
$$

- graute para as vergas e contravergas:

$$
\begin{gathered}
\text { janelas: } \mathrm{V}=0,09 \times 0,175 \times 47,98=0,756 \mathrm{~m}^{3} \\
\text { portas: } \mathrm{V}=0,09 \times 0,175 \times 17,22=0,271 \mathrm{~m}^{3} \\
\therefore \mathrm{V}_{2}=2,157 \mathrm{~m}^{3} / \mathrm{pav} . \\
\mathrm{V}_{\text {graute }}=\mathrm{V}_{1}+4 \mathrm{~V}_{2}=10,175 \mathrm{~m}^{3}
\end{gathered}
$$

O volume de concreto das lajes também pode ser calculado por:

$$
\mathrm{V}_{\text {concreto }}=4 \times 16,04 \times 7,04 \times 0,08=36,135 \mathrm{~m}^{3}
$$

Portanto, fazendo a comparação entre os dois volumes, verifica-se que o volume de graute necessário, para esta situação, é $28,2 \%$ do volume de concreto. 


\section{Situação B}

Observando os resultados, verifica-se que houve uma grande redução de grauteamento em relação à primeira situação, sendo que apenas as paredes PX14 e PX17 necessitariam de grauteamento. Os resultados para estas paredes encontram-se na Tabela 5.5.

TABELA 5.5 - Resultado de grauteamento fornecido pelo programa

\begin{tabular}{cccccccccccc}
\hline Parede & \multicolumn{4}{c}{ PX14 e PX17 } & \multicolumn{4}{c}{$\mathrm{Q} / \mathrm{G}+\mathrm{Q}=0.150$} & \multicolumn{4}{c}{ Unidade de tensão: $\mathrm{kN} / \mathrm{m}^{2}$} \\
Niv. & $\mathrm{R}$ & $\mathrm{G}+\mathrm{Q}$ & $\mathrm{G}+\mathrm{Q}+\mathrm{W}$ & $\mathrm{G}-\mathrm{W}$ & $\mathrm{Fp1}$ & $\mathrm{Fp} 2$ & $\mathrm{~F} / 0.80$ & $\mathrm{~F} / 1.20$ & $\mathrm{~F} / 1.50$ & $\mathrm{Fbk}$ & $\mathrm{Gr}$ \\
\hline 4 & .885 & -233. & -235. & -196. & 1315. & 992. & 1644. & 1096. & 877. & 4500. & - \\
3 & .885 & -466. & -472. & -390. & 2631. & 1988. & 3288. & 2192. & 1754. & 4500. & - \\
2 & .885 & -698. & -710. & -582. & 3946. & 2989. & 4932. & 3288. & 2631. & 6000. & - \\
1 & .885 & -931. & -951. & -772. & 5261. & 3994. & 6576. & 4384. & 3507. & 6000. & $\mathrm{G} 1$ \\
\hline
\end{tabular}

A partir do estudo de alternativas mais viáveis economicamente, em termos de grauteamento, chegou-se aos resultados apresentados na Tabela 5.6.

TABELA 5.6 - Resultado de grauteamento econômico

\begin{tabular}{|c|c|c|c|c|}
\hline Parede & Nível & Grauteamento & $\mathrm{f}_{\mathrm{bk}}{ }^{\prime}\left(\mathrm{kN} / \mathrm{m}^{2}\right)$ & $\mathrm{f}_{\mathrm{bk}}\left(\mathrm{kN} / \mathrm{m}^{2}\right)$ \\
\hline PX14 e PX17 & 1 & $1 \mathrm{c} / 4$ & 5261. & 6000. \\
\hline
\end{tabular}

Nota: $a) f_{b k}=f_{b k}(c /$ graute $)$

Calculando o volume de graute necessário para esta situação, tem-se:

- graute para aumentar a resistência das paredes:

$$
1^{\circ} \text { pav.: } V=\underset{P X 1}{2(0,0552)}=0,110 \mathrm{~m}^{3}
$$




$$
\mathrm{V}_{1}=0,110 \mathrm{~m}^{3}
$$

- graute para as cintas, vergas e contravergas:

$$
\begin{gathered}
\left.\mathrm{V}_{2}=2,157 \mathrm{~m}^{3} / \text { pav. } \quad \text { (Situação } \mathrm{A}\right) \\
\mathrm{V}_{\text {graute }}=\mathrm{V}_{1}+4 \mathrm{~V}_{2}=8,738 \mathrm{~m}^{3}
\end{gathered}
$$

Fazendo a comparação entre o volume de graute e o de concreto, verificase que, para esta situação, o volume de graute necessário é $24,2 \%$ do de concreto. Observa-se uma redução de $14,1 \%$ de graute em relação à situação anterior; em contrapartida, foram empregados blocos mais caros $(6,0 \mathrm{MPa})$ nos dois primeiros pavimentos.

A título de ilustração, tem-se, a seguir, a composição de custos do graute [TCPO 9 (1992)], cujo traço utilizado foi $1: 3$ (cimento e areia/pedrisco), e a comparação dos custos totais das Situações A e B. Não se teve, aqui, a pretensão de elaborar um orçamento completo, mas apenas fornecer indicativos que auxiliem no processo de tomada de decisão.

\begin{tabular}{cccc}
\hline Graute 1: 3 $(\mathrm{Cl}, \mathrm{AR} / \mathrm{PE})$ & \multicolumn{3}{c}{ Unidade: $\mathrm{m}^{3}$} \\
\hline & $\mathrm{un}$ & coef. & $\mathrm{R} \$ / \mathrm{un}$ \\
servente & $\mathrm{h}$ & 10,0000 & 1,78 \\
cimento & $\mathrm{Kg}$ & 486,0000 & 0,12 \\
areia média / pedrisco & $\mathrm{m}^{3}$ & 1,2160 & 17,00 \\
& & & 96,79 \\
\hline
\end{tabular}




\begin{tabular}{|c|c|c|c|c|}
\hline \multicolumn{5}{|c|}{ Paredes Isoladas - Situação A } \\
\hline \multirow[b]{2}{*}{ graute } & unidade & quantidade & $\mathrm{R} \$ /$ un & $\mathrm{R} \$$ \\
\hline & $m^{3}$ & 10,175 & 96,79 & 984,84 \\
\hline bloco $\quad 4,5 \mathrm{MPa}$ & un & $4 \times 3470$ & 0,761 & $10.562,68$ \\
\hline $1 / 2$ bloco $4,5 \mathrm{MPa}$ & un & $4 \times 481$ & 0,445 & 856,18 \\
\hline \multirow[t]{2}{*}{ canaleta 4,5 MPa } & un & $4 \times 311$ & 0,771 & 959,12 \\
\hline & & & & $13.362,82$ \\
\hline
\end{tabular}

\begin{tabular}{|c|c|c|c|c|c|}
\hline \multicolumn{6}{|c|}{ Paredes Isoladas - Situação B } \\
\hline \multirow{2}{*}{\multicolumn{2}{|c|}{ graute }} & unidade & quantidade & $\mathrm{R} \$ /$ un & $\mathrm{R} \$$ \\
\hline & & $\mathrm{m}^{3}$ & 8,738 & 96,79 & 845,75 \\
\hline bloco & $4,5 \mathrm{MPa}$ & un & $2 \times 3470$ & 0,761 & $5.281,34$ \\
\hline bloco & $6,0 \mathrm{MPa}$ & un & $2 \times 3470$ & 0,804 & $5.579,76$ \\
\hline $1 / 2$ bloco & $4,5 \mathrm{MPa}$ & un & $2 \times 481$ & 0,445 & 428,09 \\
\hline $1 / 2$ bloco & $6,0 \mathrm{MPa}$ & un & $2 \times 481$ & 0,457 & 439,63 \\
\hline canaleta & $4,5 \mathrm{MPa}$ & un & $2 \times 311$ & 0,771 & 479,56 \\
\hline \multirow{2}{*}{\multicolumn{2}{|c|}{ canaleta $6,0 \mathrm{MPa}$}} & un & $2 \times 311$ & 0,815 & 506,93 \\
\hline & & & & & $13.561,06$ \\
\hline
\end{tabular}

Na comparação das situações A e B foram utilizados apenas os blocos mais comuns, não se preocupando com o bloco "J", bloco compensador ou blocos especiais, pois se encontram em menor quantidade. Os preços dos blocos, bem como dos demais materiais, foram obtidos na região do interior de São Paulo e no período da elaboração desta dissertação. Apesar de poderem sofrer alterações no decorrer do tempo e de acordo com a região, o objetivo desta coleta de preços foi avaliar numericamente qual das situações é mais vantajosa.

Através dos resultados da comparação, verifica-se que o custo total da Situação $B$ ficou $1,48 \%$ maior que o da Situação $A$, sendo portanto esta última a mais econômica. Este aumento deveu-se ao custo dos blocos de resistência característica 6,0 MPa, que ocasionaram um aumento de 2,44\% no preço total dos blocos.

Posteriormente, o exemplo foi processado considerando, para a distribuição das ações verticais, o procedimento de grupos isolados de paredes, a fim de fazer 
uma comparação com o anterior. Não se optou pelo procedimento de grupos com interação, por não se ter, ainda, taxas de interação seguras e com respaldo teórico e experimental, conforme já assimilado no capítulo 3.

A definição dos grupos, representada na Figura 5.5, foi feita com base no critério da separação por aberturas, conforme justificado no item 3.4.2 do capítulo 3. 


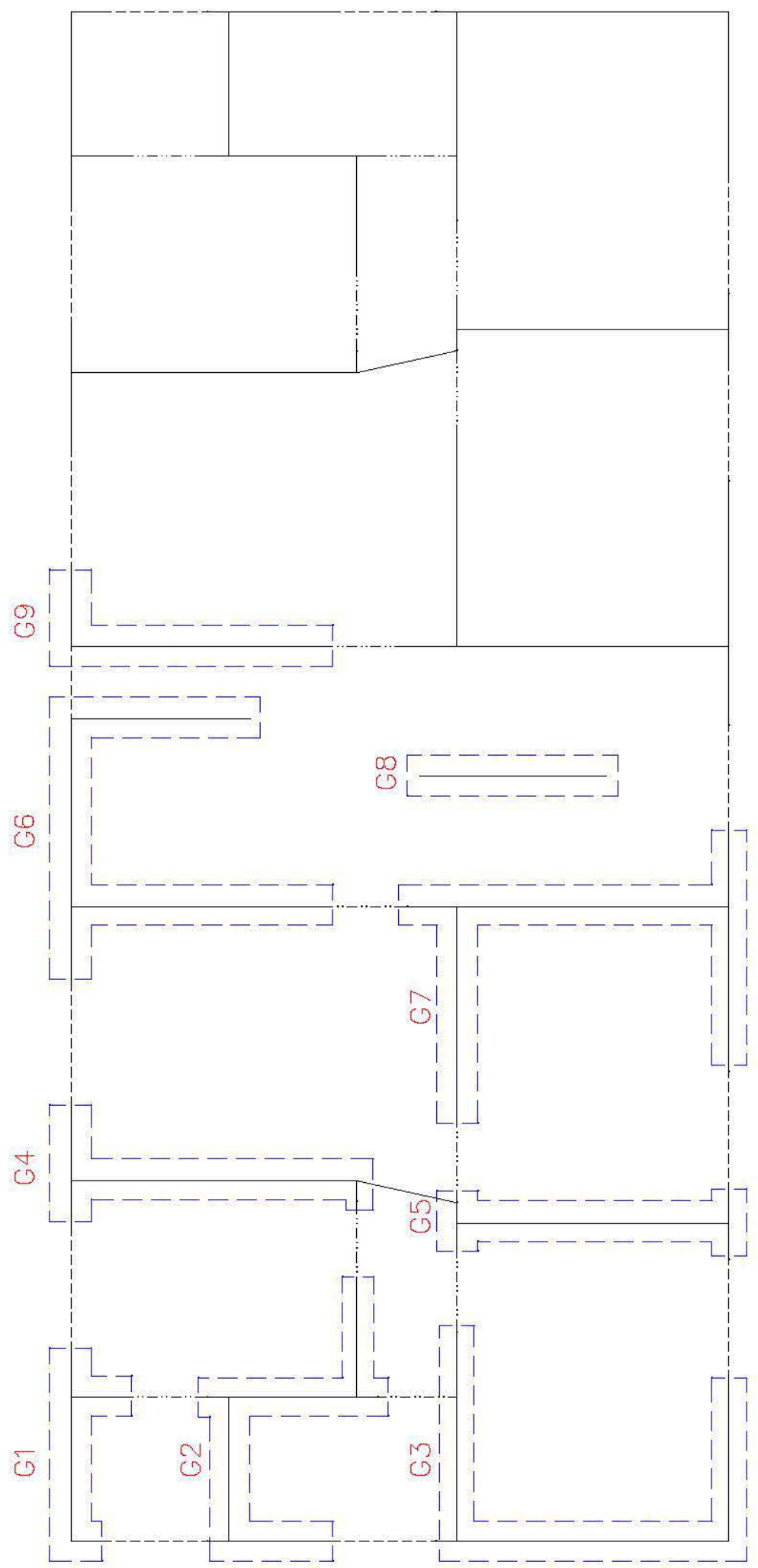

FIGURA 5.5 - Definição dos grupos de paredes 
O exemplo foi processado com blocos de resistência característica 4,5 $\mathrm{MPa}$ para todos os pavimentos, e os resultados encontrados na Tabela 5.7 mostram que apenas as paredes PX4 e PY13 precisariam de grauteamento.

TABELA 5.7 - Resultados de grauteamento fornecidos pelo programa

\begin{tabular}{cccccccccccc}
\hline $\begin{array}{c}\text { Parede } \\
\text { Niv. }\end{array}$ & $\mathrm{R}$ & $\mathrm{G} 4 \mathrm{G}$ & \multicolumn{4}{c}{$\mathrm{Q} / \mathrm{G}+\mathrm{Q}=0.150$} & \multicolumn{4}{c}{ Unidade de tensão: $\mathrm{kN} / \mathrm{m}^{2}$} \\
\hline 4 & .885 & -438. & -444. & -366. & 2473. & 1872. & 3092. & 2061. & 1649. & 4500. & - \\
3 & .885 & -535. & -554. & -435. & 3020. & 2314. & 3776. & 2517. & 2014. & 4500. & - \\
2 & .885 & -631. & -669. & -499. & 3567. & 2769. & 4459. & 2973. & 2378. & 4500. & - \\
1 & .885 & -728. & -789. & -558. & 4114. & 3237. & 5143. & 3429. & 2743. & 4500. & $\mathrm{G} 1$ \\
\hline
\end{tabular}

\begin{tabular}{cccccccccccc}
\hline Parede & \multicolumn{2}{c}{ PY13 } & \multicolumn{4}{c}{$\mathrm{Q} / \mathrm{G}+\mathrm{Q}=0.150$} & \multicolumn{4}{c}{ Unidade de tensão: $\mathrm{kN} / \mathrm{m}^{2}$} \\
Niv. & $\mathrm{R}$ & $\mathrm{G}+\mathrm{Q}$ & $\mathrm{G}+\mathrm{Q}+\mathrm{W}$ & $\mathrm{G}-\mathrm{W}$ & $\mathrm{Fp} 1$ & $\mathrm{Fp} 2$ & $\mathrm{~F} / 0.80$ & $\mathrm{~F} / 1.20$ & $\mathrm{~F} / 1.50$ & $\mathrm{Fbk}$ & $\mathrm{Gr}$ \\
\hline 4 & .885 & -438. & -458. & -352. & 2473. & 1906. & 3092. & 2061. & 1649. & 4500. & - \\
3 & .885 & -535. & -594. & -395. & 3020. & 2414. & 3776. & 2517. & 2014. & 4500. & - \\
2 & .885 & -631. & -747. & -421. & 3567. & 2965. & 4459. & 2973. & 2378. & 4500. & - \\
1 & .885 & -728. & -915. & -432. & 4114. & 3552. & 5143. & 3429. & 2743. & 4500. & $\mathrm{G} 1$ \\
\hline
\end{tabular}

Embora já bastante econômicos, pode-se substituir estes grauteamentos pelos indicados na Tabela 5.8 .

TABELA 5.8 - Resultado de grauteamento econômico

\begin{tabular}{|c|c|c|c|c|}
\hline Parede & Nível & Grauteamento & $\mathrm{f}_{\mathrm{bk}}{ }^{\prime}\left(\mathrm{kN} / \mathrm{m}^{2}\right)$ & $\mathrm{f}_{\mathrm{bk}}\left(\mathrm{kN} / \mathrm{m}^{2}\right)$ \\
\hline PX4 & 1 & $1 \mathrm{c} / 4$ & 4114. & 4500. \\
\hline PY13 & 1 & $1 \mathrm{c} / 4$ & 4114. & 4500. \\
\hline
\end{tabular}

Nota: a) $f_{b k}{ }^{\prime}=f_{b k}(c /$ graute $)$ 
O volume de graute necessário neste procedimento pode ser calculado por:

- graute para aumentar a resistência das paredes:

$$
\begin{array}{r}
1^{\circ} \text { pav.: } \mathrm{V}=2(0,0552)+0,138=0,193 \mathrm{~m}^{3} \\
\text { PX4 PY13 } \\
V_{1}=0,193 \mathrm{~m}^{3}
\end{array}
$$

- graute para as cintas, vergas e contravergas:

$$
\begin{gathered}
\mathrm{V}_{2}=2,157 \mathrm{~m}^{3} / \text { pav. } \\
\mathrm{V}_{\text {graute }}=\mathrm{V}_{1}+4 \mathrm{~V}_{2}=8,821 \mathrm{~m}^{3}
\end{gathered}
$$

Fazendo a comparação entre o volume de graute e o de concreto, verificase que, para este procedimento, o volume de graute necessário é $24,4 \%$ do de concreto, bem próximo da Situação B. Observa-se uma redução de 13,3\% de graute em relação à Situação $A$, e um aumento inexpressivo de $0,9 \%$ em relação à Situação B, a qual não compensaria pelo maior custo dos blocos de $6,0 \mathrm{MPa}$, conforme já foi visto.

\begin{tabular}{|c|c|c|c|c|}
\hline & unidade & quantidade & $\mathrm{R} \$ /$ un & $\mathrm{R} \$$ \\
\hline graute & $\mathrm{m}^{3}$ & 8,821 & 96,79 & 853,78 \\
\hline 4,5 MPa & un & $4 \times 3470$ & 0,761 & $10.562,68$ \\
\hline $1 / 2$ bloco $4,5 \mathrm{MPa}$ & un & $4 \times 481$ & 0,445 & 856,18 \\
\hline \multirow[t]{2}{*}{ canaleta 4,5 MPa } & un & $4 \times 311$ & 0,771 & 959,12 \\
\hline & & & & $13.231,76$ \\
\hline
\end{tabular}

Isto pode ser melhor compreendido através da comparação dos custos totais da Situação A e do procedimento de grupos isolados de paredes, mostrado a seguir.

\section{Grupos isolados de paredes}


Através dos resultados da comparação, verifica-se que o custo total da Situação A ficou 0,99\% maior que o do procedimento de grupos sem interação, devido ao custo total do graute. Portanto, verifica-se ser este último o procedimento mais econômico, o que confirma a teoria do capítulo 3.

Observa-se que este aumento de 0,99\% é inexpressivo, o que sugere que o procedimento usualmente empregado pelos projetistas, para edifícios de 4 pavimentos (paredes isoladas), é suficiente em termos econômicos e produz resultados bem próximos do melhor. Entretanto, deve-se ter cuidado com as fundações, pois, desde que haja amarração direta, ocorre transmissão de ações de uma para outra, o que alivia uma parede muito carregada e acrescenta tensões em outra menos carregada. Portanto, o procedimento de grupos sem interação aproxima melhor o modelo de cálculo da situação real existente.

Em termos de tensões, verifica-se que a tensão de compressão média no $1^{\circ}$ pavimento, para o procedimento de paredes isoladas (Situação A), foi de $563 \mathrm{kN} / \mathrm{m}^{2}$. Já no procedimento de grupos isolados de paredes, obteve-se uma tensão de compressão média de $522 \mathrm{kN} / \mathrm{m}^{2}$ para este mesmo pavimento, ou seja, houve uma redução de 7,28\% (Anexo $B$ ). Portanto, fazendo a análise em termos de tensões, justifica-se ainda mais o emprego do segundo procedimento.

\subsection{Edifício com 8 (oito) pavimentos}

\subsubsection{Alvenaria armada ou não-armada}

No caso deste edifício com 8 (oito) pavimentos, ao contrário do de 4 (quatro) pavimentos, houve tração em determinados trechos de algumas paredes estruturais. Assim sendo, deve-se verificar se estas tensões de tração são admissíveis, ou se há necessidade de armar tais trechos. Esta verificação será feita no item 5.3.4 deste capítulo, onde se tratará da distribuição das ações ao longo do edifício.

Apesar de algumas paredes precisarem ser armadas, não há necessidade de utilizar alvenaria armada para todo o edifício, visto o que foi exposto no item 5.2.1. Propõe-se, neste caso, que se utilize alvenaria parcialmente armada, onde algumas paredes são armadas e outras não. 
O item 5.2.13 da ABNT (NBR-10837), que trata de estruturas parcialmente armadas, estabelece que "quando, no projeto de um edifício de alvenaria nãoarmada, surge um trecho da estrutura com solicitações que provoquem tensões acima das admissíveis, deve-se projetar este trecho como alvenaria armada". Este item também estabelece que a taxa de armadura mínima indicada no item 4.9 do capítulo 4, para alvenaria armada, não se aplica neste caso. O máximo espaçamento das armaduras verticais em paredes parcialmente armadas é de $240 \mathrm{~cm}$. Além disso, as armaduras usuais, como nos cantos de aberturas, de amarração de paredes, e nas cintas, devem ser mantidas.

\subsubsection{Determinação das ações verticais}

O procedimento para a determinação das ações verticais atuantes nas paredes estruturais está descrito no item 5.2.2.

\subsubsection{Determinação das ações horizontais}

Da mesma forma que no item 5.2.3, serão consideradas apenas as ações horizontais devidas ao vento, pelos mesmo motivos.

Os parâmetros necessários à determinação das ações devidas ao vento foram retirados da ABNT (NBR-6123).

Para a determinação da velocidade básica do vento $\left(\mathrm{v}_{0}=38 \mathrm{~m} / \mathrm{s}\right)$, dos fatores topográfico $\left(S_{1}=1,0\right)$ e estatístico $\left(S_{3}=1,0\right)$, foram feitas as mesmas considerações do item 5.2.3.

$\mathrm{O}$ fator $\mathrm{S}_{2}$ considera o efeito combinado da rugosidade do terreno, da variação da velocidade do vento com a altura acima do terreno e das dimensões da edificação. A rugosidade do terreno é classificada em categorias, e neste caso considerou-se que o edifício será construído em uma cidade pequena, portanto categoria IV. As dimensões da edificação são avaliadas por classes. Neste caso, como a maior dimensão vertical ou horizontal está entre 20 m e 50 m, o edifício é de classe $B$. 
O coeficiente de arrasto $\left(C_{a}\right)$ depende da direção e do regime do vento. Por não se conhecer o regime de vento do local, decidiu-se fazer uma média entre os coeficientes para vento de alta e baixa turbulência, encontrando os valores $C x=0,90$ e Cy $=1,24$.

Os valores das forças devidas ao vento ao nível de cada andar, e dos esforços na cota superior das fundações encontram-se a seguir.

FORÇAS DEVIDAS AO VENTO

$\begin{array}{rrrrr}\text { Nível } & \text { Cota }(\mathrm{m}) & \text { Coef } \mathrm{S} 2 & \mathrm{FX}(\mathrm{kN}) & \mathrm{FY}(\mathrm{kN}) \\ 1 & 2.800 & .710 & 8.08 & 25.37 \\ 2 & 5.600 & .775 & 9.61 & 30.17 \\ 3 & 8.400 & .815 & 10.64 & 33.39 \\ 4 & 11.200 & .845 & 11.43 & 35.88 \\ 5 & 14.000 & .869 & 12.08 & 37.94 \\ 6 & 16.800 & .889 & 12.65 & 39.71 \\ 7 & 19.600 & .906 & 13.15 & 41.27 \\ 8 & 22.400 & .921 & 13.59 & 42.67\end{array}$

VALORES NA BASE

Vento $\mathrm{X}$ - Cortante $=91.228 \mathrm{kN}$

Momento $=1237.584 \mathrm{kN} \cdot \mathrm{m}$

Vento Y - Cortante $=286.378 \mathrm{kN}$

Momento $=3884.952 \mathrm{kN} \cdot \mathrm{m}$

\subsubsection{Distribuição das ações ao longo do edifício}

O programa utilizado, após determinar as ações verticais e horizontais atuantes nos elementos estruturais, faz sua distribuição ao longo do edifício.

É importante salientar que, em todos os momentos, considerou-se a contribuição das abas ou flanges nos painéis de contraventamento. Outra consideração que deve ser feita é que, para a distribuição das ações horizontais, utilizou-se apenas o procedimento de paredes isoladas.

Inicialmente, o exemplo foi processado considerando o procedimento de paredes isoladas para a distribuição das ações verticais. Deste modo, foi feita a seguinte comparação: 
A $-1^{\circ}$ pavimento com blocos de resistência característica $8,0 \mathrm{MPa}, 2^{\circ}$ e $3^{\circ}$ pavimentos com blocos de resistência característica $6,0 \mathrm{MPa}$, e os demais com blocos de 4,5 MPa. Esta escolha inicial das resistências dos blocos foi feita com base naquela regra empírica, de que um edifício de 8 pavimentos teria bloco de resistência máxima 8,0 MPa (capítulo 2). As demais resistências foram escolhidas arbitrariamente.

B $-1^{\circ}$ e $2^{\circ}$ pavimentos com blocos de resistência característica $8,0 \mathrm{MPa}, 3^{\circ}$ e $4^{\circ}$ pavimentos com blocos de resistência característica 6,0 MPa, e os demais com blocos de 4,5 MPa, já que os resultados da Situação $A$ indicaram a necessidade de grauteamento de todos os furos de algumas paredes, conforme será visto posteriormente.

A nomenclatura utilizada para as paredes, nas tabelas a seguir, está de acordo com a Figura 5.4.

\section{Situação A}

Os resultados mais significativos fornecidos pelo programa encontram-se no item 1 do Anexo C. Observa-se que algumas paredes são tracionadas em determinados pavimentos. Deve-se verificar se estas trações são ou não admissíveis, de acordo com a eq. (4.22) do capítulo 4:

$$
f_{\text {alv,f }}-0,75 f_{\text {alv }, c} \leq \bar{f}_{\text {alv,t }}
$$

Nesta equação, a ABNT (NBR-10837) está implicitamente admitindo que $75 \%$ das cargas são permanentes, o que parece ser bastante conservador. Por isto, optou-se por utilizar a real porcentagem de carga permanente atuante neste edifício, calculada a seguir:

- peso total da edificação: 8106,24 kN

- área total da edificação: 112,92 $\mathrm{m}^{2}$

$\therefore$ carga distribuída na fundação: $p=g+q=71,79 \mathrm{kN} / \mathrm{m}^{2}$

- carga total variável: $q=1,60 \mathrm{kN} / \mathrm{m}^{2} \times 8$ lajes $=12,80 \mathrm{kN} / \mathrm{m}^{2}$ 
Assim, pode-se calcular as porcentagens de carga permanente e variável em relação à carga total:

$$
\frac{q}{g+q}=\frac{12,80}{71,79}=0,18 \quad ; \quad \frac{g}{g+q}=0,82
$$

Assim, a eq. (4.22) pode ser substituída pela seguinte equação:

$$
\mathrm{f}_{\mathrm{alv}, \mathrm{f}}-0,82 \mathrm{f}_{\mathrm{alv}, \mathrm{c}} \leq \overline{\mathrm{f}}_{\mathrm{alv}, \mathrm{t}}
$$

A verificação das tensões de tração pela eq. (5.3) é feita pelo programa e encontra-se na $5^{\text {a }}$ coluna ( G-W ) das tabelas do item 1 do Anexo C, onde:

$$
\begin{aligned}
& G=0,82 f_{a l v, c} \\
& W=f_{a l v, f}
\end{aligned}
$$

Basta comparar o resultado desta coluna com $\bar{f}_{a l v, t}=100 \mathrm{kN} / \mathrm{m}^{2}$ (normal à fiada), para saber quais paredes precisam ser armadas.

O resultado do cálculo das armaduras de flexão para as paredes cujas tensões de tração superaram a tensão admissível encontra-se na Tabela 5.9. O procedimento utilizado para o dimensionamento foi o "Método Simplificado", definido no item 4.8.4 do capítulo 4. Um exemplo da utilização deste método poderá ser encontrado posteriormente no item 5.3.5, que tratará do dimensionamento à flexão composta das paredes estruturais. 
TABELA 5.9 - Armaduras verticais das paredes tracionadas

\begin{tabular}{|c|c|c|c|}
\hline Parede & Nível & $\begin{array}{c}\text { G-W } \\
\left(\mathrm{kN} / \mathrm{m}^{2}\right)\end{array}$ & $\begin{array}{c}\text { Armadura } \\
\text { vertical }\end{array}$ \\
\hline \multirow{3}{*}{ PY1 e PY18 } & 3 & 138 & $3 \phi 12,5$ \\
\cline { 2 - 4 } & 2 & 223 & $7 \phi 10,0$ \\
\hline PY6 e PY15 & 2 & 136 & $3 \phi 10,0$ \\
\cline { 2 - 4 } & 1 & 218 & $5 \phi 10,0$ \\
\hline \multirow{3}{*}{ PY7 e PY14 } & 3 & 123 & $3 \phi 10,0$ \\
\cline { 2 - 4 } & 1 & 214 & $3 \phi 10,0$ \\
\hline \multirow{3}{*}{ PY11 } & 3 & 131 & $3 \phi 12,5$ \\
\cline { 2 - 4 } & 2 & 209 & $5 \phi 10,0$ \\
\cline { 2 - 4 } & 1 & 297 & $7 \phi 10,0$ \\
\hline
\end{tabular}

Além do graute necessário para acomodar estas armaduras de tração, observa-se que, em algumas paredes, foi necessário grautear para aumentar a resistência à compressão da alvenaria. Isto é representado pelas letras G1 e G2 na última coluna ( $\mathrm{Gr}$ ) das tabelas do item 1 do Anexo C.

Conforme o estudo feito no item 5.2.4, pode-se chegar a alternativas de grauteamento mais viáveis economicamente, cujos resultados encontram-se na Tabela 5.10.

TABELA 5.10 - Resultado de grauteamento econômico

\begin{tabular}{|c|c|c|c|c|}
\hline Parede & Nível & Grauteamento & $\mathrm{f}_{\mathrm{bk}}{ }^{\prime}\left(\mathrm{kN} / \mathrm{m}^{2}\right)$ & $\mathrm{f}_{\mathrm{bk}}\left(\mathrm{kN} / \mathrm{m}^{2}\right)$ \\
\hline \multirow{3}{*}{ PX10 e PX11 } & 5 & $1 \mathrm{c} / 4$ & 3663. & 4500. \\
\cline { 2 - 5 } & 4 & $1 \mathrm{c} / 3$ & 4465. & 4500. \\
\cline { 2 - 5 } & 3 & $1 \mathrm{c} / 4$ & 5894. & 6000. \\
\cline { 2 - 5 } & 2 & $1 \mathrm{c} / 2^{(*)}$ & 5841. & 6000. \\
\hline
\end{tabular}




\begin{tabular}{|c|c|c|c|c|}
\hline \multirow{5}{*}{ PX14 e PX17 } & 5 & $1 \mathrm{c} / 4$ & 4262. & 4500. \\
\hline & 4 & todos os furos $^{(*)}$ & 3718. & 4500. \\
\hline & 3 & $1 \mathrm{c} / 2^{(*)}$ & 4595. & 6000. \\
\hline & 2 & todos os furos ${ }^{(*)}$ & 5472. & 6000. \\
\hline & 1 & $1 \mathrm{c} / 2^{(*)}$ & 7936. & 8000. \\
\hline \multirow[t]{2}{*}{ PX20 e PX23 } & 4 & $1 \mathrm{c} / 4$ & 3608. & 4500. \\
\hline & 2 & $1 \mathrm{c} / 4$ & 5207. & 6000. \\
\hline \multirow{5}{*}{ PY8 e PY12 } & 5 & $1 \mathrm{c} / 4$ & 4001. & 4500. \\
\hline & 4 & $1 \mathrm{c} / 3$ & 4250. & 4500. \\
\hline & 3 & $1 \mathrm{c} / 4$ & 5261. & 6000. \\
\hline & 2 & $1 \mathrm{c} / 3$ & 5719. & 6000. \\
\hline & 1 & $1 \mathrm{c} / 4$ & 7020. & 8000. \\
\hline \multirow{6}{*}{ PY9 } & 6 & $1 \mathrm{c} / 4$ & 3628. & 4500. \\
\hline & 5 & $1 \mathrm{c} / 4$ & 4166. & 4500. \\
\hline & 4 & $1 \mathrm{c} / 3$ & 4397. & 4500. \\
\hline & 3 & $1 \mathrm{c} / 4$ & 5244. & 6000. \\
\hline & 2 & $1 \mathrm{c} / 3$ & 5659. & 6000. \\
\hline & 1 & $1 \mathrm{c} / 4$ & 6905. & 8000. \\
\hline \multirow{6}{*}{ PY9 } & 6 & $1 \mathrm{c} / 4$ & 3628. & 4500. \\
\hline & 5 & $1 \mathrm{c} / 4$ & 4166. & 4500. \\
\hline & 4 & $1 \mathrm{c} / 3$ & 4397. & 4500. \\
\hline & 3 & $1 \mathrm{c} / 4$ & 5243. & 6000. \\
\hline & 2 & $1 \mathrm{c} / 4$ & 5870. & 6000. \\
\hline & 1 & $1 \mathrm{c} / 4$ & 6673. & 8000 \\
\hline
\end{tabular}

Notas: a) $f_{b k}{ }^{\prime}=f_{b k}(c /$ graute $)$

b) ${ }^{(*)}$ permaneceu igual ao da tabela do Anexo $\mathrm{C}$

Calculando o volume de graute necessário para esta situação, tem-se:

- graute para cintas, vergas e contravergas:

$$
\mathrm{V}_{1}=2,157 \mathrm{~m}^{3} / \text { pav. } \quad \text { (item } 5.2 .4 \text { ) }
$$


- graute para acomodar as armaduras de flexão:

$$
\begin{gathered}
\begin{array}{c}
1^{\circ} \text { pav. } V=1 / 4 \times 0,29 \times 0,14 \times 2,72 \times 37=1,021 \mathrm{~m}^{3} \\
\text { furos }
\end{array} \\
\begin{array}{c}
2^{\circ} \text { pav.: } V=1 / 4 \times 0,29 \times 0,14 \times 2,72 \times \underset{\text { furos }}{31}=0,856 \mathrm{~m}^{3} \\
3^{\circ} \text { pav.: } V=1 / 4 \times 0,29 \times 0,14 \times 2,72 \times 15=0,414 \mathrm{~m}^{3} \\
\text { furos } \\
\therefore V_{2}=2,291 \mathrm{~m}^{3}
\end{array}
\end{gathered}
$$

- graute para aumentar a resistência das paredes:

$$
\begin{aligned}
& 1^{\circ}, 3^{\circ}, 5^{\circ} \text { pav.: } V=2(0,055)+2(0,055)+2(0,166)+0,138+0,138= \\
& \begin{array}{lllll}
\text { PX1 } & \text { PX1 } & \text { PY } & \text { PY } & \text { PY13 }
\end{array} \\
& =0,828 \mathrm{~m}^{3} \\
& 2^{\circ} \text { pav.: } \mathrm{V}=2(0,055)+2(0,083)+2(0,055)+2(0,221)+0,166+0,138= \\
& \begin{array}{lllll}
\text { PX1 PX1 } & \text { PX2 } & \text { PY } & \text { PY } & \text { PY13 }
\end{array} \\
& =1,132 \mathrm{~m}^{3} \\
& 4^{\circ} \text { pav.: } V=2(0,055)+2(0,083)+2(0,055)+2(0,221)+0,166+0,166= \\
& \begin{array}{llllll}
P X 1 & P X 1 & P X 2 & P Y & P Y & P Y 13
\end{array} \\
& =1,160 \mathrm{~m}^{3} \\
& 6^{\circ} \text { pav.: } \mathrm{V}=0,138+0,138=0,276 \mathrm{~m}^{3} \\
& \text { PY9 PY13 } \\
& \therefore \mathrm{V}_{3}=5,052 \mathrm{~m}^{3} \\
& \mathrm{~V}_{\text {graute }}=8 \mathrm{~V}_{1}+\mathrm{V}_{2}+\mathrm{V}_{3}=24,599 \mathrm{~m}^{3}
\end{aligned}
$$


O volume de concreto das lajes também pode ser calculado por:

$$
\mathrm{V}_{\text {concreto }}=8 \times 16,04 \times 7,04 \times 0,08=72,270 \mathrm{~m}^{3}
$$

Portanto, fazendo a comparação entre os dois volumes, verifica-se que o volume de graute necessário, para esta situação, é $34,0 \%$ do volume de concreto das lajes.

A seguir, encontra-se a composição de custos para esta situação.

\begin{tabular}{|c|c|c|c|c|c|}
\hline \multicolumn{6}{|c|}{ Paredes Isoladas - Situação A } \\
\hline \multirow{2}{*}{\multicolumn{2}{|c|}{ graute }} & unidade & quantidade & $\mathrm{R} \$ /$ un & $\mathrm{R} \$$ \\
\hline & & $\mathrm{m}^{3}$ & 24,599 & 96,79 & $2.380,94$ \\
\hline bloco & 4,5 MPa & un & $5 \times 3470$ & 0,761 & $13.203,35$ \\
\hline 1/2 bloco & 4,5 MPa & un & $5 \times 481$ & 0,445 & $1.070,23$ \\
\hline canaleta & $4,5 \mathrm{MPa}$ & un & $5 \times 311$ & 0,771 & $1.198,91$ \\
\hline bloco & $6,0 \mathrm{MPa}$ & un & $2 \times 3470$ & 0,804 & $5.579,76$ \\
\hline 1/2 bloco & $6,0 \mathrm{MPa}$ & un & $2 \times 481$ & 0,457 & 439,63 \\
\hline canaleta & $6,0 \mathrm{MPa}$ & un & $2 \times 311$ & 0,815 & 506,93 \\
\hline bloco & $8,0 \mathrm{MPa}$ & un & 3470 & 0,884 & $3.067,48$ \\
\hline 1/2 bloco & $8,0 \mathrm{MPa}$ & un & 481 & 0,503 & 241,94 \\
\hline \multirow{2}{*}{\multicolumn{2}{|c|}{ canaleta $8,0 \mathrm{MPa}$}} & un & 311 & 0,896 & 278,66 \\
\hline & & & & & $27.967,83$ \\
\hline
\end{tabular}

\section{Situação B}

Os resultados mais significativos encontram-se no item 2 do Anexo C. Observa-se que os trechos de paredes tracionados, inclusive o valor destas trações, são os mesmos da situação anterior. Portanto, o volume de graute para acomodar as armaduras de flexão é o mesmo. 
Resta, então, calcular o volume de graute para aumentar a resistência à compressão da alvenaria, representado pelas letras G1 e G2 na última coluna ( $\mathrm{Gr}$ ) das tabelas do item 2 do Anexo C.

A partir do estudo de alternativas mais viáveis economicamente, em termos de grauteamento, chegou-se aos resultados apresentados na Tabela 5.11.

TABELA 5.11 - Resultado de grauteamento econômico

\begin{tabular}{|c|c|c|c|c|}
\hline Parede & Nível & Grauteamento & $f_{b k}{ }^{\prime}\left(k N / m^{2}\right)$ & $\mathrm{f}_{\mathrm{bk}}\left(\mathrm{kN} / \mathrm{m}^{2}\right)$ \\
\hline \multirow{4}{*}{ PX10 e PX11 } & 5 & $1 \mathrm{c} / 4$ & 3663. & 4500. \\
\hline & 3 & $1 \mathrm{c} / 4$ & 5894. & 6000. \\
\hline & 2 & $1 \mathrm{c} / 4$ & 7009. & 8000. \\
\hline & 1 & $1 \mathrm{c} / 3$ & 7593. & 8000. \\
\hline \multirow{5}{*}{ PX14 e PX17 } & 5 & $1 \mathrm{c} / 4$ & 4262. & 4500. \\
\hline & 4 & $1 \mathrm{c} / 4$ & 5578. & 6000. \\
\hline & 3 & $1 \mathrm{c} / 2^{(*)}$ & 5744. & 6000. \\
\hline & 2 & $1 \mathrm{c} / 3$ & 7671. & 8000. \\
\hline & 1 & $1 \mathrm{c} / 2^{(*)}$ & 7936. & 8000. \\
\hline \multirow{3}{*}{ PY8 e PY12 } & 5 & $1 \mathrm{c} / 4$ & 4001. & 4500. \\
\hline & 3 & $1 \mathrm{c} / 4$ & 5261. & 6000. \\
\hline & 1 & $1 \mathrm{c} / 4$ & 7020. & 8000. \\
\hline \multirow{4}{*}{ PY9 } & 6 & $1 \mathrm{c} / 4$ & 3628. & 4500. \\
\hline & 5 & $1 \mathrm{c} / 4$ & 4166. & 4500. \\
\hline & 3 & $1 \mathrm{c} / 4$ & 5244. & 6000. \\
\hline & 1 & $1 \mathrm{c} / 4$ & 6905. & 8000. \\
\hline \multirow{4}{*}{ PY13 } & 6 & $1 \mathrm{c} / 4$ & 3628. & 4500. \\
\hline & 5 & $1 \mathrm{c} / 4$ & 4166. & 4500. \\
\hline & 3 & $1 \mathrm{c} / 4$ & 5243. & 6000. \\
\hline & 1 & $1 \mathrm{c} / 4$ & 6673. & 8000. \\
\hline
\end{tabular}

Notas: a) $f_{b k}{ }^{\prime}=f_{b k}(c /$ graute $)$

b) ${ }^{(*)}$ permaneceu igual ao da tabela do Anexo $\mathrm{C}$ 
Calculando o volume de graute necessário para esta situação, tem-se:

- graute para cintas, vergas e contravergas:

$$
\left.\mathrm{V}_{1}=2,157 \mathrm{~m}^{3} / \text { pav. } \quad \text { (item } 5.2 .4\right)
$$

- graute para acomodar as armaduras de flexão:

$$
\mathrm{V}_{2}=2,291 \mathrm{~m}^{3} \quad \text { (Situação } \mathrm{A} \text { ) }
$$

- graute para aumentar a resistência das paredes:

$$
\begin{aligned}
& 1^{\circ}, 3^{\circ}, 5^{\circ} \text { pav } .: V=2(0,055)+2(0,055)+2(0,166)+0,138+0,138= \\
& \begin{array}{lllll}
\text { PX1 } & \text { PX1 } & \text { PY } & \text { PY } & \text { PY13 }
\end{array} \\
& =0,828 \mathrm{~m}^{3} \\
& 2^{\circ} \text { pav.: } V=2(0,055)+2(0,055)=0,220 \mathrm{~m}^{3} \\
& \text { PX1 PX1 } \\
& 4^{\circ} \text { pav.: } V=2(0,055)=0,110 \mathrm{~m}^{3} \\
& \text { PX1 } \\
& 6^{\circ} \text { pav.: } V=0,138+0,138=0,276 \mathrm{~m}^{3} \\
& \text { PY9 PY13 } \\
& \therefore \mathrm{V}_{3}=3,090 \mathrm{~m}^{3} \\
& \mathrm{~V}_{\text {graute }}=8 \mathrm{~V}_{1}+\mathrm{V}_{2}+\mathrm{V}_{3}=22,637 \mathrm{~m}^{3}
\end{aligned}
$$

Fazendo a comparação entre o volume de graute e o de concreto das lajes, verifica-se que o volume de graute necessário, para esta situação, é $31,3 \%$ do volume de concreto. 
A seguir, encontra-se a composição de custos para esta situação.

\begin{tabular}{|c|c|c|c|c|c|}
\hline \multicolumn{6}{|c|}{ Paredes isoladas - Situação B } \\
\hline \multirow{2}{*}{\multicolumn{2}{|c|}{ graute }} & unidade & quantidade & $\mathrm{R} \$ /$ un & $\mathrm{R} \$$ \\
\hline & & $\mathrm{m}^{3}$ & 22,637 & 96,79 & $2.191,04$ \\
\hline bloco & 4,5 MPa & un & $4 \times 3470$ & 0,761 & $10.562,68$ \\
\hline $1 / 2$ bloco & 4,5 MPa & un & $4 \times 481$ & 0,445 & 856,18 \\
\hline canaleta & $4,5 \mathrm{MPa}$ & un & $4 \times 311$ & 0,771 & 959,12 \\
\hline bloco & $6,0 \mathrm{MPa}$ & un & $2 \times 3470$ & 0,804 & $5.579,76$ \\
\hline $1 / 2$ bloco & $6,0 \mathrm{MPa}$ & un & $2 \times 481$ & 0,457 & 439,63 \\
\hline canaleta & $6,0 \mathrm{MPa}$ & un & $2 \times 311$ & 0,815 & 506,93 \\
\hline bloco & $8,0 \mathrm{MPa}$ & un & $2 \times 3470$ & 0,884 & $6.134,96$ \\
\hline $1 / 2$ bloco & $8,0 \mathrm{MPa}$ & un & $2 \times 481$ & 0,503 & 483,89 \\
\hline \multirow{2}{*}{\multicolumn{2}{|c|}{ canaleta $8,0 \mathrm{MPa}$}} & un & $2 \times 311$ & 0,896 & 557,31 \\
\hline & & & & & $28.271,50$ \\
\hline
\end{tabular}

Posteriormente, o exemplo foi processado considerando, para a distribuição das ações verticais, o procedimento de grupos isolados de paredes, a fim de fazer uma comparação com o anterior. A definição dos grupos está representada na Figura 5.5. Assim sendo, foram analisadas as seguintes situações:

C - Todos os pavimentos com blocos de resistência característica 4,5 MPa, por ser a situação mais econômica em termos de custo de bloco.

D - $1^{\circ}$ e $2^{\circ}$ pavimentos com blocos de resistência característica 6,0 MPa e os demais com blocos de 4,5 MPa, já que os resultados da Situação $\mathrm{A}$ indicaram a necessidade de grauteamento de todos os furos de algumas paredes, conforme será visto posteriormente. 


\section{Situação C}

Os resultados mais significativos fornecidos pelo programa encontram-se no item 3 do Anexo C. Como no caso de paredes isoladas, deve-se verificar, nas paredes tracionadas, em quais delas a tensão de tração supera a tensão admissível. O procedimento é análogo ao da Situação A, e o resultado do cálculo das armaduras de flexão para estas paredes encontra-se na Tabela 5.12.

TABELA 5.12 - Armaduras verticais das paredes tracionadas

\begin{tabular}{|c|c|c|c|}
\hline Parede & Nível & $\begin{array}{c}\text { G-W } \\
\left(\mathrm{kN} / \mathrm{m}^{2}\right)\end{array}$ & $\begin{array}{c}\text { Armadura } \\
\text { vertical }\end{array}$ \\
\hline PY1 e PY18 & 2 & 171 & $3 \phi 12,5$ \\
\cline { 2 - 4 } & 1 & 261 & $7 \phi 10,0$ \\
\hline PY7 e PY14 & 2 & 177 & $3 \phi 10,0$ \\
\cline { 2 - 4 } & 1 & 279 & $3 \phi 12,5$ \\
\hline PY8 e PY12 & 1 & 203 & $7 \phi 10,0$ \\
\hline PY9 & 2 & 122 & $4 \phi 10,0$ \\
\cline { 2 - 4 } & 1 & 247 & $8 \phi 10,0$ \\
\hline
\end{tabular}

Além do graute necessário para acomodar estas armaduras de tração, observa-se que, em algumas paredes, foi necessário grautear para aumentar a resistência à compressão da alvenaria. Isto é representado pelas letras G1 e G2 na última coluna ( $\mathrm{Gr}$ ) das tabelas do item 3 do Anexo C.

A partir do estudo de alternativas mais viáveis economicamente, em termos de grauteamento, chegou-se aos resultados apresentados na Tabela 5.13. 
TABELA 5.13 - Resultado de grauteamento econômico

\begin{tabular}{|c|c|c|c|c|}
\hline Parede & Nível & Grauteamento & $\mathrm{f}_{\mathrm{bk}}{ }^{\prime}\left(\mathrm{kN} / \mathrm{m}^{2}\right)$ & $\mathrm{f}_{\mathrm{bk}}\left(\mathrm{kN} / \mathrm{m}^{2}\right)$ \\
\hline PX1 e PX6 & 1 & $1 \mathrm{c} / 4$ & 3618. & 4500. \\
\hline \multirow[t]{2}{*}{ PX2 e PX5 } & 2 & $1 \mathrm{c} / 4$ & 3657. & 4500. \\
\hline & 1 & $1 \mathrm{c} / 4$ & 4224. & 4500. \\
\hline \multirow[t]{2}{*}{ PX3 } & 2 & $1 \mathrm{c} / 4$ & 4161. & 4500. \\
\hline & 1 & $1 \mathrm{c} / 3$ & 4451. & 4500. \\
\hline \multirow{5}{*}{ PX4 } & 5 & $1 \mathrm{c} / 4$ & 3823. & 4500. \\
\hline & 4 & $1 \mathrm{c} / 4$ & 4370. & 4500. \\
\hline & 3 & $1 \mathrm{c} / 2^{(\star)}$ & 4098. & 4500. \\
\hline & 2 & todos os furos $^{(*)}$ & 3643. & 4500. \\
\hline & 1 & todos os furos ${ }^{(*)}$ & 4007. & 4500. \\
\hline \multirow[t]{2}{*}{ PX10 e PX11 } & 2 & $1 \mathrm{c} / 4$ & 3657. & 4500. \\
\hline & 1 & $1 \mathrm{c} / 4$ & 4224. & 4500. \\
\hline PX13 e PX18 & 1 & $1 \mathrm{c} / 4$ & 3993. & 4500. \\
\hline \multirow[t]{2}{*}{ PX14 e PX17 } & 2 & $1 \mathrm{c} / 4$ & 4015. & 4500. \\
\hline & 1 & $1 \mathrm{c} / 3$ & 4337. & 4500. \\
\hline \multirow{3}{*}{ PX15 e PX16 } & 3 & $1 \mathrm{c} / 4$ & 4095. & 4500. \\
\hline & 2 & $1 \mathrm{c} / 4$ & 4374. & 4500. \\
\hline & 1 & $1 \mathrm{c} / 2^{(\star)}$ & 4494. & 4500. \\
\hline PX19 e PX24 & 1 & $1 \mathrm{c} / 4$ & 3690. & 4500. \\
\hline \multirow[t]{2}{*}{ PX20 e PX23 } & 2 & $1 \mathrm{c} / 4$ & 4015. & 4500. \\
\hline & 1 & $1 \mathrm{c} / 3$ & 4337. & 4500. \\
\hline \multirow{3}{*}{ PX21 e PX22 } & 3 & $1 \mathrm{c} / 4$ & 4095. & 4500. \\
\hline & 2 & $1 \mathrm{c} / 3$ & 4323. & 4500. \\
\hline & 1 & $1 \mathrm{c} / 2^{(*)}$ & 4395. & 4500. \\
\hline \multirow[t]{2}{*}{ PY1 e PY18 } & 2 & $1 \mathrm{c} / 4$ & 3684. & 4500. \\
\hline & 1 & $1 \mathrm{c} / 4$ & 4407. & 4500. \\
\hline PY2 e PY19 & 1 & $1 \mathrm{c} / 4$ & 3646. & 4500. \\
\hline PY4 e PY16 & 1 & $1 \mathrm{c} / 4$ & 3717. & 4500. \\
\hline
\end{tabular}




\begin{tabular}{|c|c|c|c|c|}
\hline \multirow{3}{*}{ PY6 e PY15 } & 3 & $1 \mathrm{c} / 4$ & 3649. & 4500. \\
\hline & 2 & $1 \mathrm{c} / 4$ & 4462. & 4500. \\
\hline & 1 & $1 \mathrm{c} / 2^{(*)}$ & 4423. & 4500. \\
\hline \multirow{3}{*}{ PY7 e PY14 } & 3 & $1 \mathrm{c} / 4$ & 3667. & 4500. \\
\hline & 2 & $1 \mathrm{c} / 3$ & 4217. & 4500. \\
\hline & 1 & $1 \mathrm{c} / 2^{(\star)}$ & 4498. & 4500. \\
\hline \multirow{4}{*}{ PY8 e PY12 } & 4 & $1 \mathrm{c} / 4$ & 3717. & 4500. \\
\hline & 3 & $1 \mathrm{c} / 3$ & 4216. & 4500. \\
\hline & 2 & $1 \mathrm{c} / 2^{(*)}$ & 4465. & 4500. \\
\hline & 1 & todos os furos ${ }^{(*)}$ & 4165. & 4500. \\
\hline \multirow{3}{*}{ PY9 } & 3 & $1 \mathrm{c} / 4$ & 3953. & 4500. \\
\hline & 2 & $1 \mathrm{c} / 3$ & 4336. & 4500. \\
\hline & 1 & $1 \mathrm{c} / 2^{(*)}$ & 4471. & 4500. \\
\hline \multirow[t]{2}{*}{ PY10 } & 2 & $1 \mathrm{c} / 4$ & 4005. & 4500. \\
\hline & 1 & $1 \mathrm{c} / 3$ & 4236. & 4500. \\
\hline \multirow[t]{2}{*}{ PY11 } & 2 & $1 \mathrm{c} / 4$ & 4088. & 4500. \\
\hline & 1 & $1 \mathrm{c} / 3$ & 4365. & 4500. \\
\hline \multirow{5}{*}{ PY13 } & 5 & $1 \mathrm{c} / 4$ & 3823. & 4500. \\
\hline & 4 & $1 \mathrm{c} / 4$ & 4370. & 4500. \\
\hline & 3 & $1 \mathrm{c} / 2^{(\star)}$ & 4098. & 4500. \\
\hline & 2 & todos os furos ${ }^{(*)}$ & 3755. & 4500. \\
\hline & 1 & todos os furos ${ }^{(*)}$ & 4294. & 4500. \\
\hline
\end{tabular}

Notas: a) $f_{b k}{ }^{\prime}=f_{b k}(c /$ graute $)$

b) ${ }^{(*)}$ permaneceu igual ao da tabela do Anexo $\mathrm{C}$

Calculando o volume de graute necessário para esta situação, tem-se:

- graute para cintas, vergas e contravergas:

$$
\mathrm{V}_{1}=2,157 \mathrm{~m}^{3} / \text { pav. } \quad \text { (item } 5.2 .4 \text { ) }
$$


- graute para acomodar as armaduras de flexão:

$$
\begin{gathered}
1^{\circ} \text { pav.: } V=1 / 4 \times 0,29 \times 0,14 \times 2,72 \times 42=1,160 \mathrm{~m}^{3} \\
2^{\circ} \text { pav.: } V=1 / 4 \times 0,29 \times 0,14 \times 2,72 \times \begin{array}{c}
\text { furos } \\
\text { furos }
\end{array}=0,442 \mathrm{~m}^{3} \\
\therefore V_{2}=1,602 \mathrm{~m}^{3}
\end{gathered}
$$

- graute para aumentar a resistência das paredes:

$$
\begin{aligned}
& 1^{\circ} \text { pav } .: V=2(0,055)+2(0,083)+0,193+0,166+2(0,055)+2(0,110)+ \\
& \begin{array}{llllll}
P X & P X & P X & P X & P X 1 & P X 1
\end{array} \\
& +2(0,055)+2(0,221)+2(0,083)+2(0,055)+2(0,248)+2(0,166) \\
& \begin{array}{llllll}
\text { PX1 } & P X 1 & P X 1 & P X 2 & P X 2 & P Y
\end{array} \\
& +2(0,083)+2(0,083)+2(0,276)+2(0,304)+2(0,635)+0,248+ \\
& \text { PY PY PY PY PY PY } \\
& +0,138+0,138+0,497=6,680 \mathrm{~m}^{3} \\
& \text { PY10 PY11 PY13 }
\end{aligned}
$$

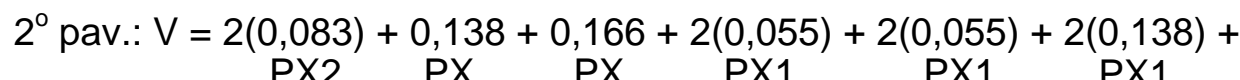

$$
\begin{aligned}
& +2(0,055)+2(0,166)+2(0,138)+2(0,138)+2(0,193)+ \\
& \begin{array}{llll}
P X 2 & P X 2 & P Y & P Y
\end{array} \\
& \begin{array}{c}
2(0,331)+\underset{P Y}{0,166}+\underset{\text { PY }}{0,110}+\underset{\text { PY } 10 \text { PY } 11}{0,110}+\underset{\text { PY } 13}{0,497}=3,891 \mathrm{~m}^{3} \\
\text { PY }
\end{array}
\end{aligned}
$$

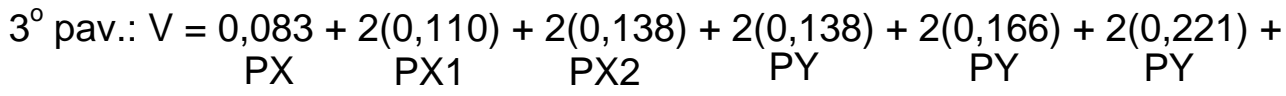

$$
\begin{aligned}
& +0,138+0,248=2,015 m^{3} \\
& \text { PY PY13 } \\
& 4^{\circ} \text { pav.: } \mathrm{V}=0,055+2(0,166)+0,138=0,525 \mathrm{~m}^{3} \\
& P X \quad P Y \quad P Y 13
\end{aligned}
$$




$$
\begin{gathered}
5^{\circ} \text { pav.: } V=0,055+0,138=0,193 \mathrm{~m}^{3} \\
\text { PX PY13 } \\
\therefore \mathrm{V}_{3}=13,304 \mathrm{~m}^{3} \\
\mathrm{~V}_{\text {graute }}=8 \mathrm{~V}_{1}+\mathrm{V}_{2}+\mathrm{V}_{3}=32,162 \mathrm{~m}^{3}
\end{gathered}
$$

Fazendo a comparação entre o volume de graute e o de concreto das lajes,

\begin{tabular}{|c|c|c|c|c|}
\hline \multicolumn{5}{|c|}{ Grupos isolados de paredes - Situação C } \\
\hline & unidade & quantidade & $\mathrm{R} \$ /$ un & $\mathrm{R} \$$ \\
\hline graute & $\mathrm{m}^{3}$ & 32,162 & 96,79 & $3.112,96$ \\
\hline $4,5 \mathrm{MPa}$ & un & $8 \times 3470$ & 0,761 & $21.125,36$ \\
\hline $1 / 2$ bloco $4,5 \mathrm{MPa}$ & un & $8 \times 481$ & 0,445 & $1.712,36$ \\
\hline \multirow[t]{2}{*}{ canaleta 4,5 MPa } & un & $8 \times 311$ & 0,771 & $1.918,25$ \\
\hline & & & & $27.868,93$ \\
\hline
\end{tabular}
verifica-se que o volume de graute necessário, para esta situação, é $48,1 \%$ do volume de concreto.

A seguir, encontra-se a composição de custos para esta situação.

\section{Situação D}

Os resultados mais significativos encontram-se no item 4 do Anexo C. Observa-se que os trechos de paredes tracionados são os mesmos da situação anterior, inclusive o valor destas trações. Portanto, o volume de graute para acomodar as armaduras de flexão é o mesmo.

Resta, então, calcular o volume de graute para aumentar a resistência das paredes, representado pelas letras $\mathrm{G} 1$ e $\mathrm{G} 2$ na última coluna ( $\mathrm{Gr}$ ) das tabelas do item 4 do Anexo C.

A partir do estudo de alternativas mais viáveis economicamente, em termos de grauteamento, chegou-se aos resultados apresentados na Tabela 5.14. 
TABELA 5.14 - Resultado de grauteamento econômico

\begin{tabular}{|c|c|c|c|c|}
\hline Parede & Nível & Grauteamento & $\mathrm{f}_{\mathrm{bk}}{ }^{\prime}\left(\mathrm{kN} / \mathrm{m}^{2}\right)$ & $\mathrm{f}_{\mathrm{bk}}\left(\mathrm{kN} / \mathrm{m}^{2}\right)$ \\
\hline \multirow{5}{*}{ PX4 } & 5 & $1 \mathrm{c} / 4$ & 3823. & 4500. \\
\hline & 4 & $1 \mathrm{c} / 4$ & 4370. & 4500. \\
\hline & 3 & $1 \mathrm{c} / 2^{(\star)}$ & 4098. & 4500. \\
\hline & 2 & $1 \mathrm{c} / 4$ & 5464. & 6000. \\
\hline & 1 & $1 \mathrm{c} / 3$ & 5618. & 6000. \\
\hline \multirow[t]{2}{*}{ PX15 e PX16 } & 3 & $1 \mathrm{c} / 4$ & 4095. & 4500. \\
\hline & 1 & $1 \mathrm{c} / 4$ & 5393. & 6000. \\
\hline \multirow[t]{2}{*}{ PX21 e PX22 } & 3 & $1 \mathrm{c} / 4$ & 4095. & 4500. \\
\hline & 1 & $1 \mathrm{c} / 4$ & 5273. & 6000. \\
\hline \multirow[t]{2}{*}{ PY6 e PY15 } & 3 & $1 \mathrm{c} / 4$ & 3649. & 4500. \\
\hline & 1 & $1 \mathrm{c} / 4$ & 5308. & 6000. \\
\hline \multirow[t]{2}{*}{ PY7 e PY14 } & 3 & $1 \mathrm{c} / 4$ & 3667. & 4500. \\
\hline & 1 & $1 \mathrm{c} / 4$ & 5397. & 6000. \\
\hline \multirow{4}{*}{ PY8 e PY12 } & 4 & $1 \mathrm{c} / 4$ & 3717. & 4500. \\
\hline & 3 & $1 \mathrm{c} / 3$ & 4216. & 4500. \\
\hline & 2 & $1 \mathrm{c} / 4$ & 5348. & 6000. \\
\hline & 1 & $1 \mathrm{c} / 3$ & 5839. & 6000. \\
\hline \multirow[t]{2}{*}{ PY9 } & 3 & $1 \mathrm{c} / 4$ & 3953. & 4500. \\
\hline & 1 & $1 \mathrm{c} / 4$ & 5365. & 6000. \\
\hline \multirow{5}{*}{ PY13 } & 5 & $1 \mathrm{c} / 4$ & 3823. & 4500. \\
\hline & 4 & $1 \mathrm{c} / 4$ & 4370. & 4500. \\
\hline & 3 & $1 \mathrm{c} / 2^{(\star)}$ & 4098. & 4500. \\
\hline & 2 & $1 \mathrm{c} / 4$ & 5632. & 6000. \\
\hline & 1 & $1 \mathrm{c} / 2^{(*)}$ & 5368. & 6000. \\
\hline
\end{tabular}

Notas: a) $f_{b k}{ }^{\prime}=f_{b k}(c /$ graute $)$

b) ${ }^{(*)}$ permaneceu igual ao da tabela do Anexo $\mathrm{C}$ 
Calculando o volume de graute necessário para esta situação, tem-se:

- graute para cintas, vergas e contravergas:

$$
\mathrm{V}_{1}=2,157 \mathrm{~m}^{3} / \text { pav. } \quad \text { (item } 5.2 .4 \text { ) }
$$

- graute para acomodar as armaduras de flexão:

$$
\mathrm{V}_{2}=1,602 \mathrm{~m}^{3} \quad \text { (Situação } \mathrm{C} \text { ) }
$$

- graute para aumentar a resistência das paredes:

$$
\begin{aligned}
& 1^{\circ} \text { pav.: } \mathrm{V}=0,055+2(0,110)+2(0,138)+2(0,138)+2(0,166)+2(0,221)+
\end{aligned}
$$

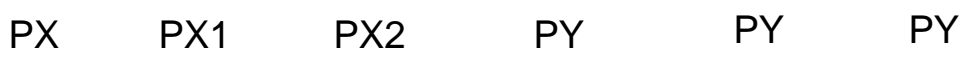

$$
\begin{aligned}
& +0,138+0,248=1,987 \mathrm{~m}^{3} \\
& \text { PY9 PY13 } \\
& 2^{\circ} \text { e } 4^{\circ} \text { pav.: } V=0,055+2(0,166)+0,138=0,525 \mathrm{~m}^{3} \\
& \text { PX PY8 PY13 }
\end{aligned}
$$

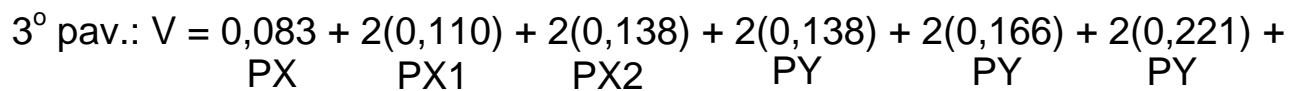

$$
\begin{aligned}
& +0,138+0,248=2,015 m^{3} \\
& \text { PY PY13 } \\
& 5^{\circ} \text { pav.: } \mathrm{V}=0,055+0,138=0,193 \mathrm{~m}^{3} \\
& \mathrm{PX} \quad \mathrm{PY} 13 \\
& \therefore \mathrm{V}_{3}=5,245 \mathrm{~m}^{3} \\
& \mathrm{~V}_{\text {graute }}=8 \mathrm{~V}_{1}+\mathrm{V}_{2}+\mathrm{V}_{3}=24,103 \mathrm{~m}^{3}
\end{aligned}
$$

Fazendo a comparação entre o volume de graute e o volume de concreto das lajes, verifica-se que o volume de graute necessário, para esta situação, é $33,3 \%$ do volume de concreto. 
A seguir, encontra-se a composição de custos para esta situação.

\begin{tabular}{|c|c|c|c|c|}
\hline \multicolumn{5}{|c|}{ Grupos isolados de paredes - Situação D } \\
\hline & unidade & quantidade & $\mathrm{R} \$ /$ un & $\mathrm{R} \$$ \\
\hline graute & $\mathrm{m}^{3}$ & 24,103 & 96,79 & $2.332,93$ \\
\hline bloco $\quad 4,5 \mathrm{MPa}$ & un & $6 \times 3470$ & 0,761 & $15.844,02$ \\
\hline $1 / 2$ bloco $4,5 \mathrm{MPa}$ & un & $6 \times 481$ & 0,445 & $1.284,27$ \\
\hline canaleta $4,5 \mathrm{MPa}$ & un & $6 \times 311$ & 0,771 & $1.438,69$ \\
\hline bloco $\quad 6,0 \mathrm{MPa}$ & un & $2 \times 3470$ & 0,804 & $5.579,76$ \\
\hline $1 / 2$ bloco $6,0 \mathrm{MPa}$ & un & $2 \times 481$ & 0,457 & 439,63 \\
\hline \multirow[t]{2}{*}{ canaleta $6,0 \mathrm{MPa}$} & un & $2 \times 311$ & 0,815 & 506,93 \\
\hline & & & & $27.426,23$ \\
\hline
\end{tabular}

\section{Conclusão:}

\begin{tabular}{|c|c|c|c|c|c|}
\hline Procedimento & & $\overline{\mathrm{APa})}$ & Graute $\left(\mathrm{m}^{3}\right)$ & Custo Total & Comparação \\
\hline \multirow{8}{*}{$\begin{array}{l}\text { paredes } \\
\text { isoladas }\end{array}$} & 8,0 & 4,5 & \multirow{4}{*}{24,599} & \multirow{4}{*}{$\mathrm{R} \$ 27.967,83$} & $\left(3^{\circ}\right)$ \\
\hline & 6,0 & 4,5 & & & $1,97 \% \uparrow 1^{\circ}$ \\
\hline & 6,0 & 4,5 & & & \\
\hline & 4,5 & 4,5 & & & \\
\hline & 8,0 & 4,5 & \multirow{4}{*}{22,637} & \multirow{4}{*}{$\mathrm{R} \$ 28.271,50$} & $\left(4^{\circ}\right)$ \\
\hline & 8,0 & 4,5 & & & $3,08 \% \uparrow 1^{\circ}$ \\
\hline & 6,0 & 4,5 & & & \\
\hline & 6,0 & 4,5 & & & ${ }^{(\star)}$ pior situação \\
\hline \multirow{8}{*}{$\begin{array}{c}\text { grupos } \\
\text { sem } \\
\text { interação } \\
\text { de paredes }\end{array}$} & 4,5 & 4,5 & \multirow{4}{*}{32,162} & \multirow{4}{*}{$\mathrm{R} \$ 27.868,93$} & $\left(2^{\circ}\right)$ \\
\hline & 4,5 & 4,5 & & & $1,61 \% \uparrow 1^{\circ}$ \\
\hline & 4,5 & 4,5 & & & \\
\hline & 4,5 & 4,5 & & & \\
\hline & 6,0 & 4,5 & \multirow{4}{*}{24,103} & \multirow{4}{*}{$\mathrm{R} \$ 27.426,23$} & \multirow[b]{4}{*}{${ }^{(*)}$ mais econômico } \\
\hline & 6,0 & 4,5 & & & \\
\hline & 4,5 & 4,5 & & & \\
\hline & 4,5 & 4,5 & & & \\
\hline
\end{tabular}


No caso deste edifício de 8 (oito) pavimentos, observa-se que o procedimento de paredes isoladas é o que fornece piores resultados, devido a maior quantidade de blocos de 6,0 MPa e de 8,0 MPa empregados, que são mais caros. Além disso, o emprego de blocos com resistências elevadas seria inviável para edifícios com um maior número de pavimentos, pois não seriam encontrados facilmente no mercado. Portanto, este procedimento não é recomendável.

Com relação às situações analisadas, dentro do procedimento de grupos isolados de paredes, a mais econômica é a Situação $D$, com apenas dois pavimentos de blocos 6,0 MPa e os demais 4,5 MPa. Na Situação C constata-se um aumento de $1,61 \%$ em relação à $D$, devido ao maior volume de graute empregado, apesar do custo dos blocos ser menor.

\subsubsection{Dimensionamento}

O dimensionamento dos elementos estruturais será feito com base nos resultados do procedimento de grupos isolados de paredes, Situação D, o qual foi constatado ser o mais econômico.

\section{A - Dimensionamento à flexão composta das paredes estruturais}

Observando os resultados do item 4 do Anexo $\mathrm{C}$, verifica-se que as únicas paredes cujas tensões de tração superaram a admissível, foram as paredes PY1 e PY18, PY7 e PY14, PY8 e PY12, PY9.

Para exemplificar o cálculo de armadura à flexão, pelo "Método Simplificado", foi escolhido o $1^{\circ}$ pavimento das paredes PY1 e PY18, representadas na Figura 5.6.

$$
1^{\circ} \text { pav. } \mid \begin{aligned}
& f_{\text {alv }, c}=597 \mathrm{kN} / \mathrm{m}^{2} \\
& \mathrm{f}_{\text {alv }, \mathrm{f}}=751 \mathrm{kN} / \mathrm{m}^{2} \\
& \mathrm{f}_{\mathrm{alv}, \mathrm{t}}=100 \mathrm{kN} / \mathrm{m}^{2}
\end{aligned} \quad 0,82 \mathrm{f}_{\mathrm{alv}, \mathrm{c}} \cong 490 \mathrm{kN} / \mathrm{m}^{2}
$$




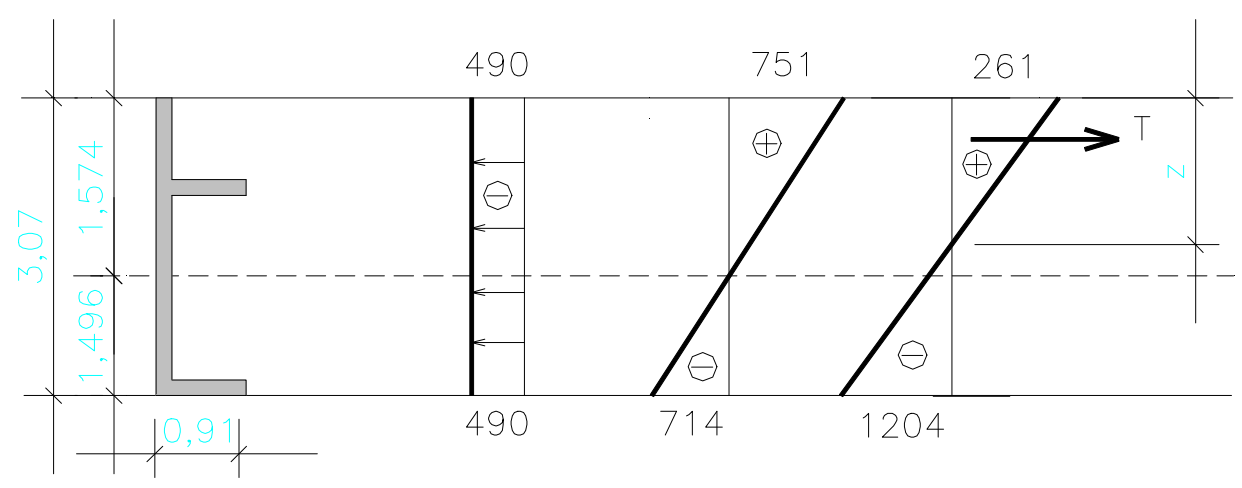

FIGURA 5.6 - Paredes PY1 e PY18

$$
\begin{gathered}
\frac{751}{1,574}=\frac{x}{1,496} \quad \frac{261}{z}=\frac{1465}{3,07} \\
x=713,78 \quad z=0,55 \\
\therefore T=\int \sigma_{+} d A=\frac{1}{2} \times 261 \times 0,55 \times 0,14+261 \times 0,91 \times 0,14=43,30 \mathrm{kN} \\
\therefore A_{s}=\frac{\bar{T}}{\alpha \cdot f_{s, t}}=\frac{43,30}{1,33 \times 16,5}=1,97 \mathrm{~cm}^{2} \quad(3 \phi 10,0)
\end{gathered}
$$

Esta armadura deve ser colocada em ambas as extremidades da parede, conforme ilustrado na Figura 5.7, uma vez que o sentido da atuação do vento é reversível.

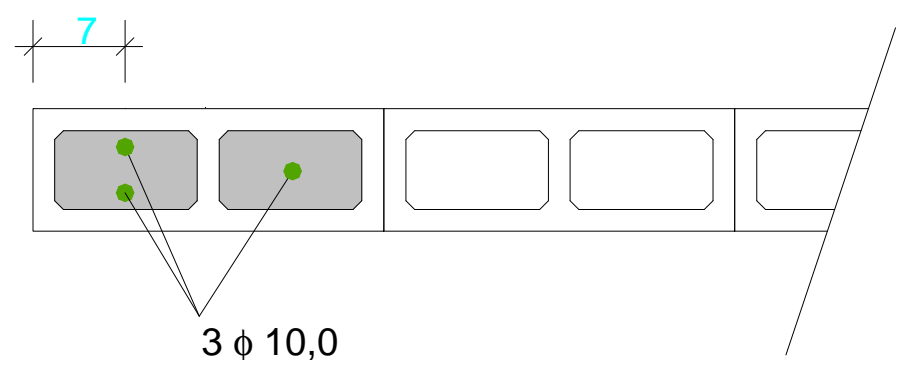

FIGURA 5.7 - Detalhe da armadura em ambas as extremidades da parede 
De acordo com o item 5.3.1, o máximo espaçamento das armaduras verticais em paredes parcialmente armadas é de $240 \mathrm{~cm}$; portanto, é necessária a colocação de mais $1 \phi 10,0 \mathrm{~mm}$ no centro da parede.

O detalhamento destas paredes encontra-se na Figura 5.8.

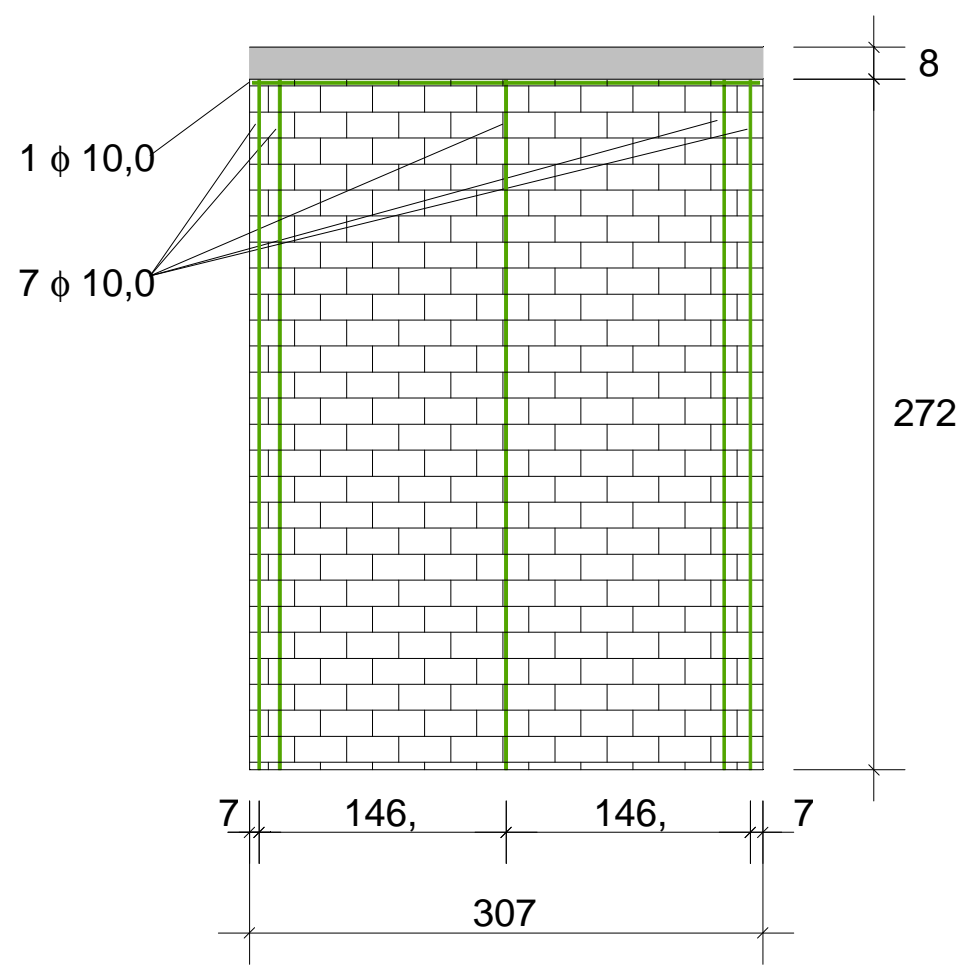

FIGURA 5.8 - Detalhamento das armaduras de flexão das paredes PY1 e PY18

\section{B - Dimensionamento ao cisalhamento das paredes estruturais}

Para exemplificar o dimensionamento ao cisalhamento foi escolhido $01^{\circ}$ pavimento das paredes PY1 e PY18. Como as forças devidas ao vento são maiores na direção y, optou-se por determinar a força cortante máxima nesta direção. 0 procedimento empregado é o mesmo utilizado no exemplo do capítulo 3, ou seja, o de paredes isoladas para a distribuição das ações horizontais.

As forças devidas ao vento atuantes na fachada do edifício, na direção y, já descritas no item 5.3.3, podem ser esquematizadas da seguinte forma: 


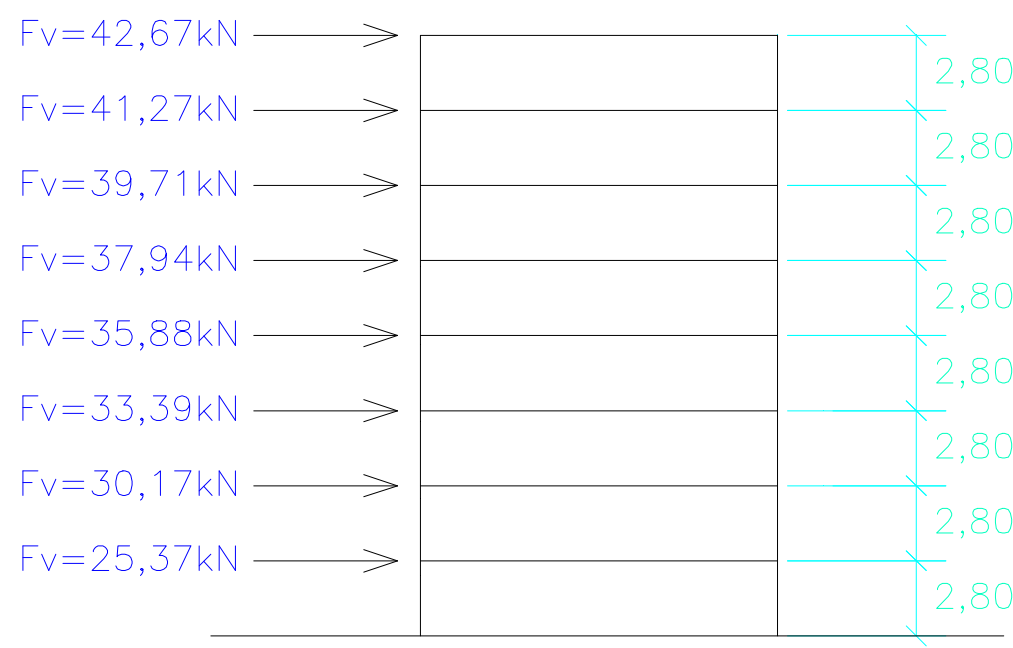

Os momentos de inércia à flexão das paredes PYi em torno dos eixos paralelos ao X, são os seguintes:

- PY1 e PY18: $0,8170 \mathrm{~m}^{4}$

- PY2 e PY19: 0,04271m ${ }^{4}$

- PY3 e PY20: $0,001822 \mathrm{~m}^{4}$

- PY4 e PY16: 0,1741 $\mathrm{m}^{4}$

- PY5 e PY17: 0,005201 $\mathrm{m}^{4}$

- PY6 e PY15: 0,5992 $\mathrm{m}^{4}$

$$
\therefore \Sigma \mathrm{R}_{\mathrm{i}}=8,1445 \quad ; \quad \mathrm{R}_{\mathrm{PY} 1}=0,1003
$$

A partir da ação do vento e da rigidez relativa das paredes PY1 / PY18, calculam-se as forças devidas ao vento na mesma, ao nível de cada pavimento. Tem-se portanto a máxima força cortante e o momento máximo atuantes na base dos painéis.
- PY7 e PY14: 0,7197 $\mathrm{m}^{4}$

- PY8 e PY12: $1,187 \mathrm{~m}^{4}$

- PY9: 0,4540 $\mathrm{m}^{4}$

- PY10: 0,08784 m

- PY11: 0,1493 m ${ }^{4}$

- PY13: 0,3599 m 


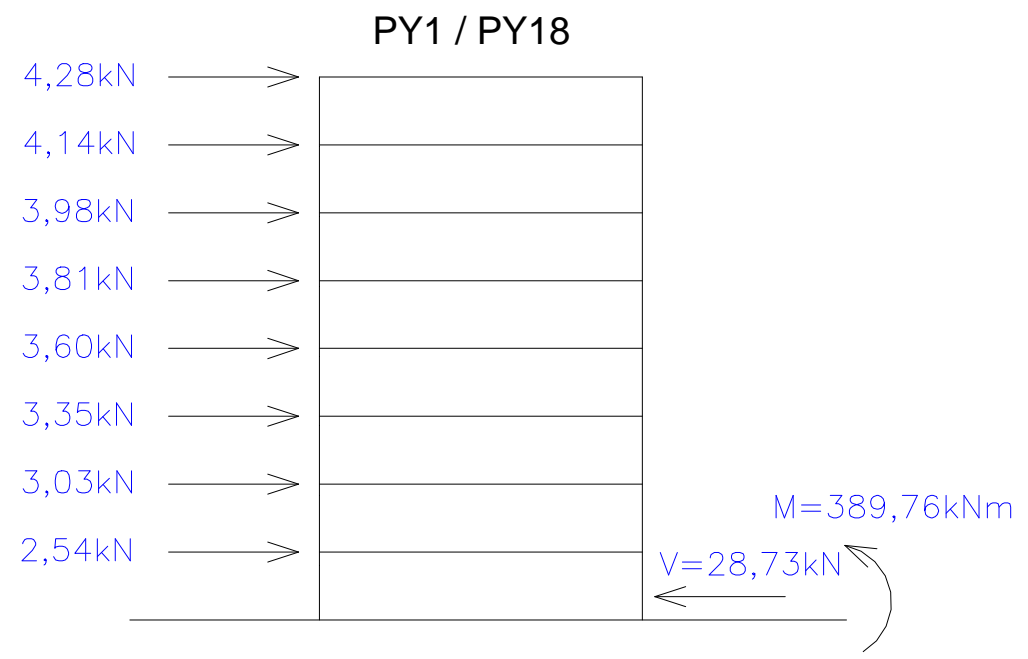

Determinada a força cortante máxima, parte-se então para o dimensionamento do $1^{\circ}$ pavimento das paredes, representado na Figura 5.9.

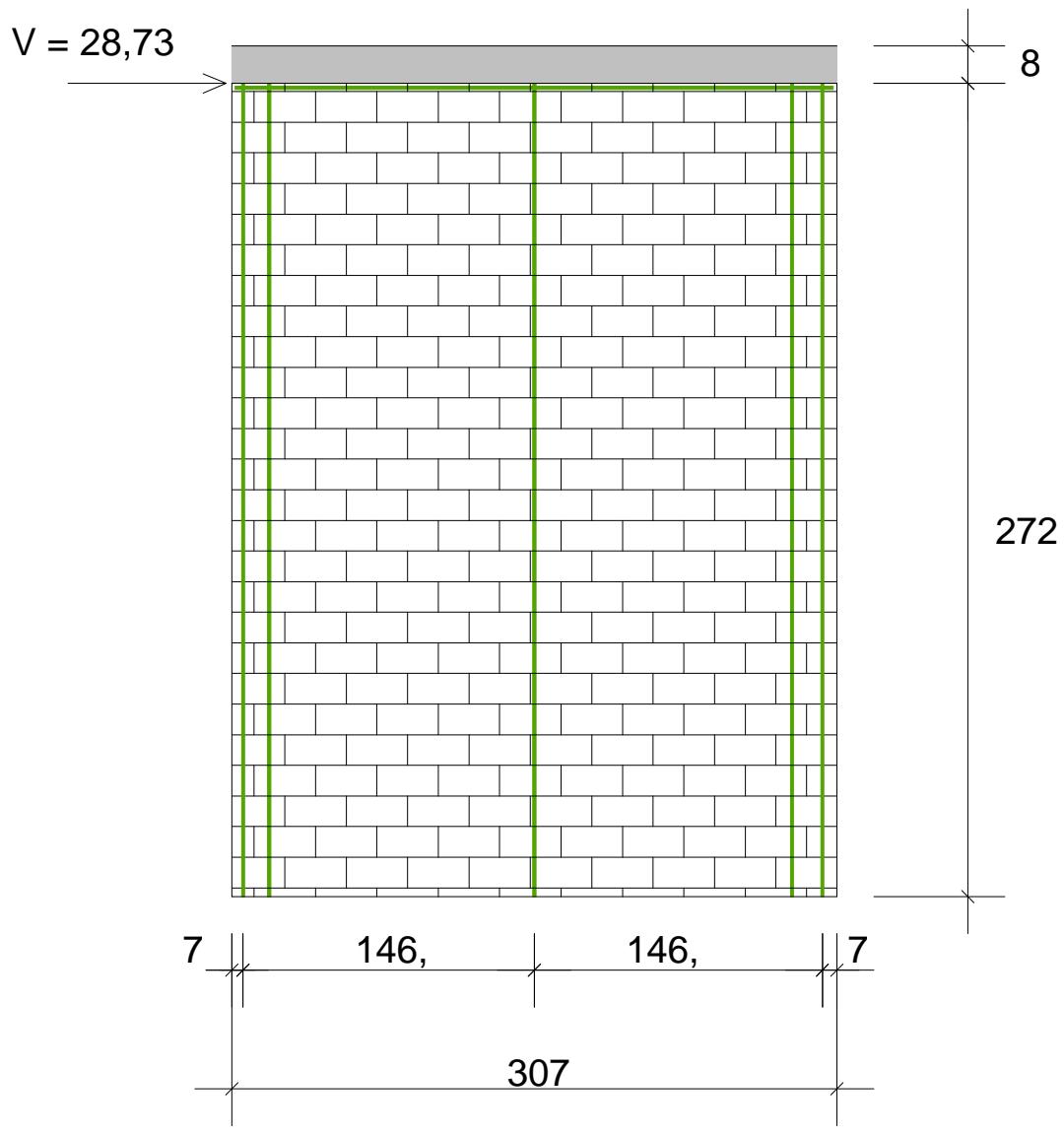

FIGURA 5.9 - Parede PY1 / PY18 - $1^{\circ}$ pavimento 
- Cálculo da tensão de cisalhamento atuante:

$$
f_{\text {cis }}=\frac{28,73}{14 \times 307}=0,00668 \mathrm{kN} / \mathrm{cm}^{2}=0,07 \mathrm{MPa}
$$

- Cálculo da tensão de cisalhamento admissível:

Adotando uma eficiência de $\eta=0,8$, calcula-se a resistência de prisma:

$$
f_{p}=\eta \times f_{b}=0,8 \times 6,0=4,8 \mathrm{MPa}
$$

Portanto, a tensão de cisalhamento admissível para paredes sem armadura de cisalhamento vale:

$$
\begin{aligned}
& \frac{M}{V \cdot d}=\frac{H \cdot V}{V \cdot d}=\frac{H}{d}=\frac{272}{293}=0,93<1 \\
& \bar{f}_{\text {cis } 1}=0,17 \sqrt{f_{p}}=0,17 \sqrt{4,8}=0,37>0,35 \quad \therefore \bar{f}_{\text {cis } 1}=0,35 \mathrm{MPa}
\end{aligned}
$$

Como $\mathrm{f}_{\text {cis1 }}<\bar{f}_{\text {cis } 1}$, não há necessidade de dispor armadura de cisalhamento nessas paredes.

\section{C - Dimensionamento à flexão simples das vergas}

Para exemplificar o cálculo de vergas, escolheu-se a verga da janela da sala, de vão 1,21 m (Figura 5.10), e a verga da porta do quarto, de vão 0,91 m (Figura 5.11). 


\section{Verga da janela da sala}
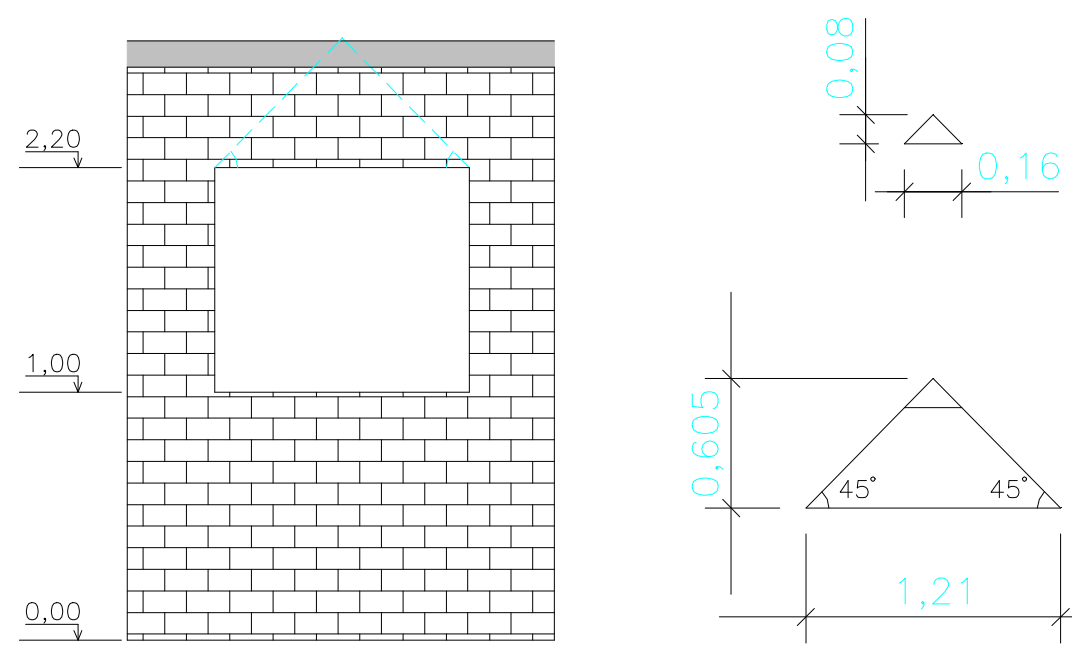

FIGURA 5.10 - Verga da janela da sala

$$
\begin{aligned}
& \text { parede }=14 \frac{\mathrm{kN}}{\mathrm{m}^{3}} \times 0,14 \mathrm{~m} \times \frac{1,21 \times 0,605}{2} \mathrm{~m}^{2} \times \frac{1}{1,21 \mathrm{~m}}=0,593 \mathrm{kN} / \mathrm{m} \\
& \text { laje }=4,193 \frac{\mathrm{kN}}{\mathrm{m}} \times \frac{0,16 \mathrm{~m}}{1,21 \mathrm{~m}}=0,554 \mathrm{kN} / \mathrm{m} \\
& \therefore p=1,147 \mathrm{kN} / \mathrm{m} \\
& M=\frac{1,147 \times 1,21^{2}}{8}=0,210 \mathrm{kN} / \mathrm{m}=21 \mathrm{kN} \cdot \mathrm{cm} \\
& f_{p}=\eta \times f_{b}=0,8 \times 0,45^{13}=0,36 \\
& \mathrm{n}=\frac{\mathrm{E}_{\mathrm{s}}}{\mathrm{E}_{\mathrm{c}}}=\frac{21000}{800 \times 0,36}=72,92 \quad ; \quad \mathrm{m}_{\mathrm{b}}=\frac{\bar{f}_{\mathrm{s}, \mathrm{t}}}{\bar{f}_{\mathrm{alv}, \mathrm{f}}}=\frac{16,5}{0,33 \times 0,36}=138,89 \\
& \mathrm{k}_{\mathrm{b}}=\frac{\mathrm{n}}{\mathrm{n}+\mathrm{m}_{\mathrm{b}}}=0,344 \quad ; \quad \mathrm{k}_{\mathrm{zb}}=1-\frac{\mathrm{k}_{\mathrm{b}}}{3}=0,885
\end{aligned}
$$

\footnotetext{
${ }^{13}$ Optou-se pelo bloco de menor resistência (dos pavimentos superiores) para o cálculo mais desfavorável das vergas e considerou-se uniformização em todos os pavimentos.
} 
$d_{b}=\sqrt{\frac{2 \times 21}{14 \times 0,344 \times 0,885 \times 0,33 \times 0,36}}=9,11<15$

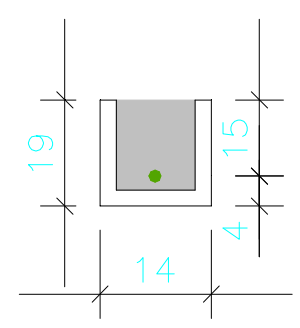

\begin{tabular}{c|c|c|c|c|c}
$\mathrm{k}_{\mathrm{z}}$ & $\mathrm{k}_{\mathrm{s}}=\frac{1}{\mathrm{f}_{\mathrm{s}, \mathrm{t}} \mathrm{k}_{\mathrm{z}}}$ & $\mathrm{A}_{\mathrm{s}}=\mathrm{k}_{\mathrm{s}} \frac{\mathrm{M}}{\mathrm{d}}$ & $\mathrm{n} \rho=\mathrm{n} \frac{\mathrm{A}_{\mathrm{s}}}{\mathrm{bd}}$ & $\mathrm{k}_{\mathrm{x}}=-\rho n+\sqrt{(\rho n)^{2}+2 \rho n}$ & $\mathrm{k}_{\mathrm{z}}=1-\frac{\mathrm{k}_{\mathrm{x}}}{3}$ \\
\hline 0,885 & 0,0685 & 0,0959 & 0,0333 & 0,227 & 0,924 \\
0,924 & 0,0656 & 0,0918 & 0,0319 & 0,223 & 0,926 \\
0,926 & 0,0655 & 0,0916 & 0,0318 & 0,222 & 0,926
\end{tabular}

$$
\therefore A_{s}=0,09 \mathrm{~cm}^{2} \quad \text { adotado: } \mid \begin{aligned}
& 1 \phi 10,0\left(0,79 \mathrm{~cm}^{2}\right) \\
& 2 \phi 8,0\left(1,00 \mathrm{~cm}^{2}\right)
\end{aligned} \text { ou }
$$

Observa-se que o valor da armadura encontrado para a verga da janela do quarto é bem inferior ao mínimo que se coloca como armadura construtiva, que é geralmente um dos valores acima. 


\section{Verga da porta do quarto}
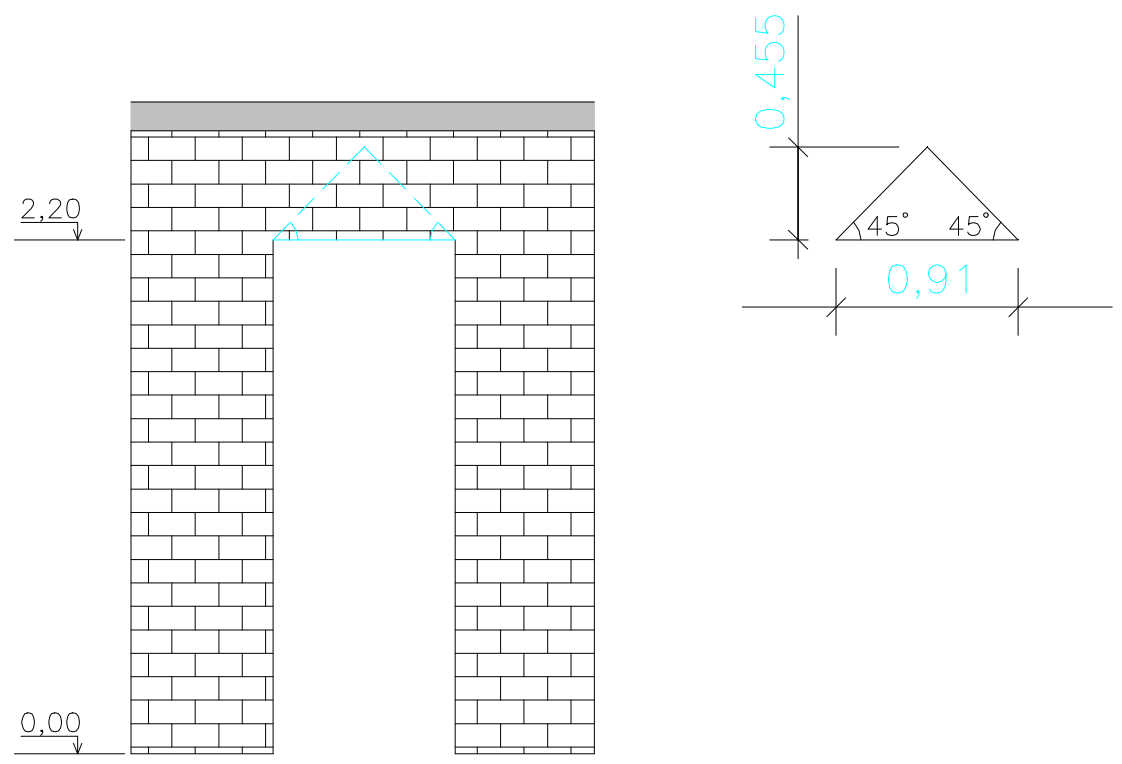

FIGURA 5.11 - Verga da porta do quarto

parede $=14 \frac{\mathrm{kN}}{\mathrm{m}^{3}} \times 0,14 \mathrm{~m} \times \frac{0,91 \times 0,455}{2} \mathrm{~m}^{2} \times \frac{1}{0,91 \mathrm{~m}}=0,446 \mathrm{kN} / \mathrm{m}$

laje $=0$

$\therefore \mathrm{p}=0,446 \mathrm{kN} / \mathrm{m}$

$M=\frac{0,446 \times 0,91^{2}}{8}=0,0462 \mathrm{kN} / \mathrm{m}=4,62 \mathrm{kN} . \mathrm{cm}$

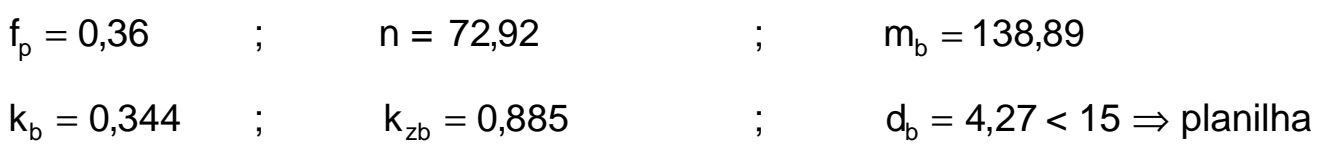

$$
\therefore A_{s}=0,0211 \mathrm{~cm}^{2} \quad \text { adotado: } \mid \begin{aligned}
& 1 \phi 10,0\left(0,79 \mathrm{~cm}^{2}\right) \\
& 2 \phi 8,0\left(1,00 \mathrm{~cm}^{2}\right)
\end{aligned} \text { ou }
$$

Observa-se, aqui também, que o valor da armadura encontrado para a verga da porta é bem inferior ao mínimo que se coloca como armadura construtiva, 
que é geralmente um dos valores acima. Mais uma vez, sugere-se o emprego da verga pré-moldada, cujas justificativas encontram-se no item 2.5.3 do capítulo 2.

\subsection{Considerações finais}

Neste capítulo procurou-se aplicar os principais pontos da teoria vista nos capítulos anteriores, na forma de exemplos práticos. Não foi possível abordar todos os pontos anteriormente tratados, mas acredita-se que os principais foram discutidos.

Para edifícios com dimensões usuais dos cômodos, a laje maciça de espessura $\mathrm{h}=8 \mathrm{~cm}$ mostrou ser suficiente para suportar os carregamentos verticais, e comportar como diafragma para a distribuição das forças horizontais devidas à ação do vento. Além disso, com esta espessura, a fluência mostrou ser muito pequena, não comprometendo assim a utilização da estrutura.

Para edifícios de 4 (quatro) pavimentos recomenda-se alvenaria nãoarmada, pois não se obteve tração em nenhuma parede. A utilização de alvenaria armada implicaria em um aumento significativo do consumo de aço e graute.

Com relação à determinação das ações horizontais, para um edifício desse porte, as ações devidas ao desaprumo representam apenas $6 \%$ das devidas à ação do vento, não sendo significativas.

Para a distribuição das ações verticais ao longo do edifício, o procedimento de paredes isoladas mostrou ser suficiente em termos econômicos, apesar de não ser o mais indicado. Com relação às duas situações analisadas, a de todos os pavimentos com blocos de resistência característica à compressão de 4,5 $\mathrm{MPa}$ é mais econômica, devido ao preço dos blocos. O procedimento mais indicado é o de grupos isolados de paredes, com todos os pavimentos com blocos de resistência 4,5 MPa. Observou-se uma redução de grauteamento e uma diminuição da tensão média nas paredes, em relação ao primeiro procedimento. Além de ser o mais econômico, é mais real porque aproxima o modelo de cálculo ao procedimento de execução das paredes amarradas, quando isto ocorrer.

Para edifícios de 8 (oito) pavimentos observou-se a existência de tração em determinados trechos de algumas paredes. A ABNT (NBR-10837) estabelece que se projete estes trechos como alvenaria armada, e permite que se considere a estrutura como um todo parcialmente armada. 
Para a distribuição das ações verticais ao longo do edifício, o procedimento de paredes isoladas forneceu os piores resultados, devido à maior quantidade de blocos de 6,0 MPa e 8,0 MPa empregados. Este procedimento pode se tornar inviável para edifícios mais altos, devido à necessidade de blocos com resistência muito elevadas, difíceis de serem encontrados no mercado. O procedimento mais indicado é o de grupos isolados de paredes, com os dois primeiros pavimentos com blocos de resistência 6,0 MPa e os demais com blocos de resistência 4,5 MPa.

Com relação ao dimensionamento das vergas, pode-se concluir que para os vãos de aberturas usuais, como as do exemplo, as armaduras construtivas normalmente empregadas ( $1 \phi 10,0 \mathrm{~mm}$ ou $2 \phi 8,0 \mathrm{~mm}$ ) são suficientes para atender os requisitos de resistência desses elementos estruturais.

Pretende-se que estes dois exemplos possam servir como modelos de resolução para edifícios usuais em alvenaria estrutural, e que os resultados encontrados sejam parâmetros significativos para auxiliarem nos processos de tomada de decisão. Nos edifícios com mais de 4 (quatro) pavimentos, a análise realizada no item 5.2 é válida para os quatro últimos, e nos edifícios com mais de 8 (oito) pavimentos, a análise realizada no item 5.3 é válida para os oito últimos, conforme ilustra a Figura 5.12.

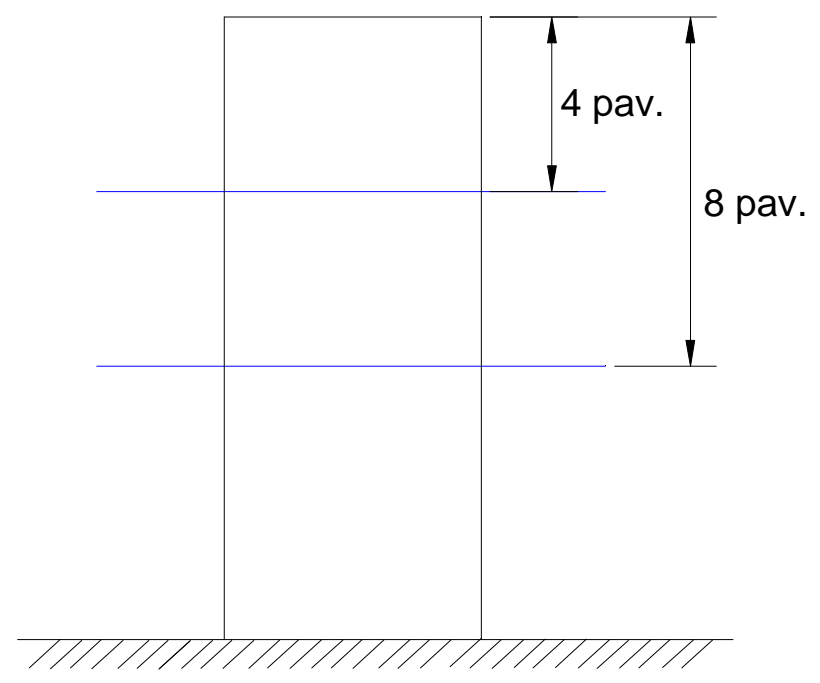

FIGURA 5.12 - Esquema de cálculo para edifícios com mais de 4 ou 8 pavimentos 
Nos prédios mais altos, com certeza há necessidade de colocar mais armaduras nas paredes, pois o efeito do vento é cada vez mais significativo. Uma opção viável é executar os primeiros pavimentos em alvenaria não-armada ou parcialmente armada, e os demais colocando armaduras apenas para absorver a tração. Desta forma, visa-se economia e segurança, que devem ser os principais objetivos a serem alcançados pelo projetista estrutural. 


\section{$\boldsymbol{6}_{\text {concususes }}$}

Neste capítulo estarão contidas as conclusões a respeito das orientações fornecidas para as tomadas de decisão relativas aos itens citados no capítulo 1 . São elas:

a - Recomenda-se o uso da alvenaria não-armada sempre que possível, pois são de mais simples execução e proporcionam maior economia. A armação de paredes só é absolutamente necessária quando as tensões de tração superam os valores admissíveis indicados na $A B N T$ (NBR-10837). Com relação à resistência à compressão, foi comprovado que o acréscimo de resistência devido à armadura é inexpressivo, não justificando o emprego da alvenaria armada para este fim.

b - A escolha do tipo de bloco estrutural a ser utilizado é condicionada por vários fatores: disponibilidade de normas de cálculo e execução, nível de exigência quanto ao aspecto estético da construção, facilidade de manuseio em obra, facilidade de obtenção por parte do construtor e oferta quanto aos aspectos dimensão, resistência e tipos.

Ainda neste item modulação, salientou-se a importância da amarração de paredes para a garantia da uniformização de tensões. Incentivou-se o emprego da amarração direta sempre que possível, já que não há resultados experimentais que assegurem a eficiência da amarração indireta.

Com relação ao tipo de modulação, sugere-se, no caso de dimensões arquitetônicas não modulares, o emprego da $M 15$, pois quanto menor o módulo 
mais fácil o ajuste de dimensões. Além disso, a M20 não é indicada quando a espessura dos blocos for $14 \mathrm{~cm}$, pois o comprimento dos mesmos não é múltiplo de sua espessura, sendo necessários, neste caso, blocos especiais para fazer as amarrações. A disponibilidade dos blocos existentes no mercado, nos aspectos dimensões e faixa de resistência, também interfere na escolha do tipo de modulação.

Finalmente, neste item modulação, sugere-se o uso da simetria na mesma, ajustando apenas as regiões centrais de escada, elevadores e hall. A opção pela perda da simetria levaria à ocorrência de juntas a prumo em vários pontos. Isto não seria desejável do ponto de vista estrutural, e provocaria uma não uniformidade na execução das paredes, sendo prejudicial ao processo construtivo.

c - Recomenda-se preencher, sempre que for necessário em termos de resistência da parede, as juntas verticais e os septos transversais das juntas horizontais de argamassa, quando do assentamento dos blocos estruturais. O não-preenchimento dos septos transversais das juntas de assentamento implica na redução da resistência à compressão e ao cisalhamento da alvenaria. $O$ não-preenchimento das juntas verticais pode agravar problemas de fissuração na parede sob a laje de cobertura, quando não tomadas as devidas precauções, devido à redução de resistência ao cisalhamento da parede. Entretanto, o não-preenchimento das juntas verticais pode ser adequado para juntas de $0,5 \mathrm{~cm}$ de espessura, com o objetivo de reduzir o tempo de execução da obra e o consumo de materiais.

d - As instalações elétricas, de telefone, de TV e de interfone passam, em sua maioria, dentro dos vazados verticais dos blocos estruturais e pelas lajes. Deve-se evitar os cortes das paredes estruturais. Caso não seja possível, um procedimento seguro é descontar as partes da parede por onde passam os cortes verticais e evitar os cortes horizontais e diagonais. As caixas e os aparelhos a serem embutidos na alvenaria devem ter medidas preferencialmente modulares, visando otimizar os procedimentos de assentamento e fixação.

O projeto das instalações hidro-sanitárias deve prever o embutimento da forma mais racionalizada possível, podendo recorrer a uma das seguintes soluções: paredes não-estruturais, "shafts" hidráulicos, enchimentos, sancas, forros falsos, etc.. O elevado número de paredes não-estruturais implica em desperdício de tempo e materiais, além de comprometer o sistema estrutural. Os "shafts" 
hidráulicos são bastante indicados por proporcionarem maior facilidade na execução das instalações e independência de serviços. Não interferem na estrutura da edificação, bem como facilitam os serviços de manutenção, por serem visitáveis. Os enchimentos, as sancas e os forros falsos são opções que resolvem o problema da passagem do trecho horizontal de tubulações de grande diâmetro.

e - Os elementos pré-moldados têm sido bastante empregados em edifícios em alvenaria estrutural, pelo fato destes dois sistemas possuírem vantagens em comum. As lajes pré-moldadas são bastante indicadas para os edifícios baixos, sendo uma solução alternativa que pode ser viável, dependendo das despesas de material e transporte. As escadas pré-moldadas, apesar de serem menos utilizadas, possuem a vantagem de proporcionar rapidez de execução da obra como um todo, pois em geral são elementos trabalhosos para serem moldados no local. A utilização de vergas pré-moldadas para portas tem alcançado ótimos resultados no sistema construtivo alvenaria estrutural. São elementos leves, fáceis de serem manuseados, e podem ser executados pela construtora no próprio canteiro de obras, já com dimensões modulares e armaduras necessárias. Além de otimizarem o ritmo da produção, não necessitam de ligações especiais com a alvenaria, dispensam cortes nos blocos e eventuais enchimentos do espaço entre a porta e a fiada superior.

f - As cintas têm função de travar o prédio como um todo, transmitir a reação da laje à alvenaria e combater efeitos provocados por variações volumétricas. São indicadas abaixo da laje, em todas as paredes, e a meia altura em especial nas paredes externas. As cintas em geral não são calculadas, admitindo-as de altura igual a um bloco canaleta e armadura construtiva. Abaixo da laje de cobertura recomenda-se fazer uma cinta dupla para dar maior travamento horizontal às paredes.

g - A concepção estrutural de um edifício consiste em se definir no projeto quais os elementos que suportarão os carregamentos provindos das ações verticais e horizontais. A escolha das paredes portantes é condicionada por fatores como a utilização da edificação, a existência ou não de simetria na estrutura, passagem de tubulações, etc.. Recomenda-se evitar estruturas de contraventamento significativamente assimétricas, sem contudo comprometer a geometria definida na 
arquitetura, pois os esforços decorrentes da torção do edifício tornam o cálculo da distribuição das ações mais complexo. Com relação à utilização da edificação pode-se empregar a classificação tradicional de HENDRY (1981), porém, mais importante que a classificação é a identificação, em cada caso, do arranjo mais adequado. Para edificações mais altas, as paredes estruturais não devem estar dispostas em apenas uma direção, a fim de proporcionar contraventamento em todas elas. Além disso, a não existência de paredes estruturais em uma das direções compromete os apoios para as lajes. Com relação às lajes, para acertar o módulo vertical das paredes é aconselhável que se tenham lajes de mesma espessura, o que implica em não se ter vãos muitos distintos. Portanto, a concepção estrutural deve ser tal que permita vencer os vãos com esta espessura.

$\mathrm{h}$ - A existência de rebaixos nas lajes também é um ponto de tomada de decisão. Deve-se lembrar que no caso do emprego da laje usual de $h=8 \mathrm{~cm}$, o rebaixo máximo permitido é de $1 \mathrm{~cm}$, pois as lajes de piso não devem ter espessura inferior a $7 \mathrm{~cm}[\mathrm{ABNT}(\mathrm{NB}-1)]$.

i - A utilização ou não de armaduras negativas nas lajes é um ponto importante de tomada de decisão, uma vez que elas podem ser necessárias para alterar o fluxo de cargas, a fim de evitarem acúmulos de tensão em determinadas paredes. Além disso, as armaduras negativas evitam o aparecimento de fissuras sobre os apoios, que ficam aparentes em especial quando da entrega do piso sem revestimento.

j - Dentre os procedimentos de distribuição das ações verticais estudados no capítulo 3, verificou-se que o procedimento de paredes isoladas é seguro e antieconômico, enquanto que o de grupos isolados de paredes é seguro e medianamente econômico. O procedimento de grupos de paredes com interação é o mais econômico de todos, entretanto não se têm ainda valores seguros para as taxas de interação.

k - Para a correta determinação da rigidez dos painéis de contraventamento, durante a distribuição das ações horizontais, a ABNT (NBR-10837) recomenda que se considere a contribuição das abas ou flanges nas paredes unidas por amarração direta. Através do exemplo final do capítulo 3, item 3.5.5, verificou-se que as tensões nas paredes devidas às ações horizontais são bem menores quando se 
consideram as abas, gerando maior economia. Além disso, a força cortante na base dos painéis é maior quando elas são consideradas, sendo a favor da segurança na determinação da tensão de cisalhamento. Portanto, a recomendação da norma tem procedência e deve ser seguida.

No capítulo 5 foi analisado um edifício padrão em alvenaria estrutural, com dimensões usuais dos cômodos, sendo seu comprimento total em planta bem maior que a largura, a fim de evidenciar os efeitos da ação do vento. O edifício foi considerado primeiramente com 4 (quatro) pavimentos, e posteriormente com 8 (oito). Nestes exemplos foi aplicada grande parte da teoria vista nos capítulos anteriores, buscando sempre justificar as tomadas de decisão efetuadas.

Para edifícios de 4 (quatro) pavimentos recomenda-se utilizar alvenaria nãoarmada, e para edifícios de 8 (oito) pavimentos, recomenda-se alvenaria parcialmente armada, pois aparecem trações em alguns trechos de paredes.

Com relação à distribuição das ações verticais, o procedimento mais indicado em ambos os casos é o de grupos isolados de paredes. Para o caso de 4 (quatro) pavimentos, é suficiente, nas situações usuais, a utilização de blocos de resistência característica à compressão de 4,5 $\mathrm{MPa}$ em todos os pavimentos. Para o caso de mais pavimentos, deve-se aumentar gradativamente a resistência característica dos blocos, com a possibilidade de utilização de $\mathrm{f}_{\mathrm{bk}}=4,5 \mathrm{MPa}$ nos quatro pavimentos superiores. É importante salientar que o procedimento de paredes isoladas pode se tornar inviável para edifícios mais altos, devido à não disponibilidade de blocos com resistências elevadas no mercado.

Com relação às vergas, para os vãos de aberturas usuais, as armaduras construtivas normalmente empregadas são suficientes para os requisitos de resistência desses componentes estruturais.

Nos edifícios com mais de 4 (quatro) pavimentos, a análise feita no primeiro exemplo é válida para os seus quatro últimos. Da mesma forma, nos edifícios com mais de 8 (oito) pavimentos, a análise feita no segundo exemplo é válida para os seus oito últimos.

Admite-se como prática segura de projeto estrutural a adoção do conceito de alvenaria parcialmente armada, dispondo barras de aço verticais apenas nas regiões em que há ocorrência de tração em níveis não suportáveis pela alvenaria não-armada, ou com função construtiva. Assim, garante-se a segurança, objetivando atender o quesito economia. Em geral, os quatro últimos pavimentos 
do edifício pode ser concebido em alvenaria não-armada, resguardando as peculiaridades dos casos não usuais.

Finalmente, acredita-se que as informações contidas nesta dissertação possam auxiliar nos cursos de graduação em Engenharia Civil, bem como nos escritórios de projeto estrutural, cumprindo assim os objetivos previamente definidos para o trabalho. 
ANEXO A

Resultados do processamento das lajes dos pavimentos-tipo do edifício do capítulo 5 


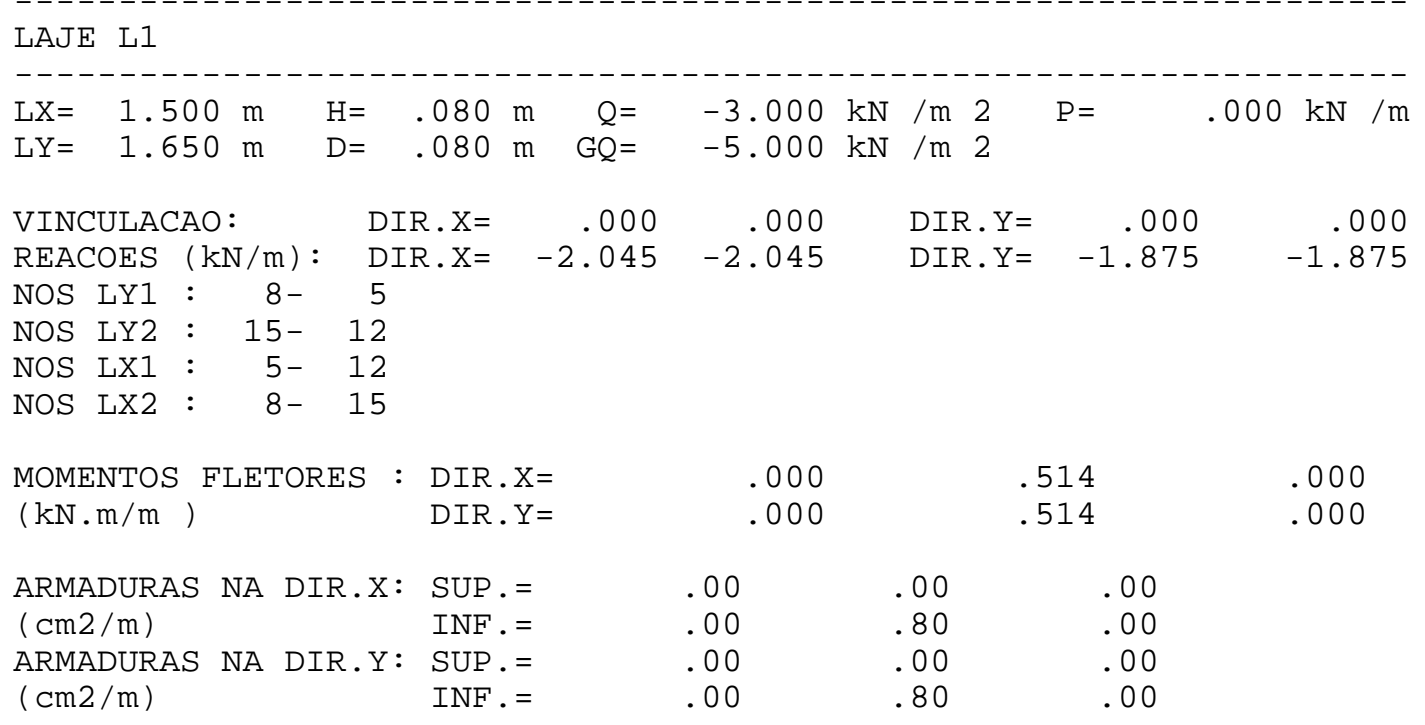

FLECHA INSTANTANEA $=-.010 \mathrm{~cm}$ FLECHA TEMPO INFINITO $=-.017 \mathrm{~cm}$

LAJE L2

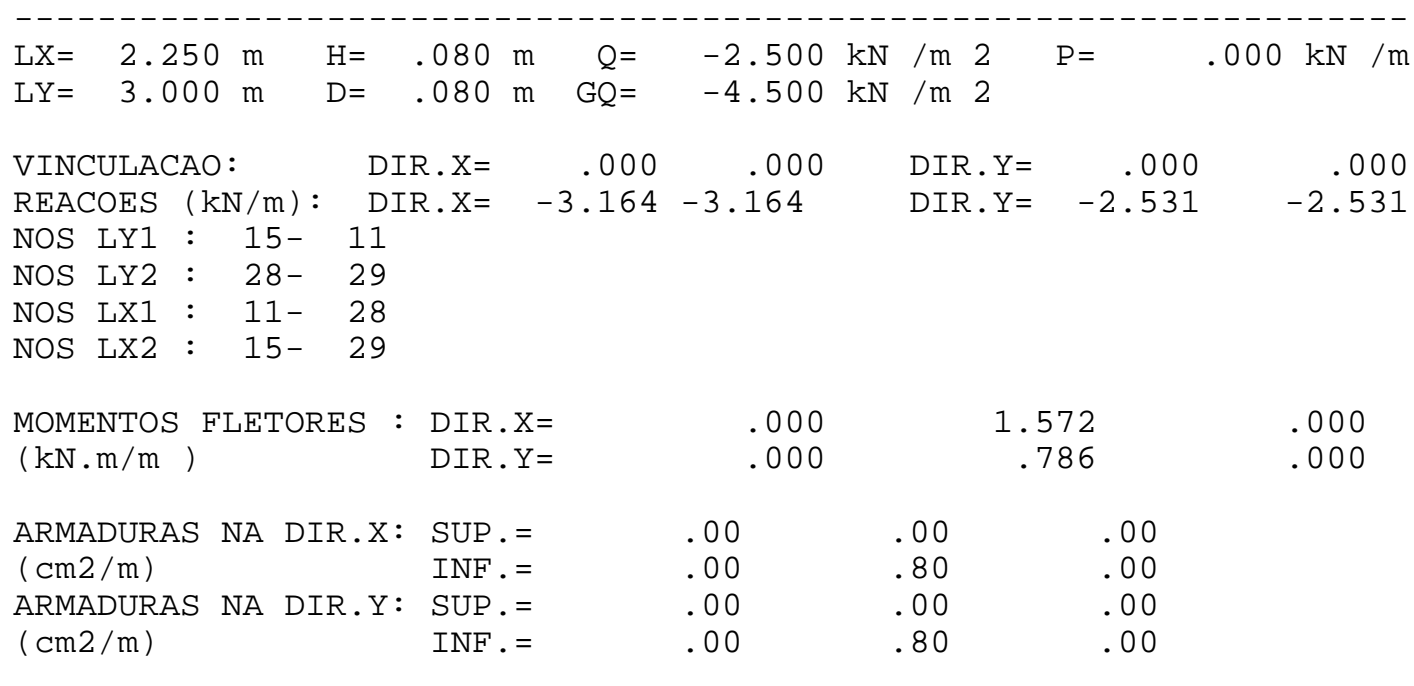

FLECHA INSTANTANEA $=-.060 \mathrm{~cm}$ FLECHA TEMPO INFINITO $=-.103 \mathrm{~cm}$

LAJE L3

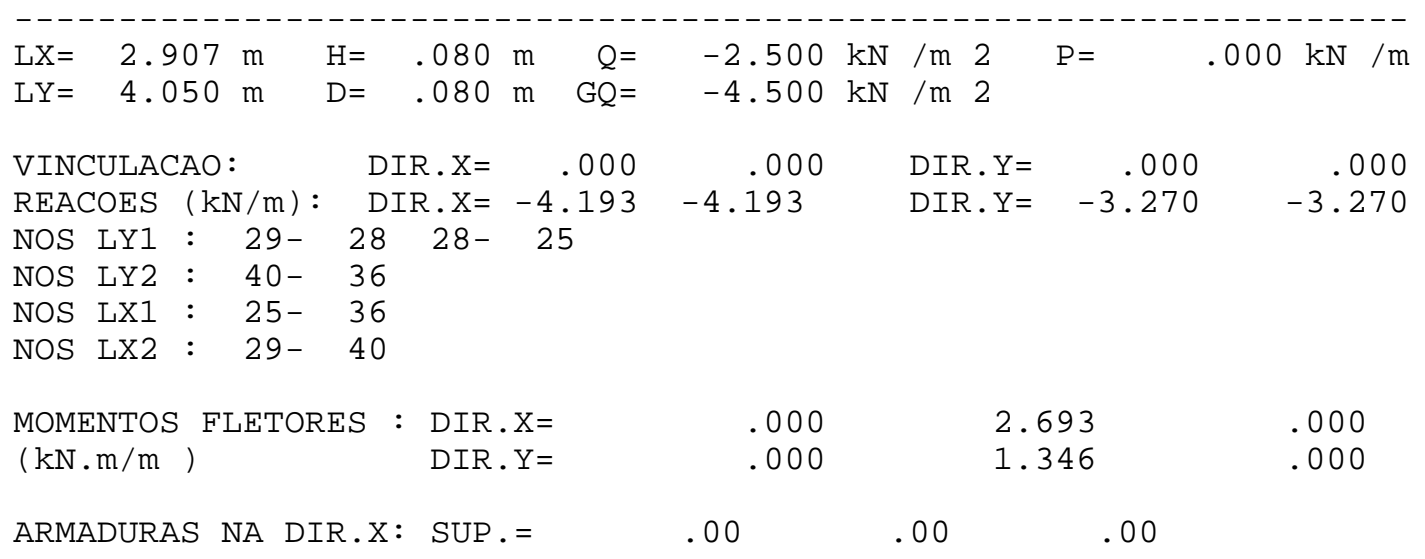




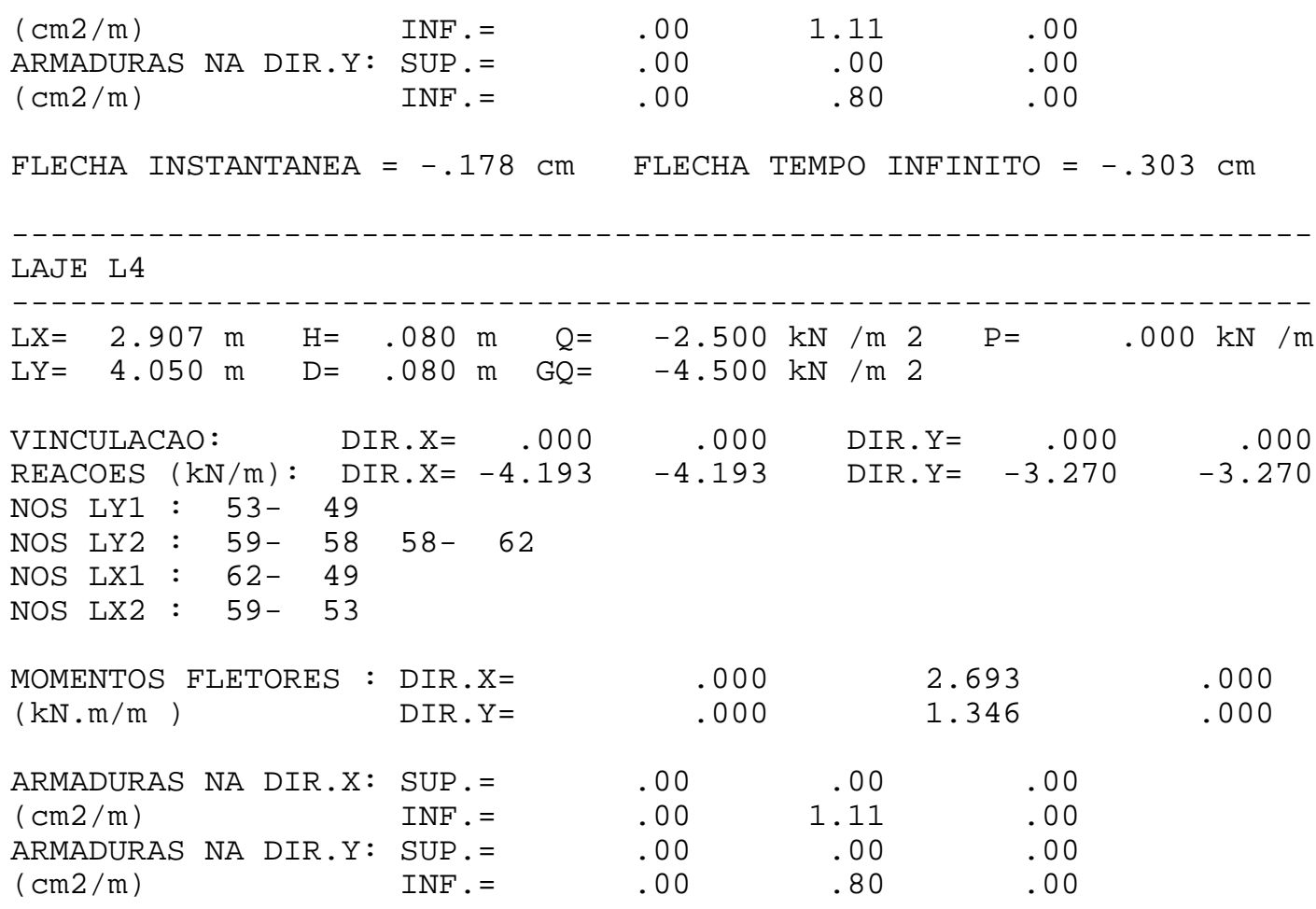

FLECHA INSTANTANEA $=-.178 \mathrm{~cm}$ FLECHA TEMPO INFINITO $=-.303 \mathrm{~cm}$

LAJE L5

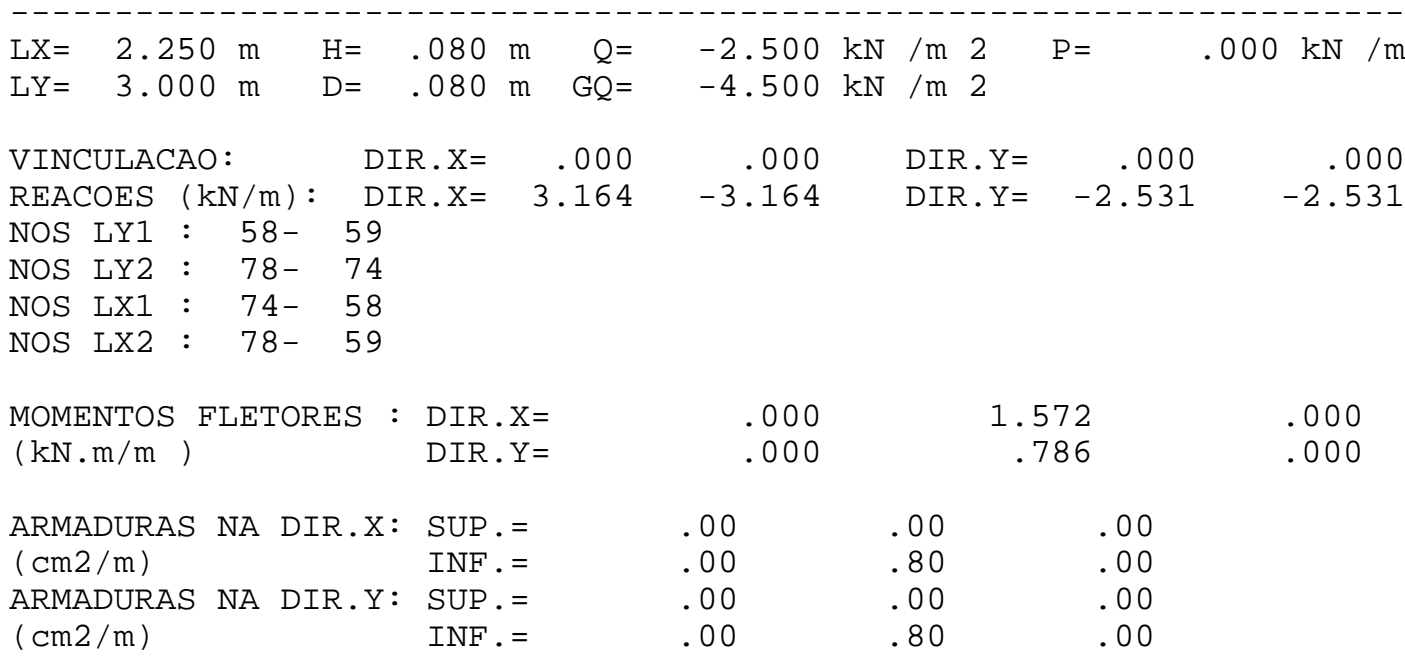

FLECHA INSTANTANEA $=-.060 \mathrm{~cm}$ FLECHA TEMPO INFINITO $=-.103 \mathrm{~cm}$

\section{LAJE L6}

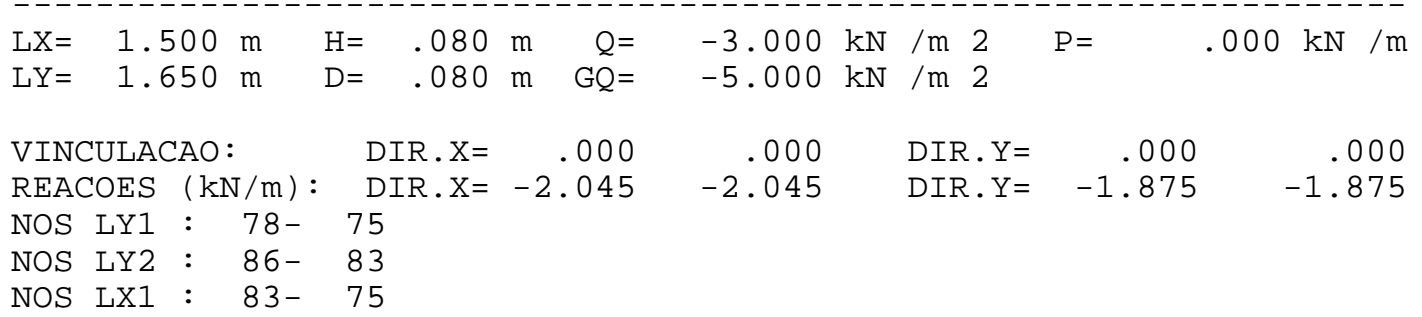




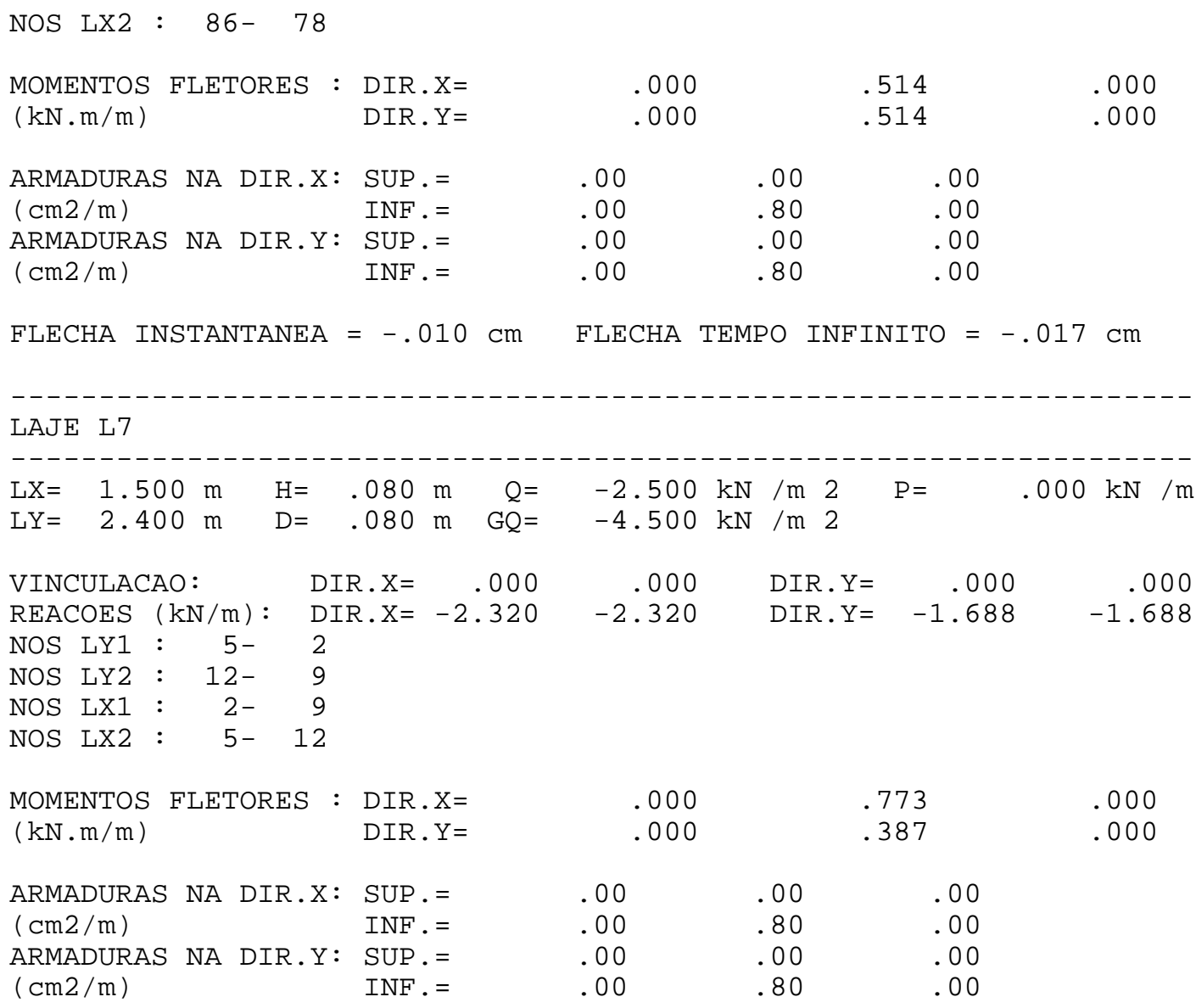

FLECHA INSTANTANEA $=-.015 \mathrm{~cm}$ FLECHA TEMPO INFINITO $=-.025 \mathrm{~cm}$

LAJE L8

$\mathrm{LX}=1.500 \mathrm{~m} \quad \mathrm{H}=.080 \mathrm{~m} \quad \mathrm{Q}=\quad-2.500 \mathrm{kN} / \mathrm{m} 2 \quad \mathrm{P}=\quad .000 \mathrm{kN} / \mathrm{m}$ $\mathrm{LY}=2.400 \mathrm{~m} \quad \mathrm{D}=.080 \mathrm{~m} \mathrm{GQ}=-4.500 \mathrm{kN} / \mathrm{m} 2$

VINCULACAO: $\quad$ DIR.X $=\quad .000 \quad .000 \quad$ DIR.Y $\quad .000 \quad .000$ $\operatorname{REACOES}(\mathrm{kN} / \mathrm{m}): \operatorname{DIR} . \mathrm{X}=-2.320 \quad-2.320 \quad$ DIR.Y $=-1.688 \quad-1.688$ NOS LY1 : 75- 72

NOS LY2 : $83-80$

NOS LX1 : $80-72$

NOS LX2 : $83-75$

MOMENTOS FLETORES : DIR.X= $(\mathrm{kN} \cdot \mathrm{m} / \mathrm{m})$

DIR.Y $=$

.000

.773

.000

ARMADURAS NA DIR.X: SUP.=

$(\mathrm{cm} 2 / \mathrm{m})$

INF. $=$

ARMADURAS NA DIR.Y: SUP. $=$

$(\mathrm{cm} 2 / \mathrm{m})$

INF. $=$

.00

.00

.00

.00

.00
.80
.00
.80

.00

.00

.00

FLECHA INSTANTANEA $=-.015 \mathrm{~cm}$ FLECHA TEMPO INFINITO $=-.025 \mathrm{~cm}$ 


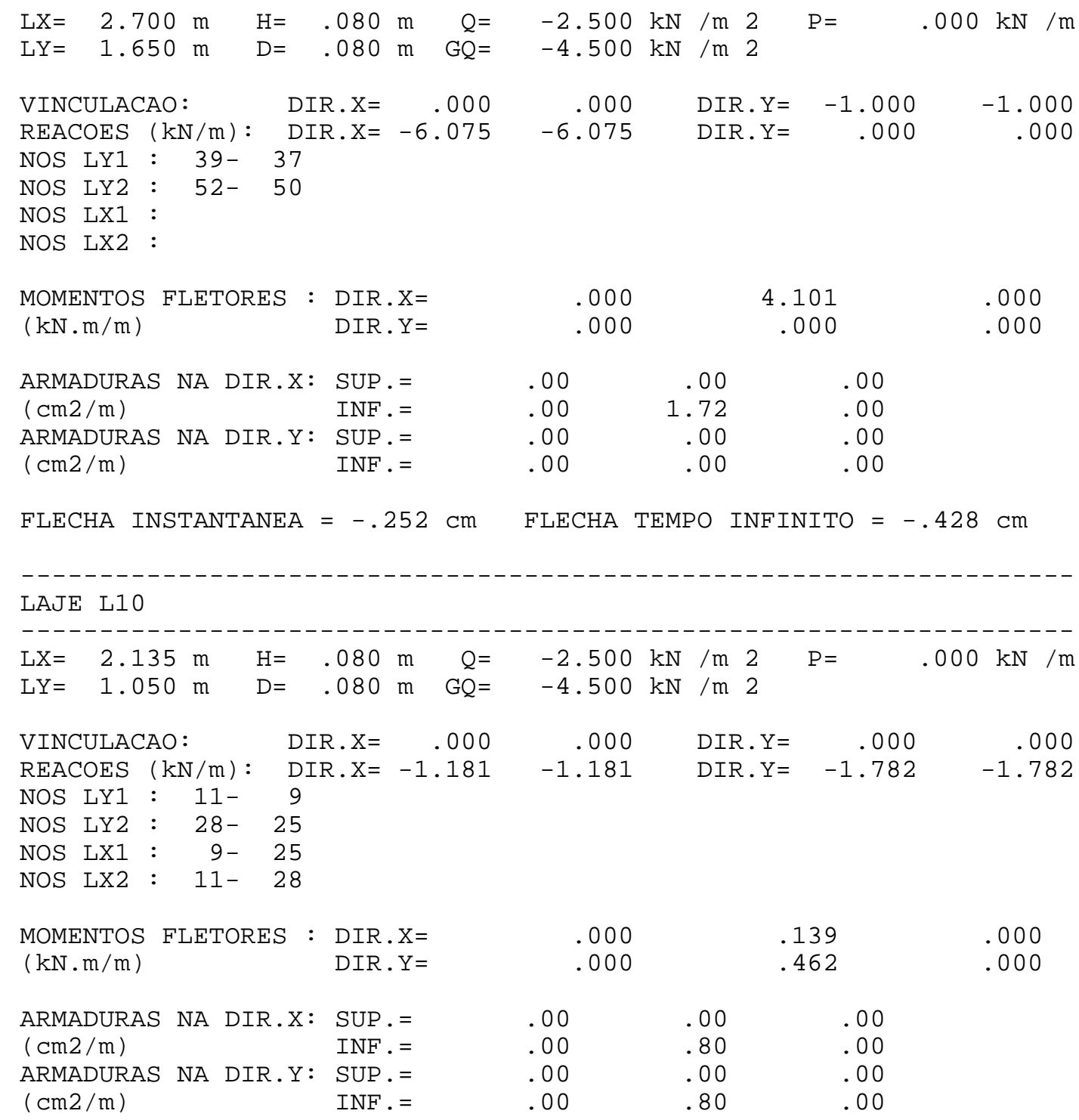

FLECHA INSTANTANEA $=-.004 \mathrm{~cm}$ FLECHA TEMPO INFINITO $=-.007 \mathrm{~cm}$

LAJE L11

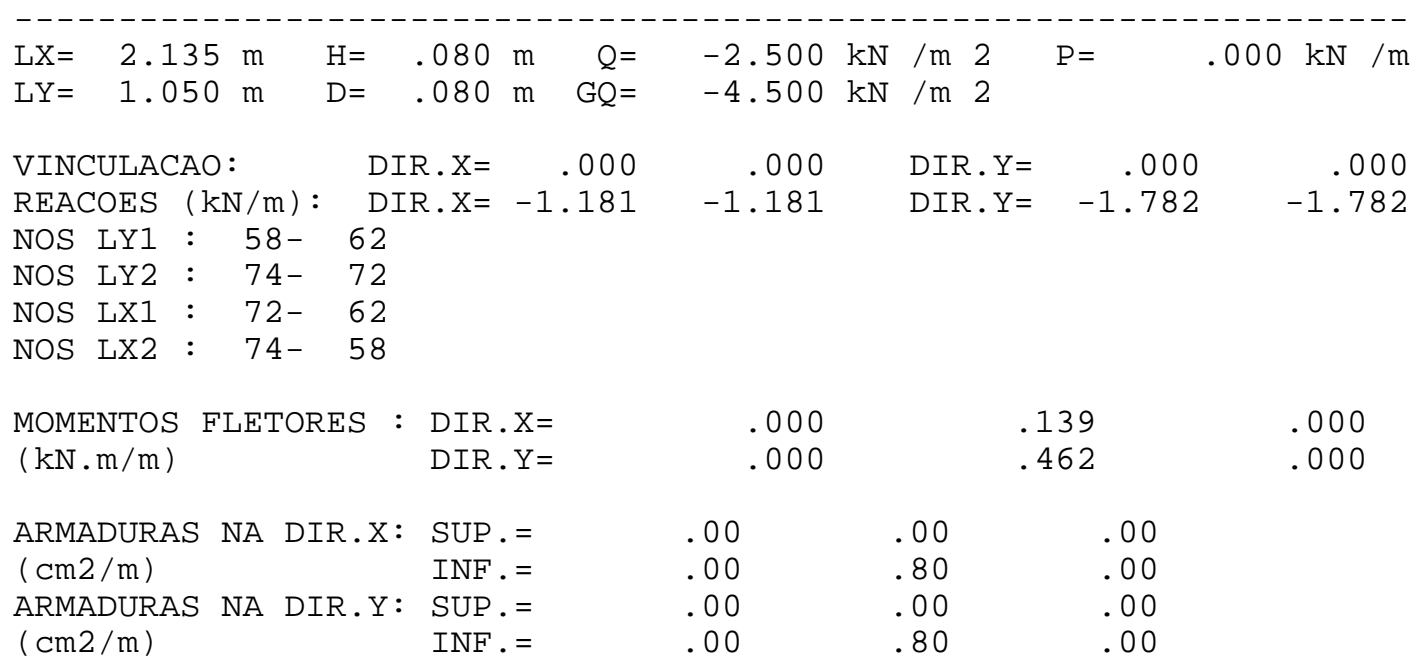


FLECHA INSTANTANEA $=-.004 \mathrm{~cm}$ FLECHA TEMPO INFINITO $=-.007 \mathrm{~cm}$

LAJE L12

$\mathrm{LX}=1.350 \mathrm{~m} \quad \mathrm{H}=.080 \mathrm{~m} \quad \mathrm{Q}=\quad-3.000 \mathrm{kN} / \mathrm{m} 2 \mathrm{P}=\quad .000 \mathrm{kN} / \mathrm{m}$

$\mathrm{LY}=2.090 \mathrm{~m} \quad \mathrm{D}=.080 \mathrm{~m} \mathrm{GQ}=-5.000 \mathrm{kN} / \mathrm{m} 2$

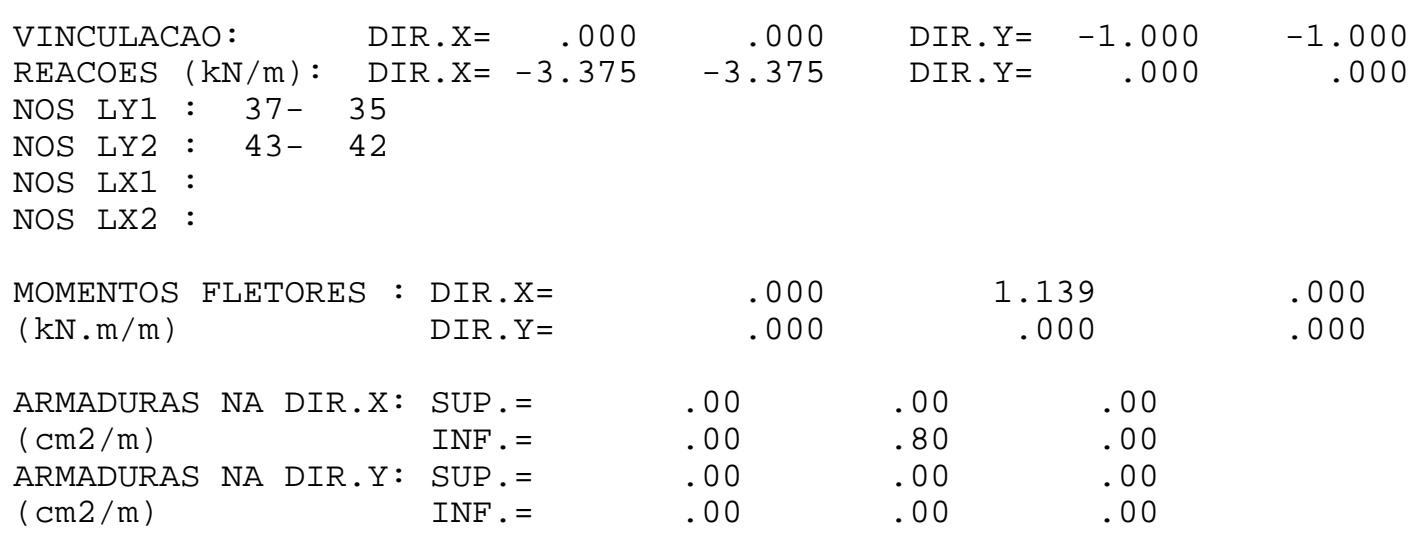

FLECHA INSTANTANEA $=-.017 \mathrm{~cm}$ FLECHA TEMPO INFINITO $=-.030 \mathrm{~cm}$

LAJE L13

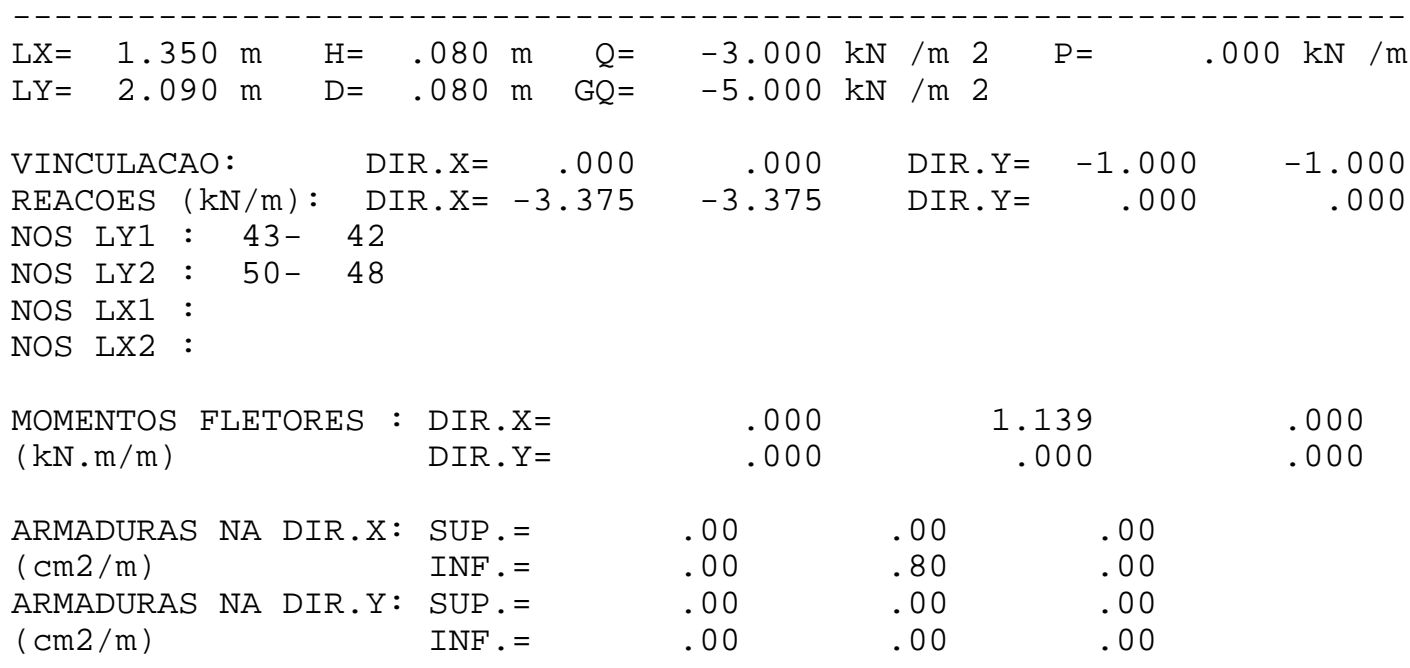

FLECHA INSTANTANEA $=-.017 \mathrm{~cm}$ FLECHA TEMPO INFINITO $=-.030 \mathrm{~cm}$

LAJE L14

$\mathrm{LX}=3.300 \mathrm{~m} \quad \mathrm{H}=.080 \mathrm{~m} \quad \mathrm{Q}=-2.500 \mathrm{kN} / \mathrm{m} 2 \mathrm{P}=000 \mathrm{kN} / \mathrm{m}$




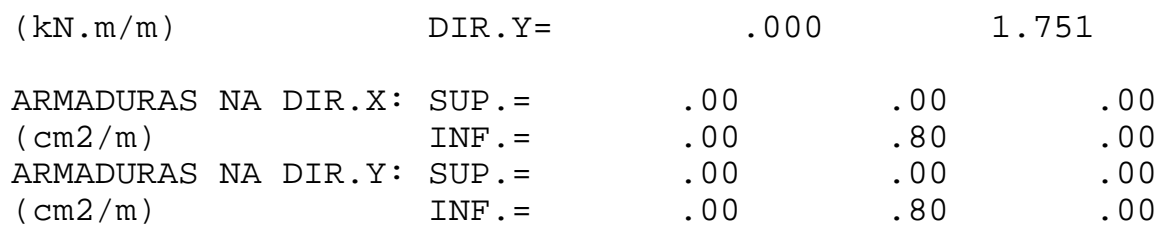

FLECHA INSTANTANEA $=-.125 \mathrm{~cm}$ FLECHA TEMPO INFINITO $=-.213 \mathrm{~cm}$

LAJE L15

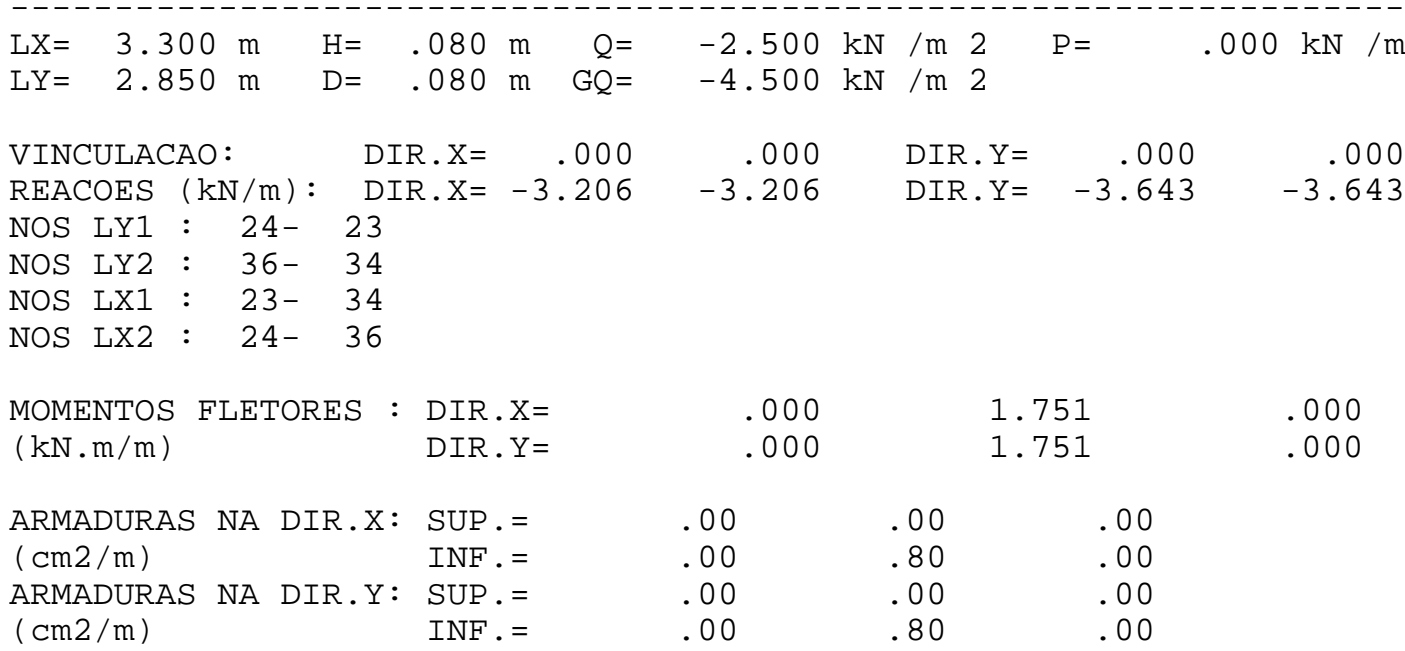

FLECHA INSTANTANEA $=-.125 \mathrm{~cm}$ FLECHA TEMPO INFINITO $=-.213 \mathrm{~cm}$

LAJE L16

$\mathrm{LX}=3.300 \mathrm{~m} \quad \mathrm{H}=.080 \mathrm{~m} \quad \mathrm{Q}=\quad-2.500 \mathrm{kN} / \mathrm{m} 2 \mathrm{P}=00 \mathrm{kN} / \mathrm{m}$ $\mathrm{LY}=2.850 \mathrm{~m} \quad \mathrm{D}=.080 \mathrm{~m} \mathrm{GQ}=-4.500 \mathrm{kN} / \mathrm{m} 2$

VINCULACAO: $\quad$ DIR.X $=\quad .000 \quad .000 \quad$ DIR.Y $\quad .000 \quad 000$ $\operatorname{REACOES}(\mathrm{kN} / \mathrm{m}): \operatorname{DIR} . \mathrm{X}=-3.206 \quad-3.206 \quad$ DIR.Y $=-3.643 \quad-3.643$ NOS LY1 : $49-47$

NOS LY2 : 64- 63

NOS LX1 : $63-47$

NOS LX2 : 64- 49

\begin{tabular}{|c|c|c|c|c|c|c|}
\hline $\begin{array}{c}\text { MOMENTOS } \\
(\mathrm{kN} \cdot \mathrm{m} / \mathrm{m})\end{array}$ & FLETORES : & $\begin{array}{l}\text { DIR. } X= \\
\text { DIR. Y }=\end{array}$ & & & & $\begin{array}{l}.000 \\
.000\end{array}$ \\
\hline $\begin{array}{l}\text { ARMADURAS } \\
(\mathrm{cm} 2 / \mathrm{m}) \\
\text { ARMADURAS } \\
(\mathrm{cm} 2 / \mathrm{m})\end{array}$ & $\begin{array}{l}\text { NA DIR.X: } \\
\text { NA DIR.Y: }\end{array}$ & $\begin{array}{l}\text { SUP. }= \\
\text { INF. }= \\
\text { SUP. }= \\
\text { INF. }=\end{array}$ & $\begin{array}{l}.00 \\
.00 \\
.00 \\
.00\end{array}$ & $\begin{array}{l}.00 \\
.80 \\
.00 \\
.80\end{array}$ & $\begin{array}{l}.00 \\
.00 \\
.00 \\
.00\end{array}$ & \\
\hline
\end{tabular}

FLECHA INSTANTANEA $=-.125 \mathrm{~cm}$ FLECHA TEMPO INFINITO $=-.213 \mathrm{~cm}$

LAJE L17

$\mathrm{LX}=3.300 \mathrm{~m} \quad \mathrm{H}=.080 \mathrm{~m} \quad \mathrm{Q}=-2.500 \mathrm{kN} / \mathrm{m} 2 \mathrm{P}=\quad .000 \mathrm{kN} / \mathrm{m}$ $\mathrm{LY}=2.850 \mathrm{~m} \quad \mathrm{D}=.080 \mathrm{~m} \mathrm{GQ}=-4.500 \mathrm{kN} / \mathrm{m} 2$ 


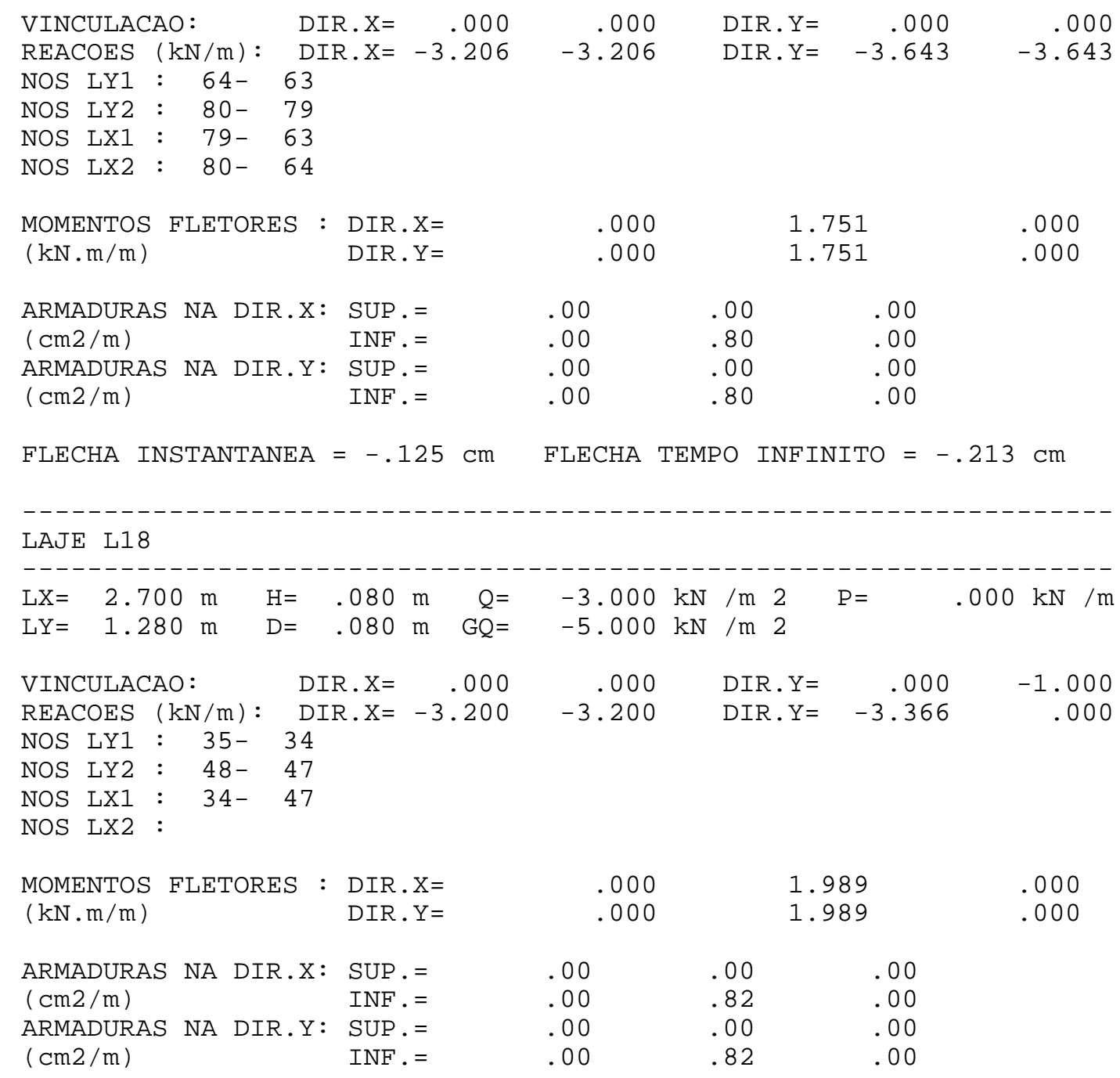

FLECHA INSTANTANEA $=.000 \mathrm{~cm}$ FLECHA TEMPO INFINITO $=.000 \mathrm{~cm}$ 
ANEXO B

Resultados da distribuição das ações verticais no edifício do capítulo 5 (com 4 pavimentos) 


\section{Procedimento: PAREDES ISOLADAS - SITUAÇÃO A}

\begin{tabular}{|c|c|c|c|}
\hline PAREDE & NIV & $\begin{array}{l}\text { CARGA } \\
(\mathrm{kN} / \mathrm{m})\end{array}$ & $\begin{array}{l}\text { TENSÃO } \\
\left(\mathrm{kN} / \mathrm{m}^{2}\right)\end{array}$ \\
\hline $\mathrm{PX} 1 / \mathrm{PX} 6$ & 4 & -9.143 & -65.306 \\
\hline $\mathrm{PX} 2 / \mathrm{PX} 5$ & 4 & -13.801 & -98.576 \\
\hline $\mathrm{PX} 7 / \mathrm{PX} 8$ & 4 & -8.894 & -63.530 \\
\hline $\mathrm{PX} 9 / \mathrm{PX} 12$ & 4 & -11.890 & -84.929 \\
\hline PX10/PX11 & 4 & -27.642 & -197.440 \\
\hline PX13/PX18 & 4 & -12.985 & -92.753 \\
\hline PX14/PX17 & 4 & -32.592 & -232.801 \\
\hline PX15/PX16 & 4 & -13.949 & -99.632 \\
\hline PX19/PX24 & 4 & -11.304 & -80.739 \\
\hline $\mathrm{PX} 20 / \mathrm{PX} 23$ & 4 & -19.802 & -141.446 \\
\hline PX21/PX22 & 4 & -35.885 & -256.322 \\
\hline $\mathrm{P} \times 3$ & 4 & -44.597 & -318.549 \\
\hline PX4 & 4 & -24.777 & -176.980 \\
\hline PY3/PY20 & 4 & -14.573 & -104.093 \\
\hline PY5/PY17 & 4 & -16.161 & -115.438 \\
\hline PY7/PY14 & 4 & -13.170 & -94.068 \\
\hline $\mathrm{PY} 2 / \mathrm{PY} 19$ & 4 & -12.154 & -86.817 \\
\hline PY $4 / \mathrm{PY} 16$ & 4 & -13.264 & -94.743 \\
\hline PY1/PY18 & 4 & -9.592 & -68.511 \\
\hline PY 6/PY15 & 4 & -11.743 & -83.880 \\
\hline $\mathrm{PY} 8 / \mathrm{PY} 12$ & 4 & -66.548 & -475.344 \\
\hline PY10 & 4 & -33.501 & -239.294 \\
\hline PY9/PY13 & 4 & -70.911 & -506.504 \\
\hline PY11 & 4 & -10.376 & -74.112 \\
\hline $\mathrm{PX} 1 / \mathrm{PX} 6$ & 3 & -18.286 & -130.612 \\
\hline $\mathrm{PX} 2 / \mathrm{PX} 5$ & 3 & -27.601 & -197.153 \\
\hline $\mathrm{PX} 7 / \mathrm{PX} 8$ & 3 & -17.788 & -127.060 \\
\hline $\mathrm{PX} 9 / \mathrm{PX} 12$ & 3 & -23.780 & -169.858 \\
\hline $\mathrm{PX} 10 / \mathrm{PX} 11$ & 3 & -55.283 & -394.880 \\
\hline $\mathrm{PX} 13 / \mathrm{PX} 18$ & 3 & -25.971 & -185.507 \\
\hline $\mathrm{PX} 14 / \mathrm{PX} 17$ & 3 & -65.184 & -465.602 \\
\hline PX15/PX16 & 3 & -27.897 & -199.264 \\
\hline PX19/PX24 & 3 & -22.607 & -161.479 \\
\hline PX20/PX23 & 3 & -39.605 & -282.892 \\
\hline $\mathrm{PX} 21 / \mathrm{PX} 22$ & 3 & -47.917 & -342.261 \\
\hline $\mathrm{P} \times 3$ & 3 & -52.463 & -374.733 \\
\hline PX4 & 3 & -38.670 & -276.217 \\
\hline $\mathrm{PY} 3 / \mathrm{PY} 20$ & 3 & -29.146 & -208.186 \\
\hline PY5/PY17 & 3 & -32.323 & -230.877 \\
\hline PY7 / PY14 & 3 & -26.339 & -188.137 \\
\hline PY2 / PY19 & 3 & -24.309 & -173.633 \\
\hline PY $4 / \mathrm{PY} 16$ & 3 & -26.528 & -189.487 \\
\hline PY1/PY18 & 3 & -19.183 & -137.023 \\
\hline PY 6/PY15 & 3 & -23.486 & -167.760 \\
\hline PY 8/PY12 & 3 & -80.097 & -572.119 \\
\hline PY10 & 3 & -45.582 & -325.589 \\
\hline PY9/PY13 & 3 & -84.251 & -601.796 \\
\hline PY11 & 3 & -16.004 & -114.314 \\
\hline $\mathrm{PX} 1 / \mathrm{PX} 6$ & 2 & -27.428 & -195.917 \\
\hline $\mathrm{PX} 2 / \mathrm{PX} 5$ & 2 & -41.402 & -295.729 \\
\hline
\end{tabular}




\begin{tabular}{|c|c|c|c|}
\hline $\mathrm{PX} 7 / \mathrm{PX} 8$ & 2 & -26.683 & -190.590 \\
\hline $\mathrm{PX} 9 / \mathrm{PX} 12$ & 2 & -35.670 & -254.786 \\
\hline $\mathrm{PX} 10 / \mathrm{PX} 11$ & 2 & -82.925 & -592.320 \\
\hline PX13/PX18 & 2 & -38.956 & -278.260 \\
\hline $\mathrm{PX} 14 / \mathrm{PX} 17$ & 2 & -97.776 & -698.403 \\
\hline $\mathrm{PX} 15 / \mathrm{PX} 16$ & 2 & -41.846 & -298.896 \\
\hline PX19/PX24 & 2 & -33.911 & -242.218 \\
\hline PX20/PX23 & 2 & -59.407 & -424.338 \\
\hline PX21/PX22 & 2 & -59.948 & -428.200 \\
\hline $\mathrm{PX} 3$ & 2 & -60.328 & -430.917 \\
\hline PX4 & 2 & -52.563 & -375.453 \\
\hline PY3/PY20 & 2 & -43.719 & -312.279 \\
\hline PY 5/PY1 7 & 2 & -48.484 & -346.315 \\
\hline PY7 / PY1 4 & 2 & -39.509 & -282.205 \\
\hline PY2 / PY1 9 & 2 & -36.463 & -260.450 \\
\hline PY $4 / P Y 16$ & 2 & -39.792 & -284.230 \\
\hline PY1/PY18 & 2 & -28.775 & -205.534 \\
\hline PY 6/PY15 & 2 & -35.230 & -251.640 \\
\hline PY8/PY12 & 2 & -93.645 & -668.893 \\
\hline PY10 & 2 & -57.664 & -411.883 \\
\hline PY9/PY13 & 2 & -97.592 & -697.087 \\
\hline PY11 & 2 & -21.632 & -154.517 \\
\hline $\mathrm{PX} 1 / \mathrm{PX} 6$ & 1 & -36.571 & -261.223 \\
\hline $\mathrm{P} \times 2 / \mathrm{PX} 5$ & 1 & -55.203 & -394.305 \\
\hline $\mathrm{PX} 7 / \mathrm{PX} 8$ & 1 & -35.577 & -254.120 \\
\hline $\mathrm{PX} 9 / \mathrm{PX} 12$ & 1 & -47.560 & -339.715 \\
\hline $\mathrm{PX} 10 / \mathrm{PX} 11$ & 1 & -110.566 & -789.760 \\
\hline PX13/PX18 & 1 & -51.942 & -371.013 \\
\hline $\mathrm{PX} 14 / \mathrm{PX} 17$ & 1 & -130.369 & -931.204 \\
\hline PX15/PX1 6 & 1 & -55.794 & -398.529 \\
\hline $\mathrm{PX} 19 / \mathrm{PX} 24$ & 1 & -45.214 & -322.958 \\
\hline $\mathrm{P} \times 20 / \mathrm{P} \times 23$ & 1 & -79.210 & -565.784 \\
\hline $\mathrm{P} \times 21 / \mathrm{P} \times 22$ & 1 & -71.980 & -514.139 \\
\hline $\mathrm{P} \times 3$ & 1 & -68.194 & -487.101 \\
\hline $\mathrm{PX} 4$ & 1 & -66.457 & -474.690 \\
\hline PY3 / PY20 & 1 & -58.292 & -416.372 \\
\hline PY 5/PY1 7 & 1 & -64.645 & -461.753 \\
\hline PY7 / PY1 4 & 1 & -52.678 & -376.274 \\
\hline PY2 / PY1 9 & 1 & -48.617 & -347.266 \\
\hline PY 4 / PY1 6 & 1 & -53.056 & -378.973 \\
\hline PY1/PY18 & 1 & -38.366 & -274.045 \\
\hline PY 6/PY15 & 1 & -46.973 & -335.520 \\
\hline $\mathrm{PY} 8 / \mathrm{PY} 12$ & 1 & -107.194 & -765.668 \\
\hline PY10 & 1 & -69.745 & -498.177 \\
\hline PY9/PY13 & 1 & -110.933 & -792.379 \\
\hline PY11 & 1 & -27.261 & -194.719 \\
\hline
\end{tabular}

COMP. TOTAL DAS ALV. PORTANTES $=\quad 77.25 \mathrm{M}$ PESO TOTAL DA EDIFICACAO $=-4763.43 \mathrm{KN}$ 


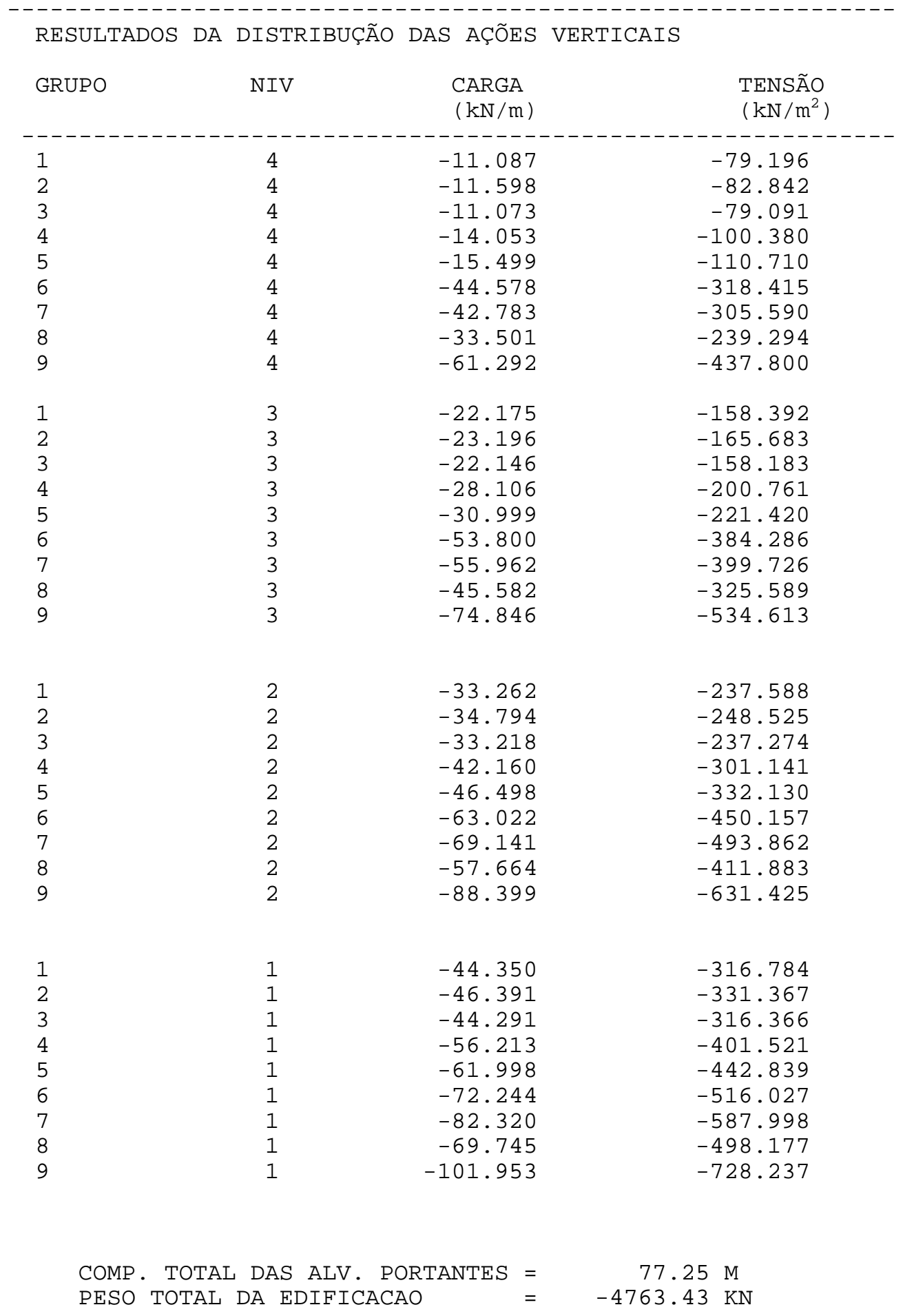




\section{ANEXO C}

Resultados da verificação das paredes de alvenaria do edifício do capítulo 5 (com 8 pavimentos) 


\section{Procedimento: PAREDES ISOLADAS - SITUAÇÃO A}

TECSOF ENGENHARIA S/C LTDA

PROGRAMA VPA - VERIFICAÇÃO DE PAREDES DE ALVENARIA - VERSÃO ABR/94

PROJETO : EXEMPLO DO CAPÍTULO 5

CLIENTE : DISSERTAÇÃO

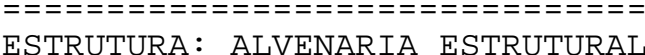

$======================0$

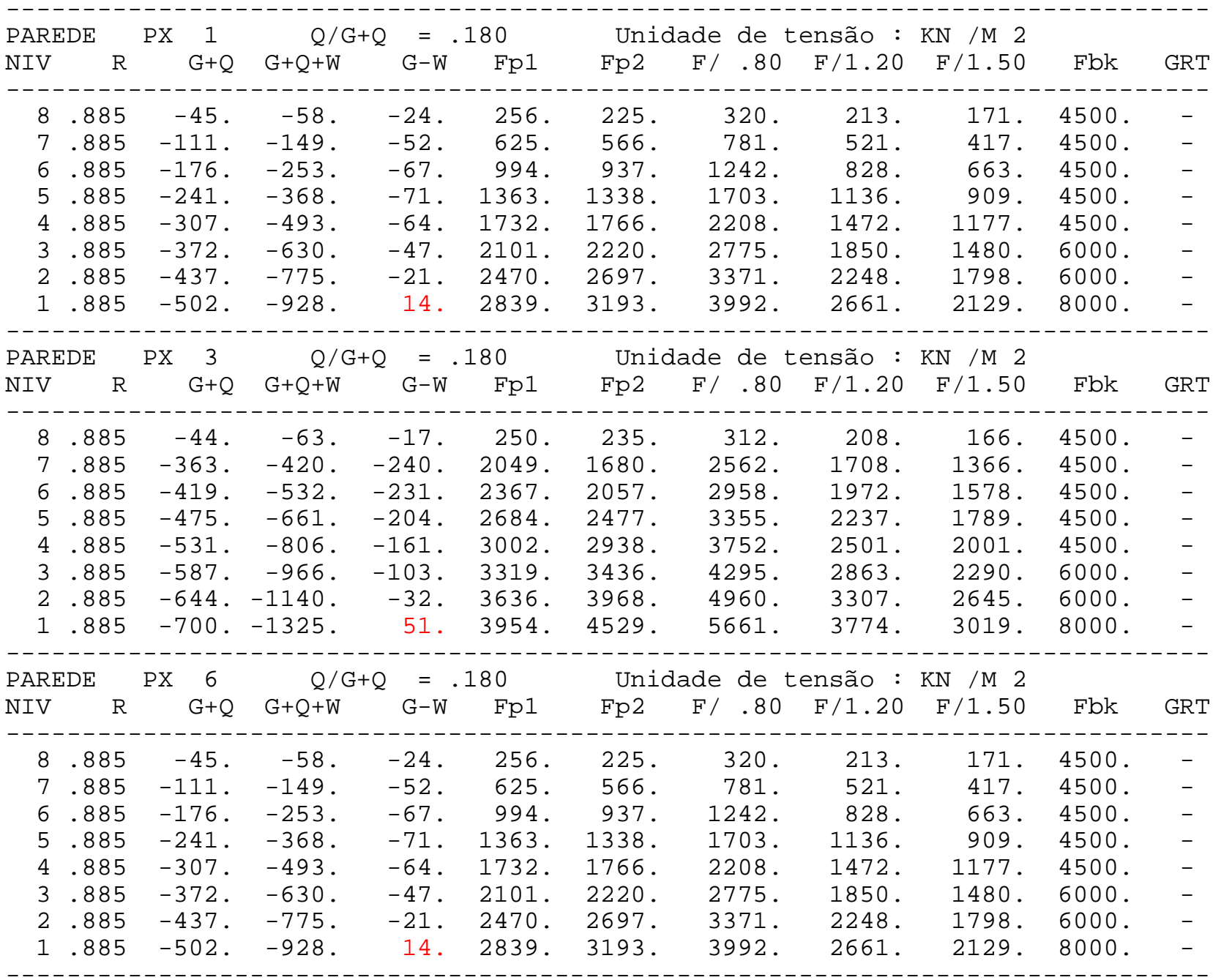




\begin{tabular}{|c|c|c|c|c|c|c|c|c|c|c|c|}
\hline \multicolumn{2}{|c|}{ PAREDE } & \multirow{2}{*}{$\begin{array}{l}10 \\
G+Q\end{array}$} & \multirow{2}{*}{$\begin{array}{c}Q / G+\mathrm{C} \\
\mathrm{G}+\mathrm{Q}+\mathrm{W}\end{array}$} & \multicolumn{2}{|c|}{$=.180$} & \multicolumn{2}{|c|}{ Unidade } & \multirow{2}{*}{$\begin{array}{r}\text { ensão: } \\
\text { F/1.20 }\end{array}$} & \multirow{2}{*}{$\begin{array}{r}\mathrm{KN} / \mathrm{M} 2 \\
\mathrm{~F} / 1.50\end{array}$} & \multirow[b]{2}{*}{ Fbok } & \multirow[b]{2}{*}{ GRT } \\
\hline NIV & $\mathrm{R}$ & & & $\mathrm{G}-\mathrm{W}$ & Fp1 & Fp2 & $\mathrm{F} /$ & & & & \\
\hline 8 & .885 & -56. & -59. & -43. & 317 . & 244. & 396. & 264 . & 211. & 4500. & - \\
\hline 7 & .885 & -253 & -261. & -200 . & 1432. & 1093. & 1790. & 1193. & 955. & 4500. & - \\
\hline 6 & .885 & -451 . & -466 . & -354. & 2548 . & 1949. & 3184 . & 2123. & 1698. & 4500 . & - \\
\hline 5 & .885 & -648 & -674 & -506 . & 3663. & 2810 & 4579. & 3053 . & 2442 . & 4500 . & G1 \\
\hline 4 & .885 & -846 & -883. & -656. & 4778 . & 3677 . & 5973. & 3982 . & 3186. & 4500 . & G1 \\
\hline 3 & .885 & -1043. & -1095 . & -804 . & 5894. & 4549 . & 7367. & 4912. & 3929. & 6000. & G1 \\
\hline 2 & .885 & -1241 & -1308 & -950. & 7009. & 5426 . & 8762 . & 5841. & 4673. & 6000. & G1 \\
\hline 1 & .885 & -1438 & -1523. & -1094 . & 8125. & 6307. & 10156 & 6771. & 5417 . & 8000 . & G1 \\
\hline
\end{tabular}

\begin{tabular}{|c|c|c|c|c|c|c|c|c|c|c|c|}
\hline \multirow{2}{*}{$\begin{array}{l}\text { PARED } \\
\text { NIV }\end{array}$} & \multirow{2}{*}{$E_{R}$} & \multirow{2}{*}{$\begin{array}{l}11 \\
\mathrm{G}+\mathrm{Q}\end{array}$} & \multirow{2}{*}{$\begin{array}{c}Q / G+S \\
G+Q+W\end{array}$} & \multirow{2}{*}{$\begin{array}{c}= \\
G-W\end{array}$} & \multirow{2}{*}{$\begin{array}{l}180 \\
\text { Fp1 }\end{array}$} & \multicolumn{2}{|c|}{ Unidade } & \multirow{2}{*}{$\begin{array}{l}\text { ensão: } \\
\text { F/1.20 }\end{array}$} & \multirow{2}{*}{$\begin{array}{r}\mathrm{KN} / \mathrm{M} 2 \\
\mathrm{~F} / 1.50\end{array}$} & \multirow[b]{2}{*}{ Fbk } & \multirow[b]{2}{*}{ GRT } \\
\hline & & & & & & Fp2 & $\mathrm{F} / .80$ & & & & \\
\hline 8 & .885 & -56. & -59. & -43 & 317 . & 244. & 396. & 264 . & 211 . & 4500 & - \\
\hline 7 & .885 & -253 & -261 & -200 . & 1432 . & 1093. & 1790. & 1193. & 955. & 4500 & - \\
\hline 6 & .885 & -451 & -466 & -354. & 2548 . & 1949. & 3184 . & 2123 . & 1698. & 4500 & - \\
\hline 5 & .885 & -648 & -674 & -506 & 3663 . & 2810 . & 4579. & 3053. & 2442 . & 4500 & G1 \\
\hline 4 & .885 & -846 & -883 & -656 & 4778 . & 3677 . & 5973. & 3982 . & 3186. & 4500 & G1 \\
\hline 3 & .885 & -1043. & -1095 & -804 & 5894. & 4549. & 7367 . & 4912. & 3929. & 6000 & $\perp$ \\
\hline 2 & .885 & -1241 & -1308 & -950 & 7009. & 5426. & 8762 . & 5841. & 4673. & 6000 & G1 \\
\hline 1 & .885 & -1438 & -1523 & -1094 & 8125 . & 6307. & 10156 & 6771. & 5417 . & 8000 & G1 \\
\hline
\end{tabular}

\begin{tabular}{|c|c|c|c|c|c|c|c|c|c|c|c|}
\hline \multirow{2}{*}{$\begin{array}{l}\text { PARED } \\
\text { NIV }\end{array}$} & \multirow{2}{*}{${ }^{E}$} & \multirow{2}{*}{$\begin{array}{l}13 \\
G+Q\end{array}$} & \multirow{2}{*}{$\begin{array}{c}Q / G+ \\
G+Q+W\end{array}$} & \multicolumn{2}{|c|}{$=.180$} & \multicolumn{2}{|c|}{ Unidade } & tensão : & $\mathrm{KN} / \mathrm{M} 2$ & \multirow[b]{2}{*}{ Fbk } & \multirow[b]{2}{*}{ GRT } \\
\hline & & & & $G-W$ & Fp1 & Fp2 & $\mathrm{F} / .80$ & $\mathrm{~F} / 1.20$ & $\mathrm{~F} / 1.50$ & & \\
\hline 8 & .885 & -42 & -60. & -16 & 235 . & 221. & 294. & 196. & 157. & 4500 & - \\
\hline 7 & .885 & -134 & -188. & -57 . & 759. & 703. & 949. & 632 . & 506. & 4500 & - \\
\hline 6 & .885 & -227 & -333. & -81. & 1283. & 1226. & 1604. & 1069. & 855 . & 4500 & - \\
\hline 5 & .885 & -320 & -494 . & -89. & 1807. & 1790. & 2259 . & 1506. & 1205. & 4500 & - \\
\hline 4 & .885 & -413 & -670. & -81. & 2331. & 2391. & 2989. & 1992. & 1594. & 4500 & - \\
\hline 3 & .885 & -505 & -860. & -60. & 2855 . & 3027 . & 3784 . & 2523. & 2018 . & 6000 & - \\
\hline 2 & .885 & -598 & -1063 . & -26 & 3379 . & 3696. & 4620 . & 3080 . & 2464 . & 6000 & - \\
\hline 1 & .885 & -691 & -1276 & 19. & 3903. & 4391. & 5488. & 3659 . & 2927 . & 8000 & - \\
\hline
\end{tabular}

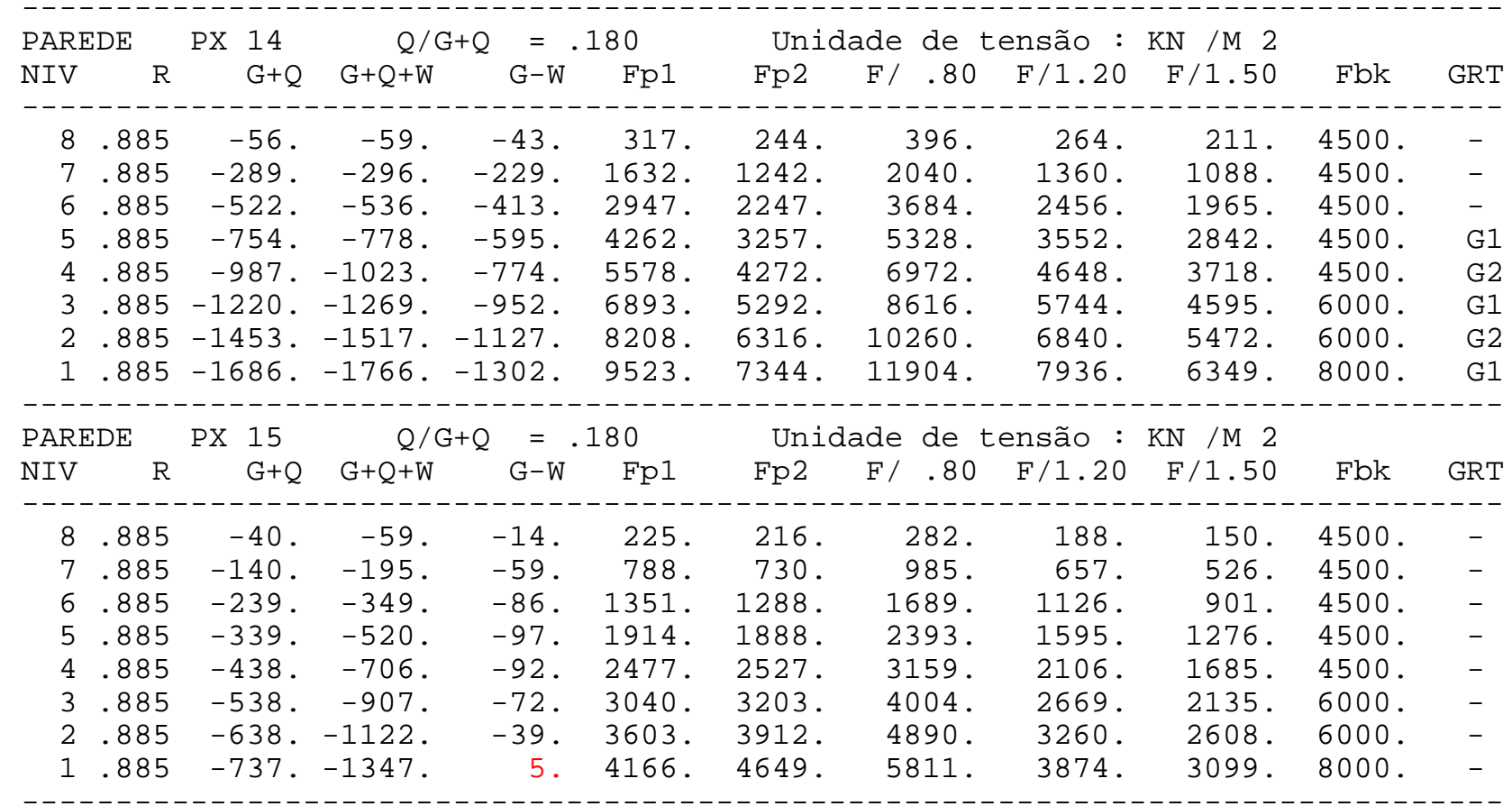




\begin{tabular}{|c|c|c|c|c|c|c|c|c|c|c|c|}
\hline \multicolumn{2}{|c|}{ PAREDE } & \multirow{2}{*}{$\begin{array}{ll}\mathrm{PX} & 16 \\
& \mathrm{G}+\mathrm{Q}\end{array}$} & $Q / G+Q$ & \multicolumn{2}{|c|}{$=.180$} & \multicolumn{2}{|c|}{ Unidade } & ensão : & $\mathrm{KN} / \mathrm{M} 2$ & \multirow[b]{2}{*}{ Fbk } & \multirow[b]{2}{*}{ GRT } \\
\hline NIV & $\mathrm{R}$ & & $\mathrm{G}+\mathrm{Q}+\mathrm{W}$ & $G-W$ & Fp1 & Fp2 & $\mathrm{F} / .80$ & $\mathrm{~F} / 1.20$ & $\mathrm{~F} / 1.50$ & & \\
\hline 8 & .885 & -40 & -59. & -14. & 225 . & 216. & 282 . & 188. & 150. & 4500 & \\
\hline 7 & .885 & -140 & -195 . & -59 & 788. & 730. & 985. & 657 . & 526. & 4500 & \\
\hline 6 & .885 & -239 & -349. & -86. & 1351. & 1288. & 1689. & 1126. & 901. & 4500 & - \\
\hline 5 & .885 & -339 & -520 . & -97 . & 1914. & 1888. & 2393. & 1595. & 1276 . & 4500 & \\
\hline 4 & .885 & -438 & -706. & -92 . & 2477 . & 2527. & 3159. & 2106 . & 1685 . & 4500 & - \\
\hline 3 & .885 & -538 & -907 . & -72. & 3040 . & 3203. & 4004. & 2669. & 2135 . & 6000 & - \\
\hline 2 & .885 & -638. & -1122 . & -39. & 3603 . & 3912 . & 4890 . & 3260 . & 2608 . & 6000 & - \\
\hline 1 & .885 & -737 & -1347 & 5. & 4166. & 4649 . & 5811. & 3874 . & 3099 . & 8000 & \\
\hline
\end{tabular}

\begin{tabular}{|c|c|c|c|c|c|c|c|c|c|c|c|}
\hline \multirow{2}{*}{$\begin{array}{l}\text { PAREDI } \\
\text { NIV }\end{array}$} & & \multirow{2}{*}{$\begin{array}{ll}\mathrm{X} & 17 \\
& \mathrm{G}+\mathrm{Q}\end{array}$} & \multirow{2}{*}{$\begin{array}{c}\mathrm{Q} / \mathrm{G}+ \\
\mathrm{G}+\mathrm{Q}+\mathrm{W}\end{array}$} & \multicolumn{2}{|c|}{$\mathrm{Q}=.180$} & \multicolumn{2}{|c|}{ Unidade } & \multirow{2}{*}{$\begin{array}{l}\text { ensão: } \\
\text { F/1.20 }\end{array}$} & $\mathrm{KN} / \mathrm{M} 2$ & \multirow[b]{2}{*}{ Fbk } & \multirow[b]{2}{*}{ GRT } \\
\hline & R & & & $G-W$ & Fp1 & $\mathrm{Fp} 2$ & $\mathrm{~F} / .80$ & & $\mathrm{~F} / 1.50$ & & \\
\hline 8 & .885 & -56 & -59. & -43 & 317. & 244 & 396. & 264 . & 211. & 4500 & - \\
\hline 7 & .885 & -289 & -296. & 29. & 1632. & 1242 . & 2040 . & 1360. & 1088 . & $\cdot$ & - \\
\hline 6 & .885 & -522 & -536. & -413 & 2947 . & 2247 . & 3684 . & 2456 . & 1965. & 4500 & - \\
\hline 5 & .885 & -754 & -778 . & -595 . & 4262 . & 3257 . & 5328. & 3552 . & 2842 . & 4500 & G1 \\
\hline 4 & .885 & -987 & -1023 & -774 & 5578. & 4272 . & 6972. & 4648 . & 3718 . & 4500 & G2 \\
\hline 3 & .885 & -1220 & -1269. & -952. & 6893. & 5292. & 8616. & 5744 . & 4595 . & 6000 & G1 \\
\hline 2 & .885 & -1453 & -1517 . & -1127 . & 8208 . & 6316. & 10260 . & 340. & 5472 . & 600 & G2 \\
\hline 1 & .885 & -1686 & -1766 & -1302 . & 9523. & 7344 . & 11904 & 7936 . & 6349. & 8000 . & G1 \\
\hline \multicolumn{2}{|c|}{ PAREDE } & $\mathrm{PX} 18$ & $Q / C$ & $Q$ & 80 & \multicolumn{3}{|c|}{ Unidade } & $\mathrm{KN} / \mathrm{M} 2$ & \multirow[b]{2}{*}{ Fbk } & \multirow[b]{2}{*}{ GRT } \\
\hline IV & $\mathrm{R}$ & $G+Q$ & $\mathrm{G}+\mathrm{Q}+\mathrm{W}$ & $G-W$ & Fp1 & Fp2 & $\mathrm{F} /$ & $\mathrm{F} / 1.20$ & $\mathrm{~F} / 1.50$ & & \\
\hline 8 & .885 & -42 & -60. & -16 & 235 & 22 & 294. & 196. & 157. & 45 & - \\
\hline 7 & .885 & -134 & -188. & -57 . & 759. & 703. & 949. & 632 . & 506. & 4500 & - \\
\hline 6 & .885 & -227 & -333 & -81 & 1283. & 1226. & 1604. & 1069. & 855 . & 4500 & - \\
\hline 5 & .885 & -320 & -494 & -89 & 1807. & 1790 . & 2259 . & 1506. & 1205 . & 4500 & - \\
\hline 4 & .885 & -413 & -670. & -81 & 2331. & 2391. & 2989. & 1992. & 1594 . & 4500 & - \\
\hline 3 & .885 & -505 & -860 & -60. & 2855 . & 3027 . & 3784 . & 2523. & 2018 & 6000 & - \\
\hline 2 & .885 & -598 & -1063 & -26 & 3379. & 3696. & 4620 . & 3080 . & 2464 . & 6000 & - \\
\hline 1 & .885 & -691 & -1276 & 19. & 3903. & 4391. & 5488 . & 3659 . & 2927 . & 8000 . & - \\
\hline
\end{tabular}

\begin{tabular}{|c|c|c|c|c|c|c|c|c|c|c|c|}
\hline \multirow{2}{*}{$\begin{array}{l}\text { PARED } \\
\text { NIV }\end{array}$} & \multirow{2}{*}{$\mathrm{E}$} & \multirow{2}{*}{$\begin{array}{ll}P X & 20 \\
& G+Q\end{array}$} & \multirow{2}{*}{$\begin{array}{c}\mathrm{Q} / \mathrm{G}+\mathrm{C} \\
\mathrm{G}+\mathrm{Q}+\mathrm{W}\end{array}$} & \multirow{2}{*}{$\begin{array}{c}= \\
G-W\end{array}$} & \multirow{2}{*}{$\begin{array}{l}180 \\
\text { Fp1 }\end{array}$} & \multicolumn{2}{|c|}{ Unidade } & \multirow{2}{*}{$\begin{array}{l}\text { ensão: } \\
\text { F/1.20 }\end{array}$} & \multirow{2}{*}{$\begin{array}{r}\mathrm{KN} / \mathrm{M} 2 \\
\mathrm{~F} / 1.50\end{array}$} & \multirow[b]{2}{*}{ Fbk } & \multirow[b]{2}{*}{ GRT } \\
\hline & & & & & & Fp2 & $\mathrm{F} / .80$ & & & & \\
\hline 8 & .885 & -73 & -77 . & -55. & 412 . & 320 & 515. & 343 . & 274 . & 4500 . & - \\
\hline 7 & .885 & -214 & -228 . & -162 & 1211. & 942 . & 1514 . & 1009. & 807 . & 4500 . & - \\
\hline 6 & .885 & -356 & -382 . & -265 & 2010 . & 1574. & 2512 . & 1675. & 1340 . & 4500 . & - \\
\hline 5 & .885 & -497 & -541. & -364 & 2809 . & 2216 . & 3511. & 2341. & 1873. & 4500 . & - \\
\hline 4 & .885 & -639. & -703 & -459 & 3608 . & 2868. & 4510 . & 3007 . & 2405 . & 4500. & G1 \\
\hline 3 & .885 & -780 & -869 & -550 & 4407 . & 3529 . & 5509. & 3673. & 2938 . & 6000. & - \\
\hline 2 & .885 & -922. & -1039. & -639. & 5207. & 4198. & 6508. & 4339. & 3471 . & 6000. & G1 \\
\hline 1 & .885 & -1063 & -1211 & -724 & 6006. & 4873. & 7507. & 5005 . & 4004 . & 8000 . & - \\
\hline
\end{tabular}

\begin{tabular}{|c|c|c|c|c|c|c|c|c|c|c|c|}
\hline \multicolumn{2}{|c|}{ PAREDE } & \multirow{2}{*}{$\begin{array}{ll}\mathrm{PX} & 23 \\
& \mathrm{G}+\mathrm{Q}\end{array}$} & $\mathrm{Q} / \mathrm{G}+\mathrm{Q}$ & \multicolumn{2}{|c|}{$2=.180$} & Unidade & \multicolumn{2}{|c|}{ de tensão : } & $\mathrm{KN} / \mathrm{M} 2$ & \multirow[b]{2}{*}{ Fbk } & \multirow[b]{2}{*}{ GRT } \\
\hline NIV & $\mathrm{R}$ & & $\mathrm{G}+\mathrm{Q}+\mathrm{W}$ & $G-W$ & Fp1 & Fp2 & $\mathrm{F} / .80$ & $\mathrm{~F} / 1.20$ & $\mathrm{~F} / 1.50$ & & \\
\hline 8 & .885 & -73 & -77 & -55. & 412 . & 320 . & 515. & 343. & 274 . & 4500 . & - \\
\hline 7 & .885 & -214 & -228 & -162 . & 1211. & 942. & 1514. & 1009. & 807 . & 4500 . & - \\
\hline 6 & .885 & -356 & -382 . & -265 & 2010 . & 1574 . & 2512 . & 1675. & 1340. & 4500. & - \\
\hline 5 & .885 & -497 & -541. & -364 & 2809 . & 2216 . & 3511. & 2341 . & 1873. & 4500 . & - \\
\hline 4 & .885 & -639. & -703 & -459 & 3608 . & 2868 . & 4510 . & 3007 . & 2405 . & 4500 . & G1 \\
\hline 3 & .885 & -780 & -869. & -550 & 4407 . & 3529 . & 5509. & 3673. & 2938. & 6000. & - \\
\hline 2 & .885 & -922 & -1039. & -639. & 5207 . & 4198. & 6508. & 4339. & 3471. & 6000 . & G1 \\
\hline 1 & .885 & -1063 & -1211 & -724 & 6006. & 4873. & 7507 . & 5005. & 4004 . & 8000 . & - \\
\hline
\end{tabular}




PAREDE
NIV

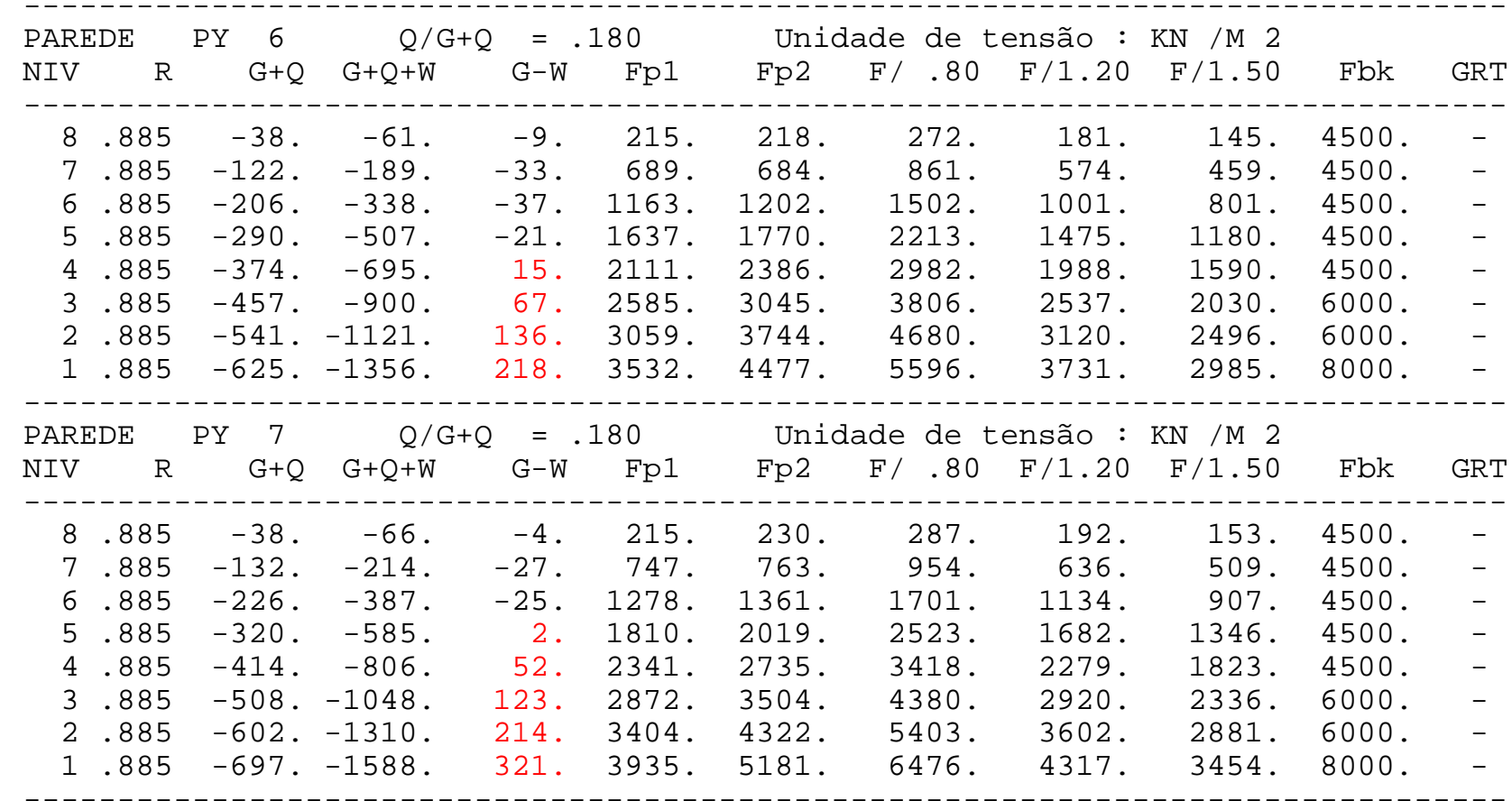

\begin{tabular}{|c|c|c|c|c|c|c|c|c|c|c|c|}
\hline \multirow{2}{*}{$\begin{array}{l}\text { PARED } \\
\text { NIV }\end{array}$} & \multirow{2}{*}{$E_{R}$} & PY & \multirow{2}{*}{$\begin{array}{c}Q / G+Q \\
G+Q+W\end{array}$} & \multicolumn{2}{|c|}{$Q=.180$} & \multicolumn{2}{|c|}{ Unidade } & \multicolumn{2}{|c|}{ tensão : KN /M 2} & \multirow[b]{2}{*}{ Fbk } & \multirow[b]{2}{*}{ GRT } \\
\hline & & $\begin{array}{c}8 \\
G+Q\end{array}$ & & $\mathrm{G}-\mathrm{W}$ & Fp1 & Fp2 & $\mathrm{F} / .80$ & $\mathrm{~F} / 1.20$ & $\mathrm{~F} / 1.50$ & & \\
\hline 8 & .885 & -39. & -69. & -3 & 222 . & 239. & 299. & 200 . & 160. & 4500 & - \\
\hline 7 & .885 & -515 . & -601. & -335 & 2907 . & 2398 . & 3634 . & 2423 . & 1938 . & 4500 & - \\
\hline 6 & .885 & -611. & -783. & -330 & 3454 . & 3020 . & 4318. & 2878 . & 2303 . & 4500 & - \\
\hline 5 & .885 & -708 & -991 & -298 & 4001 . & 3707 . & 5001. & 3334 . & 2667 . & 4500 & G1 \\
\hline 4 & .885 & -805 & -1223 & -242 & 4548 . & 4455 . & 5684. & 3790. & 3032 . & 4500 & G1 \\
\hline 3 & .885 & -902. & -1478 & -163 & 5094 . & 5261 . & 6576. & 4384 & 3507 . & 6000 & G1 \\
\hline 2 & .885 & -998 & -1754 . & -64. & 5641. & 6119. & 7648. & 5099. & 4079. & 6000 & G1 \\
\hline 1 & .885 & -1095 . & -2047 & 53. & 6188. & 7020 . & 8775 . & 5850. & 4680 & 8000 & G1 \\
\hline
\end{tabular}

PAREDE PY $9 \quad \mathrm{Q} / \mathrm{G}+\mathrm{Q}=.180 \quad$ Unidade de tensão : $\mathrm{KN} / \mathrm{M} 2$

\begin{tabular}{|c|c|c|c|c|c|c|c|c|c|c|c|}
\hline $\mathrm{NIV}$ & $\mathrm{R}$ & $\mathrm{G}+\mathrm{Q}$ & $\mathrm{G}+\mathrm{Q}+\mathrm{W}$ & $G-W$ & Fp1 & Fp2 & $\mathrm{F} / .80$ & $\mathrm{~F} / 1.20$ & $\mathrm{~F} / 1.50$ & Fbk & GRT \\
\hline 8 & .885 & -40 & -67 & -6 & 228 . & 238. & 297. & 198. & 158. & 4500 . & - \\
\hline 7 & .885 & -547 & -626 & -369 & 3090 . & 2515 & 3862 . & 2575 . & 2060 . & 4500 . & - \\
\hline 6 & .885 & -642 & -798. & -370 & 3628 . & 3112 . & 4535 . & 3023 . & 2419 . & 4500 . & G1 \\
\hline 5 & .885 & -737 & -995 & -348 & 4166 . & 3767 . & 5208 . & 3472 . & 2778 & 4500 . & G1 \\
\hline 4 & .885 & -833 & -1213 & -302 & 4705 . & 4479 . & 5881. & 3921. & 3136 . & 4500 . & G1 \\
\hline 3 & .885 & -928 & -1453 & -236 & 5243 . & 5244 & 6554. & 4370 . & 3496 . & 6000. & G1 \\
\hline 2 & .885 & -1023 & -1711 & -152 & 5781 & 6055 & 7568. & 5046 . & 4036 . & 6000. & G1 \\
\hline 1 & .885 & -1119. & -1985 & -51. & 6320 & 6905 & 8632. & 5755 . & 4604 . & 8000 . & G1 \\
\hline
\end{tabular}




\begin{tabular}{|c|c|c|c|c|c|c|c|c|c|c|c|}
\hline \multirow{2}{*}{\multicolumn{2}{|c|}{$\begin{array}{l}\text { PAREDE } \\
\text { NIV R }\end{array}$}} & \multirow{2}{*}{$\begin{array}{ll}\text { PY } & 11 \\
& \mathrm{G}+\mathrm{Q}\end{array}$} & \multirow{2}{*}{$\begin{array}{l}Q / G+\mathrm{Q} \\
G+Q+W\end{array}$} & \multirow{2}{*}{$2=$} & \multirow{2}{*}{$\begin{array}{l}180 \\
\text { Fp1 }\end{array}$} & Unidade & \multicolumn{2}{|c|}{ de tensão: } & $\mathrm{KN} / \mathrm{M} 2$ & \multirow[b]{2}{*}{ Fbk } & \multirow[b]{2}{*}{ GRT } \\
\hline & & & & & & Fp2 & $\mathrm{F} / .80$ & $\mathrm{~F} / 1.20$ & $\mathrm{~F} / 1.50$ & & \\
\hline 8 & .885 & -40 & -58 & -15 & 227 . & 216 . & 284. & 189. & 151. & 4500 . & - \\
\hline 7 & .885 & -114 & -168 & -40 & 646. & 619. & 807. & 538. & 431. & 4500 . & - \\
\hline 6 & .885 & -155. & -261 & -21 & 873. & 920. & 1150. & 767 . & 613. & 4500 . & - \\
\hline 5 & .885 & -195 & -369 & 15. & 1100 . & 1262 . & 1577 . & 1051. & 841 . & 4500 . & - \\
\hline 4 & .885 & -235 & -493 & 66. & 1327. & 1642 . & 2052 . & 1368. & 1094 . & 4500 . & - \\
\hline 3 & .885 & -275 & -631 & 131. & 1554. & 2057 . & 2571 . & 1714. & 1371. & 6000. & - \\
\hline 2 & .885 & -315 & -782 & 209. & 1782 . & 2504 . & 3130 . & 2087 . & 1669. & 6000 . & - \\
\hline 1 & .885 & -356 & -944 & 297 . & 2009 . & 2978 & 3722 . & 2482 . & 1985. & 8000 . & - \\
\hline
\end{tabular}

\begin{tabular}{|c|c|c|c|c|c|c|c|c|c|c|c|}
\hline \multirow{2}{*}{$\begin{array}{l}\text { PARED } \\
\text { NIV }\end{array}$} & \multirow{2}{*}{$\mathrm{E}_{\mathrm{R}}$} & \multirow{2}{*}{$\begin{array}{ll}\text { PY } & 12 \\
& \mathrm{G}+\mathrm{Q}\end{array}$} & \multirow{2}{*}{$\begin{array}{c}Q / G+Q \\
G+Q+W\end{array}$} & \multicolumn{2}{|c|}{$2=.180$} & \multicolumn{2}{|c|}{ Unidade } & \multirow{2}{*}{$\begin{array}{c}\text { ensão: } \\
\text { F/1.20 }\end{array}$} & $\mathrm{KN} / \mathrm{M} 2$ & \multirow[b]{2}{*}{ Fbk } & \multirow[b]{2}{*}{ GRT } \\
\hline & & & & $\mathrm{G}-\mathrm{W}$ & Fp1 & Fp2 & $\mathrm{F} / .80$ & & $\mathrm{~F} / 1.50$ & & \\
\hline 8 & .885 & -39 & -69. & -3 & 222 . & 239. & 299. & 200 . & 160. & 4500 & - \\
\hline 7 & .885 & -515 & -601. & -335 & 2907. & 2398. & 3634 . & 2423 . & 1938 . & 4500 . & - \\
\hline 6 & .885 & -611. & -783. & -330 & 3454 . & 3020 . & 4318 & 2878 . & 2303. & 4500 . & - \\
\hline 5 & .885 & -708 & -991. & -298 & 4001 . & 3707 . & 5001. & 3334. & 2667 . & 4500 . & G1 \\
\hline 4 & .885 & -805 & -1223 & -242 & 4548 . & 4455 . & 5684 . & 3790 . & 3032 . & 4500 . & G1 \\
\hline 3 & .885 & -902 & -1478 & -163 & 5094. & 5261. & 6576. & 4384 . & 3507 . & 6000 & G1 \\
\hline 2 & .885 & -998 & -1754 & -64. & 5641. & 6119. & 7648 . & 5099. & 4079 . & 6000 & G1 \\
\hline 1 & .885 & -1095 & -2047 & 53. & 6188. & 7020 . & 8775 . & 5850 & 4680 & 8000 & G1 \\
\hline \multicolumn{2}{|c|}{ PAREDE } & \multirow{2}{*}{$\begin{array}{ll}\text { PY } & 13 \\
& \mathrm{G}+\mathrm{Q}\end{array}$} & $Q / C$ & \multicolumn{2}{|c|}{$=.180$} & \multicolumn{2}{|c|}{ Unidade } & são: & $\mathrm{KN} / \mathrm{M} 2$ & \multirow[b]{2}{*}{ Fbk } & \multirow[b]{2}{*}{ GRT } \\
\hline NIV & $\mathrm{R}$ & & $\mathrm{G}+\mathrm{Q}+\mathrm{W}$ & $G-W$ & Fp1 & Fp2 & $\mathrm{F} / .80$ & $\mathrm{~F} / 1.20$ & $\mathrm{~F} / 1.50$ & & \\
\hline 8 & .885 & -40 & -64. & -9 . & 228. & 230. & 288 & 192. & 154 . & 4500 . & - \\
\hline 7 & .885 & -547 & -617. & -378 & 3090 . & 2494. & 3862 . & 2575 . & 2060 . & 4500 & - \\
\hline 6 & .885 & -642 & -782 . & -387 & 3628 . & 3070 . & 4535 . & 3023 . & 2419 . & 4500 & G1 \\
\hline 5 & .885 & -737 & -967. & -375 & 4166. & 3699. & 5208 . & 3472 . & 2778 . & 4500 & G1 \\
\hline 4 & .885 & -833 & -1172 & -343 & 4705 . & 4377 . & 5881. & 3921 . & 3136 . & 4500 & G1 \\
\hline 3 & .885 & -928 & -1396. & -293 & 5243. & 5103. & 6554 . & 4369 . & 3495 . & 6000 & G1 \\
\hline 2 & .885 & -1023. & -1637. & -225 & 5781. & 5870 . & 7338 . & 4892 . & 3914 . & 6000 & G1 \\
\hline 1 & .885 & -1119 & -1892 & -144 & 6320. & 6673. & 8341 . & 5561. & 4449 . & 8000 & G1 \\
\hline \multicolumn{2}{|c|}{ PAREDE } & \multirow{2}{*}{$\begin{array}{ll}\text { PY } & 14 \\
& G+Q\end{array}$} & $Q / C$ & \multicolumn{2}{|c|}{$=.180$} & \multicolumn{2}{|c|}{ Unidade } & Isão & \multirow{2}{*}{$\begin{array}{r}\mathrm{KN} / \mathrm{M} 2 \\
\mathrm{~F} / 1.50\end{array}$} & \multirow[b]{2}{*}{ Fbk } & \multirow[b]{2}{*}{ GRT } \\
\hline NIV & R & & $\mathrm{G}+\mathrm{Q}+\mathrm{W}$ & $G-W$ & Fp1 & Fp2 & 80 & $\mathrm{~F} / 1.20$ & & & \\
\hline 8 & .885 & -38 & -66. & -4 . & 21 & 230. & 287. & 192. & 153. & 4500 & - \\
\hline 7 & .885 & -132. & -214. & -27 . & 747. & 763. & 954. & 636. & 509. & 4500 & - \\
\hline 6 & .885 & -226 & -387 & -25 . & 1278. & 1361. & 1701. & 1134 . & 907. & 4500 & - \\
\hline 5 & .885 & -320 & -585. & 2 . & 1810. & 2019. & 2523 . & 1682 . & 1346 . & 4500 & - \\
\hline 4 & .885 & -414 & -806 . & 52 . & 2341 . & 2735 . & 3418 . & 2279 . & 1823 . & 4500 & - \\
\hline 3 & .885 & -508 & -1048 & 123. & 2872 . & 3504 . & 4380 & 2920 . & 2336 . & 6000 & - \\
\hline 2 & .885 & -602 & -1310 & 214. & 3404 . & 4322 . & 5403. & 3602 . & 2881 . & 6000 & - \\
\hline 1 & .885 & -697 & -1588 & 321. & 3935. & 5181. & 6476 . & 4317 . & 3454 . & 8000 & - \\
\hline
\end{tabular}

\begin{tabular}{|c|c|c|c|c|c|c|c|c|c|c|c|}
\hline \multirow{2}{*}{$\begin{array}{l}\text { PARED } \\
\text { NIV }\end{array}$} & \multirow{2}{*}{$E_{R}$} & \multirow{2}{*}{$\begin{array}{l}15 \\
G+Q\end{array}$} & \multirow{2}{*}{$\begin{array}{c}Q / G+Q \\
G+Q+W\end{array}$} & \multicolumn{2}{|c|}{$=.180$} & \multicolumn{2}{|c|}{ Unidade } & \multirow{2}{*}{$\begin{array}{l}\text { ensão: } \\
\text { F/1.20 }\end{array}$} & \multirow{2}{*}{$\begin{array}{r}\mathrm{KN} / \mathrm{M} 2 \\
\mathrm{~F} / 1.50\end{array}$} & \multirow[b]{2}{*}{ Fbk } & \multirow[b]{2}{*}{ GRT } \\
\hline & & & & $G-W$ & Fp1 & Fp2 & $\mathrm{F} / .80$ & & & & \\
\hline 8 & .885 & -38 & -61. & -9 . & 215 . & 218 . & 272 . & 181. & 145 . & 4500 . & - \\
\hline 7 & .885 & -122 . & -189. & -33 . & 689. & 684. & 861. & 574 . & 459 . & 4500 . & - \\
\hline 6 & .885 & -206. & -338. & -37 & 1163. & 1202 . & 1502 . & 1001 . & 801. & 4500 . & - \\
\hline 5 & .885 & -290 . & -507 . & -21 & 1637. & 1770 . & 2213 . & 1475 . & 1180 . & 4500 . & - \\
\hline 4 & .885 & -374 & -695. & 15. & 2111. & 2386. & 2982 . & 1988 . & 1590 . & 4500 . & - \\
\hline 3 & .885 & -457 . & -900 . & 67. & 2585 . & 3045. & 3806 . & 2537 . & 2030 . & 6000. & - \\
\hline 2 & .885 & -541. & -1121 & 136. & 3059 . & 3744 . & 4680. & 3120 . & 2496 . & 6000 . & - \\
\hline 1 & .885 & -625. & -1356. & 218 . & 3532 . & 4477 . & 5596 . & 3731 . & 2985. & 8000 . & - \\
\hline
\end{tabular}




\begin{tabular}{|c|c|c|c|c|c|c|c|c|c|c|c|}
\hline \multirow{2}{*}{$\begin{array}{l}\text { PARED } \\
\text { NIV }\end{array}$} & \multirow{2}{*}{$E_{R}$} & \multirow{2}{*}{$\begin{array}{ll}\mathrm{PY} & 18 \\
& \mathrm{G}+\mathrm{Q}\end{array}$} & \multirow{2}{*}{$\begin{array}{l}Q / G+Q \\
G+Q+W\end{array}$} & \multirow{2}{*}{$\begin{array}{c}= \\
G-W\end{array}$} & \multirow{2}{*}{$\begin{array}{l}180 \\
\text { Fp1 }\end{array}$} & \multicolumn{2}{|c|}{ Unidade } & \multirow{2}{*}{$\begin{array}{r}\text { tensão : } \\
F / 1.20\end{array}$} & \multirow{2}{*}{$\begin{array}{r}\mathrm{KN} / \mathrm{M} 2 \\
\mathrm{~F} / 1.50\end{array}$} & \multirow[b]{2}{*}{ Fbk } & \multirow[b]{2}{*}{ GRT } \\
\hline & & & & & & Fp2 & $\mathrm{F} / .80$ & & & & \\
\hline 8 & .885 & -43 & -66 & -12 & 244 . & 241 . & 305 . & 203. & 163. & 4500 & - \\
\hline 7 & .885 & -112 . & -180 & -23 & 631. & 645. & 806. & 537. & 430 & 4500 & - \\
\hline 6 & .885 & -180. & -316 & -12 & 1018. & 1102 . & 1378 . & 919. & 735. & 4500 & - \\
\hline 5 & .885 & -249. & -472 & 19. & 1405. & 1611 & 2014 . & 1343 . & 1074 . & 4500 & - \\
\hline 4 & .885 & -317 . & -647 & 70 . & 1792. & 2169 & 2711 . & 1807 . & 1446 . & 4500 & - \\
\hline 3 & .885 & -386. & -840 & 138. & 2179. & 2771 & 3464 . & 2309 . & 1847 . & 6000 & - \\
\hline 2 & .885 & -454. & -1050. & 223. & 2567 . & 3415 . & 4268 & 2846 . & 2276 . & 6000 & - \\
\hline 1 & .885 & -523. & -1274 & 322 . & 2954 . & 4092 & 5115. & 3410 . & 2728 & 8000 & - \\
\hline
\end{tabular}

\section{Procedimento: PAREDES ISOLADAS - SITUAÇÃO B}

TECSOF ENGENHARIA S/C LTDA

PROGRAMA VPA - VERIFICAÇÃO DE PAREDES DE ALVENARIA - VERSÃO ABR/94

PROJETO : EXEMPLO DO CAPÍTULO 5

CLIENTE : DISSERTAÇÃO

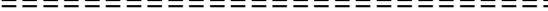

ESTRUTURA: ALVENARIA ESTRUTURAL

$=========$

\begin{tabular}{|c|c|c|c|c|c|c|c|c|c|c|c|}
\hline \multirow{2}{*}{$\begin{array}{l}\text { PARED } \\
\text { NIV }\end{array}$} & \multirow{2}{*}{$\mathrm{E}$} & \multirow{2}{*}{$\begin{array}{cc}\mathrm{PX} & 1 \\
& \mathrm{G}+\mathrm{Q}\end{array}$} & \multirow{2}{*}{$\begin{array}{c}Q / G+ \\
G+Q+W\end{array}$} & \multirow{2}{*}{$\begin{array}{c}= \\
G-W\end{array}$} & \multirow{2}{*}{$\begin{array}{r}180 \\
\text { Fp1 }\end{array}$} & \multicolumn{4}{|c|}{ Unidade de tensão : KN /M 2} & \multirow[b]{2}{*}{ Fbk } & \multirow[b]{2}{*}{ GRT } \\
\hline & & & & & & Fp2 & $\mathrm{F} / .80$ & $\mathrm{~F} / 1.20$ & $\mathrm{~F} / 1.50$ & & \\
\hline 8 & .885 & -45 & -58 & -24 & 256. & 225 . & 320. & 213. & 171. & 4500 & - \\
\hline 7 & .885 & -111 & -149 & -52 & 625. & 566. & 781. & 521 & 417 . & 4500 & - \\
\hline 6 & .885 & -176 & -253 & -67 & 994. & 937. & 1242 . & 828 . & 663. & 4500 & - \\
\hline 5 & .885 & -241 & -368 & -71 & 1363. & 1338 & 1703 . & 1136 . & 909. & 4500 & - \\
\hline 4 & .885 & -307 & -493 & -64. & 1732 . & 1766 & 2208 & 1472 . & 1177 . & 6000 & - \\
\hline 3 & .885 & -372 & -630 & -47 & 2101. & 2220 & 2775 . & 1850 & 1480 & 6000 & - \\
\hline 2 & .885 & -437 & -775 & -21 & 2470 . & 2697 . & 3371. & 2248 & 1798. & 8000 & - \\
\hline 1 & .885 & -502 . & -928 & 14 & 2839. & 3193. & 3992 . & 2661 . & 2129. & 8000 & - \\
\hline \multicolumn{2}{|c|}{ PAREDE } & \multirow{2}{*}{$\begin{array}{cc}P X & 3 \\
& G+Q\end{array}$} & \multirow{2}{*}{$\begin{array}{c}Q / G+C \\
G+Q+W\end{array}$} & $+Q$ & 80 & \multicolumn{2}{|c|}{ Unidade } & ensão : & $\mathrm{KN} / \mathrm{M} 2$ & & \\
\hline NIV & $\mathrm{R}$ & & & $G-W$ & Fp1 & Fp2 & $\mathrm{F} / .80$ & $\mathrm{~F} / 1.20$ & $\mathrm{~F} / 1.50$ & Fbk & GRT \\
\hline 8 & .885 & -44 & -63 & -17 . & 250. & 235 . & 312 . & 208 . & 166. & 4500 & - \\
\hline 7 & .885 & -363 & -420 & -240 & 2049 . & 1680 & 2562 . & 1708 & 1366. & 4500 & - \\
\hline 6 & .885 & -419 & -532 & -231 & 2367 . & 2057 . & 2958 . & 1972 . & 1578 & 4500 & - \\
\hline 5 & .885 & -475 & -661 & -204 & 2684 . & 2477 & 3355 . & 2237 & 1789. & 4500 & - \\
\hline 4 & .885 & -531 & -806 & -161 & 3002 . & 2938 & 3752 . & 2501. & 2001 . & 6000 & - \\
\hline 3 & .885 & -587. & -966 & -103 & 3319 . & 3436 . & 4295 . & 2863 & 2290 & 6000 & - \\
\hline 2 & .885 & -644 & -1140 & -32 & 3636 . & 3968 & 4960 . & 3307 . & 2645 . & 8000 & - \\
\hline 1 & .885 & -700 & -1325 & 51. & 3954 . & 4529 . & 5661. & 3774 . & 3019. & 8000 & - \\
\hline
\end{tabular}




\begin{tabular}{|c|c|c|c|c|c|c|c|c|c|c|c|}
\hline \multirow{2}{*}{$\begin{array}{l}\text { PAREDI } \\
\text { NIV }\end{array}$} & \multirow{2}{*}{$E_{R}$} & \multirow{2}{*}{$\begin{array}{cc}P X & 6 \\
& G+Q\end{array}$} & \multirow{2}{*}{$\begin{array}{l}Q / G+C \\
G+Q+W\end{array}$} & \multirow{2}{*}{$\mathrm{Q}_{\mathrm{G}-\mathrm{W}}^{=}$. } & \multirow{2}{*}{$\begin{array}{l}180 \\
\text { Fp1 }\end{array}$} & \multicolumn{2}{|c|}{ Unidade } & \multirow{2}{*}{$\begin{array}{l}\text { tensão: } \\
\text { F/1.20 }\end{array}$} & \multirow{2}{*}{$\begin{array}{r}\mathrm{KN} / \mathrm{M} 2 \\
\mathrm{~F} / 1.50\end{array}$} & \multirow[b]{2}{*}{ Fbk } & \multirow[b]{2}{*}{ GRT } \\
\hline & & & & & & Fp2 & $\mathrm{F} / .80$ & & & & \\
\hline 8 & .885 & -45 & -58 & -24 & 256. & 225 . & 320 . & 213. & 171. & 4500 & - \\
\hline 7 & .885 & -111 & -149 . & -52 & 625. & 566 . & 781. & 521. & 417 . & 500 . & - \\
\hline 6 & .885 & -176 & -253 & -67 & 994. & 937. & 1242 . & 828. & 663. & 00 & - \\
\hline 5 & .885 & -241 & -368 & -71 & 1363. & 1338 & 1703. & 1136. & 909. & 4500 & - \\
\hline 4 & .885 & -307 & -493 & -64 & 1732 . & 1766 & 2208 . & 1472 . & 1177 . & 6000 & - \\
\hline 3 & .885 & -372 & -630 & -47 & 2101 . & 2220 & 2775 . & 1850 . & 1480 . & 6000 & - \\
\hline 2 & .885 & -437 & -775 & -21 & 2470 . & 2697 & 3371. & 2248 & 1798 . & 8000 . & - \\
\hline 1 & .885 & -502 & -928 & 14 & 283 & 193. & 3992 . & 2661. & 2129 & 000 & - \\
\hline \multirow{2}{*}{\multicolumn{2}{|c|}{$\begin{array}{l}\text { PAREDE } \\
\text { NIV }\end{array}$}} & \multirow{2}{*}{$\begin{array}{ll}P X & 10 \\
& G+Q\end{array}$} & \multirow{2}{*}{$\begin{array}{l}\mathrm{Q} / \mathrm{G}+\mathrm{Q} \\
\mathrm{G}+\mathrm{Q}+\mathrm{W}\end{array}$} & $+Q$ & 30 & \multicolumn{3}{|c|}{ Unidade de tensão : } & \multirow{2}{*}{$\begin{array}{r}\mathrm{KN} / \mathrm{M} 2 \\
\mathrm{~F} / 1.50\end{array}$} & \multirow[b]{2}{*}{ Fbk } & \multirow[b]{2}{*}{ GRT } \\
\hline & & & & $G-W$ & Fp1 & Fp2 & $\mathrm{F} / .80$ & $\mathrm{~F} / 1.20$ & & & \\
\hline 8 & .885 & -56 & -59 & -43 & 31 & 244 . & 396. & 264 . & 211 & 500 & - \\
\hline 7 & .885 & -253 & -261 . & -200 & 1432 . & 1093 & 1790. & 1193. & 955. & 500 & - \\
\hline 6 & .885 & -451 & -466 & -354 & 2548 . & 1949 . & 3184 . & 2123 . & 1698. & 500 & - \\
\hline 5 & .885 & -648 & -674 & -506 & 3663 . & 2810 & 4579. & 3053 . & 2442 . & 4500 & G1 \\
\hline 4 & .885 & -846 & -883 & -656 & 4778 . & 3677 . & 5973. & 3982 . & 3186. & 6000 & - \\
\hline 3 & .885 & -1043 & -1095 & -804 & 5894 . & 4549 & 7367 . & 4912 . & 3929. & 60 & G] \\
\hline 2 & .885 & -1241 & -1308 & -950 & 7009 . & 5426 & 8762 . & 5841 . & 4673. & 8000 & G1 \\
\hline 1 & .885 & -1438 & -1523 & 1094 & 8125. & 6307 & 10156 & 6771. & 5417 . & 8000 & G1 \\
\hline \multirow{2}{*}{\multicolumn{2}{|c|}{$\begin{array}{ll}\text { PAREDE } & \\
\text { NIV R }\end{array}$}} & \multirow{2}{*}{$\begin{array}{ll}\mathrm{PX} & 11 \\
& \mathrm{G}+\mathrm{Q}\end{array}$} & \multirow{2}{*}{\multicolumn{2}{|c|}{$\begin{array}{cc}Q / G+Q & = \\
G+Q+W & G-W\end{array}$}} & 30 & \multirow{2}{*}{$\begin{array}{l}\text { Uni } \\
\text { Fp2 }\end{array}$} & ade & 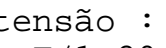 & \multirow{2}{*}{$\begin{array}{r}\mathrm{KN} / \mathrm{M} 2 \\
\mathrm{~F} / 1.50\end{array}$} & \multirow[b]{2}{*}{ Fbk } & \multirow[b]{2}{*}{ GRT } \\
\hline & $\mathrm{R}$ & & & & Fp1 & & $\mathrm{F} / .80$ & $\mathrm{~F} / 1.20$ & & & \\
\hline 8 & .885 & -56 & -59. & -43 & & 24 & 396 & 264 . & & & - \\
\hline 7 & .885 & -253 & -261. & -200 & 1432 . & 1093 & 1790. & 1193. & 955. & . & - \\
\hline 6 & .885 & -451 & -466 & -354 & 2548 . & 1949 & 3184 . & 2123 & 1698 & 4500 & - \\
\hline 5 & .885 & -648 & -674 & -506 & 3663 . & 2810 & 4579 . & 3053 . & 2442 . & 4500 & G1 \\
\hline 4 & .885 & -846 & -883. & -656 & 4778 . & 3677 . & 5973. & 3982 . & 3186. & 6000 & - \\
\hline 3 & .885 & -1043 & -1095 & -804 & 5894 . & 4549 & 7367 . & 4912 . & 3929. & 6000 & G1 \\
\hline 2 & .885 & -1241 & -1308 . & -950 & 7009 . & 5426 & 8762 . & 5841 . & 4673 . & 8000 & G1 \\
\hline 1 & .885 & -1438 & -1523 & -1094 . & 8125 . & 6307 & 10156 & 6771 . & 5417 . & 8000 & G1 \\
\hline
\end{tabular}

\begin{tabular}{|c|c|c|c|c|c|c|c|c|c|c|c|}
\hline \multirow{2}{*}{$\begin{array}{l}\text { PAREDI } \\
\text { NIV }\end{array}$} & \multirow{2}{*}{${ }^{E}{ }_{R} P$} & \multirow{2}{*}{$\begin{array}{ll}\mathrm{PX} & 13 \\
& \mathrm{G}+\mathrm{Q}\end{array}$} & \multirow{2}{*}{$\begin{array}{c}Q / G+Q \\
G+Q+W\end{array}$} & \multirow{2}{*}{$2 \underset{G-W}{=}}$. & \multirow{2}{*}{$\begin{array}{l}180 \\
\text { Fp1 }\end{array}$} & \multicolumn{2}{|c|}{ Unidade } & \multirow{2}{*}{$\begin{array}{l}\text { ensão: } \\
\text { F/1.20 }\end{array}$} & \multirow{2}{*}{$\begin{array}{r}\mathrm{KN} / \mathrm{M} 2 \\
\mathrm{~F} / 1.50\end{array}$} & \multirow[b]{2}{*}{ Fbk } & \multirow[b]{2}{*}{ GRT } \\
\hline & & & & & & Fp2 & $\mathrm{F} / .80$ & & & & \\
\hline 8 & .885 & -42 . & -60. & -16 & 235 . & 221 . & 294. & 196. & 157. & 4500 & - \\
\hline 7 & .885 & -134 & -188. & -57 & 759. & 703. & 949. & 632. & 506. & 4500 & - \\
\hline 6 & .885 & -227 & -333. & -81 & 1283. & 1226 & 1604. & 1069. & 855. & 4500 & - \\
\hline 5 & .885 & -320 . & -494. & -89 & 1807. & 1790 . & 2259 . & 1506. & 1205 . & 4500 & - \\
\hline 4 & .885 & -413 & -670 & -81 & 2331. & 2391 & 2989 . & 1992. & 1594 . & 6000 & - \\
\hline 3 & .885 & -505 & -860 & -60 & 2855 . & 3027 . & 3784 . & 2523. & 2018 . & 6000 & \\
\hline 2 & .885 & -598 & -1063 . & -26 & 3379. & 3696 . & 4620 & 3080 . & 2464 . & 8000 & \\
\hline 1 & .885 & -691 & -1276 & 19. & 3903. & 4391 & 5488 & 3659. & 2927. & 8000 & \\
\hline
\end{tabular}

\begin{tabular}{|c|c|c|c|c|c|c|c|c|c|c|c|}
\hline \multicolumn{2}{|c|}{ PAREDE } & \multirow{2}{*}{$\begin{array}{ll}\mathrm{PX} & 14 \\
& \mathrm{G}+\mathrm{Q}\end{array}$} & \multirow{2}{*}{$\begin{array}{c}Q / G+Q \\
G+Q+W\end{array}$} & \multicolumn{2}{|c|}{$Q=.180$} & \multicolumn{2}{|c|}{ Unidade } & \multirow{2}{*}{$\begin{array}{r}\text { tensão: } \\
\text { F/1.20 }\end{array}$} & $\mathrm{KN} / \mathrm{M} 2$ & \multirow[b]{2}{*}{ Fbk } & \multirow[b]{2}{*}{ GRT } \\
\hline NIV & $\mathrm{R}$ & & & $G-W$ & Fp1 & Fp2 & $\mathrm{F} / .80$ & & $\mathrm{~F} / 1.50$ & & \\
\hline 8 & .885 & -56 & -59. & -43 & 317. & 244 . & 396. & 264 . & 211. & 45 & - \\
\hline 7 & .885 & -289 & -296. & -229 . & 1632 . & 1242 . & 2040 . & 1360. & 1088 . & 4500 . & - \\
\hline 6 & .885 & -522 . & -536 . & -413 . & 2947 . & 2247 . & 3684 . & 2456 . & 1965. & 4500 . & - \\
\hline 5 & .885 & -754 & -778 & -595 . & 4262 . & 3257 . & 5328. & 3552 . & 2842 . & 4500 & G1 \\
\hline 4 & .885 & -987 & -1023 & -774 & 5578. & 4272 & 6972 . & 4648. & 3718 . & 6000 & G1 \\
\hline 3 & .885 & -1220 & -1269 & -952. & 6893. & 5292 & 8616. & 5744 . & 4595 . & 6000 & G1 \\
\hline 2 & .885 & -1453 . & -1517 . & -1127 . & 8208. & 6316 & 10260 . & 6840. & 5472 . & 8000 . & G1 \\
\hline 1 & .885 & -1686 & -1766 & -1302 . & 9523. & 7344 . & 11904 . & 7936. & 6349. & 8000 . & G1 \\
\hline
\end{tabular}




\begin{tabular}{|c|c|c|c|c|c|c|c|c|c|c|c|}
\hline \multirow{2}{*}{$\begin{array}{l}\text { PAREDI } \\
\text { NIV }\end{array}$} & \multirow{2}{*}{$\mathrm{E}_{\mathrm{R}}$} & \multirow{2}{*}{$\begin{array}{l}15 \\
G+Q\end{array}$} & \multirow{2}{*}{$\begin{array}{l}Q / G+Q \\
G+Q+W\end{array}$} & \multirow{2}{*}{$2 \underset{G-W}{=}}$. & \multirow{2}{*}{$\begin{array}{l}180 \\
\text { Fp1 }\end{array}$} & \multicolumn{2}{|c|}{ Unidade } & \multirow{2}{*}{$\begin{array}{l}\text { ensão: } \\
\text { F/1.20 }\end{array}$} & \multirow{2}{*}{$\begin{array}{r}\mathrm{KN} / \mathrm{M} 2 \\
\mathrm{~F} / 1.50\end{array}$} & \multirow[b]{2}{*}{ Fbk } & \multirow[b]{2}{*}{ GRT } \\
\hline & & & & & & Fp2 & $\mathrm{F} / .80$ & & & & \\
\hline 8 & .885 & -40 . & -59. & -14 & 225 . & 216. & 282 . & 188. & 150. & 4500 . & - \\
\hline 7 & .885 & -140. & -195. & -59. & 788. & 730. & 985. & 657 . & 526. & 4500 . & - \\
\hline 6 & .885 & -239 & -349 & -86 & 1351. & 1288. & 1689. & 1126. & 901. & 4500 . & - \\
\hline 5 & .885 & -339. & -520. & -97 & 1914. & 1888. & 2393 . & 1595. & 1276 . & 4500 . & - \\
\hline 4 & .885 & -438 . & -706. & -92 & 2477 . & 2527 . & 3159 . & 2106 . & 1685. & 6000. & - \\
\hline 3 & .885 & -538. & -907 & -72 & 3040 . & 3203. & 4004 . & 2669 . & 2135 . & 6000. & 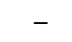 \\
\hline 2 & .885 & -638 & -1122 . & -39 & 3603 . & 3912 . & 4890 . & 3260 . & 2608 . & 8000 . & - \\
\hline 1 & .885 & -737 & -1347 . & 5. & 4166. & 4649. & 5811. & 3874 . & 3099 . & 8000 . & - \\
\hline
\end{tabular}

\begin{tabular}{|c|c|c|c|c|c|c|c|c|c|c|c|}
\hline \multirow{2}{*}{$\begin{array}{l}\text { PARED } \\
\text { NIV }\end{array}$} & \multirow{2}{*}{$E_{R}$} & \multirow{2}{*}{$\begin{array}{ll}P X & 16 \\
& G+Q\end{array}$} & \multirow{2}{*}{$\begin{array}{c}\mathrm{Q} / \mathrm{G}+\mathrm{Q} \\
\mathrm{G}+\mathrm{Q}+\mathrm{W}\end{array}$} & \multirow{2}{*}{$\begin{array}{c}= \\
G-W\end{array}$} & \multirow{2}{*}{$\begin{array}{l}180 \\
\text { Fp1 }\end{array}$} & \multicolumn{2}{|c|}{ Unidade } & \multirow{2}{*}{$\begin{array}{l}\text { tensão: } \\
\text { F/1.20 }\end{array}$} & \multirow{2}{*}{$\begin{array}{r}\mathrm{KN} / \mathrm{M} 2 \\
\mathrm{~F} / 1.50\end{array}$} & \multirow[b]{2}{*}{ Fbk } & \multirow[b]{2}{*}{ GRT } \\
\hline & & & & & & $\mathrm{Fp} 2$ & $\mathrm{~F} / .80$ & & & & \\
\hline 8 & .885 & -40 . & -59 . & -14 & 225 . & 216 . & 282 . & 188. & 150. & 4500 & - \\
\hline 7 & .885 & -140 & -195. & -59. & 788. & 730. & 985. & 657. & 526. & 4500 & _ \\
\hline 6 & .885 & -239 & -349. & -86 & 1351. & 1288. & 1689. & 1126. & 901. & 4500 & - \\
\hline 5 & .885 & -339 & -520 . & -97 & 1914. & 1888. & 2393 . & 1595 . & 1276 . & 4500 & \\
\hline 4 & .885 & -438 . & -706. & -92 & 2477 . & 2527 . & 3159. & 2106 . & 1685. & 6000 & \\
\hline 3 & .885 & -538. & -907 . & -72 & 3040 . & 3203. & 4004 & 2669 . & 2135 . & 6000 & \\
\hline 2 & .885 & -638 & -1122 & -39 & 3603 . & 3912. & 4890. & 3260 . & 2608 . & 8000 & \\
\hline 1 & .885 & -737 & -1347 & 5 . & 4166. & 4649 . & 5811. & 3874 . & 3099 . & 8000 & \\
\hline
\end{tabular}

\begin{tabular}{|c|c|c|c|c|c|c|c|c|c|c|c|}
\hline \multirow{2}{*}{$\begin{array}{l}\text { PAREDI } \\
\text { NIV }\end{array}$} & $\mathrm{DE}$ & \multirow{2}{*}{$\begin{array}{ll}X & 17 \\
& G+Q\end{array}$} & \multirow{2}{*}{$\begin{array}{l}Q / G+Q \\
G+Q+W\end{array}$} & \multirow{2}{*}{$\begin{array}{c}= \\
G-W\end{array}$} & \multirow{2}{*}{$\begin{array}{l}180 \\
\text { Fp1 }\end{array}$} & \multicolumn{2}{|c|}{ Unidade } & \multirow{2}{*}{$\begin{array}{r}\text { tensão: } \\
\text { F/1.20 }\end{array}$} & \multirow{2}{*}{$\begin{array}{r}\mathrm{KN} / \mathrm{M} 2 \\
\mathrm{~F} / 1.50\end{array}$} & \multirow[b]{2}{*}{ Fbk } & \multirow[b]{2}{*}{ GRT } \\
\hline & $\mathrm{R}$ & & & & & Fp2 & $\mathrm{F} / .80$ & & & & \\
\hline 8 & .885 & -56 & -59. & -43 & 317 . & 244 . & 396. & 264 . & 211. & 4500 & - \\
\hline 7 & .885 & -289 & -296 . & -229. & 1632. & 1242 . & 2040 . & 1360 . & 1088 & 4500 . & - \\
\hline 6 & .885 & -522 & -536. & -413. & 2947 . & 2247 . & 3684 . & 2456 . & 1965. & 4500 & - \\
\hline 5 & .885 & -754 & -778 . & -595. & 4262 . & 3257 . & 5328. & 3552 . & 2842 . & 4500 & G1 \\
\hline 4 & .885 & -987 & -1023. & -774 & 5578 . & 4272 . & 6972 . & 4648 . & 3718 . & 6000 & G1 \\
\hline 3 & .885 & -1220 & -1269 . & -952 . & 6893. & 5292. & 8616. & 5744. & 4595 . & 6000 & G1 \\
\hline 2 & .885 & -1453 & -1517 . & -1127 . & 8208 . & 6316. & 10260 . & 6840. & 5472 . & 8000 & G1 \\
\hline 1 & .885 & -1686 & -1766 & -1302 & 9523. & 7344 . & 11904 . & 7936 . & 6349. & 8000 & G1 \\
\hline \multicolumn{2}{|c|}{ PAREDE } & \multirow{2}{*}{$\begin{array}{ll}P X & 18 \\
& G+Q\end{array}$} & $Q / G$ & $+Q$ & 80 & \multicolumn{3}{|c|}{ Unidade de tensão : } & \multirow{2}{*}{$\begin{array}{r}\mathrm{KN} / \mathrm{M} 2 \\
\mathrm{~F} / 1.50\end{array}$} & \multirow[b]{2}{*}{ Fbk } & \multirow[b]{2}{*}{ GRT } \\
\hline NIV & $\mathrm{R}$ & & $\mathrm{G}+\mathrm{Q}+\mathrm{W}$ & $\mathrm{G}-\mathrm{W}$ & Fp1 & Fp2 & $\mathrm{F} / .80$ & $\mathrm{~F} / 1.20$ & & & \\
\hline 8 & .885 & -42 & -60. & -16 & 235 . & 221. & 294. & 196. & 157. & 4500 & - \\
\hline 7 & .885 & -134 & -188. & -57 & 759 . & 703. & 949. & 632. & 506. & 4500 & - \\
\hline 6 & .885 & -227 & -333. & -81 & 1283. & 1226. & 1604. & 1069. & 855. & 4500 & - \\
\hline 5 & .885 & -320 & -494 & -89 & 1807. & 1790. & 2259 . & 1506. & 1205 . & 4500 & - \\
\hline 4 & .885 & -413 & -670. & -81 & 2331. & 2391. & 2989. & 1992. & 1594 . & 6000 & - \\
\hline 3 & .885 & -505 & -860 & -60. & 2855 . & 3027 . & 3784 . & 2523 . & 2018 . & 6000 & - \\
\hline 2 & .885 & -598 & -1063 & -26 & 3379 . & 3696. & 4620 . & 3080 . & 2464 . & 8000 & - \\
\hline 1 & .885 & -691 & -1276 . & 19. & 3903 . & 4391. & 5488 . & 3659. & 2927 . & 8000 & - \\
\hline \multicolumn{2}{|c|}{ PAREDE } & \multirow{2}{*}{$\begin{array}{lc}P Y & 1 \\
G+Q\end{array}$} & $Q / G$ & $=$ & 80 & \multicolumn{2}{|c|}{ Unidade } & ensão & \multirow{2}{*}{$\begin{array}{r}\mathrm{KN} / \mathrm{M} 2 \\
\mathrm{~F} / 1.50\end{array}$} & \multirow[b]{2}{*}{ Fbk } & \multirow[b]{2}{*}{ GRT } \\
\hline NIV & $\mathrm{R}$ & & $G+Q+W$ & $G-W$ & Fp1 & Fp2 & $\mathrm{F} / .80$ & $\mathrm{~F} / 1.20$ & & & \\
\hline 8 & .885 & -43 & -66. & -12 . & 244 . & 241 & 305 . & 203. & 163. & 4500 & - \\
\hline 7 & .885 & -112 & -180. & -23 & 631. & 645. & 806 . & 537. & 430 & 4500 & - \\
\hline 6 & .885 & -180 & -316. & -12. & 1018. & 1102 . & 1378. & 919. & 735. & 4500 & - \\
\hline 5 & .885 & -249 & -472 . & 19. & 1405 . & 1611. & 2014 . & 1343. & 1074 . & 4500 & - \\
\hline 4 & .885 & -317 & -647 & 70. & 1792. & 2169. & 2711 . & 1807. & 1446 . & 6000 & - \\
\hline 3 & .885 & -386 & -840. & 138. & 2179 . & 2771 . & 3464 . & 2309 . & 1847 . & 6000 & - \\
\hline 2 & .885 & -454 & -1050 . & 223. & 2567 . & 3415 . & 4268 . & 2846 . & 2276 . & 8000 & - \\
\hline 1 & .885 & -523 & -1274 . & 322 . & 2954 . & 4092 . & 5115. & 3410 . & 2728 . & 8000 & - \\
\hline
\end{tabular}




\begin{tabular}{|c|c|c|c|c|c|c|c|c|c|c|c|}
\hline \multicolumn{2}{|c|}{ PAREDE } & \multirow{2}{*}{$\begin{array}{c}6 \\
G+Q\end{array}$} & $Q / G+Q$ & \multicolumn{2}{|c|}{$=.180$} & \multicolumn{2}{|c|}{ Unidade } & \multirow{2}{*}{$\begin{array}{l}\text { ensão: } \\
\text { F/1.20 }\end{array}$} & $\mathrm{KN} / \mathrm{M} 2$ & \multirow[b]{2}{*}{ Fbk } & \multirow[b]{2}{*}{ GRT } \\
\hline NIV & R & & $\mathrm{G}+\mathrm{Q}+\mathrm{W}$ & $G-W$ & Fp1 & Fp2 & $\mathrm{F} / .80$ & & $\mathrm{~F} / 1.50$ & & \\
\hline 8 & .885 & -38 & -61 & -9 . & 215 & 21 & 272 . & 181 & 145 . & 4500. & - \\
\hline 7 & .885 & -122 . & -189. & -33 & 689. & 684. & 861. & 574. & 459. & 4500. & - \\
\hline 6 & .885 & -206 . & -338 & -37 & 1163. & 1202 . & 1502 . & 1001. & 801. & 4500 . & - \\
\hline 5 & .885 & -290. & -507. & -21 & 1637. & 1770 . & 2213. & 1475. & 1180 . & 4500 . & - \\
\hline 4 & .885 & -374 & -695. & 15. & 2111. & 2386 . & 2982 . & 1988. & 1590 . & 6000. & - \\
\hline 3 & .885 & -457 & -900. & 67. & 2585 . & 3045 . & 3806 . & 2537 . & 2030 . & 6000. & - \\
\hline 2 & .885 & -541. & -1121 & 136. & 3059 . & 3744 . & 4680 . & 3120 . & 2496 . & 8000 . & - \\
\hline 1 & .885 & -625 & -1356 & 218 . & 3532 . & 4477 . & 5596. & 3731 . & 2985 . & 8000 . & - \\
\hline
\end{tabular}

\begin{tabular}{|c|c|c|c|c|c|c|c|c|c|c|c|}
\hline PAREI & $\mathrm{DE}$ & PY & $Q / G+Q$ & $=$ & 80 & . & ade de & nsão : & $\mathrm{KN} / \mathrm{M} 2$ & & \\
\hline NIV & $\mathrm{R}$ & $\mathrm{G}+\mathrm{Q}$ & $\mathrm{G}+\mathrm{Q}+\mathrm{W}$ & $G-W$ & Fp1 & $\mathrm{Fp} 2$ & $\mathrm{~F} / .80$ & $\mathrm{~F} / 1.20$ & $\mathrm{~F} / 1.50$ & $\mathrm{Fbk}$ & GRT \\
\hline 8 & .885 & -38 & -66. & -4 & 215 . & 230 . & 287. & 192. & 153. & 4500 & - \\
\hline 7 & .885 & -132 & -214. & -27 & 747 . & 763. & 954. & 636 & 509. & 4500 & - \\
\hline 6 & .885 & -226 & -387 . & -25 & 1278 . & 1361. & 1701 . & 1134 & 907. & 4500 & - \\
\hline 5 & .885 & -320 & -585. & 2. & 1810. & 019. & 2523. & 1682 . & 1346 . & 4500 & - \\
\hline 4 & .885 & -414 & -806 . & 52. & 2341 . & 735. & 3418 . & 2279 & 1823. & 6000 & - \\
\hline 3 & .885 & -508 & -1048 & 123. & 2872 . & 3504 . & 4380. & 2920 . & 2336 . & 6000 & - \\
\hline 2 & .885 & -602. & -1310. & 214 . & 3404 . & 4322 . & 5403. & 3602 . & 2881. & 8000 & - \\
\hline 1 & .885 & -697. & -1588 & 321. & 3935 . & 5181. & 6476. & 4317 . & 3454 . & 3000 & - \\
\hline$A R E I$ & & PY 8 & Q/ & $=$ & & Uni & ade de & nsão : & $\mathrm{KN} / \mathrm{M} 2$ & & \\
\hline IV & $\mathrm{R}$ & $G+Q$ & $\mathrm{G}+\mathrm{Q}+\mathrm{W}$ & $G-W$ & Fp1 & Fp2 & $\mathrm{F} / .80$ & $\mathrm{~F} / 1.20$ & $\mathrm{~F} / 1.50$ & Fbk & GRT \\
\hline 8 & .885 & -39 & -69. & -3 & 222 . & 239. & 299. & 200 & 160. & • & - \\
\hline 7 & .885 & -515. & -601. & -335. & 2907. & 2398 & 3634 . & 2423 & 1938 . & 500 & - \\
\hline 6 & .885 & -611. & -783. & -330. & 3454 . & 3020 . & 4318. & 2878 . & 2303 . & 4500 & - \\
\hline 5 & .885 & -708. & -991. & -298. & 4001. & 3707 . & 5001. & 3334 . & 2667 . & 500 & G1 \\
\hline 4 & .885 & -805 . & -1223 & -242 . & 4548. & 4455 & 5684 . & 3790 . & 3032 . & 5000 & - \\
\hline 3 & .885 & -902 . & -1478 & -163. & 5094. & 5261. & 6576 . & 4384 & 3507 . & 6000. & G1 \\
\hline 2 & .885 & -998 & -1754 & -64 & 5641. & 6119 & 7648 . & 5099. & 4079 & 8000 . & - \\
\hline 1 & .885 & -1095. & -2047 & 53. & 6188. & 7020 . & 8775 . & 5850 & 4680 & 3000. & G1 \\
\hline AREI & & PY & $Q / C$ & $=$ & 80 & Uni & ade de & nsão : & $\mathrm{KN} / \mathrm{M} 2$ & & \\
\hline IV & $\mathrm{R}$ & $\mathrm{G}+\mathrm{Q}$ & $\mathrm{G}+\mathrm{Q}+\mathrm{W}$ & $G-W$ & Fp1 & Fp2 & $\mathrm{F} / .80$ & $\mathrm{~F} / 1.20$ & $\mathrm{~F} / 1.50$ & Fbok & GRT \\
\hline 8 & .885 & -40 & -67 . & -6 . & 228 . & 238 . & 297. & 198. & 158. & • & - \\
\hline 7 & .885 & -547 & -626 & -369. & 3090 . & 2515 & 3862 . & 2575 . & 2060 . & 500. & - \\
\hline 6 & .885 & -642 . & -798 . & -370 . & 3628 . & 3112 . & 4535 . & 3023 . & 2419 & $\$ 500$ & G1 \\
\hline 5 & .885 & -737 & -995. & -348 & 4166. & 3767 . & 5208 . & 3472 . & 2778 & 4500 & G1 \\
\hline 4 & .885 & -833 & -1213. & -302 . & 4705 . & 4479 & 5881. & 3921 . & 3136 . & 6000. & - \\
\hline 3 & .885 & -928 & -1453 . & -236 & 5243. & 5244 . & 6554. & 4370 & 3496 . & 6000 & G1 \\
\hline 2 & .885 & -1023 & -1711. & -152 . & 5781. & 6055 & 7568 . & 5046 . & 4036. & 8000 & - \\
\hline 1 & .885 & -1119. & -1985 & -51 & 6320. & 6905 & 8632 . & 5755 . & 4604 . & 8000 & G1 \\
\hline AREI & & PY 11 & $Q$ & $=$ & 80 & & t & 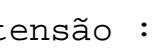 & $\mathrm{KN} / \mathrm{M} 2$ & & \\
\hline IV & $\mathrm{R}$ & $G+Q$ & $\mathrm{G}+\mathrm{Q}+\mathrm{W}$ & $G-W$ & Fp1 & Fp2 & $\mathrm{F} / .80$ & $\mathrm{~F} / 1.20$ & $\mathrm{~F} / 1.50$ & Fbk & GRT \\
\hline 8 & .885 & -40 & -58 & -15 & 227 & 21 & 284. & 189. & 151. & 00 . & - \\
\hline 7 & .885 & -114 & -168 . & -40 & 646. & 619. & 807 . & 538. & 431 & 500 . & - \\
\hline 6 & .885 & -155. & -261. & -21 & 873. & 920. & 1150. & 767 . & 613. & 4500 & - \\
\hline 5 & .885 & -195. & -369 . & 15. & 1100. & 1262 & 1577 . & 1051. & 841. & 4500 & - \\
\hline 4 & .885 & -235 & -493 & 66. & 1327. & 1642 . & 2052 . & 1368 . & 1094 . & 6000 & - \\
\hline 3 & .885 & -275 & -631. & 131. & 1554. & 2057 . & 2571 . & 1714. & 1371. & 6000 & - \\
\hline 2 & .885 & -315. & -782 . & 209 . & 1782. & 2504 . & 3130 . & 2087 . & 1669. & 8000 & - \\
\hline 1 & .885 & -356 & -944 . & 297 . & 2009 . & 2978 & 3722 . & 2482 & 1985 . & 8000 & - \\
\hline
\end{tabular}




\begin{tabular}{|c|c|c|c|c|c|c|c|c|c|c|c|}
\hline \multirow{2}{*}{$\begin{array}{l}\text { PAREDI } \\
\text { NIV }\end{array}$} & \multirow{2}{*}{$\mathrm{E}_{\mathrm{R}}$} & \multirow{2}{*}{$\begin{array}{ll}\text { PY } & 12 \\
& G+Q\end{array}$} & $Q / G+Q$ & \multicolumn{2}{|c|}{$=.180$} & \multicolumn{2}{|c|}{ Unidade } & \multirow{2}{*}{$\begin{array}{l}\text { ensão: } \\
\text { F/1.20 }\end{array}$} & \multirow{2}{*}{$\begin{array}{r}\mathrm{KN} / \mathrm{M} 2 \\
\mathrm{~F} / 1.50\end{array}$} & \multirow[b]{2}{*}{ Fbk } & \multirow[b]{2}{*}{ GRT } \\
\hline & & & $\mathrm{G}+\mathrm{Q}+\mathrm{W}$ & $\mathrm{G}-\mathrm{W}$ & Fp1 & $\mathrm{Fp} 2$ & $\mathrm{~F} / .80$ & & & & \\
\hline 8 & .885 & -39 & -69 & -3 & 222 . & 23 & 299. & 200 . & 160. & 4500 & 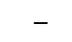 \\
\hline 7 & .885 & -515 & -601 . & -335 & 2907. & 2398. & 3634 . & 2423 . & 1938. & 4500 & - \\
\hline 6 & .885 & -611. & -783. & -330 & 3454 . & 3020 . & 4318. & 2878 . & 2303 & 4500 & . \\
\hline 5 & .885 & -708 & -991 & -298 & 4001. & 3707 . & 5001. & 3334 . & 2667 . & 4500 & G1 \\
\hline 4 & .885 & -805 & -1223 & -242 & 4548 . & 4455 . & 5684. & 3790 . & 3032 . & 6000 & - \\
\hline 3 & .885 & -902 & -1478 & -163 & 5094. & 5261. & 6576. & 4384 . & 3507 . & 6000 & G1 \\
\hline 2 & .885 & -998 & -1754 & -64 . & 5641. & 6119. & 7648 . & 5099 . & 4079 . & 8000 . & 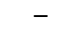 \\
\hline 1 & .885 & -1095 & -2047 & 53. & 6188. & 7020 . & 8775 . & 5850 . & 4680 . & 8000 . & 0 \\
\hline
\end{tabular}

\begin{tabular}{|c|c|c|c|c|c|c|c|c|c|c|c|}
\hline \multirow{2}{*}{$\begin{array}{l}\text { PAREDI } \\
\text { NIV }\end{array}$} & \multirow{2}{*}{$E_{R}$} & \multirow{2}{*}{$\begin{array}{ll}\text { PY } & 13 \\
& \mathrm{G}+\mathrm{Q}\end{array}$} & \multirow{2}{*}{$\begin{array}{c}Q / G+ \\
G+Q+W\end{array}$} & \multicolumn{2}{|c|}{$=.180$} & \multicolumn{2}{|c|}{ Unidade } & \multirow{2}{*}{$\begin{array}{l}\text { ensão: } \\
\text { F/1.20 }\end{array}$} & \multirow{2}{*}{$\begin{array}{r}\mathrm{KN} / \mathrm{M} 2 \\
\mathrm{~F} / 1.50\end{array}$} & \multirow[b]{2}{*}{ Fbk } & \multirow[b]{2}{*}{ GRT } \\
\hline & & & & $G-W$ & Fp1 & Fp2 & $\mathrm{F} / .80$ & & & & \\
\hline 8 & .885 & -40 & -64. & -9 . & 228 . & 230. & 288 . & 192. & 154. & 4500 & - \\
\hline 7 & .885 & -547 & -617. & -378 & 3090 . & 2494 & 3862 . & 2575 . & 2060 . & 500. & - \\
\hline 6 & .885 & -642 & -782 . & -387 & 3628 . & 3070 . & 4535 . & 3023 . & 2419. & 4500 & G1 \\
\hline 5 & .885 & -737 & -967 . & -375 & 4166. & 3699. & 5208 . & 3472 . & 2778 . & 4500 & G1 \\
\hline 4 & .885 & -833 & -1172 & -343 & 4705 . & 4377. & 5881. & 3921 . & 3136 . & 6000 & - \\
\hline 3 & .885 & -928 & -1396 & -293 & 5243 . & 5103. & 6554 & 4369. & 3495 . & 6000 & G1 \\
\hline 2 & .885 & -1023 & -1637 . & -225 & 5781. & 5870 & 7338 . & 4892 . & 3914 . & 8000 & - \\
\hline 1 & .885 & -1119 & -1892 & -144 & 6320. & 6673 & 8341 . & 5561. & 4449 . & 8000 & G1 \\
\hline \multicolumn{2}{|c|}{ PAREDE } & PY 14 & \multicolumn{2}{|c|}{$Q / G+Q$} & 30 & \multicolumn{2}{|c|}{ Unidade } & 1são : & $\mathrm{KN} / \mathrm{M} 2$ & \multirow[b]{2}{*}{ Fbk } & \multirow[b]{2}{*}{ GRT } \\
\hline IV & $\mathrm{R}$ & $G+Q$ & $\mathrm{G}+\mathrm{Q}+\mathrm{W}$ & $G-W$ & Fp1 & Fp2 & $\mathrm{F} / .80$ & $\mathrm{~F} / 1.20$ & $\mathrm{~F} / 1.50$ & & \\
\hline 8 & .885 & -38 & -66. & -4 & 215 . & 230 & 287 & 192. & 153. & 4500 . & - \\
\hline 7 & .885 & -132. & -214. & -27 & 747 . & 763. & 954. & 636. & 509. & 4500 & - \\
\hline 6 & .885 & -226 & -387. & -25 & 1278 . & 1361. & 1701. & 1134. & 907. & 4500 & - \\
\hline 5 & .885 & -320 & -585 . & 2 . & 1810. & 2019 . & 2523 . & 1682 . & 1346 . & 4500 & - \\
\hline 4 & .885 & -414 & -806 . & 52 . & 2341 . & 2735 . & 3418 & 2279 & 1823 & 6000 & - \\
\hline 3 & .885 & -508 & -1048 & 123. & 2872 . & 3504 . & 4380 & 2920 . & 2336 . & 6000 & - \\
\hline 2 & .885 & -602 & -1310 & 214 . & 3404 . & 4322 . & 5403 . & 3602 . & 2881 . & 8000 & _- \\
\hline 1 & .885 & -697 & -1588 & 321. & 3935. & 5181. & 6476 . & 4317 . & 3454 . & 8000 . & - \\
\hline
\end{tabular}

\begin{tabular}{|c|c|c|c|c|c|c|c|c|c|c|c|}
\hline \multirow{2}{*}{$\begin{array}{l}\text { PAREDI } \\
\text { NIV }\end{array}$} & \multirow{2}{*}{${ }^{E}$} & \multirow{2}{*}{$\begin{array}{ll}\text { PY } & 15 \\
& G+Q\end{array}$} & \multirow{2}{*}{$\begin{array}{c}Q / G+Q \\
G+Q+W\end{array}$} & \multicolumn{2}{|c|}{$2=.180$} & \multicolumn{2}{|c|}{ Unidade } & \multirow{2}{*}{$\begin{array}{l}\text { tensão: } \\
\text { F/1.20 }\end{array}$} & \multirow{2}{*}{$\begin{array}{r}\mathrm{KN} / \mathrm{M} 2 \\
\mathrm{~F} / 1.50\end{array}$} & \multirow[b]{2}{*}{ Fbok } & \multirow[b]{2}{*}{ GRT } \\
\hline & & & & $G-W$ & Fp1 & Fp2 & $\mathrm{F} / .80$ & & & & \\
\hline 8 & .885 & -38 & -61. & -9. & 215 . & 218 . & 272 . & 181. & 145 . & 4500 . & - \\
\hline 7 & .885 & -122 . & -189. & -33 & 689. & 684. & 861. & 574 . & 459. & 4500 . & - \\
\hline 6 & .885 & -206 & -338 & -37 & 1163. & 1202 . & 1502 . & 1001. & 801. & 4500 . & - \\
\hline 5 & .885 & -290 & -507 . & -21 & 1637. & 1770 . & 2213. & 1475 . & 1180 . & 4500 . & - \\
\hline 4 & .885 & -374 & -695. & 15. & 2111. & 2386 . & 2982 . & 1988. & 1590 . & 6000 & - \\
\hline 3 & .885 & -457 & -900 . & 67. & 2585 . & 3045 . & 3806 . & 2537 . & 2030 . & 6000 & - \\
\hline 2 & .885 & -541 & -1121 & 136. & 3059 . & 3744 . & 4680 . & 3120 . & 2496 . & 8000 & - \\
\hline 1 & .885 & -625 & -1356 . & 218 . & 3532 . & 4477 . & 5596. & 3731 . & 2985 . & 8000 . & - \\
\hline
\end{tabular}

\begin{tabular}{|c|c|c|c|c|c|c|c|c|c|c|c|}
\hline \multirow{2}{*}{$\begin{array}{l}\text { PARED } \\
\text { NIV }\end{array}$} & \multirow{2}{*}{$E_{R}$} & \multirow{2}{*}{$\begin{array}{ll}\text { PY } & 18 \\
& G+Q\end{array}$} & \multirow{2}{*}{$\begin{array}{c}Q / G+Q \\
G+Q+W\end{array}$} & \multicolumn{2}{|c|}{$=.180$} & \multicolumn{2}{|c|}{ Unidade } & \multirow{2}{*}{$\begin{array}{l}\text { ensão: } \\
\text { F/1.20 }\end{array}$} & \multirow{2}{*}{$\begin{array}{r}\mathrm{KN} / \mathrm{M} 2 \\
\mathrm{~F} / 1.50\end{array}$} & \multirow[b]{2}{*}{ Fbk } & \multirow[b]{2}{*}{ GRT } \\
\hline & & & & $G-W$ & Fp1 & Fp2 & .80 & & & & \\
\hline 8 & .885 & -43 & -66 & -12 & 244 & 24 & 305 & 203 & 163. & 4500 & - \\
\hline 7 & .885 & -112 & -180 . & -23 & 631. & 645 & 806 . & 537. & 430. & 4500 & - \\
\hline 6 & .885 & -180 & -316 & -12 & 1018. & 1102 . & 1378. & 919. & 735. & 4500 & - \\
\hline 5 & .885 & -249 & -472 . & 19. & 1405. & 1611. & 2014 . & 1343. & 1074 . & 4500 . & - \\
\hline 4 & .885 & -317 & -647. & 70. & 1792. & 2169. & 2711. & 1807. & 1446 . & 6000 & - \\
\hline 3 & .885 & -386 & -840 . & 138. & 2179 . & 2771 . & 3464 . & 2309 . & 1847 . & 6000 & - \\
\hline 2 & .885 & -454 & -1050 & 223. & 2567 . & 3415 . & 4268 . & 2846 . & 2276 . & 8000 . & - \\
\hline 1 & .885 & -523 & -1274 . & 322 . & 2954 . & 4092 . & 5115. & 3410 . & 2728 . & 8000 & - \\
\hline
\end{tabular}




\title{
3. Procedimento: GRUPOS ISOLADOS DE PAREDES - SITUAÇÃO C
}

\author{
TECSOF ENGENHARIA S/C LTDA \\ PROGRAMA VPA - VERIFICAÇÃO DE PAREDES DE ALVENARIA - VERSÃO ABR/94 \\ PROJETO : EXEMPLO DO CAPÍTULO 5 \\ CLIENTE : DISSERTAÇÃO
}

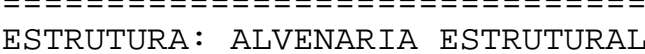

$=========================0$

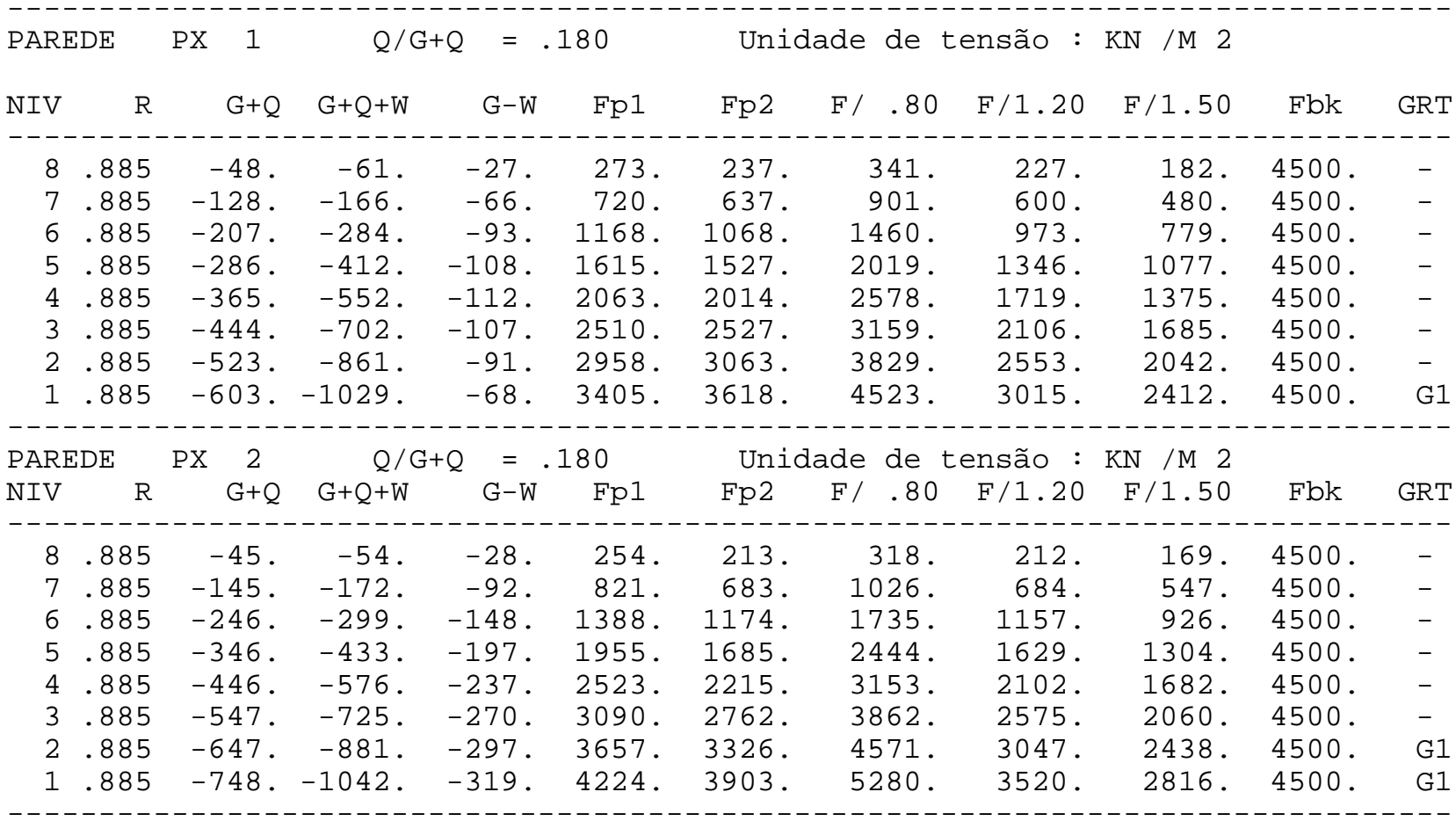

PAREDE




\begin{tabular}{|c|c|c|c|c|c|c|c|c|c|c|c|}
\hline \multicolumn{2}{|c|}{ PAREDE } & \multirow{2}{*}{$\begin{array}{c}4 \\
\mathrm{G}+\mathrm{Q}\end{array}$} & \multicolumn{2}{|c|}{$Q / G+Q$} & \multirow{2}{*}{$\begin{array}{r}180 \\
\text { Fp1 }\end{array}$} & \multicolumn{2}{|c|}{ Unidade } & \multirow{2}{*}{$\begin{array}{l}\text { ensão: } \\
\text { F/1.20 }\end{array}$} & $\mathrm{KN} / \mathrm{M} 2$ & \multirow[b]{2}{*}{ Fbk } & \multirow[b]{2}{*}{ GRT } \\
\hline NIV & $\mathrm{R}$ & & $\mathrm{G}+\mathrm{Q}+\mathrm{W}$ & $\mathrm{G}-\mathrm{W}$ & & $\mathrm{Fp} 2$ & $\mathrm{~F} / .80$ & & $\mathrm{~F} / 1.50$ & & \\
\hline 8 & .885 & -45 . & -53. & -29 & 256 . & 21 & 320 . & 213 . & 171. & 4500 & . \\
\hline 7 & .885 & -483 & -506. & -373 & 2729 . & 2105 . & 3412 . & 2274 . & 1820. & 4500 & 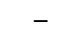 \\
\hline 6 & .885 & -580 & -626. & -430 & 3276 . & 2571. & 4095 . & 2730 & 2184 . & 4500 & 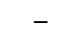 \\
\hline 5 & .885 & -677 & -752 . & -480 & 3823. & 3055 . & 4779 . & 3186 . & 2549 . & 4500 & \\
\hline 4 & .885 & -774 & -885. & -523 & 4370 . & 3555 . & 5463. & 3642 . & 2913 . & 4500 & \\
\hline 3 & .885 & -870 & -1023. & -561 & 4917. & 4071 . & 6146. & 4098 & 3278 . & 4500 & G1 \\
\hline 2 & .885 & -967 & -1168 & -592 . & 5464 . & 4600 . & 6830. & 4553 . & 3643 . & 4500 & 2 \\
\hline 1 & .885 & -1064. & -1317 & -620 & 6011. & 5140 . & 7514 . & 5009 . & 4007 . & 4500 & G2 \\
\hline
\end{tabular}

\begin{tabular}{|c|c|c|c|c|c|c|c|c|c|c|c|}
\hline \multirow{2}{*}{\multicolumn{2}{|c|}{$\begin{array}{l}\text { PAREDE } \\
\text { NIV R R }\end{array}$}} & \multirow{2}{*}{$\begin{array}{cc}P X & 5 \\
& G+Q\end{array}$} & \multirow{2}{*}{$\begin{array}{l}Q / G+Q \\
G+Q+W\end{array}$} & \multicolumn{2}{|c|}{$=.180$} & \multicolumn{2}{|c|}{ Unidade } & Eensão: & $\mathrm{KN} \quad / \mathrm{M} 2$ & \multirow[b]{2}{*}{ Fbk } & \multirow[b]{2}{*}{ GRT } \\
\hline & & & & $G-W$ & Fp1 & Fp2 & $\mathrm{F} / .80$ & $\mathrm{~F} / 1.20$ & $\mathrm{~F} / 1.50$ & & \\
\hline 8 & .885 & -45 & -54. & -28 & 254 . & 213. & 318. & 212 . & 169. & 4500 & - \\
\hline 7 & .885 & -145 . & -172 . & -92 . & 821. & 683. & 1026. & 684. & 547 . & 500. & - \\
\hline 6 & .885 & -246 & -299. & -148 & 1388. & 1174. & 1735. & 1157. & 926. & 4500 & - \\
\hline 5 & .885 & -346 & -433 & -197 & 1955. & 1685. & 2444 . & 1629. & 1304 . & 4500 & - \\
\hline 4 & .885 & -446 & -576 & -237 & 2523. & 2215 . & 3153. & 2102 . & 1682 . & 4500 & - \\
\hline 3 & .885 & -547 & -725 & -270 & 3090 . & 2762 . & 3862 . & 2575 . & 2060 . & 4500 . & - \\
\hline 2 & .885 & -647 & -881 & -297 & 3657 . & 3326 . & 4571. & 3047 . & 2438 . & 450 & G1 \\
\hline 1 & .885 & -748 & -1042 & -319 & 4224 . & 3903. & 5280. & 3520 . & 2816 . & 4500. & G1 \\
\hline \multicolumn{2}{|c|}{ PAREDE } & $\mathrm{PX}$ & $Q / C$ & $+Q$ & 80 & \multicolumn{3}{|c|}{ Unidade } & \multirow{2}{*}{$\mathrm{KN} / \mathrm{M} 2$} & & \\
\hline IV & $\mathrm{R}$ & $G+Q$ & $G+Q+W$ & $G-W$ & Fp1 & Fp2 & .80 & $\mathrm{~F} / 1.20$ & & Fbk & GRT \\
\hline 8 & .885 & -48 & -61 . & -27 . & 273 & $23^{\circ}$ & 341 & 227 . & 182 . & 45 & - \\
\hline 7 & .885 & -128 & -166. & -66. & 720. & 637. & 901. & 600. & 480. & 4500 & - \\
\hline 6 & .885 & -207 & -284 & -93. & 1168. & 1068. & 1460 . & 973. & 779. & 4500 & - \\
\hline 5 & .885 & -286 & -412 . & -108 & 1615. & 1527. & 2019. & 1346. & 1077 . & 4500 & - \\
\hline 4 & .885 & -365 & -552 . & -112 & 2063. & 2014. & $257 \varepsilon$ & 1719. & 1375 . & 4500 & - \\
\hline 3 & .885 & -444 & -702 & -107 & 2510 . & 2527. & 3159. & 2106. & 1685 . & 4500 & - \\
\hline 2 & .885 & -523 & -861 & -91. & 2958. & 3063 . & 3829. & 2553. & 2042 . & 4500 & - \\
\hline 1 & .885 & -603 & -1029. & -68. & 3405 . & 3618. & 4523. & 3015 . & 2412 . & 4500 & G1 \\
\hline
\end{tabular}

\begin{tabular}{|c|c|c|c|c|c|c|c|c|c|c|c|}
\hline \multirow{2}{*}{$\begin{array}{l}\text { PARED } \\
\text { NIV }\end{array}$} & & \multirow{2}{*}{$\begin{array}{ll}P X & 10 \\
& G+Q\end{array}$} & \multirow{2}{*}{$\begin{array}{c}Q / G+C \\
G+Q+W\end{array}$} & \multirow{2}{*}{$\begin{array}{l}= \\
G-W\end{array}$} & \multirow{2}{*}{$\begin{array}{l}180 \\
\text { Fp1 }\end{array}$} & \multicolumn{2}{|c|}{ Unidade } & \multirow{2}{*}{$\begin{array}{l}\text { ensão: } \\
\text { F/1.20 }\end{array}$} & \multirow{2}{*}{$\begin{array}{r}\mathrm{KN} / \mathrm{M} 2 \\
\mathrm{~F} / 1.50\end{array}$} & \multirow[b]{2}{*}{ Fbk } & \multirow[b]{2}{*}{ GRI } \\
\hline & R & & & & & Fp2 & $\mathrm{F} / .80$ & & & & \\
\hline 8 & .885 & -45 & -48 & -34 & 254. & 197. & 318. & 212 . & 169. & 4500 & - \\
\hline 7 & .885 & -145 . & -153 & -111 & 821. & 635. & 1026. & 684. & 547. & 4500 & - \\
\hline 6 & .885 & -246 & -261 & -186 & 1388. & 1080 . & 1735. & 1157. & 926. & 4500 & - \\
\hline 5 & .885 & -346 & -371 & -259 & 1955. & 1530. & 2444 . & 1629. & 1304. & 4500 & . \\
\hline 4 & .885 & -446 & -484 & -329 & 2523. & 1985. & 3153. & 2102 . & 1682. & 4500 & - \\
\hline 3 & .885 & -547 . & -598 & -397 & 3090 . & 2446 . & 3862 . & 2575 . & 2060 . & 4500 & - \\
\hline 2 & .885 & -647. & -715 & -463 & 3657 . & 2911. & 4571. & 3047 . & 2438 . & 4500 & \\
\hline 1 & .885 & -748 & -833 & -528 & 4224 . & 3381. & 5280. & 3520 . & 2816 . & 4500 & \\
\hline
\end{tabular}

PAREDE PX $11 \quad \mathrm{Q} / \mathrm{G}+\mathrm{Q}=.180 \quad$ Unidade de tensão : $\mathrm{KN} / \mathrm{M} 2$

\begin{tabular}{|c|c|c|c|c|c|c|c|c|c|c|c|}
\hline IV & $\mathrm{R}$ & $\mathrm{G}+\mathrm{Q}$ & $\mathrm{G}+\mathrm{Q}+\mathrm{W}$ & $G-W$ & Fp1 & Fp2 & $\mathrm{F} / .80$ & $\mathrm{~F} / 1.20$ & $\mathrm{~F} / 1.50$ & Fbk & GRT \\
\hline 8 & .885 & -45 & -48 & -34. & 254 . & 197. & 318. & 212 . & 169 & 4500 & \\
\hline 7 & .885 & -145 & -153 & -111 & 821. & 635. & 1026. & 684. & 547 . & 4500 & \\
\hline 6 & .885 & -246 & -261 & -186 & 1388 & 1080 & 1735. & 1157 . & 926. & 4500 & \\
\hline 5 & .885 & -346 & -371 & -259 & 1955. & 1530 . & 2444 & 1629 . & 1304 . & 4500 & \\
\hline 4 & .885 & -446 & -484 & -329 & 2523 & 1985 . & 3153 . & 2102 . & 1682 . & 4500 & \\
\hline 3 & .885 & -547 . & -598 & -397 & 3090 . & 2446 . & 3862 . & 2575 . & 2060 . & 4500 & \\
\hline 2 & .885 & -64 & -715 & -463 & 3657 . & 2911. & 4571. & 3047 . & 2438 . & 4500 & \\
\hline 1 & .885 & -74 & -833 & -528 & 4224 & 3381. & 5280 . & 3520 . & 2816 & 4500 & 0 \\
\hline
\end{tabular}




\begin{tabular}{|c|c|c|c|c|c|c|c|c|c|c|c|}
\hline \multirow{2}{*}{$\begin{array}{l}\text { PARED } \\
\text { NIV }\end{array}$} & \multirow{2}{*}{$\mathrm{E}_{\mathrm{R}}$} & \multirow{2}{*}{$\begin{array}{ll}\mathrm{PX} & 13 \\
& \mathrm{G}+\mathrm{Q}\end{array}$} & \multirow{2}{*}{$\begin{array}{c}Q / G+Q \\
G+Q+W\end{array}$} & \multicolumn{2}{|c|}{$=.180$} & \multicolumn{2}{|c|}{ Unidade } & \multirow{2}{*}{$\begin{array}{l}\text { ensão: } \\
\text { F/1.20 }\end{array}$} & \multirow{2}{*}{$\begin{array}{r}\mathrm{KN} / \mathrm{M} 2 \\
\mathrm{~F} / 1.50\end{array}$} & \multirow[b]{2}{*}{ Fbk } & \multirow[b]{2}{*}{ GRT } \\
\hline & & & & $G-W$ & Fp1 & Fp2 & .80 & & & & \\
\hline 8 & .885 & -43 & -61 & -17. & 244 . & $22 \varepsilon$ & 306 . & 204 & 163. & 4500 & - \\
\hline 7 & .885 & -122 & -176 . & -47 & 691. & 652 & 864 . & 576. & 461. & 4500 & - \\
\hline 6 & .885 & -201 & -307 & -60 & 1138. & 1118 & 1423. & 948. & 759. & 4500 & - \\
\hline 5 & .885 & -281 & -454 & -56 & 1585. & 1623. & 2029. & 1353. & 1082 . & 4500 & - \\
\hline 4 & .885 & -360 & -617 & -38 & 2032 . & 2167. & 2708 . & 1805. & 1444 . & 4500 & - \\
\hline 3 & .885 & -439 & -793 & -5 & 2479 . & 2745 . & 3431 . & 2288 . & 1830. & 4500 & - \\
\hline 2 & .885 & -518 & -982 & 40. & 2926 . & 3356 . & 4195. & 2796 . & 2237 . & 4500 & - \\
\hline 1 & .885 & -597 & -1182 & 96. & 3372 . & 3993. & 4991. & 3327 . & 2662 . & 4500 & G1 \\
\hline
\end{tabular}

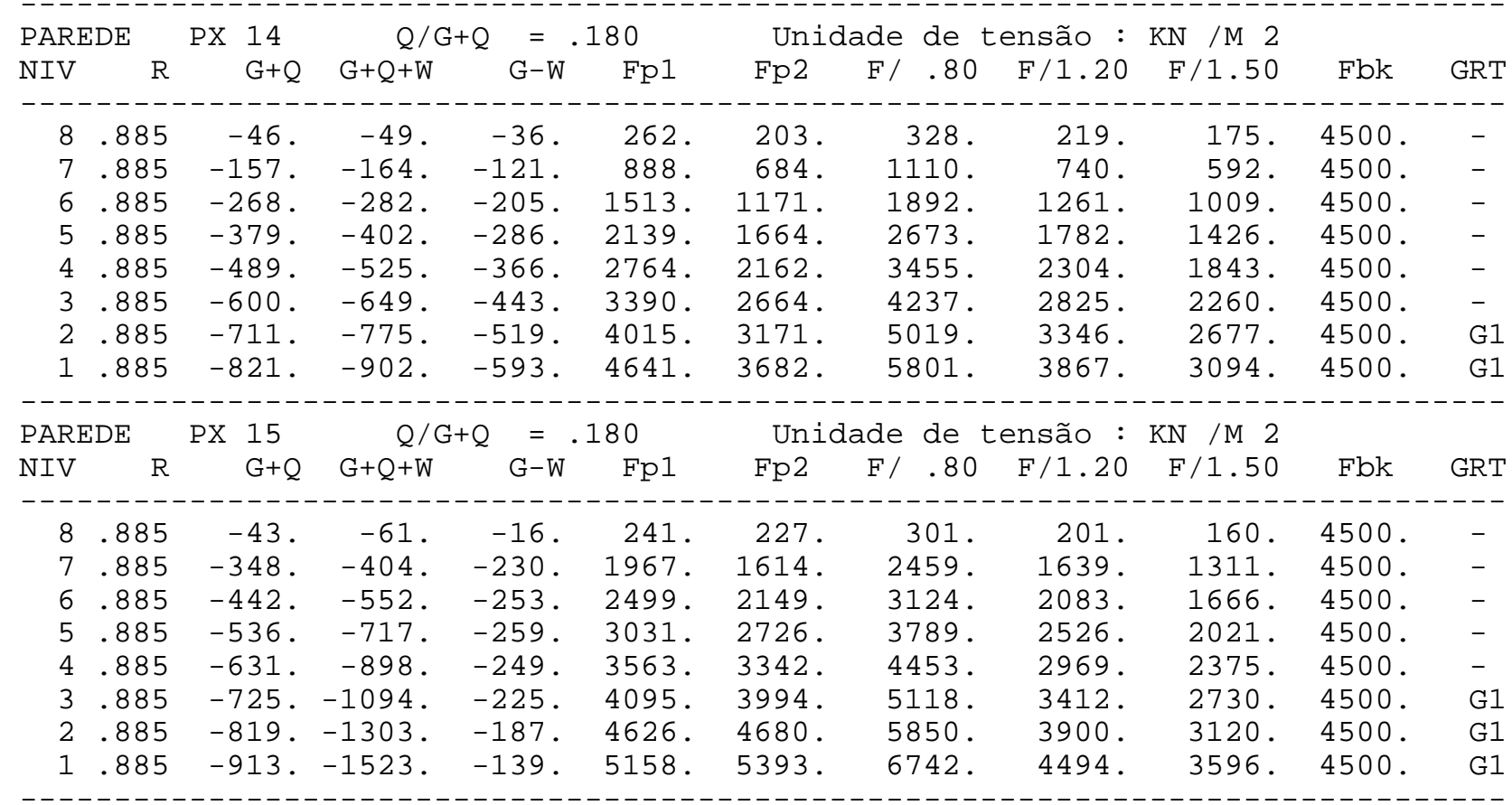

\begin{tabular}{|c|c|c|c|c|c|c|c|c|c|c|c|}
\hline \multirow{2}{*}{$\begin{array}{l}\text { PARED } \\
\text { NIV }\end{array}$} & \multirow{2}{*}{$E_{R}$} & \multirow{2}{*}{$\begin{array}{ll}P X & 16 \\
& G+Q\end{array}$} & \multirow{2}{*}{$\mathrm{Q} / \mathrm{G}+\mathrm{C}$} & \multicolumn{2}{|c|}{$\mathrm{Q}=.180$} & \multicolumn{2}{|c|}{ Unidade } & \multicolumn{2}{|c|}{ tensão : KN /M 2} & \multirow{2}{*}{ Fbk } & \multirow[b]{2}{*}{ GRT } \\
\hline & & & & $G-W$ & Fp1 & Fp2 & $\mathrm{F} / .80$ & $\mathrm{~F} / 1.20$ & $\mathrm{~F} / 1.50$ & & \\
\hline 8 & .885 & -43 & -61 & -16 & 241 . & 227 . & 301. & 201. & 160. & 4500 & - \\
\hline 7 & .885 & -348 & -404 . & -230 & 1967. & 1614 . & 2459 . & 1639. & 1311. & 4500 & - \\
\hline 6 & .885 & -442 & -552 & -253 & 2499 . & 2149 . & 3124 . & 2083 . & 1666 . & 4500 & - \\
\hline 5 & .885 & -536 & -717 & -259 & 3031. & 2726 . & 3789. & 2526 . & 2021 . & 4500 & - \\
\hline 4 & .885 & -631 & -898. & -249 & 3563. & 3342 . & 4453 . & 2969 . & 2375 . & 4500 & - \\
\hline 3 & .885 & -725. & -1094 & -225 & 4095. & 3994. & 5118 . & 3412 . & 2730 . & 4500 & G1 \\
\hline 2 & .885 & -819. & -1303 & -187 & 4626. & 4680. & 5850 . & 3900 . & 3120 . & 4500 & G1 \\
\hline 1 & .885 & -913. & -1523 & -139 & 5158. & 5393. & 6742 & 4494 . & 3596 . & 4500 & G1 \\
\hline
\end{tabular}

\begin{tabular}{|c|c|c|c|c|c|c|c|c|c|c|c|}
\hline \multirow{2}{*}{$\begin{array}{l}\text { PARED } \\
\text { NIV }\end{array}$} & \multirow{2}{*}{${ }^{\mathrm{D}}$} & \multirow{2}{*}{$\begin{array}{l}17 \\
G+Q\end{array}$} & \multirow{2}{*}{$\begin{array}{r}Q / C \\
G+Q+W\end{array}$} & \multirow{2}{*}{$\begin{array}{c}= \\
G-W\end{array}$} & \multirow{2}{*}{$\begin{array}{l}180 \\
\text { Fp1 }\end{array}$} & \multicolumn{2}{|c|}{ Unidade } & \multirow{2}{*}{$\begin{array}{c}\text { ensão: } \\
\text { F/1.20 }\end{array}$} & \multirow{2}{*}{$\begin{array}{r}\mathrm{KN} / \mathrm{M} 2 \\
\mathrm{~F} / 1.50\end{array}$} & \multirow[b]{2}{*}{ Fbk } & \multirow[b]{2}{*}{ GRI } \\
\hline & & & & & & $\mathrm{Fp} 2$ & $\mathrm{~F} /$ & & & & \\
\hline 8 & .885 & -46 & -49 . & -36. & 262 . & 203. & 328. & 219. & 175. & 4500 . & - \\
\hline 7 & .885 & -157 & -164 & -121 & 888. & 684. & 1110. & 740 . & 592 . & 4500 . & \\
\hline 6 & .885 & -268 & -282 & -205 & 1513. & 1171. & 1892. & 1261. & 1009. & 4500 . & \\
\hline 5 & .885 & -379 & -402 & -286 & 2139. & 1664. & 2673. & 1782. & 1426. & 4500 . & \\
\hline 4 & .885 & -489 & -525 & -366 & 2764 . & 2162 . & 3455 . & 2304 . & 1843. & 4500 . & \\
\hline 3 & .885 & -600 & -649 & -443 & 3390. & 2664 . & 4237 . & 2825 . & 2260 . & 4500 . & \\
\hline 2 & .885 & -711. & -775 & -519 & 4015 . & 3171. & 5019. & 3346 . & 2677 . & 4500 . & \\
\hline 1 & .885 & -821 & -902 & -593 & 4641. & 3682 . & 5801. & 3867 . & 3094 . & 4500 . & \\
\hline
\end{tabular}




\begin{tabular}{|c|c|c|c|c|c|c|c|c|c|c|c|}
\hline \multicolumn{2}{|c|}{ PAREDE } & \multirow{2}{*}{$\begin{array}{ll}\mathrm{PX} & 18 \\
& \mathrm{G}+\mathrm{Q}\end{array}$} & \multicolumn{2}{|c|}{$Q / G+Q$} & 180 & \multicolumn{2}{|c|}{ Unidade } & \multirow{2}{*}{$\begin{array}{l}\text { ensão: } \\
\text { F/1.20 }\end{array}$} & $\mathrm{KN} / \mathrm{M} 2$ & \multirow[b]{2}{*}{ Fbk } & \multirow[b]{2}{*}{ GRT } \\
\hline NIV & R & & $\mathrm{G}+\mathrm{Q}+\mathrm{W}$ & $G-W$ & Fp1 & $\mathrm{Fp} 2$ & $\mathrm{~F} / .80$ & & $\mathrm{~F} / 1.50$ & & \\
\hline 8 & .885 & -43 & -61 & -17. & 244 . & 228 & 306 . & 204 . & 163. & 4500 . & - \\
\hline 7 & .885 & -122 & -176 & -47 & 691. & 652 . & 864 . & 576. & 461. & 4500. & - \\
\hline 6 & .885 & -201 & -307 & -60 & 1138. & 1118. & 1423. & 948. & 759. & 4500 . & - \\
\hline 5 & .885 & -281 & -454 & -56 & 1585. & 1623. & 2029. & 1353. & 1082 . & 4500 . & - \\
\hline 4 & .885 & -360 & -617 & -38 & 2032 . & 2167. & 2708 . & 1805. & 1444 . & 4500 . & - \\
\hline 3 & .885 & -439 & -793 & -5 & 2479 . & 2745 . & 3431 . & 2288 . & 1830. & 4500 . & - \\
\hline 2 & .885 & -518 & -982 & 40. & 2926 . & 3356 . & 4195. & 2796 . & 2237 . & 4500 . & - \\
\hline 1 & .885 & -597 & -1182 & 96. & 3372 . & 3993. & 4991. & 3327 . & 2662 . & 4500 . & G1 \\
\hline
\end{tabular}

PAREDE
NIV

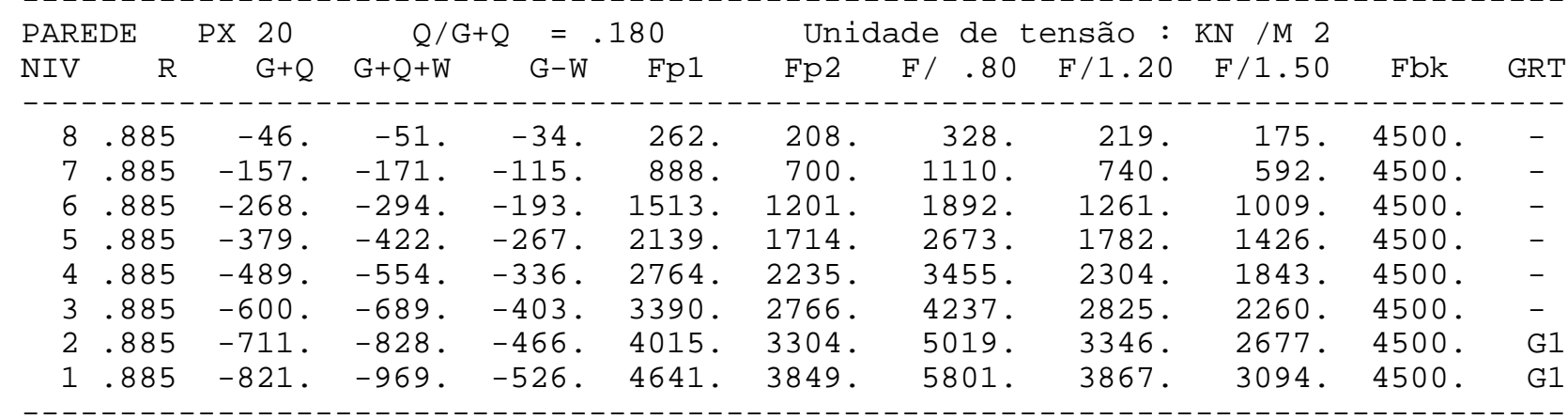

\begin{tabular}{|c|c|c|c|c|c|c|c|c|c|c|c|}
\hline \multirow{2}{*}{$\begin{array}{l}\text { PAREDI } \\
\text { NIV }\end{array}$} & \multirow{2}{*}{$E_{R}$} & \multirow{2}{*}{$\begin{array}{ll}P X & 21 \\
& G+Q\end{array}$} & \multirow{2}{*}{$\begin{array}{c}Q / G+\mathrm{C} \\
\mathrm{G}+\mathrm{Q}+\mathrm{W}\end{array}$} & \multicolumn{2}{|c|}{$Q=.180$} & \multicolumn{2}{|c|}{ Unidade } & \multicolumn{2}{|c|}{ tensão : $\mathrm{KN} / \mathrm{M} 2$} & \multirow[b]{2}{*}{ Fbk } & \multirow[b]{2}{*}{ GRT } \\
\hline & & & & $\mathrm{G}-\mathrm{W}$ & Fp1 & Fp2 & $\mathrm{F} / .80$ & $\mathrm{~F} / 1.20$ & $\mathrm{~F} / 1.50$ & & \\
\hline 8 & .885 & -43 & -60 . & -18 & 241. & 224 . & 301. & 201 . & 160. & 4500 & - \\
\hline 7 & .885 & -348 & -399 . & -234 & 1967. & 1604 . & 2459 . & 1639. & 1311. & 4500 . & - \\
\hline 6 & .885 & -442 . & -544. & -261 & 2499. & 2128 & 3124 . & 2083 . & 1666 . & 4500 & - \\
\hline 5 & .885 & -536. & -703. & -273 & 3031 . & 2690 . & 3789. & 2526 . & 2021 . & 4500 & 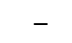 \\
\hline 4 & .885 & -631. & -877. & -270 & 3563 . & 3289 . & 4453 . & 2969 . & 2375 . & 4500 & - \\
\hline 3 & .885 & -725 & -1065 & -254 & 4095. & 3921 . & 5118. & 3412 . & 2730 . & 4500 & 1 \\
\hline 2 & .885 & -819. & -1265 & -226 & 4626. & 4585 . & 5783. & 3855 . & 3084 . & 4500 . & 1 \\
\hline 1 & .885 & -913. & -1475 & -187 & 5158. & 5273 & 6592. & 4395. & 3516 . & 4500 & 1 \\
\hline
\end{tabular}

PAREDE PX $22 \quad \mathrm{Q} / \mathrm{G}+\mathrm{Q}=.180 \quad$ Unidade de tensão: $\mathrm{KN} / \mathrm{M} 2$

\begin{tabular}{|c|c|c|c|c|c|c|c|c|c|c|c|}
\hline NIV & $\mathrm{R}$ & $\mathrm{G}+\mathrm{Q}$ & $\mathrm{G}+\mathrm{Q}+\mathrm{W}$ & $G-W$ & Fp1 & $\mathrm{Fp} 2$ & $\mathrm{~F} / .80$ & $\mathrm{~F} / 1.20$ & $\mathrm{~F} / 1.50$ & Fbk & GRT \\
\hline 8 & .885 & -43. & -60 & -18 & 241 . & 224 . & 301 & 201 . & 160. & 4500 . & - \\
\hline 7 & .885 & -348 & -399. & -234 & 1967. & 1604. & 2459. & 1639. & 1311. & 4500 . & - \\
\hline 6 & .885 & -442 . & -544 & -261 & 2499. & 2128 . & 3124. & 2083 . & 1666 . & 4500 . & 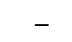 \\
\hline 5 & .885 & -536 & -703 & -273 & 3031 . & 2690. & 3789. & 2526 . & 2021 . & 4500 . & - \\
\hline 4 & .885 & -631 & -877 & -270 & 3563. & 3289. & 4453. & 2969. & 2375 . & 4500 . & - \\
\hline 3 & .885 & -725 & -1065 & -254 & 4095. & 3921. & 5118. & 3412 . & 2730 & 4500 . & G1 \\
\hline 2 & .885 & -819 & -1265 & -226 & 4626. & 4585. & 5783. & 3855 . & 3084 . & 4500 . & G1 \\
\hline 1 & .885 & -913 & -1475 & -187 & 5158. & 5273. & 6592 & 4395. & 3516 . & 4500 . & G1 \\
\hline
\end{tabular}




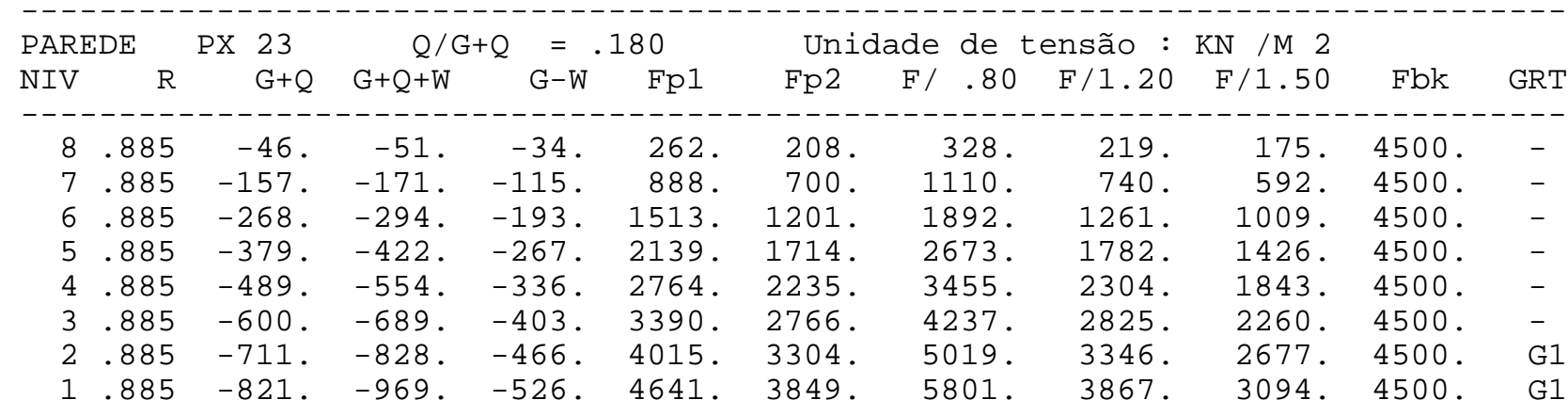

\begin{tabular}{|c|c|c|c|c|c|c|c|c|c|c|c|}
\hline \multirow{2}{*}{$\begin{array}{l}\text { PAREDI } \\
\text { NIV }\end{array}$} & \multirow{2}{*}{$E_{R}$} & \multirow{2}{*}{$\begin{array}{ll}P X & 24 \\
& G+Q\end{array}$} & \multirow{2}{*}{$\begin{array}{c}Q / G+Q \\
G+Q+W\end{array}$} & \multirow{2}{*}{$\begin{array}{c}= \\
G-W\end{array}$} & \multirow{2}{*}{$\begin{array}{r}180 \\
\text { Fp1 }\end{array}$} & \multicolumn{2}{|c|}{ Unidade } & \multirow{2}{*}{$\begin{array}{l}\text { ensão: } \\
\text { F/1.20 }\end{array}$} & \multirow{2}{*}{$\begin{array}{r}\mathrm{KN} / \mathrm{M} 2 \\
\mathrm{~F} / 1.50\end{array}$} & \multirow[b]{2}{*}{ Fbk } & \multirow[b]{2}{*}{ GRT } \\
\hline & & & & & & Fp2 & $\mathrm{F} / .80$ & & & & \\
\hline 8 & .885 & -43 & -58. & -21 & 244 & 219. & 306. & 204 . & 163. & 4500 . & - \\
\hline 7 & .885 & -122. & -165. & -58 & 691. & 624. & 864. & 576. & 461. & 4500 . & - \\
\hline 6 & .885 & -201 & -285. & -81 & 1138. & 1063. & 1423. & 948. & 759. & 4500 . & - \\
\hline 5 & .885 & -281 & -418 . & -92 . & 1585. & 1533. & 1981. & 1321. & 1057 . & 4500. & - \\
\hline 4 & .885 & -360 & -563 & -91. & 2032 . & 2033. & 2542 . & 1694. & 1356 . & 4500 . & - \\
\hline 3 & .885 & -439 & -720 . & -79. & 2479 . & 2562 . & 3202 . & 2135 . & 1708 . & 4500 . & - \\
\hline 2 & .885 & -518 & -886 & -56. & 2926. & 3115. & 3894 . & 2596 . & 2077 . & 4500 . & - \\
\hline 1 & .885 & -597 & -1061 . & -25 & 3372 . & 3690. & 4612 . & 3075 . & 2460 & 4500 . & G1 \\
\hline
\end{tabular}

PAREDE PY $1 \quad \mathrm{Q} / \mathrm{G}+\mathrm{Q}=.180 \quad$ Unidade de tensão: $\mathrm{KN} / \mathrm{M} 2$

$\begin{array}{llllllllllll}N I V & R & G+Q & G+Q+W & G-W & F p 1 & F p 2 & F / .80 & F / 1.20 & F / 1.50 & \text { Fbk } & \text { GRT }\end{array}$

\begin{tabular}{|c|c|c|c|c|c|c|c|c|c|c|c|}
\hline 8 & .885 & -43 & -66. & -12 & 244 . & 241 . & 306. & 204 . & 163. & 4500 & - \\
\hline 7 & .885 & -122 . & -191. & -32 . & 691. & 690. & 864 . & 576. & 461. & 4500 & - \\
\hline 6 & .885 & -201 . & -337 & -30 & 1138. & 1192 . & 1490 . & 993. & 795. & 4500 & - \\
\hline 5 & .885 & -281. & -503. & -7 . & 1585. & 1746 . & 2182 . & 1455 . & 1164 . & 4500 & - \\
\hline 4 & .885 & -360. & -689. & 35. & 2032 . & 2348 . & 2935. & 1957 . & 1565 . & 4500 & - \\
\hline 3 & .885 & -439. & -893 & 95. & 2479 . & 2996 . & 3745 . & 2496 . & 1997. & 4500 & - \\
\hline 2 & .885 & -518. & -1114. & 171. & 2926. & 3684 . & 4605 . & 3070 . & 2456 . & 4500 & G1 \\
\hline 1 & .885 & -597. & -1348 & 261. & 3372 . & 4407 & 5508. & 3672 . & 2938 . & 4500 & G1 \\
\hline
\end{tabular}

\begin{tabular}{|c|c|c|c|c|c|c|c|c|c|c|c|}
\hline \multirow{2}{*}{$\begin{array}{l}\text { PARED } \\
\text { NIV }\end{array}$} & \multirow{2}{*}{${ }^{E}$} & \multirow{2}{*}{$\begin{array}{c}2 \\
G+Q\end{array}$} & \multirow{2}{*}{$\begin{array}{c}Q / G+\mathrm{C} \\
\mathrm{G}+\mathrm{Q}+\mathrm{W}\end{array}$} & \multicolumn{2}{|c|}{$Q=.180$} & \multicolumn{2}{|c|}{ Unidade } & \multicolumn{2}{|c|}{ tensão : KN /M 2} & \multirow[b]{2}{*}{ Fbk } & \multirow[b]{2}{*}{ GRT } \\
\hline & & & & $\mathrm{G}-\mathrm{W}$ & Fp1 & Fp2 & 80 & $\mathrm{~F} / 1.20$ & $\mathrm{~F} / 1.50$ & & \\
\hline 8 & .885 & -45 & -57. & -24 . & 253. & 220 . & 316. & 211. & 169. & 4500 & - \\
\hline 7 & .885 & -128 & -164 & -68 & 721. & 632. & 901. & 601. & 481 . & 4500 & - \\
\hline 6 & .885 & -210 & -283 & -101 & 1189. & 1072 . & 1486 . & 991. & 793. & 4500 & - \\
\hline 5 & .885 & -293 & -412 & -122 & 1657. & 1539 . & 2071 . & 1381 . & 1105 . & 4500 & 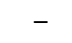 \\
\hline 4 & .885 & -376 & -552 & -133 & 2125 . & 2032 . & 2656 . & 1771 . & 1417 . & 4500 & - \\
\hline 3 & .885 & -459 & -701 & -135 & 2593. & 2550 . & 3241 . & 2161 . & 1729 . & 4500 & - \\
\hline 2 & .885 & -542 & -859 & -127 & 3061 . & 3088 . & 3861 . & 2574 . & 2059 . & 4500 & - \\
\hline 1 & .885 & -625 & -1024 & -113 & 3529 . & 3646 . & 4557 & 3038 . & 2430 & 4500 & 1 \\
\hline
\end{tabular}

\begin{tabular}{|c|c|c|c|c|c|c|c|c|c|c|c|}
\hline \multirow{2}{*}{$\begin{array}{l}\text { PARED } \\
\text { NIV }\end{array}$} & \multirow{2}{*}{${ }^{E} R$} & \multirow{2}{*}{$\begin{array}{c}4 \\
G+Q\end{array}$} & \multirow{2}{*}{$\begin{array}{c}Q / G+\mathrm{C} \\
G+Q+W\end{array}$} & \multicolumn{2}{|c|}{$2=.180$} & \multicolumn{2}{|c|}{ Unidade } & \multirow{2}{*}{$\begin{array}{l}\text { ensão: } \\
\text { F/1.20 }\end{array}$} & \multirow{2}{*}{$\begin{array}{r}\mathrm{KN} / \mathrm{M} 2 \\
\mathrm{~F} / 1.50\end{array}$} & \multirow[b]{2}{*}{ Fbk } & \multirow[b]{2}{*}{ GRT } \\
\hline & & & & $\mathrm{G}-\mathrm{W}$ & Fp1 & Fp2 & $\mathrm{F} / .80$ & & & & \\
\hline 8 & .885 & -45 & -58 & -24 . & 253. & 223. & 316. & 211 . & 169. & 4500 & - \\
\hline 7 & .885 & -128 & -167. & -66. & 721. & 638. & 901 & 601. & 481. & 4500 . & - \\
\hline 6 & .885 & -210 & -288 & -95 & 1189. & 1085 . & 1486. & 991. & 793. & 4500 & - \\
\hline 5 & .885 & -293. & -420 & -113 & 1657. & 1560 . & 2071. & 1381. & 1105. & 4500 . & - \\
\hline 4 & .885 & -376 . & -564 . & -120 & 2125 . & 2064 . & 2656. & 1771. & 1417. & 4500 & - \\
\hline 3 & .885 & -459. & -718 & -117 & 2593. & 2593. & 3241. & 2161. & 1729. & 4500 & - \\
\hline 2 & .885 & -542 . & -882. & -105 & 3061 . & 3145 . & 3931. & 2621. & 2097. & 4500 & - \\
\hline 1 & .885 & -625. & -1053 & -84 & 3529. & 3717 . & 4646 . & 3098 . & 2478 . & 4500 & G1 \\
\hline
\end{tabular}




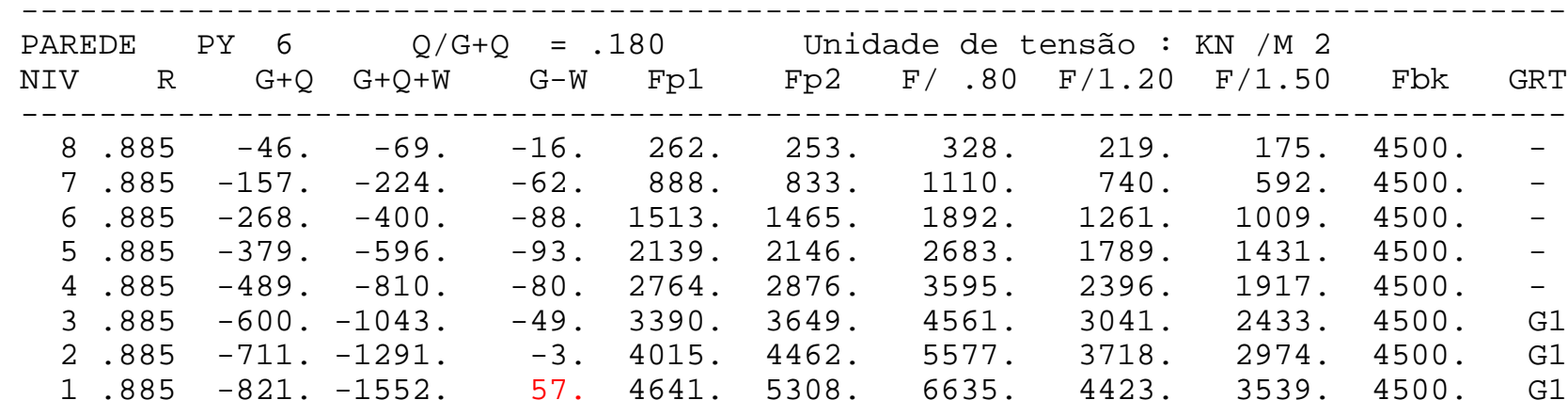

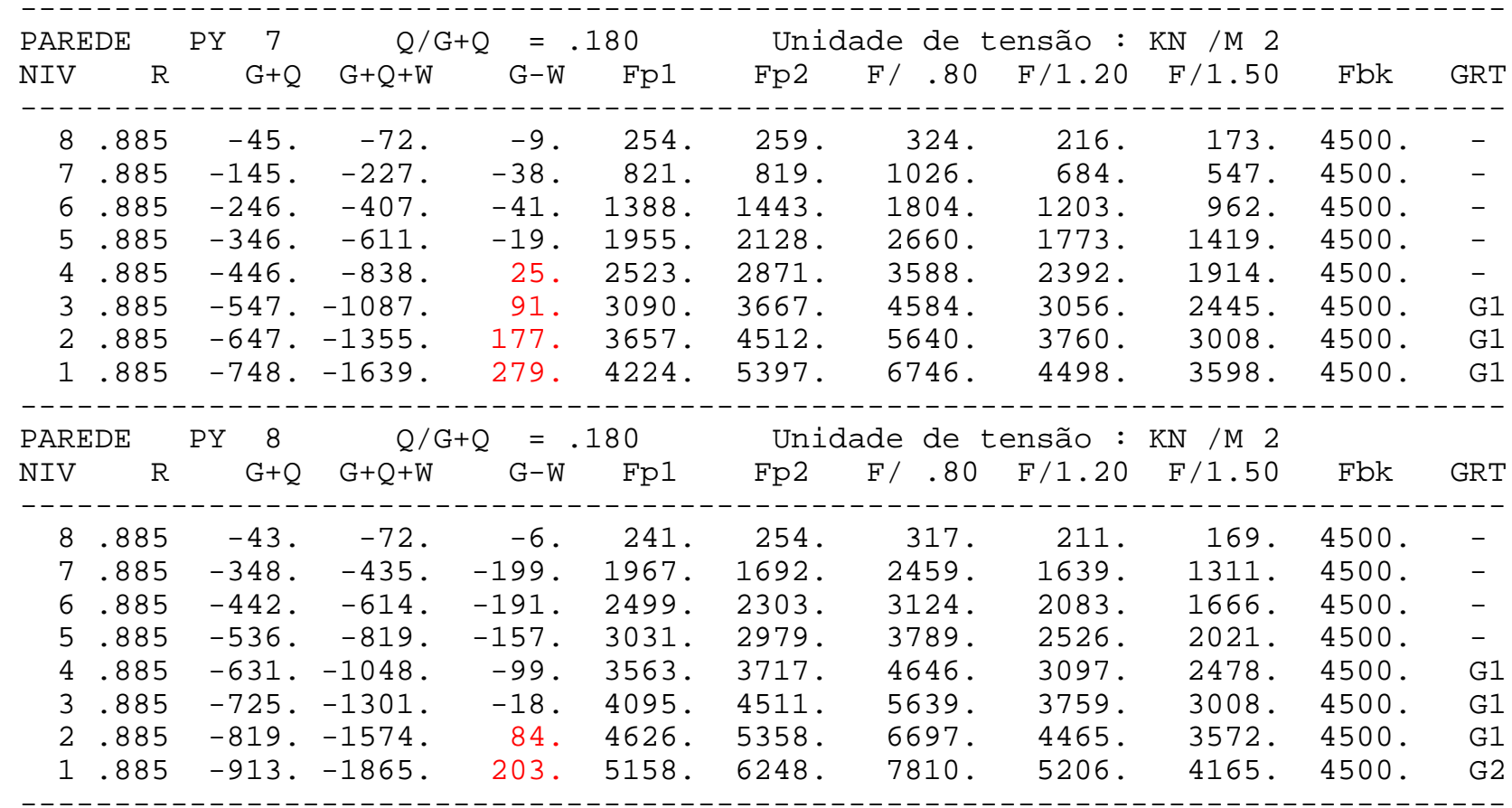

\begin{tabular}{|c|c|c|c|c|c|c|c|c|c|c|c|}
\hline \multirow{2}{*}{$\begin{array}{l}\text { PARED } \\
\text { NIV }\end{array}$} & \multirow{2}{*}{$E_{R}$} & PY & \multirow{2}{*}{$\begin{array}{c}Q / G+C \\
G+Q+W\end{array}$} & \multicolumn{2}{|c|}{$=.180$} & \multicolumn{2}{|c|}{ Unidade } & \multicolumn{2}{|c|}{ tensão : KN /M 2} & \multirow{2}{*}{ Fbk } & \multirow[b]{2}{*}{ GRT } \\
\hline & & $\begin{array}{c}9 \\
G+Q\end{array}$ & & $\mathrm{G}-\mathrm{W}$ & Fp1 & Fp2 & $\mathrm{F} / .80$ & $\mathrm{~F} / 1.20$ & $\mathrm{~F} / 1.50$ & & \\
\hline 8 & .885 & -41 & -68 & -7 & 234 . & 242 . & 303. & 202 . & 162. & 4500 & - \\
\hline 7 & .885 & -360 & -439 & -216 & 2033. & 1723 . & 2542 . & 1694 . & 1356 . & 4500 & - \\
\hline 6 & .885 & -426 & -582 & -193 & 2406 . & 2195 . & 3007 . & 2005 . & 1604 . & 4500 & - \\
\hline 5 & .885 & -492 & -749. & -146 & 2778 . & 2726 . & 3472 . & 2315 . & 1852 . & 4500 & - \\
\hline 4 & .885 & -558 & -938 & -77 & 3150 . & 3313 . & 4142 . & 2761 . & 2209 . & 4500 & - \\
\hline 3 & .885 & -623 & -1148 & 13. & 3522 . & 3953 . & 4941 . & 3294 . & 2635 . & 4500 & G1 \\
\hline 2 & .885 & -689. & -1377 & 122 . & 3894. & 4639 . & 5799. & 3866 . & 3093 . & 4500 & G1 \\
\hline 1 & .885 & -755. & -1621 & 247 . & 4266. & 5365 . & 6707 & 4471 . & 3577 . & 4500 & G1 \\
\hline
\end{tabular}

PAREDE PY $10 \quad \mathrm{Q} / \mathrm{G}+\mathrm{Q}=.180 \quad$ Unidade de tensão: $\mathrm{KN} / \mathrm{M} 2$

\begin{tabular}{|c|c|c|c|c|c|c|c|c|c|c|c|}
\hline $\mathrm{NIV}$ & R & $\mathrm{G}+\mathrm{Q}$ & $\mathrm{G}+\mathrm{Q}+\mathrm{W}$ & $G-W$ & Fp1 & Fp2 & $\mathrm{F} / .80$ & $\mathrm{~F} / 1.20$ & $\mathrm{~F} / 1.50$ & Fbk & GRT \\
\hline 8 & .885 & -38 & -52 & -17 . & 215 . & 197. & 269. & 179. & 143. & 4500 & - \\
\hline 7 & .885 & -277 & -320 & -185 & 1567 . & 1282 . & 1959. & 1306. & 1045 . & 4500 & - \\
\hline 6 & .885 & -364 & -448 & -214 & 2055 . & 1751. & 2568 & 1712 . & 1370 . & 4500 & - \\
\hline 5 & .885 & -450 & -588 & -231 & 2542 . & 2252 & 3178 . & 2118 . & 1695. & 4500 & - \\
\hline 4 & .885 & -536. & -741. & -235 & 3030 . & 2783 & 3787 . & 2525 . & 2020 . & 4500 & - \\
\hline 3 & .885 & -623 & -904 & -229 & 3517 . & 3343 . & 4397 . & 2931. & 2345 . & 4500 & - \\
\hline 2 & .885 & -709 & -1078 & -212 & 4005 & 3927 . & 5006 . & 3337. & 2670 . & 4500 & G1 \\
\hline 1 & .885 & -795 & -1261. & -186 & 4492 . & 4533 . & 5666 . & 3778 . & 3022 . & 4500 & G1 \\
\hline
\end{tabular}




\begin{tabular}{|c|c|c|c|c|c|c|c|c|c|c|c|}
\hline \multirow{2}{*}{$\begin{array}{l}\text { PAREDI } \\
\text { NIV }\end{array}$} & \multirow{2}{*}{$E_{R}$} & \multirow{2}{*}{$\begin{array}{ll}\text { PY } & 11 \\
& \mathrm{G}+\mathrm{Q}\end{array}$} & \multicolumn{2}{|c|}{$Q / G+Q$} & \multirow{2}{*}{$\begin{array}{r}180 \\
\text { Fp1 }\end{array}$} & \multicolumn{2}{|c|}{ Unidade } & \multirow{2}{*}{$\begin{array}{l}\text { ensão: } \\
\text { F/1.20 }\end{array}$} & \multirow{2}{*}{$\begin{array}{r}\mathrm{KN} / \mathrm{M} 2 \\
\mathrm{~F} / 1.50\end{array}$} & \multirow[b]{2}{*}{ Fbk } & \multirow[b]{2}{*}{ GRT } \\
\hline & & & $\mathrm{G}+\mathrm{Q}+\mathrm{W}$ & $\mathrm{G}-\mathrm{W}$ & & $\mathrm{Fp} 2$ & .80 & & & & \\
\hline 8 & .885 & -41 & -60 & -16. & 234. & 22 & 293. & 195. & 156. & 4500 & - \\
\hline 7 & .885 & -360 & -414. & -241 & 2033. & 1659. & 2542 . & 1694. & 1356. & 4500 & - \\
\hline 6 & .885 & -426 & -532 & -243 & 2406 . & 2070 . & 3007 . & 2005 . & 1604 . & 4500 & - \\
\hline 5 & .885 & -492 & -666 & -228 & 2778 . & 2520 . & 3472 . & 2315 . & 1852 . & 4500 & - \\
\hline 4 & .885 & -558 & -816 & -199 & 3150 . & 3008 . & 3937. & 2625 . & 2100 & 4500 & - \\
\hline 3 & .885 & -623 & -980 & -155 & 3522 . & 3532 . & 4415 . & 2944 . & 2355 . & 4500 & - \\
\hline 2 & .885 & -689 & -1156 & -98 & 3894 . & 4088 . & 5110. & 3407 . & 2726 . & 4500 & G1 \\
\hline 1 & .885 & -755 & -1344 & -31 & 4266 . & 4671. & 5839. & 3893 . & 3114. & 4500 & G1 \\
\hline
\end{tabular}

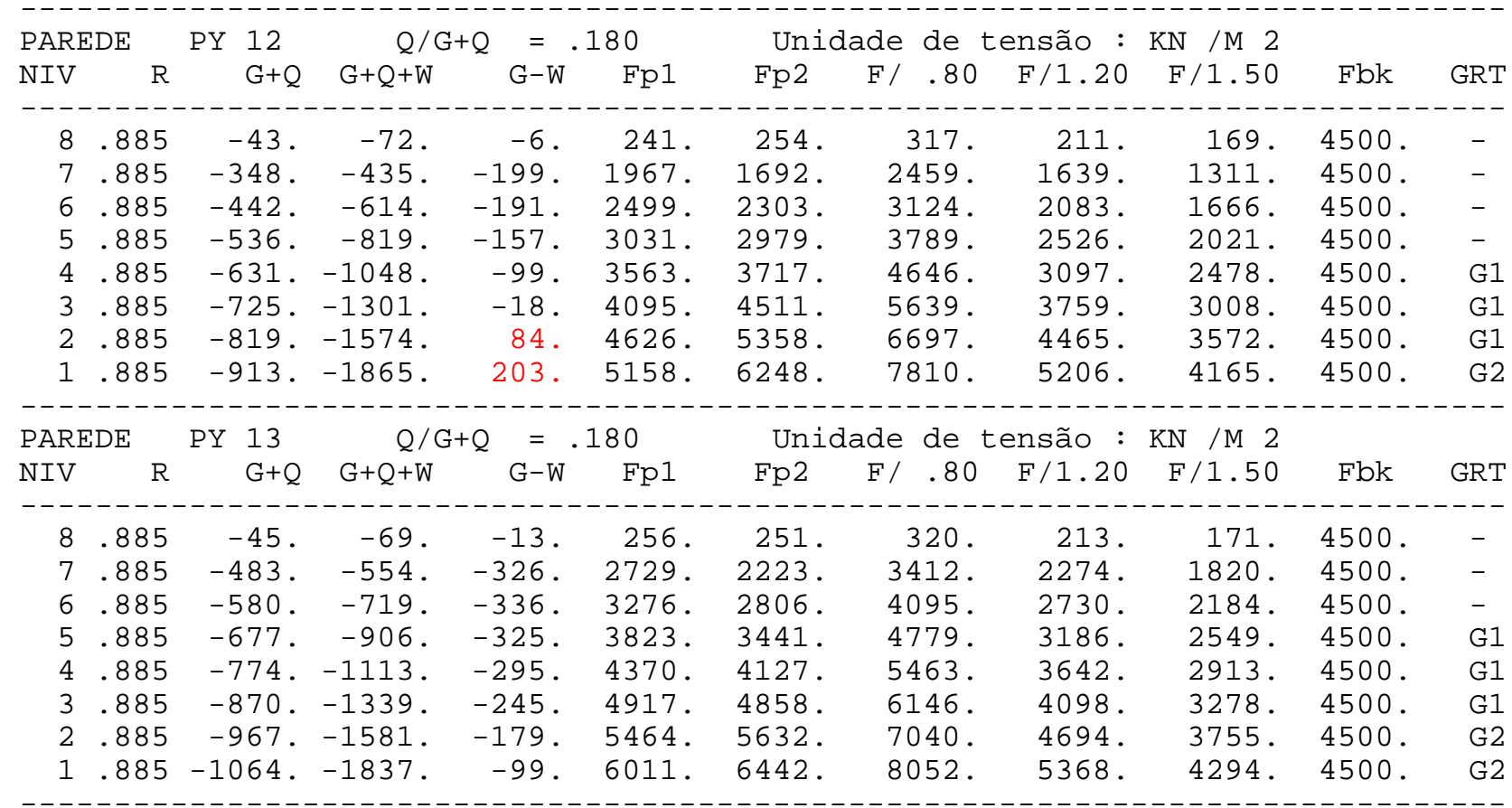

\begin{tabular}{|c|c|c|c|c|c|c|c|c|c|c|c|}
\hline \multirow{2}{*}{$\begin{array}{l}\text { PAREDF } \\
\text { NIV }\end{array}$} & \multirow{2}{*}{$E_{R}$} & \multirow{2}{*}{$\begin{array}{ll}\text { PY } & 14 \\
& G+Q\end{array}$} & \multirow{2}{*}{$\begin{array}{c}Q / G+Q \\
G+Q+W\end{array}$} & \multicolumn{2}{|c|}{$2=.180$} & \multicolumn{2}{|c|}{ Unidade } & \multicolumn{2}{|c|}{ ensão : KN /M 2} & \multirow[b]{2}{*}{ Fbk } & \multirow[b]{2}{*}{ GRT } \\
\hline & & & & $\mathrm{G}-\mathrm{W}$ & Fp1 & Fp2 & $\mathrm{F} / .80$ & $\mathrm{~F} / 1.20$ & $\mathrm{~F} / 1.50$ & & \\
\hline 8 & .885 & -45 & -72 & -9 . & 254 . & 259. & 324 . & 216 . & 173. & 4500 . & - \\
\hline 7 & .885 & -145 & -227 . & -38 & 821. & 819. & 1026 . & 684. & 547. & 4500 . & - \\
\hline 6 & .885 & -246 & -407 . & -41 & 1388. & 1443 . & 1804 . & 1203 . & 962. & 4500 . & - \\
\hline 5 & .885 & -346 & -611. & -19. & 1955. & 2128 & 2660 . & 1773 . & 1419. & 4500 . & - \\
\hline 4 & .885 & -446 & -838. & 25 . & 2523. & 2871 . & 3588 . & 2392 . & 1914 . & 4500 . & - \\
\hline 3 & .885 & -547. & -1087 & 91. & 3090 . & 3667 . & 4584 . & 3056 . & 2445 . & 4500 . & G1 \\
\hline 2 & .885 & -647. & -1355 . & 177 . & 3657 . & 4512 & 5640 . & 3760 . & 3008 . & 4500 . & G1 \\
\hline 1 & .885 & -748 . & -1639. & 279 . & 4224 . & 5397. & 6746 & 4498 . & 3598 . & 4500 . & G1 \\
\hline
\end{tabular}

\begin{tabular}{|c|c|c|c|c|c|c|c|c|c|c|c|}
\hline \multirow{2}{*}{$\begin{array}{l}\text { PARED } \\
\text { NIV }\end{array}$} & \multirow{2}{*}{${ }^{E} \quad$} & \multirow{2}{*}{$\begin{array}{l}15 \\
G+Q\end{array}$} & \multirow{2}{*}{$\begin{array}{c}Q / G+Q \\
G+Q+W\end{array}$} & \multicolumn{2}{|c|}{$=.180$} & \multicolumn{2}{|c|}{ Unidade } & \multirow{2}{*}{$\begin{array}{l}\text { ensão: } \\
\text { F/1.20 }\end{array}$} & \multirow{2}{*}{$\begin{array}{r}\mathrm{KN} / \mathrm{M} 2 \\
\mathrm{~F} / 1.50\end{array}$} & \multirow[b]{2}{*}{ Fbk } & \multirow[b]{2}{*}{ GRI } \\
\hline & & & & $G-W$ & Fp1 & Fp2 & .80 & & & & \\
\hline 8 & .885 & -46 & -69. & -16 & 262 . & 253. & 328. & 219. & 175. & 4500 & - \\
\hline 7 & .885 & -157 & -224 . & -62. & 888. & 833. & 1110. & 740. & 592 . & 4500 & \\
\hline 6 & .885 & -268 & -400 . & -88 & 1513 & 1465. & 1892. & 1261. & 1009. & 4500 & \\
\hline 5 & .885 & -379 & -596. & -93. & 2139 . & 2146 . & 2683. & 1789. & 1431 . & 4500 & \\
\hline 4 & .885 & -489 & -810. & -80 & 2764 & 2876 . & 3595 . & 2396. & 1917 . & 4500 & \\
\hline 3 & .885 & -600 & -1043 & -49 . & 3390 & 3649 . & 4561 . & 3041 . & 2433 . & 4500 & \\
\hline 2 & .885 & -711 & -1291. & -3 & 4015 & 4462 . & 5577. & 3718 . & 2974 . & 4500 & \\
\hline 1 & .885 & -821 & -1552. & 57. & 4641 & 5308. & 6635. & 4423 . & 3539 . & 4500 & $G$ \\
\hline
\end{tabular}




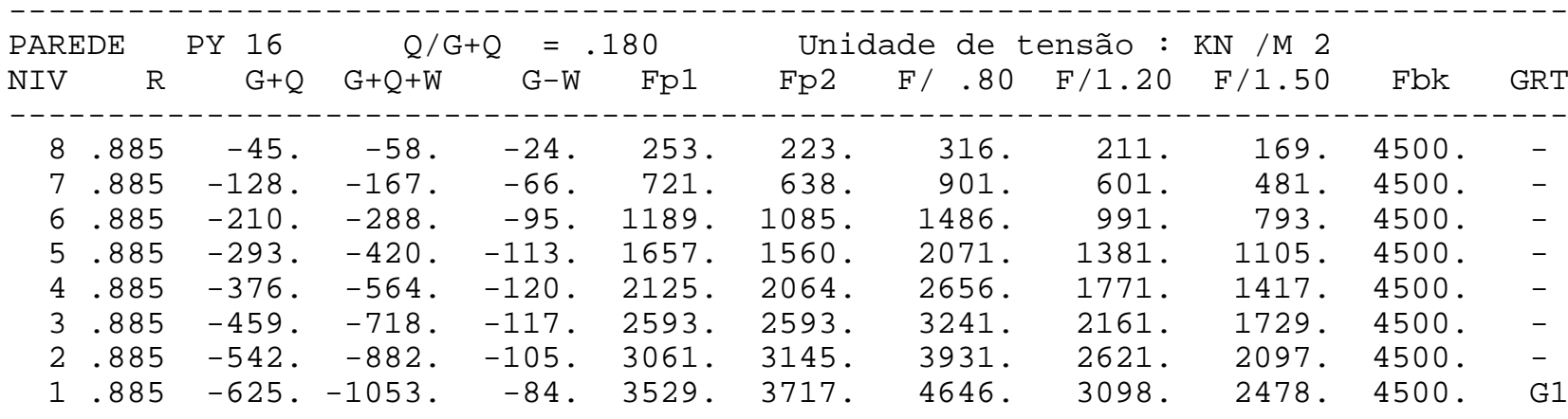

\begin{tabular}{|c|c|c|c|c|c|c|c|c|c|c|c|}
\hline \multirow{2}{*}{$\begin{array}{l}\text { PARED } \\
\text { NIV }\end{array}$} & \multirow{2}{*}{$E_{R}$} & \multirow{2}{*}{$\begin{array}{ll}\text { PY } & 18 \\
& G+Q\end{array}$} & \multirow{2}{*}{$\begin{array}{c}Q / G+C \\
G+Q+W\end{array}$} & \multicolumn{2}{|c|}{$Q=.180$} & \multicolumn{4}{|c|}{ Unidade de tensão : KN /M 2} & \multirow[b]{2}{*}{ Fbk } & \multirow[b]{2}{*}{ GRT } \\
\hline & & & & $\mathrm{G}-\mathrm{W}$ & Fp1 & Fp2 & $\mathrm{F} / .80$ & $\mathrm{~F} / 1.20$ & $\mathrm{~F} / 1.50$ & & \\
\hline 8 & .885 & -43 & -66 . & -12 & 244 . & 241. & 306. & 204. & 1 & 4500 & - \\
\hline 7 & .885 & -122 & -191. & -32 & 691. & 690. & 864 . & 576. & 461. & 4500 & - \\
\hline 6 & .885 & -201 & -337 & -30 & 1138. & 1192 . & 1490. & 993. & 795. & 4500 & - \\
\hline 5 & .885 & -281 & -503 & -7 & 1585. & 1746 . & 2182 . & 1455 . & 1164 . & 4500 & - \\
\hline 4 & .885 & -360 & -689. & 35. & 2032 . & 2348. & 2935. & 1957 . & 1565. & 4500 & - \\
\hline 3 & .885 & -439 & -893 & 95. & 2479. & 2996. & 3745 . & 2496 . & 1997. & 4500 & - \\
\hline 2 & .885 & -518 & -1114 & 171. & 2926. & 3684 . & 4605 . & 3070 . & 2456 . & 4500 & G1 \\
\hline 1 & .885 & -597 & -1348 & 261 . & 3372 . & 4407 . & 5508. & 3672 . & 2938. & 4500 & G1 \\
\hline \multicolumn{2}{|c|}{ PAREDE } & PY 19 & Q/ & $=$ & 80 & \multicolumn{3}{|c|}{ Unidade } & $\mathrm{KN} / \mathrm{M} 2$ & & \\
\hline IV & $\mathrm{R}$ & $G+Q$ & $\mathrm{G}+\mathrm{Q}+\mathrm{W}$ & $G-W$ & Fp1 & $\mathrm{Fp} 2$ & $\mathrm{~F} / .80$ & $\mathrm{~F} / 1.20$ & $\mathrm{~F} / 1.50$ & Fbk & GRT \\
\hline 8 & .885 & -45 & -57 & -24 & 253. & 220. & 316. & 211. & 169. & 4500 & - \\
\hline 7 & .885 & -128 & -164 & -68. & 721. & 632. & 901. & 601. & 481. & 4500 & - \\
\hline 6 & .885 & -210 & -283 & -101. & 1189. & 1072 & 1486. & 991. & 793. & 4500 & - \\
\hline 5 & .885 & -293 & -412 . & -122 . & 1657. & 1539. & 2071. & 1381. & 1105. & 4500 & - \\
\hline 4 & .885 & -376 & -552 & -133. & 2125 . & 2032 . & 2656 . & 1771. & 1417. & 4500 & - \\
\hline 3 & .885 & -459 & -701 . & -135. & 2593. & 2550 . & 3241 . & 2161. & 1729. & 4500 & - \\
\hline 2 & .885 & -542 & -859 & -127 . & 3061 . & 3088. & 3861 . & 2574 . & 2059. & 4500 & - \\
\hline 1 & .885 & -625 & -1024 & -113 & 3529. & 3646 . & 4557 . & 3038 . & 2430 . & 4500 & G1 \\
\hline
\end{tabular}

\section{Procedimento: GRUPOS ISOLADOS DE PAREDES - SITUAÇÃO D}

TECSOF ENGENHARIA S/C LTDA PROGRAMA VPA - VERIFICAÇÃO DE PAREDES DE ALVENARIA - VERSÃO ABR/94

PROJETO : EXEMPLO DO CAPÍTULO 5

CLIENTE : DISSERTAÇÃO

ESTRUTURA: ALVENARIA ESTRUTURAI 


\begin{tabular}{|c|c|c|c|c|c|c|c|c|c|c|c|}
\hline \multirow{2}{*}{$\begin{array}{l}\text { PARED } \\
\text { NIV }\end{array}$} & \multirow{2}{*}{$\mathrm{E}$} & \multirow{2}{*}{$\begin{array}{cc}\mathrm{PX} & 3 \\
& \mathrm{G}+\mathrm{Q}\end{array}$} & \multirow{2}{*}{$\begin{array}{c}Q / G+C \\
G+Q+W\end{array}$} & \multicolumn{2}{|c|}{$Q=.180$} & \multicolumn{2}{|c|}{ Unidade } & \multirow{2}{*}{$\begin{array}{l}\text { tensão: } \\
\text { F/1.20 }\end{array}$} & \multirow{2}{*}{$\begin{array}{r}\mathrm{KN} / \mathrm{M} 2 \\
\mathrm{~F} / 1.50\end{array}$} & \multirow[b]{2}{*}{ Fbk } & \multirow[b]{2}{*}{ GRT } \\
\hline & & & & $G-W$ & Fp1 & Fp2 & $\mathrm{F} / .80$ & & & & \\
\hline 8 & .885 & -41 & -61. & -15 & 234 . & 224 . & 293. & 195. & 156. & 4500 & - \\
\hline 7 & .885 & -360 & -417 . & -238 & 2033. & 1668 & 2542 . & 1694. & 1356 . & 4500 & - \\
\hline 6 & .885 & -426 & -539. & -236 & 2406 . & 2086 . & 3007 . & 2005 . & 1604 . & 4500 & - \\
\hline 5 & .885 & -492 & -677 . & -218 & 2778 . & 2547 . & 3472 . & 2315 . & 1852 . & 4500 & - \\
\hline 4 & .885 & -558 & -832 . & -183 & 3150 . & 3049 . & 3937 . & 2625 . & 2100 . & 4500 & - \\
\hline 3 & .885 & -623 & -1002 . & -133 & 3522 . & 3588 . & 4485 . & 2990 . & 2392 . & 4500 & - \\
\hline 2 & .885 & -689 & -1186 & -69. & 3894 . & 4161 . & 5201. & 3468 . & 2774 . & 6000 & - \\
\hline 1 & .885 & -755 & -1380 & 6. & 4266 . & 4763 & 5954 . & 3969 . & 3175 . & 6000 & - \\
\hline \multicolumn{2}{|c|}{ PAREDE } & $\mathrm{PX}$ & Q/ & $=$ & & \multicolumn{3}{|c|}{ Unidade } & \multirow{2}{*}{$\begin{array}{r}\mathrm{KN} / \mathrm{M} 2 \\
\mathrm{~F} / 1.50\end{array}$} & & \\
\hline NIV & $\mathrm{R}$ & $G+Q$ & $G+Q+W$ & $G-W$ & Fp1 & Fp2 & $\mathrm{F} / .80$ & $\mathrm{~F} / 1.20$ & & Flok & GRT \\
\hline 8 & .885 & -45 & -53. & -29 & 256 . & 211. & 320 . & 213. & 171. & 4500 & - \\
\hline 7 & .885 & -483 & -506 . & -373 & 2729 . & 2105 & 3412 . & 2274 & 1820 . & 4500 & - \\
\hline 6 & .885 & -580 & -626. & -430 & 3276 . & 2571 & 4095 . & 2730 & 2184 & 4500 & - \\
\hline 5 & .885 & -677 & -752 . & -480 & 3823 . & 3055 . & 4779 . & 3186 . & 2549 . & 4500 & G1 \\
\hline 4 & .885 & -774 & -885. & -523. & 4370. & 3555 . & 5463. & 3642 . & 2913. & 45 & G1 \\
\hline 3 & .885 & -870 & -1023 & -561. & 4917. & 4071 & 6146. & 4098 & 3278 . & 45 & G1 \\
\hline 2 & .885 & -967 & -1168 & -592 . & 5464. & 4600 & 6830. & 4553 & 3643 . & 60 & G1 \\
\hline 1 & .885 & -1064 & -1317 & -620 & 6011. & 5140 & 7514 . & 5009 . & 4007 & 6000 & G1 \\
\hline \multicolumn{2}{|c|}{ PAREDE } & \multirow{2}{*}{$\begin{array}{ll}P X & 13 \\
& G+Q\end{array}$} & $Q / G$ & $=$ & 80 & \multicolumn{2}{|c|}{ Unidade } & hsão : & \multirow{2}{*}{$\begin{array}{r}\mathrm{KN} / \mathrm{M} 2 \\
\mathrm{~F} / 1.50\end{array}$} & & \\
\hline NIV & $\mathrm{R}$ & & $\mathrm{G}+\mathrm{Q}+\mathrm{W}$ & $G-W$ & Fp1 & Fp2 & .80 & $\mathrm{E} / 1.20$ & & Fbk & GRT \\
\hline 8 & .885 & -43 & -61. & -17 & 244 . & 228 . & 306 . & 204 . & 163. & & - \\
\hline 7 & .885 & -122 & -176 . & -47 & 691. & 652 . & 864 . & 576. & 461. & 0 . & - \\
\hline 6 & .885 & -201 & -307 . & -60 & 1138. & 1118 & 1423. & 948. & 759. & 4500 & - \\
\hline 5 & .885 & -281 & -454 . & -56 & 1585. & 1623 & 2029 . & 1353. & 1082 & 4500 & - \\
\hline 4 & .885 & -360 & -617. & -38 & 2032 . & 2167 & 2708 . & 1805 . & 1444 . & 4500 & - \\
\hline 3 & .885 & -439 & -793. & -5 & 2479 . & 2745 . & 3431 . & 2288 & 1830 . & 4500 & - \\
\hline 2 & .885 & -518 & -982 & 40. & 2926. & 3356 . & 4195 . & 2796 . & 2237 . & 6000 & - \\
\hline 1 & .885 & -597 & -1182 & 96. & 3372 . & 3993. & 4991. & 3327 . & 2662 . & 6000 & - \\
\hline
\end{tabular}

PAREDE PX $15 \quad \mathrm{Q} / \mathrm{G}+\mathrm{Q}=.180 \quad$ Unidade de tensão: $\mathrm{KN} / \mathrm{M} 2$

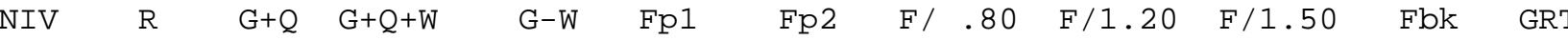

\begin{tabular}{|c|c|c|c|c|c|c|c|c|c|c|c|}
\hline 8 & .885 & -43 & -61. & -16. & 241 . & 227 . & 301. & 201 . & 160 . & 4500 & - \\
\hline 7 & .885 & -348 & -404 & -230 & 1967 . & 1614. & 2459. & 1639. & 1311 & 4500 & - \\
\hline 6 & .885 & -442 & -552 & -253 & 2499 . & 2149. & 3124. & 2083 & 1666 & 4500 & - \\
\hline 5 & .885 & -536 & -717 & -259 & 3031 . & 2726 . & 3789. & 2526 . & 2021 . & 4500 & - \\
\hline 4 & .885 & -631 & -898 & -249 & 3563 . & 3342 . & 4453 . & 2969 . & 2375 . & 4500 & - \\
\hline 3 & .885 & -725 & -1094 . & -225 & 4095 & 3994. & 5118. & 3412 . & 2730 & 4500 & G1 \\
\hline 2 & .885 & -819 & -1303 & -187 & 4626 & 4680 . & 5850. & 3900 . & 3120 . & 6000 & - \\
\hline 1 & .885 & -913 & -1523 & -139. & 5158 & 5393. & 6742 . & 4494 . & 3596 . & 6000 & $G \perp$ \\
\hline
\end{tabular}

\begin{tabular}{|c|c|c|c|c|c|c|c|c|c|c|c|}
\hline \multicolumn{2}{|c|}{ PAREDE } & PX 16 & \multicolumn{2}{|c|}{$Q / G+Q$} & .180 & \multicolumn{2}{|c|}{ Unidade } & :ensão : & $\mathrm{KN} / \mathrm{M} 2$ & \multirow[b]{2}{*}{ Fbk } & \multirow[b]{2}{*}{ GRT } \\
\hline NIV & $\mathrm{R}$ & $\mathrm{G}+\mathrm{Q}$ & $\mathrm{G}+\mathrm{Q}+\mathrm{W}$ & $G-W$ & Fp1 & Fp2 & $\mathrm{F} / .80$ & $\mathrm{~F} / 1.20$ & $\mathrm{~F} / 1.50$ & & \\
\hline 8 & .885 & -43 & -61 & -16. & 241 . & 227. & 301. & 201. & 160. & 4500 . & - \\
\hline 7 & .885 & -348 . & -404. & -230 & 1967. & 1614. & 2459 . & 1639. & 1311. & 4500 . & - \\
\hline 6 & .885 & -442 . & -552 . & -253 & 2499. & 2149 & 3124 . & 2083. & 1666 . & 4500 . & - \\
\hline 5 & .885 & -536 & -717 & -259 & 3031. & 2726 . & 3789. & 2526 . & 2021 . & 4500 . & - \\
\hline 4 & .885 & -631. & -898 & -249 & 3563. & 3342 . & 4453 . & 2969. & 2375 . & 4500 . & - \\
\hline 3 & .885 & -725. & -1094 & -225 & 4095 . & 3994. & 5118. & 3412 . & 2730 & 4500 . & G1 \\
\hline 2 & .885 & -819 & -1303 & -187 & 4626. & 4680. & 5850 . & 3900 . & 3120 . & 6000. & - \\
\hline 1 & .885 & -913. & -1523 & -139 & 5158. & 5393. & 6742 . & 4494. & 3596 . & 6000. & G1 \\
\hline
\end{tabular}




\begin{tabular}{|c|c|c|c|c|c|c|c|c|c|c|c|}
\hline \multirow{2}{*}{$\begin{array}{l}\text { PAREDI } \\
\text { NIV }\end{array}$} & \multirow{2}{*}{$E_{R}$} & \multirow{2}{*}{$\begin{array}{ll}P X & 18 \\
& G+Q\end{array}$} & \multirow{2}{*}{$\begin{array}{l}\mathrm{Q} / \mathrm{G}+\mathrm{Q} \\
\mathrm{G}+\mathrm{Q}+\mathrm{W}\end{array}$} & \multirow{2}{*}{$2=$} & \multirow{2}{*}{$\begin{array}{l}180 \\
\text { Fp1 }\end{array}$} & \multicolumn{2}{|c|}{ Unidade } & \multirow{2}{*}{$\begin{array}{l}\text { ensão: } \\
\text { F/1.20 }\end{array}$} & \multirow{2}{*}{$\begin{array}{r}\mathrm{KN} / \mathrm{M} 2 \\
\mathrm{~F} / 1.50\end{array}$} & \multirow[b]{2}{*}{ Fbk } & \multirow[b]{2}{*}{ GRT } \\
\hline & & & & & & Fp2 & $\mathrm{F} / .80$ & & & & \\
\hline 8 & .885 & -43 . & -61. & -17 & 244 . & 228. & 306. & 204 . & 163. & 4500 . & - \\
\hline 7 & .885 & -122 . & -176. & -47 & 691. & 652. & 864. & 576. & 461. & 4500 . & - \\
\hline 6 & .885 & -201. & -307 . & -60. & 1138. & 1118. & 1423 . & 948. & 759. & 4500 . & - \\
\hline 5 & .885 & -281. & -454. & -56 & 1585. & 1623. & 2029 . & 1353. & 1082 . & 4500 . & - \\
\hline 4 & .885 & -360 & -617 & -38 & 2032 . & 2167. & 2708 . & 1805 . & 1444 . & 4500 . & - \\
\hline 3 & .885 & -439. & -793. & -5 & 2479 . & 2745 . & 3431 . & 2288 . & 1830 . & 4500 . & - \\
\hline 2 & .885 & -518. & -982 . & 40. & 2926. & 3356 . & 4195 . & 2796 . & 2237 . & 6000 . & - \\
\hline 1 & .885 & -597 & -1182 & 96. & 3372 . & 3993. & 4991. & 3327 . & 2662 & 6000. & - \\
\hline
\end{tabular}

\begin{tabular}{|c|c|c|c|c|c|c|c|c|c|c|c|}
\hline \multirow{2}{*}{$\begin{array}{l}\text { PARED } \\
\text { NIV }\end{array}$} & \multirow{2}{*}{$E_{R}$} & \multirow{2}{*}{$\begin{array}{ll}\mathrm{PX} & 21 \\
& \mathrm{G}+\mathrm{Q}\end{array}$} & \multirow{2}{*}{$\begin{array}{c}Q / G+Q \\
G+Q+W\end{array}$} & \multicolumn{2}{|c|}{$\mathrm{Q}=.180$} & \multicolumn{2}{|c|}{ Unidade } & \multicolumn{2}{|c|}{ tensão : KN /M 2} & \multirow[b]{2}{*}{ Fbk } & \multirow[b]{2}{*}{ GRT } \\
\hline & & & & $\mathrm{G}-\mathrm{W}$ & Fp1 & Fp2 & $\mathrm{F} / .80$ & $\mathrm{~F} / 1.20$ & $\mathrm{~F} / 1.50$ & & \\
\hline 8 & .885 & -43 . & -60 & -18 & 241 . & 224 . & 301. & 201. & 160. & 4500 . & - \\
\hline 7 & .885 & -348 & -399. & -234 & 1967. & 1604 . & 2459 . & 1639. & 1311. & 4500 & - \\
\hline 6 & .885 & -442 & -544 . & -261. & 2499 . & 2128 . & 3124 . & 2083 . & 1666. & 4500 . & - \\
\hline 5 & .885 & -536 & -703 & -273 & 3031 . & 2690. & 3789. & 2526 . & 2021 . & 4500 & - \\
\hline 4 & .885 & -631. & -877 & -270 & 3563 . & 3289 . & 4453 . & 2969 . & 2375 . & 4500 & - \\
\hline 3 & .885 & -725. & -1065 & -254 & 4095 . & 3921 & 5118 . & 3412 . & 2730 & 4500 & G1 \\
\hline 2 & .885 & -819 & -1265 & -226 & 4626 & 4585 . & 5783. & 3855 . & 3084 . & 6000 & - \\
\hline 1 & .885 & -913 & -1475 & -187 & 5158. & 5273. & 6592 . & 4395 . & 3516 . & 6000 & G1 \\
\hline
\end{tabular}

PAREDE PX $22 \quad \mathrm{Q} / \mathrm{G}+\mathrm{Q}=.180 \quad$ Unidade de tensão : KN /M 2

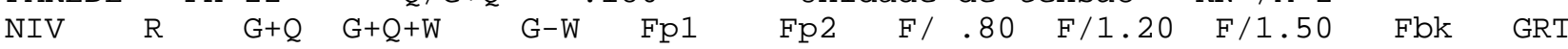

\begin{tabular}{|c|c|c|c|c|c|c|c|c|c|c|c|}
\hline 8 & .885 & -43 & -60. & -18 & 241 . & 224 . & 301. & 201. & 160. & 4500 & - \\
\hline 7 & .885 & -348 & -399. & -234 & 1967 . & 1604. & 2459 . & 1639. & 1311. & 4500 & - \\
\hline 6 & .885 & -442 & -544 & -261. & 2499 . & 2128 . & 3124 . & 2083 . & 1666. & 4500 & - \\
\hline 5 & .885 & -536 & -703 & -273 & 3031 . & 2690. & 3789. & 2526 & 2021 . & 4500 & - \\
\hline 4 & .885 & -631. & -877 & -270 & 3563 . & 3289. & 4453 . & 2969 . & 2375 . & 4500 & - \\
\hline 3 & .885 & -725 & -1065 & -254 & 4095 & 3921. & 5118. & 3412 . & 2730 . & 4500 & $\mathrm{G} 1$ \\
\hline 2 & .885 & -819 & -1265 & -226 & 4626 & 4585 . & 5783. & 3855 . & 3084 . & 6000 & - \\
\hline 1 & .885 & -913 & -1475 & -187 & 5158 & 5273. & 6592. & 4395 & 3516 . & 6000 & s1 \\
\hline
\end{tabular}

\begin{tabular}{|c|c|c|c|c|c|c|c|c|c|c|c|}
\hline \multicolumn{2}{|c|}{ PAREDE } & PY & $Q / G+Q$ & \multicolumn{2}{|c|}{$=.180$} & \multicolumn{2}{|c|}{ Unidade de } & ensão : & $\mathrm{KN} / \mathrm{M} 2$ & \multirow[b]{2}{*}{ Fbk } & \multirow[b]{2}{*}{ GRT } \\
\hline NIV & $\mathrm{R}$ & $\begin{array}{c}1 \\
G+Q\end{array}$ & $G+Q+W$ & $G-W$ & Fp1 & Fp2 & $\mathrm{F} / .80$ & $\mathrm{~F} / 1.20$ & $\mathrm{~F} / 1.50$ & & \\
\hline 8 & .885 & -43 & -66. & -12 & 244 . & 241. & 306. & 204 . & 163. & 4500 . & - \\
\hline 7 & .885 & -122 . & -191. & -32 & 691. & 690. & 864 . & 576. & 461. & 4500 . & - \\
\hline 6 & .885 & -201. & -337. & -30 & 1138 & 1192. & 1490 . & 993. & 795. & 4500 . & - \\
\hline 5 & .885 & -281. & -503 & -7 & 1585 & 1746. & 2182 & 1455 . & 1164. & 4500 . & - \\
\hline 4 & .885 & -360 . & -689 & 35 . & 2032 & 2348 . & 2935. & 1957. & 1565. & 4500 . & - \\
\hline 3 & .885 & -439. & -893 & 95. & 2479 . & 2996. & 3745 . & 2496 . & 1997. & 4500 . & - \\
\hline 2 & .885 & -518. & -1114 & 171. & 2926 & 3684 . & 4605 . & 3070 . & 2456 . & 6000. & - \\
\hline 1 & .885 & -597 . & -1348 . & 261. & 3372 . & 4407 . & 5508 . & 3672 . & 2938 . & 6000. & - \\
\hline
\end{tabular}

\begin{tabular}{|c|c|c|c|c|c|c|c|c|c|c|c|}
\hline \multirow{2}{*}{$\begin{array}{l}\text { PARED } \\
\text { NIV }\end{array}$} & \multirow{2}{*}{$E_{R}$} & \multirow{2}{*}{$\begin{array}{c}6 \\
G+Q\end{array}$} & \multirow{2}{*}{$\begin{array}{c}Q / G+Q \\
G+Q+W\end{array}$} & \multirow{2}{*}{$\begin{array}{c}= \\
G-W\end{array}$} & \multirow{2}{*}{$\begin{array}{l}180 \\
\text { Fp1 }\end{array}$} & \multicolumn{2}{|c|}{ Unidade } & \multirow{2}{*}{$\begin{array}{l}\text { ensão : } \\
\text { F/1.20 }\end{array}$} & \multirow{2}{*}{$\begin{array}{r}\mathrm{KN} / \mathrm{M} 2 \\
\mathrm{~F} / 1.50\end{array}$} & \multirow[b]{2}{*}{ Fbk } & \multirow[b]{2}{*}{ GRT } \\
\hline & & & & & & Fp2 & $\mathrm{F} / .80$ & & & & \\
\hline 8 & .885 & -46 & -69. & -16 & 262 . & 253. & 328 . & 219. & 175. & 4500. & - \\
\hline 7 & .885 & -157 & -224 . & -62. & 888. & 833. & 1110 . & 740. & 592 . & 4500 . & - \\
\hline 6 & .885 & -268 & -400 . & -88 & 1513. & 1465. & 1892 . & 1261 . & 1009 . & 4500 . & - \\
\hline 5 & .885 & -379 & -596. & -93 & 2139. & 2146. & 2683. & 1789 . & 1431. & 4500 . & - \\
\hline 4 & .885 & -489 & -810. & -80 & 2764 . & 2876 . & 3595. & 2396 . & 1917 . & 4500 . & - \\
\hline 3 & .885 & -600 & -1043 . & -49 & 3390. & 3649. & 4561. & 3041 . & 2433 . & 4500 . & G1 \\
\hline 2 & .885 & -711 & -1291. & -3 & 4015 . & 4462 . & 5577. & 3718 . & 2974 . & 6000. & - \\
\hline 1 & .885 & -821 & -1552 . & 57. & 4641 . & 5308. & 6635. & 4423 . & 3539 . & 6000. & G1 \\
\hline
\end{tabular}




\begin{tabular}{|c|c|c|c|c|c|c|c|c|c|c|c|}
\hline \multicolumn{2}{|c|}{ PAREDE } & 7 & \multicolumn{2}{|c|}{$Q / G+Q$} & 180 & \multicolumn{2}{|c|}{ Unidade } & \multirow{2}{*}{$\begin{array}{r}\text { ensão: } \\
\text { F/1.20 }\end{array}$} & $\mathrm{KN} / \mathrm{M} 2$ & \multirow[b]{2}{*}{ Fbk } & \multirow[b]{2}{*}{ GRT } \\
\hline NIV & $\mathrm{R}$ & $\mathrm{G}+\mathrm{Q}$ & $\mathrm{G}+\mathrm{Q}+\mathrm{W}$ & $G-W$ & Fp1 & $\mathrm{Fp} 2$ & $\mathrm{~F} / .80$ & & $\mathrm{~F} / 1.50$ & & \\
\hline 8 & .885 & -45 & -72 & -9 & 254 . & 25 & 324 & 216 . & 173. & 4500 & - \\
\hline 7 & .885 & -145 & -227 . & -38 & 821. & 819. & 1026. & 684. & 547 . & 4500 & - \\
\hline 6 & .885 & -246 & -407 & -41 & 1388. & 1443. & 1804. & 1203. & 962 . & 4500 & - \\
\hline 5 & .885 & -346 & -611 & -19 & 1955. & 2128. & 2660 . & 1773. & 1419. & 4500 & - \\
\hline 4 & .885 & -446 & -838 & 25. & 2523. & 2871. & 3588 . & 2392 . & 1914 . & 4500 & - \\
\hline 3 & .885 & -547 & -1087 & 91. & 3090. & 3667 . & 4584 . & 3056 . & 2445 . & 4500 & G1 \\
\hline 2 & .885 & -647 & -1355 & 177 . & 3657 . & 4512 . & 5640 . & 3760 . & 3008 . & 6000 & - \\
\hline 1 & .885 & -748 & -1639. & 279. & 4224 . & 5397. & 6746. & 4498 . & 3598 . & 6000 & G1 \\
\hline
\end{tabular}

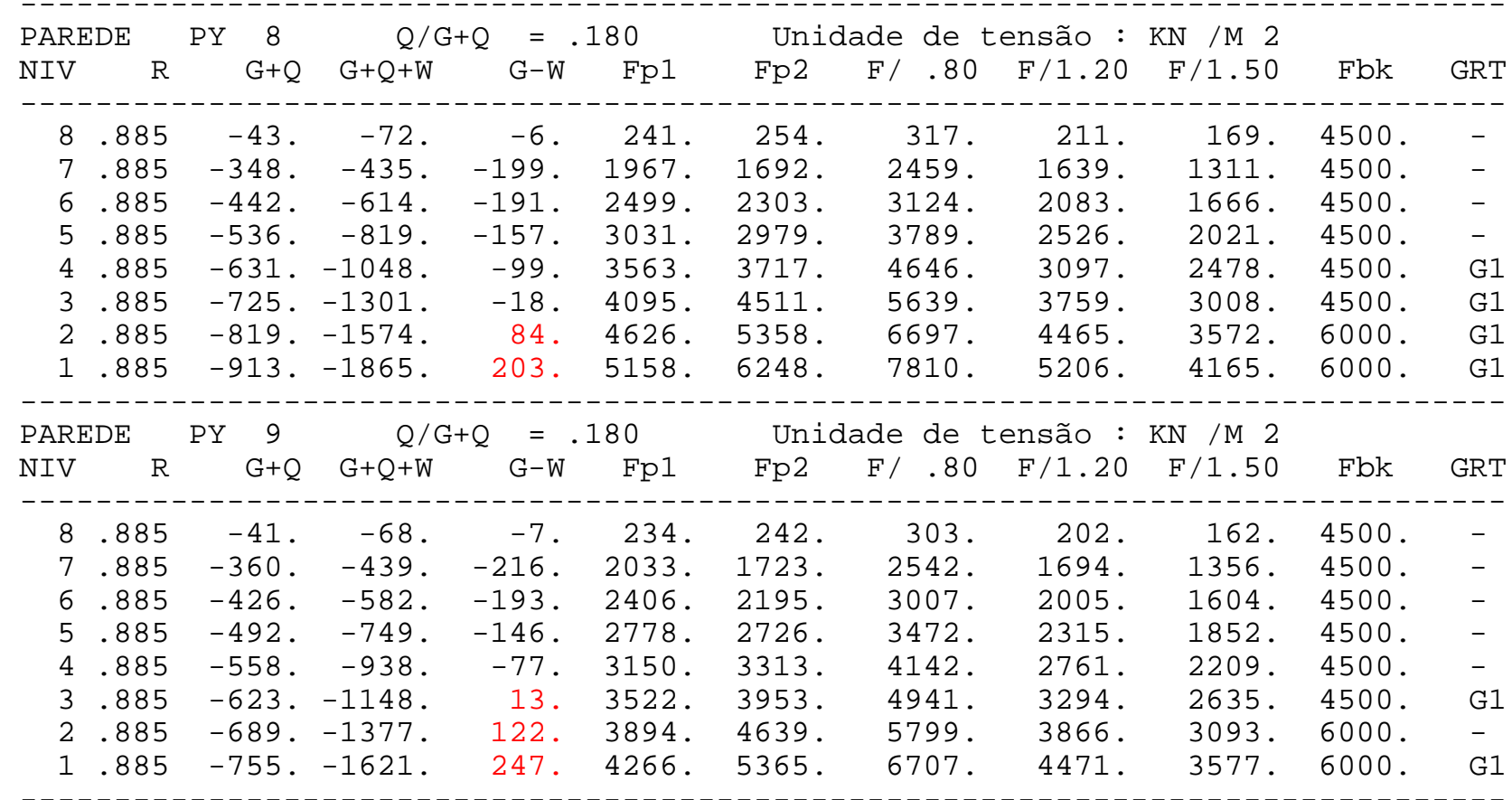

\begin{tabular}{|c|c|c|c|c|c|c|c|c|c|c|c|}
\hline \multirow{2}{*}{$\begin{array}{l}\text { PARED } \\
\text { NIV }\end{array}$} & \multirow{2}{*}{$E_{R}$} & \multirow{2}{*}{$\begin{array}{l}12 \\
G+Q\end{array}$} & \multirow{2}{*}{$\begin{array}{c}Q / G+\mathrm{C} \\
\mathrm{G}+\mathrm{Q}+\mathrm{W}\end{array}$} & \multicolumn{2}{|c|}{$\mathrm{Q}=.180$} & \multicolumn{2}{|c|}{ Unidade } & \multicolumn{2}{|c|}{ tensão : KN /M 2} & \multirow[b]{2}{*}{ Fbk } & \multirow[b]{2}{*}{ GRT } \\
\hline & & & & $G-W$ & Fp1 & Fp2 & $\mathrm{F} /$ & $\mathrm{F} / 1.20$ & $\mathrm{~F} / 1.50$ & & \\
\hline 8 & .885 & -43 & -72 . & -6 & 241 . & 254 . & 317 . & 211 & 169. & 4500 . & - \\
\hline 7 & .885 & -348 & -435 & -199. & 1967. & 1692 . & 2459 . & 1639. & 1311. & 4500 . & - \\
\hline 6 & .885 & -442 & -614. & -191 & 2499 . & 2303 & 3124 . & 2083 . & 1666. & 4500 . & - \\
\hline 5 & .885 & -536 & -819 & -157 & 3031 . & 2979 . & 3789 . & 2526 . & 2021 . & 4500 . & - \\
\hline 4 & .885 & -631. & -1048 & -99. & 3563 . & 3717 . & 4646 . & 3097 . & 2478 . & 4500 . & G1 \\
\hline 3 & .885 & -725 & -1301 & -18 & 4095 . & 4511 . & 5639. & 3759 . & 3008 . & 4500 . & G1 \\
\hline 2 & .885 & -819. & -1574 & 84. & 4626 & 5358. & 6697. & 4465 . & 3572 . & 6000. & G1 \\
\hline 1 & .885 & -913 & -1865 & 203. & 5158. & 6248 & 7810 . & 5206 . & 4165 & 6000. & G1 \\
\hline
\end{tabular}

\begin{tabular}{|c|c|c|c|c|c|c|c|c|c|c|c|}
\hline \multirow{2}{*}{$\begin{array}{l}\text { PAREDI } \\
\text { NIV }\end{array}$} & \multirow{2}{*}{$E_{R}$} & \multirow{2}{*}{$\begin{array}{l}13 \\
G+Q\end{array}$} & \multirow{2}{*}{$\begin{array}{c}Q / G+C \\
G+Q+W\end{array}$} & \multirow{2}{*}{$\begin{array}{c}= \\
G-W\end{array}$} & \multirow{2}{*}{$\begin{array}{l}180 \\
\text { Fp1 }\end{array}$} & \multicolumn{2}{|c|}{ Unidade } & \multirow{2}{*}{$\begin{array}{l}\text { ensão: } \\
\text { F/1.20 }\end{array}$} & \multirow{2}{*}{$\begin{array}{r}\mathrm{KN} / \mathrm{M} 2 \\
\mathrm{~F} / 1.50\end{array}$} & \multirow[b]{2}{*}{ Fbk } & \multirow[b]{2}{*}{ GRT } \\
\hline & & & & & & Fp2 & $\mathrm{F} / .80$ & & & & \\
\hline 8 & .885 & -45 . & -69. & -13. & 256 . & 251 & 320 . & 213. & 171. & 4500 . & - \\
\hline 7 & .885 & -483. & -554. & -326 & 2729. & 2223 & 3412 . & 2274 . & 1820. & 4500 . & - \\
\hline 6 & .885 & -580. & -719. & -336 & 3276 . & 2806 & 4095 . & 2730 . & 2184 . & 4500 . & - \\
\hline 5 & .885 & -677 . & -906 & -325 . & 3823. & 3441 & 4779 . & 3186 . & 2549 . & 4500 . & G1 \\
\hline 4 & .885 & -774 . & -1113 & -295. & 4370 . & 4127 & 5463 . & 3642 . & 2913. & 4500 . & G1 \\
\hline 3 & .885 & -870 . & -1339 & -245 . & 4917 . & 4858 & 6146 & 4098 & 3278 . & 4500 . & G1 \\
\hline 2 & .885 & -967 & -1581 & -179. & 5464. & 5632 & 7040 & 4694. & 3755 . & 6000 . & G1 \\
\hline 1 & .885 & -1064 . & -1837 & -99. & 6011. & 6442 & 8052 . & 5368. & 4294. & 6000. & G1 \\
\hline
\end{tabular}




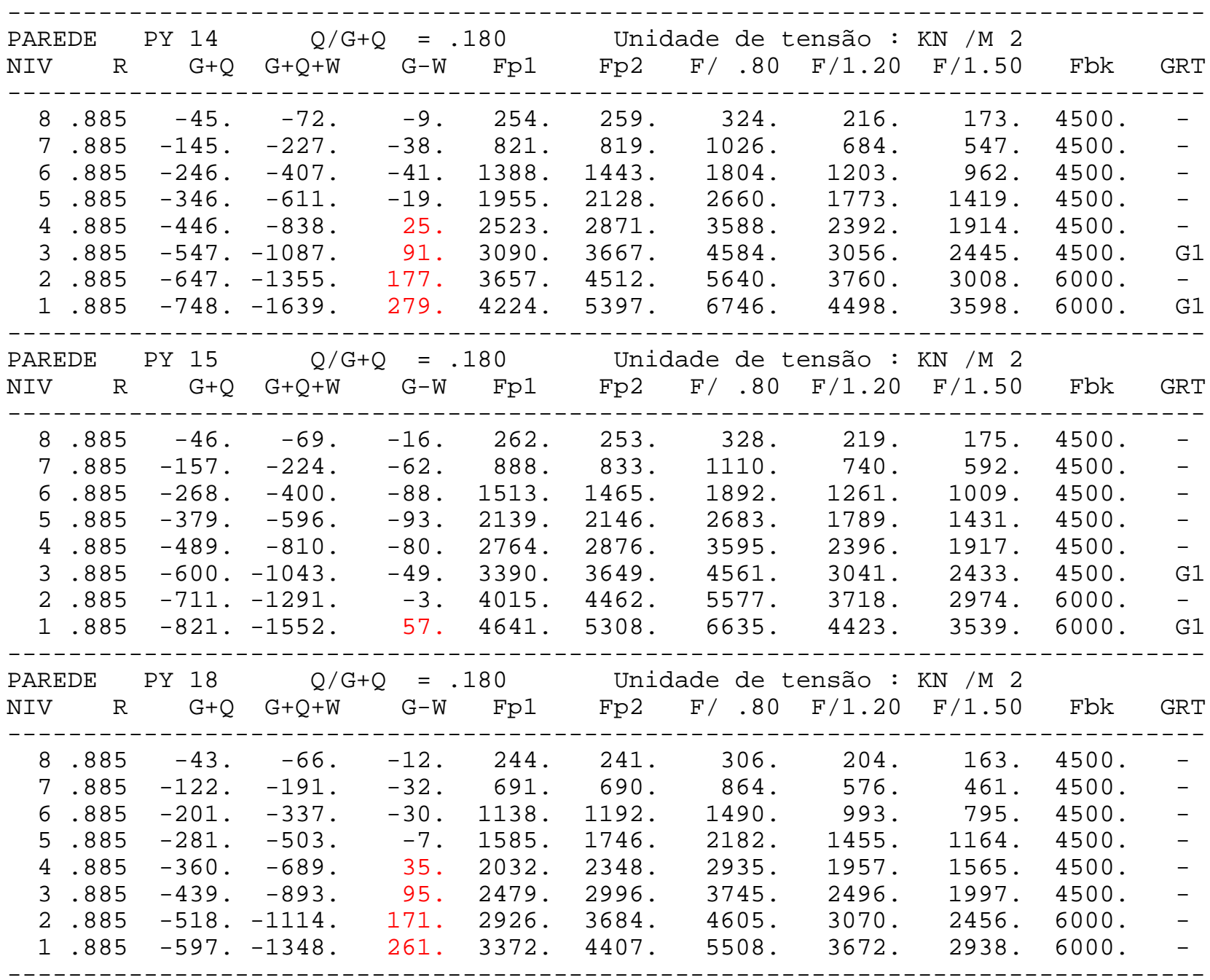




\section{REFERÊNCIAS BIBLIOGRÁFICAS}

AMRHEIN, J. E. (1978). Reinforced masonry engineering handbook: clay and concrete masonry. Los Angeles, Institute of America. 445p.

ASSOCIAÇÃO BRASILEIRA DA CONSTRUÇÃO INDUSTRIALIZADA (1990). Manual técnico de alvenaria. São Paulo, $\mathrm{ABCl} /$ Projeto.

ASSOCIAÇÃO BRASILEIRA DE NORMAS TÉCNICAS (1978). NB-1 - Projeto e execução de obras de concreto armado. Rio de Janeiro.

ASSOCIAÇÃO BRASILEIRA DE NORMAS TÉCNICAS (1980). NB-5 - Cargas para o cálculo de estruturas de edificações. Rio de Janeiro.

ASSOCIAÇÃO BRASILEIRA DE NORMAS TÉCNICAS (1989). NBR 6123 - Forças devidas ao vento em edificações. Rio de Janeiro.

ASSOCIAÇÃO BRASILEIRA DE NORMAS TÉCNICAS (1994). NBR 6136 - Blocos vazados de concreto simples para alvenaria estrutural. Rio de Janeiro.

ASSOCIAÇÃO BRASILEIRA DE NORMAS TÉCNICAS (1982). NBR 7186 - Bloco vazado de concreto simples para alvenaria com função estrutural. Rio de Janeiro. 
ASSOCIAÇÃO BRASILEIRA DE NORMAS TÉCNICAS (1983). NBR 8215 -Prismas de blocos vazados de concreto simples para alvenaria estrutural: preparo e ensaio à compressão. Rio de Janeiro.

ASSOCIAÇÃO BRASILEIRA DE NORMAS TÉCNICAS (1984). NBR 8681 - Ações e segurança nas estruturas. Rio de Janeiro.

ASSOCIAÇÃO BRASILEIRA DE NORMAS TÉCNICAS (1985). NBR 8798 Execução e controle de obras de alvenaria estrutural de blocos vazados de concreto. Rio de Janeiro.

ASSOCIAÇÃO BRASILEIRA DE NORMAS TÉCNICAS (1985). NBR 8949-Paredes de alvenaria estrutural - ensaio à compressão simples. Rio de Janeiro.

ASSOCIAÇÃO BRASILEIRA DE NORMAS TÉCNICAS (1989). NBR 10837 Cálculo de alvenaria estrutural de blocos vazados de concreto. Rio de Janeiro.

BASSO, A. ; CORRÊA, M. R. S. ; RAMALHO, M. A. (1997). Fissuras em paredes de alvenaria estrutural sob lajes de cobertura de edifícios. In: CONGRESSO IBEROAMERICANO DE PATOLOGIA DAS CONSTRUÇÕES, $4 . \quad$ / CONGRESSO DE CONTROLE DE QUALIDADE, 6., Porto Alegre, 21-24 outubro 1997. Anais. Porto Alegre, UFRGS-CPGEC. v. 1, p. 367-374.

BASTOS, P.S. S. (1993). Contribuições ao projeto de edifícios de alvenaria estrutural pelo método das tensões admissíveis. São Carlos. 242 p. Dissertação (Mestrado) - Escola de Engenharia de São Carlos, Universidade de São Paulo.

BRANDÃO, A. M. S. (1996). Instabilidade global e local em estruturas prémoldadas: estudo comparativo. São Carlos, EESC-USP. (Apresentado à disciplina "SET-861 - Estruturas pré-moldadas de concreto"). 
CARMO, R. M. S. (1995). Efeitos de segunda ordem em edifícios usuais de concreto armado. 112 p. Dissertação (Mestrado) - Escola de Engenharia de São Carlos, Universidade de São Paulo.

CARMO, R. M. S. ; CORRÊA, M. R. S. ; RAMALHO, M. A. (1997). Comparação entre processos de análise estrutural de segunda ordem de edifícios. In: JORNADAS SUL-AMERICANAS DE ENGENHARIA ESTRUTURAL, 28., São Carlos, 1-5 setembro 1997. Anais. São Carlos, EESC-USP. v. 1, p. 497-506.

CASTRO, L. A. (1997). Introdução da segurança no projeto de estruturas: método dos estados limites. 115 p. Dissertação (Mestrado) - Escola de Engenharia de São Carlos, Universidade de São Paulo.

CORRÊA, M. R. S. (1991). Aperfeiçoamento de modelos usualmente empregados no projeto de sistemas estruturais de edifícios. 331 p. Tese (Doutorado) Escola de Engenharia de São Carlos, Universidade de São Paulo.

CORRÊA, M. R. S. ; RAMALHO, M. A. (1990-1992). Relatórios sobre o comportamento de paredes estruturais de alvenaria: modelos em elementos finitos. Brasília. / Relatório técnico para a ENCOL S/A /

CORRÊA, M. R. S. ; RAMALHO, M. A. (1994a). Efeitos de aberturas em painéis de alvenaria estrutural. In: INTERNATIONAL SEMINAR ON STRUCTURAL MASONRY FOR DEVELOPING CONTRIES, 5., Florianópolis, Brazil, 21-24 Aug. 1994. Proceedings. Florianópolis, Univ. Fed. Santa Catarina / University of Edinburgh/ ANTAC, p. 359-367.

CORRÊA, M. R. S. ; RAMALHO, M. A. (1994b). Procedimento para análise de edifícios de alvenaria estrutural submetidos a ações verticais. In: INTERNATIONAL SEMINAR ON STRUCTURAL MASONRY FOR DEVELOPING CONTRIES, 5., Florianópolis, Brazil, 21-24 Aug. 1994. Proceedings. Florianópolis, Univ. Fed. Santa Catarina / University of Edinburgh/ ANTAC, p. 305-314. 
CORRÊA, M. R. S. ; RAMALHO, M. A. (1996). Alvenaria estrutural. São Carlos, EESC-USP. (Notas de aula da disciplina "SET-606 - Alvenaria estrutural").

DAVIES, S. R. ; KESKIN, O. (1974). The effect of torsion on multi-storey structures. In: INTERNATIONAL SYMPOSIUM ON LOADBEARING BRICKWORK, London, Jun. 1974. Proceedings. p.127-137.

DEUTSCH INDUSTRIE NORMEN. (1974). DIN 1053 - Alvenaria: cálculo e execução. Tradução de H. J. Okorn. São Paulo.

DICKEY, W. L. ; SCHNEIDER, R. R. (1994). Reinforced mansory design. Englewood Cliffs, Prentice Hall.

EL DEBS, M. K. (1996). Estruturas pré-moldadas de concreto. São Carlos, EESCUSP. (Notas de aula da disciplina "SET-861 - Estruturas pré-moldadas de concreto").

FRANCO, L. S. et al (1991). Desenvolvimento de um novo processo construtivo em alvenaria estrutural não-armada de blocos de concreto. Manual do processo construtivo Poli-ENCOL: projeto. São Paulo. 184p. Convênio EPUSP / CPqDCC - Projeto EP / EN-5, Relatório técnico R5-25/91.

FRANCO, M. ; VASCONCELOS, A. C. (1991). Practical assessment of second order effects in tall buildings. In: COLLOQUIUM ON THE CEB-FIP MC90, Rio de Janeiro. Proceedings. p.307-324.

HENDRY, A. W. et al (1981). An introduction to load bearing brickwork design. New York, Halsted Press.

HENDRY, A. W. (1981). Structural brickwork. London, MacMillan Press.

MEDEIROS, J. S. (1993). Alvenaria estrutural não-armada de blocos de concreto: produção de componentes e parâmetros de projeto. 449 p. Dissertação (Mestrado) - Escola Politécnica da Universidade de São Paulo. 
OLIVEIRA JÚNIOR, V. (1992). Recomendações para o projeto de edifícios em alvenaria estrutural . 266 p. Dissertação (Mestrado) - Escola de Engenharia de São Carlos, Universidade de São Paulo.

OLIVEIRA JR., V. ; PINHEIRO, L. M. (1994a). Análise de paredes de alvenaria estrutural calculadas no estado limite último. In: INTERNATIONAL SEMINAR ON STRUCTURAL MASONRY FOR DEVELOPING CONTRIES, 5., Florianópolis, Brazil, 21-24 Aug. 1994. Proceedings. Florianópolis, Univ. Fed. Santa Catarina / University of Edinburgh/ ANTAC, p.295-304.

OLIVEIRA JR., V. ; PINHEIRO, L. M. (1994b) Método prático para distribuição das ações verticais em paredes de alvenaria. In: INTERNATIONAL SEMINAR ON STRUCTURAL MASONRY FOR DEVELOPING CONTRIES, 5., Florianópolis, Brazil, 21-24 Aug. 1994. Proceedings. Florianópolis, Univ. Fed. Santa Catarina / University of Edinburgh/ ANTAC, p.315-322.

PARSEKIAN, G. A. (1986). Cálculo e armação de lajes de concreto armado com a consideração do momento volvente. 116 p. Dissertação (Mestrado) - Escola de Engenharia de São Carlos, Universidade de São Paulo.

SAP90 (1991). A series of computer programs for the finite element analysis of structures. Berkeley, Computers and Structures Inc.

SILVA, I. M. (1996). Análise de edifícios de alvenaria estrutural sujeitos as ações do vento. 80 p. Dissertação (Mestrado) - Escola de Engenharia de São Carlos, Universidade de São Paulo.

SOLÓRZANO, M. G. P. (1994). Características e desempenho de juntas de argamassa na alvenaria estrutural de blocos de concreto. 203 p. Dissertação (Mestrado) - Escola Politécnica da Universidade de São Paulo.

TCPO 9: Tabelas de composições de preços para orçamentos (1992). 9. ed. São Paulo, Pini. 846 p. 
TOMAZELA, C. A. (1995). Ação conjunta parede-viga na alvenaria estrutural. 249 p. Dissertação (Mestrado) - Escola de Engenharia de São Carlos, Universidade de São Paulo.

VARGAS, H. G. (1988). Alvenaria estrutural. Porto Alegre, CPGEC-UFRGS. (Notas de aula). 